\title{
Identification of potential core genes in hepatoblastoma via bioinformatics analysis
}

Basavaraj Vastrad ${ }^{1}$, Chanabasayya Vastrad ${ }^{2}$, Iranna Kotturshetti ${ }^{3}$

1. Department of Biochemistry, Basaveshwar College of Pharmacy, Gadag, Karnataka 582103, India.

2. Biostatistics and Bioinformatics, Chanabasava Nilaya, Bharthinagar, Dharwad, Karnataka 580001, India.

3. Department of Ayurveda, Rajiv Gandhi Education Society`s Ayurvedic Medical College, Ron, Karnataka 562209, India.

* Chanabasayya Vastrad

channu.vastrad@gmail.com

Ph: +919480073398

Chanabasava Nilaya, Bharthinagar,

Dharwad 580001 , Karanataka, India 


\begin{abstract}
Hepatoblastoma is the childhood liver cancer. Profound efforts have been made to illuminate the pathology, but the molecular mechanisms of hepatoblastoma are still not well understood. To identify the candidate genes in the carcinogenesis and progression of hepatoblastoma, microarray dataset GSE131329 was downloaded from Gene Expression Omnibus (GEO) database. The differentially expressed genes (DEGs) were identified, and pathway and Gene Ontology (GO) enrichment analysis were performed. The protein-protein interaction network (PPI), module analysis, target gene - miRNA regulatory network and target gene - TF regulatory network were constructed and analyzed. A total of 996 DEGs were identified, consisting of 499 up regulated genes and 497 down regulated genes. The pathway and Gene Ontology (GO) enrichment analysis of the DEGs include proline biosynthesis, superpathway of tryptophan utilization, chromosome organization and organic acid metabolic process. Twenty-four hub genes were identified and biological process analysis revealed that these genes were mainly enriched in cell cycle, chromosome organization, lipid metabolic process and oxidation-reduction process. Validation of hub genes showed that TP53, PLK1, AURKA, CDK1, ANLN, ESR1, FGB, ACAT1, GOT1 and ALAS1 may be involved in the carcinogenesis, invasion or recurrence of hepatoblastoma. In conclusion, DEGs and hub genes identified in the present study help us understand the molecular mechanisms underlying the carcinogenesis and progression of hepatoblastoma, and provide candidate targets for diagnosis and treatment of hepatoblastoma.
\end{abstract}

Keywords: bioinformatics; hepatoblastoma; hub genes; miRNA; survival analysis 
medRxiv preprint doi: https://doi.org/10.1101/2020.12.22.20248756; this version posted December 26, 2020. The copyright holder for this

\section{Introduction}

Hepatoblastoma is a highly complex and uncommon malignant type of liver cancer appears in infants and children [Kremer et al 2014], and accounting for just over $1 \%$ of pediatric cancers [Spector and Birch, 2012]. Despite significant advancements in treatments, including surgery [Busweiler et al 2017], chemotherapeutic [Hiyama et al 2016] and liver transplantation [Cruz Jr et al 2013], the survival rate of patients with hepatoblastoma has not sufficiently improved. The high rates of recurrence and metastasis in patients with hepatoblastoma require the critical advancement of novel diagnostic strategies and therapeutic agents to enhance patient prognosis. As the molecular mechanisms of hepatoblastoma tumorigenesis and development are not yet fully understood, there remains to be a number of unsolved issues in the diagnosis and treatment of hepatoblastoma. Therefore, it is important to identify new biomarkers and pathways linked with tumorigenesis and patient prognosis, in order to help resolve the suitable basic molecular mechanisms, and to help discover novel diagnostic and prognostic markers, and therapeutic targets.

Altered expression and mutations of genes, and signalling pathways are associated in the advancement and development of hepatoblastoma. Genes such as $\beta$-catenin [Koch et al. 1999], Axin [Miao et al. 2003], SOCS-1 [Nagai et al. 2003], lipin 1 [Ishimoto et al. 2009] and MT1G [Sakamoto et al. 2010] were linked with development of hepatoblastoma. Signalling pathways such as PI3K/Akt, ERK and p38 signaling pathways [Cui et al. 2016], MAPK signaling pathways [Yuan et al. 2013], notch signalling pathway [Aktaş et al. 2010], $\mathrm{Wnt} / \beta \square$ catenin signalling pathway [Cui et al. 2020] and EGFR-ASAP1 signaling pathway [Ranganathan et al. 2016] were responsible for progression hepatoblastoma. Hepatoblastoma remains a require disease to treat, and more investigations are required to develop the understanding of the underlying molecular mechanisms to diagnose genes and signaling for the progression of new therapies. Therefore, the pathogenesis of hepatoblastoma warrants further studies.

With the accelerated advancement of microarray technology, some high throughput platforms for analysis of gene expression are extensively used to examine the differentially expressed genes (DEGs) during cancer progression [Ma et al. 2019]. Many gene expression profiling studies on hepatoblastoma have been implemented using microarray technology and identified many up 
medRxiv preprint doi: https://doi.org/10.1101/2020.12.22.20248756; this version posted December 26, 2020. The copyright holder for this

and down regulated genes linked with progression of hepatoblastoma [Liu et al. 2018; Adesina et al. 2009].

Therefore, the purpose of the current investigations was to download and analyze expression profiling dataset of human samples from the Gene Expression Omnibus (GEO) database, and to identify DEGs between hepatoblastoma tissues samples and noncancerous liver tissue samples. Subsequently, pathway and Gene Ontology (GO) enrichment analysis were carried out. Protein $\square$ protein interaction (PPI) network analysis, module analysis, target gene - miRNA regulatory network and target gene - TF regulatory network were used to establish the molecular pathogenesis underlying carcinogenesis and progression of hepatoblastoma. Finally, the hub genes were further verified based on UALCAN, cBio Portal, The Human Protein Atlas, receiver operator characteristic (ROC) curve analysis, RT-PCR analysis and immune infiltration analysis. The results may provide new diagnostic and prognostic biomarkers, and therapeutic target molecules in hepatoblastoma metastasis.

\section{Materials and methods}

\section{Access to public data}

The GEO (http://www.ncbi.nlm.nih.gov/geo) is a wide platform for accumulate genomic or microarray data [Edgar et al. 2002]. Expression profiling datasets [GSE131329] were obtained from GEO. The GSE131329 dataset was tested based on the GPL6244 platform [HuGene-1_0-st] Affymetrix Human Gene 1.0 ST Array [transcript (gene) version], including 53 hepatoblastoma tissues samples and 14 noncancerous liver tissue samples.

\section{Data pre-processing}

The GSE131329 gene expression profiles were preprocessed using affyPLM software

(https://www.bioconductor.org/packages/release/bioc/html/affyPLM.html) in the Release (3.10) package [Heber and Sick, 2006]. The original microarray data were transformed into gene symbols according to annotation information of the array platform. If certain probes coincided with the same gene, the moderate scores were determined as the gene expression value of these probes. Robust multiarray average (RMA) in R affy package [Gautier et al. 2004] was used to normalize the matrix. 
medRxiv preprint doi: https://doi.org/10.1101/2020.12.22.20248756; this version posted December 26, 2020. The copyright holder for this

\section{DEGs analysis}

The DEGs in hepatoblastoma samples compared with noncancerous liver samples were diagnosed using the Limma package (https://www.bioconductor.org/packages/release/bioc/html/limma.html) [Ritchie et al. 2015] in R Bioconductor. Finally, $\mid \log$ foldchange (FC) $>1.07$ for up regulated genes; $\mid \log$ foldchange $(\mathrm{FC}) \mid<-1.25$ for down regulated genes and $\mathrm{P} \square$ value $<0.05$ were used as the threshold values for considering the DEGs.

\section{Pathway enrichment analysis of DEGs}

BIOCYC (https://biocyc.org/) [Caspi et al. 2016], Kyoto Encyclopedia of Genes and Genomes (KEGG) (http://www.genome.jp/kegg/pathway.html) [Kanehisa et al. 2018], Pathway Interaction Database (PID) (https://wiki.nci.nih.gov/pages/viewpage.action?pageId=315491760) [Schaefer et al. 2009], REACTOME (https://reactome.org/) [Fabregat et al. 2018], GenMAPP (http://www.genmapp.org/) [Dahlquist et al. 2002], MSigDB C2 BIOCARTA (http://software.broadinstitute.org/gsea/msigdb/collections.jsp) [Subramanian et al. 2005], PantherDB (http://www.pantherdb.org/) [Mi et al. 2017], Pathway Ontology (http://www.obofoundry.org/ontology/pw.html) [Petri et al. 2017] and Small Molecule Pathway Database (SMPDB) (http://smpdb.ca/) [Jewison et al. 2014] are a bioinformatics resource that links genomes to metabolic pathways. Pathway enrichment analysis for DEGs (up and down regulated genes) was performed by using ToppGene (ToppFun) (https://toppgene.cchmc.org/enrichment.jsp) [Chen et al 2009]. P-value $<0.05$ was chosen as the cut-off criteria for significant pathway enrichment analysis.

\section{GO enrichment analysis of DEGs}

ToppGene (ToppFun) (https://toppgene.cchmc.org/enrichment.jsp) [Chen et al 2009] was used to perform Gene Ontology (GO) (http://www.geneontology.org/) [Lewis, 2017] enrichment analyses. P-value < 0.05 was chosen as the cut-off criteria for significant GO enrichment analysis.

\section{Construction of the PPI network and module analysis}

The PPI network was constructed based on all the DEGs (up and down regulated genes) using IID (Integrated Interactions Database) from a well $\square$ known online server (http://iid.ophid.utoronto.ca) [Kotlyar et al 2019], which integrates different PPI databases such as Biological General Repository for Interaction Datasets (BioGRID) (https://thebiogrid.org/) [Oughtred et al 
medRxiv preprint doi: https://doi.org/10.1101/2020.12.22.20248756; this version posted December 26, 2020. The copyright holder for this preprint (which was not certified by peer review) is the author/funder, who has granted medRxiv a license to display the preprint in perpetuity.

2019], IntAct Molecular Interaction Database (https://www.ebi.ac.uk/intact/) [Orchard et al 2014], the Molecular INTeraction database (MINT) (https://mint.bio.uniroma2.it/) [Licata et al 2012], InnateDB (https://www.innatedb.com/) [Breuer et al 2013], Database of Interacting Proteins (DIP) (http://dip.doe-mbi.ucla.edu/dip/Main.cgi) [Salwinski et al 2004], Human Protein Reference Database (HPRD) (http://www.hprd.org/) [Keshava Prasad et al 2009] and Biomolecular Interaction Network Database (BIND) (http://bond.unleashedinformatics.com/) [Willis and Hogue, 2006]. A united score of $>0.4$ was determine as the threshold value for constructing the PPI network. The PPI network was visualized using Cytoscape software (version 3.7.2, http://cytoscape.org/) [Shannon et al 2003]. Five topological characteristics of the genes in the PPI network, including node degree [Przulj et al 2004], betweenness centrality [Nguyen et al 2011], stress centrality [Shi and Zhang, 2011], closeness centrality [Li et al 2018] and clustering coefficient [Wang et al 2012], were calculated using the Network Analyzer plugin in Cytoscape software (http://apps.cytoscape.org/apps/NetworkAnalyzer). In addition, PEWCC1 (http://apps.cytoscape.org/apps/PEWCC1) in Cytoscape software was used to analyze the most significant module, with the threshold value of 5 [Zaki et al 2013].

\section{Construction of target genes - miRNA regulatory network}

The miRNAs (microRNA) that can regulate the up and down regulated genes were predicted using the miRNet database (https://www.mirnet.ca/) [Fan and Xia, 2018] with default significant parameters. Only the interaction relationships can be predicted by ten common algorithms, including TarBase (http://diana.imis.athena-innovation.gr/DianaTools/index.php?r=tarbase/index)
[Vlachos
et
al.
2015],
miRTarBase

(http://mirtarbase.mbc.nctu.edu.tw/php/download.php) [Chou et al. 2018], miRecords (http://miRecords.umn.edu/miRecords) [Xiao et al. 2009], miR2Disease (http://www.mir2disease.org/) [Jiang et al. 2009], HMDD (http://www.cuilab.cn/hmdd) [Huang et al. 2019], PhenomiR (http://mips.helmholtz-muenchen.de/phenomir/) [Ruepp et al. 2010], SM2miR (http://bioinfo.hrbmu.edu.cn/SM2miR/) [Liu et al. 2013], PharmacomiR (http://www.pharmaco-mir.org/) [Rukov et al. 2014], EpimiR (http://bioinfo.hrbmu.edu.cn/EpimiR/) [Dai et al. 2014] and starBase (http://starbase.sysu.edu.cn/) [Li et al. 2014], were included to construct the target gene- miRNA regulatory network using the Cytoscape software. 
medRxiv preprint doi: https://doi.org/10.1101/2020.12.22.20248756; this version posted December 26, 2020. The copyright holder for this preprint (which was not certified by peer review) is the author/funder, who has granted medRxiv a license to display the preprint in perpetuity. All rights reserved. No reuse allowed without permission.

\section{Construction of target genes - TF regulatory network}

The TFs (transcription factors) that can regulate the up and down regulated genes were predicted using the NetworkAnalyst database (https://www.networkanalyst.ca/) [Zhou et al 2019] with default significant parameters. Only the interaction relationships can be predicted by ENCODE (http://cistrome.org/BETA/) [Wang et al 2013],were included to construct the target gene- TF regulatory network using the Cytoscape software.

\section{Validation of hub genes}

UALCAN (http://ualcan.path.uab.edu/analysis.html) [Chandrashekar et al 2017] is a website that offers an online validation of survival biomarkersand analyzes the overall survival (OS) of patients with high and low expression of certain genes. In our investigation, up and down regulated hub genes were detected, and a survival curve was drawn. The log-rank p-value was calculated. And the UALCAN [Chandrashekar et al 2017] platform was applied to further verify the expression level of up and down regulated hub genes between hepatoblastoma and normal samples from The Cancer Genome Atlas (TCGA) portal. Next, UALCAN [Chandrashekar et al 2017] platform was applied to further verify the expression level of up and down regulated hub genes from normal to all stages of hepatoblastoma from The Cancer Genome Atlas (TCGA) portal. Mutaion analysis of up and down regulated hub gens was performed by cBioPortal online platform (http://www.cbioportal.org) [Gao et al 2013]. We also evaluated the protein expression of up and down regulated hub genes by using the human protein atlas (HPA, www.proteinatlas.org) [Uhlen et al 2010] database considering that gene expression was not always consistent with its protein level. Receiver operating characteristic (ROC) analysis was conducted by using the generalized linear model (GLM) in machine learning algorithms [Robinet al. 2011] to show the potential diagnostic and prognostic value of up and down regulated hub genes. $\mathrm{P}<0.05$ was considered to indicate a statistically significant difference. Up and down regulated hub genes was quantified using real-time PCR. Total RNA was isolated from cultured Hep G2 and normal liver cells using a TRI Reagent ${ }^{\circledR}$ (Sigma, USA). RNA was then reverse transcribed into cDNA according to the instructions of a FastQuant RT kit (with gDNase; Tiangen Biotech Co., Ltd.). RT-PCR was performed using a QuantStudio 7 Flex real-time PCR system (Thermo Fisher Scientific, Waltham, MA, USA). The reaction conditions were as follows: predenaturation at $95{ }^{\circ} \mathrm{C}$ for $10 \mathrm{~min}$ and 40 cycles of denaturation at $95^{\circ} \mathrm{C}$ for $10 \mathrm{sec}$, annealing at $60{ }^{\circ} \mathrm{C}$ for $20 \mathrm{sec}$ 
and extension at $72{ }^{\circ} \mathrm{C}$ for 34 sec. $\beta$-actin was used as the internal reference for up and down regulated hub genes. The primers for up and down regulated hub genes are listed in Table 1 . The $2^{-\Delta \Delta C t}$ technique was engaged to measure the ratio of the relative expression of a target gene in the experimental group to that in the control group with the following formulas: $\Delta \Delta \mathrm{Ct}=\Delta \mathrm{Ct}$ experimental group $\Delta \mathrm{Ct}_{\text {control group }}$ and $\Delta \mathrm{Ct}=\mathrm{Ct}$ target gene $-\mathrm{Ct}$ internal reference. $\mathrm{Ct}$ was the amplification cycle. Three separate experiments were conducted [Livak and Schmittgen, 2001]. The immune infiltration analysis for up and down regulated hub genes have been conducted with the scatter plot in TIMER (https://cistrome.shinyapps.io/timer/) [Li et al. 2017] is a RNA-Seq expression profiling database from The Cancer Genome Atlas (TCGA) portal. Immune infiltration analysis was used to check the immune infiltrates (B cells, CD4+ T cells, CD8+ T cells, neutrophils, macrophages, and dendritic cells) across hepatoblastoma.

\section{Results}

\section{Data pre-processing}

Gene expression profile (GSE131329) was collected from the GEO database. A total of 67 samples included 53 hepatoblastoma tissues samples and 14 noncancerous liver tissue samples. The dataset was then performed normalization and batch effect correction (Fig. 1A and 1B).

\section{DEGs analysis}

The series from each chip was analyzed separately using limma in R software, and finally, the DEGs, using adjusted $\mathrm{P}$ value $<0.05$ and log foldchange $(\mathrm{FC}) \mid>$ 1.07 for up regulated genes; $\mid \log$ foldchange $(\mathrm{FC}) \mid<-1.25$ for down regulated genes as the cut-off criteria, were identified. A total of 996 DEGs, including 499 up regulated genes and 497 down regulated genes, were detected in hepatoblastoma are listed in Table 2. The heatmap of the up and down regulated hub genes are shown in Fig. 2 and Fig. 3. The volcano plot of gene expression profile data was shown in Fig. 4.

\section{Pathway enrichment analysis of DEGs}

Pathway enrichment analyses for the up regulated and down regulated genes were performed by ToppGene. The up regulated genes were mainly enriched in proline biosynthesis, epoxysqualene biosynthesis, alcoholism, cell cycle, HDACs deacetylate histones, sterol biosynthesis, urea cycle and metabolism of 
medRxiv preprint doi: https://doi.org/10.1101/2020.12.22.20248756; this version posted December 26, 2020. The copyright holder for this

amino groups, PLK1 signaling events, aurora B signaling, CDK regulation of DNA replication, Wnt/beta-catenin pathway, Wnt signaling pathway, DNA replication, G2/M DNA damage checkpoint, steroid biosynthetic, lysinuric protein intolerance and risedronate pathway are listed in Table 3. Similarly, the down regulated genes were mainly enriched in superpathway of tryptophan utilization, bile acid biosynthesis, neutral pathway, metabolic pathways, complement and coagulation cascades, ATF-2 transcription factor network, IL6mediated signaling events, biological oxidations, complement cascade, fatty acid metabolism, tryptophan metabolism, complement pathway, intrinsic prothrombin activation pathway, blood coagulation, pyrimidine metabolism, tryptophan metabolic, statin pharmacokinetics pathway, enoxaparin pathway and glycine, serine and threonine metabolism are listed Table 4.

\section{GO enrichment analysis of DEGs}

The enriched GO terms for up and down regulated genes, which are expressed by biological process (BP), cellular component (CC) and molecular function (MF), are shown in Table 5 and Table 6. The GO functional annotation analysis of these up regulated genes revealed that (1) the BPs were mainly involved in chromosome organization and DNA conformation change, (2) the CCs of the altered genes were mainly involved in DNA packaging complex and chromosomal region, and (3) the MFs were mainly involved in DNA binding, bending and protein dimerization activity. Similarly, GO functional annotation analysis of these down regulated genes revealed that (1) the BPs were mainly involved in organic acid metabolic process and small molecule catabolic process, 2) the CCs of the altered genes were mainly involved in blood microparticle and endoplasmic reticulum membrane, and (3) the MFs were mainly involved in cofactor binding and oxidoreductase activity.

\section{Construction of the PPI network and module analysis}

To further explore the biological role of overlapping up and down regulated genes, a PPI network was created using the IID database. The PPI network for up regulated genes consisted of 4396 nodes and 7665 interactions (Fig. 5). The 12 up regulated hub genes TP53, TCTN2, PLK1, AURKA, CDK1, ANLN, TRIM28, BMP4, PLPPR1, FOXRED2, SERPINE2 and EFNA4 were screened with the highest node degree distribution, betweenness centrality, stress centrality, closeness centrality and lowest clustring coefficient using Cytoscape software (Table 6), and scatter plot along with statistical results for node degree 
medRxiv preprint doi: https://doi.org/10.1101/2020.12.22.20248756; this version posted December 26, 2020. The copyright holder for this

distribution, betweenness centrality, stress centrality, closeness centrality and clustring coefficient are presented in Fig. 6A - 6E. These up regulated hub genes were enriched in cell cycle, chromosome organization, metabolism of proteins, gene expression, nuclear division, DNA metabolic process, pathways in cancer, integral component of plasma membrane, ensemble of genes encoding extracellular matrix and extracellular matrix-associated proteins, and generation of neurons. Similarly, PPI network for down regulated genes consisted of 5582 nodes and 10377 interactions (Fig. 7). The 12 down regulated hub genes ESR1, LRRK2, AR, FOS, ICAM1, CLU, MYO1B, NPY1R, SLC22A1, FGGY, SLC10A1 and CYP4X1 were screened with the highest node degree distribution, betweenness centrality, stress centrality, closeness centrality and lowest clustring coefficient using Cytoscape software (Table 6), and scatter plot along with statistical results for node degree distribution, betweenness centrality, stress centrality, closeness centrality and clustring coefficient are presented in Fig. 8A - 8E. These down regulated hub genes were enriched in lipid metabolic process, oxidation-reduction process, response to lipid, ATF-2 transcription factor network, NF-kappa B signaling pathway, complement and coagulation cascades, ion transport, intrinsic component of plasma membrane, identical protein binding, metabolism of lipids and lipoproteins, and superpathway of tryptophan utilization.

The PEWCC1 plug-in was also used to identify significant modules. As a result, 4 significant modules (up and down regulated genes) were identified. Modules (Module 6, Module 9, Module 36 and Module 43) for up regulated genes consisted of 137 nodes and 302 edges, 128 nodes and 130 edges, 55 nodes and 103 edges, and 46 nodes and 145 edges are shown in Fig. 9. These modules included up regulated hub genes such as RRM2, PBK, CHEK1, CDC25C, SKP2, TP53, KIF11, CCNA2, CCNB2, CDK1, TOP2A, CDC6, SORT1, FOXM1, CCNB1, CDC20, RACGAP1, RCN2, CAD, HJURP, HDAC11, IGF2BP3, BUB1, NDC80, SKA1, SPC25, NUF2, SPC24, PLK1, MCM7, MCM5, ASF1B, MCM4, MCM6, MCM3, FOXQ1, MCM2 and MMS22, which exhibited the highest score. These up regulated hub genes were enriched in superpathway of pyrimidine deoxyribonucleotides de novo biosynthesis, nuclear division, cell cycle, nuclear division, pathways in cancer, chromosome organization, cell division, DNA double-strand break repair, HTLV-I infection, $\mathrm{M}$ phase, metabolism of proteins, E2F transcription factor network, p75(NTR)mediated signalling, FOXM1 transcription factor network, gene expression, RHO GTPase effectors, aurora B signalling, metabolic pathways, DNA 
medRxiv preprint doi: https://doi.org/10.1101/2020.12.22.20248756; this version posted December 26, 2020. The copyright holder for this

conformation change, alcoholism, PLK1 signaling events, regulation of cell cycle, chromosomal region, protein-containing complex binding, spindle, CDK regulation of DNA replication, DNA metabolic process, embryo development, C-MYB transcription factor network, cellular protein-containing complex assembly, microtubule cytoskeleton, nuclear chromatin, and DNA binding, bending. Modules (Module 6, Module 7, Module 9 and Module 10) for up regulated genes consisted of 147 nodes and 158 edges, 116 nodes and 134 edges, 107 nodes and 113 edges, and 105 nodes and 118 edges are shown in Fig. 10. These modules included down regulated hub genes such as C7, FOS, C8B, PON1, CLU, FGB, CTH, FGG, LPA, USP2, RNF125, HOOK1, PLA2G2A, MAP3K5, GADD45B, SOCS3, MACF1 and GLRX, which exhibited the highest score. These down regulated hub genes were enriched in complement and coagulation cascades, ATF-2 transcription factor network, defense response, metabolic pathways, lipid metabolic process, response to metal ion, organic acid metabolic process, IL6-mediated signaling events, amb2 integrin signalling, ion transport, endoplasmic reticulum membrane, identical protein binding, glypican 1 network, p38 MAPK signaling pathway, response to other organism, golgi apparatus oxidation-reduction process.

\section{Construction of target genes - miRNA regulatory network}

We constructed a target genes - miRNA regulatory network, and the network is shown in Fig. 11 and Fig. 12, which illustrates that certain miRNAs play important roles in regulating up and down regulated genes. In Fig. 11, nodes with greater degrees tend to be up regulated target genes. In this network, PLAGL2 was targeted by the 189 miRNAs (ex, hsa-mir-4710), CDK6 was targeted by the 188 miRNAs (ex, hsa-mir-4657), CCND2 was targeted by the 179 miRNAs (ex, hsa-mir-5192), SLC1A5 was targeted by the 174 miRNAs (ex, hsa-mir-4284) and PKM was targeted by the 160 miRNAs (ex, hsa-mir4525) are listed in Table 7. These up regulated target genes were enriched in nuclear chromatin, cell cycle, nuclear division, integral component of plasma membrane and glycolysis. In Fig. 12, nodes with greater degrees tend to be down regulated target genes. In this network, SOD2 was targeted by the 257 miRNAs (ex, hsa-mir-4803), WEE1 was targeted by the 182 miRNAs (ex, hsamir-4647), SULT1B1 was targeted by the 131 miRNAs (ex, hsa-mir-3163), APOL6 was targeted by the 127 miRNAs (ex, hsa-mir-4455) and DHODH was targeted by the 119 miRNAs (ex, hsa-mir-1200) are listed in Table 7. These 
medRxiv preprint doi: https://doi.org/10.1101/2020.12.22.20248756; this version posted December 26, 2020. The copyright holder for this

down regulated target genes were enriched in peroxisome, biological oxidations, lipid binding and metabolic pathways.

\section{Construction of target genes - TF regulatory network}

We constructed a target gene - TF regulatory network, and the network is shown in Fig. 13 and Fig. 14, which illustrates that certain TFs play important roles in regulating up and down regulated genes. In Fig. 13, nodes with greater degrees tend to be up regulated target genes. In this network, DCDC2 was targeted by the 121 TFs (ex, KLF9), WFS1 was targeted by the 120 TFs (ex, TFDP1), ERCC2 was targeted by the 117 TFs (ex, ZNF580), DLX5 was targeted by the 107 TFs (ex, MXD3) and CCNB1 was targeted by the 105 TFs (ex, SMAD5) are listed in Table 8. These up regulated target genes were enriched in generation of neurons, metabolism of proteins, gene expression, embryo development and cell cycle. In Fig. 14, nodes with greater degrees tend to be down regulated target genes. In this network, MASP2 was targeted by the 115 TFs (ex, ATF3), OTC was targeted by the 82 TFs (ex, YY1), ACMSD was targeted by the 76 TFs (ex, MYBL2), AGXT was targeted by the 76 TFs (ex, MBD4) and SLC15A1 was targeted by the 76 TFs (ex, HNF4G) are listed in Table 8. These down regulated target genes were enriched in complement and coagulation cascades, metabolic pathways, superpathway of tryptophan utilization, glycine biosynthesis and ion transport.

\section{Validation of hub genes}

To explore the prognostic role of up and down regulated hub genes, we analyzed the relationship between mRNA expression and overall survival (OS) using the UALCAN online tool. Interestingly, we found that high expression of TP53, PLK1, AURKA, CDK1 and ANLN were resulted in shorter OS in hepatoblastoma patients (Fig. 15), whereas low expression of ESR1, FGB, ACAT1, GOT1 and ALAS1 were resulted in shorter OS in hepatoblastoma patients (Fig. 16). To further validate the results, we examined the expression of ten hub genes using the UALCAN database. The expression levels of five up regulated hub genes (TP53, PLK1, AURKA, CDK1 and ANLN) and five down regulated hub genes (ESR1, FGB, ACAT1, GOT1 and ALAS1) were significantly different between hepatoblastoma samples and noncancerous liver samples (Fig. 17). The expression trends of the ten hub genes were consistent with the results we obtained. The stage analyses of TP53, PLK1, AURKA, CDK1, ANLN, ESR1, FGB, ACAT1, GOT1 and ALAS1 in human tissues were 
medRxiv preprint doi: https://doi.org/10.1101/2020.12.22.20248756; this version posted December 26, 2020. The copyright holder for this

visualized using UALCAN online tool. The present study revealed that TP53, PLK1, AURKA, CDK1 and ANLN exhibited higher expression levels in all stage of hepatoblastoma compared with the noncancerous liver samples (Fig. 18 A-E), whereas ESR1, FGB, ACAT1, GOT1 and ALAS1 exhibited lower expression levels in all stage of hepatoblastoma compared with the noncancerous liver samples (Fig. 18 F-J). We explored the genetic mutations of up and down regulated hub genes using the cBioPortal tool in TCGA data and found that TP53 (32\%), PLK1 (0.3\%), AURKA (2\%), CDK1 (0.6\%), ANLN (1.7\%), ESR1 (2.8\%), FGB (2\%), ACAT1 (1.1\%), GOT1 (0.8\%) and ALAS1 $(1.1 \%)$ were the most frequently muted genes in the ten query genes, including inframe mutation (putative driver), missense mutation (putative driver), truncating mutation (putative driver), deep deletion, missense mutation (unknown significance), amplification, truncating mutation (unknown significance) and fusion (Fig. 19). Based on the immunohistochemical staining results from HPA database, the protein expression level of TP53, PLK1, AURKA, CDK1 and ANLN was consistent with their gene expression, that is, the protein levels of hub genes were also in a higher expression state in hepatoblastoma tissues compared to noncancerous liver (Fig. 20 A-E), whereas the protein expression level of ESR1, FGB, ACAT1, GOT1 and ALAS1 was consistent with their gene expression, that is, the protein levels of hub genes were also in a lower expression state in hepatoblastoma tissues compared to noncancerous liver (Fig. 20 F-J). ROC curve analysis revealed that five up regulated hub genes (TP53, PLK1, AURKA, CDK1 and ANLN) and five down regulated hub genes (ESR1, FGB, ACAT1, GOT1 and ALAS1) serve valuable biomarkers for distinguishing hepatoblastoma from those with noncancerous liver, with the AUC exceeded 0.90 (Fig. 21). For up regulated genes, the AUC was 0.934 for TP53, 0.973 for PLK1, 0.956 for AURKA, 0.976 for CDK1 and 0.942 for ANLN. For down regulated genes, the AUC was 0.950 for ESR1, 0.950 for FGB, 0.957 for ACAT1, 0.972 for GOT1 and 0.933 for ALAS1. Consistent with the bioinformatics analysis results, the RT-PCR results revealed. As shown in Fig. 22, the expression levels of TP53, PLK1, AURKA, CDK1 and ANLN were significantly higher in the hepatoblastoma than in the noncancerous liver, whereas expression levels of ESR1, FGB, ACAT1, GOT1 and ALAS1 were significantly lower in the hepatoblastoma than in the noncancerous liver. Immune infiltration analysis was found that the high expression level of TP53, PLK1, AURKA, CDK1 and ANLN were all negatively associated with tumor purity (Fig. 23 A-E), whereas low expression 
medRxiv preprint doi: https://doi.org/10.1101/2020.12.22.20248756; this version posted December 26, 2020. The copyright holder for this

level of ESR1, FGB, ACAT1, GOT1 and ALAS1 were all positively associated with tumor purity (Fig. 23 F-J). This finding further confirmed the key role of these up and down regulated hub genes probably expressed not in the microenvironment, but expressed in the tumor cells. These findings further confirmed the key role of these up and down regulated hub genes in the onset of hepatoblastoma.

\section{Discussion}

Presently, the speedy forward in microarray and high-throughput technologies has spread the function biomedicine in clinical practice, such as cancer initial diagnosis, new targeted drug exploration and prognosis prediction. GEO database, as a public repository for archiving high-throughput microarray experimental gene expression data, has contributed the dynamic tools to resolve important genes and pathways linked with the molecular pathogenesis of tumors [Wu et al. 2019]. In the current investigation, based on the GEO database, single gene expression profile including 53 hepatoblastoma tissues samples and 14 noncancerous liver tissue samples were integrated for a comprehensive bioinformatics analysis. The aim of our investigation was to identify the possible small molecule drugs for the treatment of hepatoblastoma and to determine the new biomarkers correspond with the molecular pathogenesis and prognosis of hepatoblastoma. A total of 996 DEGs between hepatoblastoma tissues and corresponding noncancerous liver tissues were diagnosed, which consisted of 499 up regulated genes and 497 down regulated genes. Genes such as DLK1 [Falix et al. 2012] and EPCAM (epithelial cell adhesion molecule) [Lopez-Nunez et al. 2019] were linked with development of hepatoblastoma. Genes such as NKD1 [Wang et al. 2017] and TNFRSF19 [Guo et al. 2020] were liable for proliferation of hepatocellular carcinoma cells, but these genes may be linked with development of proliferation of hepatoblastoma cells. NPNT (nephronectin) was associated with invasion of breast cancer cells [Wang et al. 2018], but this gene may be responsible for invasion of hepatoblastoma cells. Decrease expression of tumour suppressor genes such as C3P1 [Zhong et al. 2018], SLC22A1 [Grimm et al. 2016], RDH16 [Zhu et al. 2020], HAO2 [Mattu et al. 2016] and GLS2 [Kuo et al. 2016] were linked with progression of hepatocellular carcinoma, but low expression of these genes may associated with invasion of hepatoblastoma cells.

Pathway enrichment analyses were performed using the 499 up regulated genes to elucidate the action of hepatoblastoma. PYCR1 was associated with 
medRxiv preprint doi: https://doi.org/10.1101/2020.12.22.20248756; this version posted December 26, 2020. The copyright holder for this

metabolism in hepatocellular carcinoma [Zhuang et al. 2019], but this gene may be liable for linked with metabolism in hepatoblastoma. Enriched genes such as ALDH18A1 [Guo et al. 2020] and HDAC11 [Thole et al. 2017] were linked with development of neuroblastoma, but these genes may be involved in progression of hepatoblastoma. Enriched methylated enriched genes such as GNG4 [Pal et al. 2016], CCND2 [Tsutsui et al. 2010], CDH13 [Moelans et al. 2011] and HELLS (helicase, lymphoid specific) [Law et al. 2019] were liable for progression of various cancer types, but these methylated genes may be important for advancement of hepatoblastoma. Enriched genes such as KIF18A [Luo et al. 2018], MCM6 [Liu et al. 2018], SKA1 [Xiao et al. 2019] and ACTG2 [Wu et al. 2017] were involved in invasion of hepatocellular carcinoma cells, but these genes may be associated with invasion of hepatoblastoma cells. Enriched genes such as PTTG1 [Lin et al. 2019], CENPF (centromere protein F) [Li et al. 2018], HJURP (Holliday junction recognition protein) [Chen et al. 2018], MCM2 [Yang et al. 2018], MCM7 [Qu et al. 2017], RRM2 [Wang et al. 2016], SGO1 [Wang et al. 2015], NDC80 [Ju et al. 2017], FOXM1 [Yu et al. 2016], SKP2 [Wei et al. 2018], TPX2 [Chen et al. 2018], PLK4 [Bao et al. 2018], NUF2 [Wang et al. 2019], CENPK (centromere protein K) [Wang et al. 2019], NCAPG (non-SMC condensin I complex subunit G) [Zhang et al. 2018], BUB1 [Xu et al. 2017], E2F5 [Sun et al. 2016], RFC3 [Yao et al. 2015], NCAPH (non-SMC condensin I complex subunit H) [Sun et al. 2019], CCNB1 [Gu et al. 2019], CDK1 [Gao et al. 2018], CDC25C [Sun et al. 2015], MAD2L1 [Li et al. 2017], CDK6 [Zhu et al. 2016], DKK1 [Zhang et al. 2016], DKK4 [Chouhan et al. 2016], DKK2 [Lin et al. 2016] and LEF1 [Hu et al. 2018] were important for proliferation of hepatocellular carcinoma cells, but these genes may be involved in proliferation of hepatoblastoma cells. High expression of enriched genes such as SPC25 [Chen et al. 2018], MCM4 [Xie et al. 2017], TYMS (thymidylatesynthetase) [Lee et al. 2013], KNTC1 [Liu et al. 2019] and CDH11 [Chen et al. 2018] were responsible for advancement of various cancer types, but over expression these gene may be liable for progression of hepatoblastoma. Elevated expression of enriched genes such as MCM3 [Meng et al. 2019], CHEK1 [Gong et al. 2020], SPC24 [Zhu et al. 2015], MYBL2 [Guan et al. 2018], KIF20A [Lu et al. 2018], CCNB2 [Li et al. 2019], CDC20 [Zhuang et al. 2018], SQLE (squaleneepoxidase) [Liu et al. 2018], ECT2 [Yu et al. 2019], SFRP4 [Xu et al. 2015], FRZB (frizzled related protein) [Shen et al. 2015] and BCL9 [Xu et al. 2017] were associated with advancement of hepatocellular carcinoma, but over expression of these genes may be linked 
medRxiv preprint doi: https://doi.org/10.1101/2020.12.22.20248756; this version posted December 26, 2020. The copyright holder for this

with development of hepatoblastoma. Enriched genes such as MCM5 [Mio et al. 2016], PRIM1 [Lee et al. 2019], GINS2 [Chi et al. 2020], GINS1 [Tang et al. 2019] and CCNA2 [Li et al. 2019] were responsible for proliferation of various cancer types, but these genes may be linked with proliferation of hepatoblastoma cells. Mutation in TUBG1 was liable for advancement of breast cancer [Blanco et al. 2015], but alteration in this gene may be liable for progression of hepatoblastoma. Enriched genes such as PLK1 [Yamada et al. 2004], AURKA (aurora kinase A) [Zhang et al. 2018], TP53 [Yang et al. 2019], CDK4 [Kim et al. 1998] and AXIN2 [Koch et al. 2004] were involved in development of hepatoblastoma. Enriched genes such as POLE2 [Li et al. 2018], CENPI (centromere protein I) [Ding et al. 2018] and SPDL1 [Kodama et al. 2019] were responsible for invasion of various cancer cell types, but these genes may be involved in invasion of hepatoblastoma cells. Single nucleotide polymorphism (SNP) in CDC6 was liable for advancement of hepatocellular carcinoma [Xiong et al. 2009], but this polymorphic gene may be involved in development of hepatoblastoma. Our study found that $\mathrm{H} 4 \mathrm{C}$, $\mathrm{H} 2 \mathrm{AC} 15$, H2AC14, H2AC16, H2AC6, H2AC4, H2AC17, H2AC20, H2BC8, H2BC13, Н2BC14, Н2BC7, Н2BC6, Н2BC9, Н2BC10, Н3С1, Н3С3, Н3С6, Н3С11, H3C8, H3C12, H3C10, H3C2, H4C4, H4C2, H4C5, H4C13, H4C14, MACROH2A2, H2AC12, H2AC21, H3C7, H2AC11, H2AC8, H2AZ1, H2BC5, H2BC3, MND1, RPS27, NCAPD2, RHNO1, FDFT1, MYH7B, MYCN (MYCN proto-oncogene, bHLH transcription factor) and SLC7A6 are up regulated in hepatoblastoma and has potential as a novel diagnostic and prognostic biomarker, and therapeutic target. Similarly, pathway enrichment analyses were performed using the 497 down regulated genes to elucidate the action of hepatoblastoma. SNP in enriched genes such as ADH1B [Shih et al. 2018], NAT2 [Farker et al. 2003], CYP1A1 [Abo-Hashem et al. 2016], CYP2D6 [Agundez et al. 1996], GSTA1 [Akhdar et al. 2016], MBL2 [Wang et al. 2016] C6 [Wang et al. 2016] and SERPINE1 [Divella et al. 2015] were linked with advancement of hepatocellular carcinoma, but these polymorphic genes may be responsible for progression of hepatoblastoma. Enriched genes such as KMO (kynurenine 3-monooxygenase) [Jin et al. 2015], HMGCS2 [Wang et al. 2019], LIPG (lipase G, endothelial type) [Cadenas et al. 2019], PON3 [Cai et al. 2016], AASS (aminoadipate-semialdehyde synthase) [Xue et al. 2019], PCK2 [Liu et al. 2012], PPARGC1A [Wang et al. 2018] and JUNB (JunB proto-oncogene, AP-1 transcription factor subunit) [Kim et al. 2001] were associated with proliferation of hepatocellular carcinoma cells, but these 
medRxiv preprint doi: https://doi.org/10.1101/2020.12.22.20248756; this version posted December 26, 2020. The copyright holder for this

genes may be associated with proliferation of hepatoblastoma cells. Enriched genes such as CYP1A2 [Biazi et al. 2017], ADH4 [Wei et al. 2012], ACSL1 [Cui et al. 2014], UGT2B4 [Wijayakumara et al. 2017], ALDH1A1 [Yan et al. 2016], PON1 [Shu et al. 2017], ASS1 [Frulio et al. 2019], AKR1D1 [Nikolaou et al. 2019], PTGS2 [Chen et al. 2019], NNMT (nicotinamide Nmethyltransferase) [Kim et al. 2009], GPT (glutamic--pyruvic transaminase) [Shimokawa et al. 1977], NNT (nicotinamide nucleotide transhydrogenase) [Lu et al. 2017] and PCK1 [Xiang et al. 2020] were linked with metabolic activity in hepatocellular carcinoma, but these genes may be involved in metabolic activity in hepatoblastoma. Low expression of enriched genes such as CYP2C19 [Ashida et al. 2018], ABAT (4-aminobutyrate aminotransferase) [Jansen et al. 2015], ACOX1 [Chen et al. 2018], ACSM3 [Ruan et al. 2017], FBP1 [Liu et al. 2018], ST3GAL6 [Souady et al. 2011], AGXT (alanine--glyoxylate and serine-pyruvate aminotransferase) [Sun et al. 2019], ALDOB (aldolase, fructosebisphosphate B) [Tao et al. 2015], ALDH6A1 [Shin et al. 2020], XDH (xanthine dehydrogenase) [Chen et al. 2017], OGDHL (oxoglutarate dehydrogenase like) [Jiao et al. 2019], CYP2C8 [Li et al. 2019], CYP2C9 [Yu et al. 2015], CYP3A5 [Jiang et al. 2015], BHMT (betaine--homocysteine Smethyltransferase) [Jin et al. 2016], TAT (tyrosine aminotransferase) [Fu et al. 2010], SLC27A5 [Gao et al. 2020], GYS2 [Chen et al. 2019], GLYAT (glycineN-acyltransferase) [Matsuo et al. 2012], CES3 [Quiroga et al. 2016], MASP2 [Ding et al. 2014], C7 [Seol et al. 2016] and F11 [Du et al. 2019] were involved in progression of hepatocellular carcinoma, but decrease expression these genes may be identified with growth of hepatoblastoma. Enriched genes such as SULT1A2 [Fernandez-Santander et al. 2013], PIK3C2G [Li et al. 2015], AGL (amylo-alpha-1, 6-glucosidase, 4-alpha-glucanotransferase) [Richmond et al. 2018], UGT2B10 [Lu et al. 2018], CTH (cystathionine gamma-lyase) [Xu et al. 2020] and CYP26A1 [Osanai and Lee, 2015] were involved in metabolic activity of various cancer types, but these genes may liable for metabolic activity of in hepatoblastoma. Enriched genes such as TDO2 [Pham et al. 2018], EPHX2 [Vainio et al. 2011], PLA2G2A [Ganesan et al. 2008], INPP1 [Li et al. 2019], GCH1 [Gao et al. 2016], GNE (glucosamine (UDP-N-acetyl)-2epimerase/N-acetylmannosamine kinase) [Kemmner et al. 2012], PAPSS2 [Zhang et al. 2019], GLYATL1 [Eich et al. 2019], CFB (complement factor B) [Kim et al. 2019], C1R [Riihilä et al. 2020], C1S [Riihilä et al. 2020], C9 [Chong et al. 2010], FGB (fibrinogen beta chain) [Repetto et al. 2018] and KNG1 [Quesada-Calvo et al. 2017] were linked with development of various 
medRxiv preprint doi: https://doi.org/10.1101/2020.12.22.20248756; this version posted December 26, 2020. The copyright holder for this

cancer types, but these genes may be culpable for advancement of hepatoblastoma. Methylation inactivation of tumor suppressor enriched genes such as HAAO (3-hydroxyanthranilate 3,4-dioxygenase) [Huang et al. 2010] and AOX1 [Vantaku et al. 2019] were identified with growth of various cancer types, but loss of these genes may be liable for progression of hepatoblastoma. Epigenetic inactivation of enriched tumor suppressor genes such as CDO1 [Choi et al. 2017], DUSP5 [Liu et al. 2017] and SOCS3 [Zhang et al. 2015] were liable for progression of hepatocellular carcinoma, but loss of these genes may be linked with development of hepatoblastoma. Enriched genes such as SGMS2 [Zheng et al. 2019], ACAT1 [Ye et al. 2016], UGP2 [Zeng et al. 2019], GOT1 [Wang et al. 2019], CDA (cytidinedeaminase) [Ye et al. 2015] and FOS (Fos proto-oncogene, AP-1 transcription factor subunit) [Liu et al. 2018] were important for proliferation of various cancer cells types, but these genes may be involved in proliferation of hepatoblastoma cells. SNP in enriched genes such as MAT1A [Mumbrekar et al. 2017], ADH1C [Hidaka et al. 2015], UGT2B7 [Sutiman et al. 2016], HSD11B1 [Wang et al. 2013], CYP2B6 [Kuo et al. 2017], CHST9 [Yuan et al. 2017], CYP39A1 [Melchardt et al. 2015], FMO3 [Bae et al. 2006], CYP3A43 [Han et al. 2015], CYP4F3 [Yin et al. 2017], CYP4F11 [Cardenas-Rodriguez et al. 2012], SULT2A1 [Wilborn et al. 2006], GSTA2 [Maekawa et al. 2011] and GSTA3 [Duan et al. 2018] were involved in progression of various cancer types, but these polymorphic genes may be linked with development of hepatoblastoma. Enriched genes such as MGLL (monoglyceride lipase) [Yang et al. 2018], DMGDH (dimethylglycine dehydrogenase) [Liu et al. 2016], SHMT1 [Dou et al. 2019], ARG1 [You et al. 2018], CXCL8 [Li et al. 2015] and FGG (fibrinogen gamma chain) [Zhang et al. 2019] were involved in invasion of hepatocellular carcinoma cells, but these genes may be responsible for invasion of hepatoblastoma cells. Enriched genes such as CYP3A4 [Holownia and Braszko, 2004], OTC (ornithine carbamoyltransferase) [Mavri-Damelin et al. 2007] and DUSP1 [Casteel et al. 2010] were associated with development of hepatoblastoma. GCLM (glutamatecysteine ligase modifier subunit) was linked with drug resistance in lung cancer [Nishi et al. 2005], but this gene may be linked with chemoresitance in hepatoblastoma. Our study found that CYP4X1, KYNU (kynureninase), ACMSD (aminocarboxymuconatesemialdehyde decarboxylase), HGD (homogentisate 1,2-dioxygenase), ACACB (acetyl-CoA carboxylase beta), ACADL (acyl-CoA dehydrogenase long chain), ACADSB (acyl-CoA dehydrogenase short/branched chain), CES1, PIPOX (pipecolic acid and 
medRxiv preprint doi: https://doi.org/10.1101/2020.12.22.20248756; this version posted December 26, 2020. The copyright holder for this

sarcosine oxidase), AKR1C4, HAO1, NDST3, HPD (4-hydroxyphenylpyruvate dioxygenase), SCP2, ALAS1, ALPL (alkaline phosphatase, biomineralization associated), AGPAT2, CYP4F2, ETNPPL (ethanolamine-phosphate phospholyase), GBA3, AGXT2, GDA (guanine deaminase), HSD17B6, LPIN2, MMUT (methylmalonyl-CoA mutase), UPB1, CYP2C18, MBOAT1, CYP4A11, CYP8B1, BAAT (bile acid-CoA:amino acid N-acyltransferase), GATM (glycine amidinotransferase), DAO (D-amino acid oxidase), UROC1, SUCLG2, PTS (6-pyruvoyltetrahydropterin synthase), DHODH (dihydroorotate dehydrogenase (quinone)), ACSM5, SDS (serine dehydratase), CNDP1, DPYS (dihydropyrimidinase), GPAT3, AMDHD1, NAMPT (nicotinamidephosphoribosyltransferase), EHHADH (enoyl-CoA hydratase and 3-hydroxyacyl CoA dehydrogenase), HAL (histidine ammonia-lyase), AADAT (aminoadipate aminotransferase), AADAC (arylacetamidedeacetylase), AKR7L, CYP4F22, SULT1B1, CYP4V2, CYP4A22, ACADM (acyl-CoA dehydrogenase medium chain), C5, C8A, F8, F9, F13B, SERPINC1 and KLKB1 are down regulated in hepatoblastoma and has potential as a novel diagnostic and prognostic biomarker, and therapeutic target.

GO enrichment analyses were performed using the 499 up regulated genes to elucidate the action of hepatoblastoma. Enriched genes such as NUSAP1 [Garrido-Rodríguez et al. 2019], ASF1B [Han et al. 2018] and PRKAA2 [Zhang et al. 2020] were associated with proliferation of various cancer types cells, but these genes may be linked with proliferation of hepatoblastoma cells. SNP in enriched genes such as ERCC2 [Zhao et al. 2019] and MSH2 [Zhu et al. 2018] were involved in progression of hepatocellular carcinoma, but these polymorphic genes may be linked with development of hepatoblastoma. Enriched genes such as TTK (TTK protein kinase) [Miao et al. 2016], MKI67 [Yang et al. 2017], TET1 [Lin et al. 2015], DLGAP5 [Liao et al. 2013] and SMYD2 [Zuo et al. 2018] were involved in proliferation of hepatocellular carcinoma cells, but these genes may be responsible for proliferation of hepatoblastoma cells. Over expression of USP21 was liable for progression of pancreatic cancer [Hou et al. 2019], but high expression of this gene may be linked with advancement of hepatoblastoma. Increased expression of enriched genes such as RACGAP1 [Wang et al. 2011], PRKD1 [Döppler et al. 2016], EHMT2 [Song et al. 2019], KIFC1 [Han et al. 2019], TERC (telomerase RNA component) [Baena $\square$ Del et al. 2018], TRIM28 [Jin et al. 2017] and TOP2A [Panvichian et al. 2015] were involved in progression of hepatocellular carcinoma, but over expression these genes may be associated 
medRxiv preprint doi: https://doi.org/10.1101/2020.12.22.20248756; this version posted December 26, 2020. The copyright holder for this

with advancement of hepatoblastoma. Enriched genes such as UHRF1 [Beck et al. 2018] and HMGA2 [Li et al. 2020] were responsible for advancement of hepatoblastoma. NAP1L1 was linked with chemoresistance in hepatocellular carcinoma [Le et al. 2019], but this gene may liable for drug resistance in hepatoblastoma. PRC1 was associated with invasion of hepatocellular carcinoma cell [Tang et al. 2019], but this gene may be liable for invasion of hepatoblastoma cells. Our study found that NPM3, SUPT3H, PCGF2, H1-2 (H1.2 linker histone, cluster member) and H1-5 (H1.5 linker histone, cluster member) are up regulated in hepatoblastoma and has potential as a novel diagnostic and prognostic biomarker, and therapeutic target. Similarly, GO enrichment analyses were performed using the 497 down regulated genes to elucidate the action of hepatoblastoma. Enriched genes such as HGF (hepatocyte growth factor) [Purcell et al. 2011], ABCB11 [Vilarinho et al. 2014] and TLR4 [Hsiao et al. 2015] were linked with advancement of hepatoblastoma. Enriched genes such as VNN3 [Ha et al. 2019], HPGD (15hydroxyprostaglandin dehydrogenase) [He et al. 2016], VNN2 [Chen et al. 2018], VNN1 [Zhang et al. 2017], GPD1 [Zhou et al. 2017], CFH (complement factor H) [Campa et al. 2015], SERPINA3 [Cao et al. 2018], AFM (afamin) [Shen et al. 2016], HPR (haptoglobin-related protein) [Epelbaum et al. 1998], C4BPA [Sogawa et al. 2016], CYP4Z1 [Zheng et al. 2019], SRD5A1 [Sinreih et al. 2015] and STEAP4 [Xue et al. 2017] were linked with progression of various cancer types, but these genes may be involved in development of hepatoblastoma. Low expression of enriched genes such as ETFDH (electron transfer flavoprotein dehydrogenase) [Wu et al. 2019], GNMT (glycine Nmethyltransferase) [Chen et al. 1998], DCN (decorin) [Ju et al. 2015], ITIH4 [Li et al. 2018], GHR (growth hormone receptor) [Qi et al. 2016], LYVE1 [Kitagawa et al. 2013] and HP (haptoglobin) [Mondal et al. 2016] were identified with development of hepatocellular carcinoma, but decrease expression of these genes may be associated with development of hepatoblastoma. SNP in PRKAG2 was responsible for advancement of colon and rectal cancer [Slattery et al. 2010], but this polymorphic gene may be liable for progression of hepatoblastoma. Enriched genes such as STAB2 [Wu et al. 2018], IGF1 [Shi and Teng, 2015], HRG (histidine rich glycoprotein) [Zhang et al. 2015], CFHR3 [Liu et al. 2020] and CD5L [Aran et al. 2018] were linked with proliferation of hepatocellular carcinoma cells, but these genes may be involved in proliferation of hepatoblastoma cells. Methylation inactivation of ADHFE1 was identified with growth of colorectal cancer [Hu et al. 2019], but 
medRxiv preprint doi: https://doi.org/10.1101/2020.12.22.20248756; this version posted December 26, 2020. The copyright holder for this

loss this gene may be responsible for progression of hepatoblastoma. Enriched genes such as ANGPTL3 [El-Shal et al. 2017], CLU (clusterin) [Zheng et al. 2016], FCN2 [Yang et al. 2016], HPX (hemopexin) [Kobayashi et al. 2012], CP (ceruloplasmin) [Pousset et al. 2001] and BCHE (butyrylcholinesterase) [Yokoyama et al. 1982] were involved in invasion of hepatocellular carcinoma cells, but these genes may be associated invasion of hepatoblastoma cells. Enriched genes such as SLC27A2 [Chen et al. 2018] and ABHD2 [Yamanoi et al. 2016] were important for drug resistance in various cancer types, but these genes may be involved in chemo resistance in hepatoblastoma. Our study found that RIDA (reactive intermediate imine deaminase A homolog), ALDH8A1, PFKFB1, PHYH (phytanoyl-CoA 2-hydroxylase), DHTKD1, IYD (iodotyrosinedeiodinase), APOC3, SLC7A2, ART4, CYP2D7, SLC17A3, AVPR1A, INSIG1, GCKR (glucokinase regulator), APOA5, ASPG (asparaginase), BCO2, CFHR1, APCS (amyloid P component, serum), APOL1, FCN3, C8G, PZP (PZP alpha-2-macroglobulin like), ORM1, ASPDH (aspartate dehydrogenase domain containing) and FMO4 are down regulated in hepatoblastoma and has potential as a novel diagnostic and prognostic biomarker, and therapeutic target.

In PPI network and module analysis, we found out the top up regulated hub genes. Over expression of hub genes such as ANLN (anillin actin binding protein) [Zhang et al. 2018], CHEK1 [Yang et al. 2017], IGF2BP3 [Li et al. 2015] and FOXQ1 [Huang et al. 2015] were linked with progression of hepatocellular carcinoma, but these genes may be involved in the advancement of hepatoblastoma. Hub genes such as BMP4 [Deng et al. 2018] and RCN2 [Ding et al. 2017] were responsible for proliferation of hepatocellular carcinoma cells, but this gene may be associated with proliferation of hepatoblastoma cells. Elevated expression of hub genes such as SERPINE2 [Stępień et al. 2017] and KIF11 [Schneider et al. 2017] were liable for progression of thyroid cancer, but this gene may be identified with growth of hepatoblastom. Our study found that TCTN2, PLPPR1, FOXRED2, EFNA4, SORT1, CAD (carbamoyl-phosphate synthetase 2, aspartate transcarbamylase, and dihydroorotase) and MMS22 are up regulated in hepatoblastoma and has potential as a novel diagnostic and prognostic biomarker, and therapeutic target. Similarly, PPI network and module analysis, we found out the top down regulated hub genes. Methylation inactivation tumor suppressor ESR1 was linked with development of hepatocellular carcinoma [Dou et al. 2016], but loss of this gene may be responsible for progression of hepatoblastom. Low expression of hub genes 
medRxiv preprint doi: https://doi.org/10.1101/2020.12.22.20248756; this version posted December 26, 2020. The copyright holder for this

such as AR (androgen receptor) [Shi et al. 2017] and NPY1R [Lv et al. 2016] were liable for progression of hepatocellular carcinoma, but decrease expression of this gene may be identified with growth of hepatoblastom. Hub genes such as ICAM1 [Guo et al. 2016], LPA (lipoprotein(a)) [Malaguarnera et al. 2017], HOOK1 [Sun et al. 2017] and GADD45B [Xia et al. 2017] were responsible for invasion of hepatocellular carcinoma cells, but this gene may be involved in invasion of hepatoblastom cells. Hub genes such as FGGY (FGGY carbohydrate kinase domain containing) [Zhang et al. 2019], USP2 [Davis et al. 2016] and MAP3K5 [Stark et al. 2011] were involved inprogression of various cancer types, but these gene may be involved in development of hepatoblastom. SNP in SLC10A1 was responsible for advancement of hepatocellular carcinoma [Hu et al. 2016], but this polymorphic gene may associated with development of hepatoblastom. Our study found that LRRK2, MYO1B, C8B, RNF125, MACF1 and GLRX (glutaredoxin) are down regulated in hepatoblastoma and has potential as a novel diagnostic and prognostic biomarker, and therapeutic target.

In target genes - miRNA regulatory network analysis, we found out the top up regulated target genes. High expression of target genes such as PLAGL2 [Xu et al. 2018] and SLC1A5 [Toda et al. 2017] were involved in progression of various cancer types, but elevated expression of these genes may be associated with development of hepatoblastom. Our study found that PKM (pyruvate kinase $\mathrm{M} 1 / 2$ ) is up regulated in hepatoblastoma and has potential as a novel diagnostic and prognostic biomarker, and therapeutic target. Similarly, target genes - miRNA regulatory network analysis, we found out the top down regulated target genes. Decreased expression of target genes such as SOD2 [Wang et al. 2016] and WEE1 [Cuneo et al. 2016] were liable for advancement of hepatocellular carcinoma, but reduced expression these genes may be involved in development of hepatoblastoma. Our study found that APOL6 is down regulated in hepatoblastoma and has potential as a novel diagnostic and prognostic biomarker, and therapeutic target.

In target genes - TF regulatory network analysis, we found out the top up regulated target genes. Methylation inactivation of DCDC2 was responsible for progression of hepatocellular carcinoma [Inokawa et al. 2013], but loss of this gene may be liable for development of hepatoblastoma. Increase expression of DLX5 was important for proliferation of ovarian cancer cells [Tan et al. 2010], but this gene may be associated with proliferation of hepatoblastoma 
medRxiv preprint doi: https://doi.org/10.1101/2020.12.22.20248756; this version posted December 26, 2020. The copyright holder for this

cells. Our study found that WFS1 is up regulated in hepatoblastoma and has potential as a novel diagnostic and prognostic biomarker, and therapeutic target. Similarly, target genes - TF regulatory network analysis, we found out the top down regulated target genes. Our study found that SLC15A1 is down regulated in hepatoblastoma and has potential as a novel diagnostic and prognostic biomarker, and therapeutic target.

Ten candidate genes (TP53, PLK1, AURKA, CDK1, ANLN, ESR1, FGB, ACAT1, GOT1 and ALAS1) that were closely related to the survival rate of patients with hepatoblastoma were diagonised by analyzing the corresponding total survival information from patients with hepatoblastoma from TCGA program. Survival analysis, expression verification, stage analysis, mutation analysis, immunio infiltration analysis and immunio histochemical analysis of these candidate genes were analyzed according to the TCGA database and the human protein atlas database. ROC analysis of these candidate genes were analyzed according to the GSE131329 dataset for prognostic and diagonsitic value of candidate genes. Semelateniously, these ten candidate genes were further verified by RT $\square$ PCR using hepatoblastoma patient samples. Overall, the survival characteristics of the ten candidate genes may suggest the prognosis and diagnosis of hepatoblastoma, and thus may be a promising biomarker and therapeutic target for hepatoblastoma.

In summary, the current study used the GEO database, TCGA database and the human protein atlas database to diagonise ten candidate genes as possible biomarkers for patients with hepatoblastoma and documented the existence of the ten candidate genes by RT $\square$ PCR. The results of the current study provide a potential biomarker for hepatoblastoma screening and diagnosis, therapeutic targets, and prognosis. However, further invedtigations and follow $\square$ up of clinical cases are required to expose the molecular pathogenesis and prognosis of hepatoblastoma.

\section{Acknowledgement}

I thank Eiso Hiyama, Hiroshima University, Natural Science Center for Basic Research and Deve, LIfe Science, Hiroshima, Japan, very much, the author who deposited their microarray dataset, GSE131329, into the public GEO database.

\section{Conflict of interest}

The authors declare that they have no conflict of interest. 


\section{Ethical approval}

This article does not contain any studies with human participants or animals performed by any of the authors.

\section{Informed consent}

No informed consent because this study does not contain human or animals participants.

\section{Availability of data and materials}

The datasets supporting the conclusions of this article are available in the GEO (Gene Expression Omnibus) (https://www.ncbi.nlm.nih.gov/geo/) repository. [(GSE131329)

(https://www.ncbi.nlm.nih.gov/geo/query/acc.cgi?acc=GSE131329]

\section{Consent for publication}

Not applicable.

\section{Funding}

Not applicable

\section{Competing interests}

The authors declare that they have no competing interests.

\section{Author Contributions}

B. V. - Writing original draft, and review and editing

C. V. - Software and investigation

I. K. - Supervision and resources

\section{Authors}

Basavaraj Vastrad

ORCID ID: 0000-0003-2202-7637

Chanabasayya Vastrad

ORCID ID: 0000-0003-3615-4450

Iranna Kotturshetti

ORCID ID: 0000-0003-1988-7345 
medRxiv preprint doi: https://doi.org/10.1101/2020.12.22.20248756; this version posted December 26, 2020. The copyright holder for this

\section{References}

Abo-Hashem EM, El-Emshaty WM, Farag Rel S, Zakaria S, Abd El-Aziz M, Ghonaim A (2016) Genetic Polymorphisms of Cytochrome P4501A1 (CYP1A1) and Glutathione S-Transferase P1 (GSTP1) and Risk of Hepatocellular Carcinoma Among Chronic Hepatitis C Patients in Egypt. Biochem Genet 54:696-713. doi:10.1007/s10528-016-9749-6

Adesina AM, Lopez-Terrada D, Wong KK, Gunaratne P, Nguyen Y, Pulliam J, Margolin J, Finegold MJ (2009) Gene expression profiling reveals signatures characterizing histologic subtypes of hepatoblastoma and global deregulation in cell growth and survival pathways. Hum Pathol 40:843-853. doi:10.1016/j.humpath.2008.10.022

Agundez JA, Olivera M, Ladero JM, Rodriguez-Lescure A, Ledesma MC, Diaz-Rubio M, Meyer UA, Benitez J (1996) Increased risk for hepatocellular carcinoma in NAT2-slow acetylators and CYP2D6-rapid metabolizers. Pharmacogenetics 6:501-512. doi:10.1097/00008571-199612000-00003

Akhdar H, El Shamieh S, Musso O, Désert R, Joumaa W, Guyader D, Aninat C, Corlu A, Morel F (2016) The rs3957357C>T SNP in GSTA1 Is Associated with a Higher Risk of Occurrence of Hepatocellular Carcinoma in European Individuals. PLoS One 11:e0167543. doi:10.1371/journal.pone.0167543

Aktaş S, Zadeoğlulari Z, Erçetin P, Olgun N (2010) The effect of differentiating and apoptotic agents on notch signalling pathway in hepatoblastoma. Hepatogastroenterology 57:891-898.

Aran G, Sanjurjo L, Bárcena C, Simon-Coma M, Téllez É, Vázquez-Vitali M, Garrido M, Guerra L, Díaz E, Ojanguren I et al (2018) CD5L is upregulated in hepatocellular carcinoma and promotes liver cancer cell proliferation and antiapoptotic responses by binding to HSPA5 (GRP78). FASEB J 32:38783891. doi:10.1096/fj.201700941RR

Ashida R, Okamura Y, Ohshima K, Kakuda Y, Uesaka K, Sugiura T, Ito T, Yamamoto Y, Sugino T, Urakami K et al (2018) The down-regulation of the CYP2C19 gene is associated with aggressive tumor potential and the poorer recurrence-free survival of hepatocellular carcinoma. Oncotarget 9:2205822068. doi:10.18632/oncotarget.25178 
medRxiv preprint doi: https://doi.org/10.1101/2020.12.22.20248756; this version posted December 26, 2020. The copyright holder for this

Bae SY, Choi SK, Kim KR, Park CS, Lee SK, Roh HK, Shin DW, Pie JE, Woo ZH, Kang JH (2006) Effects of genetic polymorphisms of MDR1, FMO3 and CYP1A2 on susceptibility to colorectal cancer in Koreans. Cancer Sci 97:774779. doi:10.1111/j.1349-7006.2006.00241.x

Baena $\square$ Del Valle JA, Zheng Q, Esopi DM, Rubenstein M, Hubbard GK, Moncaliano MC, Hruszkewycz A, Vaghasia A, Yegnasubramanian S, Wheelan SJ et al (2018) MYC drives overexpression of telomerase RNA (hTR/TERC) in prostate cancer. J Pathol 244:11-24. doi:10.1002/path.4980

Bao J, Yu Y, Chen J, He Y, Chen X, Ren Z, Xue C, Liu L, Hu Q, Li J et al (2018) MiR-126 negatively regulates PLK-4 to impact the development of hepatocellular carcinoma via ATR/CHEK1 pathway. Cell Death Dis 9:1045. doi:10.1038/s41419-018-1020-0

Beck A, Trippel F, Wagner A, Joppien S, Felle M, Vokuhl C, Schwarzmayr T, Strom TM, von Schweinitz D, Längst G et al (2018) Overexpression of UHRF1 promotes silencing of tumor suppressor genes and predicts outcome in hepatoblastoma. Clin Epigenetics 10:27. doi:10.1186/s13148-018-0462-7

Biazi BI, Zanetti TA, Baranoski A, Corveloni AC, Mantovani MS (2017) CisNerolidol Induces Endoplasmic Reticulum Stress and Cell Death in Human Hepatocellular Carcinoma Cells through Extensive CYP2C19 and CYP1A2 Oxidation. Basic Clin Pharmacol Toxicol 121:334-341. doi:10.1111/bcpt.12772

Blanco I, Kuchenbaecker K, Cuadras D, Wang X, Barrowdale D, De Garibay GR, Librado P, Sánchez-Gracia A, Rozas J, Bonifaci N et al (2015) Assessing associations between the AURKA-HMMR-TPX2-TUBG1 functional module and breast cancer risk in BRCA1/2 mutation carriers. PLoS One 10:e0120020. doi:10.1371/journal.pone.0120020

Breuer K, Foroushani AK, Laird MR, Chen C, Sribnaia A, Lo R, Winsor GL, Hancock RE, Brinkman FS, Lynn DJ (2013) InnateDB: systems biology of innate immunity and beyond--recent updates and continuing curation. Nucleic Acids Res 41:D1228-D1233. doi:10.1093/nar/gks1147

Busweiler LA, Wijnen MH, Wilde JC, Sieders E, van Scheltinga SE, van Heurn LE, Ziros J, Bakx R, Heij HA (2017) Surgical treatment of childhood hepatoblastoma in the Netherlands (1990-2013). Pediatr Surg Int 33:23-31. doi:10.1007/s00383-016-3989-8 
medRxiv preprint doi: https://doi.org/10.1101/2020.12.22.20248756; this version posted December 26, 2020. The copyright holder for this

Cadenas C, Vosbeck S, Edlund K, Grgas K, Madjar K, Hellwig B, Adawy A, Glotzbach A, Stewart JD, Lesjak MS et al (2019) LIPG-promoted lipid storage mediates adaptation to oxidative stress in breast cancer. Int $\mathbf{J}$ Cancer 145:901915. doi:10.1002/ijc.32138

Cai J, Yuan SX, Yang F, Tao QF, Yang Y, Xu QG, Wang ZG, Yu J, Lin KY, Wang ZY et al (2016) Paraoxonase 3 inhibits cell proliferation and serves as a prognostic predictor in hepatocellular carcinoma. Oncotarget 7:70045-70057. doi:10.18632/oncotarget.12145

Campa MJ, Gottlin EB, Bushey RT, Patz EF Jr (2015) Complement Factor H Antibodies from Lung Cancer Patients Induce Complement-Dependent Lysis of Tumor Cells, Suggesting a Novel Immunotherapeutic Strategy. Cancer Immunol Res 3:1325-1332. doi:10.1158/2326-6066.CIR-15-0122

Cao LL, Pei XF, Qiao X, Yu J, Ye H, Xi CL, Wang PY, Gong ZL (2018) SERPINA3 Silencing Inhibits the Migration, Invasion, and Liver Metastasis of Colon Cancer Cells. Dig Dis Sci 63:2309-2319. doi:10.1007/s10620-018-5137$\mathrm{X}$

Cardenas-Rodriguez N, Lara-Padilla E, Bandala C, López-Cruz J, UscangaCarmona C, Lucio-Monter PF, Floriano-Sánchez E (2012) CYP2W1, CYP4F11 and CYP8A1 polymorphisms and interaction of CYP2W1 genotypes with risk factors in Mexican women with breast cancer. Asian Pac J Cancer Prev 13:837846. doi:10.7314/apjcp.2012.13.3.837

Caspi R, Billington R, Ferrer L, Foerster H, Fulcher CA, Keseler IM, Kothari A, Krummenacker M, Latendresse M, Mueller LA et al (2016) The MetaCyc database of metabolic pathways and enzymes and the BioCyc collection of pathway/genome databases. Nucleic Acids Res 44:D471-D480. doi:10.1093/nar/gkv1164

Casteel M, Nielsen C, Kothlow S, Dietrich R, Märtlbauer E (2010) Impact of DUSP1 on the apoptotic potential of deoxynivalenol in the epithelial cell line HepG2. Toxicol Lett 199:43-50. doi:10.1016/j.toxlet.2010.08.004

Chandrashekar DS, Bashel B, Balasubramanya SAH, Creighton CJ, PonceRodriguez I, Chakravarthi BVSK, Varambally S (2017) UALCAN: A Portal for Facilitating Tumor Subgroup Gene Expression and Survival Analyses. Neoplasia 19:649-658. doi:10.1016/j.neo.2017.05.002 
medRxiv preprint doi: https://doi.org/10.1101/2020.12.22.20248756; this version posted December 26, 2020. The copyright holder for this

Chen FD, Chen HH, Ke SC, Zheng LR, Zheng XY (2018) SLC27A2 regulates miR-411 to affect chemo-resistance in ovarian cancer. Neoplasma 65:915-924. doi:10.4149/neo_2018_180122N48

Chen HN, Chen Y, Zhou ZG, Wei Y, Huang C (2019) A novel role for ketoconazole in hepatocellular carcinoma treatment: linking PTGS2 to mitophagy machinery. Autophagy 15:733-734. doi:10.1080/15548627.2019.1569934

Chen GL, Ye T, Chen HL, Zhao ZY, Tang WQ, Wang LS, Xia JL (2017) Xanthine dehydrogenase downregulation promotes TGF $\beta$ signaling and cancer stem cell-related gene expression in hepatocellular carcinoma. Oncogenesis 6:e382. . doi:10.1038/oncsis.2017.81

Chen J, Bardes EE, Aronow BJ, Jegga AG (2009) ToppGene Suite for gene list enrichment analysis and candidate gene prioritization. Nucleic Acids Res 37:W305-W311. doi:10.1093/nar/gkp427

Chen J, Chen H, Yang H, Dai H (2018) SPC25 upregulation increases cancer stem cell properties in non-small cell lung adenocarcinoma cells and independently predicts poor survival. Biomed Pharmacother 100:233-239. doi:10.1016/j.biopha.2018.02.015

Chen PF, Wang F, Nie JY, Feng JR, Liu J, Zhou R, Wang HL, Zhao Q (2018) Co-expression network analysis identified CDH11 in association with progression and prognosis in gastric cancer. Onco Targets Ther 11:6425-6436. doi:10.2147/OTT.S176511

Chen SL, Zhang CZ, Liu LL, Lu SX, Pan YH, Wang CH, He YF, Lin CS, Yang X, Xie D et al (2019) A GYS2/p53 Negative Feedback Loop Restricts Tumor Growth in HBV-Related Hepatocellular Carcinoma. Cancer Res 79:534-545. doi:10.1158/0008-5472.CAN-18-2357

Chen T, Huang H, Zhou Y, Geng L, Shen T, Yin S, Zhou L, Zheng S (2018) HJURP promotes hepatocellular carcinoma proliferation by destabilizing p21 via the MAPK/ERK1/2 and AKT/GSK3 $\beta$ signaling pathways. J Exp Clin Cancer Res 37:193. doi:10.1186/s13046-018-0866-4

Chen XF, Tian MX, Sun RQ, Zhang ML, Zhou LS, Jin L, Chen LL, Zhou WJ, Duan KL, Chen YJ et al (2018) SIRT5 inhibits peroxisomal ACOX1 to prevent 
medRxiv preprint doi: https://doi.org/10.1101/2020.12.22.20248756; this version posted December 26, 2020. The copyright holder for this

oxidative damage and is downregulated in liver cancer. EMBO Rep 19:e45124. doi:10.15252/embr.201745124

Chen Y, Huang T, Yang X, Liu C, Li P, Wang Z, Zhi S (2018) MicroRNA $\square 106 \mathrm{a}$ regulates the proliferation and invasion of human osteosarcoma cells by targeting VNN2. Oncol Rep 40:2251-2259. doi:10.3892/or.2018.6601

Chen YC, Chen IS, Huang GJ, Kang CH, Wang KC, Tsao MJ, Pan HW (2018) Targeting DTL induces cell cycle arrest and senescence and suppresses cell growth and colony formation through TPX2 inhibition in human hepatocellular carcinoma cells. Onco Targets Ther 11:1601-1616. doi:10.2147/OTT.S147453

Chen YM, Shiu JY, Tzeng SJ, Shih LS, Chen YJ, Lui WY, Chen PH (1998) Characterization of glycine-N-methyltransferase-gene expression in human hepatocellular carcinoma. Int J Cancer 75:787-793. doi:10.1002/(sici)10970215(19980302)75:5<787::aid-ijc20>3.0.co;2-2

Chi F, Wang Z, Li Y, Chang N (2020) Knockdown of GINS2 inhibits proliferation and promotes apoptosis through the p53/GADD45A pathway in non-small cell lung cancer. Biosci Rep BSR20193949. doi:10.1042/BSR20193949

Choi JI, Cho EH, Kim SB, Kim R, Kwon J, Park M, Shin HJ, Ryu HS, Park SH, Lee KH (2017) Promoter methylation of cysteine dioxygenase type 1: gene silencing and tumorigenesis in hepatocellular carcinoma. Ann Hepatobiliary Pancreat Surg 21:181-187. doi:10.14701/ahbps.2017.21.4.181

Chong PK, Lee H, Loh MC, Choong LY, Lin Q, So JB, Lim KH, Soo RA, Yong WP, Chan SP et al (2010) Upregulation of plasma C9 protein in gastric cancer patients. Proteomics 10:3210-3221. doi:10.1002/pmic.201000127

Chou CH, Shrestha S, Yang CD, Chang NW, Lin YL, Liao KW, Huang WC, Sun TH, Tu SJ, Lee WH et al (2018) miRTarBase update 2018: a resource for experimentally validated microRNA-target interactions. Nucleic Acids Res 46:D296-D302. doi:10.1093/nar/gkx1067

Chouhan S, Singh S, Athavale D, Ramteke P, Pandey V, Joseph J, Mohan R, Shetty PK, Bhat MK (2016) Glucose induced activation of canonical Wnt signaling pathway in hepatocellular carcinoma is regulated by DKK4. Sci Rep 6:27558. doi:10.1038/srep27558 
medRxiv preprint doi: https://doi.org/10.1101/2020.12.22.20248756; this version posted December 26, 2020. The copyright holder for this

Cruz Jr RJ, Ranganathan S, Mazariegos G, Soltys K, Nayyar N, Sun Q, Bond G, Shaw PH, Haberman K, Krishnamurti L et al (2013) Analysis of national and single-center incidence and survival after liver transplantation for hepatoblastoma: new trends and future opportunities. Surgery 153:150-159. doi:10.1016/j.surg.2012.11.006

Cui M, Wang Y, Sun B, Xiao Z, Ye L, Zhang X (2014) MiR-205 modulates abnormal lipid metabolism of hepatoma cells via targeting acyl-CoA synthetase long-chain family member 1 (ACSL1) mRNA. Biochem Biophys Res Commun 444:270-275. doi:10.1016/j.bbrc.2014.01.051

Cui X, Wang Z, Li J, Zhu J, Ren Z, Zhang D, Zhao W, Fan Y, Zhang D, Sun R (2020) Cross talk between RNA N6-methyladenosine methyltransferase-like 3 and miR-186 regulates hepatoblastoma progression through $\mathrm{Wnt} / \beta$-catenin signalling pathway. Cell Prolif e12768. doi:10.1111/cpr.12768

Cui Y, Lu P, Song G, Liu Q, Zhu D, Liu X (2016) Involvement of PI3K/Akt, ERK and p38 signaling pathways in emodin-mediated extrinsic and intrinsic human hepatoblastoma cell apoptosis. Food Chem Toxicol 92:26-37. doi:10.1016/j.fct.2016.03.013

Cuneo KC, Morgan MA, Davis MA, Parcels LA, Parcels J, Karnak D, Ryan C, Liu N, Maybaum J, Lawrence TS (2016) Wee1 Kinase Inhibitor AZD1775 Radiosensitizes Hepatocellular Carcinoma Regardless of TP53 Mutational Status Through Induction of Replication Stress. Int J Radiat Oncol Biol Phys 95:782-790. doi:10.1016/j.ijrobp.2016.01.028

Dahlquist KD, Salomonis N, Vranizan K, Lawlor SC, Conklin BR (2002) GenMAPP, a new tool for viewing and analyzing microarray data on biological pathways. Nat Genet 31:19-20. doi:10.1038/ng0502-19

Dai E, Yu X, Zhang Y, Meng F, Wang S, Liu X, Liu D, Wang J, Li X, Jiang W (2014) EpimiR: a database of curated mutual regulation between miRNAs and epigenetic modifications. Database (Oxford) 2014:bau023. doi:10.1093/database/bau023

Davis MI, Pragani R, Fox JT, Shen M, Parmar K, Gaudiano EF, Liu L, Tanega C, McGee L, Hall MD et al (2016) Small Molecule Inhibition of the Ubiquitinspecific Protease USP2 Accelerates cyclin D1 Degradation and Leads to Cell Cycle Arrest in Colorectal Cancer and Mantle Cell Lymphoma Models. J Biol Chem 291:24628-24640. doi:10.1074/jbc.M116.738567 
medRxiv preprint doi: https://doi.org/10.1101/2020.12.22.20248756; this version posted December 26, 2020. The copyright holder for this

Deng G, Zeng S, Qu Y, Luo Q, Guo C, Yin L, Han Y, Li Y, Cai C, Fu Y et al (2018) BMP4 promotes hepatocellular carcinoma proliferation by autophagy activation through JNK1-mediated Bcl-2 phosphorylation. J Exp Clin Cancer Res 37:156. doi:10.1186/s13046-018-0828-X

Ding D, Huang H, Jiang W, Yu W, Zhu H, Liu J, Saiyin H, Wu J, Jiang S, Yu L (2017) Reticulocalbin-2 enhances hepatocellular carcinoma proliferation via modulating the EGFR-ERK pathway. Oncogene 36:6691-6700. doi:10.1038/onc.2017.230

Ding N, Li R, Shi W, He C (2018) CENPI is overexpressed in colorectal cancer and regulates cell migration and invasion. Gene 674:80-86. doi:10.1016/j.gene.2018.06.067

Ding W, Qiu Q, Liu G, Liu J, Mao R, Lin B (2014) Metadata checklist: identification of CHI3L1 and MASP2 as a biomarker pair for liver cancer through integrative secretome and transcriptome analysis. OMICS 18:658-661. doi:10.1089/omi.2014.0090

Divella R, Daniele A, Abbate I, Savino E, Casamassima P, Sciortino G, Simone G, Gadaleta-Caldarola G, Fazio V, Gadaleta CD et al (2015) Circulating Levels of PAI-1 and SERPINE1 4G/4G Polymorphism Are Predictive of Poor Prognosis in HCC Patients Undergoing TACE. Transl Oncol 8:273-278. doi:10.1016/j.tranon.2015.05.002

Döppler H, Panayiotou R, Reid EM, Maimo W, Bastea L, Storz P (2016) The PRKD1 promoter is a target of the KRas-NF- $\kappa \mathrm{B}$ pathway in pancreatic cancer. Sci Rep 6:33758. doi:10.1038/srep33758

Dou C, Xu Q, Liu J, Wang Y, Zhou Z, Yao W, Jiang K, Cheng J, Zhang C, Tu K (2019) SHMT1 inhibits the metastasis of HCC by repressing NOX1-mediated ROS production. J Exp Clin Cancer Res 38:70. doi:10.1186/s13046-019-1067-5

Dou CY, Fan YC, Cao CJ, Yang Y, Wang K (2016) Sera DNA Methylation of CDH1, DNMT3b and ESR1 Promoters as Biomarker for the Early Diagnosis of Hepatitis B Virus-Related Hepatocellular Carcinoma. Dig Dis Sci 61:11301138. doi:10.1007/s10620-015-3975-3

Du J, Chen M, Liu J, Hu P, Guan H, Jiao X (2019) LncRNA F11-AS1 suppresses liver hepatocellular carcinoma progression by competitively binding 
medRxiv preprint doi: https://doi.org/10.1101/2020.12.22.20248756; this version posted December 26, 2020. The copyright holder for this

with miR-3146 to regulate PTEN expression. J Cell Biochem 120:1845718464. doi:10.1002/jcb.29163

Duan S, Gong B, Wang P, Huang H, Luo L, Liu F (2018) Novel prognostic biomarkers of gastric cancer based on gene expression microarray: COL12A1, GSTA3, FGA and FGG. Mol Med Rep 18:3727-3736. doi:10.3892/mmr.2018.9368

Edgar R, Domrachev M, Lash AE (2002) Gene Expression Omnibus: NCBI gene expression and hybridization array data repository. Nucleic Acids Res 30:207-210. doi:10.1093/nar/30.1.207

Eich ML, Chandrashekar DS, Rodriguez Pen $\square$ a MD, Robinson AD, Siddiqui J, Daignault $\square$ Newton S, Chakravarthi BV, Kunju LP, Netto GJ, Varambally S (2019) Characterization of glycine-N-acyltransferase like 1 (GLYATL1) in prostate cancer. Prostate 79:1629-1639. doi:10.1002/pros.23887

El-Shal AS, Zidan HE, Rashad NM, Wadea FM (2017) Angiopoietin-like protein 3 and 4 expression 4 and their serum levels in hepatocellular carcinoma. Cytokine 96:75-86. doi:10.1016/j.cyto.2017.03.006

Epelbaum R, Shalitin C, Segal R, Valansi C, Arselan I, Faraggi D, Leviov M, Ben-Shahar M, Haim N (1998) Haptoglobin-related protein as a serum marker in malignant lymphoma. Pathol Oncol Res 4:271-276. doi:10.1007/bf02905217

Fabregat A, Jupe S, Matthews L, Sidiropoulos K, Gillespie M, Garapati P, Haw R, Jassal B, Korninger F, May B et al (2018) The Reactome Pathway Knowledgebase. Nucleic Acids Res 46:D649-D655. doi:10.1093/nar/gkx1132

Falix FA, Aronson DC, Lamers WH, Hiralall JK, Seppen J (2012) DLK1, a serum marker for hepatoblastoma in young infants. Pediatr Blood Cancer 59:743-745. doi:10.1002/pbc.24024

Fan Y, Xia J (2018) miRNet-Functional Analysis and Visual Exploration of miRNA-Target Interactions in a Network Context. Methods Mol Biol 1819:215233. doi:10.1007/978-1-4939-8618-7_10

Fernandez-Santander A, Gaibar M, Novillo A, Romero-Lorca A, Rubio M, Chicharro LM, Tejerina A, Bandres F (2013) Relationship between genotypes Sult1a2 and Cyp2d6 and tamoxifen metabolism in breast cancer patients. PLoS One 8:e70183. doi:10.1371/journal.pone.0070183 
medRxiv preprint doi: https://doi.org/10.1101/2020.12.22.20248756; this version posted December 26, 2020. The copyright holder for this

Frulio N, Balabaud C, Laurent C, Trillaud H, Bioulac-Sage P (2019) Unclassified hepatocellular adenoma expressing ASS1 associated with inflammatory hepatocellular adenomas. Clin Res Hepatol Gastroenterol 43:e63e67. doi:10.1016/j.clinre.2019.03.012

Fu L, Dong SS, Xie YW, Tai LS, Chen L, Kong KL, Man K, Xie D, Li Y, Cheng $Y$ et al (2010) Down-regulation of tyrosine aminotransferase at a frequently deleted region $16 \mathrm{q} 22$ contributes to the pathogenesis of hepatocellular carcinoma. Hepatology 51:1624-1634. doi:10.1002/hep.23540

Ganesan K, Ivanova T, Wu Y, Rajasegaran V, Wu J, Lee MH, Yu K, Rha SY, Chung HC, Ylstra B et al (2008) Inhibition of gastric cancer invasion and metastasis by PLA2G2A, a novel beta-catenin/TCF target gene. Cancer Res 68:4277-4286. doi:10.1158/0008-5472.CAN-07-6517

Gao CL, Wang GW, Yang GQ, Yang H, Zhuang L (2018) Karyopherin subunit$\alpha 2$ expression accelerates cell cycle progression by upregulating CCNB2 and CDK1 in hepatocellular carcinoma. Oncol Lett 15:2815-2820. doi:10.3892/ol.2017.7691

Gao J, Aksoy BA, Dogrusoz U, Dresdner G, Gross B, Sumer SO, Sun Y, Jacobsen A, Sinha R, Larsson E et al (2013) Integrative analysis of complex cancer genomics and clinical profiles using the cBioPortal. Sci Signal 6(269):pl1. doi:10.1126/scisignal.2004088

Gao Q, Zhang G, Zheng Y, Yang Y, Chen C, Xia J, Liang L, Lei C, Hu Y, Cai $\mathrm{X}$ et al (2020) SLC27A5 deficiency activates NRF2/TXNRD1 pathway by increased lipid peroxidation in HCC. Cell Death Differ 27:1086-1104. doi:10.1038/s41418-019-0399-1

Gao Y, Wang W, Cao J, Wang F, Geng Y, Cao J, Xu X, Zhou J, Liu P, Zhang S (2016) Upregulation of AUF1 is involved in the proliferation of esophageal squamous cell carcinoma through GCH1. Int $J$ Oncol 49:2001-2010. doi:10.3892/ijo.2016.3713

Garrido-Rodríguez M, Ortea I, Calzado MA, Muñoz E, García V (2019) SWATH proteomic profiling of prostate cancer cells identifies NUSAP1 as a potential molecular target for Galiellalactone. J Proteomics 193:217-229. doi:10.1016/j.jprot.2018.10.012 
medRxiv preprint doi: https://doi.org/10.1101/2020.12.22.20248756; this version posted December 26, 2020. The copyright holder for this

Gautier L, Cope L, Bolstad BM, Irizarry RA (2004) affy--analysis of Affymetrix GeneChip data at the probe level. Bioinformatics 20:307-315. doi:10.1093/bioinformatics/btg405

Gong D, Feng PC, Ke XF, Kuang HL, Pan LL, Ye Q, Wu JB (2020) Silencing Long Non-coding RNA LINC01224 Inhibits Hepatocellular Carcinoma Progression via MicroRNA-330-5p-Induced Inhibition of CHEK1. Mol Ther Nucleic Acids 19:482-497. doi:10.1016/j.omtn.2019.10.007

Grimm D, Lieb J, Weyer V, Vollmar J, Darstein F, Lautem A, Hoppe-Lotichius M, Koch S, Schad A, Schattenberg JM et al (2016) Organic Cation Transporter 1 (OCT1) mRNA expression in hepatocellular carcinoma as a biomarker for sorafenib treatment. BMC Cancer 16:94. doi:10.1186/s12885-016-2150-3

Gu J, Liu X, Li J, He Y (2019) MicroRNA-144 inhibits cell proliferation, migration and invasion in human hepatocellular carcinoma by targeting CCNB1. Cancer Cell Int 19:15. doi:10.1186/s12935-019-0729-x

Guan Z, Cheng W, Huang D, Wei A (2018) High MYBL2 expression and transcription regulatory activity is associated with poor overall survival in patients with hepatocellular carcinoma. Curr Res Transl Med 66:27-32. doi:10.1016/j.retram.2017.11.002

Guo L, Gao R, Gan J, Zhu Y, Ma J, Lv P, Zhang Y, Li S, Tang H (2020) Downregulation of TNFRSF19 and RAB43 by a novel miRNA, miR-HCC3, promotes proliferation and epithelial-mesenchymal transition in hepatocellular carcinoma cells. Biochem Biophys Res Commun S0006-291X(20)30379-X. doi:10.1016/j.bbrc.2020.02.105

Guo W, Liu S, Cheng Y, Lu L, Shi J, Xu G, Li N, Cheng K, Wu M, Cheng S et al (2016) ICAM-1-Related Noncoding RNA in Cancer Stem Cells Maintains ICAM-1 Expression in Hepatocellular Carcinoma. Clin Cancer Res 22:20412050. doi:10.1158/1078-0432.CCR-14-3106

Guo YF, Duan JJ, Wang J, Li L, Wang D, Liu XZ, Yang J, Zhang HR, Lv J, Yang YJ et al (2020) Inhibition of the ALDH18A1-MYCN positive feedback loop attenuates MYCN-amplified neuroblastoma growth. Sci Transl Med 12:eaax8694. doi:10.1126/scitranslmed.aax 8694

Ha M, Jeong H, Roh JS, Lee B, Lee D, Han ME, Oh SO, Sohn DH, Kim YH (2019) VNN3 is a potential novel biomarker for predicting prognosis in clear 
medRxiv preprint doi: https://doi.org/10.1101/2020.12.22.20248756; this version posted December 26, 2020. The copyright holder for this

cell renal cell carcinoma. Anim Cells Syst (Seoul) 23:112-117. doi:10.1080/19768354.2019.1583126

Han G, Zhang X, Liu P, Yu Q, Li Z, Yu Q, Wei X (2018) Knockdown of antisilencing function $1 \mathrm{~B}$ histone chaperone induces cell apoptosis via repressing PI3K/Akt pathway in prostate cancer. Int $J$ Oncol 53:2056-2066. doi:10.3892/ijo.2018.4526

Han J, Wang F, Lan Y, Wang J, Nie C, Liang Y, Song R, Zheng T, Pan S, Pei T et al (2019) KIFC1 regulated by miR-532-3p promotes epithelial-tomesenchymal transition and metastasis of hepatocellular carcinoma via gankyrin/AKT signaling. Oncogene 38:406-420. doi:10.1038/s41388-0180440-8

Han JH, Lee YS, Kim HJ, Lee SY, Myung SC (2015) Association between cytochrome CYP17A1, CYP3A4, and CYP3A43 polymorphisms and prostate cancer risk and aggressiveness in a Korean study population. Asian J Androl 17:285-291. doi:10.4103/1008-682X.133320

He Q, Chen Z, Dong Q, Zhang L, Chen D, Patel A, Koya A, Luan X, Cabay RJ, Dai Y et al (2016) MicroRNA-21 regulates prostaglandin E2 signaling pathway by targeting 15-hydroxyprostaglandin dehydrogenase in tongue squamous cell carcinoma. BMC Cancer 16:685. doi:10.1186/s12885-016-2716-0

Heber S, Sick B (2006) Quality assessment of Affymetrix GeneChip data. OMICS 10:358-368. doi:10.1089/omi.2006.10.358

Hidaka A, Sasazuki S, Matsuo K, Ito H, Sawada N, Shimazu T, Yamaji T, Iwasaki M, Inoue M, Tsugane S (2015) Genetic polymorphisms of ADH1B, ADH1C and ALDH2, alcohol consumption, and the risk of gastric cancer: the Japan Public Health Center-based prospective study. Carcinogenesis 36:223231. doi:10.1093/carcin/bgu244

Hiyama E, Hishiki T, Watanabe K, Ida K, Yano M, Oue T, Iehara T, Hoshino K, Koh K, Tanaka Y et al (2016) Resectability and tumor response after preoperative chemotherapy in hepatoblastoma treated by the Japanese Study Group for Pediatric Liver Tumor (JPLT)-2 protocol. J Pediatr Surg 51:20532057. doi:10.1016/j.jpedsurg.2016.09.038 
medRxiv preprint doi: https://doi.org/10.1101/2020.12.22.20248756; this version posted December 26, 2020. The copyright holder for this

Holownia A, Braszko JJ (2004) Tamoxifen cytotoxicity in hepatoblastoma cells stably transfected with human CYP3A4. Biochem Pharmacol 67:1057-1064. doi:10.1016/j.bcp.2003.10.027

Hou P, Ma X, Zhang Q, Wu CJ, Liao W, Li J, Wang H, Zhao J, Zhou X, Guan $\mathrm{C}$ et al (2019) USP21 deubiquitinase promotes pancreas cancer cell stemness via Wnt pathway activation. Genes Dev 33:1361-1366. doi:10.1101/gad.326314.119

Hsiao CC, Chen PH, Cheng CI, Tsai MS, Chang CY, Lu SC, Hsieh MC, Lin YC, Lee PH, Kao YH (2015) Toll-like receptor-4 is a target for suppression of proliferation and chemoresistance in HepG2 hepatoblastoma cells. Cancer Lett 368:144-152. doi:10.1016/j.canlet.2015.08.004

Hu HH, Liu J, Lin YL, Luo WS, Chu YJ, Chang CL, Jen CL, Lee MH, Lu SN, Wang LY et al (2016) The rs2296651 (S267F) variant on NTCP (SLC10A1) is inversely associated with chronic hepatitis B and progression to cirrhosis and hepatocellular carcinoma in patients with chronic hepatitis B. Gut 65:15141521. doi:10.1136/gutjnl-2015-310686

Hu Y, Guo X, Wang J, Liu Y, Gao H, Fan H, Nong X, Yang X, Liu M, Li S et al (2018) A novel microRNA identified in hepatocellular carcinomas is responsive to LEF1 and facilitates proliferation and epithelial-mesenchymal transition via targeting of NFIX. Oncogenesis 7:22. doi:10.1038/s41389-0170010-x

Hu YH, Ma S, Zhang XN, Zhang ZY, Zhu HF, Ji YH, Li J, Qian XL, Wang YX (2019) Hypermethylation Of ADHFE1 Promotes The Proliferation Of Colorectal Cancer Cell Via Modulating Cell Cycle Progression. Onco Targets Ther 12:8105-8115. doi:10.2147/OTT.S223423

Huang W, Chen Z, Shang X, Tian D, Wang D, Wu K, Fan D, Xia L (2015) Sox 12, a direct target of FoxQ1, promotes hepatocellular carcinoma metastasis through up-regulating Twist1 and FGFBP1. Hepatology 61:1920-1933. doi:10.1002/hep. 2775

Huang YW, Luo J, Weng YI, Mutch DG, Goodfellow PJ, Miller DS, Huang TH (2010) Promoter hypermethylation of CIDEA, HAAO and RXFP3 associated with microsatellite instability in endometrial carcinomas. Gynecol Oncol 117:239-247. doi:10.1016/j.ygyno.2010.02.006 
medRxiv preprint doi: https://doi.org/10.1101/2020.12.22.20248756; this version posted December 26, 2020. The copyright holder for this

Huang Z, Shi J, Gao Y, Cui C, Zhang S, Li J, Zhou Y, Cui Q (2019) HMDD v3.0: a database for experimentally supported human microRNA-disease associations. Nucleic Acids Res 47:D1013-D1017. doi:10.1093/nar/gky1010Z

Inokawa Y, Nomoto S, Hishida M, Hayashi M, Kanda M, Nishikawa Y, Takeda S, Sugimoto H, Fujii T, Yamada S et al (2013) Detection of doublecortin domain-containing 2 (DCDC2), a new candidate tumor suppressor gene of hepatocellular carcinoma, by triple combination array analysis. J Exp Clin Cancer Res 32:65. doi:10.1186/1756-9966-32-65

Ishimoto K, Nakamura H, Tachibana K, Yamasaki D, Ota A, Hirano KI, Tanaka T, Hamakubo T, Sakai J, Kodama T et al (2009) Sterol-mediated regulation of human lipin 1 gene expression in hepatoblastoma cells. J Biol Chem 284:22195-22205. doi:10.1074/jbc.M109.028753

Jansen MP, Sas L, Sieuwerts AM, Van Cauwenberghe C, Ramirez-Ardila D, Look M, Ruigrok-Ritstier K, Finetti P, Bertucci F, Timmermans MM et al (2015) Decreased expression of ABAT and STC2 hallmarks ER-positive inflammatory breast cancer and endocrine therapy resistance in advanced disease. Mol Oncol 9:1218-1233. doi:10.1016/j.molonc.2015.02.006

Jewison T, Su Y, Disfany FM, Liang Y, Knox C, Maciejewski A, Poelzer J, Huynh J, Zhou Y, Arndt D et al (2014) SMPDB 2.0: big improvements to the Small Molecule Pathway Database. Nucleic Acids Res 42:D478-D484. doi:10.1093/nar/gkt1067

Jiang F, Chen L, Yang YC, Wang XM, Wang RY, Li L, Wen W, Chang YX, Chen CY, Tang J et al (2015) CYP3A5 Functions as a Tumor Suppressor in Hepatocellular Carcinoma by Regulating mTORC2/Akt Signaling. Cancer Res75:1470-1481. doi:10.1158/0008-5472.CAN-14-1589

Jiang Q, Wang Y, Hao Y, Juan L, Teng M, Zhang X, Li M, Wang G, Liu Y (2009) miR2Disease: a manually curated database for microRNA deregulation in human disease. Nucleic Acids Res 37:D98-104. doi:10.1093/nar/gkn714

Jiao Y, Li Y, Fu Z, Hou L, Chen Q, Cai Y, Jiang P, He M, Yang Z (2019) OGDHL Expression as a Prognostic Biomarker for Liver Cancer Patients. Dis Markers 2019:9037131. doi:10.1155/2019/9037131

Jin B, Gong Z, Yang N, Huang Z, Zeng S, Chen H, Hu S, Pan G (2016) Downregulation of betaine homocysteine methyltransferase (BHMT) in 
medRxiv preprint doi: https://doi.org/10.1101/2020.12.22.20248756; this version posted December 26, 2020. The copyright holder for this

hepatocellular carcinoma associates with poor prognosis. Tumour Biol 37:5911-5917. doi:10.1007/s13277-015-4443-6

Jin H, Zhang Y, You H, Tao X, Wang C, Jin G, Wang N, Ruan H, Gu D, Huo X et al (2015) Prognostic significance of kynurenine 3-monooxygenase and effects on proliferation, migration, and invasion of human hepatocellular carcinoma. Sci Rep 5:10466. doi:10.1038/srep10466

Jin X, Pan Y, Wang L, Zhang L, Ravichandran R, Potts PR, Jiang J, Wu H, Huang H (2017) MAGE-TRIM28 complex promotes the Warburg effect and hepatocellular carcinoma progression by targeting FBP1 for degradation. Oncogenesis 6:e312. doi:10.1038/oncsis.2017.21

Ju LL, Chen L, Li JH, Wang YF, Lu RJ, Bian ZL, Shao JG (2017) Effect of NDC80 in human hepatocellular carcinoma. World J Gastroenterol 23:36753683. doi:10.3748/wjg.v23.i20.3675

Ju W, Li S, Wang Z, Liu Y, Wang D (2015) Decorin protects human hepatoma HepG2 cells against oxygen-glucose deprivation via modulating autophagy. Int J Clin Exp Med 8:13347-13352.

Kanehisa M, Sato Y, Furumichi M, Morishima K, Tanabe M (2019) New approach for understanding genome variations in KEGG. Nucleic Acids Res 47:D590-D595. doi:10.1093/nar/gky962

Kemmner W, Kessel P, Sanchez-Ruderisch H, Möller H, Hinderlich S, Schlag PM, Detjen K (2012) Loss of UDP-N-acetylglucosamine 2-epimerase/Nacetylmannosamine kinase (GNE) induces apoptotic processes in pancreatic carcinoma cells. FASEB J 26:938-946. doi:10.1096/fj.11-186700

Keshava Prasad TS, Goel R, Kandasamy K, Keerthikumar S, Kumar S, Mathivanan S, Telikicherla D, Raju R, Shafreen B, Venugopal A et al (2009) Human Protein Reference Database--2009 update. Nucleic Acids Res 37:D767D772. doi:10.1093/nar/gkn892

Kim H, Ham EK, Kim YI, Chi JG, Lee HS, Park SH, Jung YM, Myung NK, Lee MJ, Jang JJ (1998) Overexpression of cyclin D1 and cdk4 in tumorigenesis of sporadic hepatoblastomas. Cancer Lett131:177-183. doi:10.1016/s03043835(98)00151-7 
medRxiv preprint doi: https://doi.org/10.1101/2020.12.22.20248756; this version posted December 26, 2020. The copyright holder for this

Kim J, Hong SJ, Lim EK, Yu YS, Kim SW, Roh JH, Do IG, Joh JW, Kim DS (2009) Expression of nicotinamide N-methyltransferase in hepatocellular carcinoma is associated with poor prognosis. J Exp Clin Cancer Res 28:20. doi:10.1186/1756-9966-28-20

Kim SA, Um SJ, Kang JH, Hong KJ (2001) Expression of thrombospondin-1 in human hepatocarcinoma cell lines and its regulation by transcription factor Jun/AP-1. Mol Cell Biochem 216:21-29. doi:10.1023/a:1011022822077

Kim SH, Lee MJ, Hwang HK, Lee SH, Kim H, Paik YK, Kang CM (2019) Prognostic potential of the preoperative plasma complement factor $\mathrm{B}$ in resected pancreatic cancer: A pilot study. Cancer Biomark 24:335-342. doi:10.3233/CBM-181847

Kitagawa K, Nakajima G, Kuramochi H, Ariizumi SI, Yamamoto M (2013) Lymphatic vessel endothelial hyaluronan receptor-1 is a novel prognostic indicator for human hepatocellular carcinoma. Mol Clin Oncol 1:1039-1048. doi: $10.3892 / \mathrm{mco} .2013 .167$

Kobayashi S, Nouso K, Kinugasa H, Takeuchi Y, Tomoda T, Miyahara K, Hagihara H, Kuwaki K, Onishi H, Nakamura S et al (2012) Clinical utility of serum fucosylated hemopexin in Japanese patients with hepatocellular carcinoma. Hepatol Res 42:1187-1195. doi:10.1111/j.1872-034X.2012.01044.X

Koch A, Denkhaus D, Albrecht S, Leuschner I, von Schweinitz D, Pietsch T (1999) Childhood hepatoblastomas frequently carry a mutated degradation targeting box of the beta-catenin gene. Cancer Res 59:269-273.

Koch A, Weber N, Waha A, Hartmann W, Denkhaus D, Behrens J, Birchmeier W, Schweinitz DV, Pietsch T (2004) Mutations and elevated transcriptional activity of conductin (AXIN2) in hepatoblastomas. J Pathol 204:546-554. doi:10.1002/path.1662

Kodama T, Marian TA, Lee H, Kodama M, Li J, Parmacek MS, Jenkins NA, Copeland NG, Wei Z (2019) MRTFB suppresses colorectal cancer development through regulating SPDL1 and MCAM. Proc Natl Acad Sci U S A 116:2362523635. doi:10.1073/pnas.1910413116

Kotlyar M, Pastrello C, Malik Z, Jurisica I (2019) IID 2018 update: contextspecific physical protein-protein interactions in human, model organisms and 
medRxiv preprint doi: https://doi.org/10.1101/2020.12.22.20248756; this version posted December 26, 2020. The copyright holder for this

domesticated species. Nucleic Acids Res 47:D581-D589. doi:10.1093/nar/gky1037

Kremer N, Walther AE, Tiao GM (2014) Management of hepatoblastoma: an update. Curr Opin Pediatr 26:362-369. doi:10.1097/MOP.0000000000000081

Kuo SH, Yang SY, You SL, Lien HC, Lin CH, Lin PH, Huang CS (2017) Polymorphisms of ESR1, UGT1A1, HCN1, MAP3K1 and CYP2B6 are associated with the prognosis of hormone receptor-positive early breast cancer. Oncotarget 8:20925-20938. doi:10.18632/oncotarget.14995

Kuo TC, Chen CK, Hua KT, Yu P, Lee WJ, Chen MW, Jeng YM, Chien MH, Kuo KT, Hsiao M et al (2016) Glutaminase 2 stabilizes Dicer to repress Snail and metastasis in hepatocellular carcinoma cells. Cancer Lett 383:282-294. doi:10.1016/j.canlet.2016.10.012

Law CT, Wei L, Tsang FH, Chan CY, Xu IM, Lai RK, Ho DW, Lee JM, Wong CC, Ng IO et al (2019) HELLS Regulates Chromatin Remodeling and Epigenetic Silencing of Multiple Tumor Suppressor Genes in Human Hepatocellular Carcinoma. Hepatology 69:2013-2030. doi:10.1002/hep.30414

Le Y, Kan A, Li QJ, He MK, Chen HL, Shi M (2019) NAP1L1 is a prognostic biomarker and contribute to doxorubicin chemotherapy resistance in human hepatocellular carcinoma. Cancer Cell Int 19:228. doi:10.1186/s12935-0190949-0

Lee SW, Chen TJ, Lin LC, Li CF, Chen LT, Hsing CH, Hsu HP, Tsai CJ, Huang HY, Shiue YL (2013) Overexpression of thymidylate synthetase confers an independent prognostic indicator in nasopharyngeal carcinoma. Exp Mol Pathol 95:83-90. doi:10.1016/j.yexmp.2013.05.006

Lee WH, Chen LC, Lee CJ, Huang CC, Ho YS, Yang PS, Ho CT, Chang HL, Lin IH, Chang HW et al (2019) DNA primase polypeptide 1 (PRIM1) involves in estrogen-induced breast cancer formation through activation of the G2/M cell cycle checkpoint. Int J Cancer 144:615-630. doi:10.1002/ijc.31788

Lewis SE (2017) The Vision and Challenges of the Gene Ontology. Methods Mol Biol 1446:291-302. doi:10.1007/978-1-4939-3743-1_21 
medRxiv preprint doi: https://doi.org/10.1101/2020.12.22.20248756; this version posted December 26, 2020. The copyright holder for this

Li A, Chen H, Lin M, Zhang C, Tang E, Peng J, Wei Q, Li H, Yin L (2015) PIK3C2G copy number is associated with clinical outcomes of colorectal cancer patients treated with oxaliplatin. Int J Clin Exp Med 8:1137-1143.

Li C, Zhou D, Jiang X, Liu M, Tang H, Mei Z (2019) Identifying hepatocellular carcinoma-related hub genes by bioinformatics analysis and CYP2C8 is a potential prognostic biomarker. Gene 698:9-18. doi:10.1016/j.gene.2019.02.062

Li G, Li M, Wang J, Li Y, Pan Y (2018) United neighborhood closeness centrality and orthology for predicting essential proteins. IEEE/ACM Trans Comput Biol Bioinform 10.1109/TCBB.2018.2889978. doi:10.1109/TCBB.2018.2889978

Li J, Wang J, Yu J, Zhao Y, Dong Y, Fan Y, Li N, Zhang Y, Wang Y (2018) Knockdown of POLE2 expression suppresses lung adenocarcinoma cell malignant phenotypes in vitro. Oncol Rep 40:2477-2486. doi:10.3892/or.2018.6659

Li J, Ying Y, Xie H, Jin K, Yan H, Wang S, Xu M, Xu X, Wang X, Yang K et al (2019) Dual regulatory role of CCNA2 in modulating CDK6 and METmediated cell-cycle pathway and EMT progression is blocked by miR-381-3p in bladder cancer. FASEB J 33:1374-1388. doi:10.1096/fj.201800667R

Li JH, Liu S, Zhou H, Qu LH, Yang JH (2014) starBase v2.0: decoding miRNA-ceRNA, miRNA-ncRNA and protein-RNA interaction networks from large-scale CLIP-Seq data. Nucleic Acids Res 42:D92-D97. doi:10.1093/nar/gkt1248

Li L, Zhuo Z, Yang Z, Zhu J, He X, Yang Z, Zhang J, Xin Y, He J, Zhang T (2020) HMGA2 Polymorphisms and Hepatoblastoma Susceptibility: A FiveCenter Case-Control Study. Pharmgenomics Pers Med 13:51-57. doi:10.2147/PGPM.S241100

Li M, Zhang L, Ge C, Chen L, Fang T, Li H, Tian H, Liu J, Chen T, Jiang G et al (2015) An isocorydine derivative (d-ICD) inhibits drug resistance by downregulating IGF2BP3 expression in hepatocellular carcinoma. Oncotarget 6:25149-25160. doi:10.18632/oncotarget.4438

Li P, Zhang Q, Tang H 2019 ( ) INPP1 up-regulation by miR-27a contributes to the growth, migration and invasion of human cervical cancer. J Cell Mol Med 23:7709-7716. doi:10.1111/jcmm.14644 
medRxiv preprint doi: https://doi.org/10.1101/2020.12.22.20248756; this version posted December 26, 2020. The copyright holder for this

Li R, Jiang X, Zhang Y, Wang S, Chen X, Yu X, Ma J, Huang X (2019) Cyclin B2 Overexpression in Human Hepatocellular Carcinoma is Associated with Poor Prognosis. Arch Med Res 50:10-17. doi:10.1016/j.arcmed.2019.03.003

Li S, Li X, Xu A, Zhang B, He X, Chen H, Huang J (2018) Screening and clinical evaluation of dominant peptides of centromere protein $F$ antigen for early diagnosis of hepatocellular carcinoma. Mol Med Rep 17:4720-4728. doi:10.3892/mmr.2018.8372

Li T, Fan J, Wang B, Traugh N, Chen Q, Liu JS, Li B, Liu XS (2017) TIMER: A Web Server for Comprehensive Analysis of Tumor-Infiltrating Immune Cells. Cancer Res 77:e108-e110. doi:10.1158/0008-5472.CAN-17-0307

Li X, Li B, Li B, Guo T, Sun Z, Li X, Chen L, Chen W, Chen P, Mao Y et al (2018) Effective Serum Marker, Early Warning and Diagnosis, Hepatocellular Carcinoma. Pathol Oncol Res 24:663-670. doi:10.1007/s12253-017-0285-4

Li XP, Yang XY, Biskup E, Zhou J, Li HL, Wu YF, Chen ML, Xu F (2015) Coexpression of CXCL8 and HIF-1 $\alpha$ is associated with metastasis and poor prognosis in hepatocellular carcinoma. Oncotarget 6:22880-22889. doi:10.18632/oncotarget.4412

Li Y, Bai W, Zhang J (2017) MiR-200c-5p suppresses proliferation and metastasis of human hepatocellular carcinoma (HCC) via suppressing MAD2L1. Biomed Pharmacother 92:1038-1044. doi:10.1016/j.biopha.2017.05.092

Liao W, Liu W, Yuan Q, Liu X, Ou Y, He S, Yuan S, Qin L, Chen Q, Nong K et al (2013) ilencing of DLGAP5 by siRNA significantly inhibits the proliferation and invasion of hepatocellular carcinoma cells. PLoS One 8:e80789. doi:10.1371/journal.pone.0080789

Licata L, Briganti L, Peluso D, Perfetto L, Iannuccelli M, Galeota E, Sacco F, Palma A, Nardozza AP, Santonico E et al (2012) MINT, the molecular interaction database: 2012 update. Nucleic Acids Res 40:D857-D861. doi:10.1093/nar/gkr930

Lin LL, Wang W, Hu Z, Wang LW, Chang J, Qian H (2015) Erratum to: Negative feedback of miR-29 family TET1 involves in hepatocellular cancer. Med Oncol 32:39. doi:10.1007/s12032-014-0437-2 
medRxiv preprint doi: https://doi.org/10.1101/2020.12.22.20248756; this version posted December 26, 2020. The copyright holder for this

Lin X, Yang Y, Guo Y, Liu H, Jiang J, Zheng F, Wu B (2019) PTTG1 is involved in TNF- $\alpha$-related hepatocellular carcinoma via the induction of c-myc. Cancer Med 8:5702-5715. doi:10.1002/cam4.2473

Lin YF, Li LH, Lin CH, Tsou MH, Chuang MT, Wu KM, Liao TL, Li JC, Wang WJ, Tomita A et al (2016) Selective Retention of an Inactive Allele of the DKK2 Tumor Suppressor Gene in Hepatocellular Carcinoma. PLoS Genet 1:e1006051. doi:10.1371/journal.pgen.1006051

Liu B, Li J, Liu X, Zheng M, Yang Y, Lyu Q, Jin L (2017) Long non-coding RNA HOXA11-AS promotes the proliferation HCC cells by epigenetically silencing DUSP5. Oncotarget 8:109509-109521. doi:10.18632/oncotarget.22723

Liu BH, Zhang BB, Liu XQ, Zheng S, Dong KR, Dong R (2018) Expression Profiling Identifies Circular RNA Signature in Hepatoblastoma. Cell Physiol Biochem 45:706-719. doi:10.1159/000487163

Liu CT, Min L, Wang YJ, Li P, Wu YD, Zhang ST (2019) shRNA $\square$ mediated knockdown of KNTC1 suppresses cell viability and induces apoptosis in esophageal squamous cell carcinoma. Int $\mathrm{J}$ Oncol 54:1053-1060. doi:10.3892/ijo.2019.4672

Liu D, Wong CC, Fu L, Chen H, Zhao L, Li C, Zhou Y, Zhang Y, Xu W, Yang $Y$ et al (2018) Squalene epoxidase drives NAFLD-induced hepatocellular carcinoma and is a pharmaceutical target. Sci Transl Med 10:eaap9840. doi:10.1126/scitranslmed.aap9840

Liu G, Hou G, Li L, Li Y, Zhou W, Liu L (2016) Potential diagnostic and prognostic marker dimethylglycine dehydrogenase (DMGDH) suppresses hepatocellular carcinoma metastasis in vitro and in vivo. Oncotarget 7:3260732616. doi:10.18632/oncotarget.8927

Liu GM, Li Q, Zhang PF, Shen SL, Xie WX, Chen B, Wu J, Hu WJ, Huang XY, Peng BG (2018) Restoration of FBP1 suppressed Snail-induced epithelial to mesenchymal transition in hepatocellular carcinoma. Cell Death Dis 9:1132. doi:10.1038/s41419-018-1165-x

Liu J, Li W, Zhao H (2020) CFHR3 is a potential novel biomarker for hepatocellular carcinoma. J Cell Biochem 121:2970-2980. doi:10.1002/jcb.29551 
medRxiv preprint doi: https://doi.org/10.1101/2020.12.22.20248756; this version posted December 26, 2020. The copyright holder for this

Liu M, Hu Q, Tu M, Wang X, Yang Z, Yang G, Luo R (2018) MCM6 promotes metastasis of hepatocellular carcinoma via MEK/ERK pathway and serves as a novel serum biomarker for early recurrence. J Exp Clin Cancer Res 37:10. doi:10.1186/s13046-017-0669-z

Liu S, Luan J, Ding Y (2018) miR-144-3p Targets FosB Proto-oncogene, AP-1 Transcription Factor Subunit (FOSB) to Suppress Proliferation, Migration, and Invasion of PANC-1 Pancreatic Cancer Cells. Oncol Res 26:683-690. doi:10.3727/096504017X14982585511252

Liu X, Wang S, Meng F, Wang J, Zhang Y, Dai E, Yu X, Li X, Jiang W (2013) SM2miR: a database of the experimentally validated small molecules' effects on microRNA expression. Bioinformatics 29:409-411. doi:10.1093/bioinformatics/bts698

Liu YX, Zhang SF, Ji YH, Guo SJ, Wang GF, Zhang GW (2012) Whole-exome sequencing identifies mutated PCK2 and HUWE1 associated with carcinoma cell proliferation in a hepatocellular carcinoma patient. Oncol Lett 4:847-851. doi:10.3892/ol.2012.825

Livak KJ, Schmittgen TD (2001) Analysis of relative gene expression data using real-time quantitative PCR and the 2(-Delta Delta C(T)) Method. Methods 25:402-408. doi:10.1006/meth.2001.1262

Lopez-Nunez O, Ranganathan S (2019) Immunohistochemical Expression Analysis of EpCAM in Hepatoblastomas. Appl Immunohistochem Mol Morphol 10.1097/PAI.0000000000000826. doi:10.1097/PAI.0000000000000826

Lu D, Dong D, Xie Q, Li Z, Wu B (2018) Disposition of Mianserin and Cyclizine in UGT2B10-Overexpressing Human Embryonic Kidney 293 Cells: Identification of UGT2B10 as a Novel N-Glucosidation Enzyme and Breast Cancer Resistance Protein as an N-Glucoside Transporter. Drug Metab Dispos 46:970-979. doi:10.1124/dmd.118.080804

Lu M, Huang X, Chen Y, Fu Y, Xu C, Xiang W, Li C, Zhang S, Yu C (2018) Aberrant KIF20A expression might independently predict poor overall survival and recurrence-free survival of hepatocellular carcinoma. IUBMB Life 70:328335. doi:10.1002/iub. 1726 
medRxiv preprint doi: https://doi.org/10.1101/2020.12.22.20248756; this version posted December 26, 2020. The copyright holder for this

Lu YB, Jiang Q, Yang MY, Zhou JX, Zhang Q (2017) Long noncoding RNA NNT-AS1 promotes hepatocellular carcinoma progression and metastasis through miR-363/CDK6 axis. Oncotarget 8:88804-88814. doi:10.18632/oncotarget.21321

Luo W, Liao M, Liao Y, Chen X, Huang C, Fan J, Liao W (2018) The role of kinesin KIF18A in the invasion and metastasis of hepatocellular carcinoma. World J Surg Oncol 16:36. doi:10.1186/s12957-018-1342-5

Lv X, Zhao F, Huo X, Tang W, Hu B, Gong X, Yang J, Shen Q, Qin W (2016) Neuropeptide $\mathrm{Y} 1$ receptor inhibits cell growth through inactivating mitogenactivated protein kinase signal pathway in human hepatocellular carcinoma. Med Oncol 33:70. doi:10.1007/s12032-016-0785-1

Ma Q, Xu Y, Liao H, Cai Y, Xu L, Xiao D, Liu C, Pu W, Zhong X, Guo X (2019) Identification and validation of key genes associated with non-small-cell lung cancer. J Cell Physiol 234:22742-22752. doi:10.1002/jcp.28839

Maekawa K, Hamaguchi T, Saito Y, Tatewaki N, Kurose K, Kaniwa N, Nakajima TE, Kato K, Yamada Y, Shimada Y et al (2011) Genetic variation and haplotype structures of the glutathione S-transferase genes GSTA1 and GSTA2 in Japanese colorectal cancer patients. Drug Metab Pharmacokinet 26:646-658. doi:10.2133/dmpk.DMPK-11-SC-050

Malaguarnera G, Catania VE, Francaviglia A, Malaguarnera M, Drago F, Motta M, Latteri S (2017) Lipoprotein(a) in patients with hepatocellular carcinoma and portal vein thrombosis. Aging Clin Exp Res 29:185-190. doi:10.1007/s40520-016-0653-z

Miao R, Wu Y, Zhang H, Zhou H, Sun X, Csizmadia E, He L, Zhao Y, Jiang C, Miksad RA et al (2016) Utility of the dual-specificity protein kinase TTK as a therapeutic target for intrahepatic spread of liver cancer. Sci Rep 6:33121. doi:10.1038/srep33121

Matsuo M, Terai K, Kameda N, Matsumoto A, Kurokawa Y, Funase Y, Nishikawa K, Sugaya N, Hiruta N, Kishimoto T (2012) Designation of enzyme activity of glycine-N-acyltransferase family genes and depression of glycine-Nacyltransferase in human hepatocellular carcinoma. Biochem Biophys Res Commun 420:901-906. doi:10.1016/j.bbrc.2012.03.099 
medRxiv preprint doi: https://doi.org/10.1101/2020.12.22.20248756; this version posted December 26, 2020. The copyright holder for this

Mattu S, Fornari F, Quagliata L, Perra A, Angioni MM, Petrelli A, Menegon S, Morandi A, Chiarugi P, Ledda-Columbano GM et al (2016) The metabolic gene $\mathrm{HAO} 2$ is downregulated in hepatocellular carcinoma and predicts metastasis and poor survival. J Hepatol 64:891-898. doi:10.1016/j.jhep.2015.11.029

Mavri-Damelin D, Eaton S, Damelin LH, Rees M, Hodgson HJ, Selden C (2007) Ornithine transcarbamylase and arginase I deficiency are responsible for diminished urea cycle function in the human hepatoblastoma cell line HepG2. Int J Biochem Cell Biol 39:555-564. doi:10.1016/j.biocel.2006.10.007

Melchardt T, Hufnagl C, Magnes T, Weiss L, Hutarew G, Neureiter D, Schlattau A, Moser G, Gaggl A, Tränkenschuh W et al (2015) CYP39A1 polymorphism is associated with toxicity during intensive induction chemotherapy in patients with advanced head and neck cancer. BMC Cancer 15:725. doi:10.1186/s12885-015-1776-X

Meng W, Xie B, Yang Q, Jia C, Tang H, Zhang X, Zhang Y, Zhang J, Li H, Fu B (2019) Minichromosome maintenance 3 promotes hepatocellular carcinoma radioresistance by activating the $\mathrm{NF}-\kappa \mathrm{B}$ pathway. J Exp Clin Cancer Res 38:263. doi:10.1186/s13046-019-1241-9

Mi H, Huang X, Muruganujan A, Tang H, Mills C, Kang D, Thomas PD (2017) PANTHER version 11: expanded annotation data from Gene Ontology and Reactome pathways, and data analysis tool enhancements. Nucleic Acids Res 45:D183-D189. doi:10.1093/nar/gkw1138

Miao J, Kusafuka T, Udatsu Y, Okada A (2003) Sequence variants of the Axin gene in hepatoblastoma. Hepatol Res 25:174-179. doi:10.1016/s13866346(02)00264-4

Mio C, Lavarone E, Conzatti K, Baldan F, Toffoletto B, Puppin C, Filetti S, Durante C, Russo D, Orlacchio A et al (2016) MCM5 as a target of BET inhibitors in thyroid cancer cells. Endocr Relat Cancer 23:335-347. doi:10.1530/ERC-15-0322

Moelans CB, Verschuur-Maes AH, van Diest PJ (2011) Frequent promoter hypermethylation of BRCA2, CDH13, MSH6, PAX5, PAX6 and WT1 in ductal carcinoma in situ and invasive breast cancer. J Pathol 225:222-231. doi:10.1002/path.2930 
medRxiv preprint doi: https://doi.org/10.1101/2020.12.22.20248756; this version posted December 26, 2020. The copyright holder for this

Mondal G, Saroha A, Bose PP, Chatterjee BP (2016) Altered glycosylation, expression of serum haptoglobin and alpha-1-antitrypsin in chronic hepatitis $\mathrm{C}$, hepatitis $\mathrm{C}$ induced liver cirrhosis and hepatocellular carcinoma patients. Glycoconj J 33:209-218. doi:10.1007/s10719-016-9658-2

Mumbrekar KD, Sadashiva SR, Kabekkodu SP, Fernandes DJ, Vadhiraja BM, Suga T, Shoji Y, Nakayama F, Imai T, Satyamoorthy K (2017) Genetic Variants in CD44 and MAT1A Confer Susceptibility to Acute Skin Reaction in Breast Cancer Patients Undergoing Radiation Therapy. Int J Radiat Oncol Biol Phys 97:118-127. doi:10.1016/j.ijrobp.2016.09.017

Nagai H, Naka T, Terada Y, Komazaki T, Yabe A, Jin E, Kawanami O, Kishimoto T, Konishi N, Nakamura M. et al (2003) Hypermethylation associated with inactivation of the SOCS-1 gene, a JAK/STAT inhibitor, in human hepatoblastomas. J Hum Genet 48:65-69. doi:10.1007/s100380300008

Nguyen TP, Liu WC, Jordán F (2011) Inferring pleiotropy by network analysis: linked diseases in the human PPI network. BMC Syst Biol 5:179. doi:10.1186/1752-0509-5-179

Nikolaou N, Gathercole LL, Kirkwood L, Dunford JE, Hughes BA, Gilligan LC, Oppermann U, Penning TM, Arlt W, Hodson L et al (2019) AKR1D1 regulates glucocorticoid availability and glucocorticoid receptor activation in human hepatoma cells. J Steroid Biochem Mol Biol 189:218-227. doi:10.1016/j.jsbmb.2019.02.002

Nishi M, Abe Y, Fujimori S, Hamamoto A, Inoue Y, Miyazaki N, Oida Y, Ikoma N, Ohnishi Y, Yamazaki $\mathrm{H}$ et al (2005) The modifier subunit of glutamate cysteine ligase relates to cisplatin resistance in human small cell lung cancer xenografts in vivo. Oncol Rep 14:421-424.

Orchard S, Ammari M, Aranda B, Breuza L, Briganti L, Broackes-Carter F, Campbell NH, Chavali G, Chen C, del-Toro N, Duesbury M et al (2014) The MIntAct project--IntAct as a common curation platform for 11 molecular interaction databases. Nucleic Acids Res 42:D358-D363. doi:10.1093/nar/gkt1115

Osanai M, Lee GH (2015) The retinoic acid-metabolizing enzyme CYP26A1 upregulates fascin and promotes the malignant behavior of breast carcinoma cells. Oncol Rep 34:850-858. doi:10.3892/or.2015.4042 
medRxiv preprint doi: https://doi.org/10.1101/2020.12.22.20248756; this version posted December 26, 2020. The copyright holder for this

Oughtred R, Stark C, Breitkreutz BJ, Rust J, Boucher L, Chang C, Kolas N, O'Donnell L, Leung G, McAdam R et al (2019) The BioGRID interaction database: 2019 update. Nucleic Acids Res 47:D529-D541. doi:10.1093/nar/gky1079

Pal J, Patil V, Mondal B, Shukla S, Hegde AS, Arivazhagan A, Santosh V, Somasundaram K (2016) Epigenetically silenced GNG4 inhibits SDF1 $\alpha /$ CXCR4 signaling in mesenchymal glioblastoma. Genes Cancer 7:136147. doi:10.18632/genesandcancer.105

Panvichian R, Tantiwetrueangdet A, Angkathunyakul N, Leelaudomlipi S (2015) TOP2A amplification and overexpression in hepatocellular carcinoma tissues. Biomed Res Int 2015:381602. doi:10.1155/2015/381602

Petri V, Jayaraman P, Tutaj M, Hayman GT, Smith JR, De Pons J, Laulederkind SJ, Lowry TF, Nigam R, Wang SJ et al (2014) The pathway ontology - updates and applications. J Biomed Semantics 5:7. doi:10.1186/2041-1480-5-7

Pham QT, Oue N, Sekino Y, Yamamoto Y, Shigematsu Y, Sakamoto N, Sentani K, Uraoka N, Yasui W (2018) TDO2 Overexpression Is Associated with Cancer Stem Cells and Poor Prognosis in Esophageal Squamous Cell Carcinoma. Oncology 95:297-308. doi:10.1159/000490725

Pousset D, Piller V, Bureaud N, Piller F (2001) High levels of ceruloplasmin in the serum of transgenic mice developing hepatocellular carcinoma. Eur $\mathbf{J}$ Biochem 268:1491-1499. doi:10.1046/j.1432-1327.2001.02015.x

Przulj N, Wigle DA, Jurisica I (2004) Functional topology in a network of protein interactions. Bioinformatics 20:340-348. doi:10.1093/bioinformatics/btg415

Purcell R, Childs M, Maibach R, Miles C, Turner C, Zimmermann A, Sullivan M (2011) HGF/c-Met related activation of $\beta$-catenin in hepatoblastoma. J Exp Clin Cancer Res 30:96. doi:10.1186/1756-9966-30-96

Qi HL, Li CS, Qian CW, Xiao YS, Yuan YF, Liu QY, Liu ZS (2016) The long noncoding RNA, EGFR-AS1, a target of GHR, increases the expression of EGFR in hepatocellular carcinoma. Tumour Biol 37:1079-1089. doi:10.1007/s13277-015-3887-z 
medRxiv preprint doi: https://doi.org/10.1101/2020.12.22.20248756; this version posted December 26, 2020. The copyright holder for this

Quesada-Calvo F, Massot C, Bertrand V, Longuespée R, Blétard N, Somja J, Mazzucchelli G, Smargiasso N, Baiwir D, De Pauw-Gillet M et al (2017) OLFM4, KNG1 and Sec24C identified by proteomics and immunohistochemistry as potential markers of early colorectal cancer stages. Clin Proteomics 14:9. doi:10.1186/s12014-017-9143-3

Quiroga AD, Ceballos MP, Parody JP, Comanzo CG, Lorenzetti F, Pisani GB, Ronco MT, Alvarez MD, Carrillo MC (2016) Hepatic carboxylesterase 3 (Ces3/Tgh) is downregulated in the early stages of liver cancer development in the rat. Biochim Biophys Acta 1862:2043-2053. doi:10.1016/j.bbadis.2016.08.006

Ranganathan S, Ningappa M, Ashokkumar C, Higgs BW, Min J, Sun Q, Schmitt L, Subramaniam S, Hakonarson H, Sindhi R (2016) Loss of EGFRASAP1 signaling in metastatic and unresectable hepatoblastoma. Sci Rep 6:38347. doi:10.1038/srep38347

Repetto O, Maiero S, Magris R, Miolo G, Cozzi MR, Steffan A, Canzonieri V, Cannizzaro R, De Re V (2018) Quantitative Proteomic Approach Targeted to Fibrinogen $\beta$ Chain in Tissue Gastric Carcinoma. Int J Mol Sci 19:759. doi:10.3390/ijms19030759

Richmond CS, Oldenburg D, Dancik G, Meier DR, Weinhaus B, Theodorescu D, Guin S (2018) Glycogen Debranching Enzyme (AGL) Is a Novel Regulator of Non-Small Cell Lung Cancer Growth. Glycogen debranching enzyme (AGL) is a novel regulator of non-small cell lung cancer growth. Oncotarget 9:1671816730. doi:10.18632/oncotarget. 24676

Riihilä P, Viiklepp K, Nissinen L, Farshchian M, Kallajoki M, Kivisaari A, Meri S, Peltonen J, Peltonen S, Kähäri VM (2020) umour-cell-derived complement components $\mathrm{C} 1 \mathrm{r}$ and $\mathrm{C} 1 \mathrm{~s}$ promote growth of cutaneous squamous cell carcinoma. Br J Dermatol 182:658-670. doi:10.1111/bjd.18095

Ritchie ME, Phipson B, Wu DI, Hu Y, Law CW, Shi W, Smyth GK (2015) limma powers differential expression analyses for RNA-sequencing and microarray studies. Nucleic Acids Res 43:e47. doi:10.1093/nar/gkv007

Robin X, Turck N, Hainard A, Tiberti N, Lisacek F, Sanchez JC, Müller M (2011) pROC: an open-source package for $\mathrm{R}$ and $\mathrm{S}+$ to analyze and compare ROC curves. BMC Bioinformatics 12:77. doi:10.1186/1471-2105-12-77 
medRxiv preprint doi: https://doi.org/10.1101/2020.12.22.20248756; this version posted December 26, 2020. The copyright holder for this

Ruan HY, Yang C, Tao XM, He J, Wang T, Wang H, Wang C, Jin GZ, Jin HJ, Qin WX (2017) Downregulation of ACSM3 promotes metastasis and predicts poor prognosis in hepatocellular carcinoma. Am J Cancer Res 7:543-553.

Ruepp A, Kowarsch A, Schmidl D, Buggenthin F, Brauner B, Dunger I, Fobo G, Frishman G, Montrone C, Theis FJ (2010) PhenomiR: a knowledgebase for microRNA expression in diseases and biological processes. Genome Biol 11:R6. doi:10.1186/gb-2010-11-1-r6

Rukov JL, Wilentzik R, Jaffe I, Vinther J, Shomron N (2014) Pharmaco-miR: linking microRNAs and drug effects. Brief Bioinform 15:648-659. doi:10.1093/bib/bbs082

Sakamoto LH, DE Camargo B, Cajaiba M, Soares FA, Vettore AL (2010) MT1G hypermethylation: a potential prognostic marker for hepatoblastoma. Pediatr Res 67:387-393. doi:10.1203/PDR.0b013e3181d01863

Salwinski L, Miller CS, Smith AJ, Pettit FK, Bowie JU, Eisenberg D (2004) The Database of Interacting Proteins: 2004 update. Nucleic Acids Res 32:D449-D451. doi:10.1093/nar/gkh086

Schaefer CF, Anthony K, Krupa S, Buchoff J, Day M, Hannay T, Buetow KH (2009) PID: the Pathway Interaction Database. Nucleic Acids Res 37:D674D679. doi:10.1093/nar/gkn653

Schneider MA, Christopoulos P, Muley T, Warth A, Klingmueller U, Thomas M, Herth FJ, Dienemann H, Mueller NS, Theis F et al (2017) AURKA, DLGAP5, TPX2, KIF11 and CKAP5: Five specific mitosis-associated genes correlate with poor prognosis for non-small cell lung cancer patients. Int $\mathbf{J}$ Oncol 50:365-372. doi:10.3892/ijo.2017.3834

Seol HS, Lee SE, Song JS, Rhee JK, Singh SR, Chang S, Jang SJ (2016) Complement proteins $\mathrm{C} 7$ and CFH control the stemness of liver cancer cells via LSF-1. Cancer Lett 372:24-35. doi:10.1016/j.canlet.2015.12.005

Shannon P, Markiel A, Ozier O, Baliga NS, Wang JT, Ramage D, Amin N, Schwikowski B, Ideker T (2003) Cytoscape: a software environment for integrated models of biomolecular interaction networks. Genome Res 13:24982504. doi:10.1101/gr.1239303 
medRxiv preprint doi: https://doi.org/10.1101/2020.12.22.20248756; this version posted December 26, 2020. The copyright holder for this

Shen CT, Wei WJ, Qiu ZL, Song HJ, Luo QY (2016) Afamin promotes glucose metabolism in papillary thyroid carcinoma. Mol Cell Endocrinol 434:108-115. doi:10.1016/j.mce.2016.06.013

Shen Y, Zhang F, Lan H, Chen K, Zhang Q, Xie G, Teng L, Jin K (2015) FRZB up-regulation is correlated with hepatic metastasis and poor prognosis in colon carcinoma patients with hepatic metastasis. Int J Clin Exp Pathol 8:4083-4090.

Shi L, Yan P, Liang Y, Sun Y, Shen J, Zhou S, Lin H, Liang X, Cai X (2017) Circular RNA expression is suppressed by androgen receptor (AR)-regulated adenosine deaminase that acts on RNA (ADAR1) in human hepatocellular carcinoma. Cell Death Dis 8:e3171. doi:10.1038/cddis.2017.556

Shi X, Teng F (2015) Down-regulated miR-28-5p in human hepatocellular carcinoma correlated with tumor proliferation and migration by targeting insulin-like growth factor-1 (IGF-1). Mol Cell Biochem 408:283-293. doi:10.1007/s11010-015-2506-z

Shi Z, Zhang B (2011) Fast network centrality analysis using GPUs. BMC Bioinformatics 12:149. doi:10.1186/1471-2105-12-149

Shih S, Huang YT, Yang HI (2018) A multiple mediator analysis approach to quantify the effects of the ADH1B and ALDH2 genes on hepatocellular carcinoma risk. Genet Epidemiol 42:394-404. doi:10.1002/gepi.22120

Shimokawa Y, Okuda K, Kubo Y, Kaneko A, Arishima T, Nagata E, Hashimoto M, Sawa Y, Nagasaki Y, Kojiro M et al (1977) Serum glutamic oxalacetic transaminase/glutamic pyruvic transaminase ratios in hepatocellular carcinoma. Cancer 40:319-324. doi:10.1002/1097-0142(197707)40:1<319::aidcncr2820400145>3.0.co;2-q

Shin H, Cha HJ, Lee MJ, Na K, Park D, Kim CY, Han DH, Kim H, Paik YK (2020) Identification of ALDH6A1 as a Potential Molecular Signature in Hepatocellular Carcinoma via Quantitative Profiling of the Mitochondrial Proteome. J Proteome Res 10.1021/acs.jproteome.9b00846. doi:10.1021/acs.jproteome.9b00846

Shu H, Li W, Shang S, Qin X, Zhang S, Liu Y (2017) Diagnosis of AFPnegative early-stage hepatocellular carcinoma using Fuc-PON1. Discov Med 23:163-168. 
medRxiv preprint doi: https://doi.org/10.1101/2020.12.22.20248756; this version posted December 26, 2020. The copyright holder for this

Sinreih M, Anko M, Zukunft S, Adamski J, Rižner TL (2015) Important roles of the AKR1C2 and SRD5A1 enzymes in progesterone metabolism in endometrial cancer model cell lines. Chem Biol Interact 234:297-308. doi:10.1016/j.cbi.2014.11.012

Slattery ML, Herrick JS, Lundgreen A, Fitzpatrick FA, Curtin K, Wolff RK (2010) Genetic variation in a metabolic signaling pathway and colon and rectal cancer risk: mTOR, PTEN, STK11, RPKAA1, PRKAG2, TSC1, TSC2, PI3K and Akt1. Carcinogenesis 31:1604-1611. doi:10.1093/carcin/bgq142

Sogawa K, Takano S, Iida F, Satoh M, Tsuchida S, Kawashima Y, Yoshitomi H, Sanda A, Kodera Y, Takizawa H et al (2016) Identification of a novel serum biomarker for pancreatic cancer, C4b-binding protein $\alpha$-chain (C4BPA) by quantitative proteomic analysis using tandem mass tags. Br J Cancer 115:949956. doi:10.1038/bjc.2016.295

Song W, Gu Y, Lu S, Wu H, Cheng Z, Hu J, Qian Y, Zheng Y, Fan H (2019) LncRNA TRERNA1 facilitates hepatocellular carcinoma metastasis by dimethylating $\mathrm{H} 3 \mathrm{~K} 9$ in the $\mathrm{CDH} 1$ promoter region via the recruitment of the EHMT2/SNAI1 complex. Cell Prolif 52:e12621. doi:10.1111/cpr.12621

Souady J, Hülsewig M, Distler U, Haier J, Denz A, Pilarsky C, Senninger N, Dreisewerd K, Peter-Katalinić J, Müthing J (2011) Differences in CD75s- and iso-CD75s-ganglioside content and altered mRNA expression of sialyltransferases ST6GAL1 and ST3GAL6 in human hepatocellular carcinomas and nontumoral liver tissues. Glycobiology 21:584-594. doi:10.1093/glycob/cwq200

Spector LG, Birch J (2012) The epidemiology of hepatoblastoma. Pediatr Blood Cancer 59:776-779. doi:10.1002/pbc.24215

Stark MS, Woods SL, Gartside MG, Bonazzi VF, Dutton-Regester K, Aoude LG, Chow D, Sereduk C, Niemi NM, Tang N et al (2011) Frequent somatic mutations in MAP3K5 and MAP3K9 in metastatic melanoma identified by exome sequencing. Nat Genet 44:165-169. doi:10.1038/ng.1041

Stępień T, Brożyna M, Kuzdak K, Motylewska E, Komorowski J, Stępień H, Ławnicka H (2017) Elevated Concentrations of SERPINE2/Protease Nexin-1 and Secretory Leukocyte Protease Inhibitor in the Serum of Patients with Papillary Thyroid Cancer. Dis Markers 2017:4962137. doi:10.1155/2017/4962137 
medRxiv preprint doi: https://doi.org/10.1101/2020.12.22.20248756; this version posted December 26, 2020. The copyright holder for this

Subramanian A, Tamayo P, Mootha VK, Mukherjee S, Ebert BL, Gillette MA, Paulovich A, Pomeroy SL, Golub TR, Lander ES et al (2005) Gene set enrichment analysis: a knowledge-based approach for interpreting genome-wide expression profiles. Proc Natl Acad Sci U S A 102:15545-15550. doi:10.1073/pnas.0506580102

Sun C, Huang S, Wang H, Xie R, Zhang L, Zhou Q, He X, Ju W (2019) NonSMC condensin I complex subunit $H$ enhances proliferation, migration, and invasion of hepatocellular carcinoma. Mol Carcinog 58:2266-2275. doi:10.1002/mc.23114

Sun J, Li H, Huo Q, Cui M, Ge C, Zhao F, Tian H, Chen T, Yao M, Li J (2016) The transcription factor FOXN3 inhibits cell proliferation by downregulating E2F5 expression in hepatocellular carcinoma cells. Oncotarget 7:43534-43545. doi:10.18632/oncotarget.9780

Sun WJ, Huang H, He B, Hu DH, Li PH, Yu YJ, Zhou XH, Lv Z, Zhou L, Hu TY et al (2017) Romidepsin induces G2/M phase arrest via Erk/cdc25C/cdc2/cyclinB pathway and apoptosis induction through JNK/cJun/caspase3 pathway in hepatocellular carcinoma cells. Biochem Pharmacol 127:90-100. doi:10.1016/j.bcp.2016.12.008

Sun X, Zhang Q, Chen W, Hu Q, Lou Y, Fu QH, Zhang JY, Chen YW, Ye LY, Wang Y et al (2017) Hook1 inhibits malignancy and epithelial-mesenchymal transition in hepatocellular carcinoma. Tumour Biol 39:1010428317711098. doi:10.1177/1010428317711098

Sun Y, Li W, Shen S, Yang X, Lu B, Zhang X, Lu P, Shen Y, Ji J (2019) Loss of alanine-glyoxylate and serine-pyruvate aminotransferase expression accelerated the progression of hepatocellular carcinoma and predicted poor prognosis. J Transl Med 17:390. doi:10.1186/s12967-019-02138-5

Sutiman N, Lim JS, Muerdter TE, Singh O, Cheung YB, Ng RC, Yap YS, Wong NS, Ang PC, Dent R et al (2016) Pharmacogenetics of UGT1A4, UGT2B7 and UGT2B15 and Their Influence on Tamoxifen Disposition in Asian Breast Cancer Patients. Clin Pharmacokinet 55:1239-1250. doi:10.1007/s40262-016-0402-7

Tan Y, Cheung M, Pei J, Menges CW, Godwin AK, Testa JR (2010) Upregulation of DLX5 promotes ovarian cancer cell proliferation by enhancing 
medRxiv preprint doi: https://doi.org/10.1101/2020.12.22.20248756; this version posted December 26, 2020. The copyright holder for this

IRS-2-AKT signaling. Cancer Res 70:9197-9206. doi:10.1158/00085472.CAN-10-1568

Tang H, Zhao H, Yu ZY, Feng X, Fu BS, Qiu CH, Zhang JW (2019) MicroRNA-194 inhibits cell invasion and migration in hepatocellular carcinoma through PRC1-mediated inhibition of Wnt/ $\beta$-catenin signaling pathway. Dig Liver Dis 51:1314-1322. doi:10.1016/j.dld.2019.02.012

Tang L, Yu W, Wang Y, Li H, Shen Z (2019) Anlotinib inhibits synovial sarcoma by targeting GINS1: a novel downstream target oncogene in progression of synovial sarcoma. Clin Transl Oncol 21:1624-1633. doi:10.1007/s12094-019-02090-2

Tao QF, Yuan SX, Yang F, Yang S, Yang Y, Yuan JH, Wang ZG, Xu QG, Lin KY, Cai J et al (2015) Aldolase B inhibits metastasis through Ten-Eleven Translocation 1 and serves as a prognostic biomarker in hepatocellular carcinoma. Mol Cancer 14:170. doi:10.1186/s12943-015-0437-7

Thole TM, Lodrini M, Fabian J, Wuenschel J, Pfeil S, Hielscher T, KoppSchneider A, Heinicke U, Fulda S, Witt O et al (2017) Neuroblastoma cells depend on HDAC11 for mitotic cell cycle progression and survival. Cell Death Dis 8:e2635. doi:10.1038/cddis.2017.49

Toda K, Nishikawa G, Iwamoto M, Itatani Y, Takahashi R, Sakai Y, Kawada K (2017)Clinical Role of ASCT2 (SLC1A5) in KRAS-Mutated Colorectal Cancer. Int J Mol Sci 18:1632. doi:10.3390/ijms18081632

Tsutsui M, Iizuka N, Moribe T, Miura T, Kimura N, Tamatsukuri S, Ishitsuka H, Fujita Y, Hamamoto Y, Tsunedomi R et al (2010) Methylated cyclin D2 gene circulating in the blood as a prognosis predictor of hepatocellular carcinoma. Clin Chim Acta 411:516-520. doi:10.1016/j.cca.2010.01.004

Uhlen M, Oksvold P, Fagerberg L, Lundberg E, Jonasson K, Forsberg M, Zwahlen M, Kampf C, Wester K, Hober S et al (2010) Towards a knowledgebased Human Protein Atlas. Nat Biotechnol 28:1248-1250. doi:10.1038/nbt1210-1248

Vainio P, Gupta S, Ketola K, Mirtti T, Mpindi JP, Kohonen P, Fey V, Perälä M, Smit F, Verhaegh G et al (2011) Arachidonic acid pathway members PLA2G7, HPGD, EPHX2, and CYP4F8 identified as putative novel therapeutic targets in prostate cancer. Am J Pathol 178:525-536. doi:10.1016/j.ajpath.2010.10.002 
medRxiv preprint doi: https://doi.org/10.1101/2020.12.22.20248756; this version posted December 26, 2020. The copyright holder for this

Vantaku V, Putluri V, Bader DA, Maity S, Ma J, Arnold JM, Rajapakshe K, Donepudi SR, von Rundstedt FC, Devarakonda V et al (2019) Epigenetic loss of AOX1 expression via EZH2 leads to metabolic deregulations and promotes bladder cancer progression. Oncogene 10.1038/s41388-019-0902-7. doi:10.1038/s41388-019-0902-7

Vilarinho S, Erson-Omay EZ, Harmanci AS, Morotti R, Carrion-Grant G, Baranoski J, Knisely AS, Ekong U, Emre S, Yasuno K et al (2014) Paediatric hepatocellular carcinoma due to somatic CTNNB1 and NFE2L2 mutations in the setting of inherited bi-allelic ABCB11 mutations. J Hepatol 61:1178-1183. doi:10.1016/j.jhep.2014.07.003

Vlachos IS, Paraskevopoulou MD, Karagkouni D, Georgakilas G, Vergoulis T, Kanellos I, Anastasopoulos IL, Maniou S, Karathanou K, Kalfakakou D et al (2015) DIANA-TarBase v7.0: indexing more than half a million experimentally supported miRNA:mRNA interactions. Nucleic Acids Res 43:D153-D159. doi:10.1093/nar/gku1215

Wang C, Mou L, Chai HX, Wang F, Yin YZ, Zhang XY (2017) Long noncoding RNA HNF1A-AS1 promotes hepatocellular carcinoma cell proliferation by repressing NKD1 and P21 expression. Biomed Pharmacother 89:926-932. doi:10.1016/j.biopha.2017.01.031

Wang D, Zhao C, Gao L, Wang Y, Gao X, Tang L, Zhang K, Li Z, Han J, Xiao J (2018) NPNT promotes early-stage bone metastases in breast cancer by regulation of the osteogenic niche. J Bone Oncol 13:91-96. doi:10.1016/j.jbo.2018.09.006

Wang J, Gao Y, Wang L, Liu X, Li J, Wang Z, Zhou J, Wang K (2013) A variant (rs932335) in the HSD11B1 gene is associated with colorectal cancer in a Chinese population. Eur J Cancer Prev 22:523-528. doi:10.1097/CEJ.0b013e328365634

Wang J, Li H, Xia C, Yang X, Dai B, Tao K, Dou K (2019) Downregulation of CENPK suppresses hepatocellular carcinoma malignant progression through regulating YAP1. Onco Targets Ther 12:869-882. doi:10.2147/OTT.S190061

Wang J, Li M, Wang H, Pan Y (2012) Identification of essential proteins based on edge clustering coefficient. IEEE/ACM Trans Comput Biol Bioinform 9:1070-1080. doi:10.1109/TCBB.2011.147 
medRxiv preprint doi: https://doi.org/10.1101/2020.12.22.20248756; this version posted December 26, 2020. The copyright holder for this

Wang J, Wang B, Ren H, Chen W (2019) miR-9-5p inhibits pancreatic cancer cell proliferation, invasion and glutamine metabolism by targeting GOT1. Biochem Biophys Res Commun 509:241-248. doi:10.1016/j.bbrc.2018.12.114

Wang LH, Yen CJ, Li TN, Elowe S, Wang WC, Wang LH (2015) Sgo1 is a potential therapeutic target for hepatocellular carcinoma. Oncotarget 6:20232033. doi:10.18632/oncotarget. 2764

Wang PS, Kuai J, Li H, Wang CG, Shi BJ, Zhong L (2016) Mannose-binding lectin 2 rs11003123 polymorphism is associated with the development of hepatocellular carcinoma in patients with hepatitis B-related cirrhosis in the Chinese population. Hepatobiliary Pancreat Dis Int 15:282-288. doi:10.1016/s1499-3872(16)60050-4

Wang R, Yin C, Li XX, Yang XZ, Yang Y, Zhang MY, Wang HY, Zheng XS (2016) Reduced SOD2 expression is associated with mortality of hepatocellular carcinoma patients in a mutant p53-dependent manner. Aging (Albany NY) 8:1184-1200. doi:10.18632/aging.100967

Wang S, Sun H, Ma J, Zang C, Wang C, Wang J, Tang Q, Meyer CA, Zhang Y, Liu XS (2013) Target analysis by integration of transcriptome and ChIP-seq data with BETA. Nat Protoc 8:2502-2515. doi:10.1038/nprot.2013.150

Wang SM, Ooi LL, Hui KM (2011) Upregulation of Rac GTPase-activating protein 1 is significantly associated with the early recurrence of human hepatocellular carcinoma. Clin Cancer Res 17:6040-6051. doi:10.1158/10780432.CCR-11-0557

Wang X, Liao Z, Bai Z, He Y, Duan J, Wei L (2018) MiR-93-5p Promotes Cell Proliferation through Down-Regulating PPARGC1A in Hepatocellular Carcinoma Cells by Bioinformatics Analysis and Experimental Verification. Genes (Basel) 9:51. doi:10.3390/genes9010051

Wang Y, Tan PY, Handoko YA, Sekar K, Shi M, Xie C, Jiang XD, Dong QZ, Goh BK, Ooi LL et al (2019) NUF2 is a valuable prognostic biomarker to predict early recurrence of hepatocellular carcinoma after surgical resection. Int J Cancer 145:662-670. doi:10.1002/ijc.32134

Wang Y, Zhi Q, Ye Q, Zhou C, Zhang L, Yan W, Wu Q, Zhang D, Li P, Huo K (2016) SCYL1-BP1 affects cell cycle arrest in human hepatocellular carcinoma 
medRxiv preprint doi: https://doi.org/10.1101/2020.12.22.20248756; this version posted December 26, 2020. The copyright holder for this

cells via Cyclin F and RRM2. Anticancer Agents Med Chem 16:440-446. doi:10.2174/1871520615666150518093814

Wang YH, Liu CL, Chiu WC, Twu YC, Liao YJ (2019) HMGCS2 Mediates Ketone Production and Regulates the Proliferation and Metastasis of Hepatocellular Carcinomar Cancers (Basel) 11:1876. doi:10.3390/cancers11121876

Wang Z, Liao J, Wu S, Li C, Fan J, Peng Z (2016) Recipient C6 rs9200 genotype is associated with hepatocellular carcinoma recurrence after orthotopic liver transplantation in a Han Chinese population. Cancer Gene Ther 23:157161. doi:10.1038/cgt.2016.7

Wei RR, Zhang MY, Rao HL, Pu HY, Zhang HZ, Wang HY (2012) Identification of $\mathrm{ADH} 4$ as a novel and potential prognostic marker in hepatocellular carcinoma. Med Oncol 29:2737-2743. doi:10.1007/s12032-0110126-3

Wei X, Li X, Yan W, Zhang X, Sun Y, Zhang F (2018) SKP2 Promotes Hepatocellular Carcinoma Progression Through Nuclear AMPK-SKP2-CARM1 Signaling Transcriptionally Regulating Nutrient-Deprived Autophagy Induction. Cell Physiol Biochem 47:2484-2497. doi:10.1159/000491622

Wijayakumara DD, Mackenzie PI, McKinnon RA, Hu DG, Meech R (2017) Regulation of UDP-Glucuronosyltransferases UGT2B4 and UGT2B7 by MicroRNAs in Liver Cancer Cells. J Pharmacol Exp Ther 361:386-397. doi:10.1124/jpet.116.239707

Wilborn TW, Lang NP, Smith M, Meleth S, Falany CN (2006) Association of SULT2A1 allelic variants with plasma adrenal androgens and prostate cancer in African American men. J Steroid Biochem Mol Biol 99:209-214. doi:10.1016/j.jsbmb.2006.01.006

Willis RC, Hogue CW (2006) Searching, viewing, and visualizing data in the Biomolecular Interaction Network Database (BIND). Curr Protoc Bioinformatics Chapter 8. doi:10.1002/0471250953.bi0809s12

Wu G, Li Z, Wang Y, Ju X, Huang R (2018) miR-34a Inhibits Cell Proliferation by Targeting SATB2 in Hepatocellular Carcinoma. Biomed Res Int 2018:2863902. doi:10.1155/2018/2863902 
medRxiv preprint doi: https://doi.org/10.1101/2020.12.22.20248756; this version posted December 26, 2020. The copyright holder for this

Wu Q, Zhang B, Sun Y, Xu R, Hu X, Ren S, Ma Q, Chen C, Shu J, Qi F et al (2019) Identification of novel biomarkers and candidate small molecule drugs in non-small-cell lung cancer by integrated microarray analysis. Onco Targets Ther 12:3545-3563. doi:10.2147/OTT.S198621

Wu Y, Liu ZG, Shi MQ, Yu HZ, Jiang XY, Yang AH, Fu XS, Xu Y, Yang S, $\mathrm{Ni} \mathrm{H}$ et al (2017) Identification of ACTG2 functions as a promoter gene in hepatocellular carcinoma cells migration and tumor metastasis. Biochem Biophys Res Commun 491(2):537-544. doi:10.1016/j.bbrc.2017.04.007

Wu Y, Zhang X, Shen R, Huang J, Lu X, Zheng G, Chen X (2019) Expression and significance of ETFDH in hepatocellular carcinoma. Pathol Res Pract 215:152702. doi:10.1016/j.prp.2019.152702

Xia H, Lee KW, Chen J, Kong SN, Sekar K, Deivasigamani A, Seshachalam VP, Goh BK, Ooi LL, Hui KM (2017) Simultaneous silencing of ACSL4 and induction of GADD45B in hepatocellular carcinoma cells amplifies the synergistic therapeutic effect of aspirin and sorafenib. Cell Death Discov 3:17058. doi:10.1038/cddiscovery.2017.58

Xiang J, Zhang Y, Tuo L, Liu R, Gou D, Liang L, Chen C, Xia J, Tang N, Wang K (2019) Transcriptomic changes associated with PCK1 overexpression in hepatocellular carcinoma cells detected by RNA-seq. Genes Dis 7:150-159. doi:10.1016/j.gendis.2019.04.004

Xiao F, Zuo Z, Cai G, Kang S, Gao X, Li T (2009) miRecords: an integrated resource for microRNA-target interactions. Nucleic Acids Res 37:D105-D110. doi:10.1093/nar/gkn851

Xiao J, Yu H, Ma Z (2019) LINC00339 promotes growth and invasiveness of hepatocellular carcinoma by the miR-1182/SKA1 pathway. Onco Targets Ther 12:4481-4488. doi:10.2147/OTT.S207397

Xie L, Li T, Yang LH (2017) E2F2 induces MCM4, CCNE2 and WHSC1 upregulation in ovarian cancer and predicts poor overall survival. Eur Rev Med Pharmacol Sci 21:2150-2156.

Xiong XD, Qiu FE, Fang JH, Shen Y, Liang C, Jiang W, Zhuang SM (2009) Association analysis between the Cdc6 G1321A polymorphism and the risk for non-Hodgkin lymphoma and hepatocellular carcinoma. Mutat Res 662:10-15. doi:10.1016/j.mrfmmm.2008.11.014 
medRxiv preprint doi: https://doi.org/10.1101/2020.12.22.20248756; this version posted December 26, 2020. The copyright holder for this

Xu B, Xu T, Liu H, Min Q, Wang S, Song Q (2017) MiR-490-5p Suppresses Cell Proliferation and Invasion by Targeting BUB1 in Hepatocellular Carcinoma Cells. Pharmacology 100:269-282. doi:10.1159/000477667

Xu B, Zhang X, Wang S, Shi B (2018) MiR-449a suppresses cell migration and invasion by targeting PLAGL2 in breast cancer. Pathol Res Pract 214:790-795. doi:10.1016/j.prp.2017.12.012

Xu C, Zeng XH, Wang L, Tao SQ, Wu QX, Zhu P, Deng GH, Wang YM (2015) sFRP-4, a potential novel serum marker for chronic hepatitis B-related hepatocellular carcinoma. Hepatobiliary Pancreat Dis Int 14:164-170. doi:10.1016/s1499-3872(15)60352-6

Xu S, Pan J, Cheng X, Zheng J, Wang X, Guan H, Yu H, Bao J, Zhang L (2020) Diallyl trisulfide, a H2 S donor, inhibits cell growth of human papillary thyroid carcinoma KTC-1 cells through a positive feedback loop between H2 S and cystathionine-gamma-lyase. Phytother Res 10.1002/ptr.6586. doi:10.1002/ptr.6586

Xu W, Zhou W, Cheng M, Wang J, Liu Z, He S, Luo X, Huang W, Chen T, Yan $\mathrm{W}$ et al (2017) Hypoxia activates $\mathrm{Wnt} / \beta$-catenin signaling by regulating the expression of BCL9 in human hepatocellular carcinoma. Sci Rep 7:40446. doi:10.1038/srep40446

Xue F, Shi C, Yang L, Li C, Liu Y, Sun Y, Ge R (2019) Prognostic biomarker AASS suppresses proliferation, migration and predicts a good survival of hepatocellular carcinoma in vivo and in vitro. Life Sci S0024-3205(19)30436-9. doi:10.1016/j.1fs.2019.05.080

Xue X, Bredell BX, Anderson ER, Martin A, Mays C, Nagao-Kitamoto H, Huang S, Győrffy B, Greenson JK, Hardiman K et al (2017) Quantitative proteomics identifies STEAP4 as a critical regulator of mitochondrial dysfunction linking inflammation and colon cancer. Proc Natl Acad Sci U S A 114:E9608-E9617. doi:10.1073/pnas.1712946114

Yokoyama S, Kaneko A, Dempo K, Chisaka N, Mori M, Onoe T (1982) Histochemical and cytochemical study of butyrylcholinesterase activity in rat hepatocellular carcinomas induced by 3'-methyl-4-dimethylaminoazobenzene. Cancer Res 42:4158-4163. 
medRxiv preprint doi: https://doi.org/10.1101/2020.12.22.20248756; this version posted December 26, 2020. The copyright holder for this

Yamada SI, Ohira M, Horie H, Ando K, Takayasu H, Suzuki Y, Sugano S, Hirata T, Goto T, Matsunaga T et al (2004) Expression profiling and differential screening between hepatoblastomas and the corresponding normal livers: identification of high expression of the PLK1 oncogene as a poor-prognostic indicator of hepatoblastomas. Oncogene 23:5901-5911. doi:10.1038/sj.onc.1207782

Yamanoi K, Matsumura N, Murphy SK, Baba T, Abiko K, Hamanishi J, Yamaguchi K, Koshiyama M, Konishi I, Mandai M (2016) Suppression of ABHD2, identified through a functional genomics screen, causes anoikis resistance, chemoresistance and poor prognosis in ovarian cancer. Oncotarget 7:47620-47636. doi:10.18632/oncotarget.9951

Yan Z, Xu L, Zhang J, Lu Q, Luo S, Xu L (2016) Aldehyde dehydrogenase 1A1 stabilizes transcription factor Gli2 and enhances the activity of Hedgehog signaling in hepatocellular cancer. Biochem Biophys Res Commun 471:466473. doi:10.1016/j.bbrc.2016.02.052

Yang CK, Yu TD, Han CY, Qin W, Liao XW, Yu L, Liu XG, Zhu GZ, Su H, Lu SC (2017) Genome-Wide Association Study of MKI67 Expression and its Clinical Implications in HBV-Related Hepatocellular Carcinoma in Southern China. Cell Physiol Biochem 42:1342-1357. doi:10.1159/000478963

Yang G, Liang Y, Zheng T, Song R, Wang J, Shi H, Sun B, Xie C, Li Y, Han J et al (2016) FCN2 inhibits epithelial-mesenchymal transition-induced metastasis of hepatocellular carcinoma via TGF- $\beta / \mathrm{Smad}$ signaling. Cancer Lett 378:80-86. doi:10.1016/j.canlet.2016.05.007

Yang J, Xie Q, Zhou H, Chang L, Wei W, Wang Y, Li H, Deng Z, Xiao Y, Wu J et al (2018) Proteomic Analysis and NIR-II Imaging of MCM2 Protein in Hepatocellular Carcinoma. J Proteome Res 17:2428-2439. doi:10.1021/acs.jproteome.8b00181

Yang T, Wen Y, Li J, Yang J, Tan T, Pan J, Hu C, Zhang J, Xin Y, Li S et al (2019) Association of the TP53 rs1042522 C>G polymorphism and hepatoblastoma risk in Chinese children. J Cancer 10:3444-3449. doi:10.7150/jca.33063

Yang X, Zhang D, Liu S, Li X, Hu W, Han C (2018) KLF4 suppresses the migration of hepatocellular carcinoma by transcriptionally upregulating monoglyceride lipase. Am J Cancer Res 8:1019-1029. 
medRxiv preprint doi: https://doi.org/10.1101/2020.12.22.20248756; this version posted December 26, 2020. The copyright holder for this

Yang YF, Pan YH, Cao Y, Fu J, Yang X, Zhang MF, Tian QH (2017) PDZ binding kinase, regulated by FoxM1, enhances malignant phenotype via activation of $\beta$-Catenin signaling in hepatocellular carcinoma. Oncotarget 8:47195-47205. doi:10.18632/oncotarget.17587

Yao Z, Hu K, Huang H, Xu S, Wang Q, Zhang P, Yang P, Liu B (2015) shRNA-mediated silencing of the RFC3 gene suppresses hepatocellular carcinoma cell proliferation. Int J Mol Med 36:1393-1399. doi:10.3892/ijmm.2015.2350

Ye FG, Song CG, Cao ZG, Xia C, Chen DN, Chen L, Li S, Qiao F, Ling H, Yao L et al (2015) Cytidine Deaminase Axis Modulated by miR-484 Differentially Regulates Cell Proliferation and Chemoresistance in Breast Cancer. Cancer Res 75:1504-1515. doi:10.1158/0008-5472.CAN-14-2341

Ye K, Wu Y, Sun Y, Lin J, Xu J (2016) TLR4 siRNA inhibits proliferation and invasion in colorectal cancer cells by downregulating ACAT1 expression. Life Sci 155:133-139. doi:10.1016/j.1fs.2016.05.012

Yin J, Liu H, Liu Z, Owzar K, Han Y, Su L, Wei Y, Hung RJ, Brhane Y, McLaughlin J et al (2017) Pathway-analysis of published genome-wide association studies of lung cancer: A potential role for the CYP4F3 locus. Mol Carcinog 56:1663-1672. doi:10.1002/mc.22622

You J, Chen W, Chen J, Zheng Q, Dong J, Zhu Y (2018) The Oncogenic Role of ARG1 in Progression and Metastasis of Hepatocellular Carcinoma. Biomed Res Int 2018:2109865. doi:10.1155/2018/2109865

Yu D, Green B, Marrone A, Guo Y, Kadlubar S, Lin D, Fuscoe J, Pogribny I, Ning B (2015) Suppression of CYP2C9 by microRNA hsa-miR-128-3p in human liver cells and association with hepatocellular carcinoma. Sci Rep 5:8534. . doi:10.1038/srep08534

Yu M, Tang Z, Meng F, Tai M, Zhang J, Wang R, Liu C, Wu Q (2016) Elevated expression of FoxM1 promotes the tumor cell proliferation in hepatocellular carcinoma. Tumour Biol 37:1289-1297. doi:10.1007/s13277015-3436-9

Yu Y, Cai O, Wu P, Tan S (2019) MiR-490-5p inhibits the stemness of hepatocellular carcinoma cells by targeting ECT2. J Cell Biochem 120:967976. doi:10.1002/jcb.27459 
medRxiv preprint doi: https://doi.org/10.1101/2020.12.22.20248756; this version posted December 26, 2020. The copyright holder for this

Yuan J, Zhang N, Zhu H, Liu J, Xing H, Ma F, Yang M (2017) CHST9 rs1436904 genetic variant contributes to prognosis of triple-negative breast cancer. Sci Rep 7:11802. doi:10.1038/s41598-017-12306-6

Yuan L, Wang J, Xiao H, Wu W, Wang Y, Liu X (2013) MAPK signaling pathways regulate mitochondrial-mediated apoptosis induced by isoorientin in human hepatoblastoma cancer cells. Food Chem Toxicol 53:62-68. doi:10.1016/j.fet.2012.11.048

Zaki N, Efimov D, Berengueres J (2013) Protein complex detection using interaction reliability assessment and weighted clustering coefficient. BMC Bioinformatics 14:163. doi:10.1186/1471-2105-14-163

Zeng C, Xing W, Liu Y (2019) Identification of UGP2 as a progression marker that promotes cell growth and motility in human glioma. J Cell Biochem 120:12489-12499. doi:10.1002/jcb.28515

Zhang H, Yu C, Chen M, Li Z, Tian S, Jiang J, Sun C (2016) miR-522 contributes to cell proliferation of hepatocellular carcinoma by targeting DKK1 and SFRP2. Tumour Biol 37:11321-11329. doi:10.1007/s13277-016-4995-0

Zhang L, Li L, Gao G, Wei G, Zheng Y, Wang C, Gao N, Zhao Y, Deng J, Chen $\mathrm{H}$ et al (2017) Elevation of GPRC5A expression in colorectal cancer promotes tumor progression through $\mathrm{VNN}-1$ induced oxidative stress. Int $\mathbf{J}$ Cancer 140:2734-2747. doi:10.1002/ijc.30698

Zhang Q, Hong Z, Zhu J, Zeng C, Tang Z, Wang W, Huang H (2020) miR4999-5p Predicts Colorectal Cancer Survival Outcome and Reprograms Glucose Metabolism by Targeting PRKAA2. Onco Targets Ther 13:1199-1210. doi:10.2147/OTT.S234666

Zhang Q, Jiang K, Li Y, Gao D, Sun L, Zhang S, Liu T, Guo K, Liu Y (2015) Histidine-rich glycoprotein function in hepatocellular carcinoma depends on its $\mathrm{N}$-glycosylation status, and it regulates cell proliferation by inhibiting Erk1/2 phosphorylation. Oncotarget 6:30222-30231. doi:10.18632/oncotarget.4997

Zhang Q, Su R, Shan C, Gao C, Wu P (2018) Non-SMC Condensin I Complex, Subunit G (NCAPG) is a Novel Mitotic Gene Required for Hepatocellular Cancer Cell Proliferation and Migration. Oncol Res 26:269-276. doi:10.3727/096504017X15075967560980 
medRxiv preprint doi: https://doi.org/10.1101/2020.12.22.20248756; this version posted December 26, 2020. The copyright holder for this

Zhang R, Zhang F, Sun Z, Liu P, Zhang X, Ye Y, Cai B, Walsh MJ, Ren X, Hao X et al (2019) LINE-1 Retrotransposition Promotes the Development and Progression of Lung Squamous Cell Carcinoma by Disrupting the TumorSuppressor Gene FGGY. Cancer Res 79:4453-4465. doi:10.1158/00085472.CAN-19-0076

Zhang S, Nguyen LH, Zhou K, Tu HC, Sehgal A, Nassour I, Li L, Gopal P, Goodman J, Singal AG et al (2018) Knockdown of Anillin Actin Binding Protein Blocks Cytokinesis in Hepatocytes and Reduces Liver Tumor Development in Mice Without Affecting Regeneration. Gastroenterology 154:1421-1434. doi:10.1053/j.gastro.2017.12.013

Zhang X, Wang F, Huang Y, Ke K, Zhao B, Chen L, Liao N, Wang L, Li Q, Liu $X$ et al (2019) FGG promotes migration and invasion in hepatocellular carcinoma cells through activating epithelial to mesenchymal transition. Cancer Manag Res 11:1653-1665. doi:10.2147/CMAR.S188248

Zhang X, You Q, Zhang X, Chen X (2015) SOCS3 Methylation Predicts a Poor Prognosis in HBV Infection-Related Hepatocellular Carcinoma. Int J Mol Sci 16:22662-22675. doi:10.3390/ijms160922662

Zhang Y, Zou X, Qian W, Weng X, Zhang L, Zhang L, Wang S, Cao X, Ma L, Wei G et al (2019) Enhanced PAPSS2/VCAN sulfation axis is essential for Snail-mediated breast cancer cell migration and metastasis. Cell Death Differ 26:565-579. doi:10.1038/s41418-018-0147-y

Zhang Y, Zhao Y, Wu J, Liangpunsakul S, Niu J, Wang L (2018) MicroRNA26-5p functions as a new inhibitor of hepatoblastoma by repressing lin-28 homolog B and aurora kinase a expression. Hepatol Commun.2:861-871. doi:10.1002/hep4.1185

Zhao Y, Zhao E, Zhang J, Chen Y, Ma J, Li H (2019) A Comprehensive Evaluation of the Association between Polymorphisms in XRCC1, ERCC2, and XRCC3 and Prognosis in Hepatocellular Carcinoma: A Meta-Analysis. J Oncol 2019:2408946. doi:10.1155/2019/2408946

Zheng K, Chen Z, Feng H, Chen Y, Zhang C, Yu J, Luo Y, Zhao L, Jiang X, Shi F (2019) Sphingomyelin synthase 2 promotes an aggressive breast cancer phenotype by disrupting the homoeostasis of ceramide and sphingomyelin. Cell Death Dis 10:157. doi:10.1038/s41419-019-1303-0 
medRxiv preprint doi: https://doi.org/10.1101/2020.12.22.20248756; this version posted December 26, 2020. The copyright holder for this

Zheng L, Guo Q, Xiang C, Liu S, Jiang Y, Gao L, Ni H, Wang T, Zhao Q, Liu $\mathrm{H}$ et al (2019) Transcriptional factor six 2 promotes the competitive endogenous RNA network between CYP4Z1 and pseudogene CYP4Z2P responsible for maintaining the stemness of breast cancer cells. J Hematol Oncol 12:23. doi:10.1186/s13045-019-0697-6

Zheng W, Yao M, Sai W, Qian Q, Pan L, Qiu L, Huang J, Wu W, Yao D (2016) Diagnostic and prognostic significance of secretory clusterin expression in patients with hepatocellular carcinoma. Tumour Biol 37:999-1008. doi:10.1007/s13277-015-3875-3

Zhong L, Wang Y, Cheng Y, Wang W, Lu B, Zhu L, Ma Y (2018) Circular RNA circC3P1 suppresses hepatocellular carcinoma growth and metastasis through miR-4641/PCK1 pathway. Biochem Biophys Res Commun 499:10441049. doi:10.1016/j.bbrc.2018.03.221

Zhou C, Yu J, Wang M, Yang J, Xiong H, Huang H, Wu D, Hu S, Wang Y, Chen XZ et al (2017) Identification of glycerol-3-phosphate Dehydrogenase 1 as a Tumour Suppressor in Human Breast Cancer. Identification of glycerol-3phosphate dehydrogenase 1 as a tumour suppressor in human breast cancer. Oncotarget 8:101309-101324. doi:10.18632/oncotarget.21087

Zhou G, Soufan O, Ewald J, Hancock REW, Basu N, Xia J (2019) NetworkAnalyst 3.0: a visual analytics platform for comprehensive gene expression profiling and meta-analysis. Nucleic Acids Res 47:W234-W241. doi:10.1093/nar/gkz240

Zhu H, Wang G, Zhou X, Song X, Gao H, Ma C, Chang H, Li H, Liu FF, Lu J et al (2016) miR-1299 suppresses cell proliferation of hepatocellular carcinoma (HCC) by targeting CDK6. Biomed Pharmacother 83:792-797. doi:10.1016/j.biopha.2016.07.037

Zhu P, Jin J, Liao Y, Li J, Yu XZ, Liao W, He S (2015) A novel prognostic biomarker SPC24 up-regulated in hepatocellular carcinoma. Oncotarget 6:41383-41397. doi:10.18632/oncotarget.5510

Zhu X, Wang Z, Qiu X, Wang W, Bei C, Tan C, Qin L, Ren Y, Tan S (2018) Rs2303428 of MSH2 Is Associated with Hepatocellular Carcinoma Prognosis in a Chinese Population. DNA Cell Biol 37:634-641. doi:10.1089/dna.2018.4224 
medRxiv preprint doi: https://doi.org/10.1101/2020.12.22.20248756; this version posted December 26, 2020. The copyright holder for this preprint (which was not certified by peer review) is the author/funder, who has granted medRxiv a license to display the preprint in perpetuity. All rights reserved. No reuse allowed without permission.

Zhu YH, Li JB, Wu RY, Yu Y, Li X, Li ZL, Zhang HL, Feng GK, Deng R, Zhu XF (2020) Clinical significance and function of RDH16 as a tumor-suppressing gene in hepatocellular carcinoma. Hepatol Res 50:110-120. doi:10.1111/hepr.1343

Zhuang J, Song Y, Ye Y, He S, Ma X, Zhang M, Ni J, Wang J, Xia W (2019) PYCR1 interference inhibits cell growth and survival via c-Jun N-terminal kinase/insulin receptor substrate 1 (JNK/IRS1) pathway in hepatocellular cancer. J Transl Med 17:343. doi:10.1186/s12967-019-2091-0

Zhuang L, Yang Z, Meng Z (2018) Upregulation of BUB1B, CCNB1, CDC7, CDC20, and MCM3 in Tumor Tissues Predicted Worse Overall Survival and Disease-Free Survival in Hepatocellular Carcinoma Patients. Biomed Res Int 2018:7897346. doi:10.1155/2018/7897346

Zuo SR, Zuo XC, He Y, Fang WJ, Wang CJ, Zou H, Chen P, Huang LF, Huang LH, Xiang $\mathrm{H}$ et al (2018) Positive Expression of SMYD2 is Associated with Poor Prognosis in Patients with Primary Hepatocellular Carcinoma. J Cancer 9:321-330. doi:10.7150/jca.22218

\section{Tables}

Table 1. Primers used for quantitative PCR

\begin{tabular}{ccc}
\hline & Primer sequence $\left(\mathbf{5}^{\prime} \rightarrow \mathbf{3}^{\prime}\right)$ & \\
\hline Gene & Forward & Reverse \\
& & \\
TP53 & CAGCACATGACGGAGGTTGT & TCATCCAAATACTCCACACGC \\
PLK1 & AAAGAGATCCCGGAGGTCCTA & GGCTGCGGTGAATGGATATTTC \\
AURKA & GAGGTCCAAAACGTGTTCTCG & ACAGGATGAGGTACACTGGTTG \\
CDK1 & AAACTACAGGTCAAGTGGTAGCC & TCCTGCATAAGCACATCCTGA \\
ANLN & TGCCAGGCGAGAGAATCTTC & CGCTTAGCATGAGTCATAGACCT \\
ESR1 & CCCACTCAACAGCGTGTCTC & CGTCGATTATCTGAATTTGCCT \\
FGB & AGTGATTCAGAACCGTCAAGAC & CATCCTGGTAAGCTGGCTAATTT \\
ACAT1 & AAGGCAGGCAGTATTGGGTG & ACATCAGTTAGCCCGTCTTTTAC \\
GOT1 & ATGGCACCTCCGTCAGTCT & AGTCATCCGTGCGATATGCTC \\
ALAS1 & CGCCGCTGCCCATTCTTAT & TCTGTTGGACCTTGGCCTTAG \\
\hline
\end{tabular}


medRxiv preprint doi: https://doi.org/10.1101/2020.12.22.20248756; this version posted December 26, 2020. The copyright holder for this preprint (which was not certified by peer review) is the author/funder, who has granted medRxiv a license to display the preprint in perpetuity.

All rights reserved. No reuse allowed without permission.

Table 2 The statistical metrics for key differentially expressed genes (DEGs) 
medRxiv preprint doi: https://doi.org/10.1101/2020.12.22.20248756; this version posted December 26, 2020. The copyright holder for this preprint (which was not certified by peer review) is the author/funder, who has granted medRxiv a license to display the preprint in perpetuity. All rights reserved. No reuse allowed without permission.

\begin{tabular}{|c|c|c|c|c|c|c|c|}
\hline 7976783 & DLK1 & 4.113511 & $1.52 \mathrm{E}-24$ & 4.9E-20 & 15.80084 & Up & delta like non-canonical Notch ligand 1 \\
\hline 8080964 & GXYLT2 & 3.259808 & $2.21 \mathrm{E}-23$ & $3.58 \mathrm{E}-19$ & 15.02703 & Up & glucosidexylosyltransferase 2 \\
\hline 7995525 & NKD1 & 3.137271 & $5.93 \mathrm{E}-21$ & $3.2 \mathrm{E}-17$ & 13.47981 & Up & NKD inhibitor of WNT signaling pathway 1 \\
\hline 7968015 & TNFRSF19 & 2.516001 & $3.79 \mathrm{E}-20$ & $1.2 \mathrm{E}-16$ & 12.98412 & Up & TNF receptor superfamily member 19 \\
\hline 8041853 & EPCAM & 3.294629 & $3.87 \mathrm{E}-20$ & $1.2 \mathrm{E}-16$ & 12.97881 & Up & epithelial cell adhesion molecule \\
\hline 8096704 & NPNT & 3.225945 & $4.08 \mathrm{E}-20$ & $1.2 \mathrm{E}-16$ & 12.9651 & Up & nephronectin \\
\hline 8098439 & EPCAM & 3.830281 & $1.29 \mathrm{E}-19$ & $2.61 \mathrm{E}-16$ & 12.66176 & Up & epithelial cell adhesion molecule \\
\hline 8088919 & ROBO1 & 2.160142 & $1.81 \mathrm{E}-19$ & $3.44 \mathrm{E}-16$ & 12.5732 & Up & roundabout guidance receptor 1 \\
\hline 8006415 & TMEM98 & 1.846189 & $2.91 \mathrm{E}-19$ & $4.95 \mathrm{E}-16$ & 12.44935 & Up & transmembrane protein 98 \\
\hline 8175234 & GPC3 & 4.165105 & 4.44E-19 & $7.18 \mathrm{E}-16$ & 12.33928 & Up & glypican 3 \\
\hline 7979241 & BMP4 & 2.738247 & $8.02 \mathrm{E}-19$ & $1.23 \mathrm{E}-15$ & 12.18639 & Up & $\begin{array}{c}\text { bone morphogenetic protein } 4 \\
\text { leucine rich repeat containing } G \text { protein-coupled }\end{array}$ \\
\hline 7957140 & LGR5 & 3.866313 & $1.42 \mathrm{E}-18$ & $1.91 \mathrm{E}-15$ & 12.03904 & Up & receptor 5 \\
\hline 8019334 & NOTUM & 3.394432 & $3.47 \mathrm{E}-18$ & $3.87 \mathrm{E}-15$ & 11.81037 & Up & notum, palmitoleoyl-protein carboxylesterase \\
\hline 8105267 & ITGA2 & 2.928809 & $3.47 \mathrm{E}-18$ & $3.87 \mathrm{E}-15$ & 11.81017 & Up & integrin subunit alpha 2 \\
\hline 8040365 & TRIB2 & 1.628254 & 7.83E-18 & $7.91 \mathrm{E}-15$ & 11.60346 & Up & $\begin{array}{c}\text { tribblespseudokinase } 2 \\
\text { insulin like growth factor } 2 \text { mRNA binding protein }\end{array}$ \\
\hline 8008151 & IGF2BP1 & 3.212271 & $8.72 \mathrm{E}-18$ & $8.54 \mathrm{E}-15$ & 11.57612 & Up & 1 \\
\hline 8167656 & MAGED1 & 1.540701 & $1.58 \mathrm{E}-17$ & $1.46 \mathrm{E}-14$ & 11.42582 & Up & MAGE family member D1 \\
\hline 8059376 & SERPINE2 & 2.631715 & $2.04 \mathrm{E}-17$ & $1.66 \mathrm{E}-14$ & 11.3616 & Up & serpin family E member 2 \\
\hline 8019842 & TYMS & 2.572342 & $2.16 \mathrm{E}-17$ & $1.71 \mathrm{E}-14$ & 11.34664 & $\mathrm{Up}$ & thymidylatesynthetase \\
\hline 7926875 & BAMBI & 2.043253 & $3.37 \mathrm{E}-17$ & $2.42 \mathrm{E}-14$ & 11.23561 & Up & BMP and activin membrane bound inhibitor \\
\hline 8134339 & PEG10 & 3.579138 & $4.02 \mathrm{E}-17$ & $2.71 \mathrm{E}-14$ & 11.19104 & Up & paternally expressed 10 \\
\hline 8003116 & HSDL1 & 1.388826 & $1.11 \mathrm{E}-16$ & $6.77 \mathrm{E}-14$ & 10.9372 & Up & hydroxysteroid dehydrogenase like 1 \\
\hline 8020141 & APCDD1 & 3.490123 & $1.5 \mathrm{E}-16$ & 8.67E-14 & 10.86241 & Up & APC down-regulated 1 \\
\hline 8111892 & OXCT1 & 1.708043 & $1.5 \mathrm{E}-16$ & $8.67 \mathrm{E}-14$ & 10.86209 & Up & 3-oxoacid CoA-transferase 1 \\
\hline 7927631 & DKK1 & 4.545866 & $2.62 \mathrm{E}-16$ & $1.34 \mathrm{E}-13$ & 10.72426 & Up & $\begin{array}{l}\text { dickkopf WNT signaling pathway inhibitor } 1 \\
\text { insulin like growth factor } 2 \text { mRNA binding protein }\end{array}$ \\
\hline 8092552 & IGF2BP2 & 1.933414 & $2.78 \mathrm{E}-16$ & $1.4 \mathrm{E}-13$ & 10.7092 & Up & 2 \\
\hline 8137865 & GNA12 & 1.382382 & $4.1 \mathrm{E}-16$ & $2.04 \mathrm{E}-13$ & 10.61329 & Up & G protein subunit alpha 12 \\
\hline 7928107 & MACROH2A2 & 1.792853 & $8.06 \mathrm{E}-16$ & $3.62 \mathrm{E}-13$ & 10.44687 & Up & macroH2A.2 histone \\
\hline 8102232 & LEF1 & 2.946948 & $1.09 \mathrm{E}-15$ & 4.63E-13 & 10.37302 & Up & lymphoid enhancer binding factor 1 \\
\hline 8040292 & GREB1 & 2.435845 & $2.1 \mathrm{E}-15$ & $8.28 \mathrm{E}-13$ & 10.21171 & Up & growth regulating estrogen receptor binding 1 \\
\hline 8117372 & H2AC6 & 1.324135 & $2.22 \mathrm{E}-15$ & $8.54 \mathrm{E}-13$ & 10.1984 & Up & H2A clustered histone 6 \\
\hline 7963157 & RACGAP1 & 1.702383 & $2.31 \mathrm{E}-15$ & $8.78 \mathrm{E}-13$ & 10.18853 & Up & RacGTPase activating protein 1 \\
\hline 7953130 & RHNO1 & 1.329226 & $2.38 \mathrm{E}-15$ & $8.87 \mathrm{E}-13$ & 10.18121 & Up & RAD9-HUS1-RAD1 interacting nuclear orphan 1 \\
\hline 8068684 & FAM3B & 3.172667 & $2.44 \mathrm{E}-15$ & $8.87 \mathrm{E}-13$ & 10.1748 & Up & family with sequence similarity 3 member B \\
\hline 7996772 & SLC7A6 & 1.626316 & $2.56 \mathrm{E}-15$ & $9.21 \mathrm{E}-13$ & 10.16299 & Up & solute carrier family 7 member 6 \\
\hline 8016994 & RNF43 & 2.212143 & $2.9 \mathrm{E}-15$ & $9.96 \mathrm{E}-13$ & 10.13313 & Up & ring finger protein 43 \\
\hline 8062623 & PLCG1 & 1.389693 & $3.73 \mathrm{E}-15$ & $1.24 \mathrm{E}-12$ & 10.0716 & Up & phospholipase C gamma 1 \\
\hline 8167815 & MAGED2 & 1.335218 & $4.85 \mathrm{E}-15$ & $1.51 \mathrm{E}-12$ & 10.00733 & Up & MAGE family member D2 \\
\hline 8095907 & FRAS1 & 2.762056 & $5.67 \mathrm{E}-15$ & $1.73 \mathrm{E}-12$ & 9.969361 & Up & Fraser extracellular matrix complex subunit 1 \\
\hline 8163109 & FRRS1L & 2.992961 & $5.86 \mathrm{E}-15$ & $1.75 \mathrm{E}-12$ & 9.961646 & Up & ferric chelate reductase 1 like \\
\hline 7925250 & GNG4 & 2.985545 & $6.69 \mathrm{E}-15$ & $1.98 \mathrm{E}-12$ & 9.929134 & Up & $\mathrm{G}$ protein subunit gamma 4 \\
\hline 8046380 & ITGA6 & 2.327218 & $8.65 \mathrm{E}-15$ & $2.45 \mathrm{E}-12$ & 9.866792 & Up & integrin subunit alpha 6 \\
\hline 7976012 & NRXN3 & 2.338707 & $1.03 \mathrm{E}-14$ & $2.89 \mathrm{E}-12$ & 9.824912 & Up & neurexin 3 \\
\hline 8054395 & UXS1 & 1.161334 & $1.18 \mathrm{E}-14$ & $3.26 \mathrm{E}-12$ & 9.79133 & Up & UDP-glucuronate decarboxylase 1 \\
\hline
\end{tabular}


medRxiv preprint doi: https://doi.org/10.1101/2020.12.22.20248756; this version posted December 26, 2020. The copyright holder for this preprint (which was not certified by peer review) is the author/funder, who has granted medRxiv a license to display the preprint in perpetuity.

All rights reserved. No reuse allowed without permission.

\begin{tabular}{|c|c|c|c|c|c|c|c|}
\hline 8017718 & AXIN2 & 1.63549 & $1.66 \mathrm{E}-14$ & $4.46 \mathrm{E}-12$ & 9.709379 & Up & $\begin{array}{l}\text { axin } 2 \\
\text { transient receptor potential cation channel }\end{array}$ \\
\hline 8083166 & TRPC1 & 1.497938 & $1.91 \mathrm{E}-14$ & 4.99E-12 & 9.67533 & Up & subfamily $\mathrm{C}$ member 1 \\
\hline 7923978 & CD34 & 1.62607 & $1.92 \mathrm{E}-14$ & 4.99E-12 & 9.674077 & Up & CD34 molecule \\
\hline 7976812 & SNORD113-4 & 3.888398 & $2.07 \mathrm{E}-14$ & 5.3E-12 & 9.655838 & Up & small nucleolar RNA, C/D box 113-4 \\
\hline 7924207 & PTPN14 & 1.660471 & $2.81 \mathrm{E}-14$ & $6.89 \mathrm{E}-12$ & 9.581146 & Up & protein tyrosine phosphatase non-receptor type 14 \\
\hline 7976816 & SNORD114-3 & 2.764436 & $2.94 \mathrm{E}-14$ & 7.03E-12 & 9.570781 & Up & small nucleolar RNA, C/D box 114-3 \\
\hline 8087935 & $\begin{array}{c}\text { NT5DC2 } \\
\text { SNORD114- }\end{array}$ & 2.672105 & $3.86 \mathrm{E}-14$ & 8.97E-12 & 9.504965 & Up & 5'-nucleotidase domain containing 2 \\
\hline 7976826 & 26 & 3.500075 & $5.14 \mathrm{E}-14$ & $1.18 \mathrm{E}-11$ & 9.43543 & Up & small nucleolar RNA, C/D box 114-26 \\
\hline 8177222 & $\mathrm{CD} 24$ & 2.046121 & $5.46 \mathrm{E}-14$ & $1.23 \mathrm{E}-11$ & 9.421122 & Up & CD24 molecule \\
\hline 7918323 & SORT1 & 1.555872 & $5.79 \mathrm{E}-14$ & $1.28 \mathrm{E}-11$ & 9.406769 & Up & sortilin 1 \\
\hline 7974288 & ABHD12B & 2.969266 & $6.54 \mathrm{E}-14$ & $1.42 \mathrm{E}-11$ & 9.377584 & Up & abhydrolase domain containing $12 \mathrm{~B}$ \\
\hline 8047709 & PARD3B & 1.332102 & $6.97 \mathrm{E}-14$ & $1.5 \mathrm{E}-11$ & 9.362183 & Up & par-3 family cell polarity regulator beta \\
\hline 8072160 & ZNRF3 & 1.696436 & $8.49 \mathrm{E}-14$ & $1.77 \mathrm{E}-11$ & 9.314723 & Up & zinc and ring finger 3 \\
\hline 8101828 & TSPAN5 & 3.136839 & $8.53 \mathrm{E}-14$ & $1.77 \mathrm{E}-11$ & 9.313594 & Up & tetraspanin 5 \\
\hline 7972682 & POGLUT2 & 1.21036 & $1.1 \mathrm{E}-13$ & $2.24 \mathrm{E}-11$ & 9.252202 & Up & protein O-glucosyltransferase 2 \\
\hline 8138602 & GSDME & 1.255804 & $1.45 \mathrm{E}-13$ & $2.87 \mathrm{E}-11$ & 9.18698 & Up & gasdermin $\mathrm{E}$ \\
\hline 7929831 & HIF1AN & 1.118102 & $1.62 \mathrm{E}-13$ & $3.15 \mathrm{E}-11$ & 9.160219 & Up & hypoxia inducible factor 1 subunit alpha inhibitor \\
\hline 8013753 & RAB34 & 1.892059 & $1.78 \mathrm{E}-13$ & 3.43E-11 & 9.136603 & Up & RAB34, member RAS oncogene family \\
\hline 7977761 & SALL2 & 1.452583 & $1.84 \mathrm{E}-13$ & $3.51 \mathrm{E}-11$ & 9.129421 & Up & spalt like transcription factor 2 \\
\hline 8087254 & IMPDH2 & 1.482529 & $2.04 \mathrm{E}-13$ & $3.84 \mathrm{E}-11$ & 9.103799 & Up & inosine monophosphate dehydrogenase 2 \\
\hline 7901460 & GPX7 & 1.914138 & $2.62 \mathrm{E}-13$ & $4.87 \mathrm{E}-11$ & 9.04402 & Up & glutathione peroxidase 7 \\
\hline 8120279 & LRRC1 & 1.212828 & $2.72 \mathrm{E}-13$ & $5 \mathrm{E}-11$ & 9.035183 & Up & $\begin{array}{c}\text { leucine rich repeat containing } 1 \\
\text { feline leukemia virus subgroup } C \text { cellular receptor }\end{array}$ \\
\hline 7909628 & FLVCR1 & 2.018228 & $3.69 \mathrm{E}-13$ & $6.48 \mathrm{E}-11$ & 8.96213 & Up & \\
\hline 8115600 & ZBED8 & 1.579939 & 4.73E-13 & $8 \mathrm{E}-11$ & 8.902773 & Up & zinc finger BED-type containing 8 \\
\hline 7953351 & NCAPD2 & 1.506645 & $4.96 \mathrm{E}-13$ & $8.31 \mathrm{E}-11$ & 8.891287 & Up & non-SMC condensin I complex subunit D2 \\
\hline 8102800 & SLC7A11 & 3.383052 & $4.99 \mathrm{E}-13$ & $8.32 \mathrm{E}-11$ & 8.889747 & Up & solute carrier family 7 member 11 \\
\hline 8148280 & SQLE & 2.534481 & $5.41 \mathrm{E}-13$ & $8.83 \mathrm{E}-11$ & 8.870684 & Up & squaleneepoxidase \\
\hline 8102214 & PAPSS1 & 1.214629 & $5.48 \mathrm{E}-13$ & $8.89 \mathrm{E}-11$ & 8.867655 & $\mathrm{Up}$ & 3'-phosphoadenosine 5'-phosphosulfate synthase 1 \\
\hline 8157582 & GSN & 1.53687 & $8.98 \mathrm{E}-13$ & $1.36 \mathrm{E}-10$ & 8.749383 & Up & gelsolin \\
\hline 8124423 & $\mathrm{H} 2 \mathrm{BC} 8$ & 1.608558 & $1.12 \mathrm{E}-12$ & $1.62 \mathrm{E}-10$ & 8.696875 & Up & H2B clustered histone 8 \\
\hline 7908041 & LAMC1 & 1.4501 & $1.25 \mathrm{E}-12$ & $1.77 \mathrm{E}-10$ & 8.670225 & Up & $\begin{array}{c}\text { laminin subunit gamma } 1 \\
\text { ADP ribosylation factor like GTPase } 6 \text { interacting }\end{array}$ \\
\hline 8045768 & ARL6IP6 & 1.246577 & $1.26 \mathrm{E}-12$ & $1.77 \mathrm{E}-10$ & 8.669011 & Up & protein 6 \\
\hline 8042310 & SLC1A4 & 1.637666 & $1.31 \mathrm{E}-12$ & $1.83 \mathrm{E}-10$ & 8.659492 & Up & solute carrier family 1 member 4 \\
\hline 7915682 & ZSWIM5 & 1.82227 & $1.43 \mathrm{E}-12$ & $1.94 \mathrm{E}-10$ & 8.639109 & Up & zinc finger SWIM-type containing 5 \\
\hline 8030914 & ZNF610 & 1.138321 & $2.05 \mathrm{E}-12$ & $2.63 \mathrm{E}-10$ & 8.552415 & Up & zinc finger protein 610 \\
\hline 8148501 & PTP4A3 & 1.514481 & $2.2 \mathrm{E}-12$ & $2.76 \mathrm{E}-10$ & 8.535144 & Up & protein tyrosine phosphatase $4 \mathrm{~A} 3$ \\
\hline 7898809 & EPHB2 & 1.524627 & $3.14 \mathrm{E}-12$ & $3.67 \mathrm{E}-10$ & 8.450802 & Up & EPH receptor B2 \\
\hline 7913566 & HTR1D & 2.940729 & $3.68 \mathrm{E}-12$ & 4.17E-10 & 8.413036 & Up & 5-hydroxytryptamine receptor 1D \\
\hline 7956867 & HMGA2 & 1.890133 & $4.2 \mathrm{E}-12$ & 4.7E-10 & 8.381162 & Up & high mobility group AT-hook 2 \\
\hline 8108301 & KIF20A & 2.228882 & $4.48 \mathrm{E}-12$ & 4.99E-10 & 8.365923 & Up & kinesin family member $20 \mathrm{~A}$ \\
\hline 7933821 & RHOBTB1 & 1.619158 & $4.59 \mathrm{E}-12$ & $5.09 \mathrm{E}-10$ & 8.360403 & Up & Rho related BTB domain containing 1 \\
\hline 8018652 & RNF157 & 1.524361 & $5.05 \mathrm{E}-12$ & $5.46 \mathrm{E}-10$ & 8.337418 & Up & ring finger protein 157 \\
\hline 8167125 & USP11 & 1.22401 & $5.81 \mathrm{E}-12$ & $6.15 \mathrm{E}-10$ & 8.303935 & Up & ubiquitin specific peptidase 11 \\
\hline 8010702 & ASPSCR1 & 1.51179 & $5.97 \mathrm{E}-12$ & $6.29 \mathrm{E}-10$ & 8.297358 & Up & ASPSCR1 tether for SLC2A4, UBX domain \\
\hline
\end{tabular}




\begin{tabular}{|c|c|c|c|c|c|c|c|}
\hline 7983969 & $\mathrm{CCNB} 2$ & 2.319658 & $6.46 \mathrm{E}-12$ & $6.69 \mathrm{E}-10$ & 8.278639 & Up & cyclin B2 \\
\hline 8117589 & $\mathrm{H} 3 \mathrm{C} 10$ & 1.696874 & $7.88 \mathrm{E}-12$ & $8.04 \mathrm{E}-10$ & 8.231228 & Up & H3 clustered histone 10 \\
\hline 8179884 & EHMT2 & 1.320889 & $8.21 \mathrm{E}-12$ & $8.29 \mathrm{E}-10$ & 8.221633 & Up & euchromatic histone lysine methyltransferase 2 \\
\hline 7909568 & DTL & 2.233746 & $8.4 \mathrm{E}-12$ & $8.46 \mathrm{E}-10$ & 8.216126 & Up & denticleless E3 ubiquitin protein ligase homolog \\
\hline 7907092 & MPZL1 & 1.110293 & $8.5 \mathrm{E}-12$ & $8.53 \mathrm{E}-10$ & 8.213284 & $\mathrm{Up}$ & myelin protein zero like 1 \\
\hline 8095139 & SRD5A3 & 1.175968 & $9.52 \mathrm{E}-12$ & $9.41 \mathrm{E}-10$ & 8.186395 & Up & steroid 5 alpha-reductase 3 \\
\hline 8111524 & UGT3A2 & 2.01295 & $9.97 \mathrm{E}-12$ & $9.77 \mathrm{E}-10$ & 8.175221 & Up & UDP glycosyltransferase family 3 member A2 \\
\hline 7997962 & DPEP1 & 3.412187 & $1 \mathrm{E}-11$ & $9.77 \mathrm{E}-10$ & 8.17388 & $\mathrm{Up}$ & dipeptidase 1 \\
\hline 8139737 & PSPH & 1.589526 & $1.04 \mathrm{E}-11$ & $1 \mathrm{E}-09$ & 8.165654 & Up & phosphoserine phosphatase \\
\hline 7909689 & SMYD2 & 1.198165 & $1.13 \mathrm{E}-11$ & $1.08 \mathrm{E}-09$ & 8.146548 & Up & SET and MYND domain containing 2 \\
\hline 8015460 & ACLY & 1.170475 & $1.21 \mathrm{E}-11$ & $1.16 \mathrm{E}-09$ & 8.128833 & Up & ATP citrate lyase \\
\hline 8156923 & PLPPR1 & 2.206895 & $1.23 \mathrm{E}-11$ & 1.17E-09 & 8.124985 & Up & phospholipid phosphatase related 1 \\
\hline 8117382 & $\mathrm{H} 2 \mathrm{BC} 5$ & 1.61958 & $1.46 \mathrm{E}-11$ & $1.36 \mathrm{E}-09$ & 8.084132 & Up & $\mathrm{H} 2 \mathrm{~B}$ clustered histone 5 \\
\hline 8138289 & ETV1 & 1.561422 & $1.48 \mathrm{E}-11$ & 1.37E-09 & 8.080755 & Up & ETS variant transcription factor 1 \\
\hline 7903144 & SLC44A3 & 1.297252 & $1.59 \mathrm{E}-11$ & $1.46 \mathrm{E}-09$ & 8.063483 & Up & solute carrier family 44 member 3 \\
\hline 8117415 & H3C6 & 1.51443 & $1.63 \mathrm{E}-11$ & $1.48 \mathrm{E}-09$ & 8.058698 & $\mathrm{Up}$ & H3 clustered histone 6 \\
\hline 7920877 & ARHGEF2 & 1.092916 & $1.65 \mathrm{E}-11$ & $1.49 \mathrm{E}-09$ & 8.055614 & Up & Rho/Rac guanine nucleotide exchange factor 2 \\
\hline 8014706 & PCGF2 & 1.247281 & $1.89 \mathrm{E}-11$ & $1.69 \mathrm{E}-09$ & 8.022518 & Up & polycomb group ring finger 2 \\
\hline 7955217 & SPATS2 & 1.11028 & $1.97 \mathrm{E}-11$ & $1.74 \mathrm{E}-09$ & 8.013341 & $\mathrm{Up}$ & spermatogenesis associated serine rich 2 \\
\hline 8117408 & $\mathrm{H} 2 \mathrm{AC} 8$ & 1.98058 & $2.08 \mathrm{E}-11$ & $1.83 \mathrm{E}-09$ & 7.999654 & Up & $\begin{array}{l}\text { H2A clustered histone } 8 \\
\text { carbamoyl-phosphate } \text { synthetase } 2\end{array}$ \\
\hline 8040843 & CAD & 1.453107 & $2.09 \mathrm{E}-11$ & $1.83 \mathrm{E}-09$ & 7.999061 & Up & transcarbamylase, and dihydroorotase \\
\hline 7991234 & MFGE8 & 1.667152 & $2.13 \mathrm{E}-11$ & $1.85 \mathrm{E}-09$ & 7.995034 & Up & milk fat globule-EGF factor 8 protein \\
\hline 8131205 & SDK1 & 1.496044 & $2.21 \mathrm{E}-11$ & $1.92 \mathrm{E}-09$ & 7.985481 & Up & sidekick cell adhesion molecule 1 \\
\hline 8071758 & MMP11 & 1.897841 & $2.33 \mathrm{E}-11$ & $2 \mathrm{E}-09$ & 7.973596 & Up & matrix metallopeptidase 11 \\
\hline 8173232 & AMER1 & 1.237163 & $2.38 \mathrm{E}-11$ & 2.03E-09 & 7.968581 & Up & APC membrane recruitment protein 1 \\
\hline 7959786 & AACS & 1.233763 & $2.63 \mathrm{E}-11$ & $2.18 \mathrm{E}-09$ & 7.94434 & Up & acetoacetyl-CoA synthetase \\
\hline 7947744 & LRP4 & 1.133139 & $2.81 \mathrm{E}-11$ & 2.31E-09 & 7.928712 & Up & LDL receptor related protein 4 \\
\hline 8124388 & $\mathrm{H} 3 \mathrm{C} 2$ & 2.616121 & $2.83 \mathrm{E}-11$ & $2.31 \mathrm{E}-09$ & 7.927171 & Up & $\begin{array}{c}\text { H3 clustered histone } 2 \\
\text { SPT3 homolog, SAGA and STAGA complex }\end{array}$ \\
\hline 8126710 & SUPT3H & 1.300222 & $2.85 \mathrm{E}-11$ & $2.32 \mathrm{E}-09$ & 7.925237 & Up & component \\
\hline 7925130 & TARBP1 & 1.332726 & $2.96 \mathrm{E}-11$ & $2.38 \mathrm{E}-09$ & 7.916179 & Up & TAR (HIV-1) RNA binding protein 1 \\
\hline 8007154 & FKBP10 & 2.292068 & $3.03 \mathrm{E}-11$ & 2.41E-09 & 7.910412 & Up & FKBP prolylisomerase 10 \\
\hline 8140955 & CDK6 & 1.279018 & $3.07 \mathrm{E}-11$ & $2.44 \mathrm{E}-09$ & 7.907408 & Up & cyclin dependent kinase 6 \\
\hline 7923426 & UBE2T & 1.869772 & $3.11 \mathrm{E}-11$ & $2.46 \mathrm{E}-09$ & 7.904575 & Up & ubiquitin conjugating enzyme $\mathrm{E} 2 \mathrm{~T}$ \\
\hline 8050702 & TP53I3 & 1.552431 & $3.15 \mathrm{E}-11$ & 2.47E-09 & 7.901598 & Up & tumor protein $\mathrm{p} 53$ inducible protein 3 \\
\hline 7964271 & PRIM1 & 1.160505 & $3.18 \mathrm{E}-11$ & 2.49E-09 & 7.899112 & Up & DNA primase subunit 1 \\
\hline 8173457 & ZMYM3 & 1.168042 & $3.29 \mathrm{E}-11$ & $2.56 \mathrm{E}-09$ & 7.891207 & Up & zinc finger MYM-type containing 3 \\
\hline 7974404 & CDKN3 & 2.086537 & $3.33 \mathrm{E}-11$ & $2.58 \mathrm{E}-09$ & 7.888052 & Up & cyclin dependent kinase inhibitor 3 \\
\hline 8102643 & CCNA2 & 1.859122 & $3.83 \mathrm{E}-11$ & $2.92 \mathrm{E}-09$ & 7.854457 & Up & cyclin A2 \\
\hline 8031913 & TRIM28 & 1.211235 & $4.04 \mathrm{E}-11$ & $3.05 \mathrm{E}-09$ & 7.842322 & $\mathrm{Up}$ & tripartite motif containing 28 \\
\hline 8171725 & MAP7D2 & 1.266487 & 4.07E-11 & $3.06 \mathrm{E}-09$ & 7.840093 & Up & MAP7 domain containing 2 \\
\hline 8066051 & NDRG3 & 1.081445 & $4.37 \mathrm{E}-11$ & $3.22 \mathrm{E}-09$ & 7.823338 & Up & $\begin{array}{l}\text { NDRG family member } 3 \\
\text { small nuclear ribonucleoprotein polypeptides B }\end{array}$ \\
\hline 8064502 & SNRPB & 1.332234 & $4.41 \mathrm{E}-11$ & $3.24 \mathrm{E}-09$ & 7.821419 & Up & $\begin{array}{c}\text { and B1 } \\
\text { phytanoyl-CoA 2-hydroxylase interacting protein }\end{array}$ \\
\hline 7927694 & PHYHIPL & 2.165208 & $4.55 \mathrm{E}-11$ & $3.34 \mathrm{E}-09$ & 7.813598 & Up & like \\
\hline
\end{tabular}


medRxiv preprint doi: https://doi.org/10.1101/2020.12.22.20248756; this version posted December 26, 2020. The copyright holder for this preprint (which was not certified by peer review) is the author/funder, who has granted medRxiv a license to display the preprint in perpetuity. All rights reserved. No reuse allowed without permission.

\begin{tabular}{|c|c|c|c|c|c|c|c|}
\hline 8021349 & ST8SIA3 & 1.769577 & $4.59 \mathrm{E}-11$ & $3.35 \mathrm{E}-09$ & 7.811812 & Up & $\begin{array}{c}\text { ST8 alpha-N-acetyl-neuraminide alpha-2,8- } \\
\text { sialyltransferase } 3\end{array}$ \\
\hline 7953200 & CCND2 & 2.156667 & $5.04 \mathrm{E}-11$ & 3.63E-09 & 7.789308 & Up & $\begin{array}{c}\text { cyclin D2 } \\
\text { minichromosome maintenance complex }\end{array}$ \\
\hline 8127031 & MCM3 & 1.171845 & $5.14 \mathrm{E}-11$ & 3.67E-09 & 7.784447 & Up & component 3 \\
\hline 7964522 & CDK4 & 1.214576 & $5.21 \mathrm{E}-11$ & $3.71 \mathrm{E}-09$ & 7.781424 & Up & cyclin dependent kinase 4 \\
\hline 7899870 & ZNF362 & 1.098151 & $6.55 \mathrm{E}-11$ & 4.53E-09 & 7.727025 & Up & zinc finger protein 362 \\
\hline 7906163 & RHBG & 2.119375 & $6.94 \mathrm{E}-11$ & 4.74E-09 & 7.713065 & Up & Rh family B glycoprotein (gene/pseudogene) \\
\hline 8150529 & DKK4 & 3.254585 & $7.18 \mathrm{E}-11$ & 4.87E-09 & 7.705005 & Up & dickkopf WNT signaling pathway inhibitor 4 \\
\hline 8115099 & PDGFRB & 1.426811 & $7.8 \mathrm{E}-11$ & 5.22E-09 & 7.685287 & Up & platelet derived growth factor receptor beta \\
\hline 8101945 & H2AZ1 & 1.224085 & $7.99 \mathrm{E}-11$ & $5.31 \mathrm{E}-09$ & 7.679606 & Up & H2A.Z variant histone 1 \\
\hline 8113504 & NREP & 1.755236 & $8.08 \mathrm{E}-11$ & 5.35E-09 & 7.676911 & Up & neuronal regeneration related protein \\
\hline 8112649 & FAM169A & 1.639021 & $8.18 \mathrm{E}-11$ & $5.41 \mathrm{E}-09$ & 7.673846 & Up & family with sequence similarity 169 member A \\
\hline 8119689 & PTK7 & 1.610193 & $8.47 \mathrm{E}-11$ & $5.59 \mathrm{E}-09$ & 7.665614 & Up & protein tyrosine kinase 7 (inactive) \\
\hline 7924055 & C1orf74 & 1.2052 & $8.85 \mathrm{E}-11$ & $5.78 \mathrm{E}-09$ & 7.655279 & Up & chromosome 1 open reading frame 74 \\
\hline 8155214 & MELK & 1.740406 & $1 \mathrm{E}-10$ & $6.43 \mathrm{E}-09$ & 7.625947 & Up & maternal embryonic leucine zipper kinase \\
\hline 8117402 & $\mathrm{H} 4 \mathrm{C} 5$ & 1.499917 & $1 \mathrm{E}-10$ & $6.44 \mathrm{E}-09$ & 7.625166 & Up & H4 clustered histone 5 \\
\hline 8061471 & GINS1 & 2.259058 & $1.01 \mathrm{E}-10$ & $6.45 \mathrm{E}-09$ & 7.624055 & Up & GINS complex subunit 1 \\
\hline 8117395 & $\mathrm{H} 2 \mathrm{BC} 7$ & 2.308545 & $1.16 \mathrm{E}-10$ & $7.21 \mathrm{E}-09$ & 7.591471 & Up & H2B clustered histone 7 \\
\hline 8119016 & MAPK13 & 1.277062 & $1.24 \mathrm{E}-10$ & 7.68E-09 & 7.574291 & Up & mitogen-activated protein kinase 13 \\
\hline 7898677 & HS6ST1 & 1.399556 & $1.26 \mathrm{E}-10$ & $7.76 \mathrm{E}-09$ & 7.570808 & Up & heparansulfate 6-O-sulfotransferase 1 \\
\hline 7910694 & EDARADD & 1.312902 & $1.29 \mathrm{E}-10$ & 7.91E-09 & 7.564484 & Up & EDAR associated death domain \\
\hline 8143270 & ZC3HAV1L & 1.298956 & $1.37 \mathrm{E}-10$ & 8.26E-09 & 7.551778 & Up & zinc finger $\mathrm{CCCH}$-type containing, antiviral 1 like \\
\hline 7952268 & THY1 & 1.81187 & $1.51 \mathrm{E}-10$ & $9.03 \mathrm{E}-09$ & 7.52734 & Up & Thy-1 cell surface antigen \\
\hline 7955078 & PFKM & 1.365442 & $1.59 \mathrm{E}-10$ & 9.39E-09 & 7.51514 & Up & phosphofructokinase, muscle \\
\hline 7969243 & CKAP2 & 1.635932 & $1.6 \mathrm{E}-10$ & 9.44E-09 & 7.513267 & Up & cytoskeleton associated protein 2 \\
\hline 8014974 & TOP2A & 2.113914 & $1.68 \mathrm{E}-10$ & 9.79E-09 & 7.502838 & Up & DNA topoisomerase II alpha \\
\hline 8007302 & TUBG1 & 1.147034 & $1.87 \mathrm{E}-10$ & $1.07 \mathrm{E}-08$ & 7.477071 & Up & tubulin gamma 1 \\
\hline 8056323 & FIGN & 1.830289 & $1.89 \mathrm{E}-10$ & $1.08 \mathrm{E}-08$ & 7.474481 & Up & fidgetin, microtubule severing factor \\
\hline 7919340 & GJA5 & 1.379924 & $2.06 \mathrm{E}-10$ & $1.17 \mathrm{E}-08$ & 7.453672 & Up & gap junction protein alpha 5 \\
\hline 7961142 & OLR1 & 2.837839 & $2.06 \mathrm{E}-10$ & $1.17 \mathrm{E}-08$ & 7.453644 & Up & oxidized low density lipoprotein receptor 1 \\
\hline 7955317 & ASIC1 & 1.858678 & $2.37 \mathrm{E}-10$ & $1.32 \mathrm{E}-08$ & 7.420063 & Up & acid sensing ion channel subunit 1 \\
\hline 8077958 & HDAC11 & 1.279624 & $2.44 \mathrm{E}-10$ & $1.34 \mathrm{E}-08$ & 7.412689 & Up & $\begin{array}{l}\text { histone deacetylase } 11 \\
\text { minichromosome maintenance complex }\end{array}$ \\
\hline 8055426 & MCM6 & 1.336 & $2.61 \mathrm{E}-10$ & $1.41 \mathrm{E}-08$ & 7.396883 & Up & component 6 \\
\hline 7994109 & PLK1 & 2.38288 & $2.86 \mathrm{E}-10$ & $1.52 \mathrm{E}-08$ & 7.374901 & Up & polo like kinase 1 \\
\hline 7997504 & CDH13 & 1.283624 & 2.99E-10 & $1.58 \mathrm{E}-08$ & 7.364641 & Up & cadherin 13 \\
\hline 7905754 & ATP8B2 & 1.240409 & $3.22 \mathrm{E}-10$ & $1.69 \mathrm{E}-08$ & 7.346859 & Up & ATPase phospholipid transporting 8B2 \\
\hline 8150881 & PLAG1 & 1.439715 & $3.26 \mathrm{E}-10$ & $1.71 \mathrm{E}-08$ & 7.343913 & Up & PLAG1 zinc finger \\
\hline 8104912 & SKP2 & 1.12123 & $3.49 \mathrm{E}-10$ & $1.81 \mathrm{E}-08$ & 7.327205 & $\mathrm{Up}$ & S-phase kinase associated protein 2 \\
\hline 7909789 & TGFB2 & 2.218334 & $3.55 \mathrm{E}-10$ & $1.83 \mathrm{E}-08$ & 7.323557 & Up & transforming growth factor beta 2 \\
\hline 8044212 & SULT1C2 & 2.008067 & $3.6 \mathrm{E}-10$ & $1.85 \mathrm{E}-08$ & 7.320077 & Up & sulfotransferase family $1 \mathrm{C}$ member 2 \\
\hline 8031933 & RPS5 & 1.22843 & $3.69 \mathrm{E}-10$ & $1.88 \mathrm{E}-08$ & 7.314199 & Up & ribosomal protein $\mathrm{S} 5$ \\
\hline 8121319 & SOBP & 1.145583 & $3.71 \mathrm{E}-10$ & $1.89 \mathrm{E}-08$ & 7.312689 & Up & sine oculis binding protein homolog \\
\hline 8091757 & TRIM59 & 1.264872 & $3.84 \mathrm{E}-10$ & $1.95 \mathrm{E}-08$ & 7.304419 & Up & tripartite motif containing 59 \\
\hline 7985829 & FANCI & 1.424419 & 4.13E-10 & $2.05 \mathrm{E}-08$ & 7.287464 & Up & FA complementation group I \\
\hline 7937020 & MKI67 & 1.584887 & $4.28 \mathrm{E}-10$ & $2.12 \mathrm{E}-08$ & 7.278491 & Up & marker of proliferation $\mathrm{Ki}-67$ \\
\hline
\end{tabular}


medRxiv preprint doi: https://doi.org/10.1101/2020.12.22.20248756; this version posted December 26, 2020. The copyright holder for this preprint (which was not certified by peer review) is the author/funder, who has granted medRxiv a license to display the preprint in perpetuity. All rights reserved. No reuse allowed without permission.

\begin{tabular}{|c|c|c|c|c|c|}
\hline 8053341 & REG3A & 4.489323 & $4.3 \mathrm{E}-10$ & $2.12 \mathrm{E}-08$ & 7.277812 \\
\hline 7927710 & CDK1 & 1.999852 & $4.68 \mathrm{E}-10$ & 2.3E-08 & 7.257226 \\
\hline 8091780 & B3GALNT1 & 1.1245 & $4.71 \mathrm{E}-10$ & $2.31 \mathrm{E}-08$ & 7.255742 \\
\hline 7968563 & RFC3 & 1.084173 & $4.74 \mathrm{E}-10$ & $2.32 \mathrm{E}-08$ & 7.254523 \\
\hline 7906671 & USP21 & 1.081837 & $4.84 \mathrm{E}-10$ & $2.36 \mathrm{E}-08$ & 7.249046 \\
\hline 8041867 & MSH2 & 1.233487 & $4.92 \mathrm{E}-10$ & 2.39E-08 & 7.245238 \\
\hline 7989770 & IGDCC 3 & 1.939267 & $5.24 \mathrm{E}-10$ & $2.52 \mathrm{E}-08$ & 7.230351 \\
\hline 8116532 & SNORD95 & 1.087937 & $5.48 \mathrm{E}-10$ & $2.61 \mathrm{E}-08$ & 7.219705 \\
\hline 7935230 & ALDH18A1 & 1.187678 & $5.83 \mathrm{E}-10$ & $2.75 \mathrm{E}-08$ & 7.204798 \\
\hline 8163086 & TMEM245 & 1.116402 & $5.83 \mathrm{E}-10$ & $2.75 \mathrm{E}-08$ & 7.204595 \\
\hline 8065762 & PIGU & 1.288087 & $6.29 \mathrm{E}-10$ & $2.92 \mathrm{E}-08$ & 7.186581 \\
\hline 8001394 & TOX3 & 1.276311 & $6.37 \mathrm{E}-10$ & 2.95E-08 & 7.183457 \\
\hline 7989647 & PCLAF & 1.94471 & $6.98 \mathrm{E}-10$ & $3.19 \mathrm{E}-08$ & 7.161489 \\
\hline 8151496 & ZNF704 & 1.156776 & $7.25 \mathrm{E}-10$ & 3.3E-08 & 7.152369 \\
\hline 8180321 & $\mathrm{H} 4 \mathrm{C} 14$ & 2.262123 & $7.8 \mathrm{E}-10$ & $3.52 \mathrm{E}-08$ & 7.135014 \\
\hline 7912887 & MFAP2 & 1.788574 & $8.44 \mathrm{E}-10$ & $3.77 \mathrm{E}-08$ & 7.115996 \\
\hline 8174201 & BEX1 & 2.637884 & $8.62 \mathrm{E}-10$ & $3.84 \mathrm{E}-08$ & 7.111107 \\
\hline 8117594 & $\mathrm{H} 2 \mathrm{BC} 14$ & 2.692001 & $8.95 \mathrm{E}-10$ & $3.96 \mathrm{E}-08$ & 7.101912 \\
\hline 7960340 & FOXM1 & 1.969922 & $9.69 \mathrm{E}-10$ & 4.23E-08 & 7.082801 \\
\hline 8117537 & $\mathrm{H} 4 \mathrm{C} 9$ & 1.111644 & $1.04 \mathrm{E}-09$ & 4.49E-08 & 7.065205 \\
\hline 8065607 & PLAGL2 & 1.104062 & $1.08 \mathrm{E}-09$ & 4.62E-08 & 7.056891 \\
\hline 8029489 & BCAM & 1.55279 & $1.09 \mathrm{E}-09$ & $4.65 \mathrm{E}-08$ & 7.054641 \\
\hline 8174474 & ACSL4 & 2.16322 & $1.09 \mathrm{E}-09$ & $4.65 \mathrm{E}-08$ & 7.054027 \\
\hline 7959638 & TCTN2 & 1.231161 & $1.11 \mathrm{E}-09$ & 4.72E-08 & 7.049572 \\
\hline 7901720 & PRKAA2 & 1.824199 & $1.16 \mathrm{E}-09$ & 4.9E-08 & 7.038901 \\
\hline 8055130 & HS6ST1 & 1.142804 & 1.19E-09 & $5 \mathrm{E}-08$ & 7.034017 \\
\hline 7985873 & TICRR & 1.734731 & $1.22 \mathrm{E}-09$ & $5.11 \mathrm{E}-08$ & 7.028088 \\
\hline 7976810 & SNORD113-3 & 2.630163 & $1.23 \mathrm{E}-09$ & 5.17E-08 & 7.024914 \\
\hline 7952526 & $\mathrm{CDON}$ & 1.07604 & $1.26 \mathrm{E}-09$ & $5.28 \mathrm{E}-08$ & 7.018896 \\
\hline 8141395 & MCM7 & 1.289311 & $1.29 \mathrm{E}-09$ & 5.39E-08 & 7.013274 \\
\hline 7958031 & PARPBP & 1.561417 & $1.37 \mathrm{E}-09$ & $5.69 \mathrm{E}-08$ & 6.998999 \\
\hline 8131179 & TTYH3 & 1.19538 & $1.38 \mathrm{E}-09$ & 5.7E-08 & 6.997808 \\
\hline 7957023 & LYZ & 1.516768 & $1.49 \mathrm{E}-09$ & $6.09 \mathrm{E}-08$ & 6.978759 \\
\hline 7929438 & HELLS & 1.619774 & $1.51 \mathrm{E}-09$ & $6.15 \mathrm{E}-08$ & 6.975973 \\
\hline 8146403 & SNTG1 & 1.714133 & $1.53 \mathrm{E}-09$ & $6.21 \mathrm{E}-08$ & 6.973109 \\
\hline 8067167 & AURKA & 1.642884 & $1.55 \mathrm{E}-09$ & $6.26 \mathrm{E}-08$ & 6.970758 \\
\hline 8068180 & HUNK & 1.430039 & $1.7 \mathrm{E}-09$ & $6.83 \mathrm{E}-08$ & 6.947745 \\
\hline 8132318 & ANLN & 1.871495 & $1.74 \mathrm{E}-09$ & $6.94 \mathrm{E}-08$ & 6.942799 \\
\hline 8083063 & SLC25A36 & 1.166967 & $1.82 \mathrm{E}-09$ & 7.22E-08 & 6.931608 \\
\hline 8124531 & $\mathrm{H} 3 \mathrm{C} 11$ & 2.493895 & $1.85 \mathrm{E}-09$ & 7.33E-08 & 6.927557 \\
\hline 8019772 & ALYREF & 1.248489 & $1.92 \mathrm{E}-09$ & 7.57E-08 & 6.918898 \\
\hline 8072687 & MCM5 & 1.269489 & $1.95 \mathrm{E}-09$ & $7.71 \mathrm{E}-08$ & 6.914242 \\
\hline
\end{tabular}

regenerating family member 3 alpha cyclin dependent kinase 1 beta-1,3-N-acetylgalactosaminyltransferase 1 (globoside blood group) replication factor $\mathrm{C}$ subunit 3 ubiquitin specific peptidase 21 mutS homolog 2 immunoglobulin superfamily DCC subclass member 3

small nucleolar RNA, C/D box 95 aldehyde dehydrogenase 18 family member A1 transmembrane protein 245

phosphatidylinositol glycan anchor biosynthesis class U

TOX high mobility group box family member 3

PCNA clamp associated factor zinc finger protein 704

H4 clustered histone 14 microfibril associated protein 2 brain expressed $\mathrm{X}$-linked 1 H2B clustered histone 14 forkhead box M1

H4 clustered histone 9

PLAG1 like zinc finger 2 basal cell adhesion molecule (Lutheran blood group)

acyl-CoA synthetase long chain family member 4 tectonic family member 2

protein kinase AMP-activated catalytic subunit alpha 2

heparansulfate 6-O-sulfotransferase 1 TOPBP1 interacting checkpoint and replication regulator

small nucleolar RNA, C/D box 113-3

cell adhesion associated, oncogene regulated minichromosome maintenance complex component 7

PARP1 binding protein tweety family member 3 lysozyme

helicase, lymphoid specific syntrophin gamma 1 aurora kinase A

hormonally up-regulated Neu-associated kinase anillin actin binding protein solute carrier family 25 member 36 H3 clustered histone 11 Aly/REF export factor minichromosome maintenance complex component 5 
medRxiv preprint doi: https://doi.org/10.1101/2020.12.22.20248756; this version posted December 26, 2020. The copyright holder for this preprint (which was not certified by peer review) is the author/funder, who has granted medRxiv a license to display the preprint in perpetuity.

All rights reserved. No reuse allowed without permission.

\begin{tabular}{|c|c|c|c|c|c|c|c|}
\hline 8124397 & $\mathrm{H} 1-2$ & 1.460665 & $1.96 \mathrm{E}-09$ & 7.72E-08 & 6.913797 & Up & H1.2 linker histone, cluster member \\
\hline 8147503 & LAPTM4B & 1.648679 & 2.11E-09 & $8.2 \mathrm{E}-08$ & 6.896147 & Up & lysosomal protein transmembrane 4 beta \\
\hline 8046488 & CDCA7 & 1.829823 & $2.13 \mathrm{E}-09$ & $8.26 \mathrm{E}-08$ & 6.89368 & $\mathrm{Up}$ & cell division cycle associated 7 \\
\hline 8055872 & CACNB4 & 1.408438 & $2.38 \mathrm{E}-09$ & $9.07 \mathrm{E}-08$ & 6.866662 & Up & $\begin{array}{l}\text { calcium voltage-gated channel auxiliary subunit } \\
\text { beta } 4\end{array}$ \\
\hline 8109639 & PTTG1 & 1.409636 & $2.43 \mathrm{E}-09$ & $9.22 \mathrm{E}-08$ & 6.861809 & Up & $\begin{array}{l}\text { PTTG1 regulator of sister chromatid separation, } \\
\text { securin }\end{array}$ \\
\hline 8120088 & MEP1A & 3.099691 & $2.48 \mathrm{E}-09$ & 9.37E-08 & 6.857128 & Up & meprin A subunit alpha \\
\hline 8093906 & WFS1 & 1.247632 & $2.51 \mathrm{E}-09$ & 9.48E-08 & 6.853833 & Up & wolframin ER transmembrane glycoprotein \\
\hline 8131326 & SLC29A4 & 1.783121 & 2.63E-09 & $9.83 \mathrm{E}-08$ & 6.842322 & Up & solute carrier family 29 member 4 \\
\hline 7927876 & TET1 & 1.160637 & $2.66 \mathrm{E}-09$ & $9.88 \mathrm{E}-08$ & 6.840356 & Up & tetmethylcytosinedioxygenase 1 \\
\hline 7945014 & CHEK1 & 1.433501 & $2.92 \mathrm{E}-09$ & $1.07 \mathrm{E}-07$ & 6.817566 & Up & checkpoint kinase 1 \\
\hline 8015806 & ETV4 & 2.003846 & 2.99E-09 & $1.09 \mathrm{E}-07$ & 6.811933 & Up & ETS variant transcription factor 4 \\
\hline 8105828 & CCNB1 & 1.605348 & 3.07E-09 & $1.12 \mathrm{E}-07$ & 6.805569 & $\mathrm{Up}$ & cyclin B1 \\
\hline 8048995 & ITM2C & 1.101134 & $3.16 \mathrm{E}-09$ & $1.15 \mathrm{E}-07$ & 6.798376 & Up & integral membrane protein $2 \mathrm{C}$ \\
\hline 8149955 & PBK & 1.695675 & $3.37 \mathrm{E}-09$ & $1.21 \mathrm{E}-07$ & 6.782753 & Up & $\begin{array}{c}\text { PDZ binding kinase } \\
\text { PAD }\end{array}$ \\
\hline 8075785 & FOXRED2 & 1.137162 & $3.38 \mathrm{E}-09$ & $1.21 \mathrm{E}-07$ & 6.782334 & Up & 1 \\
\hline 8124437 & $\mathrm{H} 3 \mathrm{C} 7$ & 1.802897 & $3.59 \mathrm{E}-09$ & $1.28 \mathrm{E}-07$ & 6.767659 & Up & H3 clustered histone 7 \\
\hline 8163181 & C9orf152 & 1.297831 & 4E-09 & 1.39E-07 & 6.741575 & $\mathrm{Up}$ & chromosome 9 open reading frame 152 \\
\hline 8095043 & RASL11B & 1.58962 & $4.45 \mathrm{E}-09$ & $1.52 \mathrm{E}-07$ & 6.715665 & Up & $\begin{array}{l}\text { RAS like family } 11 \text { member B } \\
\text { spindle and kinetochore associated complex }\end{array}$ \\
\hline 7970513 & SKA3 & 1.861349 & 4.57E-09 & $1.56 \mathrm{E}-07$ & 6.709461 & Up & subunit 3 \\
\hline 7989073 & PRTG & 2.1855 & 4.57E-09 & $1.56 \mathrm{E}-07$ & 6.709058 & Up & protogenin \\
\hline 7991406 & PRC1 & 1.481765 & 4.6E-09 & $1.57 \mathrm{E}-07$ & 6.707793 & Up & protein regulator of cytokinesis 1 \\
\hline 8035297 & PLVAP & 1.101067 & 4.89E-09 & $1.65 \mathrm{E}-07$ & 6.693086 & Up & plasmalemma vesicle associated protein \\
\hline 7986757 & NDN & 1.194378 & 5.03E-09 & $1.7 \mathrm{E}-07$ & 6.685849 & Up & necdin, MAGE family member \\
\hline 8127094 & GSTA4 & 1.084808 & $5.2 \mathrm{E}-09$ & $1.75 \mathrm{E}-07$ & 6.678028 & $\mathrm{Up}$ & glutathione S-transferase alpha 4 \\
\hline 8124394 & $\mathrm{H} 2 \mathrm{BC} 3$ & 2.273395 & $5.26 \mathrm{E}-09$ & $1.76 \mathrm{E}-07$ & 6.67505 & Up & $\mathrm{H} 2 \mathrm{~B}$ clustered histone 3 \\
\hline 8048411 & TTLL4 & 1.244147 & $5.93 \mathrm{E}-09$ & $1.96 \mathrm{E}-07$ & 6.646133 & Up & tubulin tyrosine ligase like 4 \\
\hline 7923086 & ASPM & 1.819916 & $6.05 \mathrm{E}-09$ & $1.99 \mathrm{E}-07$ & 6.641488 & Up & abnormal spindle microtubule assembly \\
\hline 8012257 & TP53 & 1.137668 & $6.47 \mathrm{E}-09$ & $2.11 \mathrm{E}-07$ & 6.624957 & Up & tumor protein p53 \\
\hline 8060339 & NRSN2 & 1.263849 & $6.63 \mathrm{E}-09$ & $2.15 \mathrm{E}-07$ & 6.619348 & Up & $\begin{array}{c}\text { neurensin } 2 \\
\text { ectonucleotidepyrophosphatase/phosphodiesterase }\end{array}$ \\
\hline 8122071 & ENPP3 & 1.71035 & $6.94 \mathrm{E}-09$ & $2.22 \mathrm{E}-07$ & 6.608135 & Up & 3 \\
\hline 8117426 & H2BC9 & 2.10049 & $7.54 \mathrm{E}-09$ & 2.38E-07 & 6.588109 & $\mathrm{Up}$ & H2B clustered histone 9 \\
\hline 8100338 & ERVMER34-1 & 2.007219 & 7.92E-09 & $2.48 \mathrm{E}-07$ & 6.576121 & Up & $\begin{array}{c}\text { endogenous retrovirus group MER34 member } 1 \text {, } \\
\text { envelope }\end{array}$ \\
\hline 7976795 & MEG3 & 1.828145 & 8.77E-09 & $2.71 \mathrm{E}-07$ & 6.551152 & Up & maternally expressed 3 \\
\hline 7900699 & CDC20 & 1.7169 & $9.54 \mathrm{E}-09$ & $2.91 \mathrm{E}-07$ & 6.530873 & Up & cell division cycle 20 \\
\hline 8128329 & MMS22L & 1.170289 & $1 \mathrm{E}-08$ & 3.04E-07 & 6.518602 & Up & $\begin{array}{l}\text { MMS22 like, DNA repair protein } \\
\text { minichromosome maintenance complex }\end{array}$ \\
\hline 8082350 & MCM2 & 1.217066 & $1.1 \mathrm{E}-08$ & $3.3 \mathrm{E}-07$ & 6.495191 & Up & component 2 \\
\hline 7919642 & $\mathrm{H} 2 \mathrm{AC} 21$ & 1.956987 & $1.12 \mathrm{E}-08$ & 3.33E-07 & 6.492634 & Up & $\mathrm{H} 2 \mathrm{~A}$ clustered histone 21 \\
\hline 8026954 & PIK3R2 & 1.106202 & $1.15 \mathrm{E}-08$ & $3.42 \mathrm{E}-07$ & 6.485456 & Up & phosphoinositide-3-kinase regulatory subunit 2 \\
\hline 8040223 & RRM2 & 1.476306 & $1.31 \mathrm{E}-08$ & 3.79E-07 & 6.454468 & Up & ribonucleotidereductase regulatory subunit M2 \\
\hline 8147101 & E2F5 & 1.402752 & $1.35 \mathrm{E}-08$ & 3.89E-07 & 6.447204 & Up & E2F transcription factor 5 \\
\hline 8124527 & $\mathrm{H} 1-5$ & 2.471316 & $1.38 \mathrm{E}-08$ & $3.96 \mathrm{E}-07$ & 6.44064 & Up & H1.5 linker histone, cluster member \\
\hline 8117608 & $\mathrm{H} 2 \mathrm{AC} 16$ & 1.556151 & $1.44 \mathrm{E}-08$ & 4.11E-07 & 6.429976 & Up & H2A clustered histone 16 \\
\hline
\end{tabular}


medRxiv preprint doi: https://doi.org/10.1101/2020.12.22.20248756; this version posted December 26, 2020. The copyright holder for this preprint (which was not certified by peer review) is the author/funder, who has granted medRxiv a license to display the preprint in perpetuity.

All rights reserved. No reuse allowed without permission.

\begin{tabular}{|c|c|c|c|c|c|c|c|}
\hline 7983306 & WDR76 & 1.258491 & $1.56 \mathrm{E}-08$ & 4.41E-07 & 6.410536 & Up & WD repeat domain 76 \\
\hline 8113278 & LIX1 & 2.018797 & $1.66 \mathrm{E}-08$ & $4.65 \mathrm{E}-07$ & 6.395277 & Up & limb and CNS expressed 1 \\
\hline 7935903 & NPM3 & 1.086385 & $1.67 \mathrm{E}-08$ & $4.67 \mathrm{E}-07$ & 6.393835 & Up & nucleophosmin/nucleoplasmin 3 \\
\hline 7904907 & BCL9 & 1.106154 & $1.79 \mathrm{E}-08$ & 4.94E-07 & 6.377753 & Up & BCL9 transcription coactivator \\
\hline 8095646 & AFP & 3.83748 & $1.81 \mathrm{E}-08$ & 4.99E-07 & 6.374893 & Up & $\begin{array}{l}\text { alpha fetoprotein } \\
\text { post-GPI attachment to proteins inositol deacylase }\end{array}$ \\
\hline 8057959 & PGAP1 & 1.471941 & $1.81 \mathrm{E}-08$ & 4.99E-07 & 6.374553 & Up & 1 \\
\hline 8117535 & $\mathrm{H} 2 \mathrm{AC} 11$ & 1.107153 & $1.87 \mathrm{E}-08$ & $5.13 \mathrm{E}-07$ & 6.366871 & Up & $\begin{array}{c}\text { H2A clustered histone } 11 \\
\text { SPC24 component of NDC80 kinetochore }\end{array}$ \\
\hline 8034122 & SPC24 & 1.423052 & $1.96 \mathrm{E}-08$ & $5.36 \mathrm{E}-07$ & 6.354851 & Up & complex \\
\hline 7980828 & $\mathrm{CCDC} 88 \mathrm{C}$ & 1.407228 & $2 \mathrm{E}-08$ & $5.43 \mathrm{E}-07$ & 6.350011 & Up & coiled-coil domain containing $88 \mathrm{C}$ \\
\hline 8179839 & LSM2 & 1.15632 & $2.01 \mathrm{E}-08$ & $5.43 \mathrm{E}-07$ & 6.349736 & Up & $\begin{array}{l}\text { mRNA degradation associated } \\
\text { ERCC excision repair } 2 \text {, TFIIH core complex }\end{array}$ \\
\hline 8037537 & ERCC2 & 1.099511 & $2.12 \mathrm{E}-08$ & $5.68 \mathrm{E}-07$ & 6.33655 & Up & helicase subunit \\
\hline 8113981 & P4HA2 & 1.085801 & $2.24 \mathrm{E}-08$ & $5.98 \mathrm{E}-07$ & 6.322577 & Up & prolyl 4-hydroxylase subunit alpha 2 \\
\hline 7947189 & $\mathrm{CCDC} 34$ & 1.070471 & $2.34 \mathrm{E}-08$ & $6.19 \mathrm{E}-07$ & 6.312211 & Up & coiled-coil domain containing 34 \\
\hline 7927915 & STOX1 & 1.471997 & $2.49 \mathrm{E}-08$ & $6.51 \mathrm{E}-07$ & 6.296502 & Up & storkhead box 1 \\
\hline 7953936 & TMEM52B & 1.811869 & $2.52 \mathrm{E}-08$ & $6.57 \mathrm{E}-07$ & 6.293851 & Up & transmembrane protein 52B \\
\hline 8168794 & CENPI & 1.3902 & $2.56 \mathrm{E}-08$ & $6.65 \mathrm{E}-07$ & 6.290422 & Up & centromere protein I \\
\hline 7924996 & C1orf198 & 1.109491 & $2.58 \mathrm{E}-08$ & 6.69E-07 & 6.287933 & Up & chromosome 1 open reading frame 198 \\
\hline 8124413 & $\mathrm{H} 4 \mathrm{C} 4$ & 1.653762 & $2.62 \mathrm{E}-08$ & $6.76 \mathrm{E}-07$ & 6.283905 & Up & H4 clustered histone 4 \\
\hline 7973724 & NYNRIN & 1.663616 & $2.8 \mathrm{E}-08$ & $7.15 \mathrm{E}-07$ & 6.267648 & Up & NYN domain and retroviral integrase containing \\
\hline 7978846 & POLE2 & 1.095891 & $2.88 \mathrm{E}-08$ & 7.33E-07 & 6.260822 & Up & DNA polymerase epsilon 2 , accessory subunit \\
\hline 8112376 & CENPK & 1.477442 & $3.28 \mathrm{E}-08$ & 8.17E-07 & 6.229044 & Up & centromere protein $\mathrm{K}$ \\
\hline 8094278 & NCAPG & 1.432309 & 3.3E-08 & $8.2 \mathrm{E}-07$ & 6.228059 & Up & non-SMC condensin I complex subunit G \\
\hline 7919645 & SV2A & 1.333202 & $3.37 \mathrm{E}-08$ & $8.35 \mathrm{E}-07$ & 6.222416 & Up & synaptic vesicle glycoprotein $2 \mathrm{~A}$ \\
\hline 8168589 & ZNF711 & 1.37908 & 3.37E-08 & $8.35 \mathrm{E}-07$ & 6.222223 & Up & zinc finger protein 711 \\
\hline 7959408 & KNTC1 & 1.196141 & $3.63 \mathrm{E}-08$ & 8.87E-07 & 6.204236 & Up & kinetochore associated 1 \\
\hline 8021946 & COLEC12 & 1.380321 & 3.67E-08 & $8.96 \mathrm{E}-07$ & 6.201361 & Up & collectin subfamily member 12 \\
\hline 8155898 & PCSK5 & 1.129146 & $3.74 \mathrm{E}-08$ & $9.09 \mathrm{E}-07$ & 6.197184 & Up & proproteinconvertasesubtilisin/kexin type 5 \\
\hline 8118322 & SNORD52 & 1.208826 & 3.9E-08 & 9.4E-07 & 6.18694 & Up & small nucleolar RNA, C/D box 52 \\
\hline 7948511 & VWCE & 1.095833 & $3.94 \mathrm{E}-08$ & 9.49E-07 & 6.184463 & Up & von Willebrand factor $\mathrm{C}$ and $\mathrm{EGF}$ domains \\
\hline 8050537 & MATN3 & 2.720682 & 4.04E-08 & $9.69 \mathrm{E}-07$ & 6.178101 & Up & matrilin 3 \\
\hline 8102560 & MAD2L1 & 1.278696 & 4.07E-08 & $9.75 \mathrm{E}-07$ & 6.175993 & Up & $\begin{array}{l}\text { mitotic arrest deficient } 2 \text { like } 1 \\
\text { insulin like growth factor } 2 \text { mRNA binding protein }\end{array}$ \\
\hline 8138566 & IGF2BP3 & 1.579554 & $4.31 \mathrm{E}-08$ & $1.02 \mathrm{E}-06$ & 6.162134 & Up & 3 \\
\hline 8144669 & FDFT1 & 1.105711 & 4.44E-08 & $1.05 \mathrm{E}-06$ & 6.15497 & Up & farnesyl-diphosphatefarnesyltransferase 1 \\
\hline 7929258 & KIF11 & 1.48831 & $4.75 \mathrm{E}-08$ & $1.11 \mathrm{E}-06$ & 6.137906 & Up & kinesin family member 11 \\
\hline 7915926 & STIL & 1.173564 & 4.79E-08 & $1.11 \mathrm{E}-06$ & 6.136329 & Up & STIL centriolar assembly protein \\
\hline 7941936 & GSTP1 & 1.687065 & $5 \mathrm{E}-08$ & $1.16 \mathrm{E}-06$ & 6.125301 & Up & glutathione S-transferase pi 1 \\
\hline 8028194 & ZNF382 & 1.15122 & 5.3E-08 & $1.21 \mathrm{E}-06$ & 6.111155 & Up & zinc finger protein 382 \\
\hline 8008982 & TBX4 & 1.988481 & $5.58 \mathrm{E}-08$ & $1.27 \mathrm{E}-06$ & 6.098463 & Up & T-box transcription factor 4 \\
\hline 8061579 & TPX2 & 1.602018 & $5.8 \mathrm{E}-08$ & $1.31 \mathrm{E}-06$ & 6.089062 & Up & TPX2 microtubule nucleation factor \\
\hline 8141950 & RELN & 1.465983 & $5.86 \mathrm{E}-08$ & $1.32 \mathrm{E}-06$ & 6.086227 & Up & reelin \\
\hline 8008784 & PRR11 & 1.251565 & $6.02 \mathrm{E}-08$ & $1.35 \mathrm{E}-06$ & 6.079752 & Up & proline rich 11 \\
\hline 8124440 & $\mathrm{H} 3 \mathrm{C} 8$ & 1.356755 & $6.34 \mathrm{E}-08$ & $1.41 \mathrm{E}-06$ & 6.066925 & Up & $\mathrm{H} 3$ clustered histone 8 \\
\hline 8056730 & LINC01124 & 1.076875 & $6.38 \mathrm{E}-08$ & $1.42 \mathrm{E}-06$ & 6.065428 & Up & long intergenic non-protein coding RNA 1124 \\
\hline
\end{tabular}


medRxiv preprint doi: https://doi.org/10.1101/2020.12.22.20248756; this version posted December 26, 2020. The copyright holder for this preprint (which was not certified by peer review) is the author/funder, who has granted medRxiv a license to display the preprint in perpetuity.

All rights reserved. No reuse allowed without permission.

\begin{tabular}{|c|c|c|c|c|c|c|c|}
\hline 8117543 & $\mathrm{H} 2 \mathrm{AC} 12$ & 1.453751 & $6.42 \mathrm{E}-08$ & $1.43 \mathrm{E}-06$ & 6.063814 & Up & $\mathrm{H} 2 \mathrm{~A}$ clustered histone 12 \\
\hline 8179564 & KIFC1 & 1.166165 & $6.53 \mathrm{E}-08$ & $1.45 \mathrm{E}-06$ & 6.059474 & $\mathrm{Up}$ & kinesin family member $\mathrm{C} 1$ \\
\hline 8064904 & FERMT1 & 1.41378 & $6.62 \mathrm{E}-08$ & $1.46 \mathrm{E}-06$ & 6.056228 & Up & fermitin family member 1 \\
\hline 8056572 & SPC25 & 1.515156 & $6.93 \mathrm{E}-08$ & $1.53 \mathrm{E}-06$ & 6.044851 & Up & $\begin{array}{l}\text { SPC25 component of NDC80 kinetochore } \\
\text { complex } \\
\text { minichromosome maintenance complex }\end{array}$ \\
\hline 8146357 & MCM4 & 1.193519 & 7.06E-08 & $1.55 \mathrm{E}-06$ & 6.040466 & $\mathrm{Up}$ & component 4 \\
\hline 7920971 & GLMP & 1.189511 & 7.24E-08 & $1.58 \mathrm{E}-06$ & 6.034126 & Up & glycosylated lysosomal membrane protein \\
\hline 7981427 & $\mathrm{CKB}$ & 1.244081 & 7.38E-08 & $1.61 \mathrm{E}-06$ & 6.02945 & Up & $\begin{array}{c}\text { creatine kinase B } \\
\text { spindle and kinetochore associated complex }\end{array}$ \\
\hline 8021187 & SKA1 & 1.176912 & 7.54E-08 & $1.64 \mathrm{E}-06$ & 6.023885 & Up & subunit 1 \\
\hline 7967107 & HNF1A-AS1 & 2.094372 & $7.55 \mathrm{E}-08$ & $1.64 \mathrm{E}-06$ & 6.023575 & Up & HNF1 A antisense RNA 1 \\
\hline 8116579 & FOXQ1 & 1.161237 & 7.59E-08 & $1.65 \mathrm{E}-06$ & 6.022424 & Up & forkhead box Q1 \\
\hline 7906930 & NUF2 & 1.617239 & 7.6E-08 & $1.65 \mathrm{E}-06$ & 6.022216 & $\mathrm{Up}$ & NUF2 component of NDC80 kinetochore complex \\
\hline 8043602 & NCAPH & 1.305281 & 7.88E-08 & $1.7 \mathrm{E}-06$ & 6.013175 & Up & non-SMC condensin I complex subunit $\mathrm{H}$ \\
\hline 8044225 & SULT1C4 & 1.359027 & 8.12E-08 & $1.75 \mathrm{E}-06$ & 6.005665 & Up & sulfotransferase family $1 \mathrm{C}$ member 4 \\
\hline 7955702 & SOAT2 & 1.825381 & $8.15 \mathrm{E}-08$ & $1.75 \mathrm{E}-06$ & 6.004777 & $\mathrm{Up}$ & sterol O-acyltransferase 2 \\
\hline 8124510 & $\mathrm{H} 2 \mathrm{BC} 13$ & 1.739418 & 8.39E-08 & $1.8 \mathrm{E}-06$ & 5.997706 & Up & H2B clustered histone 13 \\
\hline 8144036 & $\mathrm{XRCC} 2$ & 1.432502 & $8.47 \mathrm{E}-08$ & $1.81 \mathrm{E}-06$ & 5.995224 & Up & $\mathrm{X}$-ray repair cross complementing 2 \\
\hline 7950906 & CTSC & 1.144283 & $8.66 \mathrm{E}-08$ & $1.84 \mathrm{E}-06$ & 5.989658 & Up & cathepsin $\mathrm{C}$ \\
\hline 8112260 & DEPDC1B & 1.289933 & $9.06 \mathrm{E}-08$ & $1.91 \mathrm{E}-06$ & 5.978501 & Up & DEP domain containing $1 \mathrm{~B}$ \\
\hline 8034772 & ASF1B & 1.316287 & $9.44 \mathrm{E}-08$ & $1.98 \mathrm{E}-06$ & 5.968251 & Up & anti-silencing function $1 \mathrm{~B}$ histone chaperone \\
\hline 8124540 & $\mathrm{H} 2 \mathrm{AC} 17$ & 1.453337 & $9.58 \mathrm{E}-08$ & $2.01 \mathrm{E}-06$ & 5.964593 & Up & $\mathrm{H} 2 \mathrm{~A}$ clustered histone 17 \\
\hline 7965048 & NAP1L1 & 1.188292 & $9.77 \mathrm{E}-08$ & $2.04 \mathrm{E}-06$ & 5.959936 & Up & nucleosome assembly protein 1 like 1 \\
\hline 7909708 & CENPF & 1.663748 & $1.01 \mathrm{E}-07$ & 2.09E-06 & 5.952622 & Up & centromere protein $\mathrm{F}$ \\
\hline 8083779 & SERPINI1 & 2.073734 & $1.07 \mathrm{E}-07$ & $2.2 \mathrm{E}-06$ & 5.937839 & Up & serpin family I member 1 \\
\hline 7989657 & PCLAF & 1.205918 & $1.15 \mathrm{E}-07$ & 2.35E-06 & 5.919128 & Up & PCNA clamp associated factor \\
\hline 8003204 & GINS2 & 1.221379 & $1.16 \mathrm{E}-07$ & $2.36 \mathrm{E}-06$ & 5.917065 & Up & GINS complex subunit 2 \\
\hline 7963750 & CBX5 & 1.168128 & $1.16 \mathrm{E}-07$ & 2.37E-06 & 5.916593 & $\mathrm{Up}$ & chromobox 5 \\
\hline 8007071 & CDC6 & 1.448856 & $1.31 \mathrm{E}-07$ & 2.62E-06 & 5.886254 & Up & cell division cycle 6 \\
\hline 7976814 & SNORD114-2 & 2.626252 & $1.33 \mathrm{E}-07$ & 2.65E-06 & 5.882831 & Up & small nucleolar RNA, C/D box 114-2 \\
\hline 8114425 & $\mathrm{CDC} 25 \mathrm{C}$ & 1.080816 & $1.4 \mathrm{E}-07$ & $2.78 \mathrm{E}-06$ & 5.870115 & Up & cell division cycle $25 \mathrm{C}$ \\
\hline 8083494 & MME & 2.403426 & $1.42 \mathrm{E}-07$ & $2.8 \mathrm{E}-06$ & 5.866764 & Up & membrane metalloendopeptidase \\
\hline 7982889 & NUSAP1 & 1.084423 & $1.42 \mathrm{E}-07$ & $2.8 \mathrm{E}-06$ & 5.866751 & Up & nucleolar and spindle associated protein 1 \\
\hline 8156783 & COL15A1 & 1.081673 & $1.42 \mathrm{E}-07$ & $2.81 \mathrm{E}-06$ & 5.866266 & Up & collagen type $\mathrm{XV}$ alpha 1 chain \\
\hline 8073775 & FBLN1 & 1.444665 & $1.43 \mathrm{E}-07$ & $2.81 \mathrm{E}-06$ & 5.865909 & Up & fibulin 1 \\
\hline 8127987 & SNORD50A & 1.30339 & $1.45 \mathrm{E}-07$ & 2.84E-06 & 5.862335 & Up & small nucleolar RNA, C/D box 50A \\
\hline 7940147 & FAM111B & 1.102513 & $1.51 \mathrm{E}-07$ & 2.95E-06 & 5.851532 & Up & family with sequence similarity 111 member B \\
\hline 8124391 & $\mathrm{H} 2 \mathrm{AC} 4$ & 1.837145 & $1.52 \mathrm{E}-07$ & 2.97E-06 & 5.849662 & Up & H2A clustered histone 4 \\
\hline 8097857 & MND1 & 1.287054 & $1.53 \mathrm{E}-07$ & $2.98 \mathrm{E}-06$ & 5.848494 & Up & meiotic nuclear divisions 1 \\
\hline 8124524 & $\mathrm{H} 2 \mathrm{AC} 15$ & 1.836025 & $1.6 \mathrm{E}-07$ & 3.09E-06 & 5.837586 & Up & H2A clustered histone 15 \\
\hline 8001197 & NETO2 & 1.566949 & $1.62 \mathrm{E}-07$ & $3.13 \mathrm{E}-06$ & 5.833735 & Up & neuropilin and tolloid like 2 \\
\hline 8054580 & BUB1 & 1.453709 & $1.64 \mathrm{E}-07$ & $3.16 \mathrm{E}-06$ & 5.831246 & Up & BUB1 mitotic checkpoint serine/threonine kinase \\
\hline 7939665 & MDK & 1.198721 & $1.64 \mathrm{E}-07$ & $3.16 \mathrm{E}-06$ & 5.831147 & Up & midkine \\
\hline 7905909 & EFNA4 & 1.257778 & $1.69 \mathrm{E}-07$ & $3.25 \mathrm{E}-06$ & 5.822645 & Up & ephrin A4 \\
\hline 8117389 & H2BC6 & 1.201097 & $1.73 \mathrm{E}-07$ & $3.29 \mathrm{E}-06$ & 5.818167 & Up & $\begin{array}{l}\mathrm{H} 2 \mathrm{~B} \text { clustered histone } 6 \\
\text { mitogen-activated protein kinase }\end{array}$ \\
\hline 8043945 & MAP4K4 & 1.102691 & $1.77 \mathrm{E}-07$ & 3.37E-06 & 5.811659 & Up & kinasekinasekinase 4 \\
\hline
\end{tabular}


medRxiv preprint doi: https://doi.org/10.1101/2020.12.22.20248756; this version posted December 26, 2020. The copyright holder for this preprint (which was not certified by peer review) is the author/funder, who has granted medRxiv a license to display the preprint in perpetuity. All rights reserved. No reuse allowed without permission.

\begin{tabular}{|c|c|c|c|c|c|c|c|}
\hline 7979307 & DLGAP5 & 1.537596 & $1.78 \mathrm{E}-07$ & $3.38 \mathrm{E}-06$ & 5.810596 & $\mathrm{Up}$ & DLG associated protein 5 \\
\hline 8148049 & $\mathrm{CCN} 3$ & 1.177401 & $1.96 \mathrm{E}-07$ & $3.67 \mathrm{E}-06$ & 5.786281 & Up & $\begin{array}{l}\text { cellular communication network factor } 3 \\
\text { solute carrier organic anion transporter family }\end{array}$ \\
\hline 8090823 & SLCO2A1 & 1.249091 & $2.26 \mathrm{E}-07$ & 4.14E-06 & 5.751146 & Up & member $2 \mathrm{~A} 1$ \\
\hline 8019737 & KPNA2 & 1.271643 & $2.39 \mathrm{E}-07$ & 4.32E-06 & 5.736739 & $\mathrm{Up}$ & karyopherin subunit alpha 2 \\
\hline 8007043 & RAPGEFL1 & 1.172339 & $2.47 \mathrm{E}-07$ & 4.45E-06 & 5.728041 & Up & Rap guanine nucleotide exchange factor like 1 \\
\hline 8007108 & TMEM99 & 1.071856 & $2.5 \mathrm{E}-07$ & 4.5E-06 & 5.724999 & Up & transmembrane protein 99 (putative) \\
\hline 8019316 & PYCR1 & 1.428201 & $2.53 \mathrm{E}-07$ & $4.55 \mathrm{E}-06$ & 5.722011 & Up & pyrroline-5-carboxylate reductase 1 \\
\hline 8124385 & $\mathrm{H} 4 \mathrm{C} 2$ & 1.446077 & $2.64 \mathrm{E}-07$ & 4.72E-06 & 5.711608 & $\mathrm{Up}$ & H4 clustered histone 2 \\
\hline 8098423 & NEIL3 & 1.087616 & $2.65 \mathrm{E}-07$ & 4.74E-06 & 5.71063 & Up & nei like DNA glycosylase 3 \\
\hline 7990151 & PKM & 1.077351 & $3.18 \mathrm{E}-07$ & $5.55 \mathrm{E}-06$ & 5.664467 & Up & pyruvate kinase $\mathrm{M} 1 / 2$ \\
\hline 8085754 & SGO1 & 1.324156 & $3.19 \mathrm{E}-07$ & $5.56 \mathrm{E}-06$ & 5.664033 & Up & shugoshin 1 \\
\hline 7985089 & $\mathrm{RCN} 2$ & 1.071374 & $3.35 \mathrm{E}-07$ & $5.78 \mathrm{E}-06$ & 5.651905 & Up & reticulocalbin 2 \\
\hline 8027297 & ZNF738 & 1.351542 & $3.52 \mathrm{E}-07$ & $6.04 \mathrm{E}-06$ & 5.639132 & Up & zinc finger protein 738 \\
\hline 8038624 & C19orf48 & 1.204102 & $3.92 \mathrm{E}-07$ & $6.63 \mathrm{E}-06$ & 5.612166 & Up & chromosome 19 open reading frame 48 \\
\hline 8124196 & DCDC2 & 1.598298 & $4.25 \mathrm{E}-07$ & 7.09E-06 & 5.591397 & Up & doublecortin domain containing 2 \\
\hline 8124537 & $\mathrm{H} 3 \mathrm{C} 12$ & 1.937416 & 4.42E-07 & 7.31E-06 & 5.581513 & $\mathrm{Up}$ & H3 clustered histone 12 \\
\hline 8083941 & ECT2 & 1.20662 & 4.57E-07 & 7.53E-06 & 5.573164 & $\mathrm{Up}$ & epithelial cell transforming 2 \\
\hline 8145418 & CDCA2 & 1.093462 & 4.79E-07 & $7.85 \mathrm{E}-06$ & 5.56127 & $\mathrm{Up}$ & cell division cycle associated 2 \\
\hline 8016387 & PRR15L & 1.181372 & 4.89E-07 & $8 \mathrm{E}-06$ & 5.555831 & Up & proline rich 15 like \\
\hline 7905088 & $\mathrm{H} 2 \mathrm{AC} 20$ & 1.156635 & $5.02 \mathrm{E}-07$ & $8.18 \mathrm{E}-06$ & 5.549327 & $\mathrm{Up}$ & $\mathrm{H} 2 \mathrm{~A}$ clustered histone 20 \\
\hline 7995681 & MMP2 & 1.565987 & $5.36 \mathrm{E}-07$ & 8.64E-06 & 5.532707 & Up & matrix metallopeptidase 2 \\
\hline 7976818 & SNORD114-6 & 1.739232 & $5.43 \mathrm{E}-07$ & $8.72 \mathrm{E}-06$ & 5.52954 & Up & small nucleolar RNA, C/D box 114-6 \\
\hline 8124518 & $\mathrm{H} 2 \mathrm{AC} 14$ & 1.847687 & $5.44 \mathrm{E}-07$ & $8.73 \mathrm{E}-06$ & 5.529042 & Up & $\mathrm{H} 2 \mathrm{~A}$ clustered histone 14 \\
\hline 8077817 & SLC6A11 & 1.437606 & $5.67 \mathrm{E}-07$ & $9.04 \mathrm{E}-06$ & 5.518368 & $\mathrm{Up}$ & solute carrier family 6 member 11 \\
\hline 7947248 & KIF18A & 1.24503 & $6.01 \mathrm{E}-07$ & $9.51 \mathrm{E}-06$ & 5.503598 & Up & kinesin family member $18 \mathrm{~A}$ \\
\hline 7934936 & SLC16A12 & 1.462218 & $6.31 \mathrm{E}-07$ & $9.92 \mathrm{E}-06$ & 5.491296 & Up & solute carrier family 16 member 12 \\
\hline 8019857 & NDC80 & 1.074707 & $6.4 \mathrm{E}-07$ & $1 \mathrm{E}-05$ & 5.487786 & Up & NDC80 kinetochore complex component \\
\hline 7924619 & ENAH & 1.118615 & $6.61 \mathrm{E}-07$ & $1.03 \mathrm{E}-05$ & 5.479597 & Up & ENAH actin regulator \\
\hline 8036302 & LINC00665 & 1.6579 & $6.87 \mathrm{E}-07$ & $1.07 \mathrm{E}-05$ & 5.469711 & Up & long intergenic non-protein coding RNA 665 \\
\hline 8109830 & SPDL1 & 1.132734 & $6.93 \mathrm{E}-07$ & $1.07 \mathrm{E}-05$ & 5.467406 & Up & spindle apparatus coiled-coil protein 1 \\
\hline 8106210 & ARHGEF28 & 1.104557 & $6.93 \mathrm{E}-07$ & $1.07 \mathrm{E}-05$ & 5.467397 & Up & Rho guanine nucleotide exchange factor 28 \\
\hline 8114964 & SPINK1 & 3.373751 & $7.06 \mathrm{E}-07$ & $1.09 \mathrm{E}-05$ & 5.462577 & Up & serine peptidase inhibitor, Kazal type 1 \\
\hline 8120838 & TTK & 1.471652 & 7.17E-07 & $1.1 \mathrm{E}-05$ & 5.458675 & Up & TTK protein kinase \\
\hline 8092067 & RPL22L1 & 1.2499 & 7.53E-07 & $1.15 \mathrm{E}-05$ & 5.446096 & Up & ribosomal protein L22 like 1 \\
\hline 8134384 & DYNC1I1 & 1.512531 & 7.54E-07 & $1.15 \mathrm{E}-05$ & 5.445869 & $\mathrm{Up}$ & dynein cytoplasmic 1 intermediate chain 1 \\
\hline 7962703 & COL2A1 & 1.174349 & $7.86 \mathrm{E}-07$ & $1.19 \mathrm{E}-05$ & 5.435142 & $\mathrm{Up}$ & collagen type II alpha 1 chain \\
\hline 8097356 & PLK4 & 1.106919 & 8.31E-07 & $1.24 \mathrm{E}-05$ & 5.421205 & $\mathrm{Up}$ & polo like kinase 4 \\
\hline 7953218 & RAD51AP1 & 1.089541 & $9.29 \mathrm{E}-07$ & $1.37 \mathrm{E}-05$ & 5.392483 & $\mathrm{Up}$ & RAD51 associated protein 1 \\
\hline 8059838 & HJURP & 1.144152 & $9.36 \mathrm{E}-07$ & $1.37 \mathrm{E}-05$ & 5.390682 & $\mathrm{Up}$ & Holliday junction recognition protein \\
\hline 8047174 & SLC39A10 & 1.183434 & 9.57E-07 & $1.4 \mathrm{E}-05$ & 5.385019 & $\mathrm{Up}$ & solute carrier family 39 member 10 \\
\hline 7993588 & TMC7 & 1.120446 & $1.04 \mathrm{E}-06$ & $1.5 \mathrm{E}-05$ & 5.363637 & $\mathrm{Up}$ & transmembrane channel like 7 \\
\hline 7978407 & PRKD1 & 1.212447 & $1.05 \mathrm{E}-06$ & $1.51 \mathrm{E}-05$ & 5.3618 & Up & protein kinase D1 \\
\hline 8068651 & PCP4 & 1.775862 & $1.06 \mathrm{E}-06$ & $1.52 \mathrm{E}-05$ & 5.357563 & $\mathrm{Up}$ & Purkinje cell protein 4 \\
\hline 8066260 & SNORA71C & 1.253776 & $1.08 \mathrm{E}-06$ & $1.55 \mathrm{E}-05$ & 5.353069 & Up & small nucleolar RNA, H/ACA box 71C \\
\hline 8013771 & TLCD1 & 1.25362 & $1.18 \mathrm{E}-06$ & $1.67 \mathrm{E}-05$ & 5.33018 & $\mathrm{Up}$ & TLC domain containing 1 \\
\hline
\end{tabular}


medRxiv preprint doi: https://doi.org/10.1101/2020.12.22.20248756; this version posted December 26, 2020. The copyright holder for this preprint (which was not certified by peer review) is the author/funder, who has granted medRxiv a license to display the preprint in perpetuity. All rights reserved. No reuse allowed without permission.

\begin{tabular}{|c|c|c|c|c|c|c|c|}
\hline 8172670 & DGKK & 1.370881 & $1.2 \mathrm{E}-06$ & $1.69 \mathrm{E}-05$ & 5.32659 & $\mathrm{Up}$ & diacylglycerol kinase kappa \\
\hline 7982358 & ARHGAP11A & 1.312616 & $1.21 \mathrm{E}-06$ & $1.7 \mathrm{E}-05$ & 5.32471 & Up & $\begin{array}{l}\text { Rho GTPase activating protein 11A } \\
\text { potassium inwardly rectifying channel subfamily } \mathrm{J}\end{array}$ \\
\hline 7945146 & KCNJ5 & 1.160467 & $1.23 \mathrm{E}-06$ & $1.72 \mathrm{E}-05$ & 5.319834 & Up & member 5 \\
\hline 7948900 & SNORD30 & 1.109137 & $1.38 \mathrm{E}-06$ & $1.9 \mathrm{E}-05$ & 5.291793 & Up & small nucleolar RNA, C/D box 30 \\
\hline 7977615 & RNASE1 & 1.104973 & $1.41 \mathrm{E}-06$ & $1.93 \mathrm{E}-05$ & 5.285302 & Up & ribonuclease A family member 1 , pancreatic \\
\hline 7901316 & SLC5A9 & 1.285379 & $1.48 \mathrm{E}-06$ & $2.02 \mathrm{E}-05$ & 5.272818 & Up & solute carrier family 5 member 9 \\
\hline 8126324 & PGC & 2.837666 & $1.62 \mathrm{E}-06$ & $2.18 \mathrm{E}-05$ & 5.250163 & Up & progastricsin \\
\hline 7921882 & OLFML2B & 1.439349 & $1.64 \mathrm{E}-06$ & $2.2 \mathrm{E}-05$ & 5.247015 & Up & olfactomedin like $2 \mathrm{~B}$ \\
\hline 8024900 & UHRF1 & 1.134639 & $1.68 \mathrm{E}-06$ & $2.25 \mathrm{E}-05$ & 5.240511 & Up & ubiquitin like with $\mathrm{PHD}$ and ring finger domains 1 \\
\hline 8114977 & HTR4 & 1.249641 & 1.79E-06 & $2.38 \mathrm{E}-05$ & 5.223864 & Up & 5-hydroxytryptamine receptor 4 \\
\hline 8065412 & CST1 & 2.95569 & $1.87 \mathrm{E}-06$ & $2.47 \mathrm{E}-05$ & 5.212371 & Up & cystatin $\mathrm{SN}$ \\
\hline 8117339 & $\mathrm{H} 3 \mathrm{C} 3$ & 1.175204 & $2.1 \mathrm{E}-06$ & $2.72 \mathrm{E}-05$ & 5.182459 & Up & H3 clustered histone 3 \\
\hline 8037835 & SLC1A5 & 1.246562 & $2.12 \mathrm{E}-06$ & $2.74 \mathrm{E}-05$ & 5.17932 & Up & solute carrier family 1 member 5 \\
\hline 8121251 & LIN28B & 2.073173 & $2.21 \mathrm{E}-06$ & 2.84E-05 & 5.168955 & Up & $\operatorname{lin}-28$ homolog B \\
\hline 8151191 & CPA6 & 1.377275 & 2.4E-06 & $3.05 \mathrm{E}-05$ & 5.147568 & Up & carboxypeptidase A6 \\
\hline 7995697 & LPCAT2 & 1.093687 & 2.64E-06 & $3.31 \mathrm{E}-05$ & 5.122589 & Up & lysophosphatidylcholineacyltransferase 2 \\
\hline 7972750 & COL4A1 & 1.120372 & $2.68 \mathrm{E}-06$ & $3.35 \mathrm{E}-05$ & 5.118795 & Up & collagen type IV alpha 1 chain \\
\hline 8139482 & SNORA5A & 1.113557 & $2.81 \mathrm{E}-06$ & $3.47 \mathrm{E}-05$ & 5.106866 & Up & small nucleolar RNA, H/ACA box 5A \\
\hline 7973727 & NYNRIN & 1.316514 & $2.81 \mathrm{E}-06$ & $3.47 \mathrm{E}-05$ & 5.106855 & $\mathrm{Up}$ & NYN domain and retroviral integrase containing \\
\hline 8018902 & DNAH17 & 1.079276 & $3.04 \mathrm{E}-06$ & $3.73 \mathrm{E}-05$ & 5.086139 & Up & dynein axonemal heavy chain 17 \\
\hline 7970448 & GJB6 & 1.151659 & $3.05 \mathrm{E}-06$ & $3.75 \mathrm{E}-05$ & 5.084986 & Up & gap junction protein beta 6 \\
\hline 7941062 & SLC22A11 & 1.090335 & $3.19 \mathrm{E}-06$ & $3.9 \mathrm{E}-05$ & 5.072988 & Up & solute carrier family 22 member 11 \\
\hline 7922410 & SNORD44 & 1.281937 & $3.33 \mathrm{E}-06$ & 4.04E-05 & 5.062197 & Up & small nucleolar RNA, C/D box 44 \\
\hline 7961524 & ERP27 & 1.711109 & $3.6 \mathrm{E}-06$ & 4.33E-05 & 5.04163 & Up & endoplasmic reticulum protein 27 \\
\hline 7915472 & SLC2A1 & 1.578424 & 3.64E-06 & 4.37E-05 & 5.038442 & Up & solute carrier family 2 member 1 \\
\hline 7922343 & TNFSF4 & 1.329627 & 3.77E-06 & 4.48E-05 & 5.029716 & Up & TNF superfamily member 4 \\
\hline 8105495 & PART1 & 1.952691 & $3.88 \mathrm{E}-06$ & 4.6E-05 & 5.022157 & Up & $\begin{array}{l}\text { prostate androgen-regulated transcript } 1 \\
\text { hes related family bHLH transcription factor with }\end{array}$ \\
\hline 8151457 & HEY1 & 1.111906 & 4.07E-06 & $4.78 \mathrm{E}-05$ & 5.009246 & Up & YRPW motif 1 \\
\hline 7922400 & SNORD81 & 1.143675 & 4.14E-06 & $4.86 \mathrm{E}-05$ & 5.004817 & Up & small nucleolar RNA, C/D box 81 \\
\hline 7898296 & SRARP & 1.145389 & $4.22 \mathrm{E}-06$ & 4.94E-05 & 4.99958 & Up & steroid receptor associated and regulated protein \\
\hline 8117330 & $\mathrm{H} 3 \mathrm{C} 1$ & 1.687935 & 4.57E-06 & $5.3 \mathrm{E}-05$ & 4.97862 & Up & H3 clustered histone 1 \\
\hline 8091078 & RBP1 & 1.12892 & 4.65E-06 & $5.38 \mathrm{E}-05$ & 4.973948 & Up & retinol binding protein 1 \\
\hline 7947274 & MPPED2 & 1.46169 & 5.39E-06 & $6.1 \mathrm{E}-05$ & 4.935059 & Up & metallophosphoesterase domain containing 2 \\
\hline 7958253 & C12orf75 & 1.082506 & $5.68 \mathrm{E}-06$ & $6.37 \mathrm{E}-05$ & 4.92133 & Up & $\begin{array}{l}\text { chromosome } 12 \text { open reading frame } 75 \\
\text { MYCN proto-oncogene, bHLH transcription }\end{array}$ \\
\hline 8040419 & MYCN & 1.747252 & 5.7E-06 & $6.39 \mathrm{E}-05$ & 4.920366 & Up & factor \\
\hline 7900157 & RPS27 & 1.213684 & $6.23 \mathrm{E}-06$ & $6.89 \mathrm{E}-05$ & 4.896722 & Up & ribosomal protein $\mathrm{S} 27$ \\
\hline 8123446 & SMOC2 & 1.285284 & $6.25 \mathrm{E}-06$ & $6.91 \mathrm{E}-05$ & 4.895744 & Up & SPARC related modular calcium binding 2 \\
\hline 8062766 & MYBL2 & 1.23121 & $6.77 \mathrm{E}-06$ & $7.38 \mathrm{E}-05$ & 4.874699 & Up & MYB proto-oncogene like 2 \\
\hline 8054702 & CKAP2L & 1.07398 & 7.57E-06 & $8.11 \mathrm{E}-05$ & 4.844738 & Up & cytoskeleton associated protein 2 like \\
\hline 8078386 & GPD1L & 1.177626 & 7.58E-06 & $8.11 \mathrm{E}-05$ & 4.844443 & Up & glycerol-3-phosphate dehydrogenase 1 like \\
\hline 8112980 & EDIL3 & 1.846642 & 7.69E-06 & $8.21 \mathrm{E}-05$ & 4.840643 & Up & EGF like repeats and discoidin domains 3 \\
\hline 8066757 & SLC13A3 & 1.330843 & $8.58 \mathrm{E}-06$ & 9E-05 & 4.811329 & Up & solute carrier family 13 member 3 \\
\hline 7940565 & FADS2 & 1.592897 & $8.65 \mathrm{E}-06$ & $9.06 \mathrm{E}-05$ & 4.809411 & Up & fatty acid desaturase 2 \\
\hline 7990309 & STRA6 & 1.331824 & $9.88 \mathrm{E}-06$ & 0.000102 & 4.773758 & Up & stimulated by retinoic acid 6 \\
\hline
\end{tabular}


medRxiv preprint doi: https://doi.org/10.1101/2020.12.22.20248756; this version posted December 26, 2020. The copyright holder for this preprint (which was not certified by peer review) is the author/funder, who has granted medRxiv a license to display the preprint in perpetuity.

All rights reserved. No reuse allowed without permission.

\begin{tabular}{|c|c|c|c|c|c|c|c|}
\hline 8180221 & LINC01549 & 1.53009 & $1.04 \mathrm{E}-05$ & 0.000106 & 4.759131 & Up & long intergenic non-protein coding RNA 1549 \\
\hline 7946661 & DKK3 & 1.130968 & $1.06 \mathrm{E}-05$ & 0.000108 & 4.75429 & $\mathrm{Up}$ & dickkopf WNT signaling pathway inhibitor 3 \\
\hline 8149465 & FGF20 & 1.073473 & $1.11 \mathrm{E}-05$ & 0.000112 & 4.742249 & $\mathrm{Up}$ & fibroblast growth factor 20 \\
\hline 8175539 & LDOC1 & 1.208443 & $1.21 \mathrm{E}-05$ & 0.00012 & 4.719431 & $\mathrm{Up}$ & LDOC1 regulator of NFKB signaling \\
\hline 8117429 & $\mathrm{H} 2 \mathrm{BC} 10$ & 1.38951 & $1.22 \mathrm{E}-05$ & 0.000121 & 4.71683 & Up & $\mathrm{H} 2 \mathrm{~B}$ clustered histone 10 \\
\hline 8124534 & $\mathrm{H} 4 \mathrm{C} 13$ & 1.307289 & $1.37 \mathrm{E}-05$ & 0.000134 & 4.685836 & $\mathrm{Up}$ & H4 clustered histone 13 \\
\hline 8052399 & BCL11A & 1.200078 & $1.41 \mathrm{E}-05$ & 0.000137 & 4.677891 & Up & $\begin{array}{l}\text { BAF chromatin remodeling complex subunit } \\
\text { BCL11A }\end{array}$ \\
\hline 7916898 & DEPDC1 & 1.146694 & $1.43 \mathrm{E}-05$ & 0.000139 & 4.672977 & Up & DEP domain containing 1 \\
\hline 7910047 & DNAH14 & 1.199719 & $1.44 \mathrm{E}-05$ & 0.00014 & 4.67228 & $\mathrm{Up}$ & dynein axonemal heavy chain 14 \\
\hline 7923034 & B3GALT2 & 1.609957 & $1.51 \mathrm{E}-05$ & 0.000145 & 4.65966 & Up & beta-1,3-galactosyltransferase 2 \\
\hline 8095456 & ODAM & 1.939405 & $1.83 \mathrm{E}-05$ & 0.000172 & 4.606453 & $\mathrm{Up}$ & odontogenic, ameloblast associated \\
\hline 8119915 & LINC01512 & 1.120676 & $1.86 \mathrm{E}-05$ & 0.000174 & 4.601874 & Up & long intergenic non-protein coding RNA 1512 \\
\hline 8092000 & TERC & 1.460588 & $1.94 \mathrm{E}-05$ & 0.000181 & 4.591415 & Up & telomerase RNA component \\
\hline 7973093 & EDDM3A & 1.630095 & $2.01 \mathrm{E}-05$ & 0.000186 & 4.581305 & $\mathrm{Up}$ & $\begin{array}{c}\text { epididymal protein } 3 \mathrm{~A} \\
\text { zeta chain of } \mathrm{T} \text { cell receptor associated protein }\end{array}$ \\
\hline 8043725 & ZAP70 & 1.198079 & 2.01E-05 & 0.000186 & 4.581065 & Up & kinase 70 \\
\hline 7974689 & DACT1 & 1.084031 & 2.13E-05 & 0.000195 & 4.565431 & Up & dishevelled binding antagonist of beta catenin 1 \\
\hline 8140534 & SEMA3C & 1.349176 & $2.29 \mathrm{E}-05$ & 0.000208 & 4.545191 & Up & semaphorin $3 \mathrm{C}$ \\
\hline 7964722 & WIF1 & 2.203195 & $2.59 \mathrm{E}-05$ & 0.000232 & 4.512239 & Up & WNT inhibitory factor 1 \\
\hline 8170695 & DUSP9 & 1.568434 & $2.77 \mathrm{E}-05$ & 0.000246 & 4.492719 & $\mathrm{Up}$ & dual specificity phosphatase 9 \\
\hline 8084704 & EIF4A2 & 1.254997 & $2.96 \mathrm{E}-05$ & 0.00026 & 4.475328 & $\mathrm{Up}$ & eukaryotic translation initiation factor $4 \mathrm{~A} 2$ \\
\hline 8046078 & B3GALT1 & 1.372365 & $3.08 \mathrm{E}-05$ & 0.000268 & 4.464103 & $\mathrm{Up}$ & beta-1,3-galactosyltransferase 1 \\
\hline 8064539 & CPXM1 & 1.143805 & $3.43 \mathrm{E}-05$ & 0.000294 & 4.433923 & Up & carboxypeptidase X, M14 family member 1 \\
\hline 8056363 & SLC38A11 & 1.23444 & 4.29E-05 & 0.000354 & 4.371576 & Up & solute carrier family 38 member 11 \\
\hline 8042788 & ACTG2 & 1.634227 & $4.35 \mathrm{E}-05$ & 0.000359 & 4.367776 & Up & actin gamma 2 , smooth muscle \\
\hline 7922408 & SNORD78 & 1.125285 & 5.42E-05 & 0.00043 & 4.306296 & Up & small nucleolar RNA, C/D box 78 \\
\hline 8106743 & VCAN & 1.710818 & $5.63 \mathrm{E}-05$ & 0.000445 & 4.295297 & $\mathrm{Up}$ & versican \\
\hline 7981974 & $\begin{array}{l}\text { SNORD116- } \\
13\end{array}$ & 1.536529 & $5.64 \mathrm{E}-05$ & 0.000445 & 4.294904 & Up & small nucleolar RNA, C/D box 116-13 \\
\hline 8079422 & TDGF1 & 1.276329 & $6.21 \mathrm{E}-05$ & 0.000483 & 4.26769 & $\mathrm{Up}$ & teratocarcinoma-derived growth factor 1 \\
\hline 7939559 & TSPAN18 & 1.474805 & $6.87 \mathrm{E}-05$ & 0.000526 & 4.239236 & $\mathrm{Up}$ & tetraspanin 18 \\
\hline 8055314 & LYPD1 & 1.101297 & 7.08E-05 & 0.000539 & 4.230705 & Up & LY6/PLAUR domain containing 1 \\
\hline 7976850 & MIR154 & 1.417225 & $7.21 \mathrm{E}-05$ & 0.000548 & 4.225565 & $\mathrm{Up}$ & microRNA 154 \\
\hline 7981945 & PWAR6 & 1.312355 & 8.34E-05 & 0.00062 & 4.184142 & Up & PraderWilli/Angelman region RNA 6 \\
\hline 7955963 & MUCL1 & 1.288673 & $9.71 \mathrm{E}-05$ & 0.000705 & 4.140575 & Up & mucin like 1 \\
\hline 7923578 & $\begin{array}{l}\text { FMOD } \\
\text { SNORD116- }\end{array}$ & 1.35917 & 0.000146 & 0.000999 & 4.021923 & $\mathrm{Up}$ & fibromodulin \\
\hline 7981970 & 11 & 1.238358 & 0.000147 & 0.001006 & 4.019603 & Up & small nucleolar RNA, C/D box 116-11 \\
\hline 8139087 & SFRP4 & 1.32531 & 0.000172 & 0.001141 & 3.975198 & Up & secreted frizzled related protein 4 \\
\hline 8141140 & DLX5 & 1.103599 & 0.000175 & 0.001161 & 3.969296 & Up & distal-less homeobox 5 \\
\hline 8062064 & MYH7B & 1.333397 & 0.000189 & 0.001241 & 3.946157 & $\mathrm{Up}$ & myosin heavy chain 7B \\
\hline 7904158 & OLFML3 & 1.126637 & 0.000208 & 0.001343 & 3.918088 & Up & $\begin{array}{c}\text { olfactomedin like } 3 \\
\text { potassium inwardly rectifying channel subfamily } \mathrm{J}\end{array}$ \\
\hline 7921533 & KCNJ10 & 1.205856 & 0.000224 & 0.00143 & 3.896127 & $\mathrm{Up}$ & member 10 \\
\hline 8016646 & COL1A1 & 1.350822 & 0.000246 & 0.001541 & 3.868442 & Up & collagen type I alpha 1 chain \\
\hline 8160168 & FREM1 & 1.4308 & 0.000249 & 0.001555 & 3.865391 & Up & FRAS1 related extracellular matrix 1 \\
\hline 8015349 & KRT19 & 1.098654 & 0.00027 & 0.001665 & 3.841552 & Up & keratin 19 \\
\hline
\end{tabular}


medRxiv preprint doi: https://doi.org/10.1101/2020.12.22.20248756; this version posted December 26, 2020. The copyright holder for this preprint (which was not certified by peer review) is the author/funder, who has granted medRxiv a license to display the preprint in perpetuity. All rights reserved. No reuse allowed without permission.

\begin{tabular}{|c|c|c|c|c|c|c|c|}
\hline 8077366 & LRRN1 & 1.102835 & 0.000302 & 0.001834 & 3.807336 & Up & leucine rich repeat neuronal 1 \\
\hline 8001800 & CDH11 & 1.339772 & 0.000319 & 0.001921 & 3.790961 & Up & cadherin 11 \\
\hline 8101659 & SPARCL1 & 1.403522 & 0.000358 & 0.002107 & 3.756636 & Up & SPARC like 1 \\
\hline 7980152 & LTBP2 & 1.120783 & 0.000412 & 0.002381 & 3.713848 & Up & $\begin{array}{l}\text { latent transforming growth factor beta binding } \\
\text { protein } 2\end{array}$ \\
\hline 8134263 & COL1A2 & 1.362936 & 0.000461 & 0.002622 & 3.679363 & Up & collagen type I alpha 2 chain \\
\hline 8057506 & FRZB & 1.236166 & 0.000536 & 0.002976 & 3.633053 & Up & frizzled related protein \\
\hline 8164215 & SNORA65 & 1.071443 & 0.000604 & 0.003295 & 3.596379 & Up & small nucleolar RNA, H/ACA box 65 \\
\hline 8102200 & DKK2 & 1.135208 & 0.000629 & 0.003412 & 3.583603 & Up & dickkopf WNT signaling pathway inhibitor 2 \\
\hline 7976842 & MIR382 & 1.163973 & 0.000747 & 0.003943 & 3.530113 & Up & microRNA 382 \\
\hline 8142270 & NRCAM & 1.090841 & 0.000915 & 0.004692 & 3.466516 & Up & neuronal cell adhesion molecule \\
\hline 7921099 & CRABP2 & 1.182176 & 0.00104 & 0.005236 & 3.425781 & Up & cellular retinoic acid binding protein 2 \\
\hline 8060805 & CHGB & 1.339338 & 0.001143 & 0.005656 & 3.395404 & Up & chromogranin B \\
\hline 8044700 & DPP10 & 1.190213 & 0.001157 & 0.005711 & 3.391597 & Up & dipeptidyl peptidase like 10 \\
\hline 8002303 & NQO1 & 1.457459 & 0.001157 & 0.005711 & 3.391563 & Up & $\mathrm{NAD}(\mathrm{P}) \mathrm{H}$ quinone dehydrogenase 1 \\
\hline 7906501 & ATP1A2 & 1.179812 & 0.001184 & 0.005816 & 3.384181 & Up & ATPase $\mathrm{Na}+\mathrm{K}+$ transporting subunit alpha 2 \\
\hline 7981998 & $\begin{array}{l}\text { SNORD116- } \\
25\end{array}$ & 1.09447 & 0.001463 & 0.00694 & 3.315816 & Up & small nucleolar RNA, C/D box 116-25 \\
\hline 7907156 & XCL1 & 1.072172 & 0.001723 & 0.007953 & 3.262539 & Up & $\mathrm{X}-\mathrm{C}$ motif chemokine ligand 1 \\
\hline 7968678 & FREM2 & 1.334139 & 0.001866 & 0.008504 & 3.236245 & Up & $\begin{array}{l}\text { FRAS1 related extracellular matrix } 2 \\
\text { multiple } \mathrm{C} 2 \text { and transmembrane domain }\end{array}$ \\
\hline 8113130 & MCTP1 & 1.120834 & 0.002095 & 0.009349 & 3.197977 & Up & containing 1 \\
\hline 8114415 & GFRA3 & 1.369131 & 0.002286 & 0.010041 & 3.169062 & Up & GDNF family receptor alpha 3 \\
\hline 8096301 & SPP1 & 1.325145 & 0.004041 & 0.016054 & 2.975164 & Up & secreted phosphoprotein 1 \\
\hline 8025522 & $\mathrm{C} 3 \mathrm{P} 1$ & -3.30609 & $8.35 \mathrm{E}-23$ & 8.99E-19 & -14.652 & Down & complement component 3 precursor pseudogene \\
\hline 8123232 & SLC22A1 & -4.39446 & $3.36 \mathrm{E}-22$ & $2.72 \mathrm{E}-18$ & -14.2635 & Down & solute carrier family 22 member 1 \\
\hline 7964292 & RDH16 & -2.8987 & $1.17 \mathrm{E}-21$ & 7.54E-18 & -13.9213 & Down & retinol dehydrogenase 16 \\
\hline 7904396 & $\mathrm{HAO} 2$ & -4.29552 & 7.31E-21 & $3.38 \mathrm{E}-17$ & -13.4236 & Down & hydroxyacid oxidase 2 \\
\hline 7964183 & GLS2 & -3.29957 & $8.52 \mathrm{E}-21$ & $3.44 \mathrm{E}-17$ & -13.3824 & Down & glutaminase 2 \\
\hline 8090433 & MGLL & -2.12582 & $5.41 \mathrm{E}-20$ & $1.34 \mathrm{E}-16$ & -12.8905 & Down & monoglyceride lipase \\
\hline 7944271 & TTC36 & -1.42939 & $1.09 \mathrm{E}-19$ & $2.35 \mathrm{E}-16$ & -12.7059 & Down & tetratricopeptide repeat domain 36 \\
\hline 7966621 & SDS & -3.73349 & $2.09 \mathrm{E}-19$ & $3.75 \mathrm{E}-16$ & -12.5359 & Down & serine dehydratase \\
\hline 8084657 & FETUB & -3.60928 & $1.18 \mathrm{E}-18$ & $1.73 \mathrm{E}-15$ & -12.0873 & Down & fetuin B \\
\hline 7960984 & PZP & -2.70226 & $1.53 \mathrm{E}-18$ & $1.98 \mathrm{E}-15$ & -12.0195 & Down & PZP alpha-2-macroglobulin like \\
\hline 8025303 & CLEC4M & -3.38324 & $1.74 \mathrm{E}-18$ & $2.17 \mathrm{E}-15$ & -11.9864 & Down & C-type lectin domain family 4 member $\mathrm{M}$ \\
\hline 8094361 & GBA3 & -2.94063 & $2.71 \mathrm{E}-18$ & $3.24 \mathrm{E}-15$ & -11.8738 & Down & glucosylceramidase beta 3 (gene/pseudogene) \\
\hline 7984862 & CYP1A2 & -3.62456 & $5.29 \mathrm{E}-18$ & $5.7 \mathrm{E}-15$ & -11.7029 & Down & cytochrome P450 family 1 subfamily A member 2 \\
\hline 8096116 & GPAT3 & -2.94539 & $9.99 \mathrm{E}-18$ & $9.5 \mathrm{E}-15$ & -11.5416 & Down & glycerol-3-phosphate acyltransferase 3 \\
\hline 7943867 & $\mathrm{BCO} 2$ & -3.65423 & $1.63 \mathrm{E}-17$ & $1.46 \mathrm{E}-14$ & -11.4187 & Down & beta-carotene oxygenase 2 \\
\hline 7977203 & ASPG & -1.45501 & $1.9 \mathrm{E}-17$ & $1.66 \mathrm{E}-14$ & -11.3796 & Down & asparaginase \\
\hline 8051322 & $\mathrm{XDH}$ & -3.34633 & $1.99 \mathrm{E}-17$ & $1.66 \mathrm{E}-14$ & -11.3676 & Down & xanthine dehydrogenase \\
\hline 8051361 & SRD5A2 & -3.13906 & $2.05 \mathrm{E}-17$ & $1.66 \mathrm{E}-14$ & -11.3598 & Down & steroid 5 alpha-reductase 2 \\
\hline 8147132 & $\mathrm{CA} 2$ & -2.38418 & $2.48 \mathrm{E}-17$ & $1.91 \mathrm{E}-14$ & -11.3125 & Down & carbonic anhydrase 2 \\
\hline 8144866 & NAT2 & -2.33039 & $2.61 \mathrm{E}-17$ & $1.96 \mathrm{E}-14$ & -11.2997 & Down & $\mathrm{N}$-acetyltransferase 2 \\
\hline 8148304 & TRIB1 & -2.00232 & $3.94 \mathrm{E}-17$ & $2.71 \mathrm{E}-14$ & -11.1962 & Down & tribblespseudokinase 1 \\
\hline 8104369 & SRD5A1 & -1.3541 & $7.83 \mathrm{E}-17$ & $5.07 \mathrm{E}-14$ & -11.0243 & Down & steroid 5 alpha-reductase 1 \\
\hline 7997179 & DHODH & -1.76163 & $7.84 \mathrm{E}-17$ & $5.07 \mathrm{E}-14$ & -11.0241 & Down & dihydroorotate dehydrogenase (quinone) \\
\hline
\end{tabular}


medRxiv preprint doi: https://doi.org/10.1101/2020.12.22.20248756; this version posted December 26, 2020. The copyright holder for this preprint (which was not certified by peer review) is the author/funder, who has granted medRxiv a license to display the preprint in perpetuity.

All rights reserved. No reuse allowed without permission.

\begin{tabular}{|c|c|c|c|c|c|}
\hline 7964142 & APOF & -4.31305 & $1.11 \mathrm{E}-16$ & $6.77 \mathrm{E}-14$ & -10.9373 \\
\hline 7939056 & BBOX1 & -2.07186 & $1.2 \mathrm{E}-16$ & 7.17E-14 & -10.9184 \\
\hline 929466 & CYP2C18 & -3.30808 & $1.61 \mathrm{E}-16$ & $9.16 \mathrm{E}-14$ & -10.8441 \\
\hline 7910950 & KMO & -3.05616 & $1.86 \mathrm{E}-16$ & $1.04 \mathrm{E}-13$ & -10.8085 \\
\hline 8028955 & CYP2B7P & -5.1472 & $1.9 \mathrm{E}-16$ & $1.04 \mathrm{E}-13$ & -10.8038 \\
\hline 7917548 & GBP7 & -2.46798 & $2.02 \mathrm{E}-16$ & $1.09 \mathrm{E}-13$ & -10.789 \\
\hline 7898655 & $\mathrm{CDA}$ & -1.90793 & $2.12 \mathrm{E}-16$ & $1.12 \mathrm{E}-13$ & -10.7766 \\
\hline 957551 & SOCS2 & -1.87597 & $4.18 \mathrm{E}-16$ & $2.05 \mathrm{E}-13$ & -10.6083 \\
\hline 7913138 & AKR7L & -2.04447 & $5.43 \mathrm{E}-16$ & $2.58 \mathrm{E}-13$ & -10.5438 \\
\hline 8093792 & HGFAC & -1.88966 & $5.59 \mathrm{E}-16$ & $2.58 \mathrm{E}-13$ & -10.5367 \\
\hline 8161174 & GNE & -1.58207 & $7.08 \mathrm{E}-16$ & $3.22 \mathrm{E}-13$ & -10.4788 \\
\hline 7979269 & GCH1 & -1.83997 & $9.28 \mathrm{E}-16$ & $4.11 \mathrm{E}-13$ & -10.4121 \\
\hline 7933537 & OGDHL & -2.50293 & $1.04 \mathrm{E}-15$ & 4.47E-13 & -10.3845 \\
\hline 7964660 & AVPR1A & -3.20147 & $1.25 \mathrm{E}-15$ & $5.25 \mathrm{E}-13$ & -10.3386 \\
\hline 8106999 & LINC01554 & -1.46225 & $1.3 \mathrm{E}-15$ & $5.4 \mathrm{E}-13$ & -10.3288 \\
\hline 8148902 & GPT & -1.30617 & $1.71 \mathrm{E}-15$ & $6.91 \mathrm{E}-13$ & -10.2621 \\
\hline 8033433 & CLEC4G & -2.18996 & $2.18 \mathrm{E}-15$ & $8.49 \mathrm{E}-13$ & -10.2025 \\
\hline 7994572 & SNX29P2 & -1.66299 & $2.43 \mathrm{E}-15$ & 8.87E-13 & -10.176 \\
\hline 8102249 & ETNPPL & -2.18886 & $2.43 \mathrm{E}-15$ & $8.87 \mathrm{E}-13$ & -10.1757 \\
\hline 8039779 & SLC27A5 & -2.25185 & $2.76 \mathrm{E}-15$ & $9.82 \mathrm{E}-13$ & -10.1447 \\
\hline 8130608 & LPA & -2.7282 & $3.55 \mathrm{E}-15$ & $1.2 \mathrm{E}-12$ & -10.0834 \\
\hline 7958931 & DTX1 & -1.88938 & $3.87 \mathrm{E}-15$ & $1.28 \mathrm{E}-12$ & -10.0627 \\
\hline 8127087 & GSTA3 & -1.44025 & $4.33 \mathrm{E}-15$ & $1.41 \mathrm{E}-12$ & -10.0353 \\
\hline 8180222 & CFHR4 & -3.45805 & 4.4E-15 & $1.41 \mathrm{E}-12$ & -10.0313 \\
\hline 8022803 & GAREM1 & -1.6652 & 4.4E-15 & $1.41 \mathrm{E}-12$ & -10.0311 \\
\hline 8159919 & SPATA6L & -1.73127 & $4.45 \mathrm{E}-15$ & $1.41 \mathrm{E}-12$ & -10.0286 \\
\hline 8098246 & ANXA10 & -1.50375 & $5.49 \mathrm{E}-15$ & $1.69 \mathrm{E}-12$ & -9.97756 \\
\hline 8129627 & VNN3 & -2.72847 & $6.82 \mathrm{E}-15$ & $2 \mathrm{E}-12$ & -9.9245 \\
\hline 7949679 & SPTBN2 & -1.42585 & $7.22 \mathrm{E}-15$ & $2.08 \mathrm{E}-12$ & -9.91075 \\
\hline 8129783 & MAP7 & -1.76963 & $7.28 \mathrm{E}-15$ & $2.08 \mathrm{E}-12$ & -9.90855 \\
\hline 8154135 & SLC1A1 & -3.71391 & $1.15 \mathrm{E}-14$ & $3.21 \mathrm{E}-12$ & -9.79728 \\
\hline 7952249 & USP2 & -1.42685 & $1.61 \mathrm{E}-14$ & $4.42 \mathrm{E}-12$ & -9.71564 \\
\hline 8119620 & GNMT & -2.93948 & $1.64 \mathrm{E}-14$ & 4.44E-12 & -9.71223 \\
\hline 8159211 & FCN2 & -1.78277 & $1.75 \mathrm{E}-14$ & 4.67E-12 & -9.69629 \\
\hline 7962884 & RND1 & -2.16105 & $1.83 \mathrm{E}-14$ & $4.86 \mathrm{E}-12$ & -9.68472 \\
\hline 8021653 & SERPINB8 & -2.22196 & $2.12 \mathrm{E}-14$ & 5.39E-12 & -9.64968 \\
\hline 7908481 & CFHR3 & -4.14346 & $2.26 \mathrm{E}-14$ & $5.68 \mathrm{E}-12$ & -9.63444 \\
\hline 7963826 & PPP1R1A & -2.05531 & $2.27 \mathrm{E}-14$ & $5.68 \mathrm{E}-12$ & -9.63341 \\
\hline 8145736 & NRG1 & -1.78632 & $2.32 \mathrm{E}-14$ & $5.76 \mathrm{E}-12$ & -9.628 \\
\hline 8133961 & RUNDC3B & -2.03249 & $2.59 \mathrm{E}-14$ & $6.39 \mathrm{E}-12$ & -9.60096 \\
\hline 7918558 & KCND3 & -1.91677 & $2.85 \mathrm{E}-14$ & $6.93 \mathrm{E}-12$ & -9.5777 \\
\hline 8028963 & CYP2B6 & -5.07072 & $2.87 \mathrm{E}-14$ & $6.93 \mathrm{E}-12$ & -9.57607 \\
\hline 8091863 & SLITRK3 & -2.21545 & $3.76 \mathrm{E}-14$ & $8.81 \mathrm{E}-12$ & -9.51088 \\
\hline
\end{tabular}

apolipoprotein $\mathrm{F}$

gamma-butyrobetaine hydroxylase 1 cytochrome P450 family 2 subfamily C member 18

kynurenine 3-monooxygenase cytochrome P450 family 2 subfamily B member 7, pseudogene

guanylate binding protein 7 cytidinedeaminase

suppressor of cytokine signaling 2 aldo-ketoreductase family 7 like (gene/pseudogene) HGF activator glucosamine (UDP-N-acetyl)-2-epimerase/Nacetylmannosamine kinase GTP cyclohydrolase 1 oxoglutarate dehydrogenase like arginine vasopressin receptor $1 \mathrm{~A}$ long intergenic non-protein coding RNA 1554 glutamic--pyruvic transaminase

C-type lectin domain family 4 member $\mathrm{G}$ sorting nexin 29 pseudogene 2

ethanolamine-phosphate phospho-lyase solute carrier family 27 member 5 lipoprotein(a)

deltex E3 ubiquitin ligase 1 glutathione S-transferase alpha 3 complement factor $\mathrm{H}$ related 4

GRB2 associated regulator of MAPK1 subtype 1 spermatogenesis associated 6 like annexin A10 vanin 3

spectrin beta, non-erythrocytic 2 microtubule associated protein 7 solute carrier family 1 member 1 ubiquitin specific peptidase 2 glycine N-methyltransferase ficolin 2

Rho family GTPase 1 serpin family B member 8

complement factor $\mathrm{H}$ related 3

protein phosphatase 1 regulatory inhibitor subunit $1 \mathrm{~A}$ neuregulin 1

RUN domain containing 3B potassium voltage-gated channel subfamily D member 3

cytochrome P450 family 2 subfamily B member 6 SLIT and NTRK like family member 3 
medRxiv preprint doi: https://doi.org/10.1101/2020.12.22.20248756; this version posted December 26, 2020. The copyright holder for this preprint (which was not certified by peer review) is the author/funder, who has granted medRxiv a license to display the preprint in perpetuity. All rights reserved. No reuse allowed without permission.

\begin{tabular}{|c|c|c|c|c|c|c|c|}
\hline 8044773 & MARCO & -1.53571 & $5.02 \mathrm{E}-14$ & $1.16 \mathrm{E}-11$ & -9.44114 & Down & macrophage receptor with collagenous structure \\
\hline 7902290 & $\mathrm{CTH}$ & -2.4056 & $5.36 \mathrm{E}-14$ & $1.21 \mathrm{E}-11$ & -9.42567 & Down & cystathionine gamma-lyase \\
\hline 8149885 & ADRA1A & -2.76568 & $5.54 \mathrm{E}-14$ & $1.23 \mathrm{E}-11$ & -9.41775 & Down & adrenoceptor alpha $1 \mathrm{~A}$ \\
\hline 8032834 & LRG1 & -2.20529 & $6 \mathrm{E}-14$ & $1.32 \mathrm{E}-11$ & -9.3985 & Down & leucine rich alpha-2-glycoprotein 1 \\
\hline 8151942 & RIDA & -2.71821 & $6.34 \mathrm{E}-14$ & $1.38 \mathrm{E}-11$ & -9.38509 & Down & $\begin{array}{l}\text { reactive intermediate imine deaminase A homolog } \\
\text { glycosylphosphatidylinositol specific }\end{array}$ \\
\hline 8124211 & GPLD1 & -2.0305 & $7.35 \mathrm{E}-14$ & $1.57 \mathrm{E}-11$ & -9.34937 & Down & phospholipase D1 \\
\hline 7908492 & CFHR4 & -3.15853 & 7.47E-14 & $1.59 \mathrm{E}-11$ & -9.34562 & Down & complement factor $\mathrm{H}$ related 4 \\
\hline 7970905 & N4BP2L1 & -1.63736 & $1.08 \mathrm{E}-13$ & $2.22 \mathrm{E}-11$ & -9.25605 & Down & NEDD4 binding protein 2 like 1 \\
\hline 7942793 & THRSP & -2.8613 & $1.25 \mathrm{E}-13$ & $2.52 \mathrm{E}-11$ & -9.22242 & Down & thyroid hormone responsive \\
\hline 8174598 & IL13RA2 & -1.39909 & $1.28 \mathrm{E}-13$ & $2.57 \mathrm{E}-11$ & -9.21564 & Down & interleukin 13 receptor subunit alpha 2 \\
\hline 7943998 & NNMT & -3.28874 & $1.34 \mathrm{E}-13$ & $2.67 \mathrm{E}-11$ & -9.2052 & Down & nicotinamide N-methyltransferase \\
\hline 8068593 & ETS2 & -1.47029 & $1.68 \mathrm{E}-13$ & $3.26 \mathrm{E}-11$ & -9.15028 & Down & ETS proto-oncogene 2, transcription factor \\
\hline 7961102 & CLEC1B & -2.34611 & $2.03 \mathrm{E}-13$ & $3.84 \mathrm{E}-11$ & -9.10496 & Down & C-type lectin domain family 1 member B \\
\hline 8070182 & RCAN1 & -1.31852 & $2.67 \mathrm{E}-13$ & $4.93 \mathrm{E}-11$ & -9.03976 & Down & regulator of calcineurin 1 \\
\hline 7940135 & GLYATL1 & -2.55705 & $2.98 \mathrm{E}-13$ & $5.34 \mathrm{E}-11$ & -9.01332 & Down & glycine-N-acyltransferase like 1 \\
\hline 7965606 & HAL & -3.8406 & $3.2 \mathrm{E}-13$ & $5.69 \mathrm{E}-11$ & -8.99606 & Down & histidine ammonia-lyase \\
\hline 8136459 & AKR1D1 & -3.07329 & $3.35 \mathrm{E}-13$ & $5.92 \mathrm{E}-11$ & -8.98508 & Down & aldo-ketoreductase family 1 member D1 \\
\hline 8146669 & TRIM55 & -1.75502 & 4.27E-13 & $7.38 \mathrm{E}-11$ & -8.92707 & Down & tripartite motif containing 55 \\
\hline 7995739 & GNAO1 & -1.94451 & $4.45 \mathrm{E}-13$ & 7.64E-11 & -8.91753 & Down & G protein subunit alpha o1 \\
\hline 8127065 & GSTA2 & -2.98827 & $4.65 \mathrm{E}-13$ & 7.91E-11 & -8.90668 & Down & glutathione S-transferase alpha 2 \\
\hline 8023598 & RNF152 & -2.08533 & $4.86 \mathrm{E}-13$ & $8.18 \mathrm{E}-11$ & -8.89618 & Down & $\begin{array}{l}\text { ring finger protein } 152 \\
\text { cytochrome P450 family } 2 \text { subfamily } \mathrm{C} \text { member }\end{array}$ \\
\hline 7929478 & CYP2C19 & -4.12324 & $5.26 \mathrm{E}-13$ & $8.73 \mathrm{E}-11$ & -8.87708 & Down & $\begin{array}{c}19 \\
\text { cytochrome P450 family } 26 \text { subfamily A member }\end{array}$ \\
\hline 7929322 & CYP26A1 & -1.39111 & $5.37 \mathrm{E}-13$ & $8.81 \mathrm{E}-11$ & -8.87235 & Down & 1 \\
\hline 8101637 & HSD17B13 & -4.66433 & $6.42 \mathrm{E}-13$ & $1.03 \mathrm{E}-10$ & -8.82952 & Down & hydroxysteroid 17-beta dehydrogenase 13 \\
\hline 8058591 & ACADL & -2.57041 & $6.57 \mathrm{E}-13$ & $1.05 \mathrm{E}-10$ & -8.8243 & Down & acyl-CoA dehydrogenase long chain \\
\hline 7933084 & NAMPT & -2.48145 & $6.68 \mathrm{E}-13$ & $1.06 \mathrm{E}-10$ & -8.82006 & Down & nicotinamidephosphoribosyltransferase \\
\hline 8000582 & SULT1A2 & -1.62619 & $6.69 \mathrm{E}-13$ & $1.06 \mathrm{E}-10$ & -8.81979 & Down & sulfotransferase family $1 \mathrm{~A}$ member 2 \\
\hline 7909446 & HSD11B1 & -3.80584 & 7.57E-13 & $1.17 \mathrm{E}-10$ & -8.79037 & Down & hydroxysteroid 11-beta dehydrogenase 1 \\
\hline 8122744 & IYD & -1.39701 & 7.67E-13 & $1.18 \mathrm{E}-10$ & -8.78696 & Down & iodotyrosinedeiodinase \\
\hline 8021169 & LIPG & -2.02788 & $8.88 \mathrm{E}-13$ & $1.35 \mathrm{E}-10$ & -8.75207 & Down & $\begin{array}{l}\text { lipase } \mathrm{G} \text {, endothelial type } \\
\text { aldo-ketoreductase family } 1 \text { member } \mathrm{C} 8 \text {, }\end{array}$ \\
\hline 7931840 & AKR1C8P & -2.05835 & $9.43 \mathrm{E}-13$ & $1.42 \mathrm{E}-10$ & -8.7377 & Down & pseudogene \\
\hline 8142120 & NAMPT & -2.52935 & $1.01 \mathrm{E}-12$ & $1.5 \mathrm{E}-10$ & -8.72041 & Down & nicotinamidephosphoribosyltransferase \\
\hline 8122843 & ESR1 & -1.44899 & $1.05 \mathrm{E}-12$ & $1.55 \mathrm{E}-10$ & -8.71108 & Down & estrogen receptor 1 \\
\hline 8099967 & RBM47 & -1.37808 & $1.07 \mathrm{E}-12$ & $1.55 \mathrm{E}-10$ & -8.70838 & Down & RNA binding motif protein 47 \\
\hline 8137526 & INSIG1 & -1.93931 & $1.14 \mathrm{E}-12$ & $1.64 \mathrm{E}-10$ & -8.6925 & Down & insulin induced gene 1 \\
\hline 8162276 & NFIL3 & -1.78475 & $1.14 \mathrm{E}-12$ & $1.64 \mathrm{E}-10$ & -8.69206 & Down & nuclear factor, interleukin 3 regulated \\
\hline 7995829 & MT1H & -2.49774 & $1.21 \mathrm{E}-12$ & $1.72 \mathrm{E}-10$ & -8.67912 & Down & metallothionein $1 \mathrm{H}$ \\
\hline 8159491 & $\mathrm{C} 8 \mathrm{G}$ & -2.04665 & $1.31 \mathrm{E}-12$ & $1.83 \mathrm{E}-10$ & -8.65911 & Down & complement $\mathrm{C} 8$ gamma chain \\
\hline 8111136 & RETREG1 & -1.95114 & $1.35 \mathrm{E}-12$ & $1.86 \mathrm{E}-10$ & -8.65192 & Down & reticulophagy regulator 1 \\
\hline 7930561 & HABP2 & -3.32781 & $1.36 \mathrm{E}-12$ & $1.86 \mathrm{E}-10$ & -8.65051 & Down & hyaluronan binding protein 2 \\
\hline 8071107 & SLC25A18 & -2.2498 & $1.54 \mathrm{E}-12$ & $2.08 \mathrm{E}-10$ & -8.62032 & Down & solute carrier family 25 member 18 \\
\hline 8132250 & BMPER & -1.38255 & $1.65 \mathrm{E}-12$ & $2.21 \mathrm{E}-10$ & -8.60362 & Down & BMP binding endothelial regulator \\
\hline 7942603 & MOGAT2 & -1.85221 & $1.74 \mathrm{E}-12$ & 2.3E-10 & -8.59133 & Down & monoacylglycerol O-acyltransferase 2 \\
\hline 8083471 & ARHGEF26 & -2.64106 & $1.75 \mathrm{E}-12$ & $2.3 \mathrm{E}-10$ & -8.59068 & Down & Rho guanine nucleotide exchange factor 26 \\
\hline
\end{tabular}


medRxiv preprint doi: https://doi.org/10.1101/2020.12.22.20248756; this version posted December 26, 2020. The copyright holder for this preprint (which was not certified by peer review) is the author/funder, who has granted medRxiv a license to display the preprint in perpetuity. All rights reserved. No reuse allowed without permission.

\begin{tabular}{|c|c|c|c|c|c|c|c|}
\hline 8027819 & HAMP & -2.65013 & $1.75 \mathrm{E}-12$ & $2.3 \mathrm{E}-10$ & -8.59054 & Down & hepcidin antimicrobial peptide \\
\hline 8100994 & CXCL2 & -2.40976 & $1.75 \mathrm{E}-12$ & $2.3 \mathrm{E}-10$ & -8.58988 & Down & $\begin{array}{l}\mathrm{C}-\mathrm{X}-\mathrm{C} \text { motif chemokine ligand } 2 \\
\text { protein kinase AMP-activated non-catalytic }\end{array}$ \\
\hline 8143961 & PRKAG2 & -1.34504 & $1.79 \mathrm{E}-12$ & $2.33 \mathrm{E}-10$ & -8.58517 & Down & subunit gamma 2 \\
\hline 7979878 & SLC10A1 & -4.00122 & $1.87 \mathrm{E}-12$ & $2.42 \mathrm{E}-10$ & -8.57446 & Down & solute carrier family 10 member 1 \\
\hline 7958466 & $\mathrm{ACACB}$ & -1.73003 & $1.89 \mathrm{E}-12$ & $2.43 \mathrm{E}-10$ & -8.57187 & Down & acetyl-CoA carboxylase beta \\
\hline 8155802 & GDA & -3.17581 & $2.16 \mathrm{E}-12$ & $2.73 \mathrm{E}-10$ & -8.53945 & Down & guanine deaminase \\
\hline 7959834 & GLT1D1 & -2.37102 & $2.18 \mathrm{E}-12$ & $2.74 \mathrm{E}-10$ & -8.53743 & Down & glycosyltransferase 1 domain containing 1 \\
\hline 7935169 & CYP2C8 & -5.51991 & $2.78 \mathrm{E}-12$ & $3.34 \mathrm{E}-10$ & -8.47972 & Down & cytochrome $\mathrm{P} 450$ family 2 subfamily $\mathrm{C}$ member 8 \\
\hline 7970793 & SLC46A3 & -2.10954 & $2.79 \mathrm{E}-12$ & $3.34 \mathrm{E}-10$ & -8.47898 & Down & solute carrier family 46 member 3 \\
\hline 7933665 & MBL2 & -2.43825 & $2.82 \mathrm{E}-12$ & 3.37E-10 & -8.47586 & Down & mannose binding lectin 2 \\
\hline 8103094 & NR3C2 & -1.26058 & $3.01 \mathrm{E}-12$ & $3.57 \mathrm{E}-10$ & -8.46055 & Down & nuclear receptor subfamily 3 group C member 2 \\
\hline 8170215 & F9 & -4.54581 & 3.13E-12 & 3.67E-10 & -8.45176 & Down & coagulation factor IX \\
\hline 7935627 & GOT1 & -1.66843 & $3.21 \mathrm{E}-12$ & $3.75 \mathrm{E}-10$ & -8.44535 & Down & glutamic-oxaloacetic transaminase 1 \\
\hline 8154153 & CDC37L1 & -1.83529 & $3.25 \mathrm{E}-12$ & $3.75 \mathrm{E}-10$ & -8.44245 & Down & cell division cycle 37 like 1 \\
\hline 8099912 & SMIM14 & -1.38867 & $3.26 \mathrm{E}-12$ & $3.75 \mathrm{E}-10$ & -8.44187 & Down & small integral membrane protein 14 \\
\hline 8024485 & GADD45B & -1.63015 & $3.27 \mathrm{E}-12$ & $3.75 \mathrm{E}-10$ & -8.44101 & Down & growth arrest and DNA damage inducible beta \\
\hline 7935270 & BLNK & -1.81437 & $3.28 \mathrm{E}-12$ & $3.75 \mathrm{E}-10$ & -8.44022 & Down & B cell linker \\
\hline 7956271 & HSD17B6 & -4.29901 & $3.82 \mathrm{E}-12$ & 4.3E-10 & -8.40396 & Down & hydroxysteroid 17-beta dehydrogenase 6 \\
\hline 8097038 & NDST3 & -1.44387 & 4.63E-12 & $5.12 \mathrm{E}-10$ & -8.35822 & Down & $\begin{array}{l}\mathrm{N} \text {-deacetylase and } \mathrm{N} \text {-sulfotransferase } 3 \\
\text { aminocarboxymuconatesemialdehyde }\end{array}$ \\
\hline 8045368 & ACMSD & -2.12824 & $5.18 \mathrm{E}-12$ & $5.58 \mathrm{E}-10$ & -8.33136 & Down & decarboxylase \\
\hline 8081386 & NFKBIZ & -1.49828 & $5.24 \mathrm{E}-12$ & $5.62 \mathrm{E}-10$ & -8.32868 & Down & NFKB inhibitor zeta \\
\hline 8144786 & SLC7A2 & -1.4625 & $5.59 \mathrm{E}-12$ & 5.99E-10 & -8.31302 & Down & solute carrier family 7 member 2 \\
\hline 7908499 & CFHR5 & -3.54183 & $5.7 \mathrm{E}-12$ & $6.06 \mathrm{E}-10$ & -8.30873 & Down & complement factor $\mathrm{H}$ related 5 \\
\hline 8084929 & SLC51A & -2.2238 & $7.24 \mathrm{E}-12$ & $7.43 \mathrm{E}-10$ & -8.25144 & Down & solute carrier family 51 alpha subunit \\
\hline 8167998 & $\mathrm{AR}$ & -2.82868 & $8.04 \mathrm{E}-12$ & 8.17E-10 & -8.2267 & Down & androgen receptor \\
\hline 8070467 & TMPRSS2 & -1.85089 & $8.98 \mathrm{E}-12$ & $8.98 \mathrm{E}-10$ & -8.20024 & Down & transmembrane serine protease 2 \\
\hline 8099612 & ADGRA3 & -1.31537 & $9.49 \mathrm{E}-12$ & $9.41 \mathrm{E}-10$ & -8.18717 & Down & adhesion $\mathrm{G}$ protein-coupled receptor A3 \\
\hline 8166243 & REPS2 & -1.51316 & $9.65 \mathrm{E}-12$ & $9.51 \mathrm{E}-10$ & -8.18314 & Down & RALBP1 associated Eps domain containing 2 \\
\hline 8109093 & ABLIM3 & -1.92407 & $1 \mathrm{E}-11$ & $9.77 \mathrm{E}-10$ & -8.17457 & Down & actin binding LIM protein family member 3 \\
\hline 7928330 & OIT3 & -2.61604 & $1.02 \mathrm{E}-11$ & $9.9 \mathrm{E}-10$ & -8.16991 & Down & oncoprotein induced transcript 3 \\
\hline 8021741 & CNDP1 & -1.70905 & $1.19 \mathrm{E}-11$ & 1.13E-09 & -8.13411 & Down & carnosinedipeptidase 1 \\
\hline 7995803 & MT1JP & -1.72208 & $1.23 \mathrm{E}-11$ & 1.17E-09 & -8.12454 & Down & metallothionein $1 \mathrm{~J}$, pseudogene \\
\hline 7943882 & PTS & -1.47906 & $1.33 \mathrm{E}-11$ & $1.25 \mathrm{E}-09$ & -8.10612 & Down & 6-pyruvoyltetrahydropterin synthase \\
\hline 8052747 & BMP10 & -2.32658 & $1.35 \mathrm{E}-11$ & $1.26 \mathrm{E}-09$ & -8.10346 & Down & $\begin{array}{c}\text { bone morphogenetic protein } 10 \\
\text { proteoglycan 3, pro eosinophil major basic protein }\end{array}$ \\
\hline 8103975 & SLED1 & -1.38012 & $1.38 \mathrm{E}-11$ & $1.29 \mathrm{E}-09$ & -8.09773 & Down & 2 pseudogene \\
\hline 8088664 & SUCLG2 & -1.35898 & $1.48 \mathrm{E}-11$ & $1.37 \mathrm{E}-09$ & -8.08195 & Down & succinate-CoA ligase GDP-forming beta subunit \\
\hline 7989023 & RAB27A & -1.47546 & $1.64 \mathrm{E}-11$ & $1.49 \mathrm{E}-09$ & -8.05674 & Down & RAB27A, member RAS oncogene family \\
\hline 8127072 & GSTA1 & -3.24627 & $1.8 \mathrm{E}-11$ & 1.62E-09 & -8.03415 & Down & glutathione S-transferase alpha 1 \\
\hline 7940737 & SLC22A10 & -3.35491 & $1.89 \mathrm{E}-11$ & 1.69E-09 & -8.02281 & Down & $\begin{array}{l}\text { solute carrier family } 22 \text { member } 10 \\
\text { LON peptidase } N \text {-terminal domain and ring finger }\end{array}$ \\
\hline 8169603 & LONRF3 & -1.93486 & $1.96 \mathrm{E}-11$ & $1.74 \mathrm{E}-09$ & -8.01449 & Down & 3 \\
\hline 8111757 & C9 & -4.7115 & $2.07 \mathrm{E}-11$ & $1.82 \mathrm{E}-09$ & -8.00103 & Down & complement C9 \\
\hline 7970892 & N4BP2L1 & -1.41185 & $2.24 \mathrm{E}-11$ & $1.93 \mathrm{E}-09$ & -7.98304 & Down & NEDD4 binding protein 2 like 1 \\
\hline 8035069 & PGLYRP2 & -2.41658 & $2.33 \mathrm{E}-11$ & 2E-09 & -7.97284 & Down & peptidoglycan recognition protein 2 \\
\hline 8129695 & ALDH8A1 & -2.35724 & $2.4 \mathrm{E}-11$ & 2.05E-09 & -7.96564 & Down & aldehyde dehydrogenase 8 family member A1 \\
\hline
\end{tabular}


medRxiv preprint doi: https://doi.org/10.1101/2020.12.22.20248756; this version posted December 26, 2020. The copyright holder for this preprint (which was not certified by peer review) is the author/funder, who has granted medRxiv a license to display the preprint in perpetuity. All rights reserved. No reuse allowed without permission.

\begin{tabular}{|c|c|c|c|c|c|c|}
\hline 8101304 & RASGEF1B & -1.90736 & $2.43 \mathrm{E}-11$ & $2.06 \mathrm{E}-09$ & -7.96279 & Down \\
\hline 8126860 & MMUT & -1.61234 & $2.44 \mathrm{E}-11$ & $2.06 \mathrm{E}-09$ & -7.96257 & Down \\
\hline 7930413 & DUSP5 & -1.25841 & $2.57 \mathrm{E}-11$ & $2.15 \mathrm{E}-09$ & -7.95008 & Down \\
\hline 8097991 & TDO2 & -4.09773 & $2.64 \mathrm{E}-11$ & $2.18 \mathrm{E}-09$ & -7.9438 & Down \\
\hline 8051799 & HAAO & -1.37137 & $2.65 \mathrm{E}-11$ & 2.19E-09 & -7.94249 & Down \\
\hline 7932433 & NSUN6 & -2.29379 & $2.79 \mathrm{E}-11$ & 2.3E-09 & -7.93016 & Down \\
\hline 7901287 & CYP4Z1 & -1.33307 & $2.85 \mathrm{E}-11$ & 2.32E-09 & -7.92514 & Down \\
\hline 8071907 & UPB1 & -2.54565 & $2.86 \mathrm{E}-11$ & $2.32 \mathrm{E}-09$ & -7.92451 & Down \\
\hline 8086330 & CSRNP1 & -1.43202 & $2.91 \mathrm{E}-11$ & 2.35E-09 & -7.92001 & Down \\
\hline 8095395 & UGT2B7 & -2.82403 & $3.61 \mathrm{E}-11$ & 2.77E-09 & -7.86872 & Down \\
\hline 8072328 & SEC14L2 & -1.86709 & 4.13E-11 & $3.1 \mathrm{E}-09$ & -7.83654 & Down \\
\hline 8180391 & CYP2D6 & -2.37754 & 4.17E-11 & 3.12E-09 & -7.83444 & Down \\
\hline 7942674 & TSKU & -1.63072 & $4.28 \mathrm{E}-11$ & 3.17E-09 & -7.8283 & Down \\
\hline 8028652 & ZFP36 & -1.80429 & $4.29 \mathrm{E}-11$ & 3.17E-09 & -7.82768 & Down \\
\hline 7900365 & MFSD2A & -2.32595 & $4.83 \mathrm{E}-11$ & $3.5 \mathrm{E}-09$ & -7.79937 & Down \\
\hline 7948344 & GLYAT & -3.82575 & $5.06 \mathrm{E}-11$ & 3.63E-09 & -7.78854 & Down \\
\hline 8103706 & AADAT & -1.56007 & $5.14 \mathrm{E}-11$ & $3.67 \mathrm{E}-09$ & -7.78466 & Down \\
\hline 7926170 & DHTKD1 & -1.35823 & $5.53 \mathrm{E}-11$ & 3.92E-09 & -7.76721 & Down \\
\hline 8130598 & LPAL2 & -1.65196 & $5.7 \mathrm{E}-11$ & 4.02E-09 & -7.75994 & Down \\
\hline 8111864 & C6 & -3.10762 & $5.74 \mathrm{E}-11$ & 4.04E-09 & -7.75836 & Down \\
\hline 8022022 & LPIN2 & -1.42389 & 7.39E-11 & 4.98E-09 & -7.69828 & Down \\
\hline 8042270 & UGP2 & -1.96632 & $7.73 \mathrm{E}-11$ & $5.2 \mathrm{E}-09$ & -7.68756 & Down \\
\hline 8047069 & INPP1 & -1.6834 & 8.67E-11 & $5.68 \mathrm{E}-09$ & -7.65995 & Down \\
\hline 8096361 & HERC5 & -1.28599 & $8.68 \mathrm{E}-11$ & $5.68 \mathrm{E}-09$ & -7.65972 & Down \\
\hline 7972461 & SLC15A1 & -1.83756 & $9.61 \mathrm{E}-11$ & 6.19E-09 & -7.63551 & Down \\
\hline 8055688 & RND3 & -1.99088 & $1.02 \mathrm{E}-10$ & $6.5 \mathrm{E}-09$ & -7.62202 & Down \\
\hline 8156706 & TMOD1 & -1.88776 & $1.05 \mathrm{E}-10$ & $6.69 \mathrm{E}-09$ & -7.61389 & Down \\
\hline 8135069 & SERPINE1 & -2.57236 & $1.08 \mathrm{E}-10$ & $6.86 \mathrm{E}-09$ & -7.6075 & Down \\
\hline 8099633 & PPARGC1A & -2.53119 & $1.09 \mathrm{E}-10$ & $6.91 \mathrm{E}-09$ & -7.60509 & Down \\
\hline 7937016 & CLRN3 & -1.47526 & $1.12 \mathrm{E}-10$ & 7E-09 & -7.59958 & Down \\
\hline 7931810 & KLF6 & -1.30168 & $1.21 \mathrm{E}-10$ & 7.48E-09 & -7.58102 & Down \\
\hline 8145766 & NRG1 & -1.75348 & $1.31 \mathrm{E}-10$ & 7.96E-09 & -7.56233 & Down \\
\hline 8076431 & CYP2D7 & -2.36353 & $1.32 \mathrm{E}-10$ & 8.02E-09 & -7.55981 & Down \\
\hline 7965573 & NTN4 & -1.28012 & $1.33 \mathrm{E}-10$ & 8.08E-09 & -7.55747 & Down \\
\hline 8020806 & RNF125 & -1.78113 & $1.45 \mathrm{E}-10$ & 8.75E-09 & -7.53672 & Down \\
\hline 8044793 & STEAP3 & -1.30611 & $1.47 \mathrm{E}-10$ & 8.82E-09 & -7.53354 & Down \\
\hline 8171472 & CLTRN & -1.42312 & $1.54 \mathrm{E}-10$ & $9.2 \mathrm{E}-09$ & -7.52265 & Down \\
\hline 7928944 & PAPSS2 & -1.60888 & $1.56 \mathrm{E}-10$ & $9.26 \mathrm{E}-09$ & -7.52052 & Down \\
\hline 7926786 & APBB1IP & -1.59777 & $1.57 \mathrm{E}-10$ & $9.28 \mathrm{E}-09$ & -7.51913 & Down \\
\hline 8066493 & SLPI & -2.32059 & $1.64 \mathrm{E}-10$ & $9.64 \mathrm{E}-09$ & -7.50755 & Down \\
\hline 7965964 & SLC41A2 & -2.64558 & $1.7 \mathrm{E}-10$ & 9.92E-09 & -7.49899 & Down \\
\hline 8156228 & CTSL & -1.38428 & $1.71 \mathrm{E}-10$ & 9.93E-09 & -7.4983 & Down \\
\hline 7995838 & MT1X & -1.97592 & $1.71 \mathrm{E}-10$ & 9.93E-09 & -7.49746 & Down \\
\hline
\end{tabular}

RasGEF domain family member 1B methylmalonyl-CoA mutase dual specificity phosphatase 5 tryptophan 2,3-dioxygenase

3-hydroxyanthranilate 3,4-dioxygenase

NOP2/Sun RNA methyltransferase 6 cytochrome $\mathrm{P} 450$ family 4 subfamily $\mathrm{Z}$ member 1 beta-ureidopropionase 1

cysteine and serine rich nuclear protein 1

UDP glucuronosyltransferase family 2 member B7 SEC14 like lipid binding 2

cytochrome P450 family 2 subfamily D member 6 tsukushi, small leucine rich proteoglycan ZFP36 ring finger protein major facilitator superfamily domain containing $2 \mathrm{~A}$

glycine-N-acyltransferase

aminoadipate aminotransferase dehydrogenase E1 and transketolase domain containing 1

lipoprotein(a) like 2, pseudogene complement $\mathrm{C} 6$ lipin 2

UDP-glucose pyrophosphorylase 2

inositol polyphosphate-1-phosphatase HECT and RLD domain containing E3 ubiquitin protein ligase 5

solute carrier family 15 member 1 Rho family GTPase 3 tropomodulin 1 serpin family E member 1 PPARG coactivator 1 alpha clarin 3

Kruppel like factor 6 neuregulin 1

cytochrome P450 family 2 subfamily D member 7 (gene/pseudogene) netrin 4

ring finger protein 125

STEAP3 metalloreductase

collectrin, amino acid transport regulator

3'-phosphoadenosine 5'-phosphosulfate synthase 2 amyloid beta precursor protein binding family $\mathrm{B}$ member 1 interacting protein

secretory leukocyte peptidase inhibitor solute carrier family 41 member 2 cathepsin $\mathrm{L}$

metallothionein $1 \mathrm{X}$ 
medRxiv preprint doi: https://doi.org/10.1101/2020.12.22.20248756; this version posted December 26, 2020. The copyright holder for this preprint (which was not certified by peer review) is the author/funder, who has granted medRxiv a license to display the preprint in perpetuity. All rights reserved. No reuse allowed without permission.

\begin{tabular}{|c|c|c|c|c|c|c|c|}
\hline 7916526 & C8B & -1.96774 & $1.75 \mathrm{E}-10$ & $1.01 \mathrm{E}-08$ & -7.49195 & Down & complement $\mathrm{C} 8$ beta chain \\
\hline 8172333 & CFP & -1.36208 & $2.07 \mathrm{E}-10$ & $1.18 \mathrm{E}-08$ & -7.45237 & Down & complement factor properdin \\
\hline 7904717 & HJV & -2.2743 & $2.1 \mathrm{E}-10$ & $1.19 \mathrm{E}-08$ & -7.44885 & Down & hemojuvelin BMP co-receptor \\
\hline 7988990 & WDR72 & -1.86418 & $2.22 \mathrm{E}-10$ & $1.25 \mathrm{E}-08$ & -7.43592 & Down & WD repeat domain 72 \\
\hline 8105121 & GHR & -2.70155 & $2.22 \mathrm{E}-10$ & $1.25 \mathrm{E}-08$ & -7.43559 & Down & growth hormone receptor \\
\hline 7961673 & GYS2 & -3.56074 & $2.35 \mathrm{E}-10$ & $1.31 \mathrm{E}-08$ & -7.42258 & Down & glycogen synthase 2 \\
\hline 7958056 & STAB2 & -2.78056 & $2.35 \mathrm{E}-10$ & $1.31 \mathrm{E}-08$ & -7.42204 & Down & stabilin 2 \\
\hline 8173120 & PFKFB1 & -2.42424 & $2.38 \mathrm{E}-10$ & $1.32 \mathrm{E}-08$ & -7.41854 & Down & $\begin{array}{l}\text { 6-phosphofructo-2-kinase/fructose-2,6- } \\
\text { biphosphatase } 1\end{array}$ \\
\hline 7917779 & GCLM & -1.25786 & $2.51 \mathrm{E}-10$ & $1.37 \mathrm{E}-08$ & -7.40665 & Down & glutamate-cysteine ligase modifier subunit \\
\hline 8066513 & SDC4 & -1.5745 & $2.61 \mathrm{E}-10$ & $1.41 \mathrm{E}-08$ & -7.3967 & Down & syndecan 4 \\
\hline 8103695 & MFAP3L & -1.86335 & $2.69 \mathrm{E}-10$ & $1.44 \mathrm{E}-08$ & -7.3901 & Down & microfibril associated protein 3 like \\
\hline 8162502 & FBP1 & -2.39102 & $2.82 \mathrm{E}-10$ & $1.51 \mathrm{E}-08$ & -7.37827 & Down & fructose-bisphosphatase 1 \\
\hline 8130556 & SOD2 & -1.94629 & $2.84 \mathrm{E}-10$ & $1.52 \mathrm{E}-08$ & -7.37694 & Down & superoxide dismutase 2 \\
\hline 8160670 & AQP3 & -1.59899 & $3.15 \mathrm{E}-10$ & $1.66 \mathrm{E}-08$ & -7.35231 & Down & aquaporin 3 (Gill blood group) \\
\hline 8103951 & ACSL1 & -2.05877 & $3.23 \mathrm{E}-10$ & $1.7 \mathrm{E}-08$ & -7.34593 & Down & $\begin{array}{c}\text { acyl-CoA synthetase long chain family member } 1 \\
\text { phosphoenolpyruvatecarboxykinase } 2,\end{array}$ \\
\hline 7973530 & PCK2 & -1.55202 & $3.49 \mathrm{E}-10$ & $1.81 \mathrm{E}-08$ & -7.32726 & Down & mitochondrial \\
\hline 8146687 & ADHFE1 & -1.55946 & $3.61 \mathrm{E}-10$ & $1.85 \mathrm{E}-08$ & -7.3197 & Down & alcohol dehydrogenase iron containing 1 \\
\hline 7937707 & FAM99A & -1.70828 & $3.65 \mathrm{E}-10$ & $1.87 \mathrm{E}-08$ & -7.31652 & Down & $\begin{array}{l}\text { family with sequence similarity } 99 \text { member A } \\
\text { acyl-CoA synthetase medium chain family }\end{array}$ \\
\hline 7993726 & ACSM5 & -2.25416 & $3.97 \mathrm{E}-10$ & $2 \mathrm{E}-08$ & -7.29699 & Down & member 5 \\
\hline 8105153 & NNT & -1.30858 & $4 \mathrm{E}-10$ & $2.01 \mathrm{E}-08$ & -7.29484 & Down & nicotinamide nucleotide transhydrogenase \\
\hline 7901513 & $\mathrm{SCP} 2$ & -1.76413 & 4.13E-10 & 2.05E-08 & -7.28753 & Down & sterol carrier protein 2 \\
\hline 8020630 & TTC39C & -1.37749 & 4.24E-10 & 2.1E-08 & -7.28108 & Down & tetratricopeptide repeat domain $39 \mathrm{C}$ \\
\hline 8149264 & PPP1R3B & -2.14794 & $4.32 \mathrm{E}-10$ & $2.13 \mathrm{E}-08$ & -7.27644 & Down & protein phosphatase 1 regulatory subunit 3B \\
\hline 8114612 & CD14 & -1.6395 & $4.46 \mathrm{E}-10$ & 2.19E-08 & -7.26884 & Down & CD14 molecule \\
\hline 8084668 & $\mathrm{HRG}$ & -3.56797 & $4.9 \mathrm{E}-10$ & $2.38 \mathrm{E}-08$ & -7.24657 & Down & histidine rich glycoprotein \\
\hline 8163149 & PTPN3 & -1.68999 & $5.05 \mathrm{E}-10$ & $2.44 \mathrm{E}-08$ & -7.23913 & Down & protein tyrosine phosphatase non-receptor type 3 \\
\hline 8141066 & PON3 & -1.83258 & $5.12 \mathrm{E}-10$ & $2.47 \mathrm{E}-08$ & -7.23584 & Down & paraoxonase 3 \\
\hline 8106418 & CRHBP & -2.78333 & $5.25 \mathrm{E}-10$ & $2.52 \mathrm{E}-08$ & -7.22964 & Down & corticotropin releasing hormone binding protein \\
\hline 7955348 & GPD1 & -1.76474 & $5.54 \mathrm{E}-10$ & 2.64E-08 & -7.21675 & Down & glycerol-3-phosphate dehydrogenase 1 \\
\hline 8090366 & UROC1 & -1.93575 & $5.55 \mathrm{E}-10$ & $2.64 \mathrm{E}-08$ & -7.2164 & Down & urocanatehydratase 1 \\
\hline 7995813 & MT1DP & -1.26488 & $5.68 \mathrm{E}-10$ & 2.69E-08 & -7.21083 & Down & metallothionein 1D, pseudogene \\
\hline 7925452 & GREM2 & -1.64378 & $5.88 \mathrm{E}-10$ & $2.77 \mathrm{E}-08$ & -7.20253 & Down & gremlin 2, DAN family BMP antagonist \\
\hline 8004534 & SHBG & -1.75486 & $6.34 \mathrm{E}-10$ & $2.94 \mathrm{E}-08$ & -7.18456 & Down & sex hormone binding globulin \\
\hline 8040960 & GCKR & -2.07768 & $6.62 \mathrm{E}-10$ & $3.05 \mathrm{E}-08$ & -7.17422 & Down & glucokinase regulator \\
\hline 7985809 & ABHD2 & -1.3522 & $6.63 \mathrm{E}-10$ & $3.05 \mathrm{E}-08$ & -7.17394 & Down & abhydrolase domain containing 2 \\
\hline 8088371 & DNASE1L3 & -2.11688 & $6.66 \mathrm{E}-10$ & $3.06 \mathrm{E}-08$ & -7.17298 & Down & deoxyribonuclease 1 like 3 \\
\hline 8013112 & RASD1 & -1.27291 & $6.92 \mathrm{E}-10$ & $3.16 \mathrm{E}-08$ & -7.16372 & Down & ras related dexamethasone induced 1 \\
\hline 8002556 & TAT & -3.99579 & $7.35 \mathrm{E}-10$ & $3.34 \mathrm{E}-08$ & -7.14924 & Down & tyrosine aminotransferase \\
\hline 8035083 & CYP4F2 & -2.51451 & $8.13 \mathrm{E}-10$ & $3.65 \mathrm{E}-08$ & -7.12513 & Down & cytochrome P450 family 4 subfamily F member 2 \\
\hline 7995907 & CETP & -1.82566 & $8.36 \mathrm{E}-10$ & 3.74E-08 & -7.11841 & Down & cholesteryl ester transfer protein \\
\hline 7960757 & C1RL & -1.26603 & $8.6 \mathrm{E}-10$ & $3.83 \mathrm{E}-08$ & -7.1115 & Down & complement $\mathrm{C} 1 \mathrm{r}$ subcomponent like \\
\hline 7946986 & SAA1 & -2.68675 & $8.69 \mathrm{E}-10$ & $3.86 \mathrm{E}-08$ & -7.10895 & Down & serum amyloid A1 \\
\hline 8081298 & ADGRG7 & -1.98044 & $8.83 \mathrm{E}-10$ & 3.91E-08 & -7.10521 & Down & $\begin{array}{l}\text { adhesion } \mathrm{G} \text { protein-coupled receptor } \mathrm{G} 7 \\
\mathrm{~T} \text { cell immunoglobulin and mucin domain }\end{array}$ \\
\hline 8115445 & TIMD4 & -2.38949 & $9 \mathrm{E}-10$ & 3.97E-08 & -7.1006 & Down & \\
\hline
\end{tabular}


medRxiv preprint doi: https://doi.org/10.1101/2020.12.22.20248756; this version posted December 26, 2020. The copyright holder for this preprint (which was not certified by peer review) is the author/funder, who has granted medRxiv a license to display the preprint in perpetuity.

All rights reserved. No reuse allowed without permission.

\begin{tabular}{|c|c|c|c|c|c|c|c|}
\hline 8126770 & CYP39A1 & -2.56861 & $9.6 \mathrm{E}-10$ & 4.19E-08 & -7.08526 & Down & cytochrome P450 family 39 subfamily A member \\
\hline 8165258 & AGPAT2 & -1.46668 & $9.83 \mathrm{E}-10$ & 4.28E-08 & -7.07956 & Down & 1-acylglycerol-3-phosphate O-acyltransferase 2 \\
\hline 8079060 & VIPR1 & -1.37382 & $9.91 \mathrm{E}-10$ & 4.31E-08 & -7.07758 & Down & vasoactive intestinal peptide receptor 1 \\
\hline 8056583 & $\mathrm{ABCB} 11$ & -3.73353 & $1.03 \mathrm{E}-09$ & 4.44E-08 & -7.06933 & Down & ATP binding cassette subfamily B member 11 \\
\hline 7995787 & MT1M & -2.67289 & $1.04 \mathrm{E}-09$ & 4.49E-08 & -7.0661 & Down & metallothionein $1 \mathrm{M}$ \\
\hline 8100798 & SULT1B1 & -1.92576 & $1.04 \mathrm{E}-09$ & 4.49E-08 & -7.06491 & Down & sulfotransferase family $1 \mathrm{~B}$ member 1 \\
\hline 8141052 & PON1 & -3.52937 & $1.05 \mathrm{E}-09$ & 4.5E-08 & -7.06421 & Down & paraoxonase 1 \\
\hline 8140840 & STEAP4 & -2.80855 & $1.16 \mathrm{E}-09$ & 4.89E-08 & -7.04016 & Down & STEAP4 metalloreductase \\
\hline 7946167 & HPX & -2.40952 & $1.45 \mathrm{E}-09$ & 5.95E-08 & -6.98567 & Down & hemopexin \\
\hline 7964834 & $\mathrm{CPM}$ & -1.51954 & $1.54 \mathrm{E}-09$ & $6.23 \mathrm{E}-08$ & -6.97213 & Down & carboxypeptidase $\mathrm{M}$ \\
\hline 8080184 & ALAS1 & -1.33461 & $1.58 \mathrm{E}-09$ & $6.39 \mathrm{E}-08$ & -6.96559 & Down & 5'-aminolevulinate synthase 1 \\
\hline 7996361 & CES3 & -1.87271 & $1.6 \mathrm{E}-09$ & $6.45 \mathrm{E}-08$ & -6.96254 & Down & carboxylesterase 3 \\
\hline 7954810 & LRRK2 & -1.55656 & $1.65 \mathrm{E}-09$ & $6.66 \mathrm{E}-08$ & -6.95433 & Down & leucine rich repeat kinase 2 \\
\hline 7914075 & FCN3 & -3.00647 & $1.72 \mathrm{E}-09$ & $6.9 \mathrm{E}-08$ & -6.94503 & Down & ficolin 3 \\
\hline 7921449 & CRP & -4.39223 & $1.72 \mathrm{E}-09$ & $6.9 \mathrm{E}-08$ & -6.94474 & Down & C-reactive protein \\
\hline 8123678 & PXDC1 & -1.29407 & $1.76 \mathrm{E}-09$ & 7E-08 & -6.93956 & Down & PX domain containing 1 \\
\hline 8045539 & KYNU & -1.7714 & $1.98 \mathrm{E}-09$ & 7.79E-08 & -6.91071 & Down & kynureninase \\
\hline 7960744 & C1R & -2.0944 & 2E-09 & $7.86 \mathrm{E}-08$ & -6.90839 & Down & complement $\mathrm{C} 1 \mathrm{r}$ \\
\hline 8013243 & SHMT1 & -1.60648 & $2.06 \mathrm{E}-09$ & 8.05E-08 & -6.90175 & Down & serine hydroxymethyltransferase 1 \\
\hline 8129618 & VNN1 & -3.69454 & $2.06 \mathrm{E}-09$ & 8.05E-08 & -6.90152 & Down & vanin 1 \\
\hline 7995793 & MT1L & -1.45389 & 2.09E-09 & $8.16 \mathrm{E}-08$ & -6.89762 & Down & metallothionein 1L, pseudogene \\
\hline 7957654 & AMDHD1 & -1.48367 & $2.1 \mathrm{E}-09$ & 8.17E-08 & -6.89713 & Down & amidohydrolase domain containing 1 \\
\hline 7898693 & ALPL & -1.99339 & $2.35 \mathrm{E}-09$ & 8.97E-08 & -6.86999 & Down & alkaline phosphatase, biomineralization associated \\
\hline 7922976 & PTGS2 & -1.74777 & $2.4 \mathrm{E}-09$ & $9.12 \mathrm{E}-08$ & -6.86494 & Down & prostaglandin-endoperoxide synthase 2 \\
\hline 8156309 & GADD45G & -1.56976 & 2.53E-09 & $9.53 \mathrm{E}-08$ & -6.85238 & Down & growth arrest and DNA damage inducible gamma \\
\hline 8180303 & SAA2 & -3.97211 & $2.57 \mathrm{E}-09$ & $9.65 \mathrm{E}-08$ & -6.84816 & Down & serum amyloid A2 \\
\hline 7934755 & MAT1A & -2.42118 & 2.9E-09 & $1.07 \mathrm{E}-07$ & -6.81906 & Down & methionine adenosyltransferase $1 \mathrm{~A}$ \\
\hline 7968734 & SLC25A15 & -1.31884 & 2.91E-09 & $1.07 \mathrm{E}-07$ & -6.81827 & Down & solute carrier family 25 member 15 \\
\hline 7921840 & NR1I3 & -2.05147 & $3.08 \mathrm{E}-09$ & $1.12 \mathrm{E}-07$ & -6.8046 & Down & nuclear receptor subfamily 1 group I member 3 \\
\hline 7943605 & ACAT1 & -1.7042 & 3.1E-09 & $1.13 \mathrm{E}-07$ & -6.80306 & Down & acetyl-CoA acetyltransferase 1 \\
\hline 8097920 & LRAT & -1.25758 & $3.17 \mathrm{E}-09$ & $1.15 \mathrm{E}-07$ & -6.79778 & Down & lecithin retinol acyltransferase \\
\hline 7938758 & SAA1 & -3.68479 & $3.23 \mathrm{E}-09$ & $1.16 \mathrm{E}-07$ & -6.79337 & Down & serum amyloid A1 \\
\hline 8072735 & APOL1 & -1.70039 & $3.27 \mathrm{E}-09$ & $1.17 \mathrm{E}-07$ & -6.79033 & Down & apolipoprotein L1 \\
\hline 7909441 & G0S2 & -1.50675 & $3.3 \mathrm{E}-09$ & $1.18 \mathrm{E}-07$ & -6.78833 & Down & G0/G1 switch 2 \\
\hline 7951545 & EXPH5 & -1.38387 & $3.5 \mathrm{E}-09$ & $1.25 \mathrm{E}-07$ & -6.77342 & Down & exophilin 5 \\
\hline 8113214 & GLRX & -1.33472 & $3.62 \mathrm{E}-09$ & $1.28 \mathrm{E}-07$ & -6.76582 & Down & glutaredoxin \\
\hline 8033248 & TNFSF14 & -1.33632 & $3.98 \mathrm{E}-09$ & $1.39 \mathrm{E}-07$ & -6.7426 & Down & $\begin{array}{l}\text { TNF superfamily member } 14 \\
\text { amylo-alpha-1, 6-glucosidase, } 4 \text {-alpha- }\end{array}$ \\
\hline 7903239 & AGL & -1.41891 & 4.15E-09 & $1.44 \mathrm{E}-07$ & -6.73235 & Down & glucanotransferase \\
\hline 8158671 & ASS1 & -1.30123 & 4.81E-09 & $1.63 \mathrm{E}-07$ & -6.69681 & Down & argininosuccinate synthase 1 \\
\hline 7972650 & FGF14 & -1.66652 & $5 \mathrm{E}-09$ & $1.69 \mathrm{E}-07$ & -6.68762 & Down & fibroblast growth factor 14 \\
\hline 8018558 & ACOX1 & -1.31806 & $5.01 \mathrm{E}-09$ & $1.69 \mathrm{E}-07$ & -6.68701 & Down & acyl-CoA oxidase 1 \\
\hline 8142554 & AASS & -1.34628 & 5.17E-09 & $1.74 \mathrm{E}-07$ & -6.67964 & Down & aminoadipate-semialdehyde synthase \\
\hline 7946983 & SAA2 & -2.8486 & $5.37 \mathrm{E}-09$ & $1.79 \mathrm{E}-07$ & -6.67046 & Down & serum amyloid A2 \\
\hline 7932094 & PHYH & -1.31377 & $6.13 \mathrm{E}-09$ & $2.02 \mathrm{E}-07$ & -6.63824 & Down & phytanoyl-CoA 2-hydroxylase \\
\hline 8075390 & SEC14L4 & -1.33014 & $6.83 \mathrm{E}-09$ & $2.2 \mathrm{E}-07$ & -6.61194 & Down & SEC14 like lipid binding 4 \\
\hline
\end{tabular}




\begin{tabular}{|c|c|c|c|c|c|c|}
\hline 8081219 & ST3GAL6 & -1.57399 & $6.84 \mathrm{E}-09$ & $2.2 \mathrm{E}-07$ & -6.61172 & Down \\
\hline 7958425 & DAO & -2.38843 & $6.92 \mathrm{E}-09$ & $2.22 \mathrm{E}-07$ & -6.60872 & Down \\
\hline 8112822 & DMGDH & -1.6327 & 7.03E-09 & $2.25 \mathrm{E}-07$ & -6.60489 & Down \\
\hline 7936494 & GFRA1 & -1.86775 & 7.99E-09 & $2.5 \mathrm{E}-07$ & -6.57387 & Down \\
\hline 8152264 & DPYS & -1.69797 & 8.22E-09 & $2.56 \mathrm{E}-07$ & -6.56702 & Down \\
\hline 8121916 & RSPO3 & -1.32827 & $8.44 \mathrm{E}-09$ & $2.62 \mathrm{E}-07$ & -6.5606 & Down \\
\hline 7931824 & AKR1C6P & -1.45603 & 8.44E-09 & 2.62E-07 & -6.56051 & Down \\
\hline 7946579 & LYVE1 & -2.02445 & 8.53E-09 & 2.64E-07 & -6.55808 & Down \\
\hline 8025601 & ICAM1 & -1.33796 & 8.92E-09 & $2.74 \mathrm{E}-07$ & -6.5472 & Down \\
\hline 7906777 & FCGR2B & -1.92992 & $9.17 \mathrm{E}-09$ & $2.81 \mathrm{E}-07$ & -6.54046 & Down \\
\hline 8077441 & BHLHE40 & -1.4694 & $9.48 \mathrm{E}-09$ & $2.9 \mathrm{E}-07$ & -6.53235 & Down \\
\hline 7905220 & ECM1 & -1.33693 & $9.53 \mathrm{E}-09$ & 2.91E-07 & -6.53115 & Down \\
\hline 8081758 & GRAMD1C & -1.65952 & $1.19 \mathrm{E}-08$ & $3.52 \mathrm{E}-07$ & -6.47716 & Down \\
\hline 7901748 & FGGY & -1.52673 & $1.22 \mathrm{E}-08$ & $3.59 \mathrm{E}-07$ & -6.47015 & Down \\
\hline 7976755 & SLC25A47 & -1.73283 & $1.27 \mathrm{E}-08$ & 3.7E-07 & -6.4619 & Down \\
\hline 7993126 & ABAT & -1.32248 & $1.29 \mathrm{E}-08$ & $3.74 \mathrm{E}-07$ & -6.45821 & Down \\
\hline 8101893 & ADH1C & -2.4717 & $1.29 \mathrm{E}-08$ & $3.74 \mathrm{E}-07$ & -6.45802 & Down \\
\hline 8008454 & $\mathrm{ABCC} 3$ & -1.7914 & $1.38 \mathrm{E}-08$ & $3.96 \mathrm{E}-07$ & -6.44061 & Down \\
\hline 8174937 & TENM1 & -1.46934 & $1.48 \mathrm{E}-08$ & $4.21 \mathrm{E}-07$ & -6.42333 & Down \\
\hline 8056491 & SCN9A & -1.34545 & $1.65 \mathrm{E}-08$ & 4.61E-07 & -6.39787 & Down \\
\hline 8027760 & FXYD1 & -1.51988 & $1.73 \mathrm{E}-08$ & 4.8E-07 & -6.38576 & Down \\
\hline 8103769 & HPGD & -2.16403 & $1.78 \mathrm{E}-08$ & 4.92E-07 & -6.37879 & Down \\
\hline 8176193 & F8 & -1.54742 & $1.88 \mathrm{E}-08$ & $5.15 \mathrm{E}-07$ & -6.36607 & Down \\
\hline 8098084 & ETFDH & -1.74079 & 2.02E-08 & $5.47 \mathrm{E}-07$ & -6.34757 & Down \\
\hline 7962559 & SLC38A4 & -2.66277 & $2.11 \mathrm{E}-08$ & $5.67 \mathrm{E}-07$ & -6.33716 & Down \\
\hline 7953603 & $\mathrm{C} 1 \mathrm{~S}$ & -2.01706 & $2.16 \mathrm{E}-08$ & 5.79E-07 & -6.33114 & Down \\
\hline 7938366 & WEE1 & -1.42515 & $2.33 \mathrm{E}-08$ & $6.19 \mathrm{E}-07$ & -6.31265 & Down \\
\hline 7917530 & GBP2 & -1.8953 & $2.56 \mathrm{E}-08$ & $6.65 \mathrm{E}-07$ & -6.28987 & Down \\
\hline 7901732 & $\mathrm{C} 8 \mathrm{~A}$ & -1.92378 & $2.83 \mathrm{E}-08$ & 7.2E-07 & -6.26583 & Down \\
\hline 8035095 & CYP4F11 & -2.38933 & 2.92E-08 & 7.4E-07 & -6.25793 & Down \\
\hline 7954729 & FGD4 & -1.40933 & $3.14 \mathrm{E}-08$ & $7.88 \mathrm{E}-07$ & -6.23957 & Down \\
\hline 8062119 & MT1P3 & -1.49548 & $3.31 \mathrm{E}-08$ & $8.22 \mathrm{E}-07$ & -6.22695 & Down \\
\hline 8088020 & ITIH4 & -1.82356 & 3.39E-08 & 8.37E-07 & -6.22122 & Down \\
\hline 8096875 & ENPEP & -1.76169 & $3.54 \mathrm{E}-08$ & $8.65 \mathrm{E}-07$ & -6.21081 & Down \\
\hline 8098637 & CYP4V2 & -1.44696 & $3.59 \mathrm{E}-08$ & $8.78 \mathrm{E}-07$ & -6.20709 & Down \\
\hline 8001531 & MT1G & -1.90291 & $3.87 \mathrm{E}-08$ & $9.35 \mathrm{E}-07$ & -6.18833 & Down \\
\hline 8038577 & ASPDH & -1.27155 & $4.13 \mathrm{E}-08$ & $9.86 \mathrm{E}-07$ & -6.1728 & Down \\
\hline 7943413 & BIRC3 & -1.63886 & 4.63E-08 & $1.09 \mathrm{E}-06$ & -6.14463 & Down \\
\hline 8026456 & CYP4F3 & -1.77709 & 4.63E-08 & $1.09 \mathrm{E}-06$ & -6.14427 & Down \\
\hline 8141317 & CYP3A4 & -3.28494 & 4.69E-08 & $1.1 \mathrm{E}-06$ & -6.14125 & Down \\
\hline 8024323 & REEP6 & -1.42033 & $4.84 \mathrm{E}-08$ & $1.13 \mathrm{E}-06$ & -6.13374 & Down \\
\hline 7951853 & APOA5 & -1.72683 & $5.12 \mathrm{E}-08$ & $1.18 \mathrm{E}-06$ & -6.11968 & Down \\
\hline 8091385 & $\mathrm{CP}$ & -3.19062 & $5.18 \mathrm{E}-08$ & $1.19 \mathrm{E}-06$ & -6.11678 & Down \\
\hline 8022666 & CHST9 & -2.52243 & $5.27 \mathrm{E}-08$ & $1.21 \mathrm{E}-06$ & -6.11256 & Down \\
\hline
\end{tabular}

ST3 beta-galactoside alpha-2,3-sialyltransferase 6

$$
\text { D-amino acid oxidase }
$$

dimethylglycine dehydrogenase

GDNF family receptor alpha 1

dihydropyrimidinase

R-spondin 3

aldo-ketoreductase family 1 member C6, pseudogene

lymphatic vessel endothelial hyaluronan receptor 1 intercellular adhesion molecule 1

Fc fragment of IgG receptor IIb

basic helix-loop-helix family member e 40 extracellular matrix protein 1

GRAM domain containing 1C

FGGY carbohydrate kinase domain containing solute carrier family 25 member 47

4-aminobutyrate aminotransferase

alcohol dehydrogenase 1C (class I), gamma polypeptide

ATP binding cassette subfamily $\mathrm{C}$ member 3 teneurintransmembrane protein 1

sodium voltage-gated channel alpha subunit 9

FXYD domain containing ion transport regulator 1

15-hydroxyprostaglandin dehydrogenase coagulation factor VIII

electron transfer flavoprotein dehydrogenase solute carrier family 38 member 4 complement $\mathrm{C} 1 \mathrm{~s}$

WEE1 G2 checkpoint kinase guanylate binding protein 2 complement $\mathrm{C} 8$ alpha chain cytochrome P450 family 4 subfamily F member 11

FYVE, RhoGEF and PH domain containing 4 metallothionein 1 pseudogene 3

inter-alpha-trypsin inhibitor heavy chain 4 glutamylaminopeptidase

cytochrome P450 family 4 subfamily V member 2 metallothionein $1 \mathrm{G}$

aspartate dehydrogenase domain containing

baculoviral IAP repeat containing 3

cytochrome P450 family 4 subfamily F member 3

cytochrome P450 family 3 subfamily A member 4 receptor accessory protein 6 apolipoprotein A5 ceruloplasmin carbohydrate sulfotransferase 9 
medRxiv preprint doi: https://doi.org/10.1101/2020.12.22.20248756; this version posted December 26, 2020. The copyright holder for this preprint (which was not certified by peer review) is the author/funder, who has granted medRxiv a license to display the preprint in perpetuity. All rights reserved. No reuse allowed without permission.

\begin{tabular}{|c|c|c|c|c|c|c|}
\hline 8047784 & ZDBF2 & -1.35095 & $5.29 \mathrm{E}-08$ & $1.21 \mathrm{E}-06$ & -6.11151 & Down \\
\hline 7923929 & PIGR & -1.72961 & 5.57E-08 & $1.27 \mathrm{E}-06$ & -6.09874 & Down \\
\hline 8140556 & HGF & -2.03352 & 5.67E-08 & $1.28 \mathrm{E}-06$ & -6.0944 & Down \\
\hline 8099760 & ARAP2 & -1.66089 & 5.84E-08 & $1.31 \mathrm{E}-06$ & -6.08737 & Down \\
\hline 7912361 & MASP2 & -1.58025 & $6.06 \mathrm{E}-08$ & $1.36 \mathrm{E}-06$ & -6.07825 & Down \\
\hline 7926451 & MRC1 & -1.4052 & 6.39E-08 & $1.42 \mathrm{E}-06$ & -6.06508 & Down \\
\hline 8129804 & МАР3К5 & -1.31322 & 7.23E-08 & $1.58 \mathrm{E}-06$ & -6.03432 & Down \\
\hline 7942135 & ANO1 & -1.34907 & $7.45 \mathrm{E}-08$ & $1.63 \mathrm{E}-06$ & -6.02692 & Down \\
\hline 7995797 & MT1E & -1.39677 & 8.35E-08 & $1.79 \mathrm{E}-06$ & -5.99878 & Down \\
\hline 7929487 & CYP2C9 & -3.50453 & $9.27 \mathrm{E}-08$ & $1.95 \mathrm{E}-06$ & -5.97288 & Down \\
\hline 8148029 & COLEC10 & -2.54783 & $9.75 \mathrm{E}-08$ & $2.04 \mathrm{E}-06$ & -5.96021 & Down \\
\hline 7908312 & PRG4 & -2.06069 & $1.04 \mathrm{E}-07$ & $2.16 \mathrm{E}-06$ & -5.94347 & Down \\
\hline 8072710 & APOL6 & -1.38091 & $1.08 \mathrm{E}-07$ & 2.22E-06 & -5.93553 & Down \\
\hline 8097628 & HHIP & -1.96877 & $1.1 \mathrm{E}-07$ & $2.26 \mathrm{E}-06$ & -5.93013 & Down \\
\hline 7938951 & ANO5 & -1.30862 & $1.12 \mathrm{E}-07$ & $2.29 \mathrm{E}-06$ & -5.9255 & Down \\
\hline 8141328 & CYP3A5 & -2.1131 & $1.12 \mathrm{E}-07$ & $2.3 \mathrm{E}-06$ & -5.92492 & Down \\
\hline 7916506 & FYB2 & -1.56566 & $1.21 \mathrm{E}-07$ & $2.45 \mathrm{E}-06$ & -5.90667 & Down \\
\hline 8146115 & TCIM & -1.31689 & $1.31 \mathrm{E}-07$ & 2.62E-06 & -5.88708 & Down \\
\hline 8096733 & SGMS2 & -1.44287 & $1.31 \mathrm{E}-07$ & 2.62E-06 & -5.88608 & Down \\
\hline 8157446 & ORM1 & -2.16082 & $1.39 \mathrm{E}-07$ & $2.76 \mathrm{E}-06$ & -5.87248 & Down \\
\hline 7902367 & ACADM & -1.32844 & $1.46 \mathrm{E}-07$ & $2.86 \mathrm{E}-06$ & -5.86008 & Down \\
\hline 7962250 & CPNE8 & -1.44212 & $1.78 \mathrm{E}-07$ & 3.39E-06 & -5.80968 & Down \\
\hline 8157524 & TLR4 & -1.30042 & $1.81 \mathrm{E}-07$ & $3.42 \mathrm{E}-06$ & -5.80672 & Down \\
\hline 8151890 & TP53INP1 & -1.32335 & $1.87 \mathrm{E}-07$ & $3.54 \mathrm{E}-06$ & -5.79778 & Down \\
\hline 7995729 & CES1P1 & -1.66875 & $2.06 \mathrm{E}-07$ & $3.84 \mathrm{E}-06$ & -5.77342 & Down \\
\hline 8119782 & SLC22A7 & -2.11006 & $2.08 \mathrm{E}-07$ & $3.87 \mathrm{E}-06$ & -5.77123 & Down \\
\hline 8163839 & $\mathrm{C} 5$ & -1.59069 & $2.17 \mathrm{E}-07$ & $4 \mathrm{E}-06$ & -5.76085 & Down \\
\hline 8018864 & SOCS3 & -1.3559 & $2.28 \mathrm{E}-07$ & $4.16 \mathrm{E}-06$ & -5.7489 & Down \\
\hline 8026047 & JUNB & -1.3023 & $2.56 \mathrm{E}-07$ & $4.59 \mathrm{E}-06$ & -5.7196 & Down \\
\hline 7909306 & C4BPB & -1.44907 & 2.6E-07 & $4.65 \mathrm{E}-06$ & -5.71562 & Down \\
\hline 7965873 & IGF1 & -1.55889 & 2.62E-07 & $4.68 \mathrm{E}-06$ & -5.71387 & Down \\
\hline 8044574 & IL1RN & -1.41944 & $2.81 \mathrm{E}-07$ & 4.99E-06 & -5.69566 & Down \\
\hline 8095585 & SLC4A4 & -2.15757 & $3.16 \mathrm{E}-07$ & $5.51 \mathrm{E}-06$ & -5.66645 & Down \\
\hline 8063590 & PCK1 & -2.67178 & $3.23 \mathrm{E}-07$ & $5.62 \mathrm{E}-06$ & -5.66069 & Down \\
\hline 8017964 & ABCA6 & -2.58625 & 3.54E-07 & $6.07 \mathrm{E}-06$ & -5.63781 & Down \\
\hline 8145532 & EPHX2 & -1.25206 & $3.67 \mathrm{E}-07$ & $6.26 \mathrm{E}-06$ & -5.62845 & Down \\
\hline 7980096 & ALDH6A1 & -1.30877 & $4.08 \mathrm{E}-07$ & $6.87 \mathrm{E}-06$ & -5.60181 & Down \\
\hline 7954208 & PIK3C2G & -1.75132 & 4.13E-07 & $6.93 \mathrm{E}-06$ & -5.59899 & Down \\
\hline 8086457 & CYP8B1 & -2.22218 & 4.13E-07 & $6.93 \mathrm{E}-06$ & -5.59874 & Down \\
\hline 8047127 & MYO1B & -1.3558 & $4.26 \mathrm{E}-07$ & 7.1E-06 & -5.59066 & Down \\
\hline 7901272 & CYP4X1 & -1.69863 & 4.29E-07 & 7.14E-06 & -5.58897 & Down \\
\hline 8062461 & LBP & -2.43644 & 4.39E-07 & 7.27E-06 & -5.58351 & Down \\
\hline 7997192 & HPR & -1.79671 & $4.45 \mathrm{E}-07$ & 7.35E-06 & -5.58016 & Down \\
\hline 8162884 & ALDOB & -2.21083 & $4.73 \mathrm{E}-07$ & 7.76E-06 & -5.56425 & Down \\
\hline
\end{tabular}

zinc finger DBF-type containing 2

polymeric immunoglobulin receptor hepatocyte growth factor

ArfGAP with RhoGAP domain, ankyrin repeat and $\mathrm{PH}$ domain 2

mannan binding lectin serine peptidase 2 mannose receptor C-type 1

mitogen-activated protein kinase kinasekinase 5 anoctamin 1

metallothionein $1 \mathrm{E}$

cytochrome P450 family 2 subfamily $\mathrm{C}$ member 9

collectin subfamily member 10 proteoglycan 4

apolipoprotein L6

hedgehog interacting protein anoctamin 5

cytochrome P450 family 3 subfamily A member 5 FYN binding protein 2

transcriptional and immune response regulator sphingomyelin synthase 2 orosomucoid 1

acyl-CoA dehydrogenase medium chain copine 8

toll like receptor 4

tumor protein $\mathrm{p} 53$ inducible nuclear protein 1 carboxylesterase 1 pseudogene 1

solute carrier family 22 member 7 complement $\mathrm{C} 5$

suppressor of cytokine signaling 3 JunB proto-oncogene, AP-1 transcription factor subunit

complement component 4 binding protein beta insulin like growth factor 1

interleukin 1 receptor antagonist

solute carrier family 4 member 4

phosphoenolpyruvatecarboxykinase 1

ATP binding cassette subfamily A member 6 epoxide hydrolase 2

aldehyde dehydrogenase 6 family member A1 phosphatidylinositol-4-phosphate 3-kinase catalytic subunit type 2 gamma

cytochrome P450 family 8 subfamily B member 1 myosin IB

cytochrome P450 family 4 subfamily X member 1 lipopolysaccharide binding protein haptoglobin-related protein aldolase, fructose-bisphosphate B 
medRxiv preprint doi: https://doi.org/10.1101/2020.12.22.20248756; this version posted December 26, 2020. The copyright holder for this preprint (which was not certified by peer review) is the author/funder, who has granted medRxiv a license to display the preprint in perpetuity. All rights reserved. No reuse allowed without permission.

\begin{tabular}{|c|c|c|c|c|c|}
\hline 3108370 & EGR1 & -1.58275 & $5.05 \mathrm{E}-07$ & $8.22 \mathrm{E}-06$ & -5.54771 \\
\hline 8037949 & SULT2A1 & -2.17964 & $5.55 \mathrm{E}-07$ & 8.87E-06 & -5.5238 \\
\hline 8111474 & AGXT2 & -1.53967 & $6.06 \mathrm{E}-07$ & $9.57 \mathrm{E}-06$ & -5.50164 \\
\hline 7972157 & EDNRB & -1.31399 & 6.07E-07 & $9.59 \mathrm{E}-06$ & -5.50118 \\
\hline 7901293 & CYP4A22 & -2.3035 & $6.22 \mathrm{E}-07$ & $9.79 \mathrm{E}-06$ & -5.49513 \\
\hline 7913216 & PLA2G2A & -2.64827 & $6.3 \mathrm{E}-07$ & $9.91 \mathrm{E}-06$ & -5.49161 \\
\hline 8018006 & ABCA10 & -1.46642 & $6.69 \mathrm{E}-07$ & $1.04 \mathrm{E}-05$ & -5.47642 \\
\hline 7983650 & SLC27A2 & -1.65365 & $6.81 \mathrm{E}-07$ & $1.06 \mathrm{E}-05$ & -5.47188 \\
\hline 8092523 & EHHADH & -1.5 & $6.83 \mathrm{E}-07$ & $1.06 \mathrm{E}-05$ & -5 \\
\hline 7947512 & PAMR1 & -1.45987 & 7.05E-07 & $1.09 \mathrm{E}-05$ & -5.46293 \\
\hline 8122807 & AKAP12 & -1.27834 & $7.28 \mathrm{E}-07$ & $1.12 \mathrm{E}-05$ & -5.45487 \\
\hline 8064928 & HAO1 & -2.12616 & $7.29 \mathrm{E}-07$ & $1.12 \mathrm{E}-05$ & -5.45461 \\
\hline 8049737 & AGXT & -1.51295 & $7.31 \mathrm{E}-07$ & $1.12 \mathrm{E}-05$ & -5.45 \\
\hline 8026424 & CYP4F22 & -1.30941 & 7.37E-07 & $1.13 \mathrm{E}-05$ & -5.45176 \\
\hline 7956426 & INHBE & -1.40106 & 7.79E-07 & $1.18 \mathrm{E}-05$ & -5.43765 \\
\hline 8023528 & ALPK2 & -1.32137 & 8.53E-07 & $1.27 \mathrm{E}-05$ & -5.4145 \\
\hline 7964872 & PTPRB & -1.28146 & $9.04 \mathrm{E}-07$ & $1.33 \mathrm{E}-05$ & -5.39961 \\
\hline 8151931 & TSPYL5 & -1.34811 & $1.02 \mathrm{E}-06$ & $1.47 \mathrm{E}-05$ & -5.36932 \\
\hline 7924058 & IRF6 & -1.28907 & $1.03 \mathrm{E}-06$ & $1.48 \mathrm{E}-05$ & -5.36692 \\
\hline 8017927 & ABCA9 & -2.02411 & $1.06 \mathrm{E}-06$ & $1.52 \mathrm{E}-05$ & -5.3 \\
\hline 8149927 & CLU & -1.4172 & $1.11 \mathrm{E}-06$ & $1.58 \mathrm{E}-05$ & -5.34696 \\
\hline 8129637 & VNN2 & -1.34704 & $1.13 \mathrm{E}-06$ & $1.6 \mathrm{E}-05$ & -5.34287 \\
\hline 8113641 & CDO1 & -1.26056 & $1.16 \mathrm{E}-06$ & $1.64 \mathrm{E}-05$ & -5.33513 \\
\hline 8103494 & NPY1R & -1.66142 & $1.2 \mathrm{E}-06$ & $1.69 \mathrm{E}-05$ & -5.32638 \\
\hline 8115831 & DUSP1 & -1.41784 & $1.21 \mathrm{E}-06$ & $1.7 \mathrm{E}-05$ & -5.32461 \\
\hline 7907297 & FMO4 & -1.32575 & $1.31 \mathrm{E}-06$ & $1.82 \mathrm{E}-05$ & -5.30372 \\
\hline 8122058 & ARG1 & -1.80372 & $1.31 \mathrm{E}-06$ & $1.82 \mathrm{E}-05$ & -5.30368 \\
\hline 8006005 & PIPOX & -1.72596 & $1.4 \mathrm{E}-06$ & $1.92 \mathrm{E}-05$ & -5.28805 \\
\hline 8143127 & FAM180A & -1.27569 & $1.41 \mathrm{E}-06$ & $1.93 \mathrm{E}-05$ & -5.28509 \\
\hline 8098654 & KLKB1 & -2.13475 & $1.47 \mathrm{E}-06$ & $2.01 \mathrm{E}-05$ & -5.27503 \\
\hline 7981078 & SERPINA11 & -1.28036 & $1.56 \mathrm{E}-06$ & $2.11 \mathrm{E}-05$ & -5.25991 \\
\hline 7967212 & HPD & -2.18315 & $1.58 \mathrm{E}-06$ & $2.14 \mathrm{E}-05$ & -5.2557 \\
\hline 8140752 & ABCB4 & -1.53619 & $1.63 \mathrm{E}-06$ & $2.2 \mathrm{E}-05$ & -5.24717 \\
\hline 7900336 & MACF1 & -1.28208 & $1.7 \mathrm{E}-06$ & $2.28 \mathrm{E}-05$ & -5.23648 \\
\hline 7901883 & ANGPTL3 & -1.94376 & $1.94 \mathrm{E}-06$ & $2.54 \mathrm{E}-05$ & -5.20343 \\
\hline 8092661 & MASP1 & -1.27925 & $2.03 \mathrm{E}-06$ & $2.65 \mathrm{E}-05$ & -5.19073 \\
\hline 7961710 & ABCC9 & -1.78491 & $2.04 \mathrm{E}-06$ & $2.66 \mathrm{E}-05$ & -5.18957 \\
\hline 7976496 & SERPINA3 & -1.51584 & $2.08 \mathrm{E}-06$ & 2.7E-05 & -5.18422 \\
\hline 7993756 & ACSM3 & -1.46892 & $2.1 \mathrm{E}-06$ & 2.72E-05 & -5.18286 \\
\hline 8106504 & BHMT & -1.73762 & $2.24 \mathrm{E}-06$ & $2.88 \mathrm{E}-05$ & -5.16524 \\
\hline 7956423 & INHBC & -1.55992 & $2.27 \mathrm{E}-06$ & $2.91 \mathrm{E}-05$ & -5.16175 \\
\hline 8049532 & LRRFIP1 & -1.26765 & $2.32 \mathrm{E}-06$ & $2.96 \mathrm{E}-05$ & -5.15669 \\
\hline 7960794 & CD163 & -1.31725 & $2.45 \mathrm{E}-06$ & $3.09 \mathrm{E}-05$ & -5.14266 \\
\hline
\end{tabular}

early growth response 1 sulfotransferase family $2 \mathrm{~A}$ member 1 alanine--glyoxylate aminotransferase 2 endothelin receptor type $\mathrm{B}$ cytochrome P450 family 4 subfamily A member 22

phospholipase A2 group IIA

ATP binding cassette subfamily A member 10 solute carrier family 27 member 2 enoyl-CoA hydratase and 3-hydroxyacyl CoA dehydrogenase

peptidase domain containing associated with muscle regeneration 1

A-kinase anchoring protein 12 hydroxyacid oxidase 1

alanine--glyoxylate and serine--pyruvate aminotransferase

cytochrome P450 family 4 subfamily F member 22

inhibin subunit beta $\mathrm{E}$ alpha kinase 2

protein tyrosine phosphatase receptor type B TSPY like 5

interferon regulatory factor 6

ATP binding cassette subfamily A member 9 clusterin vanin 2

cysteine dioxygenase type 1 neuropeptide Y receptor Y1

dual specificity phosphatase 1

flavin containing dimethylanilinemonoxygenase 4 arginase 1

pipecolic acid and sarcosine oxidase

family with sequence similarity 180 member A kallikrein B1

serpin family A member 11

4-hydroxyphenylpyruvate dioxygenase

ATP binding cassette subfamily B member 4 microtubule actin crosslinking factor 1 angiopoietin like 3

mannan binding lectin serine peptidase 1

ATP binding cassette subfamily $\mathrm{C}$ member 9 serpin family A member 3

acyl-CoA synthetase medium chain family member 3

betaine--homocysteine $\mathrm{S}$-methyltransferase inhibin subunit beta $\mathrm{C}$

LRR binding FLII interacting protein 1 CD163 molecule 


\begin{tabular}{|c|c|c|c|c|c|c|c|}
\hline 8095390 & UGT2B10 & -2.31904 & $2.46 \mathrm{E}-06$ & $3.11 \mathrm{E}-05$ & -5.14111 & Down & $\begin{array}{l}\text { UDP glucuronosyltransferase family } 2 \text { member } \\
\qquad \text { B10 }\end{array}$ \\
\hline 8102328 & CFI & -1.28523 & $2.55 \mathrm{E}-06$ & $3.21 \mathrm{E}-05$ & -5.13129 & Down & complement factor I \\
\hline 8029693 & FOSB & -1.85601 & $2.72 \mathrm{E}-06$ & $3.39 \mathrm{E}-05$ & -5.11456 & Down & $\begin{array}{c}\text { FosB proto-oncogene, AP-1 transcription factor } \\
\text { subunit }\end{array}$ \\
\hline 7954344 & SLCO1B7 & -2.11701 & $2.79 \mathrm{E}-06$ & $3.47 \mathrm{E}-05$ & -5.10783 & Down & $\begin{array}{l}\text { solute carrier organic anion transporter family } \\
\text { member 1B7 (putative) }\end{array}$ \\
\hline 8141560 & TFR2 & -1.58955 & $2.98 \mathrm{E}-06$ & $3.67 \mathrm{E}-05$ & -5.09101 & Down & transferrin receptor 2 \\
\hline 8085716 & SATB1 & -1.27231 & $3.34 \mathrm{E}-06$ & $4.06 \mathrm{E}-05$ & -5.06094 & Down & SATB homeobox 1 \\
\hline 8024754 & CREB3L3 & -1.35287 & $3.46 \mathrm{E}-06$ & 4.19E-05 & -5.05167 & Down & cAMP responsive element binding protein 3 like 3 \\
\hline 8135734 & CPED1 & -1.99578 & $3.51 \mathrm{E}-06$ & 4.24E-05 & -5.04846 & Down & cadherin like and PC-esterase domain containing 1 \\
\hline 8180234 & CES1P1 & -1.69778 & $3.61 \mathrm{E}-06$ & 4.35E-05 & -5.04047 & Down & carboxylesterase 1 pseudogene 1 \\
\hline 7990391 & CYP1A1 & -1.81291 & $3.75 \mathrm{E}-06$ & 4.47E-05 & -5.03104 & Down & cytochrome P450 family 1 subfamily A member 1 \\
\hline 7901765 & HOOK1 & -1.2878 & $3.77 \mathrm{E}-06$ & $4.49 \mathrm{E}-05$ & -5.02937 & Down & hook microtubule tethering protein 1 \\
\hline 8069676 & ADAMTS1 & -1.33452 & $3.85 \mathrm{E}-06$ & 4.58E-05 & -5.02381 & Down & $\begin{array}{l}\text { ADAM metallopeptidase with thrombospondin } \\
\text { type } 1 \text { motif } 1\end{array}$ \\
\hline 8101429 & PLAC8 & -1.47587 & 3.85E-06 & $4.58 \mathrm{E}-05$ & -5.02374 & Down & placenta associated 8 \\
\hline 8047300 & AOX1 & -1.63392 & 4.1E-06 & 4.82E-05 & -5.00711 & Down & aldehyde oxidase 1 \\
\hline 8098671 & F11 & -1.83668 & 4.18E-06 & 4.89E-05 & -5.00241 & Down & coagulation factor XI \\
\hline 8113073 & ARRDC3 & -1.52957 & 4.28E-06 & $5 \mathrm{E}-05$ & -4.99588 & Down & arrestin domain containing 3 \\
\hline 8180195 & CFHR1 & -1.82828 & $5.27 \mathrm{E}-06$ & $5.98 \mathrm{E}-05$ & -4.94131 & Down & complement factor $\mathrm{H}$ related 1 \\
\hline 8091867 & BCHE & -1.44446 & $5.66 \mathrm{E}-06$ & $6.36 \mathrm{E}-05$ & -4.92208 & Down & butyrylcholinesterase \\
\hline 8111677 & LIFR & -1.94996 & 5.79E-06 & $6.48 \mathrm{E}-05$ & -4.91621 & Down & LIF receptor subunit alpha \\
\hline 7908459 & $\mathrm{CFH}$ & -1.86945 & $6.61 \mathrm{E}-06$ & $7.25 \mathrm{E}-05$ & -4.88102 & Down & complement factor $\mathrm{H}$ \\
\hline 8117304 & SLC17A4 & -1.73901 & $6.61 \mathrm{E}-06$ & $7.26 \mathrm{E}-05$ & -4.88087 & Down & solute carrier family 17 member 4 \\
\hline 7926152 & ECHDC3 & -1.28824 & $6.79 \mathrm{E}-06$ & 7.39E-05 & -4.87399 & Down & enoyl-CoA hydratase domain containing 3 \\
\hline 7938364 & WEE1 & -1.44305 & $6.8 \mathrm{E}-06$ & $7.41 \mathrm{E}-05$ & -4.8733 & Down & WEE1 G2 checkpoint kinase \\
\hline 8001457 & CES1 & -1.64592 & $7.78 \mathrm{E}-06$ & 8.3E-05 & -4.83751 & Down & carboxylesterase 1 \\
\hline 7931168 & ACADSB & -1.2723 & $8.3 \mathrm{E}-06$ & 8.77E-05 & -4.82033 & Down & $\begin{array}{l}\text { acyl-CoA dehydrogenase short/branched chain } \\
\text { cytochrome P450 family } 3 \text { subfamily A member }\end{array}$ \\
\hline 8134655 & CYP3A43 & -2.16443 & $8.73 \mathrm{E}-06$ & $9.14 \mathrm{E}-05$ & -4.80682 & Down & \\
\hline 8124166 & MBOAT1 & -1.2583 & $9.9 \mathrm{E}-06$ & 0.000102 & -4.77302 & Down & $\begin{array}{c}\text { membrane bound O-acyltransferase domain } \\
\text { containing } 1\end{array}$ \\
\hline 7906458 & APCS & -2.84035 & $1.12 \mathrm{E}-05$ & 0.000113 & -4.73965 & Down & amyloid $\mathrm{P}$ component, serum \\
\hline 8162870 & BAAT & -2.51033 & $1.2 \mathrm{E}-05$ & 0.000119 & -4.72191 & Down & bile acid-CoA:amino acid $\mathrm{N}$-acyltransferase \\
\hline 7925939 & AKR1C4 & -2.39745 & $1.22 \mathrm{E}-05$ & 0.000122 & -4.716 & Down & aldo-ketoreductase family 1 member $\mathrm{C} 4$ \\
\hline 7908496 & CFHR2 & -2.20579 & $1.23 \mathrm{E}-05$ & 0.000122 & -4.71503 & Down & complement factor $\mathrm{H}$ related 2 \\
\hline 8114249 & CXCL14 & -1.6038 & $1.24 \mathrm{E}-05$ & 0.000123 & -4.71174 & Down & $\mathrm{C}-\mathrm{X}-\mathrm{C}$ motif chemokine ligand 14 \\
\hline 8022045 & MYOM1 & -1.49905 & $1.27 \mathrm{E}-05$ & 0.000126 & -4.70532 & Down & myomesin 1 \\
\hline 8166769 & OTC & -1.82077 & $1.29 \mathrm{E}-05$ & 0.000127 & -4.70175 & Down & ornithine carbamoyltransferase \\
\hline 8141374 & AZGP1 & -1.59014 & $1.29 \mathrm{E}-05$ & 0.000127 & -4.70117 & Down & alpha-2-glycoprotein 1, zinc-binding \\
\hline 7995825 & MT1F & -1.58273 & $1.36 \mathrm{E}-05$ & 0.000133 & -4.68805 & Down & metallothionein $1 \mathrm{~F}$ \\
\hline 7997188 & $\mathrm{HP}$ & -1.9272 & $1.38 \mathrm{E}-05$ & 0.000135 & -4.68315 & Down & haptoglobin \\
\hline 8096415 & MMRN1 & -1.37255 & $1.39 \mathrm{E}-05$ & 0.000136 & -4.68189 & Down & multimerin 1 \\
\hline 8093278 & HGD & -1.31352 & $1.48 \mathrm{E}-05$ & 0.000143 & -4.66499 & Down & $\begin{array}{l}\text { homogentisate } 1,2 \text {-dioxygenase } \\
\text { cytochrome P450 family } 4 \text { subfamily A member }\end{array}$ \\
\hline 7915902 & CYP4A11 & -2.05184 & $1.56 \mathrm{E}-05$ & 0.00015 & -4.64978 & Down & 11 \\
\hline 7921332 & CD5L & -1.61673 & $1.58 \mathrm{E}-05$ & 0.000151 & -4.64702 & Down & CD5 molecule like \\
\hline 8178115 & $\mathrm{CFB}$ & -1.30298 & $1.58 \mathrm{E}-05$ & 0.000151 & -4.64637 & Down & complement factor B \\
\hline
\end{tabular}


medRxiv preprint doi: https://doi.org/10.1101/2020.12.22.20248756; this version posted December 26, 2020. The copyright holder for this preprint (which was not certified by peer review) is the author/funder, who has granted medRxiv a license to display the preprint in perpetuity.

All rights reserved. No reuse allowed without permission.

\begin{tabular}{|c|c|c|c|c|c|c|c|}
\hline 8101881 & ADH1B & -2.26025 & $1.66 \mathrm{E}-05$ & 0.000158 & -4.63363 & Down & $\begin{array}{l}\text { alcohol dehydrogenase 1B (class I), beta } \\
\text { polypeptide } \\
\text { Fos proto-oncogene, AP-1 transcription factor }\end{array}$ \\
\hline 7975779 & FOS & -1.71493 & $1.87 \mathrm{E}-05$ & 0.000174 & -4.60171 & Down & subunit \\
\hline 8161755 & ALDH1A1 & -1.4697 & $1.95 \mathrm{E}-05$ & 0.000181 & -4.58996 & Down & aldehyde dehydrogenase 1 family member A1 \\
\hline 7922420 & SERPINC1 & -1.44163 & 2.1E-05 & 0.000193 & -4.56874 & Down & serpin family $\mathrm{C}$ member 1 \\
\hline 8077833 & SLC6A1 & -1.57349 & $2.18 \mathrm{E}-05$ & 0.0002 & -4.55894 & Down & solute carrier family 6 member 1 \\
\hline 7936734 & FGFR2 & -1.66795 & 2.4E-05 & 0.000217 & -4.53254 & Down & fibroblast growth factor receptor 2 \\
\hline 7907249 & FMO3 & -2.75355 & $2.59 \mathrm{E}-05$ & 0.000232 & -4.51151 & Down & flavin containing dimethylanilinemonoxygenase 3 \\
\hline 7923073 & F13B & -1.72855 & $2.91 \mathrm{E}-05$ & 0.000256 & -4.47984 & Down & coagulation factor XIII B chain \\
\hline 8055952 & NR4A2 & -1.32702 & $2.96 \mathrm{E}-05$ & 0.00026 & -4.47474 & Down & nuclear receptor subfamily 4 group A member 2 \\
\hline 7909318 & C4BPA & -1.66328 & $3.22 \mathrm{E}-05$ & 0.000279 & -4.45148 & Down & complement component 4 binding protein alpha \\
\hline 8101852 & $\mathrm{ADH} 4$ & -2.06117 & 4.56E-05 & 0.000374 & -4.35441 & Down & alcohol dehydrogenase 4 (class II), pi polypeptide \\
\hline 8083415 & AADAC & -2.24518 & $5.26 \mathrm{E}-05$ & 0.00042 & -4.31472 & Down & arylacetamidedeacetylase \\
\hline 8124351 & SLC17A3 & -1.28272 & $5.27 \mathrm{E}-05$ & 0.000421 & -4.31389 & Down & $\begin{array}{l}\text { solute carrier family } 17 \text { member } 3 \\
\text { solute carrier organic anion transporter family }\end{array}$ \\
\hline 7954356 & SLCO1B1 & -2.10244 & $6.11 \mathrm{E}-05$ & 0.000476 & -4.27215 & Down & member 1B1 \\
\hline 8084679 & KNG1 & -1.54993 & $7.26 \mathrm{E}-05$ & 0.000551 & -4.2234 & Down & kininogen 1 \\
\hline 7907572 & PAPPA2 & -1.29374 & 7.36E-05 & 0.000557 & -4.21958 & Down & pappalysin 2 \\
\hline 7908409 & RGS2 & -1.34148 & $7.73 \mathrm{E}-05$ & 0.000582 & -4.20576 & Down & regulator of $\mathrm{G}$ protein signaling 2 \\
\hline 8100784 & UGT2B4 & -1.64367 & 7.79E-05 & 0.000586 & -4.20353 & Down & UDP glucuronosyltransferase family 2 member B4 \\
\hline 7901565 & DIO1 & -1.43963 & $8.98 \mathrm{E}-05$ & 0.000661 & -4.16278 & Down & iodothyroninedeiodinase 1 \\
\hline 7908488 & CFHR1 & -2.11839 & $9.82 \mathrm{E}-05$ & 0.000712 & -4.13729 & Down & complement factor $\mathrm{H}$ related 1 \\
\hline 8108006 & LEAP2 & -1.36857 & 0.0001 & 0.000724 & -4.13192 & Down & liver enriched antimicrobial peptide 2 \\
\hline 8095663 & AFM & -1.9645 & 0.0001 & 0.000724 & -4.13185 & Down & afamin \\
\hline 7988414 & GATM & -1.52108 & 0.000115 & 0.000813 & -4.09211 & Down & glycine amidinotransferase \\
\hline 8103326 & FGG & -1.43724 & 0.000134 & 0.000928 & -4.04642 & Down & fibrinogen gamma chain \\
\hline 8017885 & ABCA8 & -1.46754 & 0.000155 & 0.001045 & -4.00569 & Down & ATP binding cassette subfamily A member 8 \\
\hline 8014342 & CCL16 & -1.70224 & 0.000174 & 0.001155 & -3.97141 & Down & $\mathrm{C}-\mathrm{C}$ motif chemokine ligand 16 \\
\hline 8097910 & FGB & -1.34005 & 0.000194 & 0.001265 & -3.93914 & Down & fibrinogen beta chain \\
\hline 7919055 & HMGCS2 & -1.26433 & 0.000197 & 0.001283 & -3.93429 & Down & 3-hydroxy-3-methylglutaryl-CoA synthase 2 \\
\hline 7948957 & SLC22A25 & -1.25362 & 0.000235 & 0.001483 & -3.88219 & Down & solute carrier family 22 member 25 \\
\hline 7944035 & APOC3 & -1.36125 & 0.000314 & 0.001894 & -3.79577 & Down & apolipoprotein $\mathrm{C} 3$ \\
\hline 8095680 & CXCL8 & -1.3989 & 0.000412 & 0.002381 & -3.71382 & Down & $\mathrm{C}-\mathrm{X}-\mathrm{C}$ motif chemokine ligand 8 \\
\hline 8053025 & NAT8 & -1.27147 & 0.00044 & 0.002521 & -3.69351 & Down & $\begin{array}{l}\mathrm{N} \text {-acetyltransferase } 8 \text { (putative) } \\
\text { solute carrier organic anion transporter family }\end{array}$ \\
\hline 7954330 & SLCO1B3 & -2.21836 & 0.000585 & 0.00321 & -3.60636 & Down & $\begin{array}{c}\text { member 1B3 } \\
\text { ADP-ribosyltransferase } 4 \text { (Dombrock blood }\end{array}$ \\
\hline 7961507 & ART4 & -1.26353 & 0.000935 & 0.004785 & -3.45961 & Down & group) \\
\hline 8160889 & CCL21 & -1.42737 & 0.001221 & 0.005962 & -3.37447 & Down & C-C motif chemokine ligand 21 \\
\hline 7920244 & S100A8 & -1.26434 & 0.001884 & 0.008569 & -3.23321 & Down & S100 calcium binding protein A8 \\
\hline 8105084 & $\mathrm{C} 7$ & -1.71191 & 0.004783 & 0.018432 & -2.91635 & Down & complement C7 \\
\hline 7965410 & DCN & -1.26964 & 0.014933 & 0.046094 & -2.49696 & Down & decorin \\
\hline
\end{tabular}

Table 3 The enriched pathway terms of the up regulated differentially expressed genes 
medRxiv preprint doi: https://doi.org/10.1101/2020.12.22.20248756; this version posted December 26, 2020. The copyright holder for this preprint (which was not certified by peer review) is the author/funder, who has granted medRxiv a license to display the preprint in perpetuity.

All rights reserved. No reuse allowed without permission.

\begin{tabular}{|c|c|c|c|c|c|c|c|}
\hline Pathway ID & Pathway Name & P-value & $\begin{array}{l}\text { FDR } \\
\text { B\&H }\end{array}$ & FDR B\&Y & Bonferroni & $\begin{array}{l}\text { Gene } \\
\text { Count }\end{array}$ & Gene \\
\hline 547488 & proline biosynthesis & $8.07 \mathrm{E}-04$ & $2.10 \mathrm{E}-02$ & $9.52 \mathrm{E}-02$ & $4.20 \mathrm{E}-02$ & 2 & PYCR1,ALDH18A1 \\
\hline 142287 & $\begin{array}{l}\text { epoxysqualene } \\
\text { biosynthesis }\end{array}$ & 8.07E-04 & $2.10 \mathrm{E}-02$ & $9.52 \mathrm{E}-02$ & $4.20 \mathrm{E}-02$ & 2 & FDFT1,SQLE \\
\hline 703096 & $\begin{array}{l}\text { 4-hydroxy-2-nonenal } \\
\text { detoxification }\end{array}$ & 4.53E-03 & $7.85 \mathrm{E}-02$ & $3.56 \mathrm{E}-01$ & $2.36 \mathrm{E}-01$ & 2 & GSTA4,GSTP1 \\
\hline 782390 & $\begin{array}{l}\text { superpathway of } \\
\text { pyrimidine } \\
\text { deoxyribonucleotides } \\
\text { de novo biosynthesis }\end{array}$ & $2.00 \mathrm{E}-02$ & $1.98 \mathrm{E}-01$ & 8.98E-01 & $1.00 \mathrm{E}+00$ & 3 & RRM2,TYMS,CAD \\
\hline 142445 & $\begin{array}{l}\text { acetyl-CoA } \\
\text { biosynthesis from } \\
\text { citrate }\end{array}$ & $2.89 \mathrm{E}-02$ & $1.98 \mathrm{E}-01$ & 8.98E-01 & $1.00 \mathrm{E}+00$ & 1 & ACLY \\
\hline 142185 & $\begin{array}{l}\text { UDP-D-xylose and } \\
\text { UDP-D-glucuronate } \\
\text { biosynthesis }\end{array}$ & $5.53 \mathrm{E}-02$ & $1.98 \mathrm{E}-01$ & 8.98E-01 & $1.00 \mathrm{E}+00$ & 1 & UXS1 \\
\hline 545371 & MAP kinase cascade & $5.53 \mathrm{E}-02$ & $1.98 \mathrm{E}-01$ & 8.98E-01 & $1.00 \mathrm{E}+00$ & 1 & EPHB2 \\
\hline 142427 & $\begin{array}{l}\text { sulfate activation for } \\
\text { sulfonation }\end{array}$ & $5.53 \mathrm{E}-02$ & $1.98 \mathrm{E}-01$ & $8.98 \mathrm{E}-01$ & $1.00 \mathrm{E}+00$ & 1 & PAPSS1 \\
\hline 545306 & $\begin{array}{l}\text { dolichol and dolichyl } \\
\text { phosphate biosynthesis }\end{array}$ & $5.53 \mathrm{E}-02$ & $1.98 \mathrm{E}-01$ & 8.98E-01 & $1.00 \mathrm{E}+00$ & 1 & SRD5A3 \\
\hline 782396 & glycolysis & $6.47 \mathrm{E}-02$ & $1.98 \mathrm{E}-01$ & $8.98 \mathrm{E}-01$ & $1.00 \mathrm{E}+00$ & 2 & PFKM,PKM \\
\hline \multicolumn{8}{|c|}{ KEGG } \\
\hline 585563 & Alcoholism & $5.31 \mathrm{E}-24$ & $6.51 \mathrm{E}-22$ & $3.96 \mathrm{E}-21$ & $1.30 \mathrm{E}-21$ & 39 & $\begin{array}{c}\text { HDAC11,H4C9,H2AC15, } \\
\text { H2AC14,H2AC16,H2AC6, } \\
\text { H2AC4,H2AC17,H2AC20, } \\
\text { H2BC8,H2BC13,H2BC14, } \\
\text { H2BC7,H2BC6,H2BC9,H } \\
\text { 2BC10,H3C1,H3C3,H3C6, } \mathrm{H} 3 \mathrm{C} 11, \mathrm{H} 3 \mathrm{C} 8, \mathrm{H} 3 \mathrm{C} 12, \mathrm{H} 3 \mathrm{C} \\
\mathrm{H} 3 \mathrm{H} \text {, } \\
\text { 10,H3C2,H4C4,H4C2,H4C } \\
\text { 5,H4C13,H4C14,MACRO } \\
\mathrm{H} 2 \mathrm{~A} 2, \mathrm{H} 2 \mathrm{AC} 12, \mathrm{H} 2 \mathrm{AC} 21, \\
\mathrm{GNG} 4, \mathrm{H} 3 \mathrm{C} 7, \mathrm{H} 2 \mathrm{AC} 11, \mathrm{H} 2 \\
\text { AC8,H2AZ1,H2BC5,H2B } \\
\text { C3 }\end{array}$ \\
\hline 83054 & Cell cycle & $5.66 \mathrm{E}-16$ & $4.62 \mathrm{E}-14$ & $2.81 \mathrm{E}-13$ & $1.39 \mathrm{E}-13$ & 26 & $\begin{array}{c}\text { PTTG1,MCM2,MCM3,M } \\
\text { CM4,MCM5,MCM6,MC } \\
\text { M7,CHEK1,TTK,PLK1,S } \\
\text { KP2,BUB1,E2F5,CCNA2, } \\
\text { CCNB1,CCND2,TGFB2,C } \\
\text { CNB2,CDK1,CDC6,CDC2 } \\
\text { 0,CDC25C,TP53,MAD2L1 } \\
\text {,CDK4,CDK6 }\end{array}$ \\
\hline 523016 & $\begin{array}{l}\text { Transcriptional } \\
\text { misregulation in } \\
\text { cancer }\end{array}$ & $1.22 \mathrm{E}-05$ & 4.99E-04 & $3.04 \mathrm{E}-03$ & $3.00 \mathrm{E}-03$ & 17 & $\begin{array}{c}\text { ETV1,ETV4,H3C1,H3C3, } \\
\text { H3C6,H3C11,H3C8,H3C1 } \\
\text { 2,H3C10,H3C2,ASPSCR1, } \\
\text { SUPT3H,MYCN,H3C7,C } \\
\text { CND2,HMGA2,TP53 }\end{array}$ \\
\hline 83068 & $\begin{array}{l}\text { ECM-receptor } \\
\text { interaction }\end{array}$ & $9.38 \mathrm{E}-05$ & $2.87 \mathrm{E}-03$ & $1.75 \mathrm{E}-02$ & $2.30 \mathrm{E}-02$ & 10 & $\begin{array}{c}\text { COL1A1,COL1A2,COL2 } \\
\text { A1,COL4A1,RELN,SPP1,I } \\
\text { TGA6, } \\
\text { ITGA2,SV2A,LAMC1 }\end{array}$ \\
\hline 83061 & Wntsignaling pathway & $6.88 \mathrm{E}-04$ & $1.47 \mathrm{E}-02$ & $8.92 \mathrm{E}-02$ & $1.69 \mathrm{E}-01$ & 12 & $\begin{array}{c}\text { AXIN2,BAMBI,SFRP4,N } \\
\text { KD1,DKK1,DKK4,DKK2, } \\
\text { NOTUM, } \\
\text { CCND2,WIF1,LEF1,TP53 }\end{array}$ \\
\hline 83105 & Pathways in cancer & $1.75 \mathrm{E}-03$ & 2.97E-02 & $1.81 \mathrm{E}-01$ & $4.28 \mathrm{E}-01$ & 22 & $\begin{array}{c}\text { PDGFRB,AXIN2,PIK3R2, } \\
\text { PLCG1,MMP2,COL4A1, } \\
\text { MSH2,SKP2,SLC2A1,ITG } \\
\text { A6,ITGA2,BMP4,FGF20, } \\
\text { GNA12,GNG4,LAMC1,T } \\
\text { GFB2,GSTP1,LEF1,TP53, } \\
\text { CDK4,CDK6 }\end{array}$ \\
\hline 692234 & $\begin{array}{l}\text { PI3K-Akt signaling } \\
\text { pathway }\end{array}$ & $3.62 \mathrm{E}-03$ & $5.22 \mathrm{E}-02$ & $3.17 \mathrm{E}-01$ & 8.87E-01 & 19 & $\begin{array}{c}\text { PDGFRB,PIK3R2,COL1A } \\
\text { 1,COL1A2,COL2A1,COL } \\
\text { 4A1,PRKAA2,RELN,SPP } \\
\text { 1,ITGA6,ITGA2,FGF20,G } \\
\text { NG4,LAMC1,CCND2,EF } \\
\text { NA4,TP53,CDK4,CDK6 }\end{array}$ \\
\hline 1474302 & $\begin{array}{l}\text { Fluid shear stress and } \\
\text { atherosclerosis }\end{array}$ & $6.65 \mathrm{E}-03$ & $7.41 \mathrm{E}-02$ & $4.51 \mathrm{E}-01$ & $1.00 \mathrm{E}+00$ & 10 & $\begin{array}{c}\text { PIK3R2,MMP2,PRKAA2, } \\
\text { MAPK13,BMP4,NQO1,G } \\
\text { STA4,GSTP1,ARHGEF2, } \\
\text { TP53 }\end{array}$ \\
\hline
\end{tabular}


medRxiv preprint doi: https://doi.org/10.1101/2020.12.22.20248756; this version posted December 26, 2020. The copyright holder for this preprint (which was not certified by peer review) is the author/funder, who has granted medRxiv a license to display the preprint in perpetuity. All rights reserved. No reuse allowed without permission.

373901

132956
$1.33 \mathrm{E}-02$

HTLV-I infection

Metabolic pathways
9.32E-01
$1.25 \mathrm{E}-01 \quad 7.60 \mathrm{E}-01 \quad 1.00 \mathrm{E}+00$

$9.76 \mathrm{E}-0$
$1.00 \mathrm{E}+00$

$1.00 \mathrm{E}+00$
14

28
PTTG1,PDGFRB,CHEK1, PIK3R2,POLE2,SLC2A1, MYBL2,CCND2,TGFB2, CCNB2,CDC20,TP53,MA D2L1,CDK4 ACLY,ENPP3,PFKM,RR M2,CKB,TYMS,ACSL4,F DFT1,PGAP1,PKM,PLCG 1,UXS1,POLE2,PRIM1,B3 GALNT1,B3GALT2,B3G ALT1,IMPDH2,SQLE,PSP H,LPCAT2,PYCR1,ALDH 18A1,P4HA2,CAD,PIGU, PAPSS1,DGKK

\begin{tabular}{ll}
\hline & REACTOME
\end{tabular}

1270436

1269810
HDACs deacetylate histones

M Phase
8.07E-27

5.94E-26

6.46E-26
$1.46 \mathrm{E}-30$
JURP SPC25,MCM2,MC M3,MCM4,MCM5,MCM6 M7,CHEK1,MND1, R $\mathrm{BC} 8, \mathrm{H} 2 \mathrm{BC} 13, \mathrm{H} 2 \mathrm{BC} 14, \mathrm{H} 2$ $2 \mathrm{BC} 6, \mathrm{H} 2 \mathrm{BC} 9 \mathrm{H} 2 \mathrm{~B}$ $\mathrm{H} 3 \mathrm{C} 10, \mathrm{H} 3 \mathrm{C} 2, \mathrm{H} 4 \mathrm{C} 4, \mathrm{H} 4 \mathrm{C} 2$ PC24,PRIM1,CENPI,TPX , GINS2,PLK4,MYBL2,K S1,SPDL1,AURKA,NCAP G,BUB1,NCAPD2,RHNO H,CCNA2,CCNB1, CCND 2 KIF20A, CCNB2, H2AC8 C,SKA1,TOP2A,TP53,M $\mathrm{AC} 17, \mathrm{H} 2 \mathrm{AC} 20, \mathrm{H} 2 \mathrm{BC} 8, \mathrm{H} 2$ BC13,H2BC14,H2BC7,H2 $8, \mathrm{H} 3 \mathrm{C} 12, \mathrm{H} 3 \mathrm{C} 10, \mathrm{H} 3 \mathrm{C} 2, \mathrm{H}$ , $\mathrm{H} 4 \mathrm{C} 5, \mathrm{H} 4 \mathrm{Cl} 3, \mathrm{H}$ 7, $\mathrm{H} 2 \mathrm{AC} 11, \mathrm{H} 2 \mathrm{AC} 8, \mathrm{H} 2 \mathrm{~B}$ KIF18A,PTTG1,CENPF,S PC25,RPS27,SGO1,H4C9, H2AC14,H2AC6,H2AC4 $\mathrm{H} 2 \mathrm{AC} 20, \mathrm{H} 2 \mathrm{BC} 8, \mathrm{H} 2 \mathrm{BC} 13$, $\mathrm{H} 2 \mathrm{BC} 14, \mathrm{H} 2 \mathrm{BC} 7, \mathrm{H} 2 \mathrm{BC} 6$, $\mathrm{H} 2 \mathrm{BC} 9, \mathrm{H} 2 \mathrm{BC} 10, \mathrm{H} 3 \mathrm{C} 1, \mathrm{H} 3$ $\mathrm{C} 3, \mathrm{H} 3 \mathrm{C} 6, \mathrm{H} 3 \mathrm{C} 11, \mathrm{H} 3 \mathrm{C} 8, \mathrm{~N}$ $\mathrm{DC} 80, \mathrm{H} 3 \mathrm{C} 12, \mathrm{H} 3 \mathrm{C} 10, \mathrm{H} 3 \mathrm{C}$ $2, \mathrm{H} 4 \mathrm{C} 4, \mathrm{H} 4 \mathrm{C} 2, \mathrm{H} 4 \mathrm{C} 5, \mathrm{H} 4 \mathrm{C} 1$ 3,H4C14,PLK1,SPC24,CE NPI,KNTC1,NUF2,CENP K,SPDL1,NCAPG,BUB1, NCAPD2,H3C7,NCAPH,C CNB1,KIF20A,CCNB2,H2 AC8,H2AZ1,H2BC5,H2B C3,CDK1,CDC20,SKA1, MAD2L1

$$
\text { formation }
$$

$\mathrm{H} 4 \mathrm{C} 9, \mathrm{H} 2 \mathrm{AC} 14, \mathrm{H} 2 \mathrm{AC} 6, \mathrm{H} 2$ AC4,MFGE8,H2AC20,H2 $\mathrm{BC} 8, \mathrm{H} 2 \mathrm{BC} 13, \mathrm{H} 2 \mathrm{BC} 14, \mathrm{H} 2$ BC7,H2BC6, H2BC9,H2B $\mathrm{C} 10, \mathrm{H} 3 \mathrm{C} 1, \mathrm{H} 3 \mathrm{C} 3, \mathrm{H} 3 \mathrm{C} 6, \mathrm{H} 3$ $\mathrm{C} 11, \mathrm{H} 3 \mathrm{C} 8, \mathrm{H} 3 \mathrm{C} 12, \mathrm{H} 3 \mathrm{C} 10$, 
medRxiv preprint doi: https://doi.org/10.1101/2020.12.22.20248756; this version posted December 26, 2020. The copyright holder for this preprint (which was not certified by peer review) is the author/funder, who has granted medRxiv a license to display the preprint in perpetuity. All rights reserved. No reuse allowed without permission.

\begin{tabular}{|c|c|c|c|c|c|c|c|}
\hline 1269509 & $\begin{array}{l}\text { RHO GTPase } \\
\text { Effectors }\end{array}$ & $1.81 \mathrm{E}-24$ & $8.34 \mathrm{E}-23$ & 6.13E-22 & $1.59 \mathrm{E}-21$ & 49 & $\begin{array}{c}\text { 2BC5,H2BC3,LYZ } \\
\text { KIF18A,CENPF,SPC25,R } \\
\text { PS27,SGO1,H4C9,H2AC1 } \\
\text { 4,H2AC6,H2AC4,H2AC20 } \\
\text {,H2BC8,H2BC13,H2BC14 } \\
\text {,H2BC7,H2BC6,H2BC9,H } \\
\text { 2BC10,H3C1,H3C3,H3C6, } \\
\text { H3C11,H3C8,NDC80,H3C } \\
\text { 12,H3C10,H3C2,H4C4,H4 } \\
\text { C2,H4C5,H4C13,H4C14,P } \\
\text { LK1,SPC24,CENPI,KNTC } \\
\text { 1,NUF2,CENPK,SPDL1,B } \\
\text { UB1,H3C7,PRC1,H2AC8, } \\
\text { H2AZ1,H2BC5,H2BC3,C } \\
\text { DC20,CDC25C,SKA1,MA } \\
\text { D2L1 }\end{array}$ \\
\hline 1269599 & $\begin{array}{c}\text { TCF dependent } \\
\text { signaling in response } \\
\text { to WNT }\end{array}$ & $9.64 \mathrm{E}-23$ & 3.02E-21 & $2.22 \mathrm{E}-20$ & 8.46E-20 & 43 & $\begin{array}{c}\text { AMER 1,H4C9, AXIN2,H2 } \\
\text { AC14,DACT1,H2AC6,H2 } \\
\text { AC4,H2AC20,H2BC8,H2 } \\
\text { BC13,H2BC14,H2BC7,H2 } \\
\text { BC6,H2BC9,H2BC10,H3C } \\
\text { 1,H3C3,H3C6,H3C11,H3C } \\
\text { 8,ZNRF3,H3C12,H3C10,H } \\
\text { 3C2,H4C4,H4C2,H4C5,H4 } \\
\text { C13,H4C14,LGR5,DKK1, } \\
\text { DKK4,DKK2,BCL9,RNF4 } \\
\text { 3,H3C7,CCDC88C,WIF1, } \\
\text { H2AC8,H2AZ1,H2BC5,H } \\
\text { 2BC3,LEF1 }\end{array}$ \\
\hline 1309095 & $\begin{array}{l}\text { DNA Double-Strand } \\
\text { Break Repair }\end{array}$ & $5.36 \mathrm{E}-11$ & $7.70 \mathrm{E}-10$ & $5.66 \mathrm{E}-09$ & $4.70 \mathrm{E}-08$ & 24 & $\begin{array}{c}\text { CHEK1,H4C9,H2BC8,H2 } \\
\text { BC13,H2BC14,H2BC7,H2 } \\
\text { BC6,H2BC9,H2BC10,H4C } \\
\text { 4,H4C2,H4C5,H4C13,H4C } \\
\text { 14,POLE2,XRCC2,RAD51 } \\
\text { AP1,RHNO1,KPNA2,RFC } \\
\text { 3,CCNA2,H2BC5,H2BC3, } \\
\text { TP53 }\end{array}$ \\
\hline 1270302 & $\begin{array}{l}\text { Developmental } \\
\text { Biology }\end{array}$ & $1.97 \mathrm{E}-05$ & $1.94 \mathrm{E}-04$ & $1.42 \mathrm{E}-03$ & $1.72 \mathrm{E}-02$ & 54 & $\begin{array}{c}\text { EPHB2,PDGFRB,TRPC1, } \\
\text { H4C9,H2AC14,H2AC6,H2 } \\
\text { AC4,H2AC20,H2BC8,H2 } \\
\text { BC13,H2BC14,H2BC7,H2 } \\
\text { BC6,H2BC9,H2BC10,H3C } \\
\text { 1,H3C3,H3C6,H3C11,H3C } \\
\text { 8,H3C12,H3C10,H3C2,H4 } \\
\text { C4,H4C2,H4C5,PIK3R2,H } \\
\text { 4C13,H4C14,PLCG1,MM } \\
\text { P2,COL4A1,ENAH,CD24, } \\
\text { PCGF2,ITGA2,GFRA3,FG } \\
\text { F20,CDON,H3C7,CACNB } \\
\text { 4,ARHGEF28,NRCAM,K } \\
\text { RT19,DUSP9,LAMC1,TD } \\
\text { GF1,EFNA4,H2AC8,H2A } \\
\text { Z1,H2BC5,H2BC3,ROBO } \\
\text { 1,CDK4 }\end{array}$ \\
\hline 1268677 & Metabolism of proteins & $2.55 \mathrm{E}-04$ & $2.26 \mathrm{E}-03$ & $1.66 \mathrm{E}-02$ & $2.24 \mathrm{E}-01$ & 69 & $\begin{array}{c}\text { USP11,RPS5,CTSC,RPS2 } \\
\text { 7,H4C9,AXIN2,H2AC15, } \\
\text { H2AC14,H2AC16,H2AC6, } \\
\text { H2AC4,MFGE8,H2AC17, } \\
\text { H2AC20,H2BC8,H2BC13, } \\
\text { H2BC14,H2BC7,H2BC6, } \\
\text { H2BC9,H2BC10,H3C1,H3 } \\
\text { C3,H3C6,H3C11,H3C8,H3 } \\
\text { C12,H3C10,H3C2,H4C4,H } \\
\text { 4C2,H4C5,H4C13,H4C14, } \\
\text { PGAP1,MME,RPL22L1,M } \\
\text { MP2,H2AC12,WFS1,H2A } \\
\text { C21,SKP2,USP21,UBE2T, } \\
\text { PCGF2,AURKA,LYPD1, } \\
\text { MUCL1,ODAM,GNG4,D } \\
\text { YNC1I1,H3C7,H2AC11,S } \\
\text { RD5A3,PIGU,ST8SIA3,G } \\
\text { SN,CCNA2,RAB34,THY1 }\end{array}$ \\
\hline
\end{tabular}


medRxiv preprint doi: https://doi.org/10.1101/2020.12.22.20248756; this version posted December 26, 2020. The copyright holder for this preprint (which was not certified by peer review) is the author/funder, who has granted medRxiv a license to display the preprint in perpetuity. All rights reserved. No reuse allowed without permission.

1269649
Gene Expression
$1.38 \mathrm{E}-0$
$8.59 \mathrm{E}-02 \quad 6.32 \mathrm{E}-01 \quad 1.00 \mathrm{E}+00$

,EIF4A2,H2AC8,H2AZ1,H 2BC5,H2BC3,CDC20,LY Z,TOP2A,TP53

ERCC2,RPS5,CHEK1,RP $\mathrm{S} 27, \mathrm{H} 4 \mathrm{C} 9, \mathrm{H} 2 \mathrm{AC} 14, \mathrm{H} 2 \mathrm{AC}$ 6,H2AC4,ZNF610,H2AC2 $0, \mathrm{H} 2 \mathrm{BC} 8, \mathrm{H} 2 \mathrm{BC} 13, \mathrm{H} 2 \mathrm{BC} 1$ 4,H2BC7,H2BC6,H2BC9, $\mathrm{H} 2 \mathrm{BC} 10, \mathrm{H} 3 \mathrm{C} 1, \mathrm{H} 3 \mathrm{C} 3, \mathrm{H} 3 \mathrm{C}$ 6, $\mathrm{H} 3 \mathrm{C} 11, \mathrm{H} 3 \mathrm{C} 8, \mathrm{H} 3 \mathrm{C} 12, \mathrm{H} 3$ $\mathrm{C} 10, \mathrm{H} 3 \mathrm{C} 2, \mathrm{H} 4 \mathrm{C} 4, \mathrm{H} 4 \mathrm{C} 2, \mathrm{H} 4$ C5,H4C13,H4C14,RPL22 L1,TP53I3,MSH2,ZNF711 ,IGF2BP1,IGF2BP3,IGF2 BP2,TET1,PRKAA2,TPX2 ,UHRF1,LSM2,SNRPB,M YBL2,SMYD2,AURKA,E HMT2,ZNF738,RHNO1,Z NF704,H3C7,E2F5,RFC3, CCNA2,CCNB1,TRIM28, ZNF382,FANCI,EIF4A2,H 2AC8,H2AZ1,H2BC5,H2 BC3,ALYREF,CDK1,CD C25C,TP53

\begin{tabular}{|c|c|c|c|c|c|c|c|}
\hline \multicolumn{8}{|c|}{ Gen MAPP } \\
\hline MAP00100 & Sterol biosynthesis & $3.04 \mathrm{E}-02$ & $5.22 \mathrm{E}-01$ & $1.00 \mathrm{E}+00$ & 5.77E-01 & 2 & FDFT1,SQLE \\
\hline MAP00220 & $\begin{array}{l}\text { Urea cycle and } \\
\text { metabolism of amino } \\
\text { groups }\end{array}$ & 8.08E-02 & $5.22 \mathrm{E}-01$ & $1.00 \mathrm{E}+00$ & $1.00 \mathrm{E}+00$ & 2 & CKB,PYCR1 \\
\hline MAP00240 & $\begin{array}{l}\text { Pyrimidine } \\
\text { metabolism }\end{array}$ & $1.25 \mathrm{E}-01$ & $5.22 \mathrm{E}-01$ & $1.00 \mathrm{E}+00$ & $1.00 \mathrm{E}+00$ & 3 & RRM2,TYMS,CAD \\
\hline MAP & MAP kinase activity & $2.04 \mathrm{E}-01$ & $5.22 \mathrm{E}-01$ & $1.00 \mathrm{E}+00$ & $1.00 \mathrm{E}+00$ & 1 & MAPK13 \\
\hline MAP00710 & Carbon fixation & $3.66 \mathrm{E}-01$ & $5.22 \mathrm{E}-01$ & $1.00 \mathrm{E}+00$ & $1.00 \mathrm{E}+00$ & 1 & PKM \\
\hline MAP00030_ & Pentose phosphate & 3.84E-01 & $5.22 \mathrm{E}-01$ & $1.00 \mathrm{E}+00$ & $1.00 \mathrm{E}+00$ & 1 & PFKM \\
\hline MAP00020 & $\begin{array}{l}\text { Citrate cycle TCA } \\
\text { cycle }\end{array}$ & 4.01E-01 & $5.22 \mathrm{E}-01$ & $1.00 \mathrm{E}+00$ & $1.00 \mathrm{E}+00$ & 1 & ACLY \\
\hline MAP00562 & $\begin{array}{l}\text { Inositol phosphate } \\
\text { metabolism }\end{array}$ & $4.18 \mathrm{E}-01$ & $5.22 \mathrm{E}-01$ & $1.00 \mathrm{E}+00$ & $1.00 \mathrm{E}+00$ & 1 & PLCG1 \\
\hline MAP00230 & Purine metabolism & $4.20 \mathrm{E}-01$ & $5.22 \mathrm{E}-01$ & $1.00 \mathrm{E}+00$ & $1.00 \mathrm{E}+00$ & 3 & RRM2,PKM,IMPDH2 \\
\hline MAP00480 & $\begin{array}{l}\text { Glutathione } \\
\text { metabolism }\end{array}$ & 4.65E-01 & $5.22 \mathrm{E}-01$ & $1.00 \mathrm{E}+00$ & $1.00 \mathrm{E}+00$ & 1 & GSTP1 \\
\hline \multicolumn{8}{|c|}{ Pathway Interaction Database } \\
\hline 138007 & PLK1 signaling events & $7.67 \mathrm{E}-12$ & $8.74 \mathrm{E}-10$ & $4.65 \mathrm{E}-09$ & $8.74 \mathrm{E}-10$ & 14 & $\begin{array}{c}\text { SGO1,TUBG1,NDC80,PL } \\
\text { K1,SPC24,TPX2,AURKA, } \\
\text { BUB1,ECT2,CCNB1,KIF2 } \\
\text { 0A,CDK1,CDC20,CDC25 } \\
\text { C }\end{array}$ \\
\hline 138080 & Aurora B signaling & $8.12 \mathrm{E}-08$ & 4.63E-06 & $2.46 \mathrm{E}-05$ & $9.26 \mathrm{E}-06$ & 10 & $\begin{array}{c}\text { SGO1,NDC80,RACGAP1, } \\
\text { AURKA,NCAPG,BUB1,N } \\
\text { CAPD2,NCAPH,KIF20A, } \\
\text { CBX5 }\end{array}$ \\
\hline 137935 & $\begin{array}{l}\text { FOXM1 transcription } \\
\text { factor network }\end{array}$ & $6.00 \mathrm{E}-07$ & $2.28 \mathrm{E}-05$ & $1.21 \mathrm{E}-04$ & $6.83 \mathrm{E}-05$ & 9 & $\begin{array}{c}\text { CENPF,MMP2,PLK1,FOX } \\
\text { M1,SKP2,CCNB1,CCNB2 } \\
\text {,CDK1,CDK4 }\end{array}$ \\
\hline 169351 & $\begin{array}{l}\text { Validated targets of C- } \\
\text { MYC transcriptional } \\
\text { activation }\end{array}$ & $2.42 \mathrm{E}-06$ & $6.90 \mathrm{E}-05$ & 3.67E-04 & $2.76 \mathrm{E}-04$ & 12 & $\begin{array}{c}\text { PFKM,SERPINI1,SUPT3 } \\
\text { H,LIN28B,SLC2A1,PEG1 } \\
0, \text { CAD,CCNB1,CCND2,C } \\
\text { DCA7,TP53,CDK4 }\end{array}$ \\
\hline 137934 & $\begin{array}{l}\text { E2F transcription } \\
\text { factor network }\end{array}$ & $3.40 \mathrm{E}-05$ & $7.76 \mathrm{E}-04$ & $4.13 \mathrm{E}-03$ & $3.88 \mathrm{E}-03$ & 10 & $\begin{array}{c}\text { MCM3,RRM2,TYMS,MY } \\
\text { BL2,E2F5,CCNA2,TRIM2 } \\
\text { 8,CBX5,CDK1,CDC6 }\end{array}$ \\
\hline 138073 & $\begin{array}{l}\text { C-MYB transcription } \\
\text { factor network }\end{array}$ & $3.20 \mathrm{E}-04$ & $5.02 \mathrm{E}-03$ & $2.67 \mathrm{E}-02$ & $3.65 \mathrm{E}-02$ & 9 & $\begin{array}{c}\text { MCM4,COL1A2,CCNB1, } \\
\text { TRIM28,CD34,H2AZ1,LY } \\
\text { Z,LEF1,CDK6 }\end{array}$ \\
\hline 169352 & $\begin{array}{l}\text { Regulation of Wnt- } \\
\text { mediated beta catenin } \\
\text { signaling and target } \\
\text { gene transcription }\end{array}$ & $3.52 \mathrm{E}-04$ & $5.02 \mathrm{E}-03$ & $2.67 \mathrm{E}-02$ & $4.02 \mathrm{E}-02$ & 9 & $\begin{array}{c}\text { AXIN2,MMP2,IGF2BP1, } \\
\text { DKK1,VCAN,DKK4,BCL } \\
\text { 9,CCND2,LEF1 }\end{array}$ \\
\hline 137939 & Direct p53 effectors & $3.99 \mathrm{E}-03$ & $5.06 \mathrm{E}-02$ & $2.69 \mathrm{E}-01$ & 4.55E-01 & 10 & $\begin{array}{c}\text { AFP,MMP2,MAP4K4,TP5 } \\
\text { 313,MSH2,DKK1,VCAN,S } \\
\text { PP1,CCNB1,TP53 }\end{array}$ \\
\hline 138019 & $\begin{array}{l}\text { p75(NTR)-mediated } \\
\text { signaling }\end{array}$ & $2.78 \mathrm{E}-02$ & $1.87 \mathrm{E}-01$ & $9.92 \mathrm{E}-01$ & $1.00 \mathrm{E}+00$ & 5 & $\begin{array}{c}\text { SORT1,MAGED1,BEX1, } \\
\text { NDN,TP53 }\end{array}$ \\
\hline 169347 & $\begin{array}{l}\text { Notch-mediated } \\
\text { HES/HEY network }\end{array}$ & 7.45E-01 & 8.09E-01 & $1.00 \mathrm{E}+00$ & $1.00 \mathrm{E}+00$ & 1 & HEY1 \\
\hline
\end{tabular}


medRxiv preprint doi: https://doi.org/10.1101/2020.12.22.20248756; this version posted December 26, 2020. The copyright holder for this preprint (which was not certified by peer review) is the author/funder, who has granted medRxiv a license to display the preprint in perpetuity.

All rights reserved. No reuse allowed without permission.

\begin{tabular}{|c|c|c|c|c|c|c|c|}
\hline \multicolumn{8}{|c|}{ MSigDB C2 BIOCARTA (v6.0) } \\
\hline M6682 & $\begin{array}{l}\text { CDK Regulation of } \\
\text { DNA Replication }\end{array}$ & $3.12 \mathrm{E}-07$ & $3.62 \mathrm{E}-05$ & $1.93 \mathrm{E}-04$ & $3.62 \mathrm{E}-05$ & 7 & $\begin{array}{c}\text { MCM2,MCM3,MCM4,M } \\
\text { CM5,MCM6,MCM7,CDC } \\
6\end{array}$ \\
\hline M17761 & $\begin{array}{l}\text { Wnt/beta-catenin } \\
\text { Pathway }\end{array}$ & $3.38 \mathrm{E}-06$ & $1.96 \mathrm{E}-04$ & $1.05 \mathrm{E}-03$ & $3.92 \mathrm{E}-04$ & 8 & $\begin{array}{c}\text { AXIN2,DACT1,NKD1,DK } \\
\text { K1,DKK4,DKK3,DKK2, } \\
\text { WIF1 }\end{array}$ \\
\hline M5884 & $\begin{array}{l}\text { Ensemble of genes } \\
\text { encoding core } \\
\text { extracellular matrix } \\
\text { including ECM } \\
\text { glycoproteins, } \\
\text { collagens and } \\
\text { proteoglycans }\end{array}$ & $9.91 \mathrm{E}-06$ & $3.83 \mathrm{E}-04$ & $2.04 \mathrm{E}-03$ & $1.15 \mathrm{E}-03$ & 22 & $\begin{array}{c}\text { MATN3,MFAP2,MFGE8, } \\
\text { FBLN1,SPARCL1,COL1A } \\
\text { 1,COL1A2,COL2A1,COL } \\
\text { 4A1,FRAS1,COL15A1,F } \\
\text { MOD,VCAN,RELN,SPP1, } \\
\text { SMOC2,CCN3,NPNT,LA } \\
\text { MC1,VWCE,EDIL3,LTBP } \\
2\end{array}$ \\
\hline M5889 & $\begin{array}{l}\text { Ensemble of genes } \\
\text { encoding extracellular } \\
\text { matrix and } \\
\text { extracellular matrix- } \\
\text { associated proteins }\end{array}$ & $3.02 \mathrm{E}-04$ & $5.00 \mathrm{E}-03$ & $2.67 \mathrm{E}-02$ & $3.50 \mathrm{E}-02$ & 48 & $\begin{array}{c}\text { PCSK5,CTSC,MATN3,M } \\
\text { DK,TNFSF4,MEP1A,COL } \\
\text { EC12,MFA2,MFGE8,FB } \\
\text { LN1,SERPINE2,SERPINI } \\
\text { 1,SPARCL1,MMP2,MMP } \\
\text { 11,XCL1,COL1 A1,COL1 } \\
\text { A2,COL2A1,COL4A1,SE } \\
\text { MA3C,FRAS1,SFRP4,CO } \\
\text { L15A1,FMOD,VCAN,FR } \\
\text { ZB,CST1,RELN,SPP1,SM } \\
\text { OC2,FREM1,BMP4,FRE } \\
\text { M2,GPC3,MUCL1,FGF20, } \\
\text { CCN3,NPNT,P4HA2,LA } \\
\text { MC1,TDGF1,VWCE,EDI } \\
\text { L3,TGFB2,WIF1,REG3A, } \\
\text { LTBP2 }\end{array}$ \\
\hline M3008 & $\begin{array}{l}\text { Genes encoding } \\
\text { structural ECM } \\
\text { glycoproteins }\end{array}$ & 4.16E-04 & $5.36 \mathrm{E}-03$ & $2.86 \mathrm{E}-02$ & 4.82E-02 & 15 & $\begin{array}{c}\text { MATN3,MFAP2,MFGE8, } \\
\text { FBLN1,SPARCL1,FRAS1, } \\
\text { RELN,SPP1,SMOC2,CCN } \\
\text { 3,NPNT,LAMC1,VWCE,E } \\
\text { DIL3,LTBP2 }\end{array}$ \\
\hline M5885 & $\begin{array}{l}\text { Ensemble of genes } \\
\text { encoding ECM- } \\
\text { associated proteins } \\
\text { including ECM- } \\
\text { affilaited proteins, } \\
\text { ECM regulators and } \\
\text { secreted factors }\end{array}$ & $1.58 \mathrm{E}-01$ & $5.78 \mathrm{E}-01$ & $1.00 \mathrm{E}+00$ & $1.00 \mathrm{E}+00$ & 26 & $\begin{array}{c}\text { PCSK5,CTSC,MDK,TNFS } \\
\text { F4,MEP1A,COLEC12,SE } \\
\text { RPINE2,SERPINI1,MMP2 } \\
\text {,MMP11,XCL1,SEMA3C, } \\
\text { SFRP4,FRZB,CST1,FRE } \\
\text { M1,BMP4,FREM2,GPC3, } \\
\text { MUCL1,FGF20,P4HA2,T } \\
\text { DGF1,TGFB2,WIF1,REG } \\
\text { 3A }\end{array}$ \\
\hline M5880 & $\begin{array}{l}\text { Genes encoding } \\
\text { proteins affiliated } \\
\text { structurally or } \\
\text { functionally to } \\
\text { extracellular matrix } \\
\text { proteins }\end{array}$ & $2.05 \mathrm{E}-01$ & $6.60 \mathrm{E}-01$ & $1.00 \mathrm{E}+00$ & $1.00 \mathrm{E}+00$ & 7 & $\begin{array}{c}\text { COLEC12,SEMA3C,FRE } \\
\text { M1,FREM2,GPC3,MUCL } \\
\text { 1,REG3A }\end{array}$ \\
\hline M3468 & $\begin{array}{l}\text { Genes encoding } \\
\text { enzymes and their } \\
\text { regulators involved in } \\
\text { the remodeling of the } \\
\text { extracellular matrix }\end{array}$ & $2.25 \mathrm{E}-01$ & $6.64 \mathrm{E}-01$ & $1.00 \mathrm{E}+00$ & $1.00 \mathrm{E}+00$ & 9 & $\begin{array}{c}\text { PCSK5,CTSC,MEP1A,SE } \\
\text { RPINE2,SERPINI1,MMP2 } \\
\text {,MMP11,CST1,P4HA2 }\end{array}$ \\
\hline M13863 & $\begin{array}{l}\text { MAPKinase Signaling } \\
\text { Pathway }\end{array}$ & 4.42E-01 & $6.73 \mathrm{E}-01$ & $1.00 \mathrm{E}+00$ & $1.00 \mathrm{E}+00$ & 3 & $\begin{array}{l}\text { MAP4K4,MAPK13,TGFB } \\
2\end{array}$ \\
\hline M5883 & $\begin{array}{l}\text { Genes encoding } \\
\text { secreted soluble } \\
\text { factors }\end{array}$ & 4.99E-01 & $6.73 \mathrm{E}-01$ & $1.00 \mathrm{E}+00$ & $1.00 \mathrm{E}+00$ & 10 & $\begin{array}{c}\text { MDK,TNFSF4,XCL1,SFR } \\
\text { P4,FRZB,BMP4,FGF20,T } \\
\text { DGF1,TGFB2,WIF1 }\end{array}$ \\
\hline \multicolumn{8}{|c|}{ Panther DB } \\
\hline P00057 & Wnt signaling pathway & $5.59 \mathrm{E}-03$ & $3.50 \mathrm{E}-01$ & $1.00 \mathrm{E}+00$ & $4.20 \mathrm{E}-01$ & 17 & $\begin{array}{c}\text { ACTG2,AXIN2,SFRP4,M } \\
\text { YH7B,NKD1,DKK1,FRZ } \\
\text { B,DKK4,DKK2,MYCN,B } \\
\text { CL9,GNG4,LEF1,CDH11, } \\
\text { CDH13,TP53,HELLS }\end{array}$ \\
\hline P00017 & DNA replication & $9.32 \mathrm{E}-03$ & $3.50 \mathrm{E}-01$ & $1.00 \mathrm{E}+00$ & $6.99 \mathrm{E}-01$ & 3 & H3C2,PRIM1,TOP2A \\
\hline P00034 & $\begin{array}{l}\text { Integrin signalling } \\
\text { pathway }\end{array}$ & $1.93 \mathrm{E}-02$ & $3.50 \mathrm{E}-01$ & $1.00 \mathrm{E}+00$ & $1.00 \mathrm{E}+00$ & 10 & $\begin{array}{c}\text { PIK3R2,COL1A1,COL1A } \\
\text { 2,COL2A1,COL4A1,COL } \\
\text { 15A1,MAPK13,ITGA6,IT } \\
\text { GA2,LAMC1 }\end{array}$ \\
\hline P00059 & p53 pathway & $2.33 \mathrm{E}-02$ & $3.50 \mathrm{E}-01$ & $1.00 \mathrm{E}+00$ & $1.00 \mathrm{E}+00$ & 6 & $\begin{array}{l}\text { RRM2,PIK3R2,CCNB1,C } \\
\text { DK1,CDC25C,TP53 }\end{array}$ \\
\hline P00005 & Angiogenesis & $6.04 \mathrm{E}-02$ & 4.53E-01 & $1.00 \mathrm{E}+00$ & $1.00 \mathrm{E}+00$ & 8 & EPHB2,PDGFRB,AXIN2, \\
\hline
\end{tabular}


medRxiv preprint doi: https://doi.org/10.1101/2020.12.22.20248756; this version posted December 26, 2020. The copyright holder for this preprint (which was not certified by peer review) is the author/funder, who has granted medRxiv a license to display the preprint in perpetuity. All rights reserved. No reuse allowed without permission.

\begin{tabular}{|c|c|c|c|c|c|c|c|}
\hline \multirow[b]{2}{*}{ P04391 } & \multirow[b]{2}{*}{$\begin{array}{c}\text { Oxytocin receptor } \\
\text { mediated signaling } \\
\text { pathway }\end{array}$} & \multirow[b]{2}{*}{$2.00 \mathrm{E}-01$} & \multirow[b]{2}{*}{$6.65 \mathrm{E}-01$} & \multirow[b]{2}{*}{$1.00 \mathrm{E}+00$} & \multirow[b]{2}{*}{$1.00 \mathrm{E}+00$} & \multirow[b]{2}{*}{3} & \multirow[b]{2}{*}{$\begin{array}{c}\text { KD1,DLK1 } \\
\text { PLCG1,GNG4,CACNB4 }\end{array}$} \\
\hline & & & & & & & \\
\hline P00004 & $\begin{array}{l}\text { Alzheimer disease- } \\
\text { presenilin pathway }\end{array}$ & $2.11 \mathrm{E}-01$ & $6.65 \mathrm{E}-01$ & $1.00 \mathrm{E}+00$ & $1.00 \mathrm{E}+00$ & 5 & $\begin{array}{c}\text { TRPC1,ACTG2,MMP2,LR } \\
\text { P4,LEF1 }\end{array}$ \\
\hline P00052 & $\begin{array}{l}\text { TGF-beta signaling } \\
\text { pathway }\end{array}$ & 2.52E-01 & $7.20 \mathrm{E}-01$ & $1.00 \mathrm{E}+00$ & $1.00 \mathrm{E}+00$ & 4 & $\begin{array}{c}\text { BAMBI,MAPK13,BMP4, } \\
\text { TGFB2 }\end{array}$ \\
\hline P00029 & Huntington disease & $4.54 \mathrm{E}-01$ & $7.88 \mathrm{E}-01$ & $1.00 \mathrm{E}+00$ & $1.00 \mathrm{E}+00$ & 4 & $\begin{array}{l}\text { ACTG2,TP53I3,DYNC1I1 } \\
\text { TP53 }\end{array}$ \\
\hline $\mathrm{P} 00026$ & $\begin{array}{c}\text { Heterotrimeric G- } \\
\text { protein signaling } \\
\text { pathway-Gi alpha and } \\
\text { Gs alpha mediated } \\
\text { pathway }\end{array}$ & $6.10 \mathrm{E}-01$ & $7.88 \mathrm{E}-01$ & $1.00 \mathrm{E}+00$ & $1.00 \mathrm{E}+00$ & 4 & $\begin{array}{c}\text { HTR1D,HTR4,KCNJ5,GN } \\
\text { G4 }\end{array}$ \\
\hline \multicolumn{8}{|c|}{ Pathway Ontology } \\
\hline PW:0000384 & $\begin{array}{l}\text { G2/M DNA damage } \\
\text { checkpoint }\end{array}$ & $8.56 \mathrm{E}-05$ & $6.08 \mathrm{E}-03$ & $2.95 \mathrm{E}-02$ & $6.08 \mathrm{E}-03$ & 3 & CHEK1,CCNB1,CDK1 \\
\hline PW:0000248 & steroid biosynthetic & $1.62 \mathrm{E}-03$ & $2.00 \mathrm{E}-02$ & $9.69 \mathrm{E}-02$ & $1.15 \mathrm{E}-01$ & 3 & FDFT1,SQLE,NQO1 \\
\hline PW:0000201 & $\begin{array}{c}\text { canonical } \\
\text { Wntsignaling }\end{array}$ & $1.69 \mathrm{E}-03$ & $2.00 \mathrm{E}-02$ & $9.69 \mathrm{E}-02$ & $1.20 \mathrm{E}-01$ & 6 & $\begin{array}{l}\text { AXIN2,DKK1,DKK4,DK } \\
\text { K2,WIF1,LEF1 }\end{array}$ \\
\hline PW:0000087 & G1 phase & $2.31 \mathrm{E}-03$ & $2.05 \mathrm{E}-02$ & $9.93 \mathrm{E}-02$ & $1.64 \mathrm{E}-01$ & 2 & E2F5,CDK4 \\
\hline PW:0000718 & p53 signaling pathway & $9.32 \mathrm{E}-03$ & $6.62 \mathrm{E}-02$ & $3.21 \mathrm{E}-01$ & $6.62 \mathrm{E}-01$ & 16 & CHEK1,SMYD2,TP53 \\
\hline PW:0000373 & $\begin{array}{l}\text { glutathione } \\
\text { conjugation }\end{array}$ & $2.48 \mathrm{E}-02$ & $1.46 \mathrm{E}-01$ & $7.10 \mathrm{E}-01$ & $1.00 \mathrm{E}+00$ & 9 & GSTA4,GSTP1 \\
\hline PW:0000343 & $\begin{array}{l}\text { altered Notch signaling } \\
\text { involving promoters }\end{array}$ & $2.89 \mathrm{E}-02$ & $1.46 \mathrm{E}-01$ & $7.10 \mathrm{E}-01$ & $1.00 \mathrm{E}+00$ & 1 & HEY1 \\
\hline PW:0000300 & $\begin{array}{l}\text { renal disease, renal } \\
\text { disorder }\end{array}$ & $2.89 \mathrm{E}-02$ & $1.46 \mathrm{E}-01$ & 7.10E-01 & $1.00 \mathrm{E}+00$ & 1 & SPP1 \\
\hline PW:0000301 & renal failure & $5.53 \mathrm{E}-02$ & $1.96 \mathrm{E}-01$ & $9.52 \mathrm{E}-01$ & $1.00 \mathrm{E}+00$ & 1 & SOAT2 \\
\hline PW:0000232 & $\begin{array}{l}\text { phosphatidylinositol 3- } \\
\text { kinase-Akt signaling }\end{array}$ & $6.90 \mathrm{E}-02$ & 2.33E-01 & $1.00 \mathrm{E}+00$ & $1.00 \mathrm{E}+00$ & 3 & MDK,PIK3R2,PLCG1 \\
\hline \multicolumn{8}{|c|}{ SMPDB } \\
\hline SMP00197 & $\begin{array}{l}\text { Lysinuric Protein } \\
\text { Intolerance }\end{array}$ & $2.89 \mathrm{E}-02$ & $3.58 \mathrm{E}-01$ & $1.00 \mathrm{E}+00$ & $1.00 \mathrm{E}+00$ & 1 & SLC7A6 \\
\hline SMP00112 & Risedronate Pathway & $4.30 \mathrm{E}-02$ & $3.58 \mathrm{E}-01$ & $1.00 \mathrm{E}+00$ & $1.00 \mathrm{E}+00$ & 2 & FDFT1,SQLE \\
\hline SMP00040 & Glycolysis & 4.99E-02 & 3.69E-01 & $1.00 \mathrm{E}+00$ & $1.00 \mathrm{E}+00$ & 2 & PFKM,PKM \\
\hline SMP00018 & $\begin{array}{l}\text { Alpha Linolenic Acid } \\
\text { and Linoleic Acid } \\
\text { Metabolism }\end{array}$ & $5.53 \mathrm{E}-02$ & $3.69 \mathrm{E}-01$ & $1.00 \mathrm{E}+00$ & $1.00 \mathrm{E}+00$ & 1 & FADS2 \\
\hline SMP00136 & $\begin{array}{l}\text { 2-Hydroxyglutric } \\
\text { Aciduria (D And L } \\
\text { Form) }\end{array}$ & $6.47 \mathrm{E}-02$ & 4.04E-01 & $1.00 \mathrm{E}+00$ & $1.00 \mathrm{E}+00$ & 2 & AACS,OXCT1 \\
\hline SMP00071 & $\begin{array}{l}\text { Ketone Body } \\
\text { Metabolism }\end{array}$ & $1.33 \mathrm{E}-01$ & 4.25E-01 & $1.00 \mathrm{E}+00$ & $1.00 \mathrm{E}+00$ & 1 & OXCT1 \\
\hline SMP00046 & $\begin{array}{l}\text { Pyrimidine } \\
\text { Metabolism }\end{array}$ & $1.54 \mathrm{E}-01$ & $4.25 \mathrm{E}-01$ & $1.00 \mathrm{E}+00$ & $1.00 \mathrm{E}+00$ & 2 & TYMS,CAD \\
\hline SMP00010 & $\begin{array}{l}\text { Nucleotide Sugars } \\
\text { Metabolism }\end{array}$ & $1.81 \mathrm{E}-01$ & 4.25E-01 & $1.00 \mathrm{E}+00$ & $1.00 \mathrm{E}+00$ & 1 & UXS1 \\
\hline SMP00029 & $\begin{array}{l}\text { Selenoamino Acid } \\
\text { Metabolism }\end{array}$ & $2.26 \mathrm{E}-01$ & $4.25 \mathrm{E}-01$ & $1.00 \mathrm{E}+00$ & $1.00 \mathrm{E}+00$ & 1 & PAPSS1 \\
\hline SMP00392 & Benzocaine Pathway & $2.48 \mathrm{E}-01$ & $4.25 \mathrm{E}-01$ & $1.00 \mathrm{E}+00$ & $1.00 \mathrm{E}+00$ & 1 & ATP1A2 \\
\hline
\end{tabular}

Table 4 The enriched pathway terms of the down-regulated differentially expressed genes

\begin{tabular}{|c|c|c|c|c|c|c|c|}
\hline \multicolumn{8}{|c|}{ BIOCYC } \\
\hline Pathway ID & Pathway Name & P-value & $\begin{array}{l}\text { FDR } \\
\text { B\&H }\end{array}$ & $\begin{array}{l}\text { FDR } \\
\text { B\&Y }\end{array}$ & Bonferroni & $\begin{array}{c}\text { Gene } \\
\text { Count }\end{array}$ & Gene \\
\hline 835392 & $\begin{array}{c}\text { superpathway of tryptophan } \\
\text { utilization }\end{array}$ & $4.23 \mathrm{E}-08$ & $5.12 \mathrm{E}-06$ & $2.75 \mathrm{E}-05$ & $5.12 \mathrm{E}-06$ & 10 & $\begin{array}{c}\text { ADH1B,CYP4X1,KMO,C } \\
\text { YP1A2,CYP2C19,SULT1 } \\
\text { A2,KYNU,TDO2,HAAO, } \\
\text { ACMSD }\end{array}$ \\
\hline 545316 & $\begin{array}{c}\text { bile acid biosynthesis, } \\
\text { neutral pathway }\end{array}$ & $9.20 \mathrm{E}-07$ & $5.57 \mathrm{E}-05$ & 2.99E-04 & $1.11 \mathrm{E}-04$ & 6 & $\begin{array}{l}\text { SCP2,CYP8B1,BAAT,AK } \\
\text { R1D1,SLC27A5,SLC27A2 }\end{array}$ \\
\hline 142385 & tryptophan degradation & $1.88 \mathrm{E}-06$ & $7.59 \mathrm{E}-05$ & 4.08E-04 & $2.28 \mathrm{E}-04$ & 5 & $\begin{array}{c}\text { KMO,KYNU,TDO2,HAA } \\
\text { O,ACMSD }\end{array}$ \\
\hline 782404 & $\begin{array}{c}\text { fatty acid beta-oxidation } \\
\text { (peroxisome) }\end{array}$ & 3.77E-05 & 7.61E-04 & 4.09E-03 & $4.57 \mathrm{E}-03$ & 5 & $\begin{array}{c}\text { ACOX1,ACSL1,SCP2,SL } \\
\text { C27A2,EHHADH }\end{array}$ \\
\hline 142356 & histidine degradation & $3.30 \mathrm{E}-04$ & $3.33 \mathrm{E}-03$ & $1.79 \mathrm{E}-02$ & $4.00 \mathrm{E}-02$ & 3 & UROC1,AMDHD1,HAL \\
\hline 1108778 & glycine betaine degradation & $3.30 \mathrm{E}-04$ & $3.33 \mathrm{E}-03$ & $1.79 \mathrm{E}-02$ & $4.00 \mathrm{E}-02$ & 3 & DMGDH,SHMT1,BHMT \\
\hline 142386 & tyrosine degradation & $3.30 \mathrm{E}-04$ & $3.33 \mathrm{E}-03$ & $1.79 \mathrm{E}-02$ & $4.00 \mathrm{E}-02$ & 3 & HGD,HPD,TAT \\
\hline 782398 & pyrimidine ribonucleosides & $6.44 \mathrm{E}-04$ & $5.20 \mathrm{E}-03$ & $2.80 \mathrm{E}-02$ & $7.80 \mathrm{E}-02$ & 3 & UPB 1,DPYS,CDA \\
\hline
\end{tabular}


medRxiv preprint doi: https://doi.org/10.1101/2020.12.22.20248756; this version posted December 26, 2020. The copyright holder for this preprint (which was not certified by peer review) is the author/funder, who has granted medRxiv a license to display the preprint in perpetuity.

All rights reserved. No reuse allowed without permission.

\begin{tabular}{|c|c|c|c|c|c|c|}
\hline $\begin{array}{r}1108771 \\
142151\end{array}$ & $\begin{array}{c}\text { degradation } \\
\text { allopregnanolone } \\
\text { biosynthesis } \\
\text { glycine biosynthesis }\end{array}$ & $6.44 \mathrm{E}-04$ & $5.20 \mathrm{E}-03$ & $2.80 \mathrm{E}-02$ & $7.80 \mathrm{E}-02$ & 3 \\
\hline & \multicolumn{6}{|c|}{ KEGG } \\
\hline 132956 & Metabolic pathways & $9.62 \mathrm{E}-31$ & $2.71 \mathrm{E}-28$ & $1.69 \mathrm{E}-27$ & $2.71 \mathrm{E}-28$ & 124 \\
\hline
\end{tabular}

83073

Complement and
coagulation cascades

83020

Retinol metabolism

6.17E-16

673221

Chemical carcinogenesis

8.27E-1

$5.83 \mathrm{E}-14$

$2.33 \mathrm{E}-13$
$4.41 \mathrm{E}-14 \quad 2.49 \mathrm{E}-12 \quad 1.55 \mathrm{E}-11 \quad 1.24 \mathrm{E}-11$
AKR1C4,SRD5A1,SRD5A 2 AGXT,AGXT2

EPHX2,HGD,NAT2,CDO 1,ABAT,SGMS2,ACACB, ACADL,ACADM,ACADS B,ACAT1,CES1,MAT1A, ACOX1,PIPOX,MGLL,A KR1C4,HMGCS2,HAO1, ADH1B,ADH1C,ADH4,N DST3,ACSL1,ACSM3,FB P1,ST3GAL6,PIK3C2G,H PD,LIPG,AGL,AGXT,UG P2,UGT2B4,UGT2B7,UG T2B10,SCP2,PLA2G2A,A LAS1,ALDH1 A1,HSD11B 1,ALDOB,ALDH6A1,ALP L,DMGDH,AGPAT2,AO X1,PON1,PON3,SHMT1, XDH,CYP4F2,ETNPPL,K MO,ARG1,GBA3,AGXT2, GDA,RDH16,HSD17B6,A SS1,LPIN2,OGDHL,CTH, MMUT,CYP1A1,CYP1A2 ,CYP2B6,CYP2C19,UPB1 ,CYP2C8,CYP2C9,CYP2C 18,GLS2,MBOAT1,CYP3 A4,CYP3A5,CYP4A11,IN PP1,CYP8B1,CYP26A1,B AAT,AKR1D1,GATM,DA O,CHST9,GCH1,UROC1, SUCLG2,PTGS2,BHMT,G CLM,PTS,DHODH,ACSM 5,NNMT,KYNU,SDS,TAT ,GOT1,SLC27A5,CNDP1, DPYS,GNE,GPT,GPAT3, AMDHD1,TDO2,PAPSS2, OTC,NAMPT,EHHADH, AASS,GYS2,HAAO,CDA, CYP4F3,HAL,ACMSD,A ADAT,NNT,HAO2,PCK1, PCK2

CFH,MBL2,F8,F9,F11,F13 B,CLU,FGB,FGG,CFI,SE RPINC1,MASP2,MASP1, CFB,C1R,C1S,C4BPA,C4 $\mathrm{BPB}, \mathrm{C} 5, \mathrm{C} 6, \mathrm{C} 7, \mathrm{C} 8 \mathrm{~A}, \mathrm{C} 8 \mathrm{~B}$, C8G,C9,KLKB1,KNG1,SE RPINE1

LRAT,ADH1B,ADH1C,A DH4,UGT2B4,UGT2B7,U GT2B10,ALDH1A1,AOX 1,RDH16,HSD17B6,CYP1 A1,CYP1A2,CYP2B6,CY P2C8,CYP2C9,CYP2C18, CYP3A4,CYP3A5,CYP4A 11,CYP26A1

NAT2,ADH1B,ADH1C,A DH4,UGT2B4,UGT2B7,U GT2B10,HSD11B1,CYP3 A43,CYP1A1,CYP1A2,C YP2C19,CYP2C8,CYP2C 9,CYP2C18,CYP3A4,CYP 3A5,PTGS2,SULT1A2,SU LT2A1,GSTA1,GSTA2,G STA3

ADH1B,ADH1C,ADH4,U GT2B4,UGT2B7,UGT2B1 0,FMO3,FMO4,AOX1,CY P1A2,CYP2B6,CYP2C19, CYP2C8,CYP2C9,CYP2D 6,CYP3A4,CYP3A5,GST A1,GSTA2,GSTA3 
medRxiv preprint doi: https://doi.org/10.1101/2020.12.22.20248756; this version posted December 26, 2020. The copyright holder for this preprint (which was not certified by peer review) is the author/funder, who has granted medRxiv a license to display the preprint in perpetuity.

All rights reserved. No reuse allowed without permission.

\begin{tabular}{|c|c|c|c|c|c|c|c|}
\hline 131226 & Peroxisome & $6.42 \mathrm{E}-08$ & $1.47 \mathrm{E}-06$ & $9.12 \mathrm{E}-06$ & $1.81 \mathrm{E}-05$ & 15 & $\begin{array}{c}\text { EPHX2,ACOX1,PIPOX,H } \\
\text { AO1,ACSL1,PHYH,AGX } \\
\text { T,SCP2,XDH,SOD2,BAA } \\
\text { T,DAO,SLC27A2,EHHAD } \\
\text { H,HAO2 }\end{array}$ \\
\hline 83042 & PPAR signaling pathway & $6.76 \mathrm{E}-08$ & $1.47 \mathrm{E}-06$ & $9.12 \mathrm{E}-06$ & $1.91 \mathrm{E}-05$ & 14 & $\begin{array}{c}\text { ACADL,ACADM,ACOX1 } \\
\text {,HMGCS2,ACSL1,SCP2,A } \\
\text { POC3,CYP8B1,SLC27A5, } \\
\text { SLC27A2,APOA5,EHHA } \\
\text { DH,PCK1,PCK2 }\end{array}$ \\
\hline 814926 & Carbon metabolism & $8.71 \mathrm{E}-07$ & $1.53 \mathrm{E}-05$ & $9.54 \mathrm{E}-05$ & $2.46 \mathrm{E}-04$ & 16 & $\begin{array}{c}\text { ACADM,ACAT1,HAO1,F } \\
\text { BP1,AGXT,ALDOB,ALD } \\
\text { H6A1,SHMT1,OGDHL,M } \\
\text { MUT,SUCLG2,SDS,GOT } \\
\text { 1,GPT,EHHADH,HAO2 }\end{array}$ \\
\hline 790012 & Biosynthesis of amino acids & 5.13E-06 & $7.62 \mathrm{E}-05$ & $4.74 \mathrm{E}-04$ & $1.45 \mathrm{E}-03$ & 12 & $\begin{array}{c}\text { MAT1A,ALDOB,SHMT1, } \\
\text { ARG1,ASS1,CTH,SDS,TA } \\
\text { T,GOT1,GPT,OTC,AADA } \\
\text { T }\end{array}$ \\
\hline 634527 & $\begin{array}{c}\text { NF-kappa B signaling } \\
\text { pathway }\end{array}$ & $5.96 \mathrm{E}-05$ & $6.00 \mathrm{E}-04$ & $3.73 \mathrm{E}-03$ & $1.68 \mathrm{E}-02$ & 12 & $\begin{array}{c}\text { BLNK,CCL21,ICAM1,BI } \\
\text { RC3,CXCL8,GADD45B,T } \\
\text { NFSF14,PTGS2,LBP,CXC } \\
\text { L2,CD14,TLR4 }\end{array}$ \\
\hline \multicolumn{8}{|c|}{ Pathway Interaction Database } \\
\hline 138006 & $\begin{array}{l}\text { ATF-2 transcription factor } \\
\text { network }\end{array}$ & $3.85 \mathrm{E}-04$ & $3.55 \mathrm{E}-02$ & $1.81 \mathrm{E}-01$ & $3.55 \mathrm{E}-02$ & 8 & $\begin{array}{c}\text { FOS,ARG1,CXCL8,PPAR } \\
\text { GC1A,JUNB,DUSP1,DUS } \\
\text { P5,SOCS3 }\end{array}$ \\
\hline 137932 & $\begin{array}{l}\text { IL6-mediated signaling } \\
\text { events }\end{array}$ & $2.57 \mathrm{E}-03$ & $1.18 \mathrm{E}-01$ & $6.04 \mathrm{E}-01$ & 2.37E-01 & 6 & $\begin{array}{c}\text { FGG,FOS,CRP,JUNB,SO } \\
\text { CS3,LBP }\end{array}$ \\
\hline 138014 & $\begin{array}{l}\text { Glucocorticoid receptor } \\
\text { regulatory network }\end{array}$ & $5.26 \mathrm{E}-03$ & $1.61 \mathrm{E}-01$ & $8.23 \mathrm{E}-01$ & 4.84E-01 & 8 & $\begin{array}{l}\text { FGG,VIPR1,FOS,ICAM1, } \\
\text { CXCL8,NR1I3,EGR1,PCK } \\
2\end{array}$ \\
\hline 137911 & $\begin{array}{c}\text { FOXA2 and FOXA3 } \\
\text { transcription factor networks }\end{array}$ & $1.39 \mathrm{E}-02$ & $2.13 \mathrm{E}-01$ & $1.00 \mathrm{E}+00$ & $1.00 \mathrm{E}+00$ & 5 & $\begin{array}{c}\text { ACADM,ALAS1,ALDOB, } \\
\text { TAT,PCK1 }\end{array}$ \\
\hline 138010 & Glypican 1 network & $5.17 \mathrm{E}-02$ & $5.29 \mathrm{E}-01$ & $1.00 \mathrm{E}+00$ & $1.00 \mathrm{E}+00$ & 3 & $\begin{array}{l}\text { NRG1,PLA2G2A,SERPIN } \\
\text { C1 }\end{array}$ \\
\hline 137943 & $\begin{array}{l}\text { p38 MAPK signaling } \\
\text { pathway }\end{array}$ & $6.77 \mathrm{E}-02$ & $5.94 \mathrm{E}-01$ & $1.00 \mathrm{E}+00$ & $1.00 \mathrm{E}+00$ & 3 & $\begin{array}{c}\text { MAP3K5,GADD45B,GAD } \\
\text { D45G }\end{array}$ \\
\hline 137945 & amb2 Integrin signaling & $7.10 \mathrm{E}-02$ & $5.94 \mathrm{E}-01$ & $1.00 \mathrm{E}+00$ & $1.00 \mathrm{E}+00$ & 4 & HP,ICAM1,KNG1,LPA \\
\hline 169347 & $\begin{array}{c}\text { Notch-mediated HES/HEY } \\
\text { network }\end{array}$ & $2.07 \mathrm{E}-01$ & $8.22 \mathrm{E}-01$ & $1.00 \mathrm{E}+00$ & $1.00 \mathrm{E}+00$ & 3 & AR,GHR,RCAN1 \\
\hline 137934 & $\begin{array}{l}\text { E2F transcription factor } \\
\text { network }\end{array}$ & $2.16 \mathrm{E}-01$ & $8.22 \mathrm{E}-01$ & $1.00 \mathrm{E}+00$ & $1.00 \mathrm{E}+00$ & 4 & $\begin{array}{c}\text { CES 1,SULT2A1,SERPINE } \\
\text { 1,CES3 }\end{array}$ \\
\hline 137939 & Direct p53 effectors & $2.63 \mathrm{E}-01$ & $8.22 \mathrm{E}-01$ & $1.00 \mathrm{E}+00$ & $1.00 \mathrm{E}+00$ & 6 & $\begin{array}{l}\text { HGF,TP53INP1,DUSP1,D } \\
\text { USP5,SERPINE1,STEAP3 }\end{array}$ \\
\hline \multicolumn{8}{|c|}{ REACTOME } \\
\hline 1270189 & Biological oxidations & $1.19 \mathrm{E}-25$ & $8.10 \mathrm{E}-23$ & $5.75 \mathrm{E}-22$ & $8.10 \mathrm{E}-23$ & 48 & $\begin{array}{c}\text { GLYAT,NAT2,AADAC,C } \\
\text { ES1,MAT1A,CYP39A1,A } \\
\text { DH1B,ADH1C,ADH4,GL } \\
\text { YATL1,UGP2,UGT2B4,U } \\
\text { GT2B7,UGT2B10,ALDH1 } \\
\text { A1,FMO3,CYP3A43,CYP } \\
\text { 4F2,AKR7L,CYP4F22,CY } \\
\text { P4F11,CYP1A1,CYP1A2, } \\
\text { CYP2B6,CYP2C19,CYP2 } \\
\text { C8,CYP2C9,CYP2C18,CY } \\
\text { P2D6,CYP3A4,CYP3A5,C } \\
\text { YP4A11,CYP8B1,CYP26 } \\
\text { A1,SULT1A2,SULT1B1,S } \\
\text { ULT2A1,GCLM,ACSM5, } \\
\text { NNMT,CYP4V2,PAPSS2, } \\
\text { CYP4A22,GSTA1,GSTA2 } \\
\text { GSTA3,CES3,CYP4F3 }\end{array}$ \\
\hline 1269241 & Complement cascade & $1.57 \mathrm{E}-20$ & $5.33 \mathrm{E}-18$ & $3.78 \mathrm{E}-17$ & $1.07 \mathrm{E}-17$ & 23 & $\begin{array}{c}\text { CFH,MBL2,CLU,FCN2,C } \\
\text { OLEC10,CFI,FCN3,CRP, } \\
\text { MASP2,MASP1,CFB,CFH } \\
\text { R3,C1R,C1S,C4BPA,C4B } \\
\text { PB,C5,C6,C7,C8A,C8B,C8 } \\
\text { G,C9 }\end{array}$ \\
\hline 1270190 & $\begin{array}{l}\text { Phase } 1 \text { - Functionalization } \\
\text { of compounds }\end{array}$ & $1.11 \mathrm{E}-18$ & $2.51 \mathrm{E}-16$ & $1.78 \mathrm{E}-15$ & $7.54 \mathrm{E}-16$ & 29 & $\begin{array}{l}\text { AADAC,CES1,CYP39A1, } \\
\text { ADH1B,ADH1C,ADH4,A } \\
\text { LDH1A1,FMO3,CYP3A43 } \\
\text {,CYP4F2,CYP4F22,CYP4 } \\
\text { F11,CYP1A1,CYP1A2,CY } \\
\text { P2B6,CYP2C19,CYP2C8, }\end{array}$ \\
\hline
\end{tabular}


medRxiv preprint doi: https://doi.org/10.1101/2020.12.22.20248756; this version posted December 26, 2020. The copyright holder for this preprint (which was not certified by peer review) is the author/funder, who has granted medRxiv a license to display the preprint in perpetuity. All rights reserved. No reuse allowed without permission.

1270001

1270158

Metabolism of amino acids and derivatives
$2.54 \mathrm{E}-13$

2.87E-1

2.04E-10

1.72E-10 phenylalanine, tyrosine, proline and tryptophan catabolism

$1270040 \quad$ Bile acid and bile salt metabolism
1270207

Phase II conjugation

1.39E-07

9.88E-07

$1.95 \mathrm{E}-06$

1269242

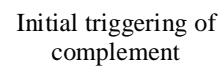

1269203
Innate Immune System
3.00E-08

$1.11 \mathrm{E}-06$

$1.10 \mathrm{E}-03$
1.39E-02
CYP2C9,CYP2C18,CYP2 D6,CYP3A4,CYP3A5,CY

P4A11,CYP8B1,CYP26A

CYP4V2,CYP4A22,CES3 ,CYP4F3

EPHX2,SGMS2,ACACB, ACADL,ACADM,ACAT1 ,CETP,ACOX1,MGLL,AK R1C4,HMGCS2,CYP39A1 ,ABCB4,ACSL1,PHYH,A CSM3,PIK3C2G,LIPG,HP GD,HSD17B13,SCP2,PLA 2G2A,ALAS1,HSD11B1,P RKAG2,DMGDH,MOGA T2,G0S2,AGPAT2,APOF, PON1,PON3,CYP4F2,ET NPPL,APOC 3,SLCO1B1, GBA3,SLC10A1,LPIN2,A BCB11,CYP4F22,CYP4F1 1,MMUT,CYP1A1,CYP1 A2,ABCC3,CYP2C19,CY P2C8,CYP2C9,MBOAT1, CYP4A11,CYP8B1,INSIG 1,BAAT,SRD5A1,SRD5A 2,AKR1D1,SLCO1B3,BC HE,PTGS2,BHMT,PPAR GC1A,SULT2A1,ANGPT L3,CREB3L3,SLC27 A5,S LC27A2,GPD1,APOA5,G PAT3,CYP4A22,MFSD2A ,THRSP,EHHADH,LPA,C ES3,CYP4F3,HAO2 HGD,CDO1,ACADSB,AC AT1,MAT1 A,PIPOX,HAO 1,HPD,AGXT,DHTKD1,B BOX1,ALDH6A1,IYD,SH MT1,KMO,ARG1,AGXT2 ,ASS1,CTH,GLS2,GATM, DAO,UROC1,GNMT,BH MT,GCLM,DIO1,NNMT, KYNU,TAT,GOT1,ASPG GPT,AMDHD1,TDO2,PA PSS2,OTC,AASS,SLC25A 15,HAAO,HAL,ACMSD AADAT

HGD,PIPOX,HPD,KMO,U ROC1,KYNU,TAT,AMD HD1,TDO2,AASS, HAAO,

HAL,ACMSD, AADAT

AKR1C4,CYP39A1,SCP2,

SLCO1B1,SLC10A1,ABC

B11,ABCC3,CYP8B1,BA

AT,AKR1D1,SLCO1B3,S LC27A5,SLC27A2

GLYAT,NAT2,MAT1A,G

LYATL1,UGP2,UGT2B4, UGT2B7,UGT2B10,CYP1 A2,SULT1A2,SULT1B1,S ULT2A1,GCLM,ACSM5, NNMT,PAPSS2,GSTA1,G STA2,GSTA3

MBL2,FCN2,COLEC10,F

CN3,CRP,MASP2,MASP1 ,CFB,C1R,C1S CFH,HGF,NRG1,SERPIN A3,MBL2,CFP,PGLYRP2, LEAP2,LRG1,PLAC8,S10 0A8,SAA1,PIGR,CLU,HP FCN2,AGL,FGB,PLA2G2 A,FGFR2,FGG,APBB1IP, FOS,AGPAT2,BIRC3,CO LEC10,CFI,FCN3,CRP,A RG1,SLPI,CTSL,MASP2, MASP1,SPTBN2,GFRA1, CFB,CFHR3,PTPRB,RNF 
medRxiv preprint doi: https://doi.org/10.1101/2020.12.22.20248756; this version posted December 26, 2020. The copyright holder for this preprint (which was not certified by peer review) is the author/funder, who has granted medRxiv a license to display the preprint in perpetuity. All rights reserved. No reuse allowed without permission.

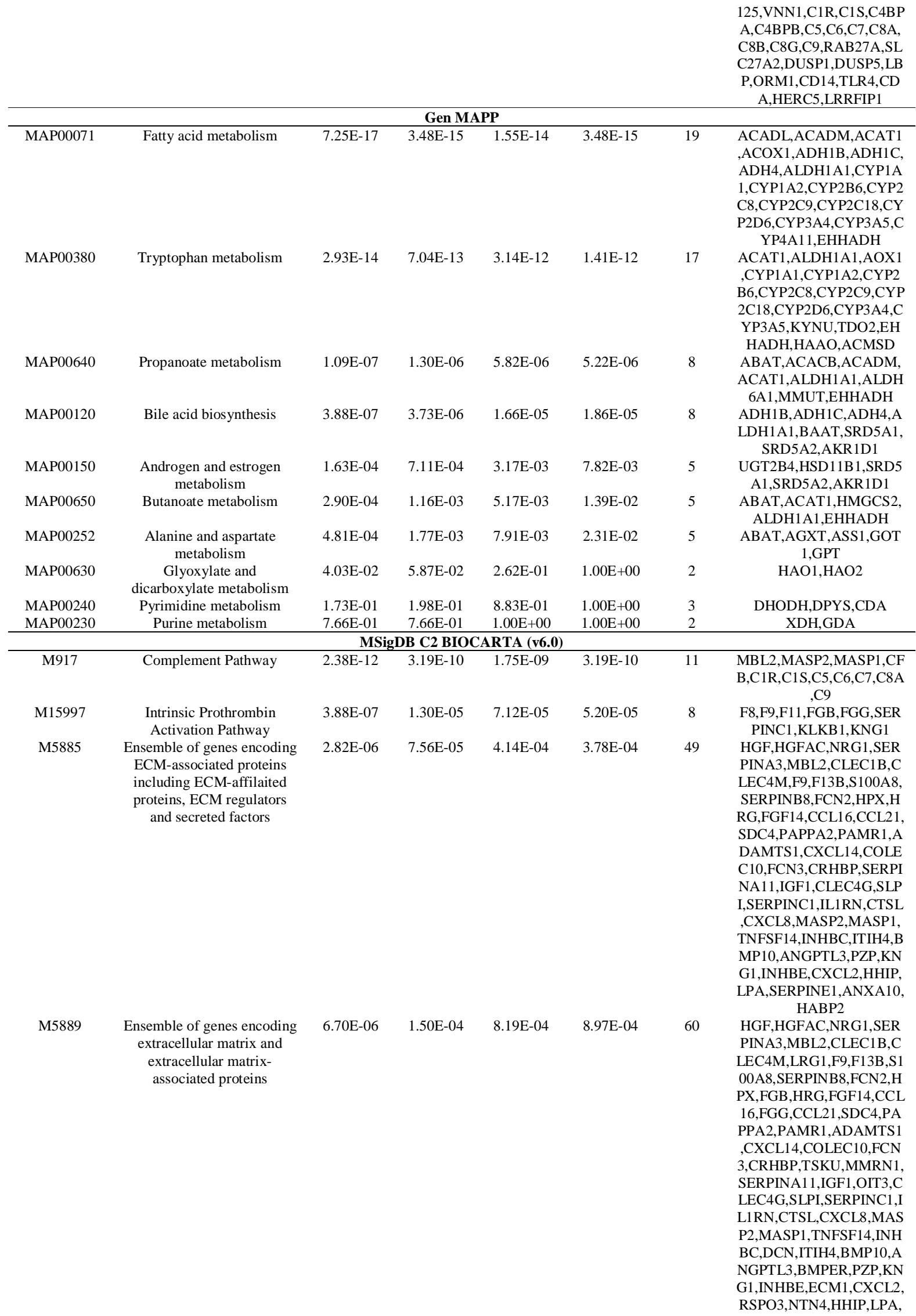


medRxiv preprint doi: https://doi.org/10.1101/2020.12.22.20248756; this version posted December 26, 2020. The copyright holder for this preprint (which was not certified by peer review) is the author/funder, who has granted medRxiv a license to display the preprint in perpetuity.

All rights reserved. No reuse allowed without permission.

\begin{tabular}{|c|c|c|c|c|c|c|c|}
\hline \multirow{3}{*}{ M3468 } & \multirow{5}{*}{$\begin{array}{l}\text { Genes encoding enzymes } \\
\text { and their regulators involved } \\
\text { in the remodeling of the } \\
\text { extracellular matrix }\end{array}$} & \multirow{4}{*}{$1.08 \mathrm{E}-04$} & \multirow{4}{*}{$1.60 \mathrm{E}-03$} & \multirow{4}{*}{$8.77 \mathrm{E}-03$} & \multirow{4}{*}{$1.44 \mathrm{E}-02$} & \multirow{3}{*}{20} & \multirow{6}{*}{$\begin{array}{c}\text { P2 } \\
\text { SERPINA3,F9,F13B,SERP } \\
\text { INB8,HRG,PAPPA2,PAM } \\
\text { R1,ADAMTS1,SERPINA1 } \\
\text { 1,SLPI,SERPINC1,CTSL, } \\
\text { MASP2,MASP1,ITIH4,PZ } \\
\text { P,KNG1,LPA,SERPINE1, } \\
\text { HABP2 }\end{array}$} \\
\hline & & & & & & & \\
\hline & & & & & & & \\
\hline & & & & & & & \\
\hline & & & & & & & \\
\hline & & & & & & & \\
\hline \multirow[t]{5}{*}{ M5883 } & \multirow{5}{*}{$\begin{array}{l}\text { Genes encoding secreted } \\
\text { soluble factors }\end{array}$} & \multirow[t]{5}{*}{$1.82 \mathrm{E}-02$} & \multirow[t]{5}{*}{$1.63 \mathrm{E}-01$} & \multirow[t]{5}{*}{$8.91 \mathrm{E}-01$} & $1.00 \mathrm{E}+00$ & 19 & HGF,HGFAC,NRG1,S100 \\
\hline & & & & & & & $\begin{array}{l}\text { A8,FGF14,CCL16,CCL21, } \\
\text { CXCL14,CRHBP,IGF1,IL }\end{array}$ \\
\hline & & & & & & & 1RN,CXCL8,TNFSF14,IN \\
\hline & & & & & & & HBC,BMP10,ANGPTL3,I \\
\hline & & & & & & & NHBE,CXCL2,HHIP \\
\hline M5880 & Genes encoding proteins & $5.42 \mathrm{E}-02$ & $3.46 \mathrm{E}-01$ & $1.00 \mathrm{E}+00$ & $1.00 \mathrm{E}+00$ & 10 & MBL2,CLEC1B,CLEC4M, \\
\hline & affiliated structurally or & & & & & & FCN2,HPX,SDC4,COLEC \\
\hline & functionally to extracellular & & & & & & 10,FCN3,CLEC4G,ANXA \\
\hline & matrix proteins & & & & & & 10 \\
\hline M3008 & Genes encoding structural & $1.10 \mathrm{E}-01$ & $5.72 \mathrm{E}-01$ & $1.00 \mathrm{E}+00$ & $1.00 \mathrm{E}+00$ & 10 & LRG1,FGB,FGG,TSKU,M \\
\hline & ECM glycoproteins & & & & & & MRN1,OIT3,BMPER,EC \\
\hline & & & & & & & M1,RSPO3,NTN4 \\
\hline M12645 & G alpha 13 Pathway & $1.19 \mathrm{E}-01$ & $5.72 \mathrm{E}-01$ & $1.00 \mathrm{E}+00$ & $1.00 \mathrm{E}+00$ & 3 & MAP3K5,CFB,LPA \\
\hline M5884 & Ensemble of genes encoding & $2.89 \mathrm{E}-01$ & 7.37E-01 & $1.00 \mathrm{E}+00$ & $1.00 \mathrm{E}+00$ & 11 & LRG1,FGB,FGG,TSKU,M \\
\hline & core extracellular matrix & & & & & & MRN1,OIT3,DCN,BMPE \\
\hline & including ECM & & & & & & R,ECM1,RSPO3,NTN4 \\
\hline & $\begin{array}{c}\text { glycoproteins, collagens and } \\
\text { proteoglycans }\end{array}$ & & & & & & \\
\hline & & & Panthe & & & & \\
\hline P00011 & Blood coagulation & $4.34 \mathrm{E}-06$ & $2.65 \mathrm{E}-04$ & $1.26 \mathrm{E}-03$ & $2.86 \mathrm{E}-04$ & 9 & F8,F9,F13B,FGB,FGG,SE \\
\hline & & & & & & & RPINC1,KLKB1,KNG1,S \\
\hline & & & & & & & ERPINE1 \\
\hline P02771 & Pyrimidine Metabolism & $8.02 \mathrm{E}-06$ & $2.65 \mathrm{E}-04$ & $1.26 \mathrm{E}-03$ & $5.29 \mathrm{E}-04$ & 5 & $\begin{array}{l}\text { ABAT,ALDH6A1,UPB1, } \\
\text { DPYS,CDA }\end{array}$ \\
\hline P00050 & Plasminogen activating & $1.91 \mathrm{E}-03$ & $4.20 \mathrm{E}-02$ & $2.01 \mathrm{E}-01$ & $1.26 \mathrm{E}-01$ & 4 & FGB,FGG,LPA,SERPINE \\
\hline P05914 & $\begin{array}{c}\text { cascade } \\
\text { Nicotine degradation }\end{array}$ & $1.68 \mathrm{E}-02$ & $1.89 \mathrm{E}-01$ & $9.04 \mathrm{E}-01$ & $1.00 \mathrm{E}+00$ & 3 & UGT2B7,FMO3,AOX1 \\
\hline P00059 & p53 pathway & $2.58 \mathrm{E}-01$ & $6.32 \mathrm{E}-01$ & $1.00 \mathrm{E}+00$ & $1.00 \mathrm{E}+00$ & 4 & PIK3C2G,GADD45B,GA \\
\hline & & & & & & & DD45G,SERPINE1 \\
\hline P00052 & TGF-beta signaling pathway & 3.47E-01 & 7.63E-01 & $1.00 \mathrm{E}+00$ & $1.00 \mathrm{E}+00$ & 4 & INHBC,JUNB,BMP10,IN \\
\hline & & & & & & & $\mathrm{HBE}$ \\
\hline P00021 & FGF signaling pathway & $6.53 \mathrm{E}-01$ & $9.22 \mathrm{E}-01$ & $1.00 \mathrm{E}+00$ & $1.00 \mathrm{E}+00$ & 3 & MAP3K5,FGF14,FGFR2 \\
\hline P00026 & Heterotrimeric G-protein & $7.28 \mathrm{E}-01$ & $9.30 \mathrm{E}-01$ & $1.00 \mathrm{E}+00$ & $1.00 \mathrm{E}+00$ & 4 & ADRA1A,CREB3L3,RGS \\
\hline & $\begin{array}{l}\text { signaling pathway-Gi alpha } \\
\text { and Gs alpha mediated } \\
\text { pathway }\end{array}$ & & & & & & $2, \mathrm{GYS} 2$ \\
\hline P00034 & Integrin signalling pathway & $8.00 \mathrm{E}-01$ & $9.30 \mathrm{E}-01$ & $1.00 \mathrm{E}+00$ & $1.00 \mathrm{E}+00$ & 4 & MAP3K5,RND3,RND1,N \\
\hline & & & & & & & $\mathrm{TN} 4$ \\
\hline P00031 & Inflammation mediated by & $9.52 \mathrm{E}-01$ & $9.86 \mathrm{E}-01$ & $1.00 \mathrm{E}+00$ & $1.00 \mathrm{E}+00$ & 3 & CCL21,CXCL8,JUNB \\
\hline & $\begin{array}{c}\text { chemokine and cytokine } \\
\text { signaling pathway }\end{array}$ & & & & & & \\
\hline & & & Pathway C & tology & & & \\
\hline PW:0000054 & tryptophan metabolic & $9.77 \mathrm{E}-10$ & $1.11 \mathrm{E}-07$ & $5.92 \mathrm{E}-07$ & $1.11 \mathrm{E}-07$ & 10 & ACAT1,AOX1,KMO,CYP \\
\hline & & & & & & & 1A1,CYP1A2,CYP2C19,K \\
\hline & & & & & & & YNU,TDO2,HAAO,AAD \\
\hline & & & & & & & AT \\
\hline PW:0000729 & statin pharmacokinetics & $5.49 \mathrm{E}-08$ & $3.13 \mathrm{E}-06$ & $1.66 \mathrm{E}-05$ & $6.26 \mathrm{E}-06$ & 7 & SLCO1B1,ABCB11,CYP2 \\
\hline & pathway & & & & & & C8,CYP2C9,CYP2D6,CY \\
\hline & & & & & & & P3A4,SLCO1B3 \\
\hline PW:0000047 & glycine, serine and threonine & $2.83 \mathrm{E}-06$ & $1.07 \mathrm{E}-04$ & $5.71 \mathrm{E}-04$ & $3.22 \mathrm{E}-04$ & 6 & AGXT,ALAS1,SHMT1,C \\
\hline & metabolic & & & & & & TH,GATM,GNMT \\
\hline PW:0000049 & cysteine metabolic & 4.12E-06 & $1.17 \mathrm{E}-04$ & $6.24 \mathrm{E}-04$ & 4.70E-04 & 5 & CDO1,CTH,SULT1A2,SD \\
\hline & & & & & & & S,GOT1 \\
\hline PW:0000058 & fatty acid metabolic & $5.90 \mathrm{E}-06$ & $1.35 \mathrm{E}-04$ & $7.16 \mathrm{E}-04$ & $6.73 \mathrm{E}-04$ & 7 & ACADL,ACADM,ACAT1 \\
\hline & & & & & & & $\begin{array}{c}\text {,ADH4,CYP1A1,CYP1A2, } \\
\text { CYP2C19 }\end{array}$ \\
\hline PW:0000028 & alanine and aspartate & $8.02 \mathrm{E}-06$ & $1.52 \mathrm{E}-04$ & $8.10 \mathrm{E}-04$ & $9.14 \mathrm{E}-04$ & 5 & ABAT,AGXT,ASS1,GOT \\
\hline & metabolic & & & & & & $1, \mathrm{GPT}$ \\
\hline PW:0000641 & gluconeogenesis pathway & $1.07 \mathrm{E}-05$ & $1.75 \mathrm{E}-04$ & $9.28 \mathrm{E}-04$ & $1.22 \mathrm{E}-03$ & 6 & PFKFB1,FBP1,ALDOB,G \\
\hline & & & & & & & OT1,PCK1,PCK2 \\
\hline PW:0000375 & bioactivation via & $1.60 \mathrm{E}-05$ & $2.28 \mathrm{E}-04$ & $1.21 \mathrm{E}-03$ & $1.83 \mathrm{E}-03$ & 4 & CYP1A1,CYP1A2,CYP2C \\
\hline & cytochrome P450 & & & & & & 19,CYP2D6 \\
\hline PW:0000726 & repaglinide & $3.59 \mathrm{E}-05$ & 4.09E-04 & $2.18 \mathrm{E}-03$ & $4.09 \mathrm{E}-03$ & 3 & SLCO1B1,CYP2C8,CYP3 \\
\hline & pharmacokinetics pathway & & & & & & A4 \\
\hline PW:0000074 & lysine biosynthetic & $3.13 \mathrm{E}-03$ & $1.55 \mathrm{E}-02$ & $8.25 \mathrm{E}-02$ & $3.57 \mathrm{E}-01$ & 2 & VNN1,AASS \\
\hline
\end{tabular}


medRxiv preprint doi: https://doi.org/10.1101/2020.12.22.20248756; this version posted December 26, 2020. The copyright holder for this preprint (which was not certified by peer review) is the author/funder, who has granted medRxiv a license to display the preprint in perpetuity.

All rights reserved. No reuse allowed without permission.

\begin{tabular}{|c|c|c|c|c|c|c|c|}
\hline \multicolumn{8}{|c|}{ SMPDB } \\
\hline SMP00272 & Enoxaparin Pathway & $1.46 \mathrm{E}-09$ & $6.40 \mathrm{E}-08$ & $3.68 \mathrm{E}-07$ & $2.56 \mathrm{E}-07$ & 9 & $\begin{array}{l}\text { F8,F9,F11,F13B,FGB,FGG } \\
\text {,SERPINC1,KLKB1,KNG } \\
1\end{array}$ \\
\hline SMP00004 & $\begin{array}{l}\text { Glycine, Serine and } \\
\text { Threonine Metabolism }\end{array}$ & $5.01 \mathrm{E}-08$ & $3.99 \mathrm{E}-07$ & $2.29 \mathrm{E}-06$ & 8.77E-06 & 9 & $\begin{array}{l}\text { AKR1C4,CYP39A1,SCP2, } \\
\text { CYP8B1,BAAT,AKR1D1, } \\
\text { SLC27A5 }\end{array}$ \\
\hline SMP00035 & Bile Acid Biosynthesis & $5.55 \mathrm{E}-07$ & 4.05E-06 & $2.33 \mathrm{E}-05$ & $9.71 \mathrm{E}-05$ & 7 & $\begin{array}{c}\text { AOX1,KMO,CYP1A1,TD } \\
\text { O2,HAAO,ACMSD,AAD } \\
\text { AT }\end{array}$ \\
\hline SMP00063 & Tryptophan Metabolism & $5.55 \mathrm{E}-07$ & $4.05 \mathrm{E}-06$ & 2.33E-05 & $9.71 \mathrm{E}-05$ & 7 & $\begin{array}{c}\text { PLA2G2A,CYP1A2,CYP2 } \\
\text { B6,CYP2C19,CYP2C9,CY } \\
\text { P3A4,CYP3A5 }\end{array}$ \\
\hline SMP00260 & Clopidogrel Pathway & $8.83 \mathrm{E}-07$ & $6.18 \mathrm{E}-06$ & $3.55 \mathrm{E}-05$ & $1.55 \mathrm{E}-04$ & 7 & $\begin{array}{c}\text { ABAT,ACADM,ACADSB } \\
\text {,ACAT1,HMGCS2,ALDH } \\
\text { 6A1,AOX1,MMUT }\end{array}$ \\
\hline SMP00032 & $\begin{array}{l}\text { Valine, Leucine and } \\
\text { Isoleucine Degradation }\end{array}$ & $3.79 \mathrm{E}-06$ & $2.55 \mathrm{E}-05$ & $1.46 \mathrm{E}-04$ & $6.63 \mathrm{E}-04$ & 8 & $\begin{array}{c}\text { ARG1,ASS1,GLS2,GPT,O } \\
\text { TC }\end{array}$ \\
\hline SMP00059 & Urea Cycle & $4.12 \mathrm{E}-06$ & $2.67 \mathrm{E}-05$ & $1.53 \mathrm{E}-04$ & 7.21E-04 & 5 & $\begin{array}{l}\text { AKR1C4,CYP39A1,SCP2, } \\
\text { CYP8B1,BAAT,AKR1D1, } \\
\text { SLC27A5 }\end{array}$ \\
\hline SMP00007 & Beta-Alanine Metabolism & $3.64 \mathrm{E}-05$ & $2.20 \mathrm{E}-04$ & $1.26 \mathrm{E}-03$ & $6.37 \mathrm{E}-03$ & 4 & $\begin{array}{c}\text { ALDH6A1,UPB 1,CNDP1, } \\
\text { DPYS }\end{array}$ \\
\hline SMP00051 & Fatty acid Metabolism & 3.77E-05 & $2.20 \mathrm{E}-04$ & $1.27 \mathrm{E}-03$ & $6.60 \mathrm{E}-03$ & 5 & $\begin{array}{c}\text { ACADL,ACADM,ACADS } \\
\text { B,ACAT1,ACSL1 }\end{array}$ \\
\hline SMP00186 & GlutaricAciduria Type III & $1.24 \mathrm{E}-04$ & $6.60 \mathrm{E}-04$ & $3.79 \mathrm{E}-03$ & $2.18 \mathrm{E}-02$ & 4 & $\begin{array}{l}\text { ACAT1,PIPOX,AASS,AA } \\
\text { DAT }\end{array}$ \\
\hline
\end{tabular}

Table 5 The enriched GO terms of the up regulated differentially expressed genes

\begin{tabular}{cccccccc}
\hline GO ID & CATEGORY & GO Name & P Value & $\begin{array}{c}\text { FDR } \\
\text { B\&H }\end{array}$ & $\begin{array}{c}\text { FDR } \\
\text { B\&Y }\end{array}$ & Bonferroni & $\begin{array}{c}\text { Gen } \\
\text { Count }\end{array}$ \\
\hline GO:0051276 & BP & $\begin{array}{l}\text { chromosome } \\
\text { organization }\end{array}$ & $1.25 \mathrm{E}-28$ & $7.36 \mathrm{E}-25$ & $6.81 \mathrm{E}-24$ & $7.36 \mathrm{E}-25$ & 103 \\
& & & & & &
\end{tabular}

DNA conformation $\quad 1.70 \mathrm{E}-27 \quad 4.98 \mathrm{E}-24 \quad 4.61 \mathrm{E}-23 \quad 9.96 \mathrm{E}-24 \quad 52$ change

Gene
NUSAP1,KIF18A,HDA
C11,PTTG1,ERCC2,CE
NPF,HJURP,MCM2,M
CM3,MCM4,MCM5,M
CM6,MCM7,CHEK1,S
GO1,H4C9,TTK,TUBG
1,NPM3,AXIN2,H2AC
15,H2AC16,H2AC6,H2
AC4,H2AC17,H2AC20,
H2BC8,H2BC13,H2BC
14,H2BC7,H2BC6,H2B
C9,H2BC10,H3C1,H3C
3,H3C6,H3C11,H3C8,N
DC80,H3C12,H3C10,H
3C2,H4C4,H4C2,H4C5,
H4C13,H4C14,MKI67,
MACROH2A2,PLK1,H
2AC12,SUPT3H,POLE
2,H2AC21,MSH2,USP2
1,ASF1B,PRIM1,TET1,
PRKAA2,CENPI,RAC
GAP1,UHRF1,GINS2,P
RKD1,PCGF2,DLGAP5
,NAP1L1,NUF2,CENP
K,GINS1,SMYD2,SPD
L1,AURKA,NCAPG,E
HMT2,BUB1,NCAPD2,
KIFC1,H3C7,H2AC11,
RFC3,PRC1,TERC,NC
APH,CCNA2,CCNB1,H
MGA2,TRIM28,H1-
2,H1-
5,H2AC8,H2AZ1,H2BC
5,H2BC3,CDK1,CDC6,
CDC20,LEF1,TOP2A,T
P53,MAD2L1,HELLS
NUSAP1,ERCC2,HJUR
P,MCM2,MCM3,MCM
4,MCM5,MCM6,MCM


medRxiv preprint doi: https://doi.org/10.1101/2020.12.22.20248756; this version posted December 26, 2020. The copyright holder for this preprint (which was not certified by peer review) is the author/funder, who has granted medRxiv a license to display the preprint in perpetuity. All rights reserved. No reuse allowed without permission.

GO:0006325

BP chromatin
organization

nuclear division

$1.01 \mathrm{E}-17 \quad 3.70 \mathrm{E}-15 \quad 3.42 \mathrm{E}-14 \quad 5.92 \mathrm{E}-14$

GO:0000280
GO:0051301 cell division

2.40E-17 8.29E-15 7.67E-14 $1.41 \mathrm{E}-13$
7. $\mathrm{H} 4 \mathrm{C} 9, \mathrm{H} 2 \mathrm{BC} 8, \mathrm{H} 2 \mathrm{BCl}$ 3,H2BC14,H2BC7,H2B C6, H2BC9, H2BC10, H3 $\mathrm{C} 1, \mathrm{H} 3 \mathrm{C} 3, \mathrm{H} 3 \mathrm{C} 6, \mathrm{H} 3 \mathrm{C} 11$, $\mathrm{H} 3 \mathrm{C} 8, \mathrm{H} 3 \mathrm{C} 12, \mathrm{H} 3 \mathrm{C} 10, \mathrm{H}$ $3 \mathrm{C} 2, \mathrm{H} 4 \mathrm{C} 4, \mathrm{H} 4 \mathrm{C} 2, \mathrm{H} 4 \mathrm{C} 5$, H4C13,H4C14,MACRO H2A2,ASF1B,CENPI, INS2,NAP1L1,CENPK, GINS1,NCAPG,NCAP D2,H3C7,RFC3,NCAP H,CCNB1,HMGA2,H1$2, \mathrm{H} 1-$

5, $\mathrm{H} 2 \mathrm{BC} 5, \mathrm{H} 2 \mathrm{BC} 3, \mathrm{CDK} 1$ ,TOP2A,TP53,HELLS HDAC11,HJURP,MCM 2,CHEK1,H4C9,NPM3, H2AC15,H2AC16, H2A $\mathrm{C} 6, \mathrm{H} 2 \mathrm{AC} 4, \mathrm{H} 2 \mathrm{AC} 17, \mathrm{H} 2$ AC20,H2BC8,H2BC13, $\mathrm{H} 2 \mathrm{BC} 14, \mathrm{H} 2 \mathrm{BC} 7, \mathrm{H} 2 \mathrm{BC}$ $6, \mathrm{H} 2 \mathrm{BC} 9, \mathrm{H} 2 \mathrm{BC} 10, \mathrm{H} 3 \mathrm{C}$ $1, \mathrm{H} 3 \mathrm{C} 3, \mathrm{H} 3 \mathrm{C} 6, \mathrm{H} 3 \mathrm{C} 11, \mathrm{H}$ $3 \mathrm{C} 8, \mathrm{H} 3 \mathrm{C} 12, \mathrm{H} 3 \mathrm{C} 10, \mathrm{H} 3$ $\mathrm{C} 2, \mathrm{H} 4 \mathrm{C} 4, \mathrm{H} 4 \mathrm{C} 2, \mathrm{H} 4 \mathrm{C} 5$, $\mathrm{H} 4 \mathrm{C} 13, \mathrm{H} 4 \mathrm{C} 14, \mathrm{MKI} 67$, MACROH2A2,H2AC12 ,SUPT3H,H2AC21,USP 21,ASF1B,TET1,PRKA A2,CENPI,UHRF1,PRK D1,PCGF2,NAP1L1,CE NPK,SMYD2,AURKA, EHMT2,H3C7,H2AC11 ,CCNA2,CCNB1,HMG A2,TRIM28,H1-2,H15,H2AC8,H2AZ1,H2BC 5,H2BC3,CDK1,LEF1, TP53, HELLS

NUSAP1,CDKN3,KIF1

8A,PTTG1,ERCC2,PD GFRB,CENPF,SPC25, MCM2,MCM3,MCM4, MCM5,MCM6,MCM7, CHEK1,MND1,RRM2, SGO1,TTK,TUBG1,TY MS,DACT1,NDC80,AN LN,MKI67,ASPM,PLK 1,FOXM1,TICRR,POL E2,DTL,MSH2,STIL, X RCC2,SKP2,PRIM1,TP X2,RACGAP1,PLK4,M YBL2,KNTC1,DLGAP 5,PBK,NUF2,STOX1,S MOC2,MELK,CENPK, GINS1,SPDL1,AURKA BMP4,NCAPG,EHMT 2,BUB1,NCAPD2,KIF1 1,KIFC1,CACNB4,E2F 5,PRC1,NCAPH,ECT2, CCNA2,CCNB1, CCND 2,KIF20A,HMGA2,CC NB2,CDK1,CKAP2,AR HGEF2,SKA3,CDC6,C DC20,CDC25C,SKA1, T OP2A,CDH13,TP53,M AD2L1,CDK4,CDK6 NUSAP1,PTTG1,ERCC 2,CENPF,SPC25,MDK, SGO1,FBLN1,NDC80, ZNRF3,ANLN,ASPM,P LK1,FERMT1,SPC24,T PX2,CD24,RACGAP1, KNTC1,NUF2,STOX1, RNF43,SPDL1,CDCA2, AURKA,BMP4,NCAP 
medRxiv preprint doi: https://doi.org/10.1101/2020.12.22.20248756; this version posted December 26, 2020. The copyright holder for this preprint (which was not certified by peer review) is the author/funder, who has granted medRxiv a license to display the preprint in perpetuity. All rights reserved. No reuse allowed without permission.

GO:0007049

BP

cell cycle

$9.50 \mathrm{E}-16$
$2.94 \mathrm{E}-13 \quad 2.72 \mathrm{E}-12 \quad 5.58 \mathrm{E}-12$

$58 \mathrm{E}-12$

GO:0006259

DNA metabolic process
3.27E-11 $\quad 6.00 \mathrm{E}-09 \quad 5.55 \mathrm{E}-08 \quad 1.92 \mathrm{E}-07$ (
63

(1)

\begin{abstract}
G,BUB1,NCAPD2,KIF 11,KIFC1,PARD3B,PR C1,FIGN,NCAPH,ECT 2,CCNA2,CCNB1,CCN D2,KIF20A,TGFB2,HM GA2,CCNB2,CD34,CD K1,CKAP2,ARHGEF2, SKA3,CDC6,CDC20,C DC25C,SKA1,EPCAM, LEF1,TOP2A,TP53,MA D2L1,CDK4,CDK6,HE
\end{abstract} LLS

NUSAP1,CDKN3,KIF1 GFRB,CENPF,HJURP, SPC25,MCM2,MCM3, MCM4,MCM5,MCM6, MCM7,CHEK1,MND1, RRM2,WDR76,SGO1, T TK,TUBG1,AXIN2,TY MS,DACT1,NDC80,AN LN,MKI67,ASPM,PLK 1,FOXM1,TICRR,WFS 1,POLE2,DTL,MSH2,S TIL,XRCC2,SKP2,SPC 24,PRIM1,PRKAA2,TP X2,RACGAP1,UHRF1, PRR11,MAPK13,PLK4, MYBL2,KNTC1,PCGF 2,PCLAF,BEX1,DLGA P5,PBK,NUF2,STOX1, SMOC2,MELK,CENPK ,GINS1,SPDL1,CDCA2 ,AURKA,BMP4,NCAP G,EHMT2,BUB1,NCA PD2,RHNO1,KIF11,KI FC1,CACNB4,PARD3B ,E2F5,RFC3,PRC1,FIG N,NCAPH,ECT2,CCN A2,CCNB1,CCND2,KI F20A,TGFB2, HMGA2, CBX5,CCNB2,FANCI, CDK1,CKAP2,ARHGE F2,SKA3,CDC6,CDC20 ,CDC25C,SKA1,LEF1, TOP2A,CDH13,TP53, MAD2L1,CDK4,CDK6, HELLS

PTTG1,ERCC2,PDGFR B,CENPF,MCM2,MCM 3,MCM4,MCM5,MCM 6,MCM7,CHEK1,MEG 3,MND1,RRM2,H4C9, AXIN2,TNFSF4,TYMS ,H4C4,H4C2, $\mathrm{H} 4 \mathrm{C} 5, \mathrm{H} 4$ C13,H4C14,NYNRIN,F OXM1,TICRR,POLE2, DTL,MSH2,XRCC2,RA D51AP1,UBE2T,PRIM 1,TET1,UHRF1,GINS2, PCLAF,NAP1L1,STOX 1,SMOC2, GINS1,EHM T2,PARPBP,RHNO1,K PNA2,MMS22L,RFC3, FIGN,TERC,CCNA2,H MGA2,TRIM28,FANCI ,H1-2,H1-

5,ALYREF,NEIL3,CD K1,CDC6,LEF1,TOP2A ,TP53, HELLS

NUSAP1,CDKN3,PTT G1,ERCC2,PDGFRB,C ENPF,CHEK1,RRM2, WDR76,TTK,TUBG1,A XIN2,DACT1,NDC80, 
medRxiv preprint doi: https://doi.org/10.1101/2020.12.22.20248756; this version posted December 26, 2020. The copyright holder for this preprint (which was not certified by peer review) is the author/funder, who has granted medRxiv a license to display the preprint in perpetuity. All rights reserved. No reuse allowed without permission.

GO:0009790

GO:0042127

BP

regulation of cell population proliferation
$1.53 \mathrm{E}-06 \quad 7.36 \mathrm{E}-05 \quad 6.81 \mathrm{E}-04 \quad 8.98 \mathrm{E}-03$

(n)

ANLN,MKI67,ASPM,P LK1,FOXM1,TICRR,W FS1,DTL,MSH2,STIL,S KP2,PRKAA2,TPX2,R ACGAP1,PRR11,PLK4, MYBL2,KNTC1,PCGF 2,PCLAF,DLGAP5,ST OX1,SMOC2,SPDL1,A URKA,BMP4,EHMT2, BUB1,RHNO1, KIF11,C ACNB4,E2F5,PRC1,EC T2,CCNA2,CCNB1, CC ND2, KIF20A,TGFB2,H MGA2,CBX5,CCNB2, CDK1,CDC6,CDC20,C DC25C,LEF1,TOP2A,T P53,MAD2L1,CDK4,C DK6

EPHB2,PCSK5,ERCC2, PDGFRB,CHEK1,MEG 3,AXIN2,ACSL4,DAC T1,MFAP2,SALL2,HS6 ST1,PGAP1,PLCG1,M MP2,COL1 A1,COL2A ,SEMA3C,FRAS1,TBX 4,FLVCR1,MSH2,STIL, XRCC2,CRABP2,NKD 1,DKK1,ASF1B,FRZB, TET1,ENAH,RACGAP 1,PLK4,MYCN,PCGF2, GJB6,DLK1,ITGA2,PS PH,STOX1,GINS1,PTK 7,BMP4,FREM2,GJA5, GPC3,GNA12,DLX5,S TRA6,CDON,KRT19,S OBP,TDGF1,CCNB1,T GFB2,HMGA2,HEY1,T RIM28,CCNB2,LRP4,C DK1,LEF1,TOP2A,TP5

CDKN3,PTTG1,PDGF RB,ENPP3,ETV4,CHE K1,LDOC1,MDK,TTK, SLC7A11,AXIN2,TNFS F4,H2AC6,H2AC4,FBL N1,SERPINE2,ASPM,P LAG1,BAMBI,PLCG1, MMP2,XCL1,FOXM1, SFRP4,MAGED1,FER MT1,LGR5,SKP2,ZAP7 0,FRZB,TET1,CD24,U HRF1,PRKD1,MYCN, GJB6,SQLE,NAP1L1,D LK1,NDN,ITGA2,STO X1,SMYD2,BMP4,GSD ME,PTPN14,GPC3,FGF 20,ODAM,DLX5,CCN3 ,CDON,CACNB4,LAM C1,TDGF1,SLC39A10, PRC1,CCNA2,CCNB1, CCND2,TGFB2,GSTP1 ,HMGA2,CDCA7,HEY 1,H2AC8,ROBO1,REG 3A,CDK1,ARHGEF2,C DC6,CDC20,EPCAM,L EF1,CDH13,TP53,CDK 4,CDK6

GO:0034622 BP cellular proteincontaining complex

6.07E-06 2.48E-04 2.29E-03 3.57E-02

56

ERCC2,CENPF,RPS5,H

JURP,MCM2,MCM3,M

$$
\text { assembly }
$$

CM4,MCM5,MCM6,M CM7,RPS27,H4C9,TUB $\mathrm{G} 1, \mathrm{H} 2 \mathrm{BC} 8, \mathrm{H} 2 \mathrm{BC} 13, \mathrm{H} 2$ $\mathrm{BC} 14, \mathrm{H} 2 \mathrm{BC} 7, \mathrm{H} 2 \mathrm{BC} 6, \mathrm{H}$ 2BC9, $\mathrm{H} 2 \mathrm{BC} 10, \mathrm{H} 3 \mathrm{C} 1, \mathrm{H}$ $3 \mathrm{C} 3, \mathrm{H} 3 \mathrm{C} 6, \mathrm{H} 3 \mathrm{C} 11, \mathrm{H} 3 \mathrm{C}$ 
medRxiv preprint doi: https://doi.org/10.1101/2020.12.22.20248756; this version posted December 26, 2020. The copyright holder for this preprint (which was not certified by peer review) is the author/funder, who has granted medRxiv a license to display the preprint in perpetuity.

All rights reserved. No reuse allowed without permission.

GO:0048699

BP

generation of neurons

9.91E-0

3.75E-04 3.47E-03 5.82E-02

DNA packaging

complex

GO:0098687

CC

chromosomal region

5.59E-20

$6.10 \mathrm{E}-17$

$3.48 \mathrm{E}-17$

45

GO:0005819

$\mathrm{CC}$

spindle

$1.29 \mathrm{E}-10$

8.95E-
8, $\mathrm{H} 3 \mathrm{C} 12, \mathrm{H} 3 \mathrm{C} 10, \mathrm{H} 3 \mathrm{C} 2$ H4C4,ANLN,H4C2,H4

C5,PIK3R2,H4C13,H4C

14,MACROH2A2,TICR

R,FMOD,ASF1B,PRKA

A2,CENPI,LSM2,SNRP

B,NAP1L1,CENPK,RH OBTB1,SV2A,H3C7,T

ERC,GSN,H1-2,H1-

5,H2BC5,H2BC3,TP53, HELLS

70

EPHB2,PCP4,PRTG,ER CC2,ETV1,ETV4,BCL 1A,MDK,NREP,RNF15 7,ACSL4,DACT1,SERP INE2,NRXN3,SERPINI 1,HS6ST1,ASPM,PLA G1,PLCG1,MME,MMP 2,MAP4K4,SEMA3C,D CDC2,ZSWIM5,XRCC 2,CRABP2,USP21,NK D1,DKK1,TMEM98,EN AH,CD24,RACGAP1,P RKD1,MYCN,RELN,S PP1,NAP1 L1,ITGA6,N DN,GFRA3,PTK7,AUR KA,BMP4,GSDME,EH MT2,FGF20,ITM2C,DL X5,SDK1,CDON,ARH GEF28,NRCAM,LAMC 1,ECT2,TGFB2,EFNA4 ,HMGA2,THY1,HEY1, LRP4,ROBO1,CDK1,A RHGEF2,CDC20,LEF1, CDH11,TP53,CDK6 H4C $9, \mathrm{H} 2 \mathrm{AC} 15, \mathrm{H} 2 \mathrm{AC} 1$ 6,H2AC6,H2AC4,H2A C17,H2AC20,H2BC8,H 2BC13,H2BC14,H2BC7 ,H2BC6,H2BC9,H2BC 0,H3C1,H3C3,H3C6,H3 $\mathrm{C} 11, \mathrm{H} 3 \mathrm{C} 8, \mathrm{H} 3 \mathrm{C} 12, \mathrm{H} 3 \mathrm{C}$ 10,H3C2,H4C4,H4C2,H 4C5,H4C13,H4C14,MA $\mathrm{CROH} 2 \mathrm{~A} 2, \mathrm{H} 2 \mathrm{AC} 12, \mathrm{H} 2$ AC21,NCAPG,NCAPD 2,H3C7,H2AC11, NCAP $\mathrm{H}, \mathrm{H} 1-2, \mathrm{H} 1-$

5,H2AC8,H2AZ1,H2BC 5,H2BC3

KIF18A,CENPF,HJURP ,SPC25,MCM2,MCM3, MCM4,MCM5,MCM6, MCM7,CHEK1,SGO1, H4C9,TTK,NDC80,H4 C4,H4C2,H4C5,H4C 13 , H4C14,MKI67,MACRO H2A2,PLK1, MSH2,SP C24,CENPI,KNTC1,NU F2,CENPK,SPDL1,AU

RKA,NCAPG,BUB1,N CAPD2,DYNC1I1,TER C,CCNB1,CBX5,H2BC 3,ALYREF,CDK1,SKA 3,SKA1,MAD2L1,HEL LS

NUSAP1,KIF18A,ERC C2,CENPF,SGO1,TTK, TUBG1,ASPM,PLK1,D CDC2,TPX2,RACGAP1 ,KNTC1,DLGAP5,SPD L1,AURKA,DYNC1I1, KIF11,KIFC1,PRC1,EC T2,CCNB1,KIF20A,CK AP2L,CDK1,CKAP2,A 
medRxiv preprint doi: https://doi.org/10.1101/2020.12.22.20248756; this version posted December 26, 2020. The copyright holder for this preprint (which was not certified by peer review) is the author/funder, who has granted medRxiv a license to display the preprint in perpetuity. All rights reserved. No reuse allowed without permission.

\begin{tabular}{|c|c|c|c|c|c|c|c|c|}
\hline \multirow{4}{*}{ GO:0062023 } & \multirow[b]{3}{*}{$\mathrm{CC}$} & \multirow{4}{*}{$\begin{array}{l}\text { collagen-containing } \\
\text { extracellular matrix }\end{array}$} & \multirow[b]{3}{*}{$2.79 \mathrm{E}-09$} & \multirow[b]{3}{*}{$1.16 \mathrm{E}-07$} & \multirow[b]{3}{*}{$8.13 \mathrm{E}-07$} & \multirow[b]{3}{*}{$1.74 \mathrm{E}-06$} & \multirow[b]{3}{*}{35} & \\
\hline & & & & & & & & CDC20,SKA1,MAD2L1 \\
\hline & & & & & & & & $\begin{array}{l}\text { CTSC,MATN3,MDK,C } \\
\text { OLEC12 MFAP2 MFG }\end{array}$ \\
\hline & & & & & & & & E8,FBLN1,SERPINE2, \\
\hline & & & & & & & & PKM,SPARCL1,MMP2 \\
\hline & & & & & & & & ,COL1A $1, \mathrm{COL} 1 \mathrm{~A} 2, \mathrm{CO}$ \\
\hline & & & & & & & & L2A1,COL4A1,SEMA3 \\
\hline & & & & & & & & C,FRAS1,COL15A1,F \\
\hline & & & & & & & & MOD,VCAN,RELN,IT \\
\hline & & & & & & & & GA6,SMOC2,FREM1,F \\
\hline & & & & & & & & REM2,GPC $3, \mathrm{CCN} 3, \mathrm{CD}$ \\
\hline & & & & & & & & ON,NPNT,LAMC1,EDI \\
\hline & & & & & & & & L3,TGFB2,LTBP2,BCA \\
\hline & & & & & & & & M,CDH13 \\
\hline GO:0015630 & $\mathrm{CC}$ & microtubule & $3.88 \mathrm{E}-05$ & 8.07E-04 & $5.66 \mathrm{E}-03$ & $2.42 \mathrm{E}-02$ & 56 & NUSAP1,KIF18A,ERC \\
\hline & & cytoskeleton & & & & & & C2,CENPF,CTSC,MCM \\
\hline & & & & & & & & 2,MCM3,CHEK1,PFK \\
\hline & & & & & & & & M,SGO1,TTK,TUBG1, \\
\hline & & & & & & & & AXIN2,NDC80,ASPM, \\
\hline & & & & & & & & PLK1,DCDC2,DTL,STI \\
\hline & & & & & & & & L,XRCC2,SLC1A4,TTL \\
\hline & & & & & & & & L4,DNAH17,TPX2,RA \\
\hline & & & & & & & & CGAP1,PLK4,KNTC1, \\
\hline & & & & & & & & PCLAF,DLGAP5,NDN, \\
\hline & & & & & & & & STOX1,DNAH14,SPDL \\
\hline & & & & & & & & 1,AURKA,MAP7D2,D \\
\hline & & & & & & & & YNC1I1,KIF11,KIFC1, \\
\hline & & & & & & & & PRC1,FIGN,ECT2,CCN \\
\hline & & & & & & & & B1,KIF20A,CCDC $88 \mathrm{C}$, \\
\hline & & & & & & & & CCNB2,CKAP2L,CDK \\
\hline & & & & & & & & 1,CKAP2,ARHGEF2,S \\
\hline & & & & & & & & KA3,CDC6,CDC20,SK \\
\hline & & & & & & & & $\mathrm{A} 1, \mathrm{TOP} 2 \mathrm{~A}, \mathrm{MAD} 2 \mathrm{~L} 1, \mathrm{C}$ \\
\hline & & & & & & & & DK6 \\
\hline GO:0000790 & $\mathrm{CC}$ & nuclear chromatin & $4.61 \mathrm{E}-03$ & 4.87E-02 & $3.42 \mathrm{E}-01$ & $1.00 \mathrm{E}+00$ & 63 & PTTG1,FOXQ1,ETV1, \\
\hline & & & & & & & & ETV4,BCL11A,H4C9,H \\
\hline & & & & & & & & $2 \mathrm{AC} 15, \mathrm{H} 2 \mathrm{AC} 16, \mathrm{H} 2 \mathrm{AC}$ \\
\hline & & & & & & & & $6, \mathrm{H} 2 \mathrm{AC} 4, \mathrm{H} 2 \mathrm{AC} 17, \mathrm{ZNF}$ \\
\hline & & & & & & & & 610,H2AC20,SALL2,H \\
\hline & & & & & & & & $3 \mathrm{C} 1, \mathrm{H} 3 \mathrm{C} 3, \mathrm{H} 3 \mathrm{C} 6, \mathrm{H} 3 \mathrm{C} 1$ \\
\hline & & & & & & & & $1, \mathrm{H} 3 \mathrm{C} 8, \mathrm{H} 3 \mathrm{C} 12, \mathrm{H} 3 \mathrm{C} 10$ \\
\hline & & & & & & & & $\mathrm{H} 3 \mathrm{C} 2, \mathrm{H} 4 \mathrm{C} 4, \mathrm{H} 4 \mathrm{C} 2, \mathrm{H} 4 \mathrm{C}$ \\
\hline & & & & & & & & $5, \mathrm{H} 4 \mathrm{C} 13, \mathrm{H} 4 \mathrm{C} 14, \mathrm{PLAG}$ \\
\hline & & & & & & & & 1,PLAGL2,MACROH2 \\
\hline & & & & & & & & $\mathrm{A} 2, \mathrm{H} 2 \mathrm{AC} 12, \mathrm{FOXM} 1, \mathrm{~T}$ \\
\hline & & & & & & & & BX4,H2AC21,ZNF711, \\
\hline & & & & & & & & RAD51AP1,ASF1B,TE \\
\hline & & & & & & & & T1,UHRF1,PLK4,MYB \\
\hline & & & & & & & & L2,MYCN,PCGF2,ND \\
\hline & & & & & & & & N,ZNF362,EHMT2,TO \\
\hline & & & & & & & & $\mathrm{X} 3, \mathrm{DLX} 5, \mathrm{H} 3 \mathrm{C} 7, \mathrm{H} 2 \mathrm{AC}$ \\
\hline & & & & & & & & 11,E2F5,HMGA2,HEY \\
\hline & & & & & & & & 1,TRIM28,CBX5,ZNF3 \\
\hline & & & & & & & & 82,H1-2,H1- \\
\hline & & & & & & & & 5,H2AC8,H2AZ1,LEF1, \\
\hline & & & & & & & & ZMYM3,TP53 \\
\hline GO:0099081 & $\mathrm{CC}$ & supramolecular & $4.80 \mathrm{E}-03$ & 4.95E-02 & $3.47 \mathrm{E}-01$ & $1.00 \mathrm{E}+00$ & 52 & PCP4,NUSAP1,KIF18A \\
\hline & & polymer & & & & & & ,CENPF,TRPC1,ACTG \\
\hline & & & & & & & & 2, PFKM,SLC7A11,TU \\
\hline & & & & & & & & BG1,MFAP2,FBLN1,A \\
\hline & & & & & & & & SPM,MME,MMP2,PLK \\
\hline & & & & & & & & $1, \mathrm{SOAT} 2, \mathrm{COL} 1 \mathrm{~A} 1, \mathrm{CO}$ \\
\hline & & & & & & & & L1 A2,COL2A1, COL4A \\
\hline & & & & & & & & 1,DCDC2,MYH7B,SLC \\
\hline & & & & & & & & 1A4,SLC2A1,IGF2BP1, \\
\hline & & & & & & & & TTLL4,DNAH17,ENA \\
\hline & & & & & & & & H,TPX2,CD24,RACGA \\
\hline & & & & & & & & P1,KNTC1,ITGA6,DN \\
\hline & & & & & & & & AH14,AURKA,ODAM, \\
\hline & & & & & & & & KCNJ10,GNA12,DYNC \\
\hline & & & & & & & & 1I1,KIF11,KIFC1,NPN \\
\hline & & & & & & & & T.DPEP1.KRT19.PRC1, \\
\hline & & & & & & & & FIGN KIF20A CDK1 C \\
\hline & & & & & & & & KAP2,ARHGEF2,SKA3 \\
\hline
\end{tabular}


medRxiv preprint doi: https://doi.org/10.1101/2020.12.22.20248756; this version posted December 26, 2020. The copyright holder for this preprint (which was not certified by peer review) is the author/funder, who has granted medRxiv a license to display the preprint in perpetuity. All rights reserved. No reuse allowed without permission.

\begin{tabular}{|c|c|c|c|c|c|c|c|c|}
\hline GO:0005887 & $\mathrm{CC}$ & $\begin{array}{l}\text { integral component } \\
\text { of plasma membrane }\end{array}$ & $3.45 \mathrm{E}-02$ & $2.09 \mathrm{E}-01$ & $\begin{array}{c}1.00 \mathrm{E}+0 \\
0\end{array}$ & $1.00 \mathrm{E}+00$ & 52 & $\begin{array}{c}\text {,SKA1 } \\
\text { EPHB2,TSPAN18,TMC } \\
\text { 7,APCDD1,PDGFRB,A } \\
\text { SIC1,TRPC1,TNFSF4, } \\
\text { MEP1A,NRXN3,ZNRF } \\
\text { 3,HS6ST1,FADS2,MM } \\
\text { E,SEMA3C,HTR1D,DP } \\
\text { P10,HTR4,FLVCR1,IG } \\
\text { DCC3,LGR5,SLC1A4,S } \\
\text { LC1A5,SLC2A1,SLC6 } \\
\text { A11,SLCO2A1,ATP1A } \\
\text { 2,SLC22A11,ITGA6,IT } \\
\text { GA2,PLPPR1,RNF43,S } \\
\text { LC16A12,PTK7,GJA5, } \\
\text { GPC3,KCNJ5,KCNJ10, } \\
\text { STRA6,CDON,NPNT,N } \\
\text { RCAM,RHBG,MPZL1, } \\
\text { SLC39A10,SLC7A6,OL } \\
\text { R1,TSPAN5,THY1,CD } \\
\text { 34,ROBO1,BCAM }\end{array}$ \\
\hline GO:0099513 & $\mathrm{CC}$ & $\begin{array}{c}\text { polymeric } \\
\text { cytoskeletal fiber }\end{array}$ & $5.72 \mathrm{E}-02$ & $2.72 \mathrm{E}-01$ & $\begin{array}{c}1.00 \mathrm{E}+0 \\
0\end{array}$ & $1.00 \mathrm{E}+00$ & 40 & $\begin{array}{c}\text { PCP4,NUSAP1,KIF18A } \\
\text {,CENPF,ACTG2,PFKM } \\
\text {,SLC7A11,TUBG1,ASP } \\
\text { M,MME,PLK1,SOAT2, } \\
\text { DCDC2,SLC1A4,IGF2 } \\
\text { BP1,TTLL4,DNAH17,E } \\
\text { NAH,TPX2,CD24,RAC } \\
\text { GAP1,KNTC1,ITGA6, } \\
\text { DNAH14,AURKA,KC } \\
\text { NJ10,GNA12,DYNC1I1 } \\
\text {,KIF11,KIFC1,DPEP1, } \\
\text { KRT19,PRC1,FIGN,KI } \\
\text { F20A,CDK1,CKAP2,A } \\
\text { RHGEF2,SKA3,SKA1 }\end{array}$ \\
\hline GO:1902494 & $\mathrm{CC}$ & catalytic complex & $2.23 \mathrm{E}-01$ & $5.44 \mathrm{E}-01$ & $\begin{array}{c}1.00 \mathrm{E}+0 \\
0\end{array}$ & $1.00 \mathrm{E}+00$ & 41 & $\begin{array}{c}\text { HDAC11,ERCC2,MCM } \\
\text { 3,PFKM,RRM2,PIK3R2 } \\
\text {,PKM,SUPT3H,DCDC2 } \\
\text {,WFS1,ZSWIM5,POLE } \\
\text { 2,DTL,SKP2,NKD1,PRI } \\
\text { M1,DNAH17,PRKAA2, } \\
\text { LSM2,SNRPB,PCGF2, } \\
\text { DNAH14,GPD1L,GNA } \\
\text { 12,GNG4,DYNC1I1,P4 } \\
\text { HA2,PIGU,TERC,PAPS } \\
\text { S1,CCNA2,CCNB1,CC } \\
\text { ND2,CBX5,CCNB2,AL } \\
\text { YREF,CDK1,CDC20,T } \\
\text { P53,CDK4,CDK6 }\end{array}$ \\
\hline GO:0008301 & MF & $\begin{array}{l}\text { DNA binding, } \\
\text { bending }\end{array}$ & $8.46 \mathrm{E}-27$ & $8.98 \mathrm{E}-24$ & $6.78 \mathrm{E}-23$ & $8.98 \mathrm{E}-24$ & 44 & $\begin{array}{c}\text { NUSAP1,HJURP,MCM } \\
\text { 2,H4C9,H2BC8,H2BC1 } \\
\text { 3,H2BC14,H2BC7,H2B } \\
\text { C6,H2BC9,H2BC10,H3 } \\
\text { C1,H3C3,H3C6,H3C11, } \\
\text { H3C8,H3C12,H3C10,H } \\
\text { 3C2,H4C4,H4C2,H4C5, } \\
\text { H4C13,H4C14,MACRO } \\
\text { H2A2,ASF1B,CENPI,N } \\
\text { AP1L1,CENPK,NCAP } \\
\text { G,NCAPD2,H3C7,NCA } \\
\text { PH,CCNB1,HMGA2,H } \\
\text { 1-2,H1- } \\
\text { 5,H2BC5,H2BC3,CDK1 } \\
\text {,LEF1,TOP2A,TP53,HE } \\
\text { LLS }\end{array}$ \\
\hline GO:0046983 & MF & $\begin{array}{l}\text { protein dimerization } \\
\text { activity }\end{array}$ & $5.56 \mathrm{E}-09$ & $1.48 \mathrm{E}-06$ & $1.11 \mathrm{E}-05$ & $5.90 \mathrm{E}-06$ & 74 & $\begin{array}{c}\text { CENPF,BCL11 A,PFKM } \\
\text {,RRM2,H4C9,TTK,TY } \\
\text { MS,H2AC15,H2AC16, } \\
\text { H2AC6,H2AC4,H2AC1 } \\
\text { 7,H2AC20,H2BC8,H2B } \\
\text { C13,H2BC14,H2BC7,H } \\
\text { 2BC6,H2BC9,H2BC10, } \\
\text { H3Cl,H3C3,H3C6,H3C } \\
\text { 11,H3C } 8, \mathrm{H} 3 \mathrm{C} 12, \mathrm{H} 3 \mathrm{C} 10 \\
\text {,H3C2,H4C4,H4C2,H4 } \\
\text { C5,PIK3R2,H4C13,H4C }\end{array}$ \\
\hline
\end{tabular}


medRxiv preprint doi: https://doi.org/10.1101/2020.12.22.20248756; this version posted December 26, 2020. The copyright holder for this preprint (which was not certified by peer review) is the author/funder, who has granted medRxiv a license to display the preprint in perpetuity. All rights reserved. No reuse allowed without permission.

GO:0032559

MF

adenylribonucleotide binding

GO:0008144

MF

drug binding

$1.06 \mathrm{E}-0$

4.68E-03 3.53E-02 $1.12 \mathrm{E}-01$

GO:0044877

\begin{abstract}
MF
\end{abstract}
protein-containing complex binding
14,MACROH2A2,MME ,XCL1,H2AC12,SUPT3 H,UXS1,OLFML2B,TP 53I3,H2AC21, MSH2,HI F1AN,MYCN,PLVAP,I TGA2,PSPH,GPD1L,A URKA,BMP4,TOX3,C DON,H3C7,H2AC11,E 2F5,PAPSS1,ECT2,GS TA4,TGFB2,OXCT1,H EY1,CBX5,H2AC8,LR $\mathrm{P} 4, \mathrm{H} 2 \mathrm{AZ} 1, \mathrm{H} 2 \mathrm{BC} 5, \mathrm{H} 2 \mathrm{~B}$ C3,TOP2A,CDH11,CD H13,TP53,MAD2L1 EPHB2,KIF18A,ERCC2 PDGFRB,ACLY,ACT G2,MCM2,MCM3,MC M4,MCM5,MCM6,MC M7,CHEK1,HUNK,PF KM,TTK,CKB,ACSL4, MKI67,PKM,PLK1,MA

P4K4,SOAT2,TRIB2,M YH7B,MSH2,XRCC2,Z AP70,UBE2T,TTLL4,D NAH17,PRKAA2,AAC S,PRKD1,ATP1A2,MA PK13,PLK4,PBK,MEL K,DNAH14,PTK7,AUR KA, KCNJ10,BUB1,AL DH18A1,ITM2C,MPPE D2,KIF11,KIFC1,CAD FIGN,PAPSS1,ATP8B2 ,KIF20A,EIF4A2,DGK K,CDK1,CDC6,TOP2A, TP53,CDK4,CDK6,HE LLS

67

EPHB2,KIF18A,ERCC2 ,PDGFRB,ACLY,ACT G2,MCM2,MCM3,MC M4,MCM5,MCM6,MC M7,CHEK1,HUNK,PF KM,TTK,CKB,TYMS, ACSL4,MKI67,PKM,P LK1,MAP4K4,FKBP10, TRIB2,MYH7B,MSH2, XRCC2,HIF1AN,ZAP7 0,UBE2T,TTLL4,DNA H17,PRKAA2,AACS,P RKD1,ATP1A2,MAPK 13,PLK4,PBK,MELK,D NAH14,PTK7,AURKA, LYPD1,KCNJ10,BUB1, ALDH18A1,ITM2C,MP PED2, KIF11, KIFC1,CA D,FIGN,PAPSS1,ATP8 B2,KIF20A,GSTP1,EIF 4A2,DGKK,CDK1,CD C6,TOP2A,TP53,CDK4 ,CDK6, HELLS

EPHB2,PTTG1,AMER1

,CENPF,TTK,COLEC 1 2,MFAP2,MFGE8,FBL N1,SALL2,H3C1,H3C3, H3C6,H3C11,H3C $8, \mathrm{H} 3$ $\mathrm{C} 12, \mathrm{H} 3 \mathrm{C} 10, \mathrm{H} 3 \mathrm{C} 2, \mathrm{PKM}$ SPARCL1,PLCG1,PLK 1,WFS1,MYH7B,FER MT1,MSH2,UHRF1,SN RPB,SPP1,ITGA6,NUF 2,ITGA2,SPDL1,GNA1 2,CCN3,NPNT,H3C7,K RT19,TERC,EDIL3,OL R1,GSN,CCNB1,HMG A2,THY1,CBX5,H12,H1- 
medRxiv preprint doi: https://doi.org/10.1101/2020.12.22.20248756; this version posted December 26, 2020. The copyright holder for this preprint (which was not certified by peer review) is the author/funder, who has granted medRxiv a license to display the preprint in perpetuity.

All rights reserved. No reuse allowed without permission.

\begin{tabular}{|c|c|c|c|}
\hline GO:0032555 & $\mathrm{MI}$ & $\begin{array}{c}\text { purine ribonucleotide } \\
\text { binding }\end{array}$ & 3.43E-04 \\
\hline
\end{tabular}

GO:0016772 MF

GO:0042802

MF

identical protein binding transferase activity,
transferring phosphorus-

containing groups
69

$1.49 \mathrm{E}-03 \quad 3.44 \mathrm{E}-02 \quad 2.60 \mathrm{E}-01 \quad 1.00 \mathrm{E}+00$

64

3.30E-03 6.27E-02 4.73E-01 $1.00 \mathrm{E}+00$
5,H2AZ1,CDC20,EPCA M,CDH13,TP53,CDK4 EPHB2,KIF18A,ERCC2 PDGFRB,ACLY,ACT G2,MCM2,MCM3,MC M4,MCM5,MCM6,MC M7,CHEK1,HUNK,PF KM,TTK,TUBG1,CKB, ACSL4,MKI67,PKM,P LK1,MAP4K4,SOAT2, TRIB2,MYH7B,MSH2, XRCC2,ZAP70,UBE2T, TTLL4,DNAH17,PRKA A2,AACS,RASL11B,P RKD1,ATP1A2,MAPK 13,PLK4,PBK,MELK,D NAH14,PTK7,AURKA, RHOBTB1,KCNJ10,BU B1,ALDH18A1,GNA12 ,ITM2C,MPPED2,KIF1 1,KIFC1,CAD,FIGN,PA PSS1,ATP8B2,KIF20A, TGFB2,RAB34,EIF4A2 ,DGKK,CDK1,CDC6,T OP2A,TP53,CDK4,CD K6,HELLS

EPHB2,PCP4,CDKN3, ERCC2,PDGFRB,CHE K1,HUNK,PFKM,TTK, AXIN2,CKB,PIK3R2,P KM,PLK1,MAP4K4,TR IB2,MAGED1,POLE2,S TIL,ZAP70,DKK1,PRI M1,PRKAA2,TPX2,CD 24,PRKD1,MAPK13,PL K4,RELN,PBK,STOX1, MELK,PTK7,AURKA, BMP4,BUB1,ALDH18 A1,CAD,DUSP9,TDGF 1,RFC3,TERC,PAPSS 1 ECT2,CCNA2,CCNB1, CCND2,TGFB2,GSTP1 ,EFNA4,HMGA2,THY1 ,TRIM28,CCNB2,EIF4 A2,DGKK,ROBO1,CD K1,CDC6,CDC25C,TO P2A,TP53,CDK4,CDK6 EPHB2,APCDD1,CENP F,CTSC,HJURP,MCM6 ,PFKM,RRM2,TTK,TU BG1,TYMS,FBLN1,H2 $\mathrm{BC} 8, \mathrm{H} 2 \mathrm{BC} 7, \mathrm{H} 2 \mathrm{BC} 6, \mathrm{H} 2$ BC10,NDC80,PKM,M ME,PLK1,XCL1,COL1 A1,COL1A2,COL2A1, UXS1,MAGED1,OLFM L2B,TP53I3,MSH2,STI L,SKP2,HIF1AN,SLC2 A1,UHRF1,PRKD1,PL K4,PLVAP,PSPH,GPD

1L,BMP4,KCNJ10,TO X3,NQO1,PYCR1,ALD H18A1,SDK1,CAD,PR C1,PAPSS1,ST8SIA3,E CT2,OLR1,GSTA4,TG FB2,OXCT1,HEY1,CB X5,LRP4,ROBO1,REG 3A,LYZ,TOP2A,CDH1 1,CDH13,TP53,MAD2L 1

FOXQ1,ETV1,ETV4,M CM2,MCM3,MCM4,M CM5,MCM6,MCM7,B CL11A,MND1,SALL2, PLAG1,MACROH2A2, 
medRxiv preprint doi: https://doi.org/10.1101/2020.12.22.20248756; this version posted December 26, 2020. The copyright holder for this preprint (which was not certified by peer review) is the author/funder, who has granted medRxiv a license to display the preprint in perpetuity.

All rights reserved. No reuse allowed without permission.

GO:0017111

MF

nucleosidetriphosphataseactivit
FOXM1,TBX4,MSH2,Z NF711,RAD51AP1,UH RF1,MYBL2,MYCN,N DN,STOX1,EHMT2,TO X3,DLX5,ZNF704,HM GA2,HEY1,H1-2,H15,H2AZ1,NEIL3,CDC6, LEF1,TP53

KIF18A,ERCC2,MCM2 ,MCM3,MCM4,MCM5, MCM6,MCM7,TUBG1, XCL1,MAP4K4,MYH7 B,DEPDC1,MSH2,XRC C2,DNAH17,RACGAP 1,UHRF1,GINS2,RASL 11B,ATP1 A2,DEPDC1 B,ITGA6,ARHGAP11 A ,GINS1,DNAH14,RHO BTB1,ODAM,GNA12, GNG4,DYNC1I1,KIF1 1 ,KIFC1,RFC3,FIGN,NC APH,ECT2,KIF20A,RA B34,THY1,EIF4A2,TO P2A,TP53,HELLS

Biological Process(BP), Cellular Component(CC) and Molecular Functions (MF)

Table 6 The enriched GO terms of the down regulated differentially expressed genes

\begin{tabular}{cccccccc}
\hline GO ID & CATEGORY & GO Name & P Value & $\begin{array}{c}\text { FDR } \\
\text { B\&H }\end{array}$ & $\begin{array}{c}\text { FDR } \\
\text { B\&Y }\end{array}$ & $\begin{array}{c}\text { Bonferroni } \\
\text { Gene } \\
\text { Count }\end{array}$ \\
\hline GO:0006082 & BP & $\begin{array}{c}\text { organic acid } \\
\text { metabolic process }\end{array}$ & $6.40 \mathrm{E}-63$ & $3.69 \mathrm{E}-59$ & $3.40 \mathrm{E}-58$ & $3.69 \mathrm{E}-59$ & 145
\end{tabular}


medRxiv preprint doi: https://doi.org/10.1101/2020.12.22.20248756; this version posted December 26, 2020. The copyright holder for this preprint (which was not certified by peer review) is the author/funder, who has granted medRxiv a license to display the preprint in perpetuity. All rights reserved. No reuse allowed without permission.

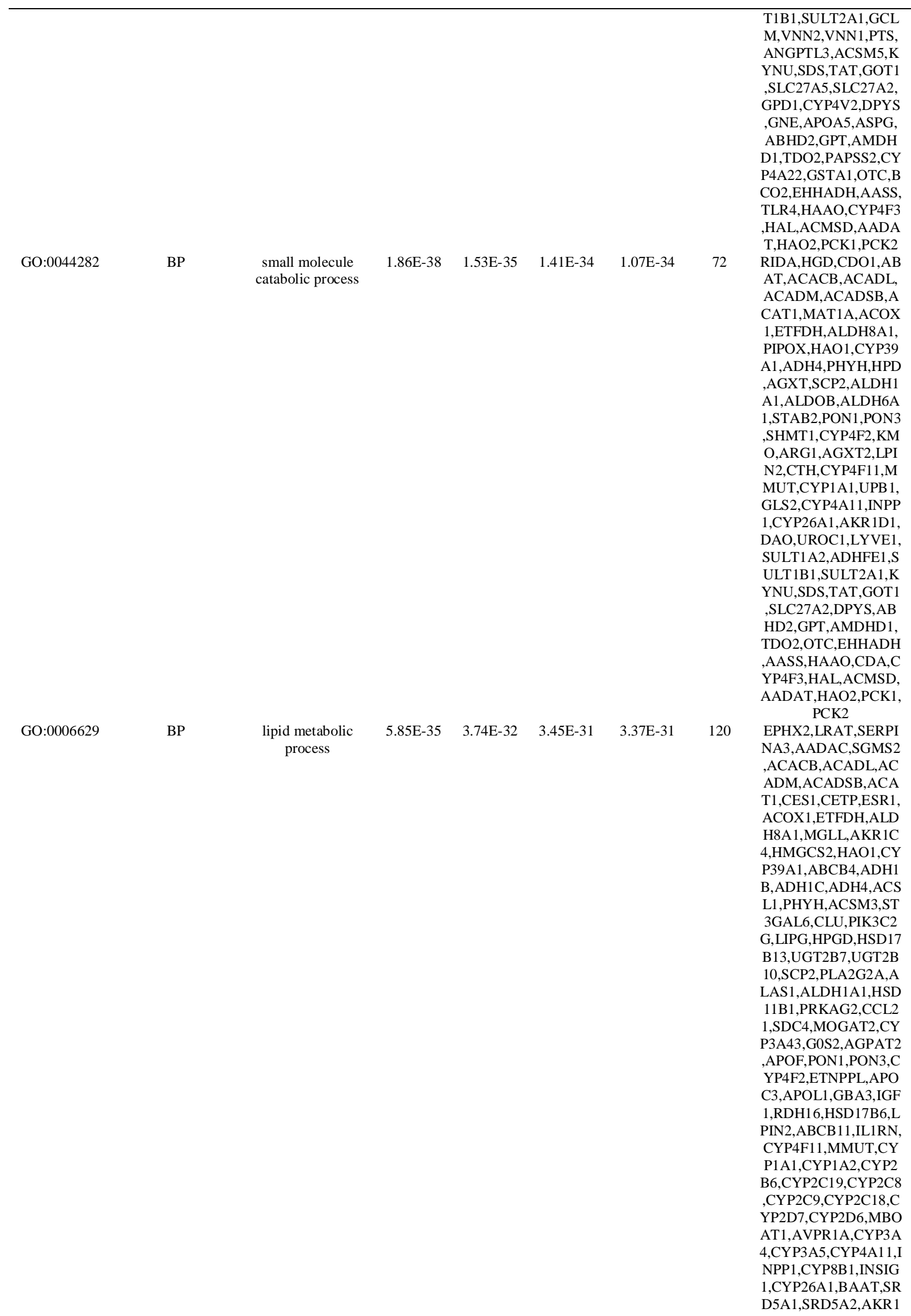


medRxiv preprint doi: https://doi.org/10.1101/2020.12.22.20248756; this version posted December 26, 2020. The copyright holder for this preprint (which was not certified by peer review) is the author/funder, who has granted medRxiv a license to display the preprint in perpetuity. All rights reserved. No reuse allowed without permission.

GO:0055114

BP

oxidationreduction process
$5.06 \mathrm{E}-34 \quad 2.91 \mathrm{E}-31 \quad 2.69 \mathrm{E}-30 \quad 2.91 \mathrm{E}-30$

\begin{abstract}
D1,PTGS2,SOCS2,PP ARGC1A,SULT1A2,S ULT1B1,SULT2A1, A NGPTL3,ACSM5,SLC 27A5,SLC27A2,GPD CYP4V2,GPLD1,AP OA5,ASPG,ABHD2,S OCS3,GPAT3,AKR1C 8P,MAP7,CYP4A22, STA1,MFSD2A,THRS P,BCO2,EGR1,EHHA DH,LPA,CES3,CYP4F 3,HAO2,PCK1,PCK2, SEC14L2
\end{abstract}

HGD,CDO1,ACACB, ACADL,ACADM,AC ADSB,ACAT1,ESR1, ACOX1,LRRK2,ETF DH,ALDH8A1,PIPOX ,AKR1C4,PFKFB1,H AO1,CYP39A1,F8,AD H1B,ADH1C,ADH4,P HYH,FBP1,HP,HPD, H PGD,AGL,HSD17B13 ,UGP2,SCP2,CYP4X1, ALDH1 A1,HSD11B 1, PRKAG2,ALDOB,DH TKD1,BBOX1,ALDH 6A1,ASPDH,DMGDH STAB2,FMO3,FMO4, CYP4Z1,CYP3A43, A OX1,IYD,XDH,CP,C YP4F2,KMO,PPP1R1 A,IGF1,RDH16,AKR7 L,HSD17B6,OGDHL CYP4F22,CYP4F11,S OD2,CYP1A1,CYP1A 2,CYP2B6,CYP2C19, CYP2C8,CYP2C9,CY P2C18,CYP2D7,CYP2 D6,CYP3A4,CYP3A5, CYP4A11,CYP8B1,C YP26A1,SRD5A1,SR D5A2,AKR1D1,DAO, GCH1,GCKR,GNMT, SUCLG2,PTGS2,PPA RGC1A,ADHFE1,GL RX,DHODH,DIO1,SL C27A2,GPD1,CYP4V 2,SLC25A18,PPP1R3 B,STEAP4,AKR1C8P. TDO2,CYP4A22,GST A1,BCO2,EHHADH, AASS,GYS2,STEAP3, HAAO,CYP4F3,NNT, $\mathrm{HAO} 2, \mathrm{PCK} 2$ CFH,EPHX2,HGF,CD O1,SERPINA3,ESR1, MBL2,LRRK2,BLNK, CLEC1B,MGLL,CFP, C1RL,PGLYRP2,CLE C4M,LEAP2,F8,CD16 3,PLAC8,MAP3K5,S1 00A8,SAA1,SAA2,FC GR2B,CLU,HP,FCN2, HPR,HPX,SCN9A,FG B,PLA2G2A,HRG,CC L16,FGG,CCL21,MR C1,STAB2,FOS,ICAM 1,APCS,BIRC3,COLE C10,APOL1,CFI,FCN 3,CRHBP,ZFP36,CRP, ARG1,SLC7A2,IGF1, ASS1,SLPI,SERPINC 1,HAMP,IL1RN,CTSL 
medRxiv preprint doi: https://doi.org/10.1101/2020.12.22.20248756; this version posted December 26, 2020. The copyright holder for this preprint (which was not certified by peer review) is the author/funder, who has granted medRxiv a license to display the preprint in perpetuity. All rights reserved. No reuse allowed without permission.

GO:0010038 BP

BP

response to lipid

GO:0033993

GO:0051707

BP

response to other organism
$1.57 \mathrm{E}-1$

$16 \quad 2.05 \mathrm{E}-14 \quad 1.89 \mathrm{E}-13$

ion

$1.38 \mathrm{E}-16 \quad 1.85 \mathrm{E}-14 \quad 1.71 \mathrm{E}-13 \quad 7.95 \mathrm{E}-13$
CYP4F11,MARCO,C XCL8,MASP2,MASP1 ,GBP7,GBP2,IRF6,GC H1, CFHR5,PTGS2,ITI H4,CFB,RNF125,VN N1,C1R,C1S,C4BPA, C4BPB,C5,C6,CREB3 L3,C7,C8A,C8B,C8G, C9,KLKB1,KYNU,D NASE1L3,RAB27A,K NG1,SOCS3,NFKBIZ, ABCC9,LBP,ECM1,C XCL2,EDNRB,TFR2, ORM1,NAMPT,CD5L ,CD14,EGR1,TLR4,SE RPINE1,HERC5

CPNE8,ABAT,LRRK2 ,S100A8,FBP1,FGB,H RG,FGG,ALDOB,FOS ,FOSB,ICAM1,XDH,C P,AQP3,CRHBP,CRP, ARG1,SLC6A1,MT1E ,MT1F,MT1G,MT1H, MT1M,MT1X,ASS1,H AMP,CYP1A1,CYP1 A2,GATM,PTGS2,PP ARGC1A,JUNB,MT1 DP,TAT,GOT1,CA2,G PLD1,DUSP1,TFR2,O TC,CD14,HAAO RIDA,LRAT,CDO1,E SR1,PFKFB1,ABCB4, ACSL1,S100A8,CLU, HPGD,AGL, AGXT,N R3C2,FGFR2,CCL21, ALPL,MRC1,FOS,FO SB,ICAM1,PON1,AQ P3,AR,CRHBP,ZFP36, KMO,AKAP12,ARG1, SLC6A1,IGF1,ASS1,S LPI,HAMP,IL1RN,GR AMD1C,CXCL8,CYP 1A1,CYP1A2,AVPR1 A,INSIG1,CYP26A1,S RD5A1,BCHE,GCH1, DCN,PTGS2,GHR,SO CS2,PPARGC1A,JUN B,SULT1A2,GLRX,T AT,NR1I3,GOT1,CA2 ,GPLD1,ABHD2,DUS P1,NR4A2,LBP,MAP7 ,CXCL2,EDNRB,CD1 4,TLR4,SERPINE1,T RIB1,PCK1,PCK2

CFH,LRAT,ESR1,MB L2,CFP,C1RL,PGLYR P2,CLEC4M,LEAP2,L RG1,PLAC8,MAP3K5 ,S100A8,SAA1,FCGR 2B,CLU,HP,FCN2,HP GD,HPX,FGB,PLA2C 2A,HRG,FGFR2,CCL 16,FGG,CCL21,ALPL, MRC1,STAB2,FOS,IC AM1,APCS,BIRC3,C OLEC10,APOL1,CFI, FCN3,ZFP36, KMO,A KAP12,CRP,ARG1,A SS1,SLPI,HAMP,IL1R $\mathrm{N}, \mathrm{CTSL}, \mathrm{MARCO}, \mathrm{CX}$ CL8,MASP2,CYP1A1, CYP1A2,MASP1,GBP 7,GBP2,IRF6, GCH1,C FHR5,DCN,PTGS2,C FB,PPARGC1A,JUNB 
medRxiv preprint doi: https://doi.org/10.1101/2020.12.22.20248756; this version posted December 26, 2020. The copyright holder for this preprint (which was not certified by peer review) is the author/funder, who has granted medRxiv a license to display the preprint in perpetuity. All rights reserved. No reuse allowed without permission.

GO:0019637

GO:0002684

GO:0006811
BP

organophosphate metabolic process
5.20E-13 4.05E-11 3.74E-10 2.99E-09

BP

of immune system process
$2.08 \mathrm{E}-09 \quad 9.96 \mathrm{E}-08 \quad 9.20 \mathrm{E}-07 \quad 1.20 \mathrm{E}-05$
,RNF125,VNN1,C1R, C1S,C4BPA,C4BPB,C 5,C6,C7,C8A,C8B,C8 G,C9,KYNU,RAB27A ,SOCS3,ABCC9,LBP, CXCL2,EDNRB,THR SP,CD14,EGR1,TLR4, SERPINE1,TRIB1,PC K1,HERC5 GLYAT,LRAT,SGMS 2,ACACB,ACADSB, ACAT1,CETP,LRRK2 ,PIPOX,HMGCS2,PF KFB1,ACSL1,ACSM3 ,FBP1,PIK3C2G,LIPG ,UGP2,SCP2,PLA2G2 A,ALDH1 A1,HSD11B 1,PRKAG2,CCL21,AL DOB,DHTKD1,ASPD H,AGPAT2,PON1,SH MT1,XDH,ETNPPL,A POC3, KMO,GDA,IGF 1,LPIN2,OGDHL,MB OAT1,INPP1,BAAT,G CH1,GCKR,SUCLG2, PTGS2,SOCS2,PPAR GC1A,SULT1A2,SUL T1B1,SULT2A1,DHO DH,ANGPTL3,ACSM 5,NNMT,KYNU,GPD 1,GPLD1,APOA5,ASP G,SOCS3,GPAT3,TD O2,PAPSS2,MFSD2A, NAMPT,EHHADH,A ASS,HAAO,CDA,AC MSD,AADAT,PCK1

CFH,CFHR1,CFHR2, ESR1,MBL2,LRRK2, CFP,C1RL,PGLYRP2, S100A8,FCGR2B,CL $\mathrm{U}, \mathrm{FCN} 2, \mathrm{HPX}, \mathrm{FGB}, \mathrm{H}$ RG,FGG,CCL21,FYB 2,FOS,ICAM1,APCS, BIRC3,CXCL14,COL EC10,CFI,FCN3,AQP 3,CRP,ARG1,IGF1,H AMP,CTSL,MARCO CXCL8,MASP2,IL13 RA2,MASP1,TNFSF1 4,CFHR5,CFB,CFHR4 ,RNF125,VNN1,C1R, C1S,C4BPA,C4BPB,C 5,C6,C7,C8A,C8B,C8 G,C9,RAB27A,CA2, G PLD1,NFKBIZ,LBP,C D5L,CD14,TLR4,SER PINE1,TRIB1

ABAT,ACACB,CETP, CLTRN,ANO5,AKR1 C4,ABCA10,ABCA9, ABCA8,ABCB4,ACS L1,SLC41A2,ADRA1 A,AGXT,HPX,SCN9A ,SCP2,PLA2G2A,HR G,FGF14,PRKAG2,C CL21,SLC51A,FXYD 1,ICAM1,CP,MYO1B, CYP4F2,APOC3,APO L1,SLCO1B1,SLC1A1 ,CRHBP,KMO,ARG1, SLC6A1,SLC7A2,IGF 1,SLC10A1,SLC15A1, SLC22A1,ABCB11,H AMP,SLC4A4,IL1RN, ABCC3,SLC22A25,G 
medRxiv preprint doi: https://doi.org/10.1101/2020.12.22.20248756; this version posted December 26, 2020. The copyright holder for this preprint (which was not certified by peer review) is the author/funder, who has granted medRxiv a license to display the preprint in perpetuity. All rights reserved. No reuse allowed without permission.

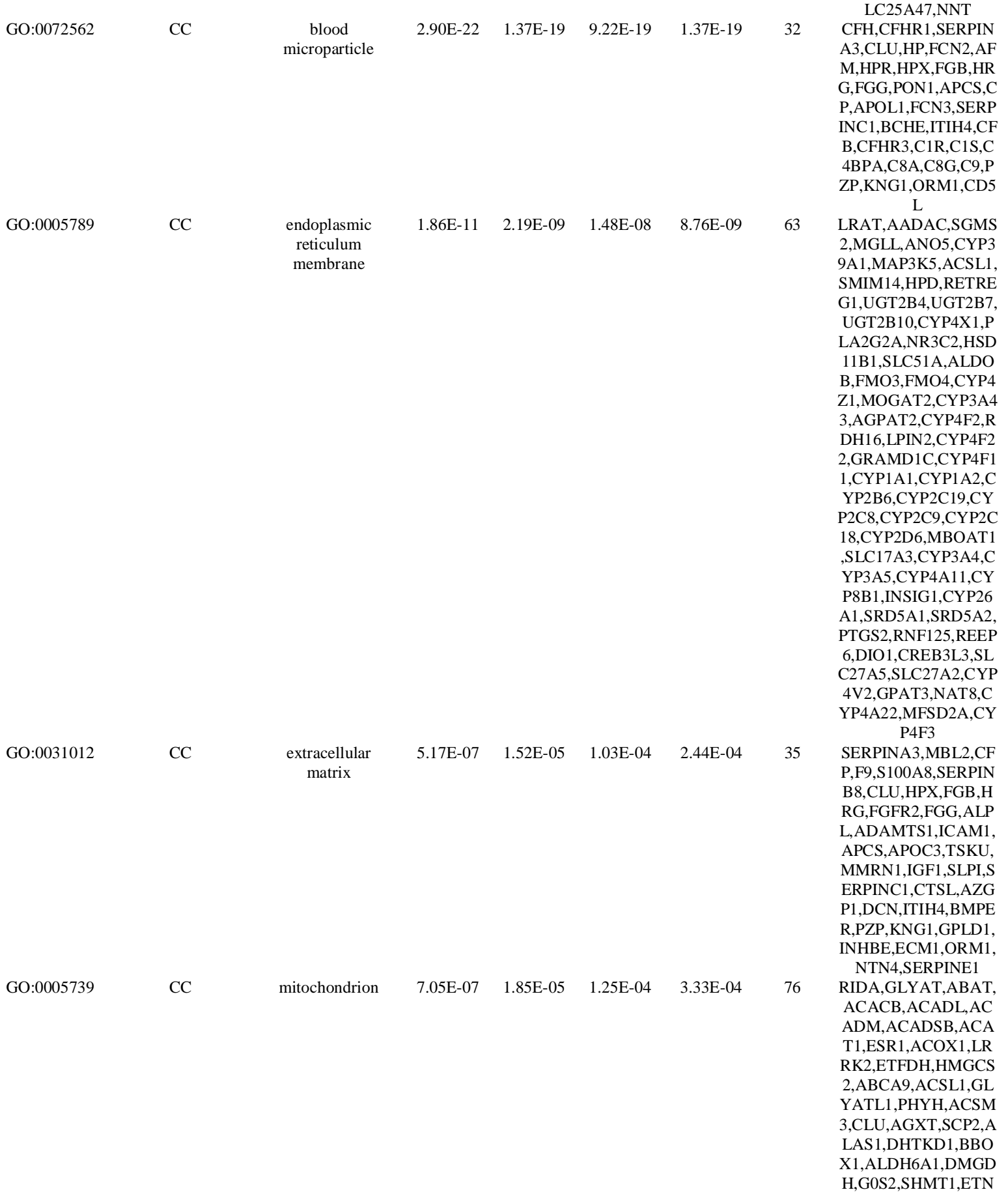


medRxiv preprint doi: https://doi.org/10.1101/2020.12.22.20248756; this version posted December 26, 2020. The copyright holder for this preprint (which was not certified by peer review) is the author/funder, who has granted medRxiv a license to display the preprint in perpetuity. All rights reserved. No reuse allowed without permission.

GO:0031226

GO:0099503

GO:0009986 intrinsic component of plasma membrane
$1.69 \mathrm{E}-04 \quad 3.20 \mathrm{E}-03 \quad 2.15 \mathrm{E}-02 \quad 8.00 \mathrm{E}-02$

$\mathrm{CC}$

$\mathrm{CC}$

CC

cell surface

$2.52 \mathrm{E}-0$

$1.69 \mathrm{E}-0$

0

CC

organelle envelope
8.47E-01
PPL,KMO,ARG1,AG XT2,ASS1,OGDHL,M MUT,SOD2,CYP1A1, CYP2D7,GLS2,CYP2 D6,GATM,DAO,GCK R,SUCLG2,DCN,GHR ,PPARGC1A,ADHFE1 ,GCLM,PTS, GLRX,D HODH,ACSM5,KYN U,SDS,TAT,GOT1,SL C27A2,GPD1,SLC25A 18,ABCC9,RGS2,ECH DC3,OTC,BCO2,EHH ADH,AASS,SLC25A1 5,ANXA10,HAAO,SL C25A47,AADAT,NNT HAO2,PCK1,PCK2 NRG1,SGMS2,CLEC1 B,CLEC4M,CD163,A BCB4,ADRA1 A,PIGR ,FCGR2B,SCN9A,FG FR2,FXYD1,SDC4,HJ V,MRC1,VIPR1,STA B2,ICAM1,IYD,CP,SL ITRK3,SLCO1B 1,AQ P3,SLC1 A1,SLC6A1, SLC7A2,SLC10A1,SL C15A1,SLC22A1,AB CB11,SLC4A4,MARC O,ABCC 3,SLC17A3, AVPR1A,SLCO1B3,S LC22A7,GHR,LYVE1 ,PTPRB,KCND3,C5,C 6,C7,C8A,C8B,C8G,C 9,NPY1R,SLC38A4,S LC17A4,ANO1,ABCC 9,EDNRB,TFR2,SLC O1B7,ADGRG7,LIFR, MFSD2A,HHIP,CD14,

TLR4,TENM1,TMPR SS2,ENPEP

HGF,SERPINA3,LRR

K2,CFP,LRG1,F8,PLA

C8,S100A8,PIGR,CL

U,HP,AGL,FGB,PLA2

G2A,HRG,FGG,AGP

AT2,CDC37L1,CRHB

P,ARG1,MMRN1,IGF 1,SLPI,SPTBN2,ITIH4 ,PTPRB,VNN1,RAB2

7A,KNG1,SLC27A2,N PY1R,ABHD2,ABCC 9,ECM1,ORM1,CD14, SERPINE1,CDA

NRG1,MBL2,CD163, MAP3K5,FCGR2B,CL U,LIPG,FGB,HRG,FG FR2,FGG,SDC4,HJV,

MRC1,STAB2,ICAM1 ,CPM,SLC6A1,IL13R A2,AZGP1,GFRA1,G HR,BMP10,ANGPTL3 ,ADGRA3,ANO1,LBP ,TFR2,LIFR,HHIP,CD 5L,CD14,TLR4,ENPE $P$

ACACB,ACADL,AC ADM,ACAT1,LRRK2 ,ETFDH,HMGCS2,AC SL1,ADRA1 A,CLU,PI K3C2G,SCP2,HSD11 B1,KMO,ARG1,OIT3, ASS1,SOD2,CYP1A1, GATM,DAO,BCHE,G CH1,GLRX,DHODH, 
medRxiv preprint doi: https://doi.org/10.1101/2020.12.22.20248756; this version posted December 26, 2020. The copyright holder for this preprint (which was not certified by peer review) is the author/funder, who has granted medRxiv a license to display the preprint in perpetuity. All rights reserved. No reuse allowed without permission.

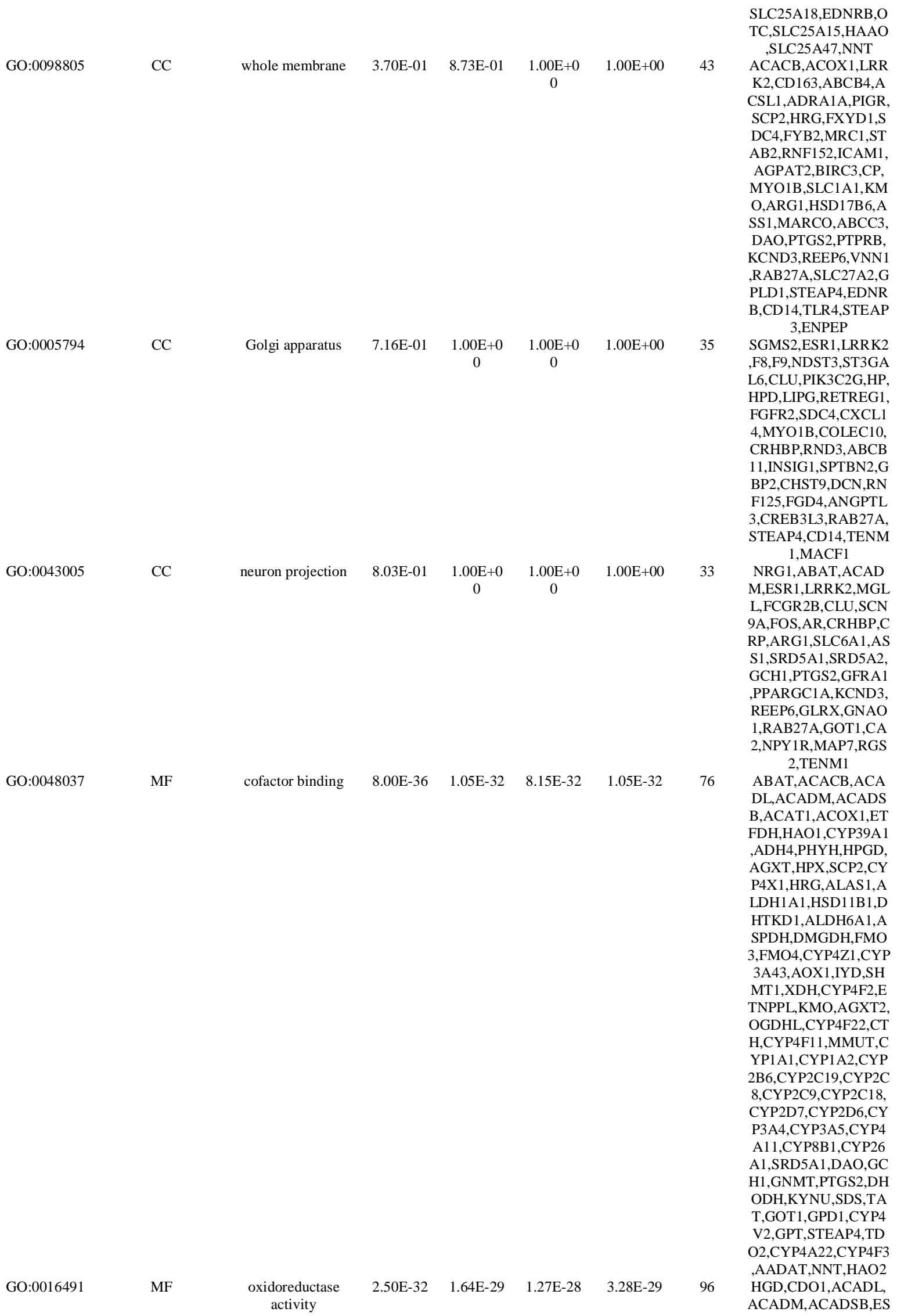


medRxiv preprint doi: https://doi.org/10.1101/2020.12.22.20248756; this version posted December 26, 2020. The copyright holder for this preprint (which was not certified by peer review) is the author/funder, who has granted medRxiv a license to display the preprint in perpetuity. All rights reserved. No reuse allowed without permission.

GO:0050662
R1,ACOX1,LRRK2,E
TFDH,ALDH8A1,PIP
OX,AKR1C4,PFKFB1
,HAO1,CYP39A1,F8,
ADH1B,ADH1C,ADH
4,PHYH,FBP1,HP,HP
D,HPGD,HSD17B13,
CYP4X1,ALDH1A1,H
SD11B1,PRKAG2,AL
DOB,DHTKD1,BBOX
1,ALDH6A1,ASPDH,
DMGDH,STAB2,FM
O3,FMO4,CYP4Z1,C
YP3A43,AOX1,IYD,X
DH,CP,CYP4F2,KMO
,IGF1,RDH16,AKR7L,
HSD17B6,OGDHL,C
YP4F22,CYP4F11,SO
D2,CYP1A1,CYP1A2,
CYP2B6,CYP2C19,C
YP2C8,CYP2C9,CYP
2C18,CYP2D7,CYP2
D6,CYP3A4,CYP3A5,
CYP4A11,CYP8B1,C
YP26A1,SRD5A1,SR
D5A2,AKR1D1,DAO,
GCH1,GCKR,SUCLG
2,PTGS2,PPARGC1A,
ADHFE1,GLRX,DHO
DH,DIO1,GPD1,CYP4
V2,STEAP4,AKR1C8
P,TDO2,CYP4A22,GS
TA1,BCO2,EHHADH,
AASS,STEAP3,HAA
O,CYP4F3,NNT,HAO
ABAT,ACACB,ACA
DB

47

DL,ACADM,ACADS

B,ACAT1,ACOX1,ET

FDH,HAO1,ADH4,PH

YH,HPGD,AGXT,SC

P2,ALAS1, ALDH1A1,

HSD11B1,DHTKD1,A

LDH6A1,ASPDH,DM

GDH,FMO3,FMO4,A

OX1,IYD,SHMT1,XD

H,ETNPPL,KMO,AG

XT2,OGDHL,CTH,SR

D5A1,DAO,GCH1,GN

MT,DHODH,KYNU,S

DS,TAT,GOT1,GPD1,

GPT,STEAP4,AADAT

NNT,HAO2

RIDA,CDO1,ESR1,PG

LYRP2,CYP39A1,F8,

ADH1B,ADH1C,ADH

4,S100A8,PHYH,CYP

4X1,HRG,NR3C2,BB

OX1,PAPPA2,CYP4Z

1,ADAMTS1,CYP3A4

3,AOX1,SHMT1,XDH

,CP,CYP4F2,ZDBF2,C

PM,AR,ARG1,MT1E,

MT1F,GDA,MT1G,M

T1H,MT1M,MT1X,C

YP4F22,HAMP,CYP4

F11,SOD2,CYP1A1,C

YP1A2,CYP2B6,CYP

2C19,UPB1,CYP2C8,

CYP2C9,CYP2C18,C

YP2D7,CYP2D6,CYP

3A4,CYP3A5,CYP4A

11,CYP8B1,CYP26A

,GCH1,BHMT,RNF12

5,TRIM55,NR1I3, KN 
medRxiv preprint doi: https://doi.org/10.1101/2020.12.22.20248756; this version posted December 26, 2020. The copyright holder for this preprint (which was not certified by peer review) is the author/funder, who has granted medRxiv a license to display the preprint in perpetuity.

All rights reserved. No reuse allowed without permission.

GO:0008289

MF

lipid binding

lyase activity

MF

GO:0016829 identical protei
binding

$5.95 \mathrm{E}-0$

$2.00 \mathrm{E}-06 \quad 1.55 \mathrm{E}-05 \quad 7.81 \mathrm{E}-05$

GO:0004175
MF
7.51E-06 $1.70 \mathrm{E}-04 \quad 1.32 \mathrm{E}-03 \quad 9.87 \mathrm{E}-03$ endopeptidase
activity
G1,CA2,CYP4V2,DP

YS,DTX1,NR4A2,CY

P4A22,HHIP,EGR1,H

AAO,CDA,CYP4F3,A

CMSD,ENPEP,PCK1, PCK2

87

EPHX2,CFHR1,RIDA, CFHR2,HGD,HGF,NR

G1,ABAT,ACACB,A

CADM,ACAT1,MAT

A,CLTRN,ESR1,ACO

X1,LRRK2,MGLL,PF

KFB1,F11,MAP3K5,F

BP1,HOOK1,HP,HPG

D,AGXT,UGP2,SCP2,

NR3C2,ALAS1,FGFR

2,FGG,SLC51 A,ALD

OB,BBOX1,SDC4,AO

$\mathrm{X} 1, \mathrm{PON} 1, \mathrm{APCS}, \mathrm{PON}$

3,SHMT 1,XDH,BHLH

E40,CRP,RDH16,SLC

22A1,ASS1,SERPINC

1,CTH,SLC4A4,MMU

T,SOD2,MASP1,UPB

1,MYOM1,TNFSF14,

GBP2,BCHE,GCH1,C

FHR5,GNMT,PTGS2,

GHR,SULT1A2,GAD

D45G,PTS,TRIM55,C

1S,CREB3L3,KYNU,

SDS,GPD1,RCAN1,N

R4A2,ANO1,ABCC9,

TDO2,GREM2,USP2,

NAMPT,THRSP,GYS

2,TLR4,TENM1,STE

AP3,CDA,AADAT,LR RFIP1

RIDA,LRAT,CPNE8, CETP,ESR1,ACOX1,

MBL2,ADH4,S100A8,

PIK3C2G,UGT2B4,U

GT2B7,SCP2,PLA2G2

A,NR3C2,HSD11B1,A

LDOB,SEC14L4,ARA

P2,SHBG,APOF,PON

1,MYO1B,APOC 3 ,AP

OL1,AR,CRP,IGF1,G

RAMD1C,CYP4F11, C

YP3A4,PXDC1,SPTB

N2,CYP26A1,AKR1D

1,VNN1,C8G,APOA5,

LBP,OTC,CD14,TLR4

,ANXA10,APOL6,SE C14L2

PFKFB1,ADRA1A,FB

P1,ALDH1A1,ARRD

C3,PRKAG2,ALDOB

DHTKD1,SHMT1,ET

NPPL,AKAP12,IGF1,

OGDHL,CTH,MARC

O,CYP1A1,GCKR,UR

OC1,PPARGC1A,PTS

,GNAO1,SDS,GOT1,C

A2,GPD1,NPY1R,RG

S2,EDNRB,ADGRG7,

EHHADH,HAL,ACM

SD,PCK1,PCK2

HGF,HGFAC,SERPIN

A3,C1RL,F9,F11,MAP

3K5,S100A8,SERPIN

B8,HP,HPR,HRG,PAP

PA2,PAMR1,ADAMT

S1,XDH,BIRC3,CFI,F

ETUB,SERPINA11,C3

P1,IGF1,SLPI,SERPIN 
medRxiv preprint doi: https://doi.org/10.1101/2020.12.22.20248756; this version posted December 26, 2020. The copyright holder for this preprint (which was not certified by peer review) is the author/funder, who has granted medRxiv a license to display the preprint in perpetuity.

All rights reserved. No reuse allowed without permission.

GO:0046983

MF

protein dimerization activity

$2.79 \mathrm{E}-05 \quad 5.38 \mathrm{E}-04 \quad 4.18 \mathrm{E}-03 \quad 3.66 \mathrm{E}-02$

64

zinc ion binding

MF

GO:0008270
C1,LPAL2,CTSL,MA
SP2,MASP1,TNFSF14
,PTGS2,ITIH4,CFB,C
1R,C1S,C5,PZP,KLK
B1,KNG1,USP2,LPA,
SERPINE1,TMPRSS2,

SERPINE1,TMPR
HABP2

EPHX2,CFHR1,RIDA,

CFHR2,HGF,NRG1,A

BAT,ACAT1,MAT1A,

CLTRN,ACOX1,LRR

K2,MGLL, ANO5,MA

P3K5,ADRA1A,HP,H

PGD,AGXT,SCP2,NR

3C2,FGFR2,FGG,SLC

$51 \mathrm{~A}, \mathrm{FOS}, \mathrm{AOX} 1, \mathrm{PON}$

1,PON3,SHMT1,XDH,

BHLHE40,AR,CRP,R

DH16,SLC22A1,MM

UT,MASP1,UPB1,MY

OM1,DAO,GBP2,GC

H1,CFHR5,SUCLG2,P

TGS2,GHR,SULT1A2

,GCLM,PTS,CREB3L

3,KYNU,SDS,GPD1,N

R4A2,ANO1,GREM2,

NAMPT,THRSP,GYS

2,TLR4,TENM1,CDA,

AADAT,LRRFIP1

ESR1,PGLYRP2,ADH

1B,ADH1C,ADH4,S1

00A8,HRG,NR3C2,B

BOX1,PAPPA2,ADA

MTS1,SHMT1,ZDBF2

,CPM,AR,MT1E,MT1

F,GDA,MT1G,MT1H,

MT1M,MT1X,UPB1,

GCH1,BHMT,RNF125

,TRIM55,NR1I3,KNG

1,CA2,DPYS,DTX1,N

R4A2,HHIP,EGR1,CD

A,ACMSD,ENPEP

Biological Process(BP), Cellular Component(CC) and Molecular Functions (MF)

Table 7 Topology table for up and down regulated genes

\begin{tabular}{|c|c|c|c|c|c|c|}
\hline Regulation & Node & Degree & Betweenness & Stress & Closeness & $\begin{array}{l}\text { Clustering } \\
\text { Coefficient }\end{array}$ \\
\hline $\mathrm{Up}$ & TP53 & 528 & 0.287608 & 69156720 & 0.377953 & 0.001861 \\
\hline $\mathrm{Up}$ & TCTN2 & 209 & 0.087158 & 17425224 & 0.283914 & $4.60 \mathrm{E}-05$ \\
\hline $\mathrm{Up}$ & PLK1 & 171 & 0.075638 & 11941560 & 0.346513 & 0.007044 \\
\hline $\mathrm{Up}$ & AURKA & 141 & 0.056164 & 6895708 & 0.337941 & 0.0049 \\
\hline $\mathrm{Up}$ & CDK1 & 138 & 0.058532 & 10959680 & 0.345207 & 0.01732 \\
\hline Up & ANLN & 137 & 0.048016 & 14980992 & 0.289589 & 0.001073 \\
\hline $\mathrm{Up}$ & CBX5 & 131 & 0.041726 & 6411634 & 0.306394 & 0.004603 \\
\hline Up & SORT1 & 128 & 0.050901 & 6390878 & 0.305958 & 4.92E-04 \\
\hline Up & HDAC11 & 127 & 0.040953 & 9836954 & 0.307423 & $1.25 \mathrm{E}-04$ \\
\hline $\mathrm{Up}$ & PLCG1 & 111 & 0.038331 & 8225866 & 0.290547 & 0.00344 \\
\hline $\mathrm{Up}$ & USP11 & 105 & 0.039087 & 4707940 & 0.317424 & 0.004378 \\
\hline $\mathrm{Up}$ & FOXQ1 & 104 & 0.032233 & 3881566 & 0.309702 & 0.00224 \\
\hline $\mathrm{Up}$ & CDK6 & 102 & 0.028674 & 5160016 & 0.306024 & 0.010707 \\
\hline $\mathrm{Up}$ & TRIM28 & 99 & 0.031277 & 5255050 & 0.324363 & 0.009235 \\
\hline $\mathrm{Up}$ & MCM7 & 96 & 0.027867 & 7236722 & 0.311631 & 0.025852 \\
\hline $\mathrm{Up}$ & CDK4 & 95 & 0.028636 & 6233742 & 0.307269 & 0.013214 \\
\hline $\mathrm{Up}$ & KIF11 & 94 & 0.032768 & 5548692 & 0.301309 & 0.001194 \\
\hline $\mathrm{Up}$ & TUBG1 & 83 & 0.022938 & 9086132 & 0.297107 & 0 \\
\hline $\mathrm{Up}$ & MAGED1 & 83 & 0.029887 & 4261058 & 0.304875 & 0.003395 \\
\hline $\mathrm{Up}$ & EHMT2 & 80 & 0.022876 & 5320996 & 0.290273 & 0.006329 \\
\hline $\mathrm{Up}$ & $\mathrm{CDC} 20$ & 78 & 0.020321 & 3395252 & 0.314892 & 0.028772 \\
\hline $\mathrm{Up}$ & CCNB1 & 76 & 0.016518 & 4768666 & 0.314524 & 0.022807 \\
\hline $\mathrm{Up}$ & STIL & 75 & 0.023122 & 5438820 & 0.291038 & 0.001802 \\
\hline $\mathrm{Up}$ & CCNA2 & 74 & 0.014526 & 3212664 & 0.303713 & 0.027027 \\
\hline $\mathrm{Up}$ & SKP2 & 73 & 0.015565 & 3487514 & 0.30188 & 0.020121 \\
\hline $\mathrm{Up}$ & PRKAA2 & 71 & 0.019643 & 7480336 & 0.281961 & 0 \\
\hline
\end{tabular}


medRxiv preprint doi: https://doi.org/10.1101/2020.12.22.20248756; this version posted December 26, 2020. The copyright holder for this

preprint (which was not certified by peer review) is the author/funder, who has granted medRxiv a license to display the preprint in perpetuity. All rights reserved. No reuse allowed without permission.

\begin{tabular}{|c|c|c|c|c|c|c|}
\hline Up & MCM2 & 70 & 0.016722 & 2962672 & 0.309368 & 0.058385 \\
\hline Up & MME & 68 & 0.023192 & 3877286 & 0.278385 & 0 \\
\hline Up & KPNA2 & 68 & 0.022268 & 5439794 & 0.306547 & 0.001865 \\
\hline Up & LDOC1 & 64 & 0.019593 & 4907268 & 0.271534 & 0 \\
\hline Up & RPS5 & 61 & 0.014909 & 9342932 & 0.260646 & 0 \\
\hline Up & RACGAP1 & 60 & 0.020049 & 2522402 & 0.301162 & 0.00605 \\
\hline $\mathrm{Up}$ & SNRPB & 59 & 0.01543 & 4402074 & 0.26682 & 0 \\
\hline Up & NDC80 & 56 & 0.013808 & 3254894 & 0.290488 & 0.032844 \\
\hline Up & PIK3R2 & 55 & 0.015636 & 3088392 & 0.283334 & 0.005387 \\
\hline Up & PKM & 55 & 0.015741 & 4453604 & 0.283764 & 7.26E-04 \\
\hline Up & PRR11 & 55 & 0.015896 & 4023928 & 0.260851 & 0 \\
\hline Up & FOXM1 & 53 & 0.015703 & 2462790 & 0.300049 & 0.018142 \\
\hline Up & NAP1L1 & 53 & 0.014305 & 3256110 & 0.289842 & 0.002353 \\
\hline Up & PDGFRB & 50 & 0.015539 & 2294394 & 0.284929 & 0.015071 \\
\hline Up & MAD2L1 & 47 & 0.012738 & 1624310 & 0.28885 & 0.010101 \\
\hline Up & MCM6 & 47 & 0.008747 & 1626358 & 0.303007 & 0.09596 \\
\hline Up & TOP2A & 46 & 0.008299 & 1885166 & 0.318812 & 0.030918 \\
\hline Up & HIF1AN & 46 & 0.01434 & 5371702 & 0.257788 & 0 \\
\hline Up & ALYREF & 44 & 0.009885 & 3750706 & 0.274181 & 0 \\
\hline Up & CHEK1 & 43 & 0.010041 & 1532280 & 0.310955 & 0.031008 \\
\hline Up & MCM3 & 43 & 0.007583 & 1452902 & 0.30468 & 0.094131 \\
\hline Up & KRT19 & 42 & 0.008917 & 2818958 & 0.270919 & 0 \\
\hline Up & MCM5 & 42 & 0.007315 & 1817608 & 0.300091 & 0.088269 \\
\hline Up & SGO1 & 42 & 0.007067 & 1569360 & 0.271466 & 0.009292 \\
\hline Up & DLK1 & 40 & 0.013366 & 3561522 & 0.241037 & 0 \\
\hline Up & BUB1 & 39 & 0.011834 & 2045032 & 0.300279 & 0.066066 \\
\hline Up & SKA1 & 39 & 0.010598 & 1481646 & 0.270884 & 0.017544 \\
\hline Up & PTP4A3 & 39 & 0.009211 & 1234758 & 0.281721 & 0.004049 \\
\hline Up & TSPAN5 & 39 & 0.014887 & 1810750 & 0.215765 & 0 \\
\hline Up & EIF4A2 & 39 & 0.0118 & 3675518 & 0.26368 & 0 \\
\hline Up & FANCI & 38 & 0.01309 & 2268286 & 0.297251 & 0.003175 \\
\hline Up & TTK & 38 & 0.008964 & 1445912 & 0.303199 & 0.015873 \\
\hline Up & GSN & 38 & 0.009753 & 3083576 & 0.279761 & 0 \\
\hline Up & MCM4 & 38 & 0.003613 & 955734 & 0.303949 & 0.152381 \\
\hline Up & MSH2 & 37 & 0.007683 & 1252274 & 0.309324 & 0.023529 \\
\hline Up & PCGF2 & 36 & 0.008136 & 1726876 & 0.273623 & 0.008913 \\
\hline Up & NUF2 & 34 & 0.008187 & 1318856 & 0.285629 & 0.069519 \\
\hline Up & CDC6 & 34 & 0.018039 & 2783104 & 0.302453 & 0.092692 \\
\hline Up & LSM2 & 34 & 0.00666 & 1852228 & 0.255994 & 0 \\
\hline Up & ASF1B & 33 & 0.006615 & 885750 & 0.273363 & 0.051136 \\
\hline Up & NDN & 32 & 0.008861 & 1267136 & 0.299694 & 0.02069 \\
\hline Up & MYBL2 & 32 & 0.005504 & 1009282 & 0.276631 & 0.013793 \\
\hline Up & ZAP70 & 32 & 0.006898 & 1145650 & 0.269139 & 0.027586 \\
\hline Up & IMPDH2 & 31 & 0.011486 & 1577314 & 0.292462 & 0.007389 \\
\hline Up & RPS27 & 31 & 0.005015 & 2667206 & 0.267883 & 0 \\
\hline Up & KIF20A & 29 & 0.007456 & 1398776 & 0.266407 & 0 \\
\hline Up & PTTG1 & 29 & 0.005157 & 589460 & 0.302092 & 0.031339 \\
\hline Up & UHRF1 & 29 & 0.005259 & 718940 & 0.301753 & 0.054131 \\
\hline Up & CAD & 29 & 0.006816 & 1259828 & 0.288734 & 0.002849 \\
\hline Up & SKA3 & 29 & 0.007885 & 1032030 & 0.260535 & 0.019704 \\
\hline Up & $\mathrm{CDC} 25 \mathrm{C}$ & 28 & 0.004534 & 733590 & 0.309502 & 0.068783 \\
\hline Up & SPC24 & 28 & 0.004283 & 783166 & 0.272152 & 0.100529 \\
\hline Up & ASPM & 28 & 0.007391 & 793284 & 0.278187 & 0.002646 \\
\hline Up & IGF2BP1 & 27 & 0.005589 & 862628 & 0.303777 & 0.048433 \\
\hline Up & MKI67 & 27 & 0.005123 & 1811602 & 0.276063 & 0 \\
\hline Up & NCAPH & 27 & 0.005462 & 1810694 & 0.26209 & 0.042735 \\
\hline Up & ARHGEF2 & 27 & 0.004835 & 1806136 & 0.277936 & 0 \\
\hline Up & CHGB & 25 & 0.009303 & 3086112 & 0.249551 & 0 \\
\hline Up & GSTP1 & 25 & 0.005588 & 1318884 & 0.258858 & 0 \\
\hline Up & PTPN14 & 25 & 0.005648 & 1010004 & 0.275322 & 0.006667 \\
\hline Up & SPC 25 & 24 & 0.002981 & 454108 & 0.26588 & 0.115942 \\
\hline Up & PRKD1 & 24 & 0.006094 & 1195410 & 0.265634 & 0 \\
\hline Up & BCL11A & 23 & 0.007557 & 826802 & 0.272083 & 0.007905 \\
\hline Up & ENAH & 23 & 0.005446 & 1405796 & 0.258905 & 0 \\
\hline Up & HELLS & 23 & 0.006398 & 1979584 & 0.286447 & 0 \\
\hline Up & SLC1A5 & 22 & 0.005961 & 845672 & 0.250948 & 0 \\
\hline Up & MAP4K4 & 22 & 0.005098 & 1055904 & 0.251785 & 0 \\
\hline Up & MAGED2 & 22 & 0.006949 & 864750 & 0.306002 & 0.017316 \\
\hline Up & CKB & 22 & 0.00433 & 1320042 & 0.261184 & 0 \\
\hline Up & KIF18A & 22 & 0.004953 & 979638 & 0.263148 & 0 \\
\hline Up & CKAP2 & 22 & 0.002002 & 820372 & 0.26588 & 0 \\
\hline Up & USP21 & 22 & 0.004655 & 1264612 & 0.249363 & 0 \\
\hline Up & ECT2 & 21 & 0.006747 & 746722 & 0.282832 & 0.02381 \\
\hline Up & DTL & 21 & 0.003192 & 400558 & 0.289277 & 0.057143 \\
\hline Up & TPX2 & 21 & 0.008379 & 1105552 & 0.295191 & 0.019048 \\
\hline
\end{tabular}


medRxiv preprint doi: https://doi.org/10.1101/2020.12.22.20248756; this version posted December 26, 2020. The copyright holder for this preprint (which was not certified by peer review) is the author/funder, who has granted medRxiv a license to display the preprint in perpetuity. All rights reserved. No reuse allowed without permission.

\begin{tabular}{|c|c|c|c|c|c|c|}
\hline Up & RRM2 & 21 & 0.010534 & 1434776 & 0.302156 & 0.038095 \\
\hline Up & PBK & 21 & 0.007725 & 885496 & 0.296554 & 0.015789 \\
\hline Up & LEF1 & 21 & 0.00414 & 1231474 & 0.254059 & 0 \\
\hline Up & PLK4 & 20 & 0.003849 & 921766 & 0.256482 & 0 \\
\hline Up & ACSL4 & 20 & 0.006802 & 897134 & 0.264963 & 0 \\
\hline Up & CCNB2 & 20 & 0.003758 & 481048 & 0.291511 & 0.078947 \\
\hline Up & ERCC2 & 20 & 0.004405 & 504734 & 0.283465 & 0.03268 \\
\hline Up & MMP2 & 20 & 0.007281 & 1225236 & 0.238248 & 0 \\
\hline Up & FBLN1 & 20 & 0.00745 & 1280400 & 0.263842 & 0 \\
\hline Up & RFC3 & 20 & 0.004242 & 1731726 & 0.269831 & 0 \\
\hline Up & ZMYM3 & 20 & 0.004768 & 704720 & 0.283185 & 0.005263 \\
\hline Up & CENPF & 20 & 0.002317 & 623860 & 0.263745 & 0 \\
\hline Up & ASPSCR1 & 20 & 0.004978 & 1417058 & 0.255189 & 0 \\
\hline Up & SUPT3H & 19 & 0.0041 & 1404600 & 0.252449 & 0 \\
\hline Up & B3GALNT1 & 19 & 0.01109 & 1445772 & 0.234126 & 0 \\
\hline Up & TDGF1 & 19 & 0.006333 & 635088 & 0.239641 & 0 \\
\hline Up & UBE2T & 19 & 0.004524 & 1151644 & 0.242546 & 0 \\
\hline Up & PTK7 & 19 & 0.005354 & 1427068 & 0.248484 & 0 \\
\hline Up & $\mathrm{RCN} 2$ & 19 & 0.006145 & 871978 & 0.275763 & 0 \\
\hline Up & COL1A2 & 18 & 0.004321 & 719206 & 0.224993 & 0 \\
\hline Up & NCAPD2 & 18 & 0.00186 & 791970 & 0.25989 & 0.098039 \\
\hline Up & NETO2 & 18 & 0.004464 & 807100 & 0.241118 & 0 \\
\hline Up & SLC2A1 & 17 & 0.003279 & 661710 & 0.260551 & 0 \\
\hline Up & POLE2 & 17 & 0.004219 & 443958 & 0.254962 & 0 \\
\hline Up & ITGA6 & 17 & 0.003751 & 1207838 & 0.223382 & 0 \\
\hline Up & ACLY & 17 & 0.002171 & 567752 & 0.253103 & 0 \\
\hline Up & HJURP & 17 & 0.003582 & 372538 & 0.26302 & 0 \\
\hline Up & IGF2BP2 & 17 & 0.001386 & 429984 & 0.27286 & 0.036765 \\
\hline Up & MYCN & 16 & 0.001753 & 285684 & 0.278692 & 0.016667 \\
\hline Up & MPZL1 & 16 & 0.003685 & 711976 & 0.222377 & 0 \\
\hline Up & PFKM & 16 & 0.003767 & 626168 & 0.262314 & 0.021978 \\
\hline Up & NEIL3 & 16 & 0.004567 & 505440 & 0.246802 & 0 \\
\hline Up & VCAN & 16 & 0.007886 & 998064 & 0.217598 & 0 \\
\hline Up & PYCR1 & 16 & 0.002228 & 798838 & 0.245689 & 0 \\
\hline Up & PCSK5 & 16 & 0.003734 & 932690 & 0.219306 & 0 \\
\hline Up & MYH7B & 15 & 0.003221 & 814324 & 0.242888 & 0 \\
\hline Up & DYNC1I1 & 15 & 0.003495 & 861976 & 0.22807 & 0 \\
\hline Up & PRC1 & 15 & 0.002451 & 278580 & 0.276649 & 0.012821 \\
\hline Up & COL1A1 & 15 & 0.005289 & 966562 & 0.245815 & 0 \\
\hline Up & ITGA2 & 15 & 0.00438 & 515656 & 0.222746 & 0 \\
\hline Up & LAPTM4B & 15 & 0.005051 & 939754 & 0.244711 & 0 \\
\hline Up & SPDL1 & 15 & 0.002573 & 711922 & 0.238182 & 0 \\
\hline Up & LRRC1 & 15 & 0.002879 & 1013596 & 0.257387 & 0 \\
\hline Up & MAPK13 & 14 & 0.004211 & 425542 & 0.256009 & 0.010989 \\
\hline Up & P4HA2 & 14 & 0.003876 & 638982 & 0.230848 & 0 \\
\hline Up & PEG10 & 14 & 0.003542 & 271700 & 0.233465 & 0 \\
\hline Up & LAMC1 & 14 & 0.003325 & 798112 & 0.247769 & 0 \\
\hline Up & CCND2 & 14 & 0.00127 & 213052 & 0.272549 & 0.164835 \\
\hline Up & ETV1 & 14 & 0.002882 & 1218408 & 0.246435 & 0 \\
\hline Up & RNF43 & 14 & 0.003234 & 893136 & 0.234304 & 0 \\
\hline Up & SALL2 & 14 & 0.003952 & 1136004 & 0.224115 & 0 \\
\hline Up & IGF2BP3 & 13 & 0.001409 & 248702 & 0.279979 & 0.076923 \\
\hline Up & NCAPG & 13 & 0.001084 & 252222 & 0.261851 & 0.179487 \\
\hline Up & SPP1 & 13 & 0.003875 & 713040 & 0.23604 & 0 \\
\hline Up & FDFT1 & 13 & 0.003312 & 636316 & 0.232809 & 0 \\
\hline Up & HMGA2 & 13 & 0.001665 & 685268 & 0.253043 & 0 \\
\hline $\mathrm{Up}$ & AXIN2 & 13 & 0.00229 & 429246 & 0.259592 & 0 \\
\hline Up & ARHGAP11A & 13 & $3.56 \mathrm{E}-04$ & 99262 & 0.258299 & 0.128205 \\
\hline Up & EDARADD & 13 & 0.002742 & 818844 & 0.234995 & 0 \\
\hline Up & HEY 1 & 13 & 0.002518 & 584936 & 0.230514 & 0 \\
\hline Up & BEX1 & 13 & 0.002062 & 646290 & 0.244225 & 0 \\
\hline $\mathrm{Up}$ & DUSP9 & 12 & 0.002101 & 350460 & 0.256742 & 0 \\
\hline Up & GNG4 & 12 & 0.003718 & 639784 & 0.233225 & 0 \\
\hline Up & COLEC 12 & 12 & 0.003004 & 404870 & 0.210787 & 0 \\
\hline Up & SLC39A10 & 12 & 0.005085 & 975630 & 0.255979 & 0 \\
\hline Up & XRCC2 & 11 & 0.003654 & 334884 & 0.251476 & 0 \\
\hline Up & DKK1 & 11 & 0.007155 & 1257912 & 0.234088 & 0 \\
\hline Up & AFP & 11 & 0.003854 & 540400 & 0.212893 & 0 \\
\hline Up & SMYD2 & 11 & 0.00134 & 157162 & 0.287096 & 0.127273 \\
\hline Up & EPHB2 & 11 & 0.001153 & 272886 & 0.227419 & 0 \\
\hline Up & PRIM1 & 11 & 0.001689 & 268382 & 0.235214 & 0 \\
\hline Up & ALDH18A1 & 11 & 0.003535 & 782850 & 0.24814 & 0 \\
\hline Up & TARBP1 & 11 & 0.001857 & 334520 & 0.247669 & 0 \\
\hline Up & GREB1 & 11 & 0.001327 & 324158 & 0.237577 & 0 \\
\hline Up & ARL6IP6 & 11 & 0.003702 & 346104 & 0.202694 & 0 \\
\hline
\end{tabular}


medRxiv preprint doi: https://doi.org/10.1101/2020.12.22.20248756; this version posted December 26, 2020. The copyright holder for this preprint (which was not certified by peer review) is the author/funder, who has granted medRxiv a license to display the preprint in perpetuity.

All rights reserved. No reuse allowed without permission.

\begin{tabular}{|c|c|c|c|c|c|c|}
\hline $\mathrm{Up}$ & PIGU & 11 & 0.003891 & 386118 & 0.238803 & 0.018182 \\
\hline $\mathrm{Up}$ & RAD51AP1 & 11 & 0.00271 & 550000 & 0.245717 & 0 \\
\hline $\mathrm{Up}$ & NUSAP1 & 11 & 0.00336 & 680684 & 0.24583 & 0 \\
\hline Up & AMER 1 & 10 & 0.001431 & 205210 & 0.26946 & 0.044444 \\
\hline Up & CDH13 & 10 & 0.002065 & 256868 & 0.265847 & 0.022222 \\
\hline $\mathrm{Up}$ & COL2A1 & 10 & 0.002568 & 462452 & 0.236858 & 0 \\
\hline $\mathrm{Up}$ & BMP4 & 10 & 1 & 56 & 1 & 0 \\
\hline $\mathrm{Up}$ & TRPC1 & 10 & 0.002437 & 988630 & 0.209107 & 0 \\
\hline $\mathrm{Up}$ & KNTC1 & 10 & 0.001471 & 454736 & 0.23456 & 0 \\
\hline Up & SPATS2 & 10 & 0.001382 & 219242 & 0.262202 & 0.022222 \\
\hline Up & CTSC & 10 & 0.001094 & 188744 & 0.241078 & 0 \\
\hline Up & GNA12 & 10 & 0.002149 & 464270 & 0.239468 & 0 \\
\hline Up & CENPK & 10 & 0.002447 & 416858 & 0.23497 & 0 \\
\hline $\mathrm{Up}$ & SULT1C2 & 9 & 0.00194 & 654556 & 0.208106 & 0 \\
\hline $\mathrm{Up}$ & DLX5 & 9 & 0.001033 & 299260 & 0.229751 & 0 \\
\hline Up & KCNJ10 & 9 & 0.002387 & 336046 & 0.226796 & 0 \\
\hline Up & MELK & 9 & 0.001529 & 325500 & 0.239069 & 0 \\
\hline Up & CDCA2 & 9 & $5.74 \mathrm{E}-04$ & 210918 & 0.24492 & 0 \\
\hline Up & WDR76 & 9 & $3.44 \mathrm{E}-04$ & 59928 & 0.261358 & 0 \\
\hline $\mathrm{Up}$ & CACNB4 & 8 & 0.00243 & 243528 & 0.208025 & 0 \\
\hline Up & LRP4 & 8 & 0.001522 & 292854 & 0.213856 & 0 \\
\hline Up & CRABP2 & 8 & 0.001867 & 274362 & 0.214517 & 0 \\
\hline $\mathrm{Up}$ & LYZ & 8 & 0.001026 & 99724 & 0.215333 & 0 \\
\hline Up & DLGAP5 & 8 & $6.45 \mathrm{E}-04$ & 171954 & 0.2537 & 0 \\
\hline Up & TMEM52B & 8 & 0.002631 & 308936 & 0.217334 & 0 \\
\hline $\mathrm{Up}$ & MAP7D2 & 8 & 8.33E-04 & 207316 & 0.237394 & 0 \\
\hline Up & FLVCR1 & 8 & 0.002268 & 285718 & 0.213814 & 0 \\
\hline $\mathrm{Up}$ & DKK3 & 7 & $7.06 \mathrm{E}-04$ & 72378 & 0.261612 & 0 \\
\hline $\mathrm{Up}$ & WIF1 & 7 & 0.002169 & 191832 & 0.255144 & 0 \\
\hline Up & PAPSS1 & 7 & 0.001544 & 124196 & 0.243603 & 0 \\
\hline $\mathrm{Up}$ & EDIL3 & 7 & 0.001513 & 253928 & 0.19215 & 0 \\
\hline $\mathrm{Up}$ & NPM3 & 7 & $5.34 \mathrm{E}-04$ & 138652 & 0.242491 & 0 \\
\hline Up & CST1 & 7 & 0.002256 & 262616 & 0.194424 & 0 \\
\hline $\mathrm{Up}$ & TP53I3 & 7 & 0.002715 & 337624 & 0.277059 & 0 \\
\hline $\mathrm{Up}$ & NQO1 & 7 & $6.68 \mathrm{E}-04$ & 73162 & 0.276952 & 0.2 \\
\hline Up & TYMS & 7 & $1.26 \mathrm{E}-04$ & 21636 & 0.242874 & 0 \\
\hline Up & CDKN3 & 7 & $9.31 \mathrm{E}-04$ & 105560 & 0.263406 & 0.2 \\
\hline $\mathrm{Up}$ & GINS2 & 7 & $6.47 \mathrm{E}-04$ & 88946 & 0.250174 & 0.238095 \\
\hline Up & MMS22L & 7 & $4.22 \mathrm{E}-05$ & 9536 & 0.245032 & 0.333333 \\
\hline $\mathrm{Up}$ & E2F5 & 7 & $9.40 \mathrm{E}-04$ & 364070 & 0.23479 & 0 \\
\hline Up & SFRP4 & 7 & 0.001891 & 317742 & 0.233668 & 0 \\
\hline $\mathrm{Up}$ & RPL22L1 & 7 & 0.001431 & 405904 & 0.219664 & 0 \\
\hline $\mathrm{Up}$ & PLPPR1 & 7 & 1 & 42 & 1 & 0 \\
\hline Up & ZNRF3 & 7 & 0.001731 & 424096 & 0.232005 & 0 \\
\hline $\mathrm{Up}$ & ROBO1 & 7 & 0.001435 & 414538 & 0.244669 & 0 \\
\hline $\mathrm{Up}$ & B3GALT2 & 6 & 0.002323 & 406490 & 0.159607 & 0 \\
\hline Up & PSPH & 6 & $5.18 \mathrm{E}-04$ & 57344 & 0.220237 & 0 \\
\hline Up & MPPED2 & 6 & $9.90 \mathrm{E}-04$ & 190630 & 0.197105 & 0 \\
\hline Up & FRAS1 & 6 & 0.001245 & 137570 & 0.206706 & 0 \\
\hline Up & DEPDC1B & 6 & 0.001624 & 160424 & 0.235678 & 0 \\
\hline $\mathrm{Up}$ & TTYH3 & 6 & 0.00166 & 630234 & 0.189176 & 0 \\
\hline Up & C1orf198 & 6 & 8.32E-04 & 260248 & 0.230329 & 0 \\
\hline $\mathrm{Up}$ & ITM2C & 6 & 0.001059 & 208564 & 0.201839 & 0 \\
\hline $\mathrm{Up}$ & DACT1 & 6 & $9.02 \mathrm{E}-05$ & 25780 & 0.244503 & 0 \\
\hline Up & GSTA4 & 5 & $4.72 \mathrm{E}-04$ & 138274 & 0.169938 & 0 \\
\hline $\mathrm{Up}$ & MATN3 & 5 & $9.66 \mathrm{E}-04$ & 186690 & 0.22201 & 0 \\
\hline $\mathrm{Up}$ & WFS1 & 5 & $7.99 \mathrm{E}-04$ & 107898 & 0.22008 & 0 \\
\hline Up & ETV4 & 5 & $4.45 \mathrm{E}-05$ & 16058 & 0.227035 & 0 \\
\hline Up & GPC3 & 5 & 0.001859 & 666124 & 0.167016 & 0 \\
\hline $\mathrm{Up}$ & SQLE & 5 & 0.001859 & 184220 & 0.207594 & 0 \\
\hline Up & HSDL1 & 5 & 0.00158 & 160992 & 0.209514 & 0 \\
\hline $\mathrm{Up}$ & FAM111B & 5 & $6.47 \mathrm{E}-04$ & 124304 & 0.23405 & 0 \\
\hline Up & FOXRED2 & 5 & 1 & 20 & 1 & 0 \\
\hline Up & TRIB2 & 5 & $6.28 \mathrm{E}-04$ & 156636 & 0.230972 & 0 \\
\hline $\mathrm{Up}$ & KIFC1 & 5 & $5.19 \mathrm{E}-05$ & 12126 & 0.230798 & 0 \\
\hline $\mathrm{Up}$ & PLVAP & 5 & 0.001505 & 198580 & 0.165398 & 0 \\
\hline $\mathrm{Up}$ & OLFML3 & 5 & 0.001493 & 196160 & 0.214581 & 0 \\
\hline $\mathrm{Up}$ & BCL9 & 4 & 0.001394 & 220608 & 0.221325 & 0 \\
\hline Up & GSDME & 4 & $8.47 \mathrm{E}-04$ & 184994 & 0.245605 & 0 \\
\hline $\mathrm{Up}$ & COL4A1 & 4 & $5.26 \mathrm{E}-04$ & 88308 & 0.231955 & 0 \\
\hline $\mathrm{Up}$ & SERPINE2 & 4 & 1 & 12 & 1 & 0 \\
\hline Up & RNASE1 & 4 & $1.07 \mathrm{E}-05$ & 2770 & 0.224243 & 0 \\
\hline Up & RBP1 & 4 & $6.21 \mathrm{E}-04$ & 100188 & 0.220057 & 0 \\
\hline $\mathrm{Up}$ & DPEP1 & 4 & $2.90 \mathrm{E}-05$ & 4032 & 0.205257 & 0 \\
\hline $\mathrm{Up}$ & GJA5 & 4 & $9.50 \mathrm{E}-04$ & 105410 & 0.194214 & 0 \\
\hline
\end{tabular}


medRxiv preprint doi: https://doi.org/10.1101/2020.12.22.20248756; this version posted December 26, 2020. The copyright holder for this preprint (which was not certified by peer review) is the author/funder, who has granted medRxiv a license to display the preprint in perpetuity. All rights reserved. No reuse allowed without permission.

\begin{tabular}{|c|c|c|c|c|c|c|}
\hline Up & PCP4 & 4 & $4.01 \mathrm{E}-05$ & 8288 & 0.209708 & 0 \\
\hline Up & ATP1A2 & 4 & 0.001394 & 129822 & 0.196709 & 0 \\
\hline Up & EFNA4 & 4 & 1 & 12 & 1 & 0 \\
\hline Up & OLR1 & 4 & $2.30 \mathrm{E}-07$ & 150 & 0.226712 & 0 \\
\hline Up & ATP8B2 & 4 & $9.67 \mathrm{E}-04$ & 180506 & 0.169757 & 0 \\
\hline Up & HTR4 & 4 & 1 & 2 & 1 & 0 \\
\hline Up & GINS1 & 4 & $3.50 \mathrm{E}-07$ & 20 & 0.205374 & 0.333333 \\
\hline Up & LIN28B & 4 & $9.36 \mathrm{E}-04$ & 175832 & 0.190685 & 0 \\
\hline Up & PGAP1 & 4 & 7.77E-04 & 140244 & 0.197195 & 0 \\
\hline Up & TRIM59 & 4 & 1 & 12 & 1 & 0 \\
\hline Up & DPP10 & 4 & 1 & 2 & 1 & 0 \\
\hline Up & GLMP & 4 & $8.52 \mathrm{E}-04$ & 140094 & 0.201933 & 0 \\
\hline Up & CENPI & 4 & $1.07 \mathrm{E}-04$ & 29502 & 0.2122 & 0 \\
\hline Up & ERP27 & 4 & $1.98 \mathrm{E}-04$ & 31920 & 0.207814 & 0 \\
\hline $\mathrm{Up}$ & ZC3HAV1L & 4 & $5.14 \mathrm{E}-04$ & 126094 & 0.250073 & 0 \\
\hline Up & GPX7 & 4 & $5.27 \mathrm{E}-04$ & 61242 & 0.195689 & 0 \\
\hline Up & RHNO1 & 4 & $1.40 \mathrm{E}-04$ & 39418 & 0.237237 & 0 \\
\hline Up & NRSN2 & 4 & 0.001394 & 205464 & 0.177487 & 0 \\
\hline Up & DCDC2 & 4 & $9.93 \mathrm{E}-04$ & 201082 & 0.236871 & 0 \\
\hline Up & GPD1L & 4 & $9.46 \mathrm{E}-04$ & 123600 & 0.19814 & 0 \\
\hline Up & NKD1 & 4 & $8.31 \mathrm{E}-05$ & 17768 & 0.236507 & 0 \\
\hline Up & HS6ST1 & 3 & $6.39 \mathrm{E}-04$ & 59796 & 0.192072 & 0 \\
\hline Up & FADS2 & 3 & $2.79 \mathrm{E}-04$ & 36586 & 0.231419 & 0 \\
\hline Up & MDK & 3 & $1.80 \mathrm{E}-04$ & 25912 & 0.218194 & 0 \\
\hline Up & SLC1A4 & 3 & $8.27 \mathrm{E}-05$ & 15618 & 0.193142 & 0 \\
\hline Up & XCL1 & 3 & 0 & 0 & 1 & 0 \\
\hline Up & KCNJ5 & 3 & $9.29 \mathrm{E}-04$ & 372754 & 0.182315 & 0 \\
\hline Up & BCAM & 3 & $6.05 \mathrm{E}-04$ & 112764 & 0.228385 & 0 \\
\hline Up & PLAG1 & 3 & $2.18 \mathrm{E}-04$ & 20484 & 0.24984 & 0 \\
\hline Up & OXCT1 & 3 & $4.85 \mathrm{E}-04$ & 46990 & 0.204934 & 0 \\
\hline Up & HUNK & 3 & 4.94E-04 & 69796 & 0.225619 & 0 \\
\hline Up & TGFB2 & 3 & $6.45 \mathrm{E}-04$ & 101128 & 0.227071 & 0 \\
\hline Up & ASIC1 & 3 & $5.44 \mathrm{E}-04$ & 71454 & 0.200915 & 0 \\
\hline Up & DNAH14 & 3 & $6.58 \mathrm{E}-04$ & 64682 & 0.207754 & 0 \\
\hline Up & REG3A & 3 & 0 & 0 & 0.203039 & 0 \\
\hline Up & DEPDC1 & 3 & $9.29 \mathrm{E}-04$ & 122506 & 0.23086 & 0 \\
\hline Up & SPARCL1 & 3 & $3.11 \mathrm{E}-04$ & 65266 & 0.230279 & 0 \\
\hline Up & NREP & 3 & $6.91 \mathrm{E}-04$ & 105760 & 0.216427 & 0 \\
\hline Up & SV2A & 3 & $8.37 \mathrm{E}-05$ & 12654 & 0.203818 & 0 \\
\hline Up & CKAP2L & 3 & $8.72 \mathrm{E}-06$ & 5920 & 0.237184 & 0 \\
\hline Up & UXS1 & 3 & $6.18 \mathrm{E}-05$ & 9870 & 0.187405 & 0 \\
\hline Up & FKBP10 & 3 & $1.02 \mathrm{E}-04$ & 23742 & 0.230477 & 0 \\
\hline Up & MUCL1 & 3 & $7.20 \mathrm{E}-04$ & 130080 & 0.189877 & 0 \\
\hline Up & MND1 & 3 & 2.35E-05 & 7456 & 0.230058 & 0 \\
\hline Up & NYNRIN & 3 & $4.71 \mathrm{E}-04$ & 71716 & 0.216068 & 0 \\
\hline Up & ACTG2 & 3 & $1.30 \mathrm{E}-04$ & 38408 & 0.222194 & 0 \\
\hline Up & SDK1 & 3 & 8.77E-04 & 158706 & 0.246336 & 0 \\
\hline Up & PHYHIPL & 3 & $9.29 \mathrm{E}-04$ & 135794 & 0.226152 & 0 \\
\hline Up & CDCA7 & 3 & $3.06 \mathrm{E}-05$ & 17280 & 0.238989 & 0 \\
\hline Up & TMEM245 & 3 & 4.91E-04 & 58934 & 0.214817 & 0 \\
\hline Up & NT5DC2 & 3 & 4.74E-04 & 51730 & 0.197639 & 0 \\
\hline Up & SLC7A11 & 3 & $6.57 \mathrm{E}-04$ & 88918 & 0.223893 & 0 \\
\hline Up & TOX3 & 2 & $4.65 \mathrm{E}-04$ & 48740 & 0.206033 & 0 \\
\hline Up & ST8SIA3 & 2 & 0 & 0 & 0 & 0 \\
\hline Up & RHOBTB1 & 2 & $4.46 \mathrm{E}-06$ & 1098 & 0.208418 & 0 \\
\hline Up & TICRR & 2 & $8.03 \mathrm{E}-06$ & 986 & 0.236481 & 0 \\
\hline Up & CCDC88C & 2 & 4.65E-04 & 116662 & 0.23763 & 0 \\
\hline Up & RELN & 2 & $4.65 \mathrm{E}-04$ & 42474 & 0.194231 & 0 \\
\hline Up & MFGE8 & 2 & $3.74 \mathrm{E}-05$ & 4528 & 0.184742 & 0 \\
\hline $\mathrm{Up}$ & TTLL4 & 2 & $1.87 \mathrm{E}-05$ & 2688 & 0.223788 & 0 \\
\hline Up & PCLAF & 2 & $8.10 \mathrm{E}-07$ & 202 & 0.236897 & 0 \\
\hline Up & UGT3A2 & 2 & $3.14 \mathrm{E}-05$ & 9378 & 0.196943 & 0 \\
\hline Up & ZNF704 & 2 & $9.23 \mathrm{E}-06$ & 3184 & 0.22801 & 0 \\
\hline Up & STOX1 & 2 & 1 & 2 & 1 & 0 \\
\hline Up & LIX1 & 2 & $4.65 \mathrm{E}-04$ & 52180 & 0.186213 & 0 \\
\hline Up & TLCD1 & 2 & $2.15 \mathrm{E}-04$ & 32522 & 0.229261 & 0 \\
\hline Up & SRD5A3 & 2 & 1 & 2 & 1 & 0 \\
\hline Up & CD24 & 2 & $4.74 \mathrm{E}-06$ & 10026 & 0.240337 & 0 \\
\hline Up & BAMBI & 2 & 1 & 2 & 1 & 0 \\
\hline Up & LTBP2 & 2 & $5.94 \mathrm{E}-06$ & 2852 & 0.223579 & 0 \\
\hline Up & MEP1A & 2 & $4.65 \mathrm{E}-04$ & 58726 & 0.151658 & 0 \\
\hline Up & $\mathrm{CDON}$ & 2 & $4.65 \mathrm{E}-04$ & 66788 & 0.219418 & 0 \\
\hline Up & FREM2 & 2 & 1 & 2 & 1 & 0 \\
\hline Up & APCDD1 & 2 & $4.65 \mathrm{E}-04$ & 81302 & 0.159559 & 0 \\
\hline Up & NRCAM & 2 & $4.65 \mathrm{E}-04$ & 57154 & 0.177795 & 0 \\
\hline
\end{tabular}


medRxiv preprint doi: https://doi.org/10.1101/2020.12.22.20248756; this version posted December 26, 2020. The copyright holder for this

\begin{tabular}{|c|c|c|c|c|c|c|}
\hline Up & SLC25A36 & 2 & $1.22 \mathrm{E}-04$ & 14216 & 0.182594 & 0 \\
\hline Up & RASL11B & 2 & 2.42E-04 & 45546 & 0.227083 & 0 \\
\hline Up & FERMT1 & 2 & $1.59 \mathrm{E}-06$ & 4156 & 0.244253 & 0 \\
\hline Up & SLC22A11 & 2 & $4.65 \mathrm{E}-04$ & 53916 & 0.210282 & 0 \\
\hline Up & PARPBP & 2 & $6.11 \mathrm{E}-06$ & 3044 & 0.229665 & 0 \\
\hline Up & PLAGL2 & 2 & 1 & 2 & 1 & 0 \\
\hline Up & ZNF711 & 2 & $1.58 \mathrm{E}-06$ & 464 & 0.200112 & 0 \\
\hline Up & GXYLT2 & 1 & 0 & 0 & 0.171359 & 0 \\
\hline Up & ODAM & 1 & 0 & 0 & 0.207164 & 0 \\
\hline Up & SOBP & 1 & 0 & 0 & 1 & 0 \\
\hline Up & SULT1C4 & 1 & 0 & 0 & 0.172265 & 0 \\
\hline Up & GFRA3 & 1 & 0 & 0 & 1 & 0 \\
\hline Up & TNFSF4 & 1 & 0 & 0 & 1 & 0 \\
\hline Up & CD34 & 1 & 0 & 0 & 0.182446 & 0 \\
\hline Up & TBX4 & 1 & 0 & 0 & 1 & 0 \\
\hline Up & FMOD & 1 & 0 & 0 & 1 & 0 \\
\hline Up & ZNF382 & 1 & 0 & 0 & 0.244934 & 0 \\
\hline Up & AACS & 1 & 0 & 0 & 0.165864 & 0 \\
\hline Up & CPA6 & 1 & 0 & 0 & 1 & 0 \\
\hline Up & CCDC34 & 1 & 0 & 0 & 1 & 0 \\
\hline Up & RHBG & 1 & 0 & 0 & 1 & 0 \\
\hline Up & EPCAM & 1 & 0 & 0 & 0.177766 & 0 \\
\hline Up & MFAP2 & 1 & 0 & 0 & 1 & 0 \\
\hline Up & CDH11 & 1 & 0 & 0 & 0.2267 & 0 \\
\hline Up & FIGN & 1 & 0 & 0 & 1 & 0 \\
\hline Up & NPNT & 1 & 0 & 0 & 1 & 0 \\
\hline Up & LPCAT2 & 1 & 0 & 0 & 0.193715 & 0 \\
\hline Up & ABHD12B & 1 & 0 & 0 & 1 & 0 \\
\hline Up & ZBED8 & 1 & 0 & 0 & 0.192012 & 0 \\
\hline Up & SLC44A3 & 1 & 0 & 0 & 0.169503 & 0 \\
\hline Up & TET1 & 1 & 0 & 0 & 1 & 0 \\
\hline Up & PARD3B & 1 & 0 & 0 & 0.224115 & 0 \\
\hline Up & RNF157 & 1 & 0 & 0 & 1 & 0 \\
\hline Up & SERPINI1 & 1 & 0 & 0 & 1 & 0 \\
\hline Up & SNTG1 & 1 & 0 & 0 & 0.17574 & 0 \\
\hline Up & DKK2 & 1 & 0 & 0 & 0.185099 & 0 \\
\hline Up & DNAH17 & 1 & 0 & 0 & 0.207364 & 0 \\
\hline Up & NDRG3 & 1 & 0 & 0 & 0.166705 & 0 \\
\hline Up & FAM169A & 1 & 0 & 0 & 0.172735 & 0 \\
\hline Down & ESR1 & 896 & 0.309979 & 299570632 & 0.386231 & 8.97E-04 \\
\hline Down & LRRK2 & 483 & 0.133172 & 158516094 & 0.342501 & $2.08 \mathrm{E}-04$ \\
\hline Down & $\mathrm{AR}$ & 415 & 0.106663 & 62216644 & 0.360041 & 0.002891 \\
\hline Down & FOS & 264 & 0.065906 & 28932854 & 0.34933 & 0.004036 \\
\hline Down & ICAM1 & 178 & 0.033095 & 51537552 & 0.303149 & $1.30 \mathrm{E}-04$ \\
\hline Down & CLU & 148 & 0.044563 & 25001298 & 0.325958 & $9.45 \mathrm{E}-04$ \\
\hline Down & FGB & 115 & 0.028557 & 20661818 & 0.298618 & 0.002593 \\
\hline Down & IL13RA2 & 108 & 0.027484 & 20955756 & 0.279672 & 0 \\
\hline Down & MAP3K5 & 106 & 0.021135 & 15381740 & 0.313573 & 0.002427 \\
\hline Down & USP2 & 106 & 0.030969 & 21121988 & 0.307701 & 7.19E-04 \\
\hline Down & FGFR2 & 99 & 0.025154 & 27949726 & 0.291426 & 0 \\
\hline Down & BIRC3 & 95 & 0.017212 & 20907718 & 0.292562 & 0 \\
\hline Down & TRIM55 & 93 & 0.017057 & 24643106 & 0.278829 & $9.77 \mathrm{E}-04$ \\
\hline Down & ASS1 & 88 & 0.020199 & 11346616 & 0.308247 & 0.004925 \\
\hline Down & SOCS3 & 84 & 0.020952 & 9302066 & 0.322588 & 0.013196 \\
\hline Down & MACF1 & 83 & 0.015233 & 8958998 & 0.304395 & $6.17 \mathrm{E}-04$ \\
\hline Down & ACAT1 & 81 & 0.013409 & 13609238 & 0.291319 & 0 \\
\hline Down & JUNB & 80 & 0.013345 & 3520692 & 0.31819 & 0.024309 \\
\hline Down & BHLHE40 & 79 & 0.015913 & 11753664 & 0.294501 & 0 \\
\hline Down & RGS2 & 78 & 0.022665 & 6500040 & 0.306783 & 0.004101 \\
\hline Down & PCK1 & 77 & 0.013103 & 12847238 & 0.302028 & 0.001367 \\
\hline Down & SOD2 & 77 & 0.015795 & 11261720 & 0.295913 & 7.40E-04 \\
\hline Down & S100A8 & 75 & 0.016715 & 7355576 & 0.329693 & 0.006088 \\
\hline Down & MYO1B & 72 & 0.015859 & 6136180 & 0.333153 & 0.010172 \\
\hline Down & PPARGC1A & 72 & 0.010329 & 4302602 & 0.321226 & 0.021127 \\
\hline Down & SHBG & 71 & 0.015597 & 9905376 & 0.282661 & 0 \\
\hline Down & CYP1A1 & 71 & 0.014919 & 20866070 & 0.270491 & 0 \\
\hline Down & NRG1 & 68 & 0.017635 & 11230792 & 0.276759 & 0 \\
\hline Down & ZFP36 & 65 & 0.011562 & 13837378 & 0.291029 & 0 \\
\hline Down & TLR4 & 64 & 0.015406 & 8208520 & 0.291533 & 0.002644 \\
\hline Down & SLC15A1 & 64 & 0.012571 & 8309474 & 0.260238 & 0 \\
\hline Down & GNAO1 & 62 & 0.017069 & 10123798 & 0.282963 & 0 \\
\hline Down & GOT1 & 62 & 0.012129 & 9981328 & 0.275155 & 0 \\
\hline Down & CRP & 61 & 0.013437 & 6180018 & 0.275237 & 0.00526 \\
\hline Down & GADD45G & 60 & 0.014125 & 3241436 & 0.319912 & 0.011864 \\
\hline Down & AGL & 60 & 0.011612 & 9273372 & 0.287638 & 0 \\
\hline
\end{tabular}


medRxiv preprint doi: https://doi.org/10.1101/2020.12.22.20248756; this version posted December 26, 2020. The copyright holder for this preprint (which was not certified by peer review) is the author/funder, who has granted medRxiv a license to display the preprint in perpetuity. All rights reserved. No reuse allowed without permission.

\begin{tabular}{|c|c|c|c|c|c|c|}
\hline Down & ALAS1 & 59 & 0.012151 & 5367252 & 0.278955 & 0.00188 \\
\hline Down & WEE1 & 59 & 0.008825 & 11362378 & 0.285626 & 0 \\
\hline Down & ACADM & 57 & 0.010367 & 7668586 & 0.286067 & 0.006734 \\
\hline Down & UGP2 & 57 & 0.011493 & 8172720 & 0.283208 & 0 \\
\hline Down & GHR & 55 & 0.008712 & 4614994 & 0.29849 & 0.011611 \\
\hline Down & SATB1 & 55 & 0.008792 & 15527466 & 0.26675 & 0 \\
\hline Down & EGR1 & 54 & 0.007556 & 3144224 & 0.297276 & 0.018868 \\
\hline Down & KNG1 & 53 & 0.01237 & 5851206 & 0.28103 & 0.004706 \\
\hline Down & PTPN3 & 53 & 0.009152 & 7438096 & 0.290755 & 0 \\
\hline Down & CTH & 51 & 0.013176 & 4082662 & 0.283773 & 0 \\
\hline Down & TMOD1 & 51 & 0.005474 & 5091854 & 0.284136 & 0.003922 \\
\hline Down & FBP1 & 50 & 0.009048 & 11285584 & 0.26684 & 0 \\
\hline Down & DUSP1 & 50 & 0.008891 & 10378298 & 0.275278 & 0 \\
\hline Down & SHMT1 & 50 & 0.01026 & 13844154 & 0.265716 & 0 \\
\hline Down & HERC5 & 50 & 0.007274 & 9914444 & 0.28025 & 0 \\
\hline Down & CTSL & 48 & 0.010586 & 4444460 & 0.280463 & 0.004831 \\
\hline Down & SPTBN2 & 47 & 0.00602 & 7556250 & 0.282187 & 0 \\
\hline Down & SUCLG2 & 47 & 0.008951 & 3779538 & 0.279911 & 0.009251 \\
\hline Down & NNT & 47 & 0.010291 & 8100184 & 0.272068 & 0 \\
\hline Down & CD14 & 46 & 0.009258 & 3323924 & 0.27135 & $9.66 \mathrm{E}-04$ \\
\hline Down & GBP2 & 46 & 0.008203 & 3779530 & 0.288445 & 0.005797 \\
\hline Down & SCP2 & 46 & 0.010354 & 4074630 & 0.279531 & 0.003865 \\
\hline Down & KYNU & 45 & 0.006811 & 2586768 & 0.285128 & 0.019192 \\
\hline Down & SERPINA3 & 44 & 0.007664 & 4502382 & 0.284368 & 0 \\
\hline Down & ACOX1 & 44 & 0.009868 & 3506656 & 0.284412 & 0.003171 \\
\hline Down & PTPRB & 44 & 0.00811 & 3926218 & 0.288835 & 0 \\
\hline Down & DCN & 43 & 0.011811 & 4945324 & 0.29563 & 0.003322 \\
\hline Down & SLC27A2 & 43 & 0.010272 & 7446722 & 0.271629 & 0 \\
\hline Down & MAP7 & 42 & 0.007337 & 6511888 & 0.28103 & 0 \\
\hline Down & ETS2 & 41 & 0.005105 & 2519244 & 0.29106 & 0.017544 \\
\hline Down & PCK2 & 41 & 0.011497 & 3698052 & 0.299197 & 0.007317 \\
\hline Down & LRRFIP1 & 41 & 0.006765 & 1884314 & 0.309467 & 0.02834 \\
\hline Down & NR113 & 41 & 0.003727 & 2540248 & 0.27827 & 0.015647 \\
\hline Down & F9 & 40 & 0.008221 & 6098910 & 0.260629 & 0.00569 \\
\hline Down & BLNK & 40 & 0.006153 & 2200960 & 0.294517 & 0.011538 \\
\hline Down & VNN2 & 39 & 0.009277 & 9185422 & 0.242649 & 0 \\
\hline Down & NAMPT & 39 & 0.009728 & 2391300 & 0.289271 & 0.006006 \\
\hline Down & ARG1 & 39 & 0.006317 & 1733142 & 0.312409 & 0.010796 \\
\hline Down & $\mathrm{NR} 3 \mathrm{C} 2$ & 39 & 0.002614 & 1794230 & 0.294267 & 0.033033 \\
\hline Down & $\mathrm{CDA}$ & 39 & 0.007883 & 6112372 & 0.261648 & 0 \\
\hline Down & PTGS2 & 39 & 0.009909 & 4682156 & 0.316251 & 0.003003 \\
\hline Down & PIGR & 38 & 0.00659 & 2067682 & 0.270254 & 0.003175 \\
\hline Down & GDA & 38 & 0.007239 & 3477776 & 0.274529 & 0.018492 \\
\hline Down & CXCL8 & 37 & 0.006908 & 3072842 & 0.281772 & 0.020168 \\
\hline Down & FGG & 37 & 0.006246 & 1777802 & 0.278522 & 0.040336 \\
\hline Down & HAL & 37 & 0.005876 & 5246022 & 0.268621 & 0 \\
\hline Down & ARRDC3 & 37 & 0.006225 & 4213558 & 0.253226 & 0 \\
\hline Down & ABAT & 36 & 0.006759 & 1741224 & 0.277547 & 0.008913 \\
\hline Down & SLC1A1 & 35 & 0.007842 & 4681630 & 0.280137 & 0 \\
\hline Down & EHHADH & 34 & 0.00772 & 2095766 & 0.284645 & 0.008913 \\
\hline Down & HOOK1 & 34 & 0.00767 & 1579368 & 0.26606 & 0.002016 \\
\hline Down & ECM1 & 34 & 0.005761 & 3075272 & 0.275797 & 0 \\
\hline Down & VIPR1 & 34 & 0.011034 & 4956966 & 0.26818 & 0.001783 \\
\hline Down & REEP6 & 34 & 0.00749 & 2931720 & 0.26275 & 0 \\
\hline Down & RCAN1 & 34 & 0.00554 & 4877812 & 0.283555 & 0 \\
\hline Down & AKAP12 & 34 & 0.005471 & 6668604 & 0.273637 & 0 \\
\hline Down & KCND3 & 34 & 0.004592 & 8695142 & 0.258976 & 0 \\
\hline Down & PLA2G2A & 33 & 0.005893 & 1257034 & 0.27795 & 0.004301 \\
\hline Down & HP & 33 & 0.006005 & 3565910 & 0.291441 & 0 \\
\hline Down & SDC4 & 33 & 0.00587 & 4262690 & 0.286422 & 0 \\
\hline Down & ADRA1A & 32 & 0.006268 & 1133850 & 0.247946 & 0.004598 \\
\hline Down & NR4A2 & 32 & 0.004645 & 2855890 & 0.280081 & 0.008065 \\
\hline Down & RAB27A & 32 & 0.007238 & 4038790 & 0.27566 & 0 \\
\hline Down & GNE & 32 & 0.007084 & 2548154 & 0.271908 & 0 \\
\hline Down & ALDOB & 31 & 0.004619 & 3948276 & 0.276745 & 0 \\
\hline Down & EDNRB & 31 & 0.006582 & 4990088 & 0.254584 & 0 \\
\hline Down & GCH1 & 31 & 0.004367 & 3991740 & 0.266353 & 0 \\
\hline Down & MBOAT1 & 31 & 0.005692 & 7498044 & 0.251631 & 0 \\
\hline Down & MASP1 & 30 & 0.002511 & 1968902 & 0.271629 & 0.026455 \\
\hline Down & GADD45B & 30 & 0.004944 & 1236040 & 0.300981 & 0.03908 \\
\hline Down & BCHE & 30 & 0.006531 & 7736328 & 0.232035 & 0 \\
\hline Down & CDC37L1 & 30 & 0.003709 & 6777390 & 0.268452 & 0 \\
\hline Down & AZGP1 & 29 & 0.00598 & 1838220 & 0.298682 & 0.005698 \\
\hline Down & REPS2 & 29 & 0.005285 & 1424822 & 0.289966 & 0.009852 \\
\hline Down & STEAP3 & 29 & 0.005471 & 2977070 & 0.244228 & 0 \\
\hline
\end{tabular}


medRxiv preprint doi: https://doi.org/10.1101/2020.12.22.20248756; this version posted December 26, 2020. The copyright holder for this preprint (which was not certified by peer review) is the author/funder, who has granted medRxiv a license to display the preprint in perpetuity. All rights reserved. No reuse allowed without permission.

\begin{tabular}{|c|c|c|c|c|c|c|}
\hline Down & RIDA & 28 & 0.004379 & 1662822 & 0.263898 & 0.003077 \\
\hline Down & RNF125 & 27 & 0.004007 & 1731534 & 0.284908 & 0.01 \\
\hline Down & PRKAG2 & 27 & 0.004832 & 2830662 & 0.261599 & 0 \\
\hline Down & NFIL3 & 26 & 0.002765 & 1041744 & 0.264024 & 0.021739 \\
\hline Down & SERPINE1 & 26 & 0.002443 & 1190408 & 0.26564 & 0 \\
\hline Down & KLF6 & 26 & 0.004385 & 3318478 & 0.283194 & 0.009231 \\
\hline Down & SERPINB8 & 26 & 0.004412 & 2379938 & 0.26643 & 0 \\
\hline Down & DTX1 & 26 & 0.003329 & 3065438 & 0.267934 & 0 \\
\hline Down & SOCS2 & 25 & 0.002013 & 625286 & 0.26879 & 0.066667 \\
\hline Down & TRIB1 & 25 & 0.004127 & 1004106 & 0.285891 & 0.033333 \\
\hline Down & FCGR2B & 25 & 0.002985 & 1979616 & 0.268478 & 0.016667 \\
\hline Down & CFH & 25 & 0.005117 & 2951108 & 0.272215 & 0.006667 \\
\hline Down & HGF & 25 & 0.004124 & 2192050 & 0.256987 & 0.009524 \\
\hline Down & GCLM & 25 & 0.004237 & 3106626 & 0.277922 & 0 \\
\hline Down & THRSP & 25 & 0.002173 & 2856688 & 0.260519 & 0 \\
\hline Down & HAO2 & 25 & 0.004285 & 4808910 & 0.25823 & 0 \\
\hline Down & SERPINC1 & 24 & 0.003345 & 1730408 & 0.262266 & 0.008658 \\
\hline Down & BAAT & 24 & 0.002957 & 2800382 & 0.260214 & 0 \\
\hline Down & CREB3L3 & 24 & 0.003062 & 1200446 & 0.270914 & 0.030303 \\
\hline Down & F8 & 23 & 0.003884 & 1039040 & 0.25923 & 0.009524 \\
\hline Down & INSIG1 & 23 & 0.004133 & 2976792 & 0.251905 & 0 \\
\hline Down & CLEC4G & 23 & 0.002899 & 1111948 & 0.2615 & 0 \\
\hline Down & CPM & 23 & 0.002059 & 1765838 & 0.266878 & 0 \\
\hline Down & GLRX & 23 & 0.00358 & 1168444 & 0.282302 & 0.003953 \\
\hline Down & GNMT & 23 & 0.003769 & 3638242 & 0.252432 & 0 \\
\hline Down & LIPG & 23 & 0.004362 & 2949902 & 0.250124 & 0 \\
\hline Down & NAT2 & 22 & 0.003077 & 2962386 & 0.269193 & 0 \\
\hline Down & SLC7A2 & 22 & 0.004698 & 908164 & 0.229182 & 0.004329 \\
\hline Down & APCS & 21 & 0.003129 & 1035782 & 0.271165 & 0.052632 \\
\hline Down & ADAMTS1 & 21 & 0.004304 & 1275184 & 0.233862 & 0 \\
\hline Down & ACACB & 20 & 0.001914 & 1684424 & 0.274665 & 0 \\
\hline Down & CA2 & 20 & 0.003389 & 4309148 & 0.261685 & 0 \\
\hline Down & CYP2C8 & 20 & 0.002339 & 888270 & 0.253168 & 0.006536 \\
\hline Down & LIFR & 20 & 0.004051 & 3817640 & 0.266111 & 0 \\
\hline Down & ALDH6A1 & 20 & 0.002834 & 1248912 & 0.258867 & 0 \\
\hline Down & PTS & 20 & 0.003577 & 2360228 & 0.230744 & 0 \\
\hline Down & BBOX1 & 19 & 0.003707 & 1741390 & 0.242311 & 0 \\
\hline Down & HRG & 19 & 0.001592 & 860580 & 0.250496 & 0.017544 \\
\hline Down & LBP & 19 & 0.003321 & 1193680 & 0.267122 & 0.017544 \\
\hline Down & DUSP5 & 19 & 0.002019 & 1791148 & 0.259569 & 0 \\
\hline Down & RETREG1 & 19 & 0.00224 & 1353492 & 0.273866 & 0 \\
\hline Down & FXYD1 & 18 & 0.003686 & 3320202 & 0.2525 & 0 \\
\hline Down & MBL2 & 18 & 0.001551 & 406976 & 0.261808 & 0.05 \\
\hline Down & PHYH & 18 & 0.003994 & 1532650 & 0.270531 & 0 \\
\hline Down & ORM1 & 18 & 0.002 & 981922 & 0.254852 & 0 \\
\hline Down & CNDP1 & 18 & 0.004334 & 850302 & 0.306107 & 0.008333 \\
\hline Down & HSD11B1 & 18 & 0.004216 & 2091866 & 0.247792 & 0 \\
\hline Down & TDO2 & 18 & 0.002662 & 1453194 & 0.251494 & 0 \\
\hline Down & FOSB & 17 & $3.45 \mathrm{E}-04$ & 164544 & 0.279124 & 0.191176 \\
\hline Down & IGF1 & 17 & 0.002724 & 2487460 & 0.241185 & 0 \\
\hline Down & GSTA1 & 17 & 0.003814 & 996750 & 0.272562 & 0.038095 \\
\hline Down & CYP3A4 & 17 & 0.003177 & 2367788 & 0.257058 & 0.009524 \\
\hline Down & CXCL2 & 17 & 0.001553 & 607104 & 0.267328 & 0.07619 \\
\hline Down & ACADSB & 17 & 0.002838 & 1569448 & 0.258362 & 0 \\
\hline Down & INHBE & 17 & 0.003291 & 1602250 & 0.278243 & 0 \\
\hline Down & MMRN1 & 17 & 0.002547 & 1037546 & 0.259085 & 0 \\
\hline Down & APBB1IP & 17 & 0.003406 & 3834888 & 0.230122 & 0 \\
\hline Down & CCL21 & 16 & 0.003278 & 577492 & 0.275756 & 0.008333 \\
\hline Down & $\mathrm{CP}$ & 16 & 0.001592 & 1151616 & 0.249517 & 0 \\
\hline Down & CFB & 16 & 0.001261 & 589046 & 0.250394 & 0.021978 \\
\hline Down & C4BPA & 16 & 0.004043 & 2098058 & 0.266226 & 0.025 \\
\hline Down & RND3 & 16 & 0.003163 & 3146786 & 0.249562 & 0 \\
\hline Down & CPNE8 & 16 & 0.003116 & 1842528 & 0.265932 & 0 \\
\hline Down & RND1 & 16 & 0.003113 & 1403764 & 0.217182 & 0 \\
\hline Down & TMPRSS2 & 15 & 2.34E-04 & 104730 & 0.283035 & 0.141026 \\
\hline Down & PAPSS2 & 15 & 0.001973 & 773082 & 0.276387 & 0 \\
\hline Down & C4BPB & 15 & 0.002637 & 1071148 & 0.236753 & 0 \\
\hline Down & SLC25A15 & 15 & 0.003605 & 775762 & 0.251551 & 0 \\
\hline Down & ACSM5 & 15 & 0.004056 & 1939834 & 0.241185 & 0 \\
\hline Down & $\mathrm{C} 1 \mathrm{R}$ & 14 & 0.001705 & 531074 & 0.276856 & 0.060606 \\
\hline Down & $\mathrm{C} 1 \mathrm{~S}$ & 14 & $6.72 \mathrm{E}-04$ & 373556 & 0.247075 & 0.045455 \\
\hline Down & CYP2C9 & 14 & 0.002265 & 643044 & 0.246943 & 0.043956 \\
\hline Down & COLEC10 & 14 & 0.001778 & 346938 & 0.241394 & 0 \\
\hline Down & MAT1A & 14 & 0.001982 & 1350222 & 0.250598 & 0 \\
\hline Down & HSD17B6 & 13 & 0.002013 & 1442426 & 0.21725 & 0 \\
\hline
\end{tabular}


medRxiv preprint doi: https://doi.org/10.1101/2020.12.22.20248756; this version posted December 26, 2020. The copyright holder for this preprint (which was not certified by peer review) is the author/funder, who has granted medRxiv a license to display the preprint in perpetuity. All rights reserved. No reuse allowed without permission.

\begin{tabular}{|c|c|c|c|c|c|c|}
\hline Down & AGPAT2 & 13 & 0.003173 & 2509068 & 0.235899 & 0 \\
\hline Down & $\mathrm{C} 5$ & 13 & 0.001127 & 343098 & 0.24917 & 0 \\
\hline Down & C6 & 13 & 0.00131 & 736740 & 0.261119 & 0 \\
\hline Down & F11 & 13 & 0.001844 & 603870 & 0.260067 & 0.054545 \\
\hline Down & HPX & 13 & 0.001729 & 667494 & 0.245894 & 0 \\
\hline Down & CRHBP & 13 & 0.001677 & 1143382 & 0.244025 & 0 \\
\hline Down & INPP1 & 13 & 0.002652 & 1613930 & 0.236643 & 0 \\
\hline Down & DHODH & 13 & 0.001463 & 1507496 & 0.23258 & 0 \\
\hline Down & TP53INP1 & 13 & 0.001799 & 1097030 & 0.25963 & 0 \\
\hline Down & ARHGEF26 & 13 & 0.002416 & 1567538 & 0.208907 & 0 \\
\hline Down & ZDBF2 & 13 & 0.001241 & 982542 & 0.252122 & 0 \\
\hline Down & MASP2 & 12 & 2.76E-04 & 165182 & 0.248201 & 0.222222 \\
\hline Down & ABCB11 & 12 & 4.93E-04 & 277198 & 0.256583 & 0.030303 \\
\hline Down & OTC & 12 & 0.001998 & 1062950 & 0.236592 & 0 \\
\hline Down & CFP & 12 & 0.001809 & 650212 & 0.252008 & 0.030303 \\
\hline Down & KLKB1 & 12 & $6.60 \mathrm{E}-04$ & 224280 & 0.249148 & 0.045455 \\
\hline Down & SLPI & 12 & $9.16 \mathrm{E}-04$ & 313580 & 0.245459 & 0.015152 \\
\hline Down & DHTKD1 & 12 & 0.003151 & 1337228 & 0.255756 & 0 \\
\hline Down & PFKFB1 & 12 & 0.001203 & 1071564 & 0.273286 & 0 \\
\hline Down & IL1RN & 12 & $9.76 \mathrm{E}-04$ & 779266 & 0.243575 & 0 \\
\hline Down & PPP1R3B & 12 & 0.001315 & 1293766 & 0.247769 & 0.015152 \\
\hline Down & ALDH8A1 & 12 & 0.00275 & 447514 & 0.289981 & 0 \\
\hline Down & BHMT & 12 & 0.001503 & 724178 & 0.199189 & 0 \\
\hline Down & CLEC4M & 12 & $8.45 \mathrm{E}-04$ & 393846 & 0.24248 & 0 \\
\hline Down & RASD1 & 12 & 0.001272 & 1360920 & 0.238789 & 0 \\
\hline Down & TFR2 & 11 & 0.00145 & 263296 & 0.265996 & 0 \\
\hline Down & TNFSF14 & 11 & 0.001222 & 821328 & 0.260825 & 0 \\
\hline Down & SULT2A1 & 11 & $9.72 \mathrm{E}-04$ & 274484 & 0.250904 & 0.027778 \\
\hline Down & HGFAC & 11 & 0.001531 & 809870 & 0.239489 & 0.054545 \\
\hline Down & PPP1R1A & 11 & 0.002515 & 5390332 & 0.215941 & 0 \\
\hline Down & GAREM1 & 11 & 0.001023 & 798762 & 0.270636 & 0 \\
\hline Down & GLS2 & 11 & $8.23 \mathrm{E}-04$ & 415740 & 0.232103 & 0 \\
\hline Down & ASPDH & 10 & 0.00149 & 823920 & 0.246998 & 0 \\
\hline Down & ABLIM3 & 10 & 0.001624 & 1312524 & 0.255662 & 0 \\
\hline Down & CXCL14 & 10 & $9.45 \mathrm{E}-04$ & 480018 & 0.26321 & 0 \\
\hline Down & ADH1B & 10 & $9.96 \mathrm{E}-04$ & 402610 & 0.260507 & 0 \\
\hline Down & ALPL & 10 & 0.001041 & 822584 & 0.247086 & 0 \\
\hline Down & ACSL1 & 10 & $9.32 \mathrm{E}-04$ & 483436 & 0.268089 & 0 \\
\hline Down & PON1 & 10 & 0.001622 & 391370 & 0.256465 & 0.066667 \\
\hline Down & CYP2C18 & 10 & 0.001389 & 249172 & 0.226675 & 0.022222 \\
\hline Down & GPD1 & 10 & 0.001592 & 635348 & 0.220222 & 0 \\
\hline Down & EXPH5 & 10 & 0.00185 & 462530 & 0.267109 & 0 \\
\hline Down & MYOM1 & 10 & 0.001147 & 924916 & 0.23037 & 0 \\
\hline Down & CDO1 & 10 & 0.001584 & 1653692 & 0.241783 & 0 \\
\hline Down & GPAT3 & 10 & 0.00178 & 962402 & 0.251825 & 0 \\
\hline Down & MGLL & 10 & 0.001476 & 851578 & 0.24009 & 0 \\
\hline Down & NTN4 & 10 & 0.003294 & 5110696 & 0.247009 & 0 \\
\hline Down & $\mathrm{ABCC} 3$ & 9 & $2.47 \mathrm{E}-04$ & 214754 & 0.246155 & 0 \\
\hline Down & ALDH1A1 & 9 & 7.63E-04 & 886116 & 0.234981 & 0 \\
\hline Down & SAA1 & 9 & $8.40 \mathrm{E}-04$ & 502730 & 0.223366 & 0 \\
\hline Down & GYS2 & 9 & 7.84E-04 & 402462 & 0.251939 & 0.027778 \\
\hline Down & GPLD1 & 9 & 0.001569 & 996420 & 0.245992 & 0 \\
\hline Down & ITIH4 & 9 & 8.06E-04 & 596242 & 0.25611 & 0 \\
\hline Down & LONRF3 & 9 & $8.77 \mathrm{E}-04$ & 645580 & 0.240558 & 0 \\
\hline Down & GRAMD1C & 9 & 0.002584 & 846258 & 0.245622 & 0 \\
\hline Down & PIPOX & 9 & 0.00221 & 1758694 & 0.233558 & 0 \\
\hline Down & ANGPTL3 & 9 & 0.001937 & 2527356 & 0.224758 & 0 \\
\hline Down & SLCO1B1 & 9 & 0.001603 & 706740 & 0.236119 & 0 \\
\hline Down & FCN2 & 8 & 2.81E-04 & 87106 & 0.241857 & 0.321429 \\
\hline Down & CYP1A2 & 8 & $5.10 \mathrm{E}-04$ & 317700 & 0.196206 & 0 \\
\hline Down & MT1X & 8 & 0.00108 & 273304 & 0.277035 & 0.071429 \\
\hline Down & AASS & 8 & $8.75 \mathrm{E}-04$ & 236390 & 0.255591 & 0 \\
\hline Down & CETP & 8 & $9.82 \mathrm{E}-04$ & 702086 & 0.246046 & 0 \\
\hline Down & DAO & 8 & 0.001228 & 718678 & 0.251164 & 0 \\
\hline Down & TAT & 8 & $6.11 \mathrm{E}-04$ & 503476 & 0.243436 & 0 \\
\hline Down & CYP3A5 & 8 & 0.001166 & 602974 & 0.238175 & 0 \\
\hline Down & SULT1A2 & 8 & 0.001478 & 1675470 & 0.184432 & 0 \\
\hline Down & AKR1D1 & 8 & 0.001232 & 929478 & 0.232006 & 0 \\
\hline Down & AOX1 & 8 & $8.17 \mathrm{E}-05$ & 56800 & 0.223142 & 0 \\
\hline Down & SEC14L4 & 8 & 0.002122 & 1129680 & 0.234485 & 0 \\
\hline Down & OGDHL & 8 & 2.07E-04 & 143330 & 0.248179 & 0 \\
\hline Down & RBM47 & 7 & $9.50 \mathrm{E}-04$ & 669862 & 0.25449 & 0 \\
\hline Down & IRF6 & 7 & 0.001805 & 1065964 & 0.220126 & 0 \\
\hline Down & HABP2 & 7 & 2.07E-04 & 33070 & 0.224949 & 0 \\
\hline Down & C9 & 7 & 0.00122 & 268198 & 0.254479 & 0.047619 \\
\hline
\end{tabular}


medRxiv preprint doi: https://doi.org/10.1101/2020.12.22.20248756; this version posted December 26, 2020. The copyright holder for this preprint (which was not certified by peer review) is the author/funder, who has granted medRxiv a license to display the preprint in perpetuity. All rights reserved. No reuse allowed without permission.

\begin{tabular}{|c|c|c|c|c|c|c|}
\hline Down & LRG1 & 7 & $7.84 \mathrm{E}-04$ & 521906 & 0.235969 & 0 \\
\hline Down & CFI & 7 & 0.001231 & 465800 & 0.232989 & 0.047619 \\
\hline Down & $\mathrm{C} 8 \mathrm{G}$ & 7 & $5.10 \mathrm{E}-04$ & 545184 & 0.217378 & 0 \\
\hline Down & PZP & 7 & 0.001109 & 655294 & 0.199928 & 0 \\
\hline Down & AGXT & 7 & $5.03 \mathrm{E}-04$ & 111720 & 0.252604 & 0 \\
\hline Down & EPHX2 & 7 & $5.80 \mathrm{E}-04$ & 385960 & 0.232628 & 0 \\
\hline Down & NNMT & 7 & $7.28 \mathrm{E}-04$ & 310450 & 0.253399 & 0 \\
\hline Down & CYP4F2 & 7 & $2.97 \mathrm{E}-04$ & 205740 & 0.251939 & 0 \\
\hline Down & FYB2 & 7 & 0.001808 & 2714948 & 0.180559 & 0 \\
\hline Down & APOA5 & 7 & $5.21 \mathrm{E}-04$ & 306366 & 0.240308 & 0 \\
\hline Down & HHIP & 7 & 0.00144 & 476860 & 0.165307 & 0 \\
\hline Down & CSRNP1 & 7 & 0.001143 & 806270 & 0.251472 & 0 \\
\hline Down & APOL6 & 7 & $5.21 \mathrm{E}-04$ & 457030 & 0.212976 & 0 \\
\hline Down & STAB2 & 7 & $1.38 \mathrm{E}-04$ & 132094 & 0.243629 & 0 \\
\hline Down & GFRA1 & 6 & 0.001197 & 219610 & 0.253967 & 0 \\
\hline Down & CCL16 & 6 & 7.39E-04 & 807116 & 0.191663 & 0 \\
\hline Down & ABCC 9 & 6 & $8.72 \mathrm{E}-04$ & 466056 & 0.230027 & 0 \\
\hline Down & APOC3 & 6 & $2.39 \mathrm{E}-04$ & 126474 & 0.238574 & 0 \\
\hline Down & LPA & 6 & $7.65 \mathrm{E}-04$ & 133348 & 0.244411 & 0.066667 \\
\hline Down & GSTA2 & 6 & 7.59E-04 & 223462 & 0.217642 & 0.133333 \\
\hline Down & GSTA3 & 6 & $3.29 \mathrm{E}-04$ & 148180 & 0.254421 & 0.5 \\
\hline Down & HPD & 6 & $1.23 \mathrm{E}-04$ & 52066 & 0.243554 & 0.066667 \\
\hline Down & HMGCS2 & 6 & 2.63E-04 & 241608 & 0.270887 & 0 \\
\hline Down & INHBC & 6 & 0.00144 & 1022782 & 0.133638 & 0 \\
\hline Down & ENPEP & 6 & 0.00108 & 520350 & 0.180003 & 0 \\
\hline Down & GLYAT & 6 & 7.51E-04 & 209042 & 0.20607 & 0 \\
\hline Down & CES3 & 6 & 0.001828 & 826294 & 0.249708 & 0 \\
\hline Down & SLC51A & 6 & 0.0018 & 499710 & 0.208101 & 0 \\
\hline Down & TTC39C & 6 & $4.23 \mathrm{E}-04$ & 338812 & 0.241447 & 0 \\
\hline Down & SGMS2 & 6 & 4.22E-04 & 279040 & 0.226002 & 0 \\
\hline Down & HGD & 6 & $7.24 \mathrm{E}-04$ & 309038 & 0.215647 & 0 \\
\hline Down & RUNDC3B & 6 & 4.91E-04 & 365238 & 0.252661 & 0 \\
\hline Down & NFKBIZ & 6 & $4.89 \mathrm{E}-04$ & 873384 & 0.244207 & 0 \\
\hline Down & CYP8B1 & 6 & $8.30 \mathrm{E}-04$ & 535726 & 0.242131 & 0 \\
\hline Down & ST3GAL6 & 6 & 0.003309 & 1133634 & 0.246735 & 0 \\
\hline Down & LRAT & 5 & $7.20 \mathrm{E}-04$ & 427634 & 0.189926 & 0 \\
\hline Down & CFHR4 & 5 & $2.52 \mathrm{E}-05$ & 6314 & 0.233126 & 0 \\
\hline Down & CFHR1 & 5 & $9.73 \mathrm{E}-05$ & 23610 & 0.235469 & 0.2 \\
\hline Down & SAA2 & 5 & $4.42 \mathrm{E}-05$ & 22766 & 0.208202 & 0 \\
\hline Down & CYP2D6 & 5 & $2.55 \mathrm{E}-05$ & 5470 & 0.208609 & 0.333333 \\
\hline Down & SRD5A1 & 5 & $1.62 \mathrm{E}-04$ & 202222 & 0.264024 & 0 \\
\hline Down & CES1 & 5 & $4.52 \mathrm{E}-04$ & 156516 & 0.196477 & 0 \\
\hline Down & GPT & 5 & 8.71E-04 & 531304 & 0.225681 & 0 \\
\hline Down & NPY1R & 5 & 1 & 20 & 1 & 0 \\
\hline Down & ADGRA3 & 5 & 0.00128 & 374516 & 0.240537 & 0 \\
\hline Down & AFM & 5 & $7.25 \mathrm{E}-04$ & 359728 & 0.230571 & 0 \\
\hline Down & HAAO & 5 & $4.21 \mathrm{E}-04$ & 207404 & 0.235979 & 0 \\
\hline Down & DPYS & 5 & $4.46 \mathrm{E}-04$ & 453896 & 0.208171 & 0 \\
\hline Down & GCKR & 5 & $9.21 \mathrm{E}-05$ & 106176 & 0.253723 & 0 \\
\hline Down & CYP4V2 & 5 & $8.43 \mathrm{E}-04$ & 570518 & 0.232346 & 0 \\
\hline Down & RNF152 & 5 & $4.72 \mathrm{E}-04$ & 435980 & 0.201964 & 0 \\
\hline Down & CLEC1B & 5 & $3.86 \mathrm{E}-04$ & 222916 & 0.24035 & 0 \\
\hline Down & TENM1 & 5 & $7.20 \mathrm{E}-04$ & 286198 & 0.183192 & 0 \\
\hline Down & SLC4A4 & 5 & $7.20 \mathrm{E}-04$ & 236454 & 0.195495 & 0 \\
\hline Down & CD163 & 5 & $1.22 \mathrm{E}-04$ & 66542 & 0.242713 & 0 \\
\hline Down & FGD4 & 5 & $3.96 \mathrm{E}-04$ & 204152 & 0.230332 & 0 \\
\hline Down & PAPPA2 & 5 & $8.00 \mathrm{E}-05$ & 92852 & 0.23106 & 0 \\
\hline Down & CYP39A1 & 5 & $4.83 \mathrm{E}-04$ & 312774 & 0.220082 & 0 \\
\hline Down & APOL1 & 4 & $7.24 \mathrm{E}-04$ & 278170 & 0.217463 & 0 \\
\hline Down & SULT1B1 & 4 & $4.20 \mathrm{E}-04$ & 82266 & 0.218593 & 0 \\
\hline Down & FCN3 & 4 & $7.70 \mathrm{E}-06$ & 3684 & 0.215849 & 0 \\
\hline Down & BMP10 & 4 & 0.002878 & 1661946 & 0.182254 & 0 \\
\hline Down & $\mathrm{ADH} 1 \mathrm{C}$ & 4 & $3.60 \mathrm{E}-04$ & 158820 & 0.206691 & 0 \\
\hline Down & $\mathrm{C} 7$ & 4 & $4.44 \mathrm{E}-04$ & 82582 & 0.260543 & 0 \\
\hline Down & CFHR3 & 4 & $6.28 \mathrm{E}-05$ & 17502 & 0.233009 & 0.166667 \\
\hline Down & AKR1C4 & 4 & $5.10 \mathrm{E}-04$ & 183362 & 0.221231 & 0 \\
\hline Down & CYP2B6 & 4 & $2.46 \mathrm{E}-04$ & 195256 & 0.208007 & 0 \\
\hline Down & ACADL & 4 & 7.39E-04 & 257702 & 0.250496 & 0 \\
\hline Down & SLC6A1 & 4 & 7.24E-04 & 442960 & 0.185833 & 0 \\
\hline Down & GATM & 4 & $2.80 \mathrm{E}-06$ & 542 & 0.208413 & 0 \\
\hline Down & CYP4A11 & 4 & $4.53 \mathrm{E}-04$ & 329054 & 0.230868 & 0 \\
\hline Down & ETFDH & 4 & $4.59 \mathrm{E}-05$ & 36792 & 0.211492 & 0 \\
\hline Down & PXDC1 & 4 & $7.05 \mathrm{E}-04$ & 491142 & 0.223654 & 0 \\
\hline Down & ADGRG7 & 4 & $4.13 \mathrm{E}-04$ & 192036 & 0.226963 & 0 \\
\hline Down & RSPO3 & 4 & 7.39E-04 & 142942 & 0.206969 & 0 \\
\hline
\end{tabular}


medRxiv preprint doi: https://doi.org/10.1101/2020.12.22.20248756; this version posted December 26, 2020. The copyright holder for this preprint (which was not certified by peer review) is the author/funder, who has granted medRxiv a license to display the preprint in perpetuity. All rights reserved. No reuse allowed without permission.

\begin{tabular}{|c|c|c|c|c|c|c|}
\hline Down & HAO1 & 4 & 0.00108 & 620136 & 0.204514 & 0 \\
\hline Down & AVPR1A & 4 & 7.33E-04 & 355980 & 0.204884 & 0 \\
\hline Down & CHST9 & 4 & $3.92 \mathrm{E}-04$ & 409662 & 0.214872 & 0 \\
\hline Down & AQP3 & 4 & 4.73E-04 & 260220 & 0.254199 & 0 \\
\hline Down & CFHR5 & 4 & $1.04 \mathrm{E}-04$ & 48504 & 0.230677 & 0 \\
\hline Down & PLAC8 & 4 & $1.05 \mathrm{E}-04$ & 89312 & 0.24454 & 0 \\
\hline Down & MARCO & 4 & 0.00108 & 354306 & 0.245286 & 0 \\
\hline Down & LYVE1 & 4 & 4.04E-04 & 175194 & 0.203742 & 0 \\
\hline Down & MT1DP & 3 & $1.25 \mathrm{E}-05$ & 6290 & 0.185535 & 0 \\
\hline Down & C1RL & 3 & $3.73 \mathrm{E}-04$ & 76172 & 0.228165 & 0 \\
\hline Down & HPR & 3 & $2.56 \mathrm{E}-05$ & 13292 & 0.214299 & 0 \\
\hline Down & $\mathrm{C} 8 \mathrm{~A}$ & 3 & $1.68 \mathrm{E}-05$ & 4780 & 0.20737 & 0.333333 \\
\hline Down & ADH4 & 3 & $6.09 \mathrm{E}-05$ & 43038 & 0.254246 & 0 \\
\hline Down & $\mathrm{ABCB} 4$ & 3 & $7.20 \mathrm{E}-04$ & 447626 & 0.224567 & 0 \\
\hline Down & MRC1 & 3 & $3.38 \mathrm{E}-05$ & 6054 & 0.227418 & 0 \\
\hline Down & $\mathrm{XDH}$ & 3 & $7.20 \mathrm{E}-04$ & 247046 & 0.23621 & 0 \\
\hline Down & MT1H & 3 & $2.03 \mathrm{E}-04$ & 49574 & 0.220274 & 0 \\
\hline Down & HAMP & 3 & $4.90 \mathrm{E}-05$ & 11464 & 0.199698 & 0 \\
\hline Down & APOF & 3 & $7.20 \mathrm{E}-04$ & 342410 & 0.205483 & 0 \\
\hline Down & IYD & 3 & $3.79 \mathrm{E}-04$ & 282996 & 0.232327 & 0 \\
\hline Down & HSD17B13 & 3 & $3.66 \mathrm{E}-04$ & 151596 & 0.180196 & 0 \\
\hline Down & SPATA6L & 3 & 3.64E-04 & 112340 & 0.212952 & 0 \\
\hline Down & ETNPPL & 3 & $3.82 \mathrm{E}-04$ & 152152 & 0.246549 & 0 \\
\hline Down & NSUN6 & 3 & $5.53 \mathrm{E}-05$ & 20424 & 0.226214 & 0 \\
\hline Down & TSKU & 3 & $7.20 \mathrm{E}-04$ & 388086 & 0.220082 & 0 \\
\hline Down & LPIN2 & 3 & $3.65 \mathrm{E}-04$ & 171480 & 0.24009 & 0 \\
\hline Down & AMDHD1 & 3 & 4.16E-04 & 154054 & 0.216818 & 0 \\
\hline Down & SMIM14 & 3 & $7.20 \mathrm{E}-04$ & 447678 & 0.222793 & 0 \\
\hline Down & SLC25A18 & 3 & $5.08 \mathrm{E}-05$ & 17890 & 0.216084 & 0 \\
\hline Down & RASGEF1B & 3 & $1.44 \mathrm{E}-04$ & 58950 & 0.248446 & 0 \\
\hline Down & ABCA9 & 3 & $1.01 \mathrm{E}-04$ & 101642 & 0.244476 & 0 \\
\hline Down & BMPER & 3 & $2.40 \mathrm{E}-04$ & 870218 & 0.124359 & 0 \\
\hline Down & ACMSD & 3 & $7.20 \mathrm{E}-04$ & 193526 & 0.210858 & 0 \\
\hline Down & SLC41A2 & 3 & $4.01 \mathrm{E}-04$ & 159456 & 0.227502 & 0 \\
\hline Down & GLT1D1 & 3 & $6.09 \mathrm{E}-04$ & 190956 & 0.208288 & 0 \\
\hline Down & NAT8 & 3 & $4.20 \mathrm{E}-05$ & 29670 & 0.244025 & 0 \\
\hline Down & KMO & 2 & $3.60 \mathrm{E}-04$ & 289722 & 0.190473 & 0 \\
\hline Down & SLC22A1 & 2 & 1 & 2 & 1 & 0 \\
\hline Down & CYP26A1 & 2 & $3.10 \mathrm{E}-07$ & 358 & 0.227055 & 0 \\
\hline Down & CD5L & 2 & $2.42 \mathrm{E}-05$ & 17014 & 0.216809 & 0 \\
\hline Down & SEC14L2 & 2 & $3.60 \mathrm{E}-04$ & 184378 & 0.159662 & 0 \\
\hline Down & SLITRK3 & 2 & 8.03E-06 & 2444 & 0.246647 & 0 \\
\hline Down & C8B & 2 & $3.91 \mathrm{E}-05$ & 26264 & 0.246976 & 0 \\
\hline Down & F13B & 2 & 0 & 0 & 0.217864 & 1 \\
\hline Down & MT1G & 2 & $1.74 \mathrm{E}-04$ & 25586 & 0.220484 & 0 \\
\hline Down & MT1F & 2 & $4.88 \mathrm{E}-06$ & 264 & 0.237665 & 0 \\
\hline Down & AGXT2 & 2 & 7.08E-06 & 768 & 0.226214 & 0 \\
\hline Down & UGT2B7 & 2 & $3.60 \mathrm{E}-04$ & 275732 & 0.204514 & 0 \\
\hline Down & CYP2C19 & 2 & 0 & 0 & 0.201861 & 1 \\
\hline Down & PON3 & 2 & 0 & 0 & 0.204131 & 1 \\
\hline Down & G0S2 & 2 & $3.60 \mathrm{E}-04$ & 462290 & 0.207665 & 0 \\
\hline Down & GBP7 & 2 & $3.60 \mathrm{E}-04$ & 131252 & 0.223897 & 0 \\
\hline Down & CFHR2 & 2 & $7.55 \mathrm{E}-05$ & 16542 & 0.246855 & 0 \\
\hline Down & DIO1 & 2 & 0 & 0 & 0 & 0 \\
\hline Down & ACSM3 & 2 & $6.30 \mathrm{E}-07$ & 460 & 0.224958 & 0 \\
\hline Down & SLC25A47 & 2 & $6.89 \mathrm{E}-06$ & 3908 & 0.199849 & 0 \\
\hline Down & ABCA10 & 2 & 7.91E-06 & 4862 & 0.231446 & 0 \\
\hline Down & FGF14 & 2 & $1.63 \mathrm{E}-05$ & 9246 & 0.209237 & 0 \\
\hline Down & ART4 & 2 & $3.90 \mathrm{E}-05$ & 32642 & 0.245242 & 0 \\
\hline Down & FGGY & 2 & 1 & 2 & 1 & 0 \\
\hline Down & MOGAT2 & 2 & $1.23 \mathrm{E}-05$ & 4986 & 0.194441 & 0 \\
\hline Down & ANO1 & 2 & $1.96 \mathrm{E}-05$ & 14720 & 0.224377 & 0 \\
\hline Down & STEAP4 & 2 & $3.60 \mathrm{E}-04$ & 124230 & 0.230332 & 0 \\
\hline Down & ANO5 & 2 & $2.17 \mathrm{E}-04$ & 89640 & 0.247958 & 0 \\
\hline Down & ADHFE1 & 2 & $3.60 \mathrm{E}-04$ & 109268 & 0.202634 & 0 \\
\hline Down & MT1M & 2 & $8.44 \mathrm{E}-06$ & 5014 & 0.209237 & 0 \\
\hline Down & CLRN3 & 2 & $4.80 \mathrm{E}-05$ & 17224 & 0.200245 & 0 \\
\hline Down & PRG4 & 2 & $9.38 \mathrm{E}-06$ & 17410 & 0.249495 & 0 \\
\hline Down & GBA3 & 2 & 4.32E-05 & 23632 & 0.225626 & 0 \\
\hline Down & GREM2 & 2 & $1.20 \mathrm{E}-04$ & 435106 & 0.124353 & 0 \\
\hline Down & FETUB & 2 & $1.46 \mathrm{E}-05$ & 14364 & 0.232921 & 0 \\
\hline Down & ANXA10 & 2 & $1.19 \mathrm{E}-05$ & 10254 & 0.221178 & 0 \\
\hline Down & SLC27A5 & 2 & $3.60 \mathrm{E}-04$ & 101338 & 0.224286 & 0 \\
\hline Down & CPED1 & 1 & 0 & 0 & 0.245221 & 0 \\
\hline Down & TTC36 & 1 & 0 & 0 & 0.221319 & 0 \\
\hline
\end{tabular}


medRxiv preprint doi: https://doi.org/10.1101/2020.12.22.20248756; this version posted December 26, 2020. The copyright holder for this preprint (which was not certified by peer review) is the author/funder, who has granted medRxiv a license to display the preprint in perpetuity. All rights reserved. No reuse allowed without permission.

\begin{tabular}{lcccccc} 
Down & MT1E & 1 & 0 & 0 & 0.230208 & 0 \\
Down & UGT2B4 & 1 & 0 & 0 & 0.222062 & 0 \\
Down & FMO4 & 1 & 0 & 0 & 0.199304 & 0 \\
Down & UGT2B10 & 1 & 0 & 0 & 0.223843 & 0 \\
Down & CYP4A22 & 1 & 0 & 0 & 0.187572 & 0 \\
Down & SLC10A1 & 1 & 0 & 0 & 1 & 0 \\
Down & TSPYL5 & 1 & 0 & 0 & 0.217565 & 0 \\
Down & CYP4F11 & 1 & 0 & 0 & 0.207308 & 0 \\
Down & HPGD & 1 & 0 & 0 & 0.245221 & 0 \\
Down & FMO3 & 1 & 0 & 0 & 0.193183 & 0 \\
Down & DNASE1L3 & 1 & 0 & 0 & 0.192961 & 0 \\
Down & SCN9A & 1 & 0 & 0 & 0.235799 & 0 \\
Down & LPAL2 & 1 & 0 & 0 & 0.186884 & 0 \\
Down & SLC46A3 & 1 & 0 & 0 & 0.186752 & 0 \\
Down & ASPG & 1 & 0 & 0 & 0.198166 & 0 \\
Down & CYP4X1 & 1 & 0 & 0 & 0.205453 & 0 \\
Down & ABCA6 & 1 & 0 & 0 & 1 & 0 \\
Down & AADAT & 1 & 0 & 0 & 0.201319 & 0 \\
Down & MFSD2A & 1 & 0 & 0 & 1 & 0 \\
Down & AKR7L & 1 & 0 & 0 & 0.17799 & 0 \\
Down & OIT3 & 1 & 0 & 0 & 1 & 0 \\
Down & ARAP2 & 1 & 0 & 0 & 0.222757 & 0 \\
Down & TCIM & 1 & 0 & 0 & 0.193055 & 0 \\
Down & UPB1 & 1 & 0 & 0 & 1 & 0 \\
Down & DMGDH & 1 & 0 & 0 & 0.232989 & 0 \\
Down & SLC17A4 & 1 & 0 & 0 & & 0 \\
Down & SLC22A7 & 1 & 0 & 0 & & 0 \\
\hline
\end{tabular}

Table 8 miRNA - target gene interaction table

\begin{tabular}{|c|c|c|c|c|c|c|c|}
\hline Regulation & Target Genes & Degree & MicroRNA & Regulation & Target Genes & Degree & MicroRNA \\
\hline Up & PLAGL2 & 189 & hsa-mir-4710 & Down & SOD2 & 257 & hsa-mir-4803 \\
\hline Up & CDK6 & 188 & hsa-mir-4657 & Down & WEE1 & 182 & hsa-mir-4647 \\
\hline $\mathrm{Up}$ & CCND2 & 179 & hsa-mir-5192 & Down & SULT1B1 & 131 & hsa-mir-3163 \\
\hline Up & SLC1A5 & 174 & hsa-mir-4284 & Down & APOL6 & 127 & hsa-mir-4455 \\
\hline Up & PKM & 160 & hsa-mir-4525 & Down & DHODH & 119 & hsa-mir- 1200 \\
\hline $\mathrm{Up}$ & CBX5 & 140 & hsa-mir-7973 & Down & ABHD2 & 116 & hsa-mir- 4284 \\
\hline Up & PEG10 & 138 & hsa-mir-8072 & Down & ACOX1 & 113 & hsa-mir-3165 \\
\hline Up & TP53 & 130 & hsa-mir-2110 & Down & $\mathrm{CPM}$ & 111 & hsa-mir-7977 \\
\hline Up & HMGA2 & 126 & hsa-mir-4418 & Down & TSKU & 107 & hsa-mir- 4505 \\
\hline Up & TMEM245 & 126 & hsa-mir-3674 & Down & HHIP & 107 & hsa-mir- 4510 \\
\hline Up & GXYLT2 & 123 & hsa-mir-3929 & Down & IGF1 & 98 & hsa-mir-3929 \\
\hline Up & PTPN14 & 116 & hsa-mir-4484 & Down & $\mathrm{AR}$ & 97 & hsa-mir-5193 \\
\hline Up & RACGAP1 & 112 & hsa-mir-2278 & Down & SHMT1 & 97 & hsa-mir-3174 \\
\hline Up & ZC3HAV1L & 111 & hsa-mir-5684 & Down & TP53INP1 & 94 & hsa-mir-6069 \\
\hline Up & PRIM1 & 111 & hsa-mir-6745 & Down & RNF125 & 92 & hsa-mir-4770 \\
\hline Up & ITGA2 & 107 & hsa-mir-5680 & Down & LIPG & 89 & hsa-mir-6085 \\
\hline Up & CDK4 & 102 & hsa-mir-7641 & Down & INSIG1 & 85 & hsa-mir- 8073 \\
\hline Up & RRM2 & 101 & hsa-mir-4510 & Down & LONRF3 & 82 & hsa-mir-6130 \\
\hline Up & SLC7A11 & 101 & hsa-mir-5193 & Down & TRIB1 & 81 & hsa-mir-4426 \\
\hline Up & RNF157 & 100 & hsa-mir-6133 & Down & ESR1 & 72 & hsa-mir-4290 \\
\hline Up & COL1A1 & 97 & hsa-mir-2392 & Down & ANGPTL3 & 70 & hsa-mir- 8054 \\
\hline Up & IGF2BP1 & 93 & hsa-mir-8485 & Down & DHTKD1 & 69 & hsa-mir-7150 \\
\hline Up & ENAH & 92 & hsa-mir-4452 & Down & CLU & 69 & hsa-mir- 8085 \\
\hline Up & FLVCR1 & 88 & hsa-mir-6131 & Down & NNT & 68 & hsa-mir-4672 \\
\hline Up & AMER1 & 87 & hsa-mir-6081 & Down & PIGR & 66 & hsa-mir-4486 \\
\hline $\mathrm{Up}$ & ZNF704 & 86 & hsa-mir-4527 & Down & CCL16 & 63 & hsa-mir- 4533 \\
\hline Up & CCNB1 & 84 & hsa-mir-4477a & Down & KLF6 & 62 & hsa-mir- 4422 \\
\hline Up & MKI67 & 84 & hsa-mir-4430 & Down & UGT2B4 & 62 & hsa-mir-3170 \\
\hline Up & PLAG1 & 83 & hsa-mir-3919 & Down & SEC14L4 & 61 & hsa-mir- 3652 \\
\hline Up & KPNA2 & 83 & hsa-mir-4302 & Down & SRD5A1 & 60 & hsa-mir- 4478 \\
\hline Up & OLR1 & 81 & hsa-mir-2054 & Down & RNF152 & 59 & hsa-mir-4499 \\
\hline Up & HIF1AN & 78 & hsa-mir-3911 & Down & FOS & 58 & hsa-mir-8081 \\
\hline Up & FOXRED2 & 76 & hsa-mir-7702 & Down & AGXT2 & 58 & hsa-mir- 1827 \\
\hline Up & BAMBI & 76 & hsa-mir-3122 & Down & C1RL & 57 & hsa-mir-4451 \\
\hline Up & LAMC1 & 75 & hsa-mir-4791 & Down & MAP7 & 56 & hsa-mir-3666 \\
\hline Up & MELK & 74 & hsa-mir-4330 & Down & LIFR & 55 & hsa-mir-6126 \\
\hline Up & AURKA & 73 & hsa-mir-4476 & Down & GNE & 55 & hsa-mir-7641 \\
\hline
\end{tabular}


medRxiv preprint doi: https://doi.org/10.1101/2020.12.22.20248756; this version posted December 26, 2020. The copyright holder for this

\begin{tabular}{|c|c|c|c|c|c|c|c|}
\hline Up & ZNF711 & 71 & hsa-mir-5701 & Down & ALDH6A1 & 54 & hsa-mir-5095 \\
\hline Up & SLC25A36 & 69 & hsa-mir-8066 & Down & ZFP36 & 53 & hsa-mir-5700 \\
\hline Up & ACSL4 & 68 & hsa-mir-3666 & Down & IYD & 51 & hsa-mir-4435 \\
\hline Up & NPM3 & 68 & hsa-mir-4429 & Down & KCND3 & 50 & hsa-mir- 8082 \\
\hline Up & ITM2C & 67 & hsa-mir-4533 & Down & AQP3 & 50 & hsa-mir-8485 \\
\hline Up & BUB1 & 67 & hsa-mir-4302 & Down & GATM & 49 & hsa-mir-8069 \\
\hline Up & FIGN & 65 & hsa-mir-3149 & Down & CNDP1 & 49 & hsa-mir-3135b \\
\hline Up & TRIM28 & 65 & hsa-mir-4481 & Down & TTC39C & 49 & hsa-mir-4464 \\
\hline Up & $\mathrm{XRCC} 2$ & 65 & hsa-mir-1470 & Down & SPTBN2 & 48 & hsa-mir-8059 \\
\hline Up & NKD1 & 65 & hsa-mir-5095 & Down & MFSD2A & 48 & hsa-mir-1913 \\
\hline Up & MMS22L & 64 & hsa-mir-3665 & Down & RCAN1 & 47 & hsa-mir-5190 \\
\hline Up & CAD & 64 & hsa-mir-4426 & Down & PPP1R3B & 47 & hsa-mir-3201 \\
\hline Up & MDK & 63 & hsa-mir-4489 & Down & MBL2 & 47 & hsa-mir-4311 \\
\hline Up & SPC25 & 63 & hsa-mir-548i & Down & LRAT & 47 & hsa-mir-6088 \\
\hline Up & SGO1 & 63 & hsa-mir-4532 & Down & ARAP2 & 46 & hsa-mir-6071 \\
\hline Up & LIN28B & 62 & hsa-mir-4718 & Down & LEAP2 & 46 & hsa-mir-4279 \\
\hline Up & PCLAF & 62 & hsa-mir-4705 & Down & TNFSF14 & 46 & hsa-mir-4292 \\
\hline Up & NRXN3 & 61 & hsa-mir-5707 & Down & SLC7A2 & 45 & hsa-mir-4666b \\
\hline Up & ERVMER34-1 & 61 & hsa-mir-2052 & Down & PTPRB & 44 & hsa-mir-548z \\
\hline Up & ZNRF3 & 60 & hsa-mir-6134 & Down & SMIM14 & 44 & hsa-mir-6078 \\
\hline Up & PRR11 & 56 & hsa-mir-3926 & Down & CYP2B6 & 43 & hsa-mir-4651 \\
\hline Up & PLCG1 & 56 & hsa-mir-4635 & Down & MAT1A & 43 & hsa-mir-6131 \\
\hline Up & TTYH3 & 56 & hsa-mir-4468 & Down & SATB1 & 42 & hsa-mir-8066 \\
\hline Up & IGF2BP3 & 52 & hsa-mir-5191 & Down & ACADL & 42 & hsa-mir-6134 \\
\hline Up & CDK1 & 52 & hsa-mir-5688 & Down & RAB27A & 40 & hsa-mir-1281 \\
\hline Up & CHEK1 & 52 & hsa-mir-466 & Down & EPHX2 & 40 & hsa-mir-1470 \\
\hline Up & NAP1L1 & 51 & hsa-mir-4803 & Down & APOC3 & 40 & hsa-mir-548s \\
\hline Up & MCM7 & 51 & hsa-mir-4283 & Down & AVPR1A & 40 & hsa-mir-1276 \\
\hline Up & DNAH17 & 51 & hsa-mir-4673 & Down & CYP4A11 & 39 & hsa-mir-4683 \\
\hline Up & SLC2A1 & 50 & hsa-mir-4434 & Down & COLEC10 & 39 & hsa-mir-3713 \\
\hline Up & MCM4 & 48 & hsa-mir-8055 & Down & CYP4F11 & 38 & hsa-mir-4439 \\
\hline Up & DEPDC1 & 48 & hsa-mir-4698 & Down & CYP4A22 & 37 & hsa-mir-4483 \\
\hline Up & CKAP2L & 47 & hsa-mir-4729 & Down & CXCL8 & 36 & hsa-mir-4426 \\
\hline Up & ZNF610 & 46 & hsa-mir-4459 & Down & SDC4 & 36 & hsa-mir-4739 \\
\hline Up & GNG4 & 46 & hsa-mir-1273e & Down & ARHGEF26 & 36 & hsa-mir-1260a \\
\hline Up & MYBL2 & 45 & hsa-mir-8089 & Down & SLC41A2 & 35 & hsa-mir-6134 \\
\hline Up & NETO2 & 44 & hsa-mir-4495 & Down & BHLHE40 & 34 & hsa-mir-3941 \\
\hline Up & EIF4A2 & 43 & hsa-mir-300 & Down & ICAM1 & 34 & hsa-mir-3975 \\
\hline Up & NCAPD2 & 43 & hsa-mir-8070 & Down & CYP2C19 & 34 & hsa-mir-5186 \\
\hline Up & MYCN & 43 & hsa-mir-6071 & Down & FGD4 & 34 & hsa-mir-302f \\
\hline Up & ROBO1 & 43 & hsa-mir-548aa & Down & RBM47 & 34 & hsa-mir-298 \\
\hline Up & MPZL1 & 43 & hsa-mir-548ab & Down & GFRA1 & 34 & hsa-mir-6129 \\
\hline Up & SRARP & 43 & hsa-mir-4641 & Down & STEAP3 & 33 & hsa-mir-1275 \\
\hline Up & SPC24 & 43 & hsa-mir-5690 & Down & PCK1 & 33 & hsa-mir-548aa \\
\hline Up & COL4A1 & 42 & hsa-mir-892a & Down & SLC1A1 & 33 & hsa-mir-2113 \\
\hline Up & FOXQ1 & 42 & hsa-mir-3973 & Down & SOCS3 & 32 & hsa-mir-8062 \\
\hline Up & HS6ST1 & 42 & hsa-mir-4419a & Down & SERPINC1 & 32 & hsa-mir-4794 \\
\hline Up & GINS2 & 41 & hsa-mir-4499 & Down & RUNDC3B & 31 & hsa-mir-4660 \\
\hline Up & SLC29A4 & 41 & hsa-mir-1321 & Down & ETS2 & 31 & hsa-mir-3662 \\
\hline Up & PLK1 & 40 & hsa-mir-4779 & Down & SLC25A15 & 31 & hsa-mir-3176 \\
\hline Up & PRKAA2 & 40 & hsa-mir-4771 & Down & ETFDH & 31 & hsa-mir-4441 \\
\hline Up & MATN3 & 40 & hsa-mir-3689c & Down & DUSP1 & 30 & hsa-mir-4500 \\
\hline Up & COLEC12 & 38 & hsa-mir-4500 & Down & PPARGC1A & 30 & hsa-mir-6083 \\
\hline Up & PYCR1 & 38 & hsa-mir-920 & Down & ACADSB & 30 & hsa-mir-5100 \\
\hline Up & LYZ & 38 & hsa-mir-4252 & Down & PLAC8 & 30 & hsa-mir-4481 \\
\hline Up & SRD5A3 & 38 & hsa-mir-4306 & Down & HAAO & 30 & hsa-mir-4770 \\
\hline Up & DKK3 & 38 & hsa-mir-4775 & Down & CDC37L1 & 29 & hsa-mir-548z \\
\hline Up & CCNA2 & 37 & hsa-mir-548aw & Down & CYP8B1 & 29 & hsa-mir-422a \\
\hline Up & ARHGAP11A & 37 & hsa-mir-548ag & Down & $\mathrm{C} 8 \mathrm{~A}$ & 29 & hsa-mir-1299 \\
\hline Up & TRIM59 & 37 & hsa-mir-4511 & Down & FMO4 & 28 & hsa-mir-3118 \\
\hline Up & TCTN2 & 37 & hsa-mir-5186 & Down & ABCA6 & 28 & hsa-mir-3135b \\
\hline Up & TGFB2 & 35 & hsa-mir-378f & Down & SGMS2 & 28 & hsa-mir-3609 \\
\hline Up & EPHB2 & 35 & hsa-mir-6077 & Down & JUNB & 28 & hsa-mir-3202 \\
\hline Up & RAB34 & 34 & hsa-mir-4295 & Down & FXYD1 & 28 & hsa-mir-3180 \\
\hline Up & GREB1 & 34 & hsa-mir-548s & Down & CES3 & 27 & hsa-mir-3689c \\
\hline Up & KCNJ10 & 34 & hsa-mir-3655 & Down & GOT1 & 27 & hsa-mir-549a \\
\hline Up & IGDCC3 & 34 & hsa-mir-378d & Down & PTPN3 & 26 & hsa-mir-4801 \\
\hline Up & ZNF738 & 33 & hsa-mir-147a & Down & ECHDC3 & 26 & hsa-mir-562 \\
\hline Up & CCDC $88 \mathrm{C}$ & 33 & hsa-mir-636 & Down & SLPI & 26 & hsa-mir-4419b \\
\hline Up & NDRG3 & 33 & hsa-mir-4478 & Down & PON1 & 26 & hsa-mir-7703 \\
\hline Up & LTBP2 & 33 & hsa-mir-8071 & Down & LRRFIP1 & 25 & hsa-mir-4267 \\
\hline Up & LRRC1 & 32 & hsa-mir-1193 & Down & MGLL & 25 & hsa-mir-938 \\
\hline Up & TMC7 & 32 & hsa-mir-4719 & Down & CYP1A1 & 25 & hsa-mir-4294 \\
\hline Up & PTK7 & 32 & hsa-mir-2110 & Down & SLCO1B3 & 25 & hsa-mir-1470 \\
\hline Up & ARHGEF2 & 32 & hsa-mir-5194 & Down & TLR4 & 24 & hsa-mir-630 \\
\hline
\end{tabular}


medRxiv preprint doi: https://doi.org/10.1101/2020.12.22.20248756; this version posted December 26, 2020. The copyright holder for this preprint (which was not certified by peer review) is the author/funder, who has granted medRxiv a license to display the preprint in perpetuity. All rights reserved. No reuse allowed without permission.

\begin{tabular}{|c|c|c|c|c|c|c|c|}
\hline Up & DUSP9 & 32 & hsa-mir-5703 & Down & GLRX & 24 & hsa-mir-608 \\
\hline Up & THY1 & 32 & hsa-mir-4706 & Down & PXDC1 & 24 & hsa-mir-4323 \\
\hline Up & SDK1 & 32 & hsa-mir-128-1-5p & Down & ART4 & 24 & hsa-mir-4417 \\
\hline Up & MMP2 & 31 & hsa-mir-451a & Down & SAA1 & 24 & hsa-mir-4792 \\
\hline Up & SOBP & 31 & hsa-mir-599 & Down & ADH1B & 24 & hsa-mir-568 \\
\hline Up & NCAPH & 31 & hsa-mir-6129 & Down & EXPH5 & 23 & hsa-mir-548p \\
\hline Up & GSN & 31 & hsa-mir- 8080 & Down & ARRDC3 & 23 & hsa-mir-4753-3p \\
\hline Up & ARL6IP6 & 30 & hsa-mir-4301 & Down & WDR72 & 23 & hsa-mir-4719 \\
\hline Up & LAPTM4B & 30 & hsa-mir-548aj-5p & Down & SERPINE1 & 22 & hsa-mir-3977 \\
\hline Up & ATP8B2 & 30 & hsa-mir-3689d & Down & SERPINA3 & 22 & hsa-mir-5096 \\
\hline Up & COL1A2 & 30 & hsa-mir-6090 & Down & TAT & 22 & hsa-mir-3689d \\
\hline Up & FDFT1 & 30 & hsa-mir-4742-5p & Down & MT1E & 21 & hsa-mir-107 \\
\hline Up & ST8SIA3 & 30 & hsa-mir-507 & Down & DUSP5 & 21 & hsa-mir-16-1-3p \\
\hline Up & SLC1A4 & 29 & hsa-mir-603 & Down & FGG & 21 & hsa-mir-623 \\
\hline Up & DEPDC1B & 29 & hsa-mir-548z & Down & AKAP12 & 21 & hsa-mir-8057 \\
\hline Up & CDC6 & 28 & hsa-mir-4421 & Down & F9 & 21 & hsa-mir-326 \\
\hline Up & ATP1A2 & 28 & hsa-mir-588 & Down & NDST3 & 21 & hsa-mir-665 \\
\hline Up & SPATS2 & 27 & hsa-mir-4680-3p & Down & DAO & 21 & hsa-mir-1587 \\
\hline Up & SLC39A10 & 27 & hsa-mir-591 & Down & PTGS2 & 20 & hsa-mir-137 \\
\hline Up & MAPK13 & 27 & hsa-mir- 8082 & Down & MAP3K5 & 20 & hsa-mir-5191 \\
\hline Up & WDR76 & 27 & hsa-mir-4755-3p & Down & CYP4V2 & 20 & hsa-mir-378a-5p \\
\hline Up & TBX4 & 27 & hsa-mir-6083 & Down & HOOK1 & 20 & hsa-mir-548n \\
\hline Up & KNTC1 & 27 & hsa-mir-633 & Down & AKR1D1 & 20 & hsa-mir-660-3p \\
\hline Up & E2F5 & 26 & hsa-mir-6501-3p & Down & CFHR5 & 20 & hsa-mir-6777-3p \\
\hline Up & AXIN2 & 26 & hsa-mir-3617-5p & Down & STEAP4 & 19 & hsa-mir-548ac \\
\hline Up & FREM2 & 26 & hsa-mir-297 & Down & PPP1R1A & 19 & hsa-mir-378g \\
\hline Up & PIK3R2 & 25 & hsa-mir-3135b & Down & SLC15A1 & 19 & hsa-mir-3929 \\
\hline Up & PGAP1 & 25 & hsa-mir-4684-5p & Down & SLC4A4 & 19 & hsa-mir-6727-3p \\
\hline Up & RPS27 & 24 & hsa-mir-4461 & Down & GCLM & 18 & hsa-mir-3155a \\
\hline Up & MCM5 & 24 & hsa-mir-4692 & Down & RGS2 & 18 & hsa-mir-4328 \\
\hline Up & GNA12 & 24 & hsa-mir-1266-5p & Down & PAPSS2 & 18 & hsa-mir-5011-5p \\
\hline Up & VCAN & 24 & hsa-mir-643 & Down & $\mathrm{CTH}$ & 18 & hsa-mir-3190-5p \\
\hline Up & CENPI & 24 & hsa-mir-1200 & Down & FGB & 18 & hsa-mir-6855-5p \\
\hline Up & HJURP & 24 & hsa-mir-1827 & Down & C6 & 18 & hsa-mir-6511a-3p \\
\hline Up & MFAP2 & 24 & hsa-mir-4454 & Down & DTX1 & 18 & hsa-mir-6888-3p \\
\hline Up & SALL2 & 23 & hsa-mir-613 & Down & GLYAT & 18 & hsa-mir-3193 \\
\hline Up & SMOC2 & 23 & hsa-mir- 8055 & Down & TENM1 & 18 & hsa-mir-7154-5p \\
\hline Up & CDCA7 & 22 & hsa-mir-550a-3-5p & Down & CYP4F3 & 18 & hsa-mir-4793-3p \\
\hline Up & NPNT & 22 & hsa-mir-526b-3p & Down & ABCB 11 & 17 & hsa-mir-4700-3p \\
\hline Up & B3GALNT1 & 22 & hsa-mir-890 & Down & AKR7L & 17 & hsa-mir-891a-3p \\
\hline Up & CDON & 22 & hsa-mir-4455 & Down & CYP3A5 & 17 & hsa-mir-599 \\
\hline Up & RHNO1 & 22 & hsa-mir-661 & Down & APOL1 & 17 & hsa-mir-1304-3p \\
\hline Up & DLGAP5 & 21 & hsa-mir-520b & Down & HSD17B13 & 17 & hsa-mir-6500-5p \\
\hline Up & LSM2 & 21 & hsa-mir-6127 & Down & NAMPT & 16 & hsa-mir-4662a-5p \\
\hline Up & KIFC1 & 20 & hsa-mir-4530 & Down & NR4A2 & 16 & hsa-mir-217 \\
\hline Up & NCAPG & 20 & hsa-mir-421 & Down & SLC46A3 & 16 & hsa-mir-6796-3p \\
\hline Up & PCGF2 & 20 & hsa-mir-3685 & Down & SUCLG2 & 16 & hsa-mir-2355-5p \\
\hline Up & EDIL3 & 20 & hsa-mir-548ac & Down & LYVE1 & 16 & hsa-mir-4691-3p \\
\hline Up & TMEM98 & 20 & hsa-mir-641 & Down & ADH4 & 16 & hsa-mir-3944-5p \\
\hline Up & EDARADD & 20 & hsa-mir-4674 & Down & SLC38A4 & 16 & hsa-mir-3150b-3p \\
\hline Up & APCDD1 & 20 & hsa-mir-7150 & Down & CYP1A2 & 15 & hsa-mir-1273g- $3 p$ \\
\hline Up & TRIB2 & 19 & hsa-mir-548z & Down & GCH1 & 15 & hsa-mir-4802-3p \\
\hline Up & TET1 & 19 & hsa-mir-3686 & Down & GREM2 & 15 & hsa-mir-6072 \\
\hline Up & TUBG1 & 19 & hsa-mir- 4477 a & Down & VNN3 & 15 & hsa-mir-3916 \\
\hline Up & SNRPB & 19 & hsa-mir-4457 & Down & KYNU & 15 & hsa-mir-4494 \\
\hline Up & LDOC1 & 19 & hsa-mir-4519 & Down & RASD1 & 15 & hsa-mir-6883-5p \\
\hline \multirow[t]{2}{*}{ Up } & & & & Down & & & hsa-mir-550b-2- \\
\hline & CDKN3 & 18 & hsa-mir-4772-3p & & EHHADH & 15 & $5 \mathrm{p}$ \\
\hline Up & CENPK & 18 & hsa-mir-507 & Down & ACACB & 15 & hsa-mir-544a \\
\hline Up & HUNK & 18 & hsa-mir-3157-5p & Down & LRG1 & 15 & hsa-mir-5011-3p \\
\hline Up & PFKM & 17 & hsa-mir-1199-5p & Down & $\mathrm{SCP} 2$ & 14 & hsa-mir-622 \\
\hline Up & CKAP2 & 17 & hsa-mir-3609 & Down & MYO1B & 14 & hsa-mir-4703-3p \\
\hline Up & PSPH & 17 & hsa-mir-4444 & Down & ZDBF2 & 14 & hsa-mir-610 \\
\hline Up & TOP2A & 17 & hsa-mir-520d-5p & Down & MACF1 & 13 & hsa-mir-296-3p \\
\hline Up & MAD2L1 & 17 & hsa-mir-3977 & Down & ASS1 & 13 & hsa-mir-606 \\
\hline Up & BCL11A & 17 & hsa-mir-6810-5p & Down & ADAMTS1 & 13 & hsa-mir-5196-3p \\
\hline Up & PRC1 & 17 & hsa-mir-4473 & Down & GPD1 & 13 & hsa-mir-5088-3p \\
\hline Up & PARD3B & 17 & hsa-mir-4267 & Down & HAL & 13 & hsa-mir-620 \\
\hline Up & STIL & 16 & hsa-mir-4266 & Down & ABAT & 13 & hsa-mir-6088 \\
\hline Up & DKK1 & 16 & hsa-mir-3177-5p & Down & DNASE1L3 & 13 & hsa-mir-6877-3p \\
\hline Up & BCAM & 16 & hsa-mir-634 & Down & VNN1 & 13 & hsa-mir-5004-5p \\
\hline Up & ALYREF & 16 & hsa-mir-4666a-5p & Down & REPS2 & 12 & hsa-mir-6780a-3p \\
\hline Up & DCDC2 & 16 & hsa-mir-5692a & Down & VIPR1 & 12 & hsa-mir-1260b \\
\hline Up & ACLY & 15 & hsa-mir-1229-3p & Down & SLC27A2 & 11 & hsa-mir-7113-3p \\
\hline Up & KCNJ5 & 15 & hsa-mir-6514-3p & Down & USP2 & 11 & hsa-mir- 2110 \\
\hline
\end{tabular}


medRxiv preprint doi: https://doi.org/10.1101/2020.12.22.20248756; this version posted December 26, 2020. The copyright holder for this

\begin{tabular}{|c|c|c|c|c|c|c|c|}
\hline Up & MCTP1 & 15 & hsa-mir-4755-5p & Down & NNMT & 11 & hsa-mir-6500-3p \\
\hline Up & UHRF1 & 14 & hsa-mir-146a-5p & Down & APOA5 & 11 & hsa-mir-4780 \\
\hline Up & RPS5 & 14 & hsa-mir-455-3p & Down & ACSL1 & 10 & hsa-mir-142-3p \\
\hline Up & SMYD2 & 14 & hsa-mir- 4516 & Down & MBOAT1 & 10 & hsa-mir-6499-5p \\
\hline Up & FOXM1 & 14 & hsa-mir-630 & Down & $\mathrm{C} 1 \mathrm{~S}$ & 10 & hsa-mir-4701-5p \\
\hline Up & MCM3 & 14 & hsa-mir-147b & Down & АВCC9 & 10 & hsa-mir-890 \\
\hline Up & NREP & 14 & hsa-mir-571 & Down & BMP10 & 10 & hsa-mir-4789-3p \\
\hline Up & ZNF362 & 14 & hsa-mir-7106-3p & Down & AADAC & 10 & hsa-mir-1179 \\
\hline Up & ZSWIM5 & 14 & hsa-mir-4325 & Down & HGFAC & 10 & hsa-mir-3607-3p \\
\hline Up & FREM1 & 14 & hsa-mir-934 & Down & HPR & 10 & hsa-mir-4311 \\
\hline Up & TYMS & 13 & hsa-mir-433-3p & Down & SLC6A1 & 10 & hsa-mir-7845-5p \\
\hline Up & ECT2 & 13 & hsa-mir-3591-5p & Down & $\mathrm{C} 7$ & 10 & hsa-mir-7162-3p \\
\hline Up & GJA5 & 13 & hsa-mir-4701-3p & Down & AGL & 9 & hsa-mir-191-5p \\
\hline Up & $\mathrm{RCN} 2$ & 13 & hsa-mir-1910-3p & Down & FGF14 & 9 & hsa-mir-6867-5p \\
\hline Up & KIF11 & 13 & hsa-mir-6507-5p & Down & SLITRK3 & 9 & hsa-mir-3130-3p \\
\hline Up & IMPDH2 & 12 & hsa-mir-378a-5p & Down & DMGDH & 9 & hsa-mir-518e-3p \\
\hline Up & DLK1 & 12 & hsa-mir-4299 & Down & UGT2B10 & 9 & hsa-mir-6804-3p \\
\hline Up & $\mathrm{CDC} 20$ & 12 & hsa-mir-188-5p & Down & BAAT & 9 & hsa-mir-5590-3p \\
\hline Up & CENPF & 12 & hsa-mir-1226-3p & Down & SCN9A & 9 & hsa-mir-548o-3p \\
\hline Up & ARHGEF28 & 12 & hsa-mir-6771-3p & Down & GRAMD1C & 9 & hsa-mir-548az-3p \\
\hline Up & SNTG1 & 12 & hsa-mir-513c-3p & Down & GYS2 & 8 & hsa-mir-4659a-3p \\
\hline Up & SKA1 & 12 & hsa-mir-519e-5p & Down & RND3 & 8 & hsa-mir-106a-5p \\
\hline Up & CRABP2 & 12 & hsa-mir-449a & Down & $\mathrm{NR} 3 \mathrm{C} 2$ & 8 & hsa-mir-548i \\
\hline Up & GLMP & 12 & hsa-mir-7162-3p & Down & FCN2 & 8 & hsa-mir-501-3p \\
\hline Up & MFGE8 & 12 & hsa-mir-4442 & Down & EGR1 & 8 & hsa-mir-377-3p \\
\hline Up & CKB & 11 & hsa-mir-551a & Down & CFHR3 & 8 & hsa-mir-5007-3p \\
\hline Up & GPX7 & 11 & hsa-mir-1255a & Down & KMO & 8 & hsa-mir-302c-5p \\
\hline Up & HELLS & 11 & hsa-mir-138-2-3p & Down & $\mathrm{C} 1 \mathrm{R}$ & 8 & hsa-mir-518c-5p \\
\hline Up & PRKD1 & 11 & hsa-mir-6740-3p & Down & HPGD & 7 & hsa-mir-4742-3p \\
\hline Up & ALDH18A1 & 11 & hsa-mir-4709-3p & Down & ST3GAL6 & 7 & hsa-mir-526b-5p \\
\hline Up & REG3A & 11 & hsa-mir-2277-3p & Down & ADGRG7 & 7 & hsa-mir-4465 \\
\hline Up & RPL22L1 & 11 & hsa-mir-3614-5p & Down & RASGEF1B & 7 & hsa-mir-1287-3p \\
\hline Up & RAPGEFL1 & 10 & hsa-mir-5692c & Down & CRP & 7 & hsa-mir-4418 \\
\hline Up & RAD51AP1 & 10 & hsa-mir-346 & Down & AGXT & 7 & hsa-mir-3606-5p \\
\hline Up & SKP2 & 10 & hsa-mir-3613-3p & Down & SLC22A1 & 7 & hsa-mir-466 \\
\hline Up & PDGFRB & 10 & hsa-mir-224-5p & Down & UGP2 & 6 & hsa-mir-32-5p \\
\hline Up & ITGA6 & 10 & hsa-mir-140-3p & Down & GBP2 & 6 & hsa-mir-433-3p \\
\hline Up & BCL9 & 10 & hsa-mir-30c-2-3p & Down & HGF & 5 & hsa-mir-199a-3p \\
\hline Up & SULT1C4 & 10 & hsa-mir-6832-3p & Down & CPNE8 & 5 & hsa-mir-4719 \\
\hline Up & MCM2 & 10 & hsa-mir-501-3p & Down & CXCL2 & 5 & hsa-mir-223-3p \\
\hline Up & SORT1 & 10 & hsa-mir-1185-5p & Down & NFKBIZ & 5 & hsa-mir-215-5p \\
\hline Up & CDH13 & 10 & hsa-mir-4307 & Down & CXCL14 & 5 & hsa-mir-2276-3p \\
\hline Up & AACS & 10 & hsa-mir-4466 & Down & SOCS2 & 4 & hsa-mir-16-5p \\
\hline Up & VWCE & 10 & hsa-mir-5088-3p & Down & NTN4 & 4 & hsa-mir-20a-5p \\
\hline Up & FAM169A & 10 & hsa-mir-3133 & Down & ACAT1 & 4 & hsa-mir-23b-3p \\
\hline Up & IGF2BP2 & 9 & hsa-mir-129-5p & Down & CA2 & 4 & hsa-mir-99b-3p \\
\hline Up & NT5DC2 & 9 & hsa-mir-760 & Down & CYP2C 8 & 4 & hsa-mir-107 \\
\hline Up & DTL & 9 & hsa-mir-138-1-3p & Down & $\mathrm{ABCC} 3$ & 4 & hsa-mir-197-3p \\
\hline Up & ASF1B & 9 & hsa-mir-3677-5p & Down & LRRK2 & 4 & hsa-mir-582-3p \\
\hline Up & HSDL1 & 9 & hsa-mir-340-5p & Down & FGFR2 & 4 & hsa-mir-19b-1-5p \\
\hline \multirow[t]{2}{*}{ Up } & & & & Down & & & hsa-mir-1185-1- \\
\hline & TNFSF4 & 9 & hsa-mir-4303 & & TMOD1 & 4 & $3 p$ \\
\hline Up & MAP4K4 & 8 & hsa-mir-5583-3p & Down & BBOX1 & 4 & hsa-mir-616-3p \\
\hline Up & PTTG1 & 8 & hsa-mir-17-5p & Down & MFAP3L & 4 & hsa-mir-6859-3p \\
\hline Up & FADS2 & 8 & hsa-mir- $423-3 p$ & Down & RIDA & 3 & hsa-mir-15a-5p \\
\hline Up & MSH2 & 8 & hsa-mir-101-3p & Down & LBP & 3 & hsa-mir-22-3p \\
\hline Up & MEG3 & 8 & hsa-mir-770-5p & Down & S100A8 & 3 & hsa-mir-125b-5p \\
\hline Up & SPDL1 & 8 & hsa-mir-944 & Down & ACADM & 3 & hsa-mir-128-3p \\
\hline Up & UXS1 & 7 & hsa-mir-519d-3p & Down & F13B & 3 & hsa-mir-124-3p \\
\hline Up & TTK & 7 & hsa-mir-376a-3p & Down & CFI & 3 & hsa-mir-181a-5p \\
\hline Up & PRR15L & 7 & hsa-mir-590-3p & Down & VNN2 & 3 & hsa-mir-124-3p \\
\hline Up & RASL11B & 7 & hsa-mir-4652-3p & Down & SLCO1B1 & 3 & hsa-mir-511-5p \\
\hline Up & SKA3 & 6 & hsa-mir-6719-3p & Down & MRC1 & 3 & hsa-mir- 4448 \\
\hline Up & ASPM & 6 & hsa-mir-218-5p & Down & ARG1 & 3 & hsa-mir-7-5p \\
\hline Up & FANCI & 6 & hsa-mir-505-3p & Down & PTS & 3 & hsa-mir-92a-3p \\
\hline Up & GINS1 & 6 & hsa-mir-19a-3p & Down & BIRC3 & 3 & hsa-mir-375 \\
\hline Up & DKK2 & 6 & hsa-mir-27a-3p & Down & $\mathrm{CFB}$ & 3 & hsa-mir-210-5p \\
\hline Up & MCM6 & 6 & hsa-mir-1180-3p & Down & NFIL3 & 3 & hsa-mir-183-5p \\
\hline Up & LEF1 & 6 & hsa-mir-34c-3p & Down & MT1F & 3 & hsa-mir-219a-5p \\
\hline Up & SPP1 & 6 & hsa-mir-193b-3p & Down & OIT3 & 3 & hsa-mir-5087 \\
\hline Up & DLX5 & 6 & hsa-mir-203a-3p & Down & BMPER & 3 & hsa-mir-212-3p \\
\hline Up & LGR5 & 6 & hsa-mir-6793-3p & Down & DIO1 & 3 & hsa-mir-383-5p \\
\hline Up & CDCA2 & 6 & hsa-mir-5586-5p & Down & ANO1 & 3 & hsa-mir-381-3p \\
\hline Up & FRRS1L & 6 & hsa-mir-501-5p & Down & CYP2C9 & 3 & hsa-mir-130b-3p \\
\hline Up & ZNF382 & 6 & hsa-mir-5095 & Down & CPED1 & 2 & hsa-mir-10a-5p \\
\hline
\end{tabular}


medRxiv preprint doi: https://doi.org/10.1101/2020.12.22.20248756; this version posted December 26, 2020. The copyright holder for this

\begin{tabular}{|c|c|c|c|c|c|c|c|}
\hline Up & CCNB2 & 5 & hsa-let-7f-5p & Down & PCK2 & 2 & hsa-mir-24-3p \\
\hline Up & FKBP10 & 5 & hsa-let-7c-5p & Down & GLS2 & 2 & hsa-mir-16-5p \\
\hline Up & EHMT2 & 5 & hsa-mir-17-5p & Down & AADAT & 2 & hsa-mir-103a-3p \\
\hline Up & KIF20A & 5 & hsa-mir-23a-3p & Down & MT1M & 2 & hsa-mir-24-3p \\
\hline Up & CD34 & 5 & hsa-mir-106b-5p & Down & SULT2A1 & 2 & hsa-mir-335-5p \\
\hline Up & GSTP1 & 5 & hsa-mir-133a-3p & Down & AGPAT2 & 2 & hsa-mir-744-5p \\
\hline Up & SLC7A6 & 5 & hsa-mir-30a-3p & Down & APOF & 2 & hsa-mir-324-5p \\
\hline Up & USP21 & 5 & hsa-mir-331-3p & Down & BCHE & 2 & hsa-mir-26b-5p \\
\hline Up & CTSC & 5 & hsa-mir-199a-5p & Down & HGD & 2 & hsa-mir-335-5p \\
\hline Up & TRPC1 & 5 & hsa-mir-192-5p & Down & HSD11B1 & 2 & hsa-mir-26b-5p \\
\hline Up & ANLN & 5 & hsa-mir-497-5p & Down & IL13RA2 & 2 & hsa-mir-148b-3p \\
\hline Up & C1orf198 & 5 & hsa-mir-31-3p & Down & CHST9 & 2 & hsa-mir-92a-3p \\
\hline Up & PBK & 5 & hsa-mir-4699-3p & Down & INHBE & 2 & hsa-mir-98-5p \\
\hline Up & ZMYM3 & 4 & hsa-mir-330-3p & Down & MT1X & 2 & hsa-mir-1225-3p \\
\hline Up & NRSN2 & 4 & hsa-let-7e-5p & Down & ABCA8 & 2 & hsa-mir-192-5p \\
\hline Up & GPD1L & 4 & hsa-mir-210-3p & Down & RND1 & 2 & hsa-mir-199a-5p \\
\hline Up & COL15A1 & 4 & hsa-mir-29c-3p & Down & $\mathrm{C} 5$ & 2 & hsa-mir-10a-5p \\
\hline Up & OXCT1 & 4 & hsa-mir-100-5p & Down & ALDH1A1 & 2 & hsa-mir-140-5p \\
\hline Up & SFRP4 & 4 & hsa-mir-203a-5p & Down & FOSB & 2 & hsa-mir-663a \\
\hline Up & FERMT1 & 4 & hsa-mir-9-5p & Down & HERC5 & 2 & hsa-mir-3529-3p \\
\hline Up & MMP11 & 4 & hsa-mir-135a-5p & Down & AMDHD1 & 2 & hsa-mir-1-3p \\
\hline Up & $\mathrm{CDC} 25 \mathrm{C}$ & 4 & hsa-mir-141-3p & Down & ALDOB & 2 & hsa-mir-378a-3p \\
\hline Up & ZAP70 & 4 & hsa-mir-631 & Down & C4BPB & 2 & hsa-mir-142-3p \\
\hline Up & WIF1 & 4 & hsa-mir-374a-5p & Down & NRG1 & 2 & hsa-mir-125a-3p \\
\hline $\mathrm{Up}$ & ERP27 & 4 & hsa-mir-210-3p & Down & GDA & 2 & hsa-mir-492 \\
\hline Up & CDH1 1 & 4 & hsa-mir-200c-3p & Down & RETREG1 & 2 & hsa-mir-1260b \\
\hline Up & FRZB & 4 & hsa-mir-125b-1-3p & Down & ENPEP & 2 & hsa-mir-320a \\
\hline $\mathrm{Up}$ & HEY 1 & 4 & hsa-mir-410-3p & Down & CYP26A1 & 2 & hsa-mir-132-3p \\
\hline Up & LPCAT2 & 4 & hsa-mir-449c-5p & Down & CYP39A1 & 2 & hsa-mir-9-5p \\
\hline $\mathrm{Up}$ & MAGED1 & 4 & hsa-let-7g-3p & Down & GAREM1 & 2 & hsa-mir-29a-5p \\
\hline Up & SQLE & 3 & hsa-mir-205-5p & Down & SLC25A18 & 2 & hsa-mir-148b-3p \\
\hline $\mathrm{Up}$ & SERPINE2 & 3 & hsa-mir-30e-3p & Down & FYB2 & 2 & hsa-mir-335-5p \\
\hline $\mathrm{Up}$ & ERCC2 & 3 & hsa-mir-770-5p & Down & LPIN2 & 2 & hsa-mir-769-5p \\
\hline Up & ETV1 & 3 & hsa-mir-20a-5p & Down & OGDHL & 2 & hsa-mir-130b-5p \\
\hline $\mathrm{Up}$ & RFC3 & 3 & hsa-mir-93-5p & Down & ALAS1 & 2 & hsa-mir-423-3p \\
\hline Up & BEX1 & 3 & hsa-mir- $15 b-5 p$ & Down & AASS & 2 & hsa-mir-591 \\
\hline Up & RHOBTB1 & 3 & hsa-mir-31-5p & Down & ABCA10 & 2 & hsa-mir-1281 \\
\hline Up & LRP4 & 3 & hsa-mir-148b-3p & Down & UROC1 & 1 & hsa-let-7e-5p \\
\hline Up & LRRN1 & 3 & hsa-mir-30a-5p & Down & CRHBP & 1 & hsa-mir-16-5p \\
\hline Up & TSPAN18 & 3 & hsa-mir-597-5p & Down & FCGR2B & 1 & hsa-mir-18a-5p \\
\hline Up & SEMA3C & 3 & hsa-mir-374b-5p & Down & PHYH & 1 & hsa-mir-20a-5p \\
\hline $\mathrm{Up}$ & PTP4A3 & 3 & hsa-mir-551a & Down & HRG & 1 & hsa-mir-23a-3p \\
\hline Up & NUF2 & 3 & hsa-mir-215-5p & Down & AOX1 & 1 & hsa-mir-26b-5p \\
\hline Up & TICRR & 3 & hsa-mir-192-5p & Down & CYP2D7 & 1 & hsa-mir-26b-5p \\
\hline $\mathrm{Up}$ & RELN & 3 & hsa-mir-138-5p & Down & CYP2D6 & 1 & hsa-mir-26b-5p \\
\hline Up & GPC3 & 3 & hsa-mir-520c-3p & Down & FMO3 & 1 & hsa-mir-26b-5p \\
\hline Up & SOAT2 & 3 & hsa-mir-377-5p & Down & GSTA1 & 1 & hsa-mir-26b-5p \\
\hline $\mathrm{Up}$ & LIX1 & 3 & hsa-mir-561-3p & Down & OTC & 1 & hsa-mir-26b-5p \\
\hline $\mathrm{Up}$ & PAPSS1 & 2 & hsa-mir-100-5p & Down & $\mathrm{XDH}$ & 1 & hsa-mir-26b-5p \\
\hline Up & TOX3 & 2 & hsa-let-7b-5p & Down & BLNK & 1 & hsa-mir-26b-5p \\
\hline Up & PRTG & 2 & hsa-mir-9-5p & Down & FGGY & 1 & hsa-mir-26b-5p \\
\hline $\mathrm{Up}$ & RNASE1 & 2 & hsa-mir-26b-5p & Down & MT1P3 & 1 & hsa-mir-26b-5p \\
\hline $\mathrm{Up}$ & FMOD & 2 & hsa-mir-21-5p & Down & SLC22A7 & 1 & hsa-mir-29a-3p \\
\hline Up & WFS1 & 2 & hsa-mir-7-5p & Down & CTSL & 1 & hsa-mir-30a-5p \\
\hline $\mathrm{Up}$ & DKK4 & 2 & hsa-mir-25-3p & Down & CES1 & 1 & hsa-mir-197-3p \\
\hline $\mathrm{Up}$ & MME & 2 & hsa-mir-1-3p & Down & PIPOX & 1 & hsa-mir-197-3p \\
\hline Up & SUPT3H & 2 & hsa-mir-15b-5p & Down & RDH16 & 1 & hsa-mir-7-5p \\
\hline Up & TP53I3 & 2 & hsa-mir-504-5p & Down & CLEC4G & 1 & hsa-mir-7-5p \\
\hline Up & P4HA2 & 2 & hsa-mir-9-5p & Down & SHBG & 1 & hsa-mir-10a-5p \\
\hline Up & SV2A & 2 & hsa-mir-222-3p & Down & GADD45G & 1 & hsa-mir-181a-5p \\
\hline Up & TTLL4 & 2 & hsa-mir-877-3p & Down & ALPL & 1 & hsa-mir-204-5p \\
\hline Up & COL2A1 & 2 & hsa-mir-29b-3p & Down & ABLIM3 & 1 & hsa-mir-214-3p \\
\hline Up & PLK4 & 2 & hsa-mir-215-5p & Down & ALPK2 & 1 & hsa-mir-214-3p \\
\hline Up & NEIL3 & 2 & hsa-mir-192-5p & Down & CYP3A4 & 1 & hsa-mir-27b-3p \\
\hline $\mathrm{Up}$ & KIF18A & 2 & hsa-mir-215-5p & Down & CDO1 & 1 & hsa-mir-124-3p \\
\hline Up & SULT1C2 & 2 & hsa-mir-7-5p & Down & HSD17B6 & 1 & hsa-mir-124-3p \\
\hline Up & CD24 & 2 & hsa-mir-373-3p & Down & ETNPPL & 1 & hsa-mir-124-3p \\
\hline $\mathrm{Up}$ & TARBP1 & 2 & hsa-mir-29c-3p & Down & AZGP1 & 1 & hsa-mir-128-3p \\
\hline $\mathrm{Up}$ & DACT1 & 2 & hsa-mir-124-3p & Down & KNG1 & 1 & hsa-mir-128-3p \\
\hline $\mathrm{Up}$ & MPPED2 & 2 & hsa-mir-448 & Down & SLC17A4 & 1 & hsa-mir-128-3p \\
\hline Up & HTR1D & 2 & hsa-mir-196b-5p & Down & CYP4Z1 & 1 & hsa-mir-9-5p \\
\hline Up & KRT19 & 2 & hsa-mir-193b-3p & Down & AKR1C8P & 1 & hsa-mir-9-5p \\
\hline Up & MAGED2 & 2 & hsa-mir-877-3p & Down & IL1RN & 1 & hsa-mir-125a-5p \\
\hline $\mathrm{Up}$ & RNF43 & 2 & hsa-mir-550a-5p & Down & MASP1 & 1 & hsa-mir-125a-5p \\
\hline Up & NRCAM & 2 & hsa-mir-708-5p & Down & $\mathrm{CFH}$ & 1 & hsa-mir-146a-5p \\
\hline
\end{tabular}


medRxiv preprint doi: https://doi.org/10.1101/2020.12.22.20248756; this version posted December 26, 2020. The copyright holder for this preprint (which was not certified by peer review) is the author/funder, who has granted medRxiv a license to display the preprint in perpetuity. All rights reserved. No reuse allowed without permission.

\begin{tabular}{|c|c|c|c|c|c|c|c|}
\hline Up & ASIC1 & 1 & hsa-let-7b-5p & Down & ITIH4 & 1 & hsa-mir-375 \\
\hline Up & NUSAP1 & 1 & hsa-let-7b-5p & Down & MYOM1 & 1 & hsa-mir-148b-3p \\
\hline Up & ASPSCR1 & 1 & hsa-let-7b-5p & Down & FETUB & 1 & hsa-mir-148b-3p \\
\hline Up & PIGU & 1 & hsa-let-7b-5p & Down & C8G & 1 & hsa-mir-335-5p \\
\hline Up & C19orf48 & 1 & hsa-let-7e-5p & Down & CD5L & 1 & hsa-mir-335-5p \\
\hline Up & SERPINI1 & 1 & hsa-mir-21-5p & Down & CD14 & 1 & hsa-mir-335-5p \\
\hline Up & CCDC34 & 1 & hsa-mir-21-5p & Down & $\mathrm{CDA}$ & 1 & hsa-mir-335-5p \\
\hline Up & NOTUM & 1 & hsa-mir-24-3p & Down & CFHR2 & 1 & hsa-mir-335-5p \\
\hline Up & CACNB4 & 1 & hsa-mir-26b-5p & Down & IRF6 & 1 & hsa-mir-335-5p \\
\hline Up & EFNA4 & 1 & hsa-mir-26b-5p & Down & NPY1R & 1 & hsa-mir-335-5p \\
\hline Up & ETV4 & 1 & hsa-mir-26b-5p & Down & CFP & 1 & hsa-mir-335-5p \\
\hline Up & MEP1A & 1 & hsa-mir-26b-5p & Down & PON3 & 1 & hsa-mir-335-5p \\
\hline Up & B3GALT1 & 1 & hsa-mir-26b-5p & Down & SLC17A3 & 1 & hsa-mir-335-5p \\
\hline Up & ODAM & 1 & hsa-mir-26b-5p & Down & MMRN1 & 1 & hsa-mir-335-5p \\
\hline Up & FBLN1 & 1 & hsa-mir-30a-3p & Down & GNMT & 1 & hsa-mir-335-5p \\
\hline Up & SPARCL1 & 1 & hsa-mir-98-5p & Down & SPATA6L & 1 & hsa-mir-335-5p \\
\hline Up & PCSK5 & 1 & hsa-mir-107 & Down & ALDH8A1 & 1 & hsa-mir-335-5p \\
\hline Up & FAM111B & 1 & hsa-mir-192-5p & Down & LPAL2 & 1 & hsa-mir-335-5p \\
\hline Up & USP11 & 1 & hsa-mir-10a-5p & Down & RSPO3 & 1 & hsa-mir-335-5p \\
\hline Up & GFRA3 & 1 & hsa-mir-34a-5p & Down & CYP4F22 & 1 & hsa-mir-335-5p \\
\hline Up & SLCO2A1 & 1 & hsa-mir-181a-5p & Down & ASPG & 1 & hsa-mir-335-5p \\
\hline Up & BMP4 & 1 & hsa-let-7i-5p & Down & FAM99A & 1 & hsa-mir-335-5p \\
\hline Up & SPINK1 & 1 & hsa-mir-1-3p & Down & ADRA1A & 1 & hsa-mir-484 \\
\hline Up & C1orf74 & 1 & hsa-mir-27b-3p & Down & TTC36 & 1 & hsa-mir-484 \\
\hline Up & OLFML2B & 1 & hsa-mir-30b-5p & Down & ANO5 & 1 & hsa-mir-432-5p \\
\hline Up & CPA6 & 1 & hsa-mir-124-3p & Down & GPLD1 & 1 & hsa-mir-505-3p \\
\hline Up & MYH7B & 1 & hsa-mir-124-3p & Down & PAMR1 & 1 & hsa-mir-93-3p \\
\hline Up & FRAS1 & 1 & hsa-mir-124-3p & Down & ECM1 & 1 & hsa-mir-486-3p \\
\hline Up & HDAC11 & 1 & hsa-mir-145-5p & Down & UGT2B7 & 1 & hsa-mir-216b-5p \\
\hline Up & GSTA4 & 1 & hsa-mir-185-5p & Down & TIMD4 & 1 & hsa-mir- 4282 \\
\hline Up & AFP & 1 & hsa-mir-106b-5p & & & & \\
\hline Up & CHGB & 1 & hsa-mir-375 & & & & \\
\hline Up & NDN & 1 & hsa-mir-148b-3p & & & & \\
\hline Up & CST1 & 1 & hsa-mir-335-5p & & & & \\
\hline Up & DYNC1I1 & 1 & hsa-mir-335-5p & & & & \\
\hline Up & RBP1 & 1 & hsa-mir-335-5p & & & & \\
\hline Up & TSPAN5 & 1 & hsa-mir-335-5p & & & & \\
\hline Up & GJB6 & 1 & hsa-mir-335-5p & & & & \\
\hline Up & FAM3B & 1 & hsa-mir-335-5p & & & & \\
\hline Up & OLFML3 & 1 & hsa-mir-335-5p & & & & \\
\hline Up & ABHD12B & 1 & hsa-mir-335-5p & & & & \\
\hline Up & STOX1 & 1 & hsa-mir-335-5p & & & & \\
\hline Up & LYPD1 & 1 & hsa-mir-423-3p & & & & \\
\hline Up & FGF20 & 1 & hsa-mir-433-3p & & & & \\
\hline Up & NYNRIN & 1 & hsa-mir- 484 & & & & \\
\hline Up & POLE2 & 1 & hsa-mir-193b-3p & & & & \\
\hline Up & NDC80 & 1 & hsa-mir-193b-3p & & & & \\
\hline Up & TPX2 & 1 & hsa-mir-193b-3p & & & & \\
\hline Up & MND1 & 1 & hsa-mir-193b-3p & & & & \\
\hline Up & TMEM99 & 1 & hsa-mir-769-3p & & & & \\
\hline Up & MAP7D2 & 1 & hsa-mir-505-5p & & & & \\
\hline
\end{tabular}

Degree - No of miRNA interact with target gene. We taken any one miRNA in table.

Table 9 TF - target gene interaction table

\begin{tabular}{|c|c|c|c|c|c|c|c|}
\hline Regulation & TF & Degree & Target Gene & Regulation & TF & Degree & Target Gene \\
\hline $\mathrm{Up}$ & KLF9 & 121 & DCDC2 & Down & ATF3 & 115 & MASP2 \\
\hline $\mathrm{Up}$ & TFDP1 & 120 & WFS1 & Down & YY1 & 82 & OTC \\
\hline Up & ZNF580 & 117 & ERCC2 & Down & MYBL2 & 76 & ACMSD \\
\hline $\mathrm{Up}$ & MXD3 & 107 & DLX5 & Down & MBD4 & 76 & AGXT \\
\hline $\mathrm{Up}$ & SMAD5 & 105 & CCNB1 & Down & HNF4G & 76 & SLC15A1 \\
\hline $\mathrm{Up}$ & POLR2A & 103 & HIST1H3G & Down & TFDP1 & 62 & G0S2 \\
\hline Up & ELF1 & 102 & VCAN & Down & KLF16 & 61 & ASPDH \\
\hline $\mathrm{Up}$ & ZNF24 & 100 & RRM2 & Down & NR2F1 & 56 & SOD2 \\
\hline $\mathrm{Up}$ & ATF1 & 96 & ABHD12B & Down & ATF1 & 55 & SCN9A \\
\hline $\mathrm{Up}$ & MAZ & 96 & TMC7 & Down & ZBTB33 & 54 & SHMT1 \\
\hline $\mathrm{Up}$ & GTF2E2 & 95 & MCM5 & Down & KLF9 & 52 & ABCC 3 \\
\hline Up & IRF1 & 94 & EDARADD & Down & MLX & 51 & PLA2G2A \\
\hline $\mathrm{Up}$ & DMAP1 & 94 & SLC13A3 & Down & SOX13 & 51 & TSKU \\
\hline $\mathrm{Up}$ & CREB3L1 & 93 & ARL6IP6 & Down & NR2F6 & 49 & ALAS1 \\
\hline Up & SSRP1 & 93 & VWCE & Down & ZNF580 & 49 & CYP4F11 \\
\hline Up & NR2F6 & 93 & GNG4 & Down & SSRP1 & 48 & CREB3L3 \\
\hline
\end{tabular}


medRxiv preprint doi: https://doi.org/10.1101/2020.12.22.20248756; this version posted December 26, 2020. The copyright holder for this

preprint (which was not certified by peer review) is the author/funder, who has granted medRxiv a license to display the preprint in perpetuity. All rights reserved. No reuse allowed without permission.

\begin{tabular}{|c|c|c|c|c|c|c|c|}
\hline Up & KLF16 & 92 & CCNA2 & Down & $\mathrm{EZH} 2$ & 47 & $\mathrm{CDA}$ \\
\hline Up & PHF8 & 91 & HIST1H2BF & Down & MXD3 & 46 & JUNB \\
\hline Up & KDM5B & 91 & MATN3 & Down & MAZ & 44 & CD14 \\
\hline Up & SAP30 & 91 & NRSN2 & Down & GATA4 & 44 & $\mathrm{HP}$ \\
\hline Up & SIN3A & 90 & PAPSS1 & Down & GATAD1 & 44 & INHBC \\
\hline Up & ZBTB26 & 88 & CDCA7 & Down & MXD4 & 42 & IL1RN \\
\hline Up & CHD1 & 86 & KPNA2 & Down & FOSL1 & 41 & $\mathrm{C} 1$ orf168 \\
\hline Up & ELK1 & 86 & RAD51AP1 & Down & KDM1A & 41 & $\mathrm{KMO}$ \\
\hline Up & KLF11 & 85 & AURKA & Down & ZBTB26 & 41 & MAT1A \\
\hline Up & ZNF76 & 85 & SNORD44 & Down & THRB & 41 & SDC4 \\
\hline Up & TAF7 & 84 & STIL & Down & RAD21 & 40 & ACADSB \\
\hline Up & ZFP2 & 83 & CD34 & Down & RCOR2 & 40 & C1RL \\
\hline Up & HBP1 & 82 & AACS & Down & ZNF197 & 40 & PCK1 \\
\hline Up & MBD1 & 82 & FBLN1 & Down & CREB1 & 40 & RBM47 \\
\hline Up & ARID4B & 81 & SLC6A11 & Down & RERE & 40 & WEE1 \\
\hline Up & NFRKB & 80 & ETV1 & Down & HMG20A & 39 & GPR128 \\
\hline Up & BCL6 & 79 & ANLN & Down & BCL6 & 38 & LEAP2 \\
\hline Up & ZEB1 & 78 & FLVCR1 & Down & IRF1 & 38 & RASD1 \\
\hline Up & NCOR1 & 78 & SNORD81 & Down & DMAP1 & 38 & $\mathrm{CP}$ \\
\hline Up & ZFX & 78 & TET1 & Down & ZNF24 & 38 & TNFSF14 \\
\hline Up & SOX13 & 74 & FAM3B & Down & KDM5B & 37 & CFB \\
\hline Up & ZNF324 & 74 & SPC24 & Down & SAP30 & 37 & ECHDC3 \\
\hline Up & ZBTB11 & 73 & NRCAM & Down & KLF11 & 37 & F11 \\
\hline Up & ZBTB7A & 72 & CDKN3 & Down & STAT3 & 37 & HSD11B1 \\
\hline Up & ZNF501 & 72 & COL2A1 & Down & PHF8 & 37 & INPP1 \\
\hline Up & TFE3 & 72 & HIST2H $2 \mathrm{AC}$ & Down & HMG20B & 37 & LBP \\
\hline Up & DDX20 & 72 & RAB34 & Down & MBD1 & 37 & PHYH \\
\hline Up & MLX & 72 & SNORA65 & Down & NR2F2 & 36 & APCS \\
\hline Up & WT1 & 71 & BCL9 & Down & THAP1 & 36 & CYP2B6 \\
\hline Up & ZNF394 & 71 & CKAP2 & Down & ZNF644 & 36 & CYP3A5 \\
\hline Up & GATA4 & 71 & SKA1 & Down & TFE3 & 36 & DUSP1 \\
\hline Up & NRF1 & 71 & SNORA71C & Down & NFIA & 36 & HMGCS2 \\
\hline Up & HMG20B & 70 & PRR15L & Down & HBP1 & 36 & NR1I3 \\
\hline Up & GTF2F1 & 69 & HIST1H2BD & Down & SIN3A & 36 & SRD5A1 \\
\hline Up & MYNN & 69 & KIF18A & Down & ARID4B & 35 & SHBG \\
\hline Up & ZNF71 & 69 & PIK3R2 & Down & ZBTB11 & 34 & CSRNP1 \\
\hline Up & TGIF2 & 69 & SLC5A9 & Down & ZFP2 & 34 & HOOK1 \\
\hline Up & ZFP37 & 68 & MKI67 & Down & SMAD5 & 34 & LONRF3 \\
\hline Up & ETS1 & 68 & MMP2 & Down & ELF1 & 34 & MUT \\
\hline Up & ZFP64 & 68 & MYH7B & Down & RXRB & 34 & SUCLG2 \\
\hline Up & NR2F1 & 67 & CDK1 & Down & ZNF639 & 33 & $\mathrm{C} 1 \mathrm{~S}$ \\
\hline Up & MXD4 & 67 & ZNF704 & Down & TFAP4 & 33 & CYP1A1 \\
\hline Up & ZNF644 & 66 & RNASE1 & Down & FOXA3 & 33 & MT1L \\
\hline Up & ZNF101 & 65 & ECT2 & Down & ELF3 & 33 & MT1M \\
\hline Up & KLF1 & 65 & OXCT1 & Down & GATAD2A & 33 & TAT \\
\hline Up & KDM5A & 64 & DLGAP5 & Down & TGIF2 & 32 & PPARGC1A \\
\hline Up & FOSL1 & 64 & ENPP3 & Down & NFRKB & 31 & AGL \\
\hline Up & $\mathrm{E} 2 \mathrm{~F} 4$ & 64 & SGOL1 & Down & ELK1 & 31 & $\mathrm{C} 8 \mathrm{G}$ \\
\hline Up & FOXJ2 & 64 & SPP1 & Down & ZFP64 & 31 & LRRFIP1 \\
\hline Up & RERE & 63 & B3GALT1 & Down & CEBPG & 31 & WDR72 \\
\hline Up & KLF7 & 63 & CKB & Down & ETV4 & 30 & C8orf4 \\
\hline Up & ZNF197 & 63 & DUSP9 & Down & NRF1 & 30 & DUSP5 \\
\hline Up & RCOR2 & 63 & MEG3 & Down & DRAP1 & 29 & MT1E \\
\hline Up & L3MBTL2 & 63 & MELK & Down & RARA & 29 & SEC14L2 \\
\hline Up & SMARCA5 & 63 & RELN & Down & ZFX & 29 & TP53INP1 \\
\hline Up & $\mathrm{NR} 2 \mathrm{C} 2$ & 63 & TP53I3 & Down & IRF4 & 28 & ACSL1 \\
\hline Up & CBFB & 62 & PRIM1 & Down & ZNF175 & 28 & BMP10 \\
\hline Up & CREM & 62 & PTP4A3 & Down & WRNIP1 & 28 & CFP \\
\hline Up & MLLT1 & 61 & HIST1H2BB & Down & FOXM1 & 28 & CYP4V2 \\
\hline Up & THRB & 61 & LGR5 & Down & NR2C2 & 28 & FGGY \\
\hline Up & PPARG & 61 & SQLE & Down & SMAD4 & 28 & MT1JP \\
\hline Up & GATAD1 & 60 & $\mathrm{H} 2 \mathrm{AFZ}$ & Down & SP1 & 27 & EGR1 \\
\hline Up & ELF3 & 60 & NREP & Down & ZBTB7A & 27 & FOSB \\
\hline Up & ZNF2 & 59 & ALDH18A1 & Down & TEAD3 & 27 & GPD1 \\
\hline Up & NR4A1 & 59 & FKBP10 & Down & ZFP37 & 27 & GREM2 \\
\hline Up & KDM1A & 59 & HTR1D & Down & ZNF589 & 27 & HPD \\
\hline Up & BCOR & 59 & IGF2BP1 & Down & BCL11B & 27 & ТTC39C \\
\hline Up & RARA & 59 & KNTC1 & Down & SUZ12 & 26 & GFRA1 \\
\hline Up & ZNF589 & 59 & PARPBP & Down & MLLT1 & 26 & GLS2 \\
\hline Up & ARNT & 59 & SLC2A1 & Down & CHD1 & 26 & GPT \\
\hline Up & ESRRA & 59 & SPATS2 & Down & ZNF76 & 26 & HHIP \\
\hline Up & ZHX2 & 59 & TBX4 & Down & NR4A1 & 26 & INSIG1 \\
\hline Up & HDGF & 59 & UBE2T & Down & ZEB1 & 26 & MFSD2A \\
\hline Up & BCL11B & 58 & BCAM & Down & ZNF501 & 26 & RND3 \\
\hline Up & GATAD2A & 58 & FDFT1 & Down & CREB3L1 & 25 & ABCA9 \\
\hline
\end{tabular}


medRxiv preprint doi: https://doi.org/10.1101/2020.12.22.20248756; this version posted December 26,2020 . The copyright holder for this

preprint (which was not certified by peer review) is the author/funder, who has granted medRxiv a license to display the preprint in perpetuity. All rights reserved. No reuse allowed without permission.

\begin{tabular}{|c|c|c|c|c|c|c|c|}
\hline Up & NFYC & 58 & FRAS1 & Down & CTCF & 25 & BMPER \\
\hline Up & MBD2 & 58 & SV2A & Down & ZNF71 & 25 & CPNE8 \\
\hline Up & SMAD4 & 57 & DPEP1 & Down & FOXJ2 & 25 & FOS \\
\hline Up & ID3 & 57 & HIST1H2BH & Down & MEF2D & 25 & GLYAT \\
\hline Up & PML & 57 & RPS5 & Down & ZNF394 & 25 & LIFR \\
\hline Up & RFXANK & 56 & BMP4 & Down & ZHX2 & 25 & TRIB1 \\
\hline Up & REST & 56 & FAM169A & Down & POLR2A & 24 & APOL1 \\
\hline Up & KLF13 & 56 & HDAC11 & Down & ZNF263 & 24 & $\mathrm{CDO} 1$ \\
\hline Up & ARID1B & 56 & NCAPH & Down & RFXANK & 24 & CETP \\
\hline Up & INSM2 & 56 & PLK4 & Down & MYNN & 24 & MAP7 \\
\hline Up & ZBTB33 & 56 & RHBG & Down & BCL11A & 24 & REEP6 \\
\hline Up & RXRB & 56 & SOAT2 & Down & SOX5 & 24 & SLC27A2 \\
\hline Up & KLF8 & 56 & TP53 & Down & DPF2 & 24 & TMOD1 \\
\hline Up & ZNF639 & 54 & DEPDC 1 & Down & GTF2E2 & 23 & CXCL2 \\
\hline Up & CCNT2 & 54 & HIST1H4E & Down & ZNF423 & 23 & SOCS3 \\
\hline Up & NFIL3 & 54 & ODAM & Down & ID3 & 22 & ABHD2 \\
\hline Up & SP3 & 54 & ZSWIM5 & Down & ESRRA & 22 & ACAT1 \\
\hline Up & ADNP & 53 & HEY1 & Down & NFYC & 22 & ACSM3 \\
\hline Up & THRAP3 & 53 & HIST1H4L & Down & L3MBTL2 & 22 & ADAMTS1 \\
\hline Up & MEF2D & 53 & MPZL1 & Down & TEAD1 & 22 & BAAT \\
\hline Up & WRNIP1 & 53 & PRC1 & Down & KLF1 & 22 & ETS2 \\
\hline Up & ZNF384 & 53 & RAPGEFL1 & Down & ZNF2 & 22 & GADD45B \\
\hline Up & GABPA & 53 & TDGF1 & Down & SP2 & 22 & GLRX \\
\hline Up & POLR2H & 53 & TRIM59 & Down & RNF2 & 21 & AKAP12 \\
\hline Up & SMARCA4 & 52 & ARHGEF2 & Down & CEBPA & 21 & CYP4F3 \\
\hline Up & SIRT6 & 52 & E2F5 & Down & ATF4 & 21 & FETUB \\
\hline Up & HMBOX1 & 52 & HIST1H3J & Down & GLIS2 & 21 & FXYD1 \\
\hline Up & NCOA1 & 52 & PCGF2 & Down & SMARCA5 & 21 & LRG1 \\
\hline Up & SP1 & 52 & $\mathrm{RCN} 2$ & Down & HDGF & 21 & MMRN1 \\
\hline Up & SP7 & 52 & ST8SIA3 & Down & СТВР2 & 21 & MT1DP \\
\hline Up & CREB1 & 51 & PRKAA2 & Down & GATA2 & 21 & PIPOX \\
\hline Up & SOX5 & 51 & SULT1C2 & Down & CREM & 21 & PRG4 \\
\hline Up & FOXA3 & 51 & TNFSF4 & Down & E2F5 & 21 & SPTBN2 \\
\hline Up & TRIM22 & 50 & ASPSCR1 & Down & GABPA & 20 & $\mathrm{CFH}$ \\
\hline Up & ZNF83 & 50 & HIST1H2AL & Down & HMGN3 & 20 & CYP26A1 \\
\hline Up & GTF2A2 & 50 & HIST1H3E & Down & KLF8 & 20 & CYP4X1 \\
\hline Up & ZKSCAN1 & 50 & KIAA0101 & Down & PBX2 & 20 & FGB \\
\hline Up & ATF3 & 50 & SLC1A4 & Down & FOSL2 & 20 & KCND3 \\
\hline Up & ZNF423 & 50 & SUPT3H & Down & BACH1 & 20 & LPIN2 \\
\hline Up & GATA2 & 49 & TNFRSF19 & Down & MIXL1 & 20 & SULT2A1 \\
\hline Up & NFIA & 48 & GSTA4 & Down & PPARG & 20 & TSPYL5 \\
\hline Up & SUPT5H & 48 & HIST1H1C & Down & ZNF384 & 20 & UGT2B7 \\
\hline Up & KLF6 & 48 & MAP4K4 & Down & GTF2F1 & 20 & ZFP36 \\
\hline Up & TEAD3 & 48 & NKD1 & Down & MTA2 & 19 & APBB1IP \\
\hline Up & DRAP1 & 48 & TTYH3 & Down & ZBTB40 & 19 & BHLHE40 \\
\hline Up & SMARCE1 & 47 & KRT19 & Down & EED & 19 & CLEC4G \\
\hline Up & HMG20A & 47 & SRD5A3 & Down & ADNP & 19 & CYP3A43 \\
\hline Up & SIN3B & 46 & FOXQ1 & Down & REST & 19 & DHODH \\
\hline Up & IKZF1 & 46 & MCM7 & Down & SIRT6 & 19 & IRF6 \\
\hline Up & TBP & 46 & SNORD52 & Down & SMARCA4 & 19 & LYVE1 \\
\hline Up & HMGN3 & 45 & CDK4 & Down & ETS1 & 19 & NPY1R \\
\hline $\mathrm{Up}$ & DNMT1 & 45 & SLC1A5 & Down & USF2 & 19 & TRIM55 \\
\hline Up & TSHZ1 & 45 & TLCD1 & Down & ZNF584 & 18 & ABLIM3 \\
\hline Up & GTF2B & 45 & WDR76 & Down & DDX20 & 18 & APOF \\
\hline Up & EGR1 & 44 & ASIC1 & Down & EBF1 & 18 & DNASE1L3 \\
\hline Up & BCL11A & 44 & CRABP2 & Down & HIC1 & 18 & NFIL3 \\
\hline Up & TEAD1 & 44 & GREB1 & Down & ARID1B & 18 & PPP1R3B \\
\hline Up & CREB3 & 44 & HIST1H2BI & Down & GLIS1 & 18 & RCAN1 \\
\hline Up & TFAP4 & 44 & IGDCC3 & Down & KLF4 & 18 & VNN3 \\
\hline Up & JUNB & 44 & PTTG1 & Down & INSM2 & 17 & CDC37L1 \\
\hline Up & GLI4 & 44 & SKP2 & Down & ZNF324 & 17 & CTH \\
\hline Up & IRF4 & 44 & TRIM28 & Down & HHEX & 17 & HAL \\
\hline Up & ZBTB40 & 43 & HIST1H2AE & Down & KLF13 & 17 & HAMP \\
\hline Up & MIXL1 & 43 & HIST1H2AH & Down & NCOR1 & 17 & ICAM1 \\
\hline Up & BACH1 & 43 & SORT1 & Down & NFE2 & 17 & MACF1 \\
\hline Up & SP2 & 42 & CCDC88C & Down & ZNF341 & 17 & MT1F \\
\hline Up & CEBPG & 42 & LYZ & Down & LEF1 & 17 & SLC27A5 \\
\hline Up & GMEB2 & 42 & MCM3 & Down & NFIC & 16 & CD5L \\
\hline Up & DPF2 & 42 & NQO1 & Down & BCOR & 16 & CES3 \\
\hline Up & ZNF207 & 42 & RPL22L1 & Down & HDAC1 & 16 & EPHX2 \\
\hline Up & ZNF18 & 41 & BAMBI & Down & KLF7 & 16 & FCN3 \\
\hline Up & ZNF335 & 41 & DTL & Down & ZKSCAN1 & 16 & GCKR \\
\hline Up & ZNF121 & 41 & GPD1L & Down & TRIM24 & 16 & HFE2 \\
\hline Up & STAT1 & 41 & HIST1H2AB & Down & TRIM22 & 16 & HPX \\
\hline Up & POU2F2 & 41 & HIST1H2AM & Down & POLR2H & 16 & UGP2 \\
\hline
\end{tabular}


medRxiv preprint doi: https://doi.org/10.1101/2020.12.22.20248756; this version posted December 26,2020 . The copyright holder for this

preprint (which was not certified by peer review) is the author/funder, who has granted medRxiv a license to display the preprint in perpetuity. All rights reserved. No reuse allowed without permission.

\begin{tabular}{|c|c|c|c|c|c|c|c|}
\hline Up & ZNF175 & 41 & HIST1H4D & Down & JUND & 15 & ABCB11 \\
\hline Up & CTCF & 41 & HUNK & Down & TAL1 & 15 & AQP3 \\
\hline Up & $\mathrm{HICl}$ & 41 & USP11 & Down & PRDM10 & 15 & ASS1 \\
\hline Up & ZNF584 & 40 & $\mathrm{CDC} 25 \mathrm{C}$ & Down & TAF7 & 15 & ETFDH \\
\hline Up & HES1 & 40 & HIST1H2BG & Down & ZNF101 & 15 & HRSP12 \\
\hline Up & TRIM24 & 39 & HIST1H3A & Down & ZNF335 & 15 & NTN4 \\
\hline Up & TBX21 & 39 & MAD2L1 & Down & SP3 & 15 & RUNDC3B \\
\hline Up & CDC5L & 38 & $\mathrm{CDC} 20$ & Down & HMBOX1 & 14 & ADHFE1 \\
\hline Up & GLIS2 & 38 & COL15A1 & Down & GTF2A2 & 14 & DIO1 \\
\hline Up & IRF2 & 38 & HIST1H2BM & Down & FOXK2 & 14 & FGG \\
\hline Up & EZH2 & 38 & LYPD1 & Down & SUPT5H & 14 & GLT1D1 \\
\hline Up & NFYB & 37 & HIST1H1B & Down & SMARCE1 & 14 & IGF1 \\
\hline Up & NFATC1 & 37 & HIST1H3H & Down & SMC3 & 14 & KLF6 \\
\hline Up & KAT2A & 37 & HIST1H3I & Down & TRIM28 & 14 & MYOM1 \\
\hline Up & MTA3 & 37 & TERC & Down & CBFB & 14 & PCK2 \\
\hline Up & TCF7 & 36 & CTSC & Down & SP7 & 14 & RND1 \\
\hline Up & RELA & 36 & GSN & Down & ZNF382 & 14 & SERPINB8 \\
\hline Up & HDAC1 & 36 & $\mathrm{HIST} 2 \mathrm{H} 2 \mathrm{AB}$ & Down & IKZF1 & 14 & THRSP \\
\hline Up & ZNF366 & 36 & PYCR1 & Down & CCNT2 & 13 & ACOX1 \\
\hline Up & ZNF341 & 35 & FREM2 & Down & HES1 & 13 & AGPAT9 \\
\hline Up & HCFC1 & 35 & RFC3 & Down & HDAC6 & 13 & ALDH6A1 \\
\hline Up & EED & 35 & TYMS & Down & RFX3 & 13 & APOC3 \\
\hline Up & CUX1 & 34 & HIST1H3C & Down & MTA1 & 13 & CA2 \\
\hline Up & ZNF623 & 34 & ITM2C & Down & EGR2 & 13 & FAM180A \\
\hline Up & TAL1 & 33 & KIFC1 & Down & CUX1 & 13 & KYNU \\
\hline Up & ZNF263 & 33 & NAP1L1 & Down & ZNF18 & 13 & NNT \\
\hline Up & ATF4 & 33 & SNRPB & Down & NCOA1 & 13 & NSUN6 \\
\hline Up & PRDM1 & 33 & STRA6 & Down & ZNF366 & 13 & PAPSS2 \\
\hline Up & USF2 & 32 & RACGAP1 & Down & HDAC2 & 13 & SLC22A7 \\
\hline Up & ZNF512 & 31 & ACTG2 & Down & ZNF83 & 12 & ARRDC3 \\
\hline Up & RNF2 & 31 & BUB1 & Down & ZNF7 & 12 & HPR \\
\hline Up & ZNF407 & 31 & DNAH14 & Down & PKNOX1 & 12 & S100A8 \\
\hline Up & GFI1B & 31 & NCAPD2 & Down & TBX21 & 12 & ST3GAL6 \\
\hline Up & CEBPA & 31 & TOX3 & Down & GATA1 & 12 & ART4 \\
\hline Up & RFX3 & 30 & AFP & Down & FOXA2 & 11 & MBL2 \\
\hline Up & GLIS 1 & 30 & HS6ST1 & Down & CEBPD & 11 & BMP10 \\
\hline Up & PBX2 & 30 & TUBG1 & Down & TEAD4 & 11 & IGF1 \\
\hline Up & JUND & 29 & EPCAM & Down & RELA & 11 & BHLHE40 \\
\hline Up & ZNF558 & 29 & LRRC1 & Down & ZNF512 & 11 & PGLYRP2 \\
\hline Up & NFE2 & 29 & ZC3HAV1L & Down & ETV1 & 11 & OIT3 \\
\hline Up & BHLHE40 & 28 & AXIN2 & Down & TSHZ1 & 11 & AGPAT2 \\
\hline Up & СТВР2 & 28 & MYCN & Down & GFI1B & 11 & SLC7A2 \\
\hline Up & RAD21 & 28 & TGFB2 & Down & ZNF610 & 11 & MFAP3L \\
\hline Up & IRF3 & 27 & HIST1H2AJ & Down & $\mathrm{HCFC1}$ & 11 & C3P1 \\
\hline Up & CHD7 & 27 & HIST1H3F & Down & CREB3 & 11 & INHBE \\
\hline Up & TARDBP & 26 & CAD & Down & GLI4 & 11 & DTX1 \\
\hline Up & GATA3 & 26 & MAGED2 & Down & MAX & 11 & ASS1 \\
\hline $\mathrm{Up}$ & ZNF7 & 26 & MYBL2 & Down & PRDM2 & 11 & C1R \\
\hline Up & FOXK2 & 24 & PRR11 & Down & TBX3 & 10 & SERPINA1 \\
\hline Up & FOSL2 & 23 & EHMT2 & Down & TCF7 & 10 & BIRC3 \\
\hline Up & SREBF2 & 23 & FADS2 & Down & PRDM1 & 10 & GCH1 \\
\hline Up & PRDM10 & 23 & RBP1 & Down & ZNF623 & 10 & AGL \\
\hline Up & HDAC6 & 22 & CDC6 & Down & MXI1 & 10 & AGXT \\
\hline Up & ZNF143 & 22 & HJURP & Down & RXRA & 10 & SERPINA3 \\
\hline Up & HDAC2 & 22 & HNF1A-AS1 & Down & GMEB2 & 10 & PTS \\
\hline Up & YY1 & 22 & MSH2 & Down & ZBTB17 & 10 & GLRX \\
\hline Up & NFIC & 22 & PGC & Down & MITF & 10 & REEP6 \\
\hline Up & GATA1 & 21 & ASF1B & Down & MBD2 & 9 & SPTBN2 \\
\hline $\mathrm{Up}$ & TEAD4 & 21 & ATP8B2 & Down & CDC5L & 9 & EGR1 \\
\hline Up & CEBPD & 21 & CPXM1 & Down & CEBPB & 9 & THRSP \\
\hline Up & FOXA2 & 21 & SNORD95 & Down & IRF2 & 9 & APOL1 \\
\hline Up & EGR2 & 20 & CCND2 & Down & WT1 & 9 & ENPEP \\
\hline Up & SUZ12 & 20 & CDH13 & Down & GATA3 & 8 & MYO1B \\
\hline Up & KLF4 & 20 & GINS2 & Down & SREBF2 & 8 & ETS2 \\
\hline Up & RUNX1 & 20 & HIST1H2BL & Down & RCOR1 & 8 & TRIB1 \\
\hline Up & RFX1 & 20 & KIF20A & Down & THRAP3 & 8 & KLF6 \\
\hline Up & MAX & 20 & MCM2 & Down & HNF4A & 8 & CCL16 \\
\hline $\mathrm{Up}$ & MITF & 20 & PLCG1 & Down & SIN3B & 8 & TAT \\
\hline Up & PKNOX1 & 20 & SEMA3C & Down & RAD51 & 8 & TP53INP1 \\
\hline Up & ZNF202 & 19 & LIN28B & Down & ZNF207 & 8 & CETP \\
\hline Up & NFE2L2 & 19 & SNORD30 & Down & DIDO1 & 8 & UGP2 \\
\hline Up & MTA1 & 18 & ALYREF & Down & JUN & 8 & ZFP36 \\
\hline Up & MNT & 18 & CST1 & Down & POU5F1 & 7 & AASS \\
\hline Up & PRDM2 & 18 & FOXM1 & Down & ZNF143 & 7 & USP2 \\
\hline Up & EP300 & 18 & HIST1H2BE & Down & SCRT2 & 7 & GCH1 \\
\hline
\end{tabular}


medRxiv preprint doi: https://doi.org/10.1101/2020.12.22.20248756; this version posted December 26, 2020. The copyright holder for this

preprint (which was not certified by peer review) is the author/funder, who has granted medRxiv a license to display the preprint in perpetuity. All rights reserved. No reuse allowed without permission.

\begin{tabular}{|c|c|c|c|c|c|c|c|}
\hline Up & PYGO2 & 18 & HIST1H3B & Down & ZNF202 & 7 & PRKAG2 \\
\hline Up & ZNF146 & 18 & PEG10 & Down & ZNF217 & 7 & FOS \\
\hline Up & ZNF641 & 18 & SNORD50A & Down & TARDBP & 7 & ETFDH \\
\hline Up & MXI1 & 17 & MCM4 & Down & TBP & 7 & JUNB \\
\hline Up & MTA2 & 17 & SLC39A10 & Down & MAFK & 6 & HFE2 \\
\hline Up & ZBTB1 & 17 & UHRF1 & Down & EP300 & 6 & CYP3A43 \\
\hline Up & NR2F2 & 16 & ACLY & Down & ZNF558 & 6 & SGMS2 \\
\hline Up & ZHX1 & 16 & ASPM & Down & CBX8 & 6 & GNAO1 \\
\hline Up & MAFF & 16 & CCDC34 & Down & RFX1 & 6 & TMPRSS2 \\
\hline Up & THAP1 & 16 & COL1A1 & Down & STAT1 & 6 & FOSB \\
\hline Up & RAD51 & 16 & GSTP1 & Down & USF1 & 5 & PPARGC1A \\
\hline Up & ZBTB17 & 16 & NUSAP1 & Down & ZNF547 & 5 & SRD5A1 \\
\hline Up & RCOR1 & 16 & RNF43 & Down & RUNX1 & 5 & TMOD1 \\
\hline Up & NFYA & 15 & HIST1H2AG & Down & NFE2L2 & 5 & C4BPB \\
\hline Up & SCRT1 & 15 & NT5DC2 & Down & ARNT & 5 & ECM1 \\
\hline Up & ZNF217 & 15 & TSPAN5 & Down & ZNF146 & 5 & FXYD1 \\
\hline Up & MAFK & 14 & GNA12 & Down & POU2F2 & 5 & RBM47 \\
\hline Up & DEK & 14 & HIF1 AN & Down & E2F6 & 5 & DUSP1 \\
\hline Up & MYB & 14 & HIST1H4B & Down & ATF2 & 5 & CFP \\
\hline Up & HHEX & 14 & NYNRIN & Down & ZNF16 & 5 & CYP4F22 \\
\hline Up & MYC & 14 & RPS27 & Down & SCRT1 & 5 & DUSP5 \\
\hline Up & E2F6 & 13 & CHEK1 & Down & ZNF121 & 5 & DHTKD1 \\
\hline Up & CEBPB & 13 & XRCC2 & Down & ZBTB1 & 5 & SOCS2 \\
\hline Up & TAF1 & 12 & USP21 & Down & ZNF8 & 5 & LRRK2 \\
\hline Up & SMC3 & 11 & CDON & Down & HLF & 5 & SERPINE1 \\
\hline Up & TBX3 & 11 & ETV4 & Down & KDM5A & 4 & CXCL2 \\
\hline Up & CTBP1 & 11 & GXYLT2 & Down & DNMT1 & 4 & NAMPT \\
\hline Up & ATF2 & 11 & LAMC1 & Down & GTF2B & 4 & ARRDC3 \\
\hline Up & EBF1 & 11 & SPATS2 & Down & SREBF1 & 4 & INSIG1 \\
\hline Up & DIDO1 & 10 & NPM3 & Down & DEK & 4 & TRIB1 \\
\hline Up & SCRT2 & 10 & PCP4 & Down & ZFP41 & 3 & GADD45B \\
\hline Up & ZNF547 & 10 & ZNF382 & Down & ZNF407 & 3 & ADHFE1 \\
\hline Up & MBD4 & 9 & C1 orf74 & Down & HDAC8 & 3 & AGL \\
\hline Up & HNF4G & 9 & FIGN & Down & AEBP2 & 3 & AMDHD1 \\
\hline Up & HLF & 9 & KCNJ5 & Down & PYGO2 & 3 & GLYAT \\
\hline Up & CBX8 & 9 & MPPED2 & Down & ZNF641 & 3 & ZFP36 \\
\hline Up & GATAD2B & 9 & OLFML3 & Down & MAFG & 3 & HFE2 \\
\hline Up & POU5F1 & 9 & SLC44A3 & Down & ZHX1 & 3 & SLC27A5 \\
\hline Up & HDAC8 & 9 & TMEM98 & Down & CTBP1 & 3 & CPNE8 \\
\hline Up & MAFG & 8 & HIST1H4I & Down & BCL3 & 3 & C8orf4 \\
\hline Up & TCF3 & 8 & IMPDH2 & Down & NFATC1 & 3 & KCND3 \\
\hline Up & STAT5A & 8 & LAPTM4B & Down & MTA3 & 3 & EGR1 \\
\hline Up & BCLAF1 & 7 & HIST1H2AB & Down & ZNF585B & 3 & F13B \\
\hline Up & ETV6 & 7 & HIST1H2AM & Down & ZNF488 & 3 & HAMP \\
\hline Up & NFE2L1 & 7 & HIST1H4I & Down & ZNF239 & 3 & FXYD1 \\
\hline Up & SREBF1 & 7 & LSM2 & Down & ZNF707 & 3 & INHBE \\
\hline Up & JUN & 6 & HIST1H2AK & Down & MYB & 3 & TTC39C \\
\hline Up & POLR3A & 6 & HIST1H2BI & Down & RUNX3 & 2 & APBB1IP \\
\hline Up & ZNF264 & 6 & SOBP & Down & SPI1 & 2 & DUSP5 \\
\hline Up & TCF7L2 & 6 & TP53 & Down & SETDB1 & 2 & HSD17B6 \\
\hline Up & RBBP5 & 5 & CTSC & Down & KAT2A & 2 & JUNB \\
\hline Up & NONO & 5 & SNORD30 & Down & TBL1XR1 & 2 & SOCS2 \\
\hline Up & PTRF & 5 & SNORD78 & Down & ETV6 & 2 & BHLHE40 \\
\hline Up & ZNF585B & 5 & SV2A & Down & MNT & 2 & GNMT \\
\hline Up & GTF3C2 & 5 & TERC & Down & MAFF & 2 & IGF1 \\
\hline Up & SIX4 & 4 & AXIN2 & Down & ZNF264 & 2 & DUSP1 \\
\hline Up & SETDB1 & 4 & CDCA7 & Down & SRF & 2 & EGR1 \\
\hline Up & CHD2 & 4 & EIF4A2 & Down & GATAD2B & 2 & JUNB \\
\hline Up & BDP1 & 4 & HIST1H2AH & Down & ELK4 & 2 & EGR1 \\
\hline Up & USF1 & 4 & PCGF2 & Down & NONO & 2 & GCH1 \\
\hline Up & FOS & 4 & SNORD114-26 & Down & CHD7 & 2 & GRAMD1C \\
\hline Up & ZNF274 & 4 & SNORD116-13 & Down & MYC & 2 & SPTBN2 \\
\hline Up & BRF1 & 4 & SNORD95 & Down & PML & 2 & ZFP36 \\
\hline Up & SPI1 & 3 & ARHGEF2 & Down & NFE2L1 & 2 & MYOM1 \\
\hline Up & CEBPZ & 3 & ASF1B & Down & YBX1 & 2 & SNX29P2 \\
\hline Up & RUNX3 & 3 & HIST1H4E & Down & EHMT2 & 2 & UGT2B7 \\
\hline Up & STAT3 & 3 & LSM2 & Down & TCF7L2 & 1 & ASPDH \\
\hline $\mathrm{Up}$ & PPARGC1A & 3 & PLCG1 & Down & PTTG1 & 1 & BHLHE40 \\
\hline Up & ZNF140 & 3 & PRKD1 & Down & PTRF & 1 & BHLHE40 \\
\hline Up & HSF1 & 3 & SNORD52 & Down & TEAD2 & 1 & BHLHE40 \\
\hline Up & ZNF8 & 3 & ZNF382 & Down & NANOG & 1 & CSRNP1 \\
\hline Up & ZNF16 & 2 & ERCC2 & Down & CHD4 & 1 & GADD45B \\
\hline Up & ESR1 & 2 & FREM2 & Down & ZNF140 & 1 & HAMP \\
\hline Up & ZC3H11A & 2 & GSTA4 & Down & ZNF354C & 1 & HAMP \\
\hline Up & ZNF239 & 2 & IMPDH2 & Down & NFYA & 1 & INSIG1 \\
\hline
\end{tabular}


medRxiv preprint doi: https://doi.org/10.1101/2020.12.22.20248756; this version posted December 26, 2020. The copyright holder for this preprint (which was not certified by peer review) is the author/funder, who has granted medRxiv a license to display the preprint in perpetuity.

All rights reserved. No reuse allowed without permission.

\begin{tabular}{|c|c|c|c|c|c|c|c|}
\hline Up & CHD4 & 2 & KIF11 & Down & HSF1 & 1 & KCND3 \\
\hline Up & RXRA & 2 & LGR5 & Down & TAF1 & 1 & KLF6 \\
\hline $\mathrm{Up}$ & ETS2 & 2 & LSM2 & Down & NR3C1 & 1 & MFSD2A \\
\hline Up & UBTF & 2 & MPZL1 & Down & $\mathrm{E} 2 \mathrm{~F} 4$ & 1 & NSUN6 \\
\hline Up & YBX1 & 2 & NYNRIN & Down & SIX4 & 1 & SPTBN2 \\
\hline Up & AEBP2 & 2 & PEG10 & Down & RFX5 & 1 & TP53INP1 \\
\hline Up & ZNF292 & 2 & PTK7 & Down & KAT2B & 1 & ZFP36 \\
\hline Up & PRDM12 & 2 & TMC7 & Down & ZNF138 & 1 & ZFP36 \\
\hline $\mathrm{Up}$ & TEAD2 & 2 & TRIM59 & & & & \\
\hline Up & ZFP41 & 1 & C19orf48 & & & & \\
\hline Up & RFX5 & 1 & CDK4 & & & & \\
\hline $\mathrm{Up}$ & NANOG & 1 & FKBP10 & & & & \\
\hline Up & TSC22D4 & 1 & HIST1H2BD & & & & \\
\hline $\mathrm{Up}$ & ZNF354C & 1 & HIST1H3E & & & & \\
\hline Up & ZNF138 & 1 & HIST1H3E & & & & \\
\hline Up & ZNF488 & 1 & NRCAM & & & & \\
\hline Up & MEF2A & 1 & PTP4A3 & & & & \\
\hline Up & MEF2C & 1 & PTP4A3 & & & & \\
\hline Up & HNF4A & 1 & SOAT2 & & & & \\
\hline
\end{tabular}

Degree - No of TF interact with target gene. We taken any one TF in table

\section{Figures}
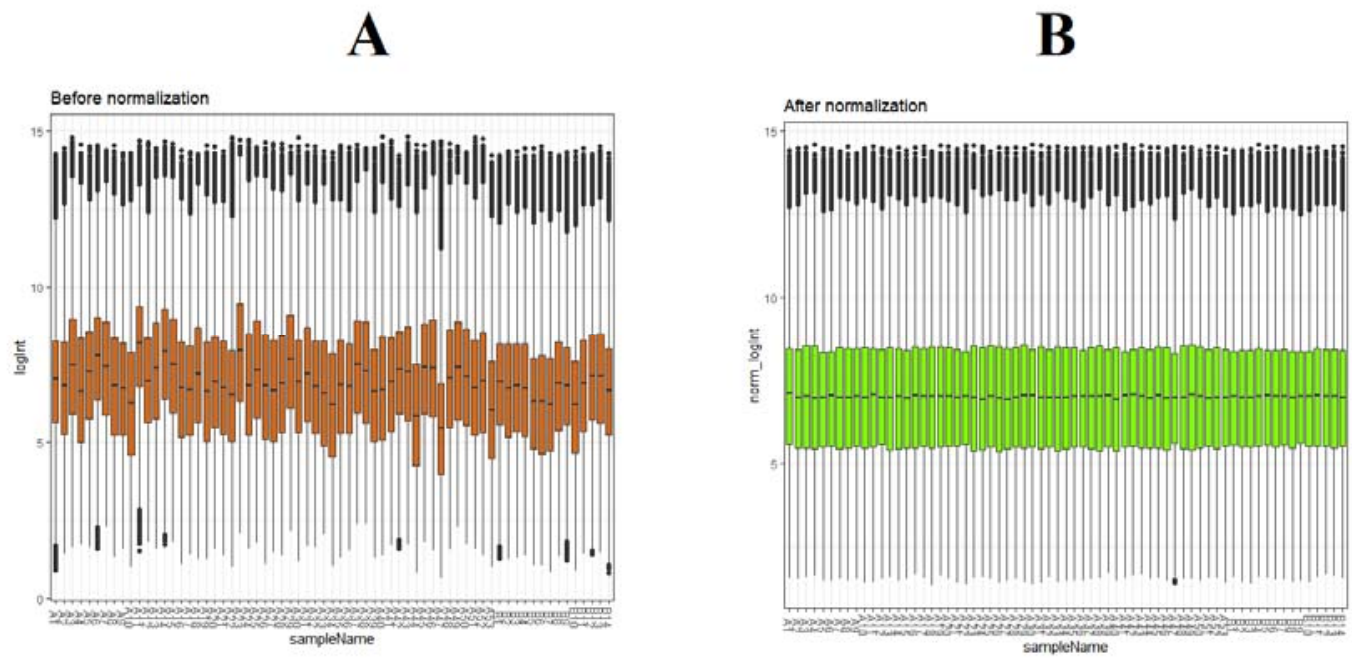

Fig. 1. Box plots of the gene expression data before normalization (A) and after normalization (B). Horizontal axis represents the sample symbol and the vertical axis represents the gene expression values. The black line in the box plot represents the median value of gene expression. (A1 - A53 = hepatoblastoma tissues samples; B1 B14 = noncancerous liver tissue samples) 

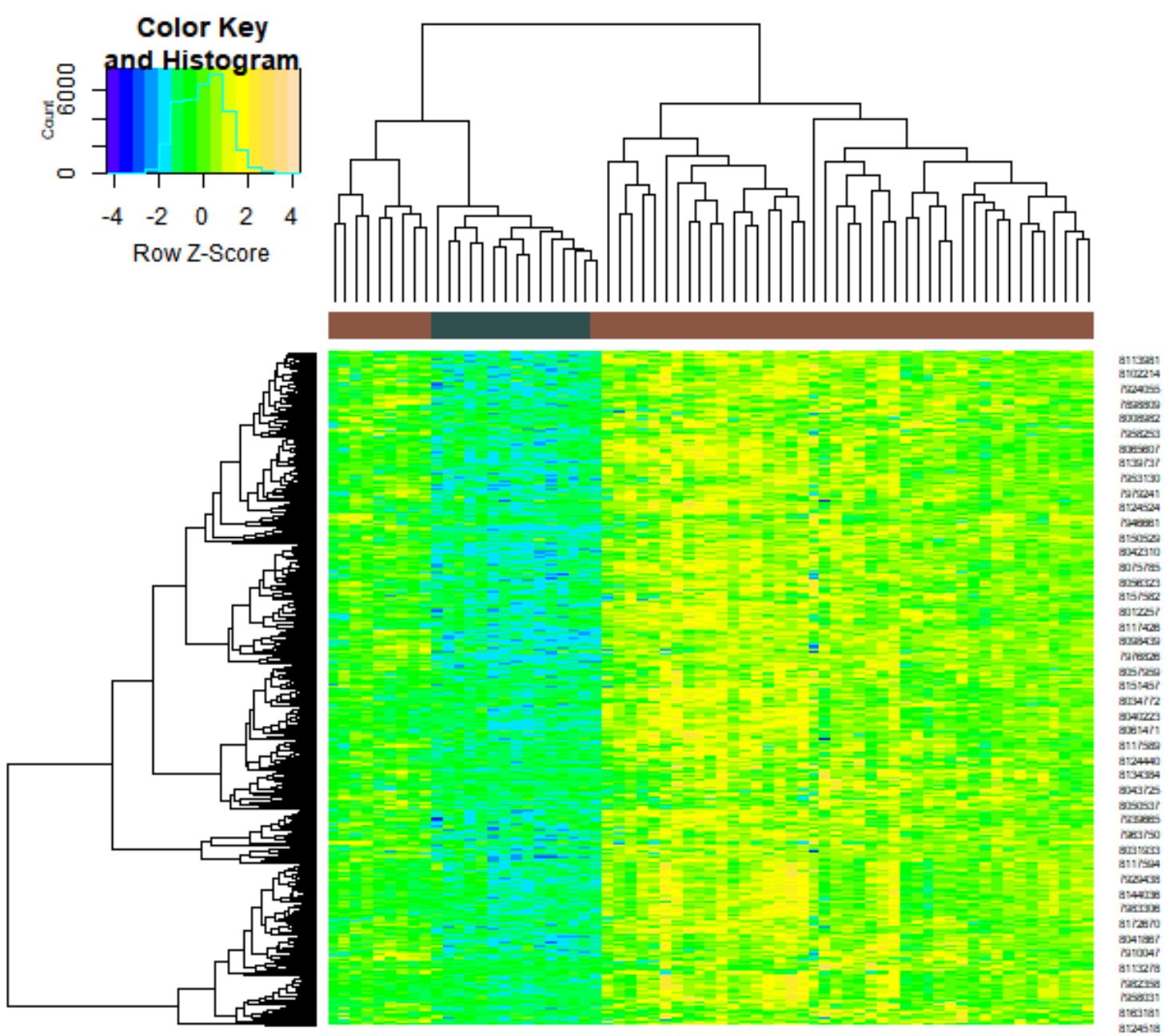

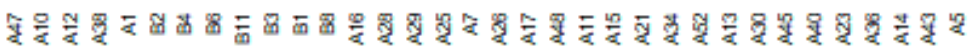

Fig. 2. Heat map of up regulated differentially expressed genes. Legend on the top left indicate log fold change of genes. (A1 - A53 = hepatoblastoma tissues samples; B1 - B14 = noncancerous liver tissue samples) 
medRxiv preprint doi: https://doi.org/10.1101/2020.12.22.20248756; this version posted December 26, 2020. The copyright holder for this preprint (which was not certified by peer review) is the author/funder, who has granted medRxiv a license to display the preprint in perpetuity.

All rights reserved. No reuse allowed without permission.
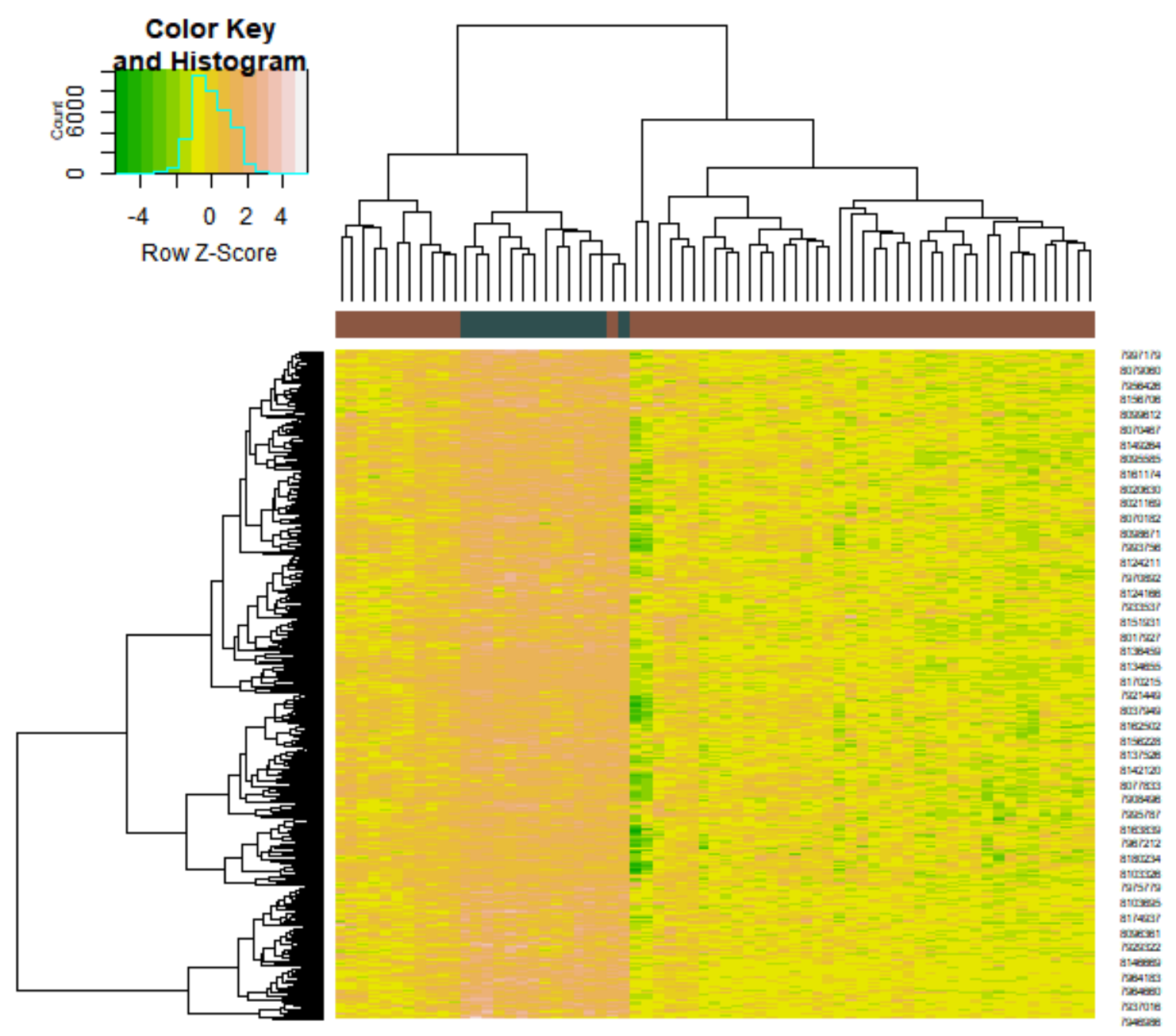

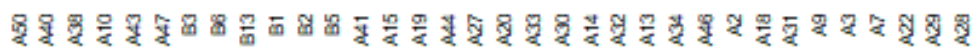

Fig. 3. Heat map of down regulated differentially expressed genes. Legend on the top left indicate log fold change of genes. (A1 - A53 = hepatoblastoma tissues samples; B1 - B14 = noncancerous liver tissue samples) 
medRxiv preprint doi: https://doi.org/10.1101/2020.12.22.20248756; this version posted December 26, 2020. The copyright holder for this preprint (which was not certified by peer review) is the author/funder, who has granted medRxiv a license to display the preprint in perpetuity.

All rights reserved. No reuse allowed without permission.

\section{Volcano plot}

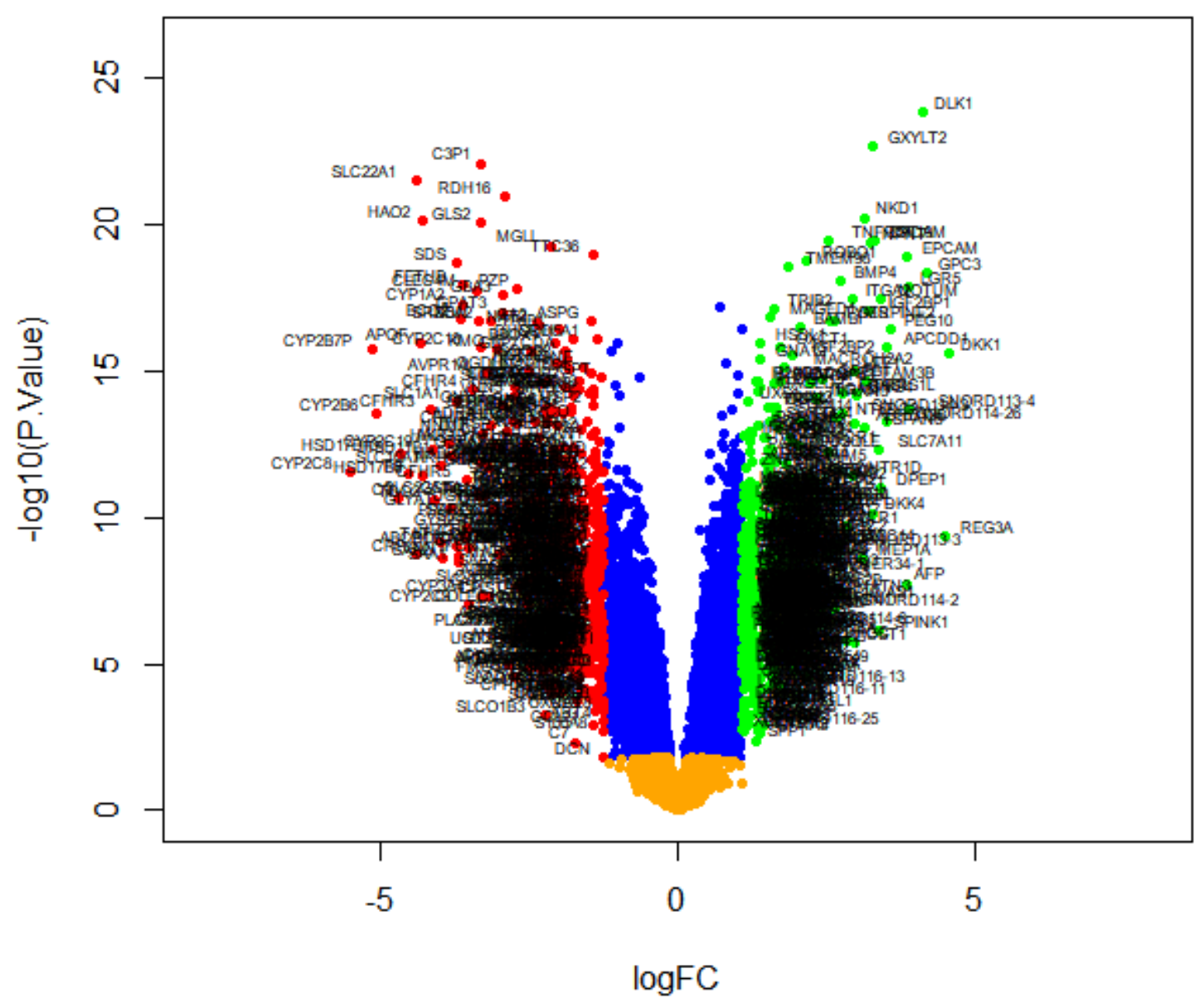

Fig. 4. Volcano plot of differentially expressed genes. Genes with a significant change of more than two-fold were selected.
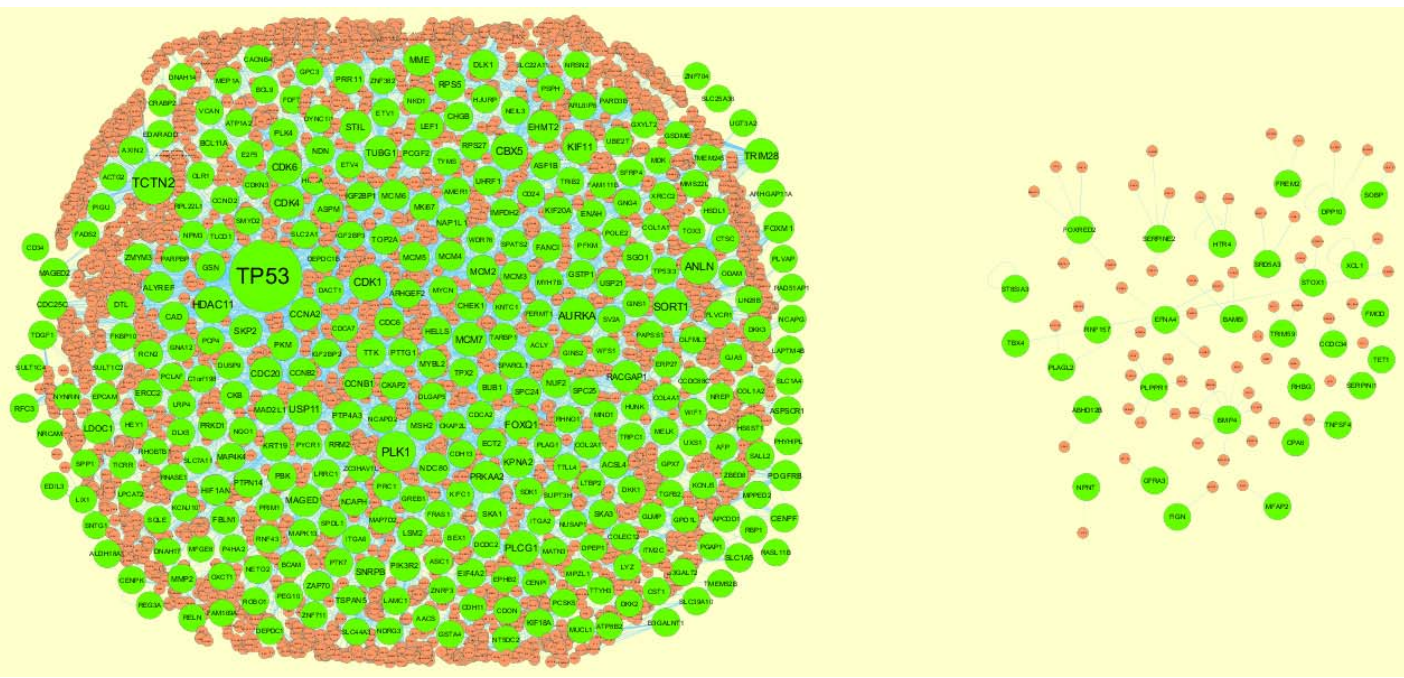
medRxiv preprint doi: https://doi.org/10.1101/2020.12.22.20248756; this version posted December 26, 2020. The copyright holder for this preprint (which was not certified by peer review) is the author/funder, who has granted medRxiv a license to display the preprint in perpetuity.

All rights reserved. No reuse allowed without permission.

Fig. 5. Protein-protein interaction network of up regulated genes. Green nodes denotes up regulated genes.

A

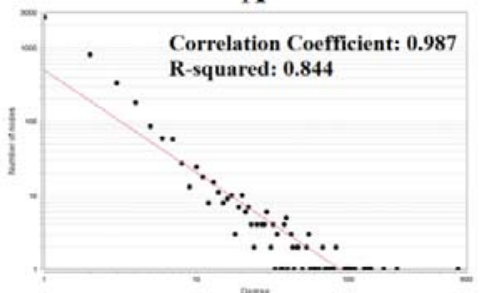

D

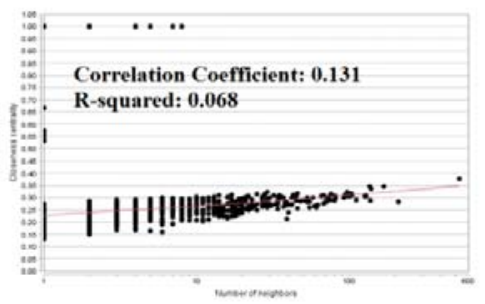

B

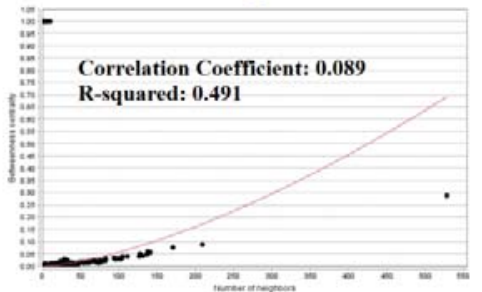

$\mathbf{E}$

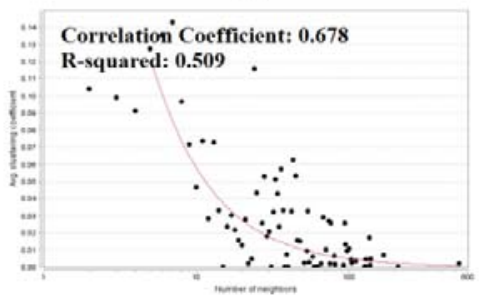

C

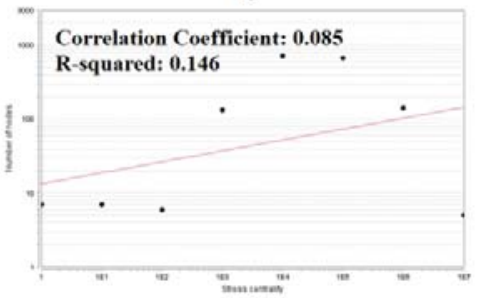

(1)

Fig. 6. Scatter plot for up regulated genes. (A- Node degree; B- Betweenness centrality; C- Stress centrality ; D-Closeness centrality; E- Clustering coefficient)

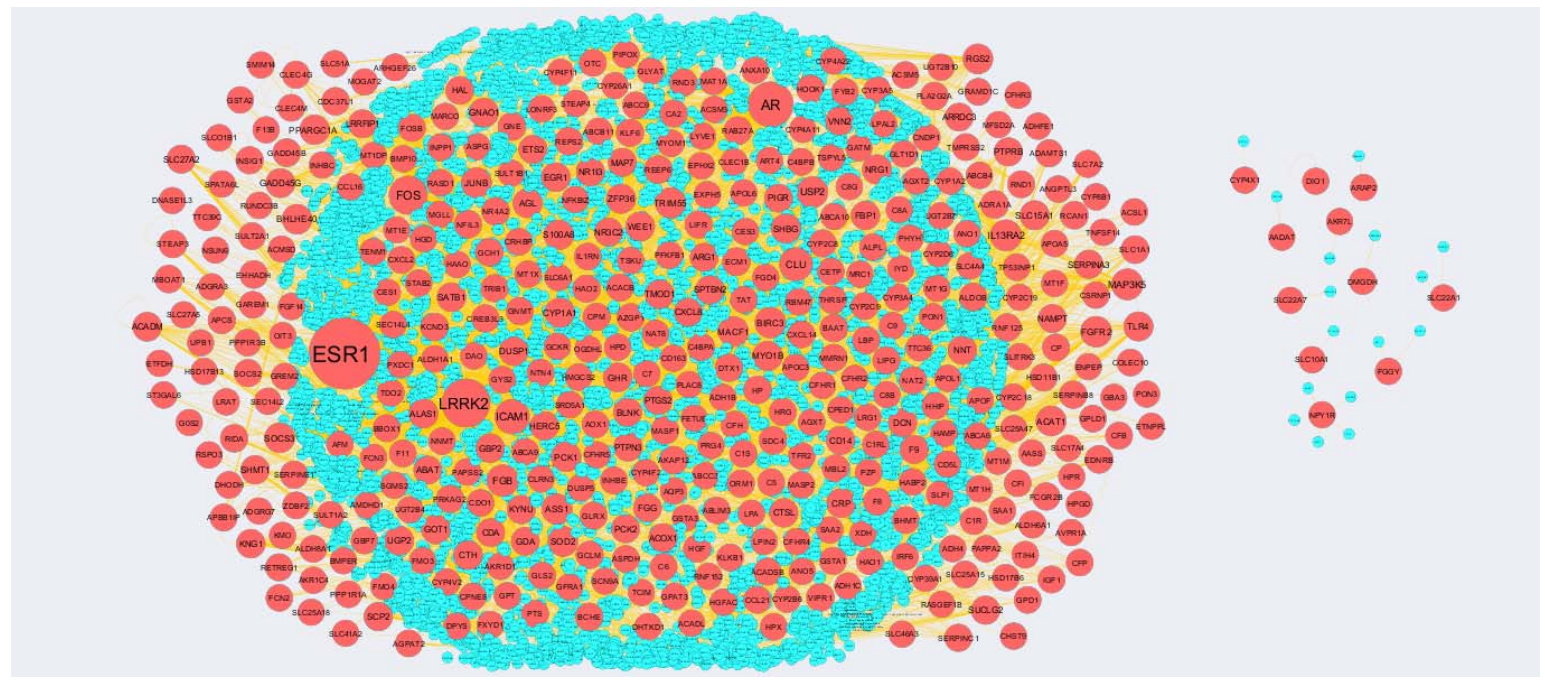

Fig. 7. Protein-protein interaction network of down regulated genes. Red nodes denotes down regulated genes. 
medRxiv preprint doi: https://doi.org/10.1101/2020.12.22.20248756; this version posted December 26, 2020. The copyright holder for this preprint (which was not certified by peer review) is the author/funder, who has granted medRxiv a license to display the preprint in perpetuity.

All rights reserved. No reuse allowed without permission.

A

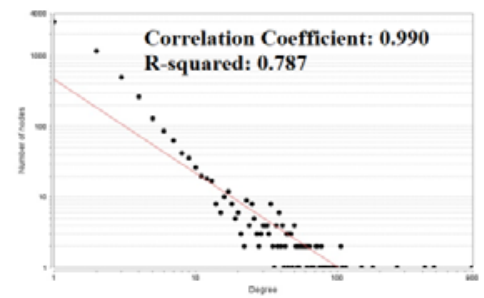

D

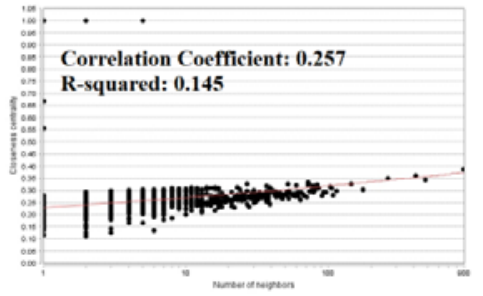

B

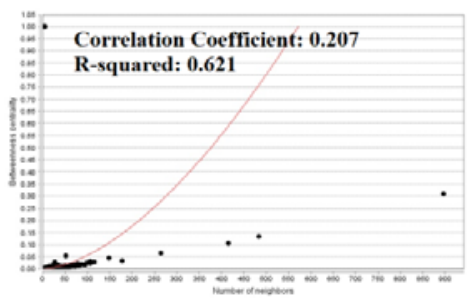

E

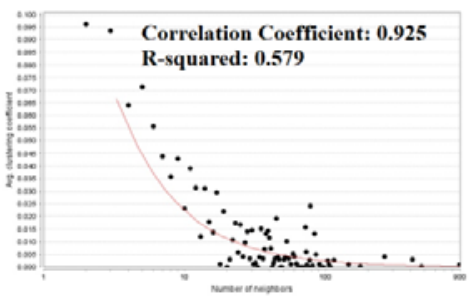

C

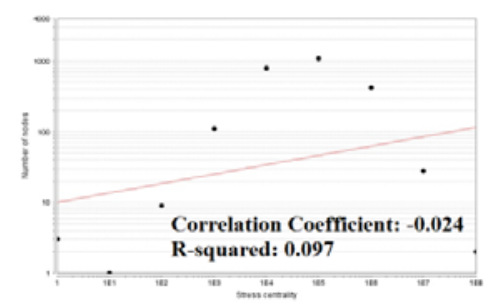

Fig. 8. Scatter plot for down regulated genes. (A- Node degree; B- Betweenness centrality; C- Stress centrality ; D-Closeness centrality; E- Clustering coefficient)

\section{Module 6}

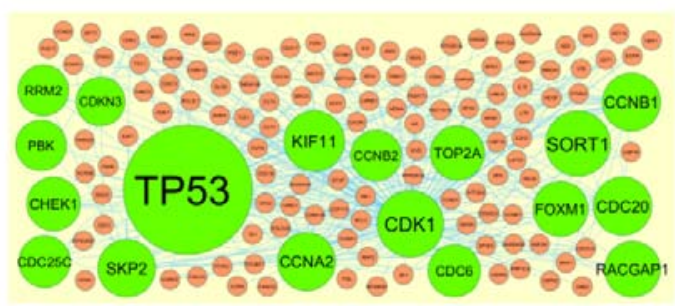

Module 36

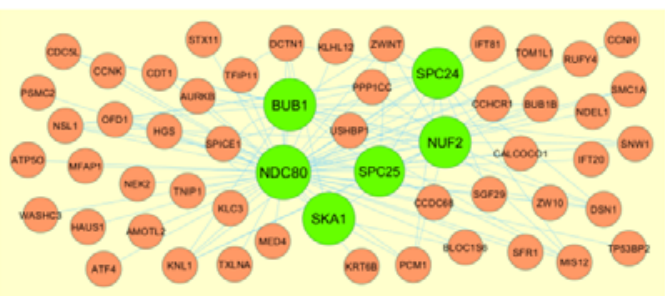

\section{Module 9}

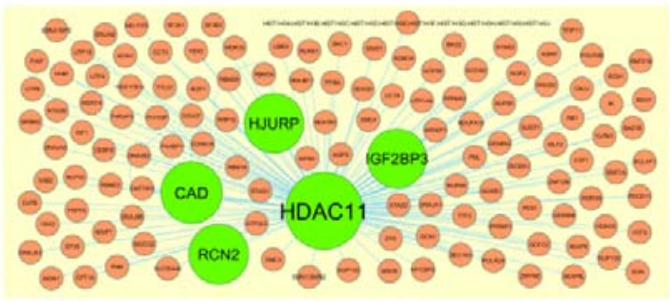

\section{Module 43}

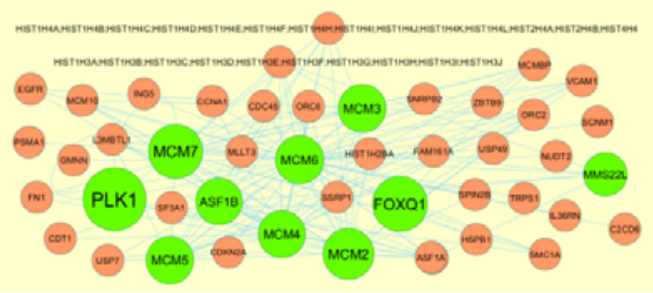

Fig. 9. Modules in PPI network. The green nodes denote the up regulated genes 
medRxiv preprint doi: https://doi.org/10.1101/2020.12.22.20248756; this version posted December 26, 2020. The copyright holder for this preprint (which was not certified by peer review) is the author/funder, who has granted medRxiv a license to display the preprint in perpetuity.

All rights reserved. No reuse allowed without permission.

\section{Module 6}

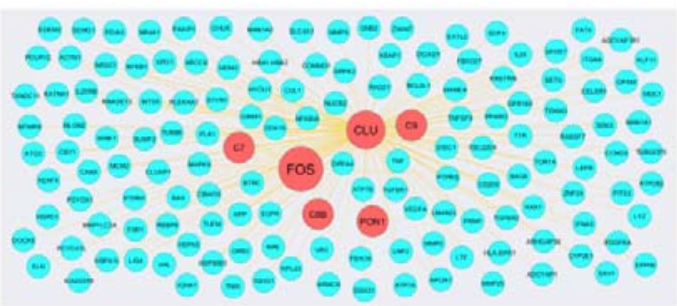

\section{Module 9}

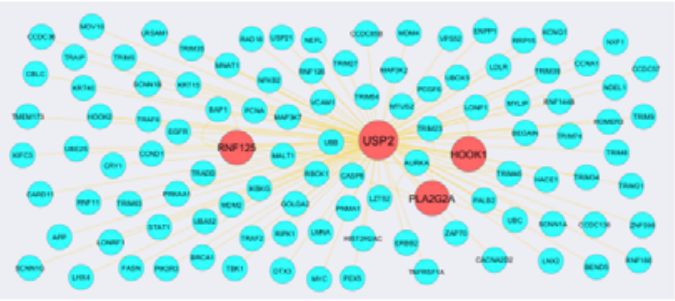

\section{Module 7}

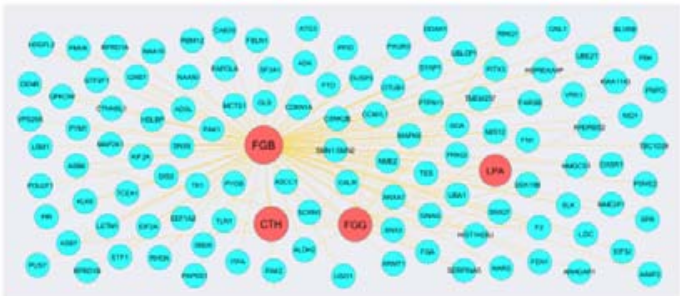

\section{Module 10}

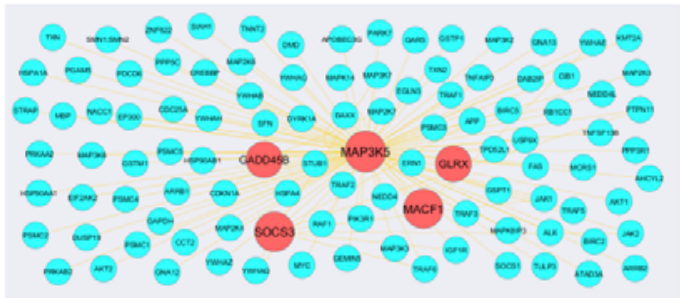

Fig. 10. Modules in PPI network. The red nodes denote the down regulated genes

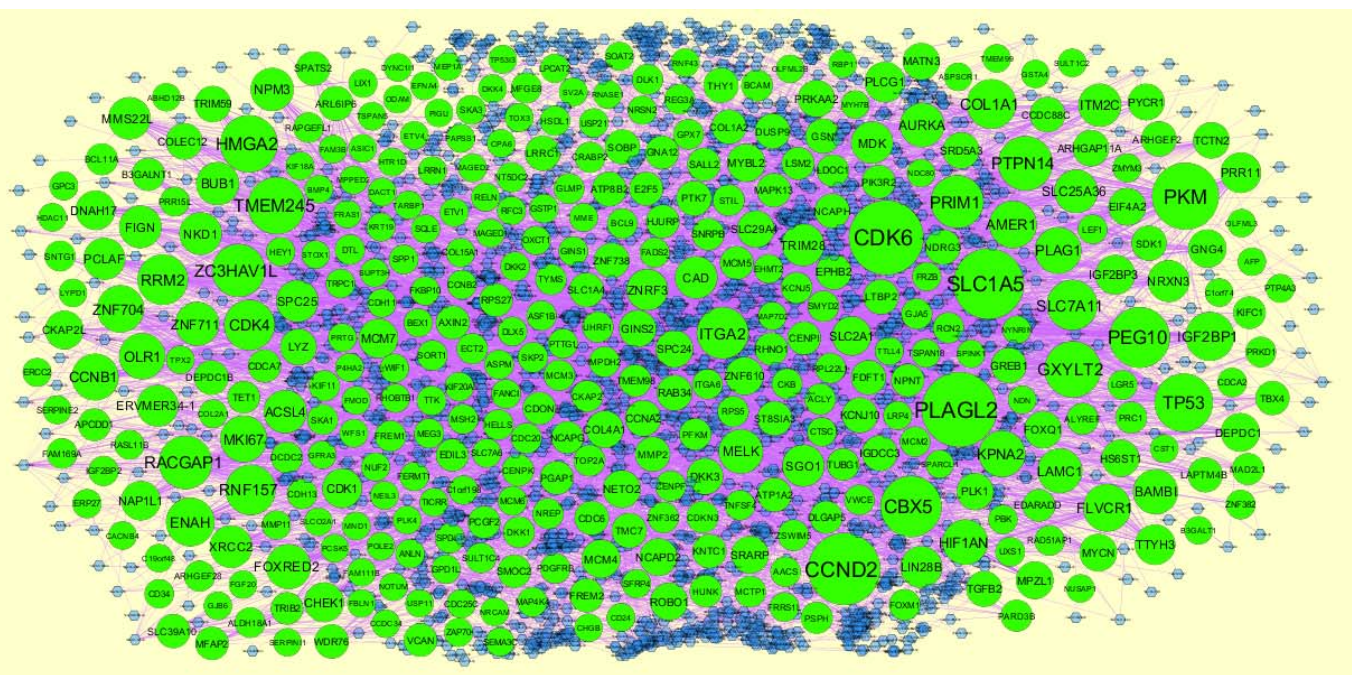

Fig. 11. The network of up regulated genes and their related miRNAs. The green circles nodes are the up regulated genes, and blue diamond nodes are the miRNAs 
medRxiv preprint doi: https://doi.org/10.1101/2020.12.22.20248756; this version posted December 26, 2020. The copyright holder for this preprint (which was not certified by peer review) is the author/funder, who has granted medRxiv a license to display the preprint in perpetuity.

All rights reserved. No reuse allowed without permission.

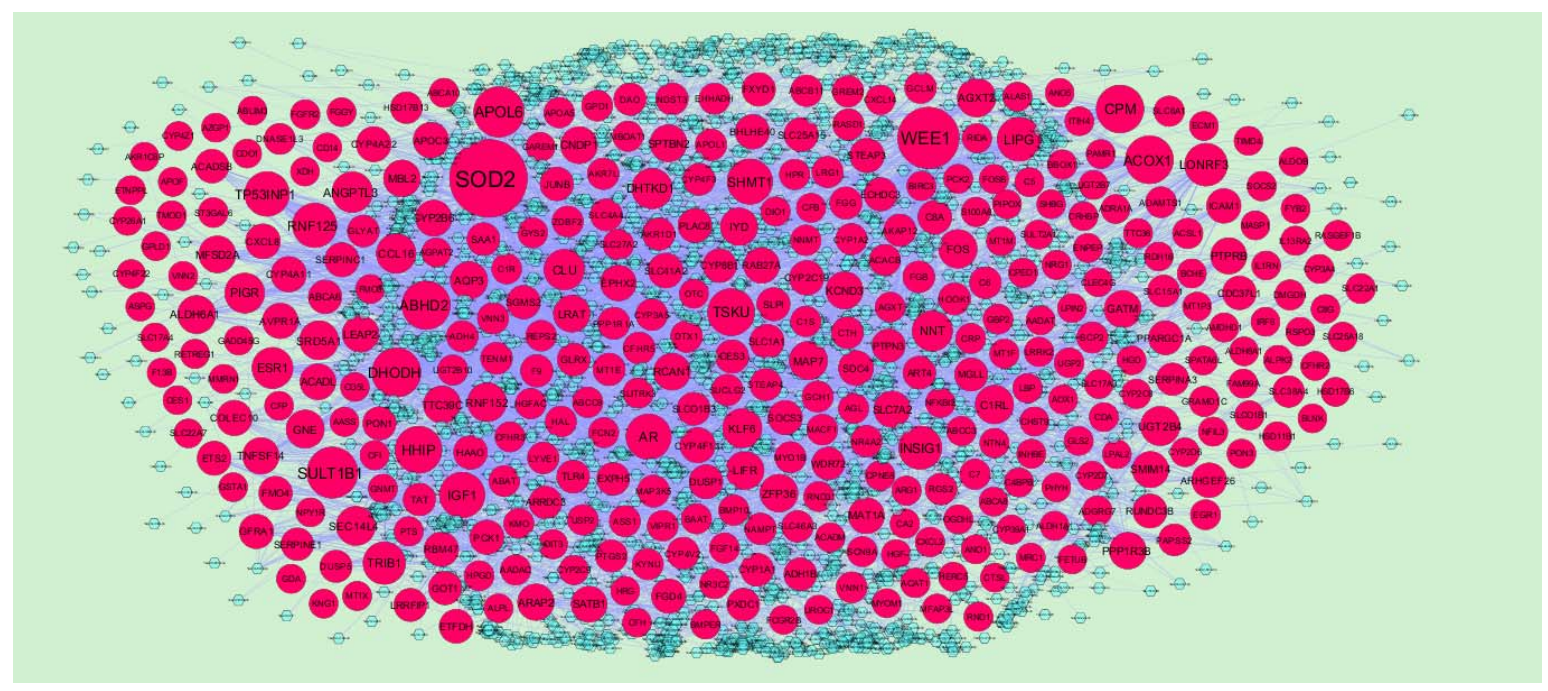

Fig. 12. The network of down regulated genes and their related miRNAs. The pink circles nodes are the down regulated genes, and sky blue diamond nodes are the miRNAs

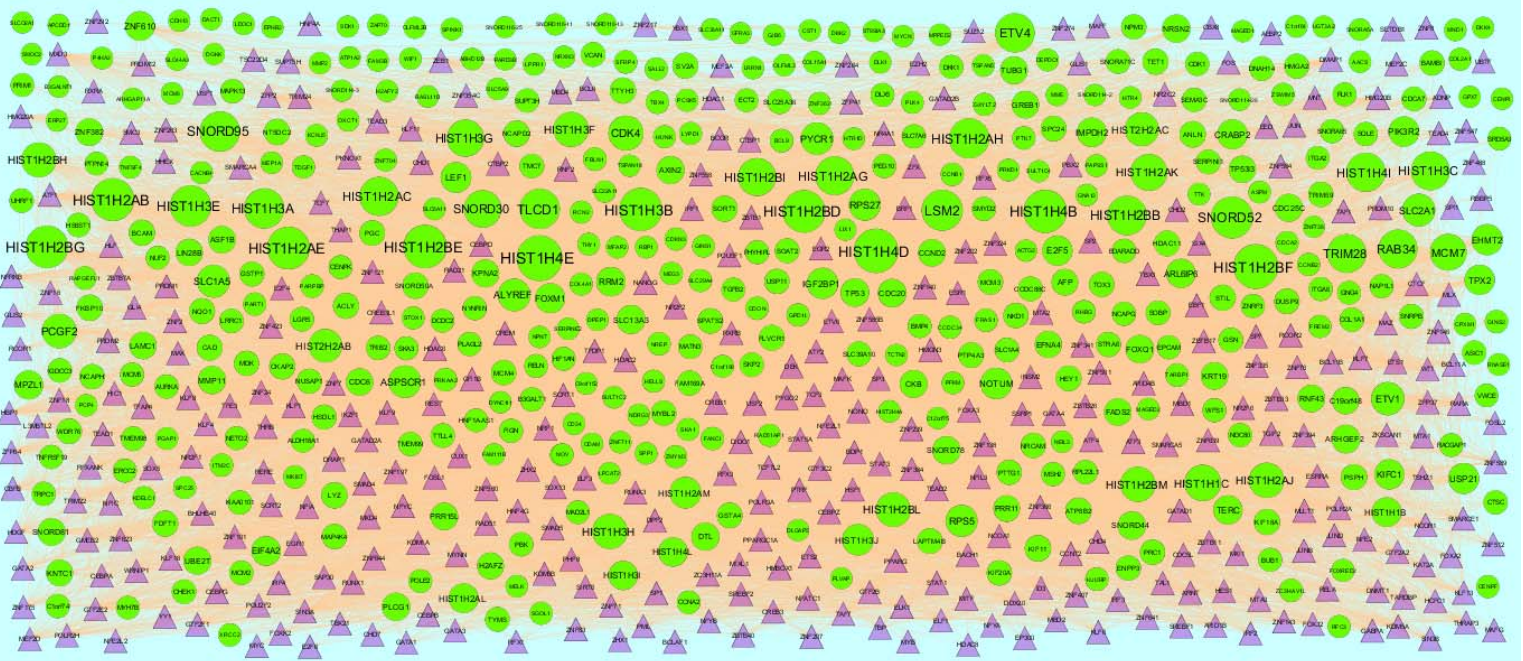

Fig. 13. The network of up regulated genes and their related TFs. The green circles nodes are the up regulated genes, and purple triangle nodes are the TFs 
medRxiv preprint doi: https://doi.org/10.1101/2020.12.22.20248756; this version posted December 26, 2020. The copyright holder for this preprint (which was not certified by peer review) is the author/funder, who has granted medRxiv a license to display the preprint in perpetuity. All rights reserved. No reuse allowed without permission.

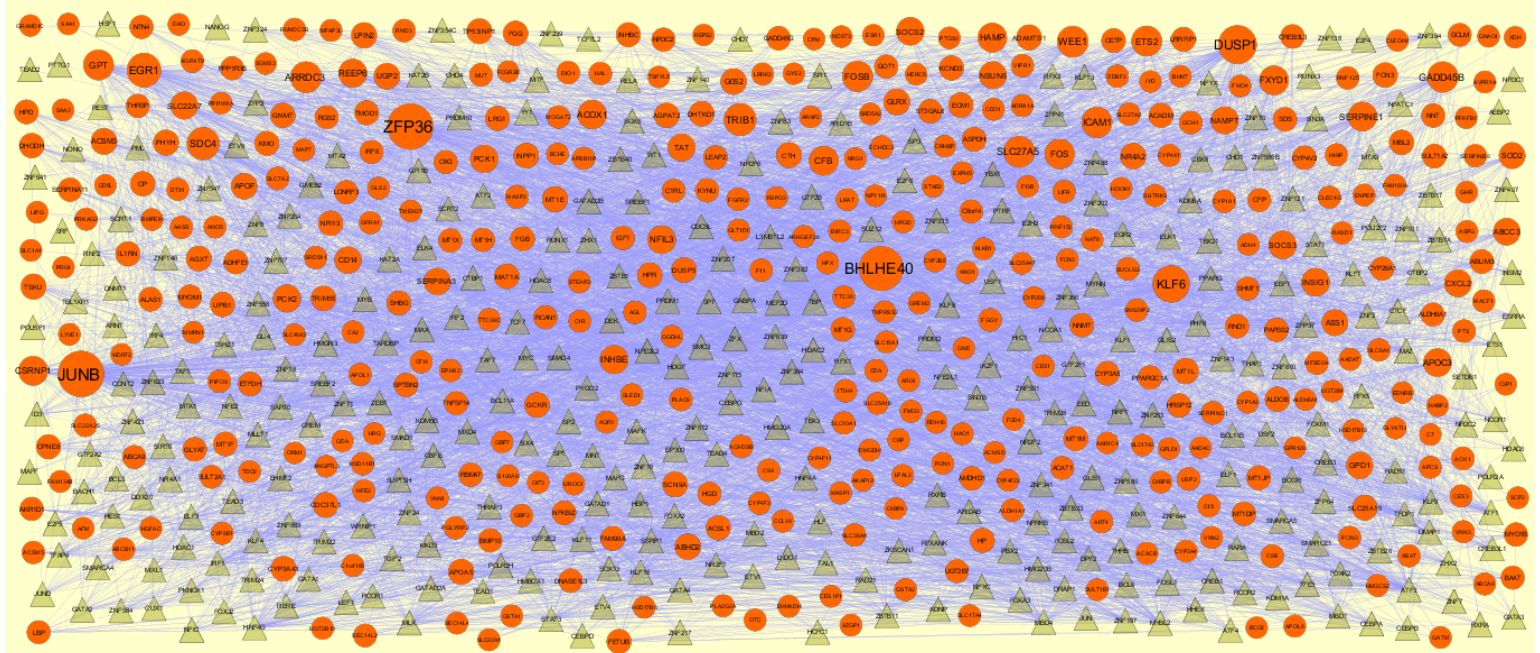

Fig. 14. The network of down regulated genes and their related TFs. The green circles nodes are the down regulated genes, and yellow triangle nodes are the TFs.
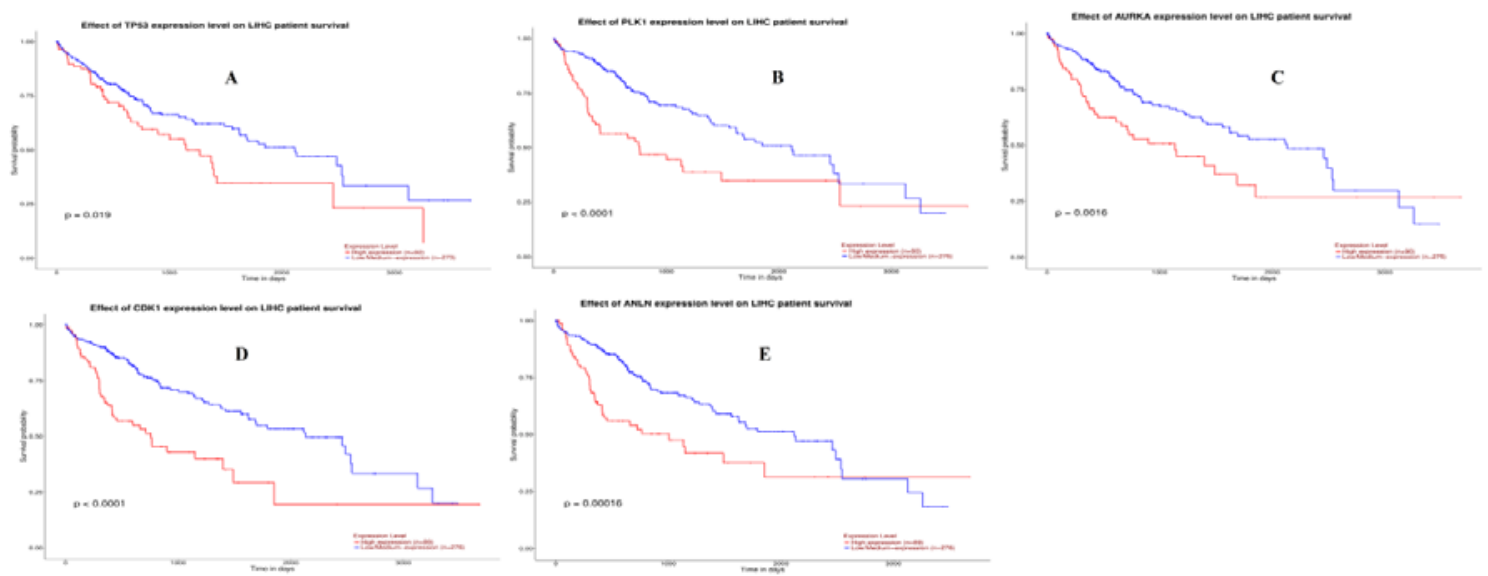

Fig. 15. Overall survival analysis of up regulated hub genes. Overall survival analyses were performed using the UALCAN online platform. Red line denotes - high expression; Blur line denotes - low expression. A) $\begin{array}{llllll}\text { TP53 B) PLK1 } & \text { C) AURKA } & \text { D) CDK1 E) ANLN }\end{array}$ 
medRxiv preprint doi: https://doi.org/10.1101/2020.12.22.20248756; this version posted December 26, 2020. The copyright holder for this preprint (which was not certified by peer review) is the author/funder, who has granted medRxiv a license to display the preprint in perpetuity.
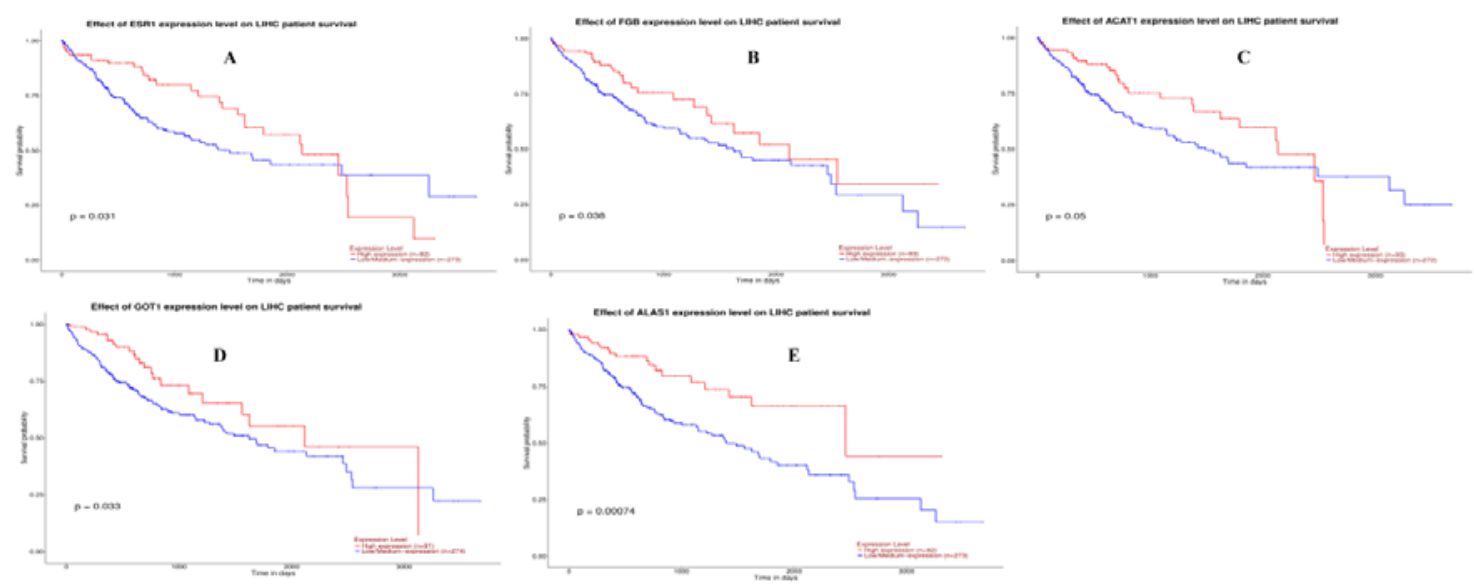

Fig. 16. Overall survival analysis of down regulated hub genes. Overall survival analyses were performed using the UALCAN online platform. Red line denotes - high expression; Blur line denotes - low expression. A) ESR1 B) FGB C) ACAT1 D) GOT1 E) ALAS1
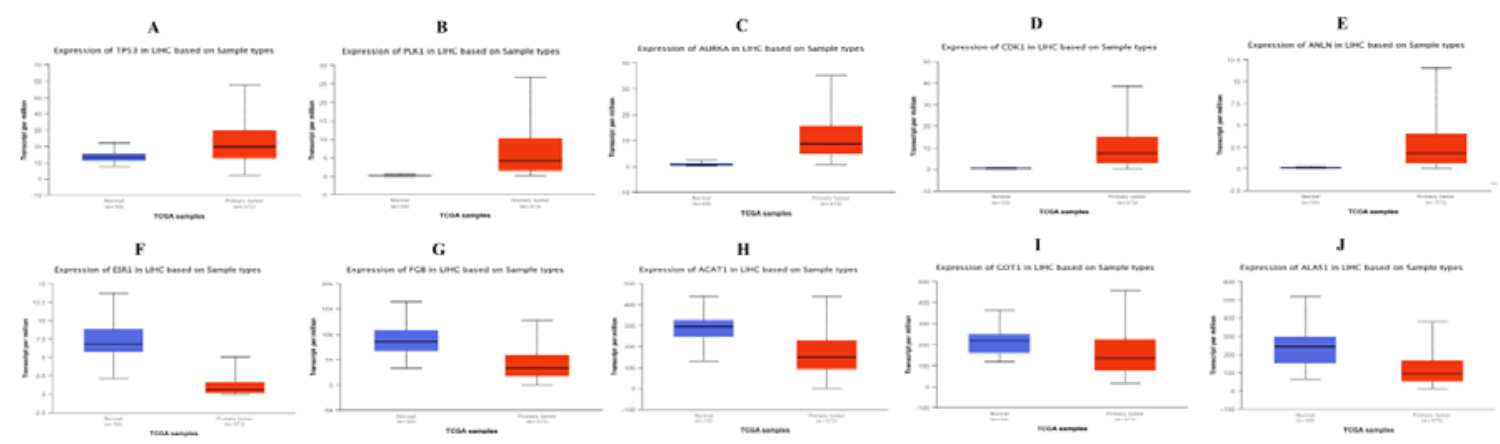

H

$\mathbf{I}$

$\mathbf{J}$
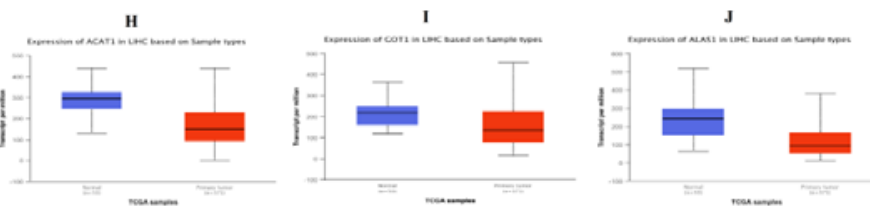

Fig. 17. Box plots (expression analysis) hub genes (up and down regulated) were produced using the

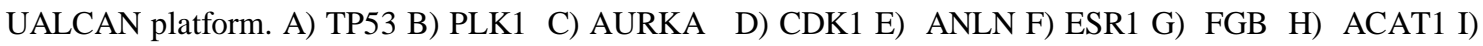
GOT1 G) ALAS1
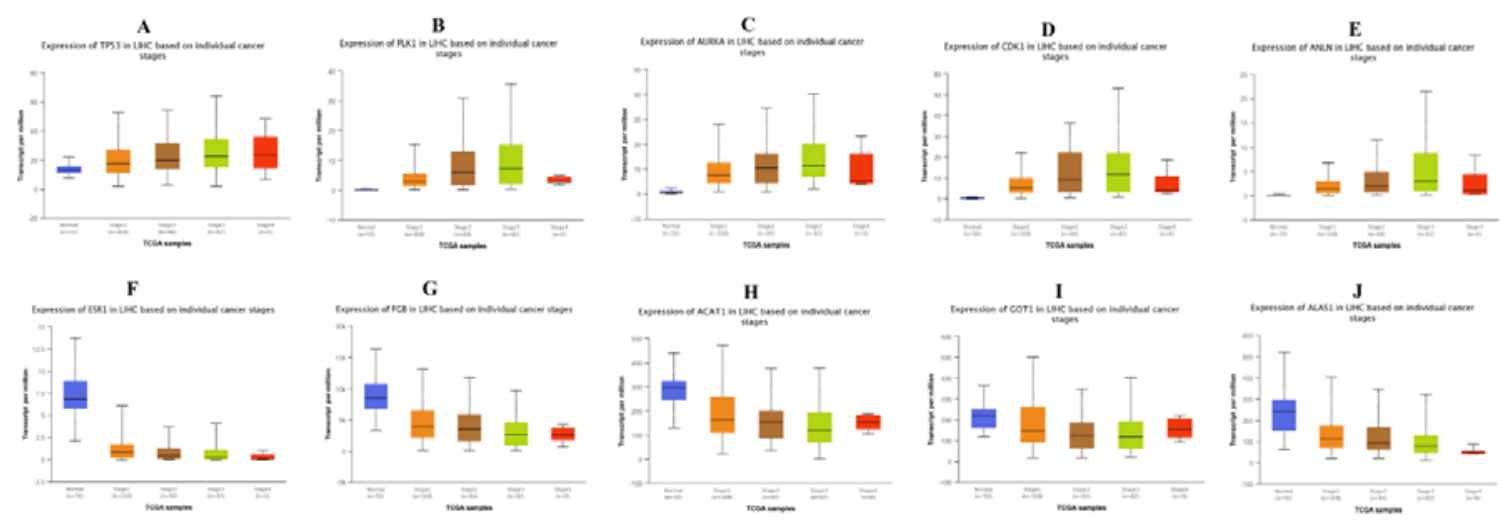

Fig. 18. Box plots (stage analysis) of hub genes (up and down regulated) were produced using the UALCAN platform A) TP53 B) PLK1 C) AURKA $\quad$ D) CDK1 E) ANLN F) ESR1 G) FGB H) ACAT1 I) GOT1 G) ALAS1 
medRxiv preprint doi: https://doi.org/10.1101/2020.12.22.20248756; this version posted December 26, 2020. The copyright holder for this preprint (which was not certified by peer review) is the author/funder, who has granted medRxiv a license to display the preprint in perpetuity.

All rights reserved. No reuse allowed without permission.

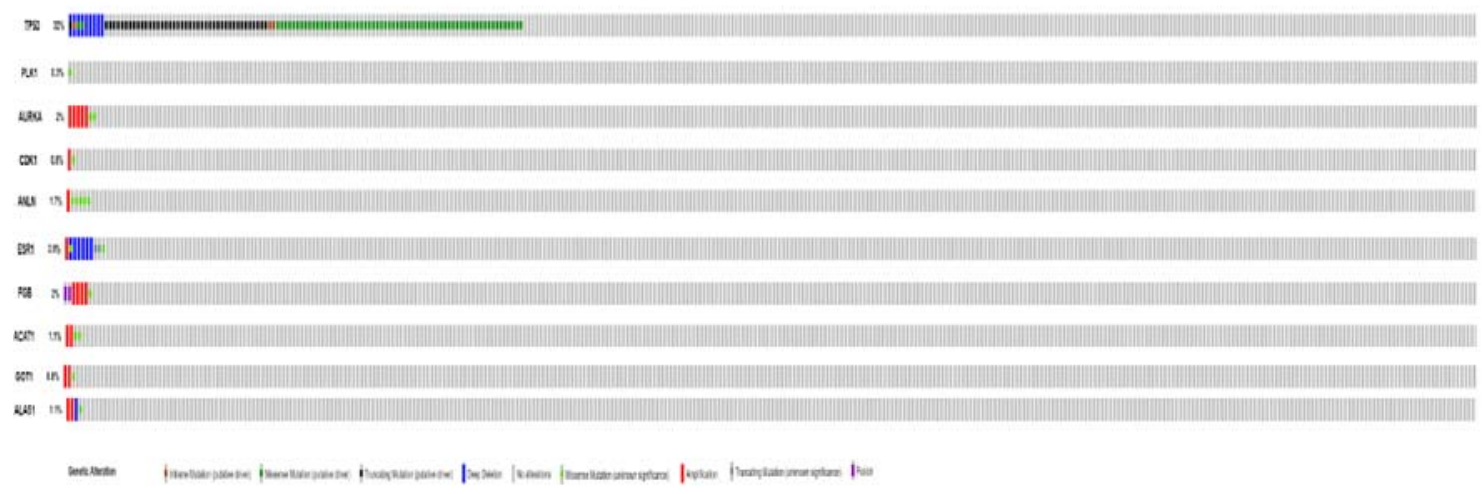

Fig. 19. Mutation analyses of hub genes were produced using the CbioPortal online platform

A

Normal tissue

Hepatoblastoma tissue

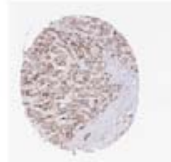

$\mathbf{F}$

Normal tissue
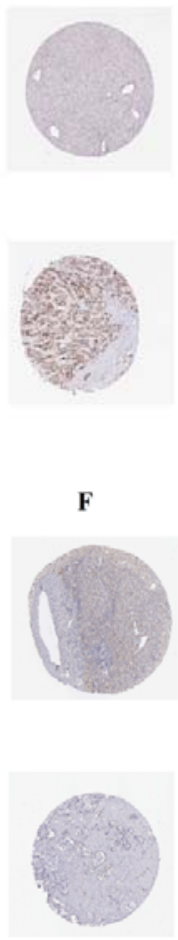

B
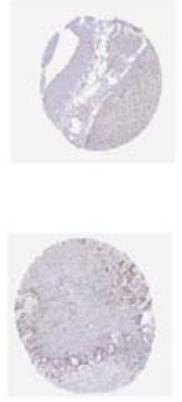

G
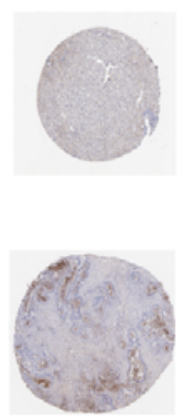

C
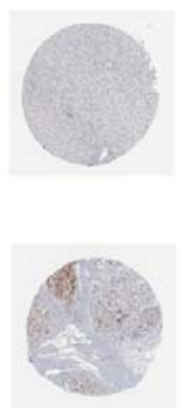

H
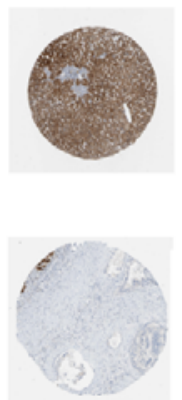

D
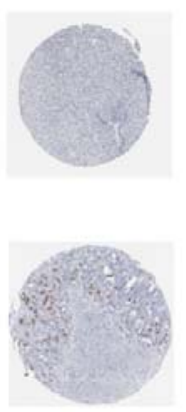

I
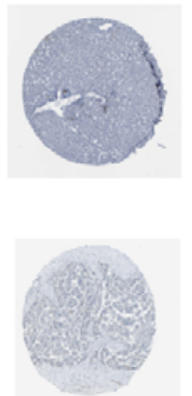

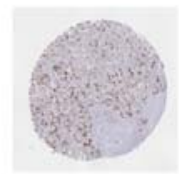

$\mathbf{E}$

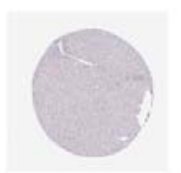

$\mathbf{J}$
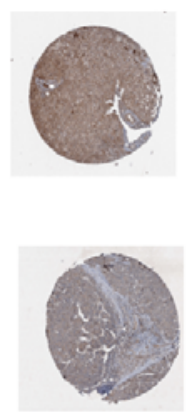

Fig. 20. Immunohisto chemical(IHC) analyses of hub genes were produced using the human protein atlas (HPA) online platform A) TP53 B) PLK1 C) AURKA $\quad$ D) CDK1 E) ANLN F) ESR1 G) FGB H) ACAT1 I) GOT1 G) ALAS1 
medRxiv preprint doi: https://doi.org/10.1101/2020.12.22.20248756; this version posted December 26, 2020. The copyright holder for this preprint (which was not certified by peer review) is the author/funder, who has granted medRxiv a license to display the preprint in perpetuity. All rights reserved. No reuse allowed without permission.
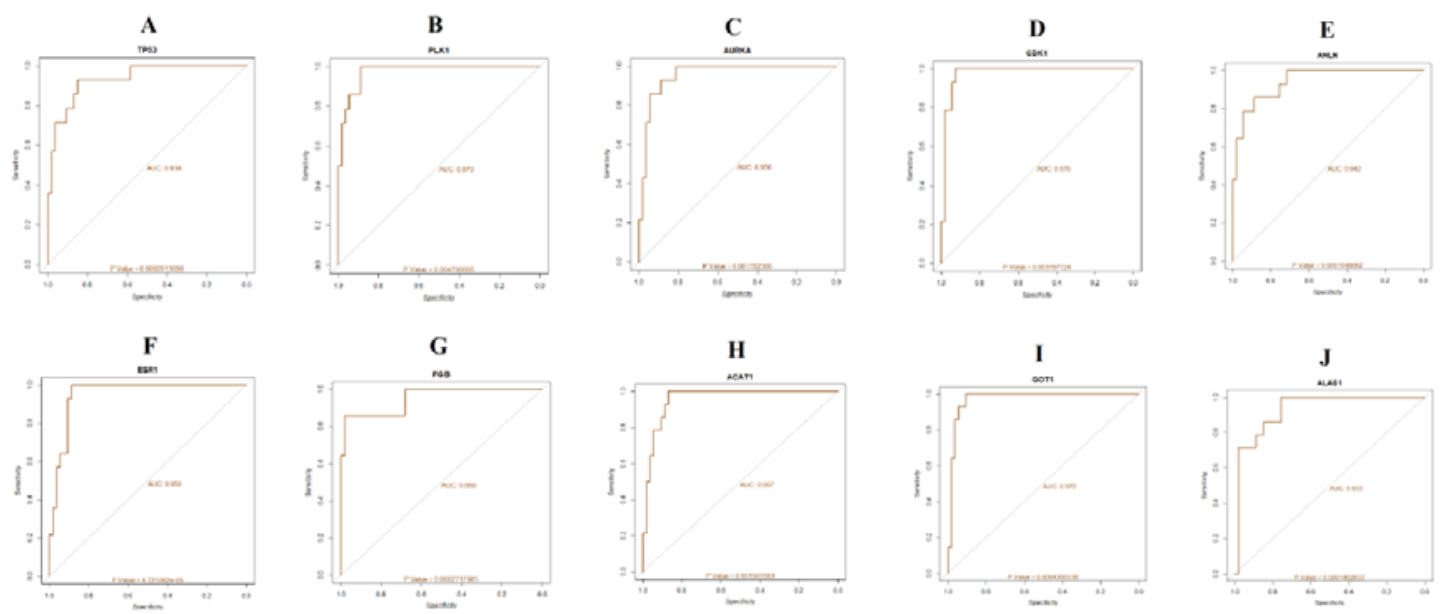

Fig. 21. ROC curve validated the sensitivity, specificity of hub genes as a predictive biomarker for

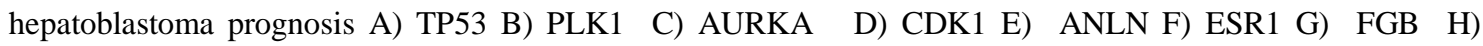
ACAT1 I) GOT1 G) ALAS1
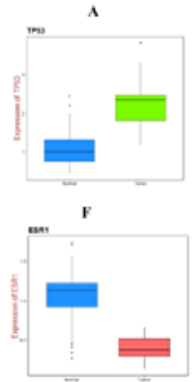
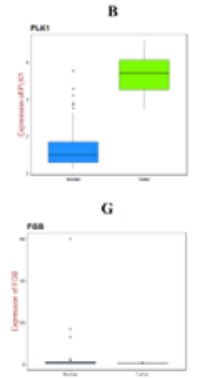
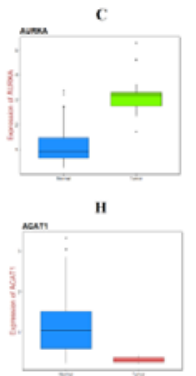
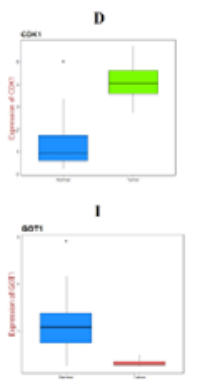
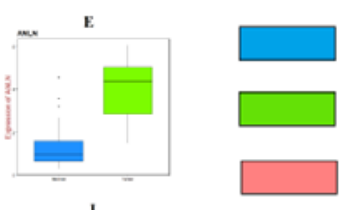

Normal control

Hepatoblastoma (Up regulated)

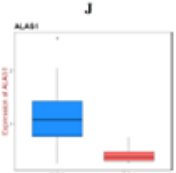

Hepatoblastoma (Down regulatec

Fig. 22. Validation of hub genes (up and down regulated) by RT- PCR. A) TP53 B) PLK1 C) AURKA D) CDK1 E) ANLN F) ESR1 G) FGB H) ACAT1 I) GOT1 G) ALAS1 
medRxiv preprint doi: https://doi.org/10.1101/2020.12.22.20248756; this version posted December 26, 2020. The copyright holder for this preprint (which was not certified by peer review) is the author/funder, who has granted medRxiv a license to display the preprint in perpetuity.

All rights reserved. No reuse allowed without permission.

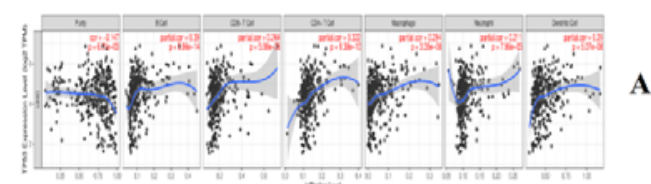

A

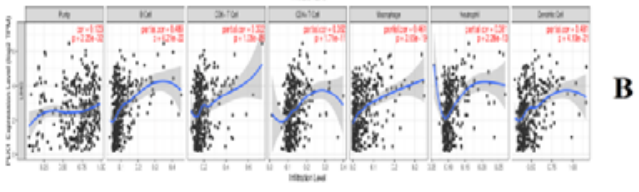

B
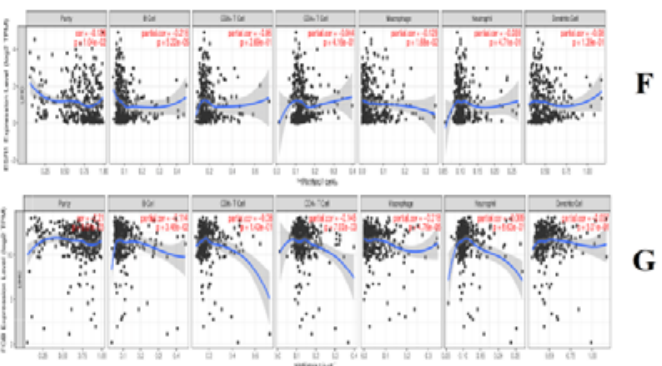

G
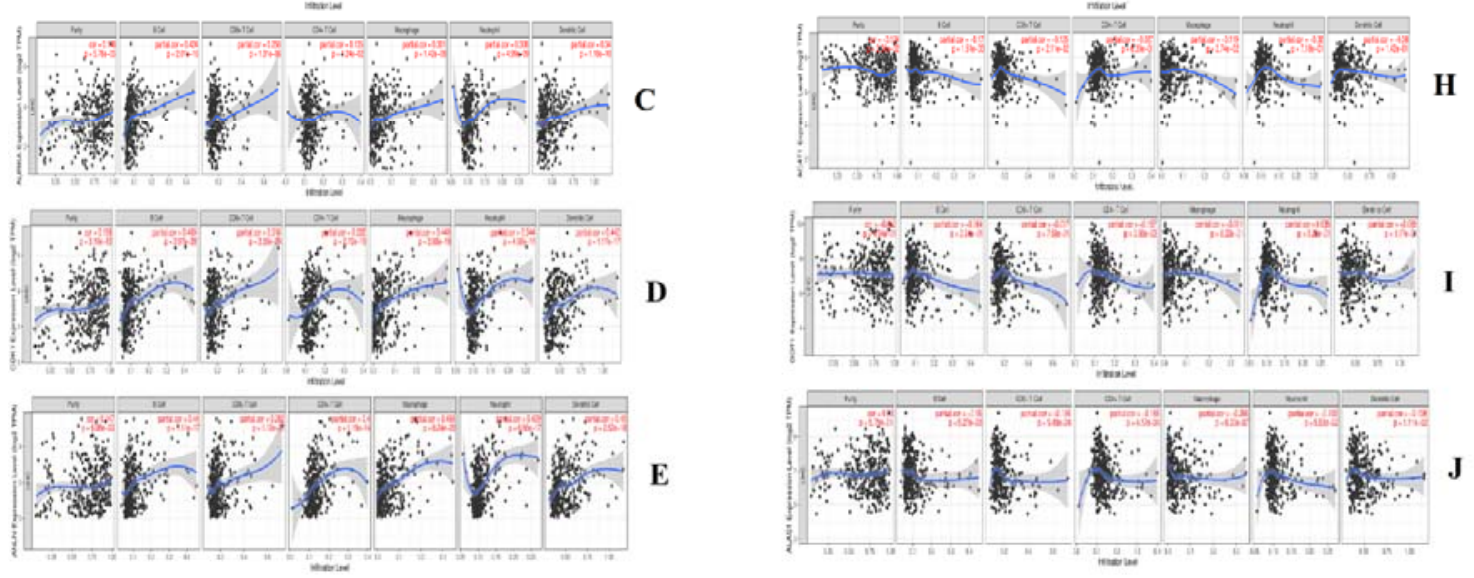

Fig. 23. Scatter plot for immune infiltration for hub genes (up and down regulated). A) TP53 B) PLK1 C) AURKA D) CDK1 E) ANLN F) ESR1 G) FGB H) ACAT1 I) GOT1 G) ALAS1 
medRxiv preprint doi: https://doi.org/10.1101/2020.12.22.20248756; this version posted December 26, 2020. The copyright holder for this preprint (which was not certified by peer review) is the author/funder, who has granted medRxiv a license to display the preprint in perpetuity.

All rights reserved. No reuse allowed without permission. 